Institute of Cytology and Genetics, Siberian Branch of the Russian Academy of Sciences Novosibirsk State University

Alexey Kochetov · Elena Salina

Editors

\title{
Current Challenges in Plant Genetics, Genomics, Bioinformatics, and Biotechnology
}

Proceedings of the Fifth International

Scientific Conference PlantGen2019

June 24-29, 2019 Novosibirsk, Russia

conf.bionet.nsc.ru/plantgen2019/en 
Current Challenges in Plant Genetics, Genomics, Bioinformatics, and Biotechnology: Proceedings of the Fifth International Scientific Conference PlantGen2019 (June 24-29, 2019, Novosibirsk, Russia) / Eds. A. Kochetov, E. Salina / Institute of Cytology and Genetics, Siberian Branch of the Russian Academy of Sciences. - Novosibirsk: ICG SB RAS, 2019. - 252 pp. - ISBN 978-5-91291-048-7.

DOI 10.18699/ICG-PlantGen2019-82

\section{Editors}

Prof. Alexey Kochetov

Institute of Cytology and Genetics, Siberian Branch of the Russian Academy of Sciences 630090 Prospekt Lavrentyeva, 10 Novosibirsk, Russian Federation e-mail: ak@bionet.nsc.ru
Prof. Elena Salina

Institute of Cytology and Genetics, Siberian Branch of the Russian Academy of Sciences 630090 Prospekt Lavrentyeva, 10 Novosibirsk, Russian Federation e-mail: salina@bionet.nsc.ru

\section{Additional Reviewers}

Alexey Kochetov, Dr. Sci. (Biology), Professor, Corr. Member of the RAS Elena Salina, Dr. Sci. (Biology), Professor

Irina Leonova, Dr. Sci. (Biology)

Dmitry Afonnikov, Cand. Sci. (Biology)

\section{Contacts}

E-mail: PlantGen2019@bionet.nsc.ru

Web: conf.bionet.nsc.ru/plantgen2019/en 


\section{Organizers}

Institute of Cytology and Genetics SB RAS (ICG SB RAS), Novosibirsk, Russia Novosibirsk State University (NSU), Novosibirsk, Russia

Ministry of Science and Higher Education of the Russian Federation, Moscow, Russia The Vavilov Society of Geneticists and Breeders (VSGB), St. Petersburg, Russia The Vavilov Society of Geneticists and Breeders (Novosibirsk Branch), Novosibirsk, Russia EUCARPIA (European Association for Research on Plant Breeding), Wageningen, Netherlands

\section{International Program Committee}

Alexey Kochetov, Institute of Cytology and Genetics, SB RAS, Novosibirsk, Russia (Conference Chair)

Elena Salina, Institute of Cytology and Genetics, SB RAS, Novosibirsk, Russia (Conference Co-Chair)

Vladimir Shumny, Institute of Cytology and Genetics, SB RAS, Novosibirsk, Russia Nikolay Kolchanov, Institute of Cytology and Genetics, SB RAS, Novosibirsk, Russia Andreas Börner, Leibniz Institute of Plant Genetics and Crop Plant Research, Gatersleben, Germany

Yerlan Turuspekov, Institute of Plant Biology and Biotechnology, Almaty, Kazakhstan Konstantin V. Krutovsky, Georg August University of Göttingen, Göttingen, Germany Olga Afanasenko, All-Russian Institute of Plant Protection, St. Petersburg, Russia Philipp B. Gannibal, All-Russian Institute of Plant Protection, St. Petersburg, Russia

Tatjana Gavrilenko, Federal Research Center the N.I. Vavilov All-Russian Institute of Plant Genetic Resources, St. Petersburg, Russia

Elena Khlestkina, Federal Research Center the N.I. Vavilov All-Russian Institute of Plant Genetic Resources, St. Petersburg, Russia

Igor Tikhonovich, All-Russian Research Institute for Agricultural Microbiology, St. Petersburg, Russia

Gennady Karlov, All-Russian Research Institute of Agricultural Biotechnology, Moscow, Russia

Alexander Kudriavtsev, Vavilov Institute of General Genetics, RAS, Moscow, Russia

Elena Kochieva, Federal Research Center Fundamentals of Biotechnology, RAS, Moscow, Russia

Nikolai Kashevarov, Siberian Federal Scientific Center of Agrobiotechnologies, RAS, Krasnoobsk, Novosibirsk region, Russia

Alexander Zhuchenko, All-Russian Breeding and Technological Institute of Horticulture and Nursery, Moscow, Russia

Vladimir Kosolapov, Federal Williams Research Center of Forage Production and Agroecology, Lobnya, Moscow region, Russia

Nikolay Goncharov, Institute of Cytology and Genetics, SB RAS, Novosibirsk, Russia 


\section{Contents}

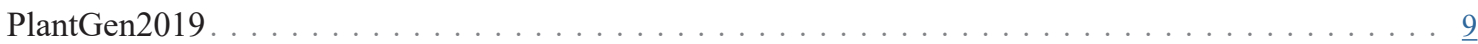

\section{Plant Genetic Resources for Breeding and Producing Functional Nutraceutical Food}

Introduction in Siberia (Russia) of new vegetable species with a high biochemical value Y.V. Fotev, A.I. Syso, O.M. Shevchuk. .

Anthocyanins in wheat grain: genetic control, health benefit and bread-making quality

E.K. Khlestkina, O.Y. Shoeva, E.I. Gordeeva, Y.S. Otmakhova, N.I. Usenko, M.A. Tikhonova,

M.V. Tenditnik, T.G. Amstislavskaya .

Identification of wheat varieties with high grain protein and gluten content

D-r.F. Askhadullin, D-l.F. Askhadullin, N.Z. Vasilova, E.V. Zuev, I.I. Khusainova, M.R. Tazutdinova,

E.Z. Bagavieva .

Wheat genetic resources for breeding on adaptability

M.A. Yessimbekova, M.Sh. Suleimenova, K.B. Mukin

Development of new forms of spring and winter wheat with the involvement of the gene pool of wheatgrass and soybean and confirmation of the applicability of these methods in practical breeding E.P. Razmakhnin, T.M. Razmakhnina, N.I. Stepochkina, V.I. Ponomarenko, V.I. Kozlov,

K.K. Musinov, A.A. Surnachev, G.V. Artemova, I.E. Likhenko, G.Y. Galycin, N.P. Goncharov . . . . . . . . 24

Breeding of soft spring wheat in a changing climate

V.V. Novokhatin

Spring common wheat breeding lines produced on the basis of distant hybridization: ecological strain testing in Bagan

B.F. Nemtsev, A.B. Nemtsev, N.P. Goncharov, S.V. Kurkova . .

Creation and study of partial waxy wheat lines adapted for the Middle Volga region of Russia D-l.F. Askhadullin, D-r.F. Askhadullin, N.Z. Vasilova, R.R. Vafin . . . . . . . . . . . . . . . 34

Internal stem features of spring wheat varieties as factors determinig resistance to lodging E.V. Ageeva, I.N. Leonova, E.A. Salina, I.E. Likhenko

Application of ISSR markers for study of genetic polymorphism of dark grain maize varieties L.S. Valiyeva, G.K. Rahimova, N.A. Nabiyeva .

Genetic structure of the ampelographic collection maintained in the Dagestan experimental station of VIR revealed by microsatellite analysis M.M. Agakhanov, V.A. Volkov, E.K. Potokina.

Genetic variation of water caltrop (Trapa L.) in several Russian populations

A.E. Artyukhin, E.V. Mikhaylova, B.R. Kuluev

Potato starch resistivity as an inheritable trait

L.M. Gvozdeva, I.V. Rozanova, V.K. Khlestkin, E.K. Khlestkina.

Evaluation of genetic variability of buckwheat varieties (Fagopyrum esculentum) using ISSR-analysis A.G. Klykov, P.V. Fisenko, A.S. Chibizova, E.N. Barsukova 


\section{Plant Resistance to Pathogens and Other Biotic Stresses}

Resistance to stem rust and a molecular marker analysis of $\mathrm{Sr}$ genes in spring bread wheat introgression lines

O.A. Baranova, S.N. Sibikeev, A.E. Druzhin

Development of the panel of SSR markers to estimate the level of genetic diversity among the Siberian stem rust population V.N. Kelbin, E.S. Skolotneva, S. Vidich, M.A. Nesterov, E.M. Sergeeva, E.A. Salina.

Study of introgression lines of common wheat Triticum aestivum/Triticum miguschovae for resistance to leaf rust R.O. Davoyan, I.V. Bebykina, E.R. Davoyan, D.S. Mikov, Y.S. Zubanova, D.M. Boldakov, A.N. Zinchenco . . . . $\underline{58}$

Development and study of new spring wheat lines containing alien genetic material from Th. intermedium and Ae. speltoides I.N. Leonova, V.V. Piskarev, N.I. Boiko, A.I. Stasyuk, I.G. Adonina, E.A. Salina .

Interaction of the Tsn1 and Tsc2 sensitivity genes with the ToxA and ToxB effector genes in Triticum L. species

N.V. Mironenko, O.A. Baranova, N.M. Kovalenko, O.P. Mitrofanova

Molecular screening of wheat entries for resistance to the toxins Ptr ToxA and Ptr ToxB from the tan spot pathogen Pyrenophora tritici-repentis

A.M. Kokhmetova, S. Ali, M.N. Atishova.

Functional characterization of Stagonospora nodorum necrotrophic effectors

S.V. Veselova, G.F. Burkhanova, T.V. Nuzhnaya, I.V. Maksimov . . . . . . . . . . . . . . . . . 69

Septoria blight of spring wheat in West Siberia

E.Yu. Toropova, O.A. Kazakova, V.V. Piskarev .

Race composition of the loose smut (Ustilago tritici) in Western Siberia

E.A. Orlova, N.P. Bechtold

Potential of ribonuclease-sinthesizing plant growth promoting rhizobacteria in plant defence against viruses

G.F. Burkhanova, A.V. Sorokan, V.U. Alekseev, A.A. Mazitova, I.V. Maksimov .

Studying the infection rate of seeds of various genotypes of sweet sorghum (Sorghum bicolor L.) by fungus and bacterial microflora

K.M. Iskakova, B.B. Anapiyayev, E.B. Beisenbek, A.B. Akhmetova, A.M. Sagimbayeva, A.S. Omarova . . . . . 80

Role of genes involved in lignin biosynthesis in flax response to Fusarium oxysporum R.O. Novakovskiy, G.S. Krasnov, T.A. Rozhmina, L.P. Kudryavtseva, A.A. Zhuchenko, E.N. Pushkova, L.V. Povkhova, P. Kezimana, A.A. Dmitriev, N.V. Melnikova . . . . . . . . . . . . . . . . . . . . . .

\section{Genetic and Epigenetic Mechanisms of Plant Resistance to Abiotic Stresses}

Epigenetic mechanisms of the karyogenomic system of mature wheat germ derived under conditions of cold stress

E.A. Ivanova, G.Kh. Vafina

Comparative characteristic of near-isogenic lines differing by the Blp locus in respect to abiotic stress resistance A.Y. Glagoleva, O.Y. Shoeva, E.K. Khlestkina

Creation of mutant populations of barley (Hordeum vulgare L.) and flax (Linum ussitatissimum L.) induced by the chemical mutagen of the phosphemide N.A. Bome, K.P. Korolev, N.V. Tetyannikov, L.I. Weisfeld, N.N. Kolokolova.

Functional characterization of drought resistance in peach (Prunus petsica (L.) Batsch) cultivars damaged with Sharka disease V.A. Brailko, I.V. Mitrofanova, N.V. Mesyats, O.V. Mitrofanova, S.V. Chirkov

Response of the antioxidant system of two varieties of potatoes to salt stress O.K. Murgan, L.V. Kolomeichuk, I.S. Kovtun, M.V. Efimova 
Mechanism of plant adaptation to changing illumination by rearrangements of their photosynthetic apparatus

V.I. Belkov, E.Yu. Garnik, Yu.M. Konstantinov

Features of the interaction of miRNAs with genes of the rice MYB family under stress

A.T. Ivashchenko, A.K. Rakhmetullina, A.U. Pyrkova.

Sensitive biomarker for assessing the effects of the environment on the population of plants

L.A. Minasbekyan, G.S. Aidarkhanova, I.A. Avagyan

Selenium nanocomposites as a protection agent from potato ring rot O.A. Nozhkina, A.I. Perfileva, I.A. Graskova, B.G. Sukhov

\section{Plant Biotechnology in the Postgenomic Era}

Modern CRISPR/Cas9 biotechnology is a current challenge to create elite disease resistant crops cultivars

O.I. Kershanskaya, D.S. Nelidova, G.L. Esenbaeva, G.S. Mukiyanova, S.N. Nelidov

Study of a region on wheat chromosome $5 \mathrm{BS}$ by targeted sequencing M.K. Bragina, D.A. Afonnikov, G.V. Vasiliev, E.A. Salina .

Intergenomic substitutions and translocations in wheat-alien lines and their use in studying the characteristics that determine adaptation and stress resistance T.T. Efremova, E.V. Chumanova

Copy number variation of the $V r n-A 1 b$ allele in emmer and spelt wheat A. Muterko

Evaluation of in vitro plant regeneration efficiency in Siberian wheat cultivars D.N. Miroshnichenko, A.A. Klementyeva, E.A. Salina, S.V. Dolgov

Improvement of sorghum grain quality using modern genetic tools L.A. Elkonin, V.M. Panin, G.A. Gerashchenkov, O.A. Kenzhegulov

New efficient gene promoters from Stellaria media for plant genetic engineering L.N. Efremova, S.R. Strelnikova, R.A. Komakhin .

Role of the expansin and xyloglucan endotransglycosylase genes in the regulation of tobacco growth under the influence of abiotic stress factors B.R. Kuluev, Kh.G. Musin, Z.A. Berezhneva, E.V. Mikhaylova, E.A. Zaikina.

Reproduction and genetic accuracy during somatic embryogenesis in Larix sibirica I.N. Tretyakova, M.E. Park, N.V. Oreshkova, D.V. Kulagin, A.V. Konstantinov, V.E. Padutov

Reactivation of VaSTS1 expression in Arabidopsis thaliana transgenic plants by retransformation with $2 b$ from the Cucumber Mosaic Virus isolate NK N.N. Nityagovsky, A.P. Tyunin, K.V. Kiselev

Development of a new method for eradication of viruses by induction of posttranscriptional gene silencing in transgenic potato plants A.M. Alexandrova, O.V. Karpova, R.M. Nargilova, R.V. Kryldakov, B.K. Iskakov

Up-regulation of the vacuolar invertase TAI gene may contribute to the accumulation of carotenoids in tomato fruits M.A. Slugina, E.A. Dzhos, A.V. Shchennikova, E.Z. Kochieva

Induction of in vitro propagation in mature embrios of maize B.M.H. Humood, O.I. Yudakova

Preparation of DNA libraries for sequencing of $S A D$ and $F A D$ genes in flax P. Kezimana, T.A. Rozhmina, G.S. Krasnov, R.O. Novakovskiy, L.V. Povkhova, E.N. Pushkova, M. Pavelek, E.V. Romanova, A.A. Dmitriev, N.V. Melnikova.

Rare species Iris scariosa and I. pumila in the Southern Urals E.V. Mikhaylova, A.N. Mustafina, Y.M. Golovanov, A.V. Kryukova

Extraction of high-molecular-weight DNA from poplar plants for Nanopore sequencing E.N. Pushkova, A.D. Beniaminov, G.S. Krasnov, R.O. Novakovskiy, L.V. Povkhova, N.V. Melnikova, 


\section{Plant Systems Biology and Digital Technologies}

Novel genomic marker for the Alm locus in barley identified based on transcriptome analysis N.A. Shmakov, A.Yu. Glagoleva, G.V. Vasiliev, D.A. Afonnikov, E.K. Khlestkina .

Comparative transcriptome analysis of Syringa vulgaris vegetative apices in vivo and in vitro A.A. Krinitsina, A.S. Speranskaya, O.A. Churikova, M.D. Logacheva, E.A. Konorov, M.S. Belenikin

Overexpression of RPOTmp, an Arabidopsis RNA-polymerase with dual-targeting, influences plant growth and transcriptome V.I. Tarasenko, A.I. Katyshev, I.V. Gorbenko, V.I. Belkov, E.Y. Garnik, Y.M. Konstantinov, M.V. Koulintchenko

$\mathrm{NDH}$ gene disruption - possible implication for adaptation of Allium species to different light conditions A.S. Speranskaya, M.S. Belenikin, E.A. Konorov, S.V. Kuptsov, M.I. Antipin, M.D. Logacheva, D.O. Omelchenko, A.A. Krinitsina

Gene expression in Scots pine populations from the Chernobyl exclusion zone: transcriptomic approach P.Yu. Volkova, G.T. Duarte, S.A. Geras'kin

Use of deep sequencing to study the genetic diversity of flax pathogens R.O. Novakovskiy, G.S. Krasnov, E.N. Pushkova, L.P. Kudryavtseva, T.A. Rozhmina, P. Kezimana, L.V. Povkhova, N.V. Melnikova, A.A. Dmitriev . . . . . . . . . . . . . . . . . . . . . .

Computer program for construction of regression function for phenotype in agroclimatic models with interactions K.N. Kozlov, S.V. Nuzhdin, M.G. Samsonova

Bioniformatics reserch of CRISPR/Cas-systems in the genomes of the phytopatogenic strain Agrobacterium fabrum C58

I.A. Portnaia, A.Yu. Borisenko, Yu.P. Dzhioev, O.G. Karnoukhova, Ju.A. Markova, L.A. Stepanenko, O.N. Reva, N.P. Peretolchina, V.I. Zlobin

\section{Plant Breeding in the $21^{\text {st }}$ Century}

Main directions of the spring bread wheat breeding in Western Siberia I.A. Belan, L.P. Rosseeva, N.P. Blokhina, L.F. Lozhnikova, V.V. Nemchenko, S.N. Abakumov, R.K. Kadikov N.V. Trubacheeva, L. A. Pershina

Improved marker for the $R h t-B 1 p$ dwarfing allele in wheat M.S. Bazhenov, L.A. Nazarova, A.G. Chernook, M.G. Divashuk

Marker-assisted selection and yield component assessment of spring wheat plants derived from crosses between spring and winter wheat cultivars A.I. Stasyuk, I.N. Leonova, E.A. Salina

Transferability of barley EST markers used for analysis T. aestivum - H. marinum subsp. gussoneanum introgression lines N.V. Trubacheeva, E.D. Badaeva, T.S. Osadchaya, L.A. Pershina

Study of introgression lines of common wheat obtained with the participation of the synthetic forms T. miguschovae and Avrodes by allelic variants of the $W x$ genes E.R. Davoyan, R.O. Davoyan, Yu.S. Zubanova, D.S. Mikov, D.M. Boldakov, A.G. Chernook, M.G. Divashuk.

Non-brittle rachis 1-A (Btr1-A) gene in di- and hexaploid wheat species V. Vavilova, I. Konopatskaia, N.P. Goncharov

Development of androgenic polyembrioids in the anther culture of alloplasmic introgression lines of (H. vulgare) - T. aestivum and (H. marinum ssp. gussoneanum) - T. aestivum L.A. Pershina, N.V. Trubacheeva, T.S. Osadchaya, I.A. Belan, L.P. Rosseeva .

Challenges and opportunities of breeding and genetic improvement of durum wheat in Russia P.N. Mal'chikov, M.A. Rozova, A.I. Ziborov, M.G. Myasnikova, T.V. Chakheeva. 
Study of 8x and 6x triticale with dominant Vrn genes P.I. Stepochkin

Breeding of potato resistant to late blight using genetic resources and DNA markers J. Śliwka, M. Brylińska, E. Stefańczyk, J. Plich, P. Smyda-Dajmund, S. Sobkowiak .

Search for genomic regions associated with potato starch granules morphology of Solanum tuberosum L. T.V. Erst, I.V. Rozanova, V.K. Khlestkin, E.K. Khlestkina .

Comprehensive evaluation of the Siberian gene pool of common bean (Phaseolus vulgaris L.) in the conditions of Western Siberia O.E. Yakubenko, O.V. Parkina.

Peculiarities of heterosis manifested by yield and fruit quality traits in pepper $\mathrm{F}_{1}$ hybrids developed using classical and MAS methods O.G. Babak, T.V. Nikitinskaya, N.A. Nevestenko, I.G. Puhacheva, M.M. Dobrodkin, L.V. Khotyleva, A.V. Kilchevsky.

Key directions of breeding and seed production of alfalfa in European Russia V.I. Cherniavskih, E.V. Dumacheva, Z.A. Borodaeva, D.V. Dumachev

\section{GWAS for Dissecting Traits and Pinpoint Candidate Genes}

High-throughput technologies for sunflower oil improvement

A.I. Chernova, E.U. Martynova.

High-throughput genotyping for association mapping of agronomically important traits in rapeseed: a brief review of the current status R.F. Gubaev, S.V. Boldyrev, D.V. Goryunov, S.V. Goryunova . . . . . . . . . . . . . . . . . . . . .

Genomic analysis in soybean breeding V.V. Barzanova, A.A. Novikova

\section{Plant Cytogenetics in the Genomic and Postgenomic Era}

Molecular cytological analysis of alien introgressions in common wheat lines with T. kiharae genetic material O.A. Orlovskaya, N.I. Dubovets, L.A. Solovey, E.B. Bondarevich, I.N. Leonova .

Expression profile of two CENH3 genes in different tissues of the Secale cereale S.S. Gatzkaya, E.V. Evtushenko, A.V. Vershinin

Chromosome constitution and activity of the centromeric histone $\mathrm{H} 3$ (CENH3) variants in octoploid triticale lines E.V. Evtushenko, Yu.A. Lipikhina, P.I. Stepochkin, A.V. Vershinin.

Karyotyping of triticale-wheat hybrid lines with the sham ramification of spike I.G. Adonina, S.P. Mehdiyeva, M.V. Prokopjeva, N.Kh. Aminov, E.A. Salina .

Identification of univalent chromosomes in monosomic lines of the Gossypium hirsutum L. cotton type with the help of cytogenetic markers M.F. Sanamyan, Sh.U. Bobokhujayev

Author index 


\section{PlantGen2019}

The Fifth International Scientific Conference "Plant Genetics, Genomics, Bioinformatics, and Biotechnology" (PlantGen2019) held in Novosibirsk on 24-29 June 2019 put together 353 scientists from 19 countries. The participants considered the most recent updates about the structural and functional organization of plant genomes and how these data are and can further be used in plant breeding practice.

In 2010, when Novosibirsk was hosting the first PlantGen conference, most papers were about wheat. That was because the Institute of Cytology and Genetics of the Siberian Branch of the Russian Academy of Sciences had obtained important wheat-related data and become a member of the International Wheat Genome Sequencing Consortium (IWGSC), wheat being an extremely important crop to humans.

With a decade gone since that event, the Conference's scope has become broader. Now it covered quite a diverse range of crops, their use in plant breeding and functional nutrition, the assessment of plant resistance to biotic and abiotic stresses, the development of plant biotechnology in the postgenomic era, plant systems biology, and digital technologies. Because separate methods like effective approaches to supporting plant selection deserved additional emphasis, special sessions related to plant selection in the XXI century, plant cytogenetics in the genomic and the postgenomic era, and genome-wide association studies were arranged.

The world's and Russia's renowned experts in plant genetics and breeding took the floor as plenary speakers and keynote speakers.

Plant Genetic Resources for Breeding and Producing Functional Nutraceutical Food was the session related to the success and issues of the storage and use of plant collections in gene banks as study material. The main focus was placed on some most important trends in using plant collections for addressing genetic and selection problems, and developing functional foods.

Plant Resistance to Pathogens and Other Biotic Stresses was the session largely related to the search for new genes for resistance to biotic factors.
Genetic and Epigenetic Mechanisms of Plant Resistance to Abiotic Stresses was the session related to the mechanisms of acquiring resistance to drought, frost, lower temperatures, soil salinization and toxic metals. Special focus was given to the search for genetic and epigenetic factors controlling plant resistance to abiotic stresses.

Because several approaches can be seen as being special in modern plant biotechnology seeking to develop new plants with improved properties, the session Plant Biotechnology in the Postgenomic Era was related to the approaches associated with methods for genetic, chromosome and cell engineering, and genome editing. Special focus was given to studies seeking to arrive at a rapid development of plants with desired genotypes using combined biotechnological approaches.

Plant Systems Biology and Digital Technologies was the session related to genomic and postgenomic approaches to analysis of the structural and functional organization of the genome and to the integration of knowledge into plant systems biology. During this session, the development and use of genetic models for systems biology were discussed. Special focus was given to the methods for bioinformatics analysis and the assembly of de novo sequenced plant genomes. In recent years, the range of whole-genome sequenced plants has expanded substantially. The question arises: how can these data be successfully integrated into the settings of systems biology so as to reach an understanding of patterns in the structural and functional organization of plant genomes executing themselves during plant organisms' development and interactions with the environment? To address the question, systems biology methods were considered for use in plant organisms with different genome sizes and ploidy.

Plant Breeding in the $21^{\text {st }}$ Century, a parallel session, was related to important problems in plant breeding and the ways to address them with reliance on marker-oriented selection, genome-based selection, and modern approaches to genome editing, for in recent years genetic technologies have been actively making their way to breeding processes. 
GWAS for Dissecting Traits and Pinpoint Candidate Genes was the session in which the importance of this approach to studying the genetic bases of commercially important traits was demonstrated. Genes that control commercially important traits can be identified using many ways. The session attendees were shown the most effective methods for plant genome-wide association mapping, and approaches to increasing the significance of the results being obtained.

In recent years, the uses of cytogenetic methods for studying plant genomes have changed substantially due to the whole-genome sequencing of a broad range of plants. The parallel session Plant Cytogenetics in the Genomic and Postgenomic Era considered important trends in plant cytogenetics, factoring in the modern technologies of studying genetic material and new approaches to analysis of digital images.

As an important part of any conference is made up by socializing instances, which at times results in joint projects, so was with PlantGen2019, some of whose participants have come to important agreements.

A selection of the PlantGen2019's best papers awaits ahead.

Alexey Kochetov, Conference Chair Elena Salina, Conference Co-Chair 


\section{Plant Genetic Resources for Breeding and Producing Functional Nutraceutical Food}




\title{
Introduction in Siberia (Russia) of new vegetable species with a high biochemical value
}

\author{
Y.V. Fotev ${ }^{1,2 *}$, A.I. Syso ${ }^{3}$, O.M. Shevchuk ${ }^{4}$ \\ ${ }^{1}$ Central Siberian Botanical Garden, SB RAS, Novosibirsk, Russia \\ ${ }^{2}$ Novosibirsk State Agrarian University, Novosibirsk, Russia \\ ${ }^{3}$ Institute of Soil Science and Agrochemistry, SB RAS, Novosibirsk, Russia \\ ${ }^{4}$ Nikita Botanical Garden RAS, Republic of Crimea, Russia
}

DOI 10.18699/ICG-PlantGen2019-01

(c) Autors, 2019

* e-mail: fotev_2009@mail.ru
Abstract: Considering the narrow range of the cultivated vegetable species in Russia and the worldwide trend for impoverishment of the biochemical composition of cultivated vegetables, simultaneously with globalization of the vegetable crop production, it is necessary to search for plant species and forms characterized by a high content of functional food ingredients (FFI) in their composition,. Based on the methodological approaches to the introduction of initial material and cultivars of warm-requiring vegetable plants (Fotev, 2018), cultivars, and selective forms of new for Russia vegetables characterized by a high content of $\mathrm{FFI}$, a short growing season and a neutral reaction to the day length have been developed: asparagus vigna, kiwano, bitter melon, wax gourd, Chinese broccoli, and fish mint. The selected species, cultivars and forms of vegetables can be used as functional foods (FF).

Key words: Introduction; asparagus vigna; kiwano; bitter melon; wax gourd; Chinese broccoli; fish mint; biochemical value.

\section{Introduction}

Archaeological data show that the food of the ancient people (the Acheulian culture, about $780 \mathrm{ka} \mathrm{BP}$ ) was characterized by a significant variety of plant food sources (Melamed, 2016), whereas the modern man receives about $75 \%$ of the food resources using only 12 plant species (FAO.ftp://ftp.fao. org/docrep/fao/007/y5609e/y5609e00.pdf). Among the fresh vegetables consumed by Russians, only 6 main crops - white cabbage, tomato, cucumber, carrots, table beet and onion - account for over $86 \%$ vegetables eaten (Ryzhkova, Silko, 2015). Besides, in the second half of the 20th century, a significant decline in the nutritional quality of agricultural products was reported. Within 50 years (1950-1999) in the USA, the Ca content in the group of 16 vegetable crops decreased by $23 \%$, $\mathrm{Fe}-$ by $27 \%$ (Davis et al., 2004). The reported rate of decrease in micronutrient concentration ranged from $0.2 \%$ to $0.3 \%$ per year. The changes that have occurred are global. In the soils and plants of the agrarian regions in the south of Siberia, Russia, the content of essential trace elements $(\mathrm{Co}, \mathrm{Cu}, \mathrm{Mo}$ and $\mathrm{Zn}$ ) has decreased, as compared with the biogeochemical norm (Syso et al., 2016). In addition, significant intraspecific variability in the content of vitamins and mineral elements has been reported. The climatic conditions of the south of western Siberia, characterized by the considerable input of solar radiation of about $100 \mathrm{kcal} / \mathrm{cm}^{2}$ per year and a significant number of hours of sunshine per year (2029), make cultivation of a wide range of species and varieties of warm-requiring vegetable plants possible. Recently, methodological approaches to the introduction of warm-requiring vegetable plants in Siberia (Fotev, 2018) and a concept of the Russian national system of functional foods have been proposed (Fotev et al., 2018). Given the narrow range of cultivated vegetable plant species in Russia and the worldwide trend of impoverishment of the biochemical composition of vegetables, simultaneously with globalization of the crop production, it is necessary to search for those species and forms of plants that are high in FFI in their composition.

\section{Materials and methods}

Research was conducted from 1996 to 2017 on a large collection of species and forms of warm-requiring vegetable plants in outdoor and indoor conditions in the Central Siberian Botanical Garden of the Siberian Branch of the Russian Academy of Sciences [CSBG SB RAS] (Novosibirsk, $54^{\circ} \mathrm{N} 83^{\circ} \mathrm{E}$ ). We used the collection of vegetable plants (UNU "Collection of living plants in indoor and outdoor conditions" No. USU 440534), including 134 species, 4 subspecies and 14 varieties belonging to 44 genera and 13 families, represented in the Genbank of seeds containing 10,754 samples. The main new for Russia species studied in the CSBG SB RAS were asparagus vigna (Vigna unguiculata (L.) Walp.), bitter melon (Momordica charantia L.), kiwano (Cucumis metuliferus E. Mey. ex Naudin), wax gourd (Benincasa hispida (Thunb.) Cogn.), fish mint (Houttuynia cordata Thunb.) and Chinese broccoli or kai-lan (Brassica oleracea L. var. alboglabra (L.H. Bailey) Musil.). The content of macroelements (K, Na, $\mathrm{Ca}, \mathrm{Mg}, \mathrm{Fe}$ ) in the seeds of $V$. unguiculata grown in CSBG SB RAS and Nikita Botanical Garden of the Russian Academy of Sciences (NBG RAS), the Republic of Crimea was determined by flame atomic absorption spectrometry (FAAS) on an Analyst400 spectrometer (PerkinElmer). Recommended methods of biochemical studies of plants were used (Ermakov, 1987).

\section{Results and discussion}

To select plant species to be introduced in Siberia and to make predictive evaluation of the results of working with them, a list of parameters was proposed: the biochemical composition, the 
Table 1

New for Russia vegetables, their main $\mathrm{FFI}^{*}$, the physiological effect on the human body (or animals) and the first cultivars created in Siberia

\begin{tabular}{|c|c|c|c|}
\hline Species & Main FFl's* & Physiological effects & $\begin{array}{l}\text { First in Russia } \\
\text { cultivars }\end{array}$ \\
\hline $\begin{array}{l}\text { Asparagus vigna } \\
\text { Vigna unguiculata (L.) Walp., } \\
\text { Fabaceae }\end{array}$ & $\begin{array}{l}\text { Ascorbic acid, carotenoids, trace elements } \\
\text { (Ca, Mg, Fe, Mo) (Fotev et al., 2013), } \\
\text { proteins, antioxidants, polyphenols, } \\
\text { chlorogenic acid, caffeic acid (Zia-Ul-Haq } \\
\text { et al., 2013) }\end{array}$ & $\begin{array}{l}\text { Antioxidant, antiradical effects (Zia-Ul-Haq } \\
\text { et al., 2013), accelerates the elimination of } \\
\text { harmful and radioactive substances (137Cs) } \\
\text { by } 29 \% \text { (Evtukhova et al., 2009) }\end{array}$ & $\begin{array}{l}\text { Sibirskiy razmer, } \\
\text { Yunnanskaya }\end{array}$ \\
\hline $\begin{array}{l}\text { Bitter melon } \\
\text { Momordica charantia L., } \\
\text { Cucurbitaceae }\end{array}$ & $\begin{array}{l}\text { Carotenoids, ascorbic acid, catechins, } \\
\text { pectins, trace elements (Fe, Zn, Mn, Cu, } \\
\text { Ni, Co) (Fotev et al., 2013), glycoalkaloids } \\
\text { (momorcharins) (Wang et al., 2017). }\end{array}$ & $\begin{array}{l}\text { Antioxidant, antiviral effect, causes apoptosis } \\
\text { of cancer cells (Dandawate et al., 2016), hypo- } \\
\text { glycemic effect in diabetes (Jia et al., 2017). }\end{array}$ & Gosha \\
\hline $\begin{array}{l}\text { Kiwano } \\
\text { Cucumis metuliferus E. Mey, } \\
\text { Cucurbitaceae }\end{array}$ & $\begin{array}{l}\text { Trace elements (Mg, Zn, Cu) (Fotev et al., } \\
\text { 2013), flavonoids, in a small amount - } \\
\text { cucurbitacins (Aliero, Gumi, 2012). }\end{array}$ & $\begin{array}{l}\text { Anti-inflammatory effect, increases the } \\
\text { activity of enzymes - alkaline phosphatase, } \\
\text { aspartate amino-transferase and alanine- } \\
\text { aminotransferase, platelet cyclooxygenase } \\
\text { inhibition (Wannang et al., 2007). }\end{array}$ & Zeleniy drakon \\
\hline $\begin{array}{l}\text { Wax gourd Benincasa hispida } \\
\text { (Thunb.) Cogn., Cucurbita- } \\
\text { ceae }\end{array}$ & $\begin{array}{l}\text { Trace elements (Mn, } \mathrm{Fe}, \mathrm{Co}, \mathrm{Cu} \text { ) (Fotev et } \\
\text { al., 2013), triterpenes - alnusenol and } \\
\text { multiflorenol, sterols and glycosides (Zaini } \\
\text { et al., 2011). }\end{array}$ & $\begin{array}{l}\text { Antioxidant, antiallergic action (Park et al., } \\
\text { 2009), anti-ulcer effect (Rachchh, Jain, 2008), } \\
\text { used in the treatment of helminth infections } \\
\text { (Al-Snafi, 2013). }\end{array}$ & Akulina \\
\hline $\begin{array}{l}\text { Fish mint } \\
\text { Houttuynia cordata Thunb., } \\
\text { Saururaceae }\end{array}$ & $\begin{array}{l}\text { Ascorbic acid, trace elements (Co, Cu, Fe, } \\
\text { Mn, Zn) (Fotev et al., 2017), flavonoids and } \\
\text { other polyphenolic compounds, pyridine } \\
\text { alkaloids, aporphine, organic and fatty } \\
\text { acids, sterols (Fu et al., 2013). }\end{array}$ & $\begin{array}{l}\text { It is used in the treatment of a significant } \\
\text { number of human diseases, such as cardio- } \\
\text { vascular diseases, cancer, anemia, diabetes } \\
\text { mellitus, dysentery, etc. (Rathi et al., 2013). }\end{array}$ & \\
\hline $\begin{array}{l}\text { Chinese broccoli or kai-lan } \\
\text { Brassica oleracea L. var. al- } \\
\text { boglabra (L.H.Bailey) Musil., } \\
\text { Brassicaceae }\end{array}$ & $\begin{array}{l}\text { Ascorbic acid, trace elements (K, Ca, } \\
\text { Mg,Cu) (Fotev et al., 2018), antioxidants, } \\
\text { polyphenolic compounds, glucosinolates } \\
\text { (Wang et al., 2017). }\end{array}$ & $\begin{array}{l}\text { Antioxidant, anti-inflammatory, antimicrobial, } \\
\text { anti-carcinogenic effects (Cartea et al., 2010) }\end{array}$ & \\
\hline
\end{tabular}

* FFI - functional food ingredients

degree of genetic diversity of species, duration of the vegetation period, warmth demand, productivity, seed production efficiency, fruit quality, a need for growing seedlings, a need for glasshouse production, resistance to diseases and pests, simplicity and manufacturability of processing the products, conformity to traditional taste preferences of population of the Russian Federation (Fotev et al., 2009). New for Russia vegetables, their main FFI, their physiological effect on the human body (or animals) and first-breeding cultivars created in Siberia are shown in the table below.

The fruits of the first created in Russia cultivar of asparagus vigna Yunnanskaya contain $83.9 \mathrm{mg} \%$ of ascorbic acid. The fruits of selected bitter melon forms have a high content of carotenoids (in the arillus of the fruits 68.9-177, in leaves $350.8-545.1 \mathrm{mg} \%$ (FW) and of ascorbic acid (72.5$127.5 \mathrm{mg} \%)$. The high content of elements of the so-called "hematopoietic complex" (Fe, Mn, Cu, Co): $\mathrm{Fe} 45.2-141.6$, Mn 9.8-18.7, Cu 2.0-5.4 and Co 0.03-0.05 $\mu \mathrm{g} / \mathrm{g}$ was found in the fruits of cultivars and samples of bitter melon, kiwano and wax gourd (the respective content of these elements in the fruits of tomato, cultivar Delta 264 is, accordingly, 38.0; 7.8; 1.7 and $0.03 \mu \mathrm{g} / \mathrm{g}$ ). Increased concentrations of $\mathrm{Zn}$ in the fruits of bitter melon, asparagus vigna and kiwano $(32.9-57.6 \mu \mathrm{g} / \mathrm{g})$ were recorded, with the comparative content in tomato fruits being $18.5 \mu \mathrm{g} / \mathrm{g}$. The fruits of the selected forms of asparagus vigna accumulate an increased amount of Mo $(5,47 \mu \mathrm{g} / \mathrm{g})$. Kiwano and asparagus vigna fruits have a high $\mathrm{Mg}$ content. The leaves of the sample of Houttuynia cordata accumulated $\mathrm{Mn}, \mathrm{Fe}$, and $\mathrm{Cu}$, and the roots $-\mathrm{Fe}, \mathrm{Co}, \mathrm{Cu}$, and $\mathrm{Zn}$. The stem part of B. oleracea var. alboglabra (cv. "Siji Xianggu jie lan") is a fairly good source of vitamin $\mathrm{C}$, accumulating $32.0 \ldots$ $46.2 \mathrm{mg} \%$, also distinguished by increased concentration of $\mathrm{K}$, $\mathrm{Ca}, \mathrm{Mg}$ and $\mathrm{Cu}$. To isolate species and forms that are stable on the basis of accumulation of FFI, evaluation of the biochemical composition of plants grown under environmentally different conditions is necessary. The smallest variability $\left(\mathrm{C}_{\mathrm{v}}\right)$ of the content of 5 macroelements in the seeds $(\mathrm{K}, \mathrm{Na}, \mathrm{Ca}, \mathrm{Mg}, \mathrm{Fe})$ of 6 samples of asparagus vigna in the CSBG SB RAS and NBG RAS was observed in the cultivar Sibirskiy razmer - $14.6 \%$. In the future, it is promising to develop agrotechnologically advanced cultivars with a high FFI content. On the basis of biochemically valuable cultivars of asparagus vigna (Sibirskiy razmer and Yunnanskaya cultivars), symbiotic systems with strains of Bradyrhizobium sp., characterized by a high level of symbiotic nitrogen fixation, were created (Fotev et al., 2016). It is also important to study the presence and the amount 
of anti-nutrients (phytates, lectins, oxalates, tannins, some biogenic amines, etc.) in FFI source plants.

\section{Conclusions}

To select promising species and forms of vegetable plants in biochemical and nutritional terms, it is recommended to use a set of selection criteria describing the characteristics and properties which include, in addition to the high content of FFI, the possibility of implementing biochemical and productive qualities of the vegetables under conditions that differ from the natural habitat of the species.

The created cultivars and selected forms of new for Russia vegetables, like asparagus vigna, bitter melon, kiwano and wax gourd, have a high content of FFI, high productivity, a short growing season and a neutral response to the day length. Fish mint and Chinese broccoli cultivars, being also FF (FF - functional food), can be successfully grown in Siberia. Individual samples of asparagus cowpea, for example, cultivar Sibirskiy razmer are characterized by high stability of accumulation of macroelements in the phytomass.

The interest of the Russian consumers in healthy foods should naturally lead to accelerated creation of new varieties both by traditional breeding methods and new technologies based on genome editing.

\section{References}

Davis D.R., Epp M.D., Riordan H.D. Changes in USDA food composition data for 43 garden crops, 1950 to 1999. J. Amer. Coll. Nutr. 2004;23(6):669-682.

Fotev Y.V. Towards a methodology of introduction of warm-requiring vegetable plants in Siberia. Vestnik NGAU (Novosibirsk State Agrarian University). 2018;4:104-118. doi.org/10.31677/2072-6724-201849-4-104-118. https://vestngau.elpub.ru/jour/article/view/1094/578

Fotev Yu.V., Pivovarov V.F., Artemyeva A.M., Kulikov I.M., Goncharova Yu.K., Syso A.I., Goncharov N.P. Concept of producing of the Russian national system of functional food. Vavilov Journal of Genetics and Breeding. 2018;22(7):776-783. DOI 10.18699/ VJ18.421. http://www.bionet.nsc.ru/vogis/download/06 Fotev.pdf

Melamed Y., Kisleva M.E., Geffenb E., Lev-Yadunc S., Goren-Inbard N. The plant component of an Acheulian diet at Gesher Benot Ya'aqov, Israel. PNAS. 2016;113(51):14674-14679. DOI 10.1073/ pnas. 1607872113 .

Ryzhkova S.M., Silko E.A. The market for vegetable products in Russia. Bulletin OrelGAU. 2015;4(55):3-7. http://dx.doi.org/10.15217/ 48484.

Syso A.I., Miadelets M.A., Siromlya T.I., Petukhov V.L., Sokolov V.A. The current state and trends in the ecological-biogeochemical situation in the south of Siberia. In: Current trends in the development of biogeochemistry. M.: GEOKHI RAS, 2016:500-510.

Conflict of interest. The authors declare no conflict of interest. 


\title{
Anthocyanins in wheat grain: genetic control, health benefit and bread-making quality
}

\author{
T.G. Amstislavskaya ${ }^{4}$ \\ 'N.I. Vavilov All-Russian Research Institute of Plant Genetic Resources (VIR), St. Petersburg, Russia \\ 2 Institute of Cytology and Genetics, SB RAS, Novosibirsk, Russia \\ ${ }^{3}$ Novosibirsk State University, Novosibirsk, Russia \\ ${ }^{4}$ Scientific Research Institute of Physiology and Basic Medicine, Novosibirsk, Russia
}

E.K. Khlestkina ${ }^{1,2 *}$, O.Y. Shoeva ${ }^{2}$, E.I. Gordeeva², Y.S. Otmakhova ${ }^{3}$, N.I. Usenko³, M.A. Tikhonova ${ }^{2,4}$, M.V. Tenditnik ${ }^{4}$,

DOI 10.18699/ICG-PlantGen2019-02

(c) Autors, 2019

*e-mail: khlest@bionet.nsc.ru

\begin{abstract}
Anthocyanins are plant secondary metabolites having multiple biological functions. In this paper, we summarize data on anthocyanins in wheat grain, including molecular-genetic mechanisms underlying the synthesis of anthocyanins in the grain pericarp, the effect of anthocyanins on bread-making quality and health benefit. Anthocyanin synthesis in wheat pericarp tissue is controlled by two complementary genes, Pp3/TaMyc1 and Pp-1, mapped to chromosome 2A and homologous group 7 chromosomes, respectively. These genes encode transcription factors with the bHLH and R2R3-MYB-regulatory domains, respectively, which activate expression of the anthocyanin biosynthesis structural genes, encoding enzymes of the pathway, in a tissue-specific manner. A comprehensive study of the effect of wheat genes associated with the level of anthocyanins in grain on the preventive effect of grain products in neurodegenerative disorders was carried out. The use of near-isogenic lines (NILs) having almost similar genomes with the exception of a small part of chromosome $2 \mathrm{~A}$, which contains $P p 3$, has allowed relating the observed differences precisely with anthocyanin biosynthesis. As a result, it was revealed that the $P p 3$ gene is related to the production of dietary products preventing neurodegenerative changes caused by Alzheimer's and Parkinson's diseases and natural aging. The beneficial effect of a grain diet with a high content of anthocyanins on the working memory and molecular processes of neuroregeneration was shown on mice. The use of the same wheat NILs for testing bread-making quality showed the resistance of anthocyanins to the backing process and a better quality and organoleptic properties of bakery products made from anthocyanin-rich grains in comparison with products obtained from control grains. An optimal scheme for the accelerated creation of wheat breeding lines with a high content of anthocyanins in the grain pericarp is considered.

Key words: structural genes; regulatory genes; purple pericarp; blue aleurone; biological activity; breeding; flour confectionery products; whole-grained bread.
\end{abstract}

\section{Introduction}

Anthocyanins are plant secondary metabolites, which are synthesized in different parts of plants, including cereal plants endosperm, aleurone, seed coat and pericarp (Ficco et al., 2014; Khlestkina et al., 2015). They are responsible for the diversity of colors observed in the nature. Besides the well-recognized role in the attraction of pollinators and seed dispersals, they participate in plant protection against adverse environmental factors, as well as in signaling (Landi et al., 2015). Anthocyanins are widespread in angiosperms and occur in some gymnosperms, while they are absent from other taxa of plants that nevertheless contain colorless intermediates preceding anthocyanins. These pigments are the last to have appeared during land plant evolution (Rausher, 2006).

Both human and animal studies considering the main anthocyanins of berries demonstrated that these compounds have wide biological activities important for human health maintenance (Tsuda, 2012). Unlike berries, bread is a daily consumption food and enriching bakery products with such high nutritional value compounds as anthocyanins is reasonable. In respect to that, there is interest in data on different aspects of wheat grain anthocyanins, including genetic control of their biosynthesis, health benefit and bread-making quality.

\section{Regulation of anthocyanin biosynthesis in wheat pericarp}

Anthocyanins belong to flavonoid compounds with a common 15-carbon skeleton C6-C3-C6 consisting of two phenyl rings (A and $B$ ) and a heterocyclic ring $(\mathrm{C})$. Different modifications of these rings determine the whole diversity of flavonoids that count more than 500 individual compounds (Andersen, Jordheim, 2006). Anthocyanins differ from the other flavonoids by a positive charge and a double bond present in C-ring. They are derived in course of the general phenylpropanoid and anthocyanin branch of the flavonoid biosynthesis pathways (Winkel-Shirley, 2001). At the first stage of synthesis, phenylalanine is converted, in a stepwise manner, by phenylalanine ammonia-lyase (PAL), cinnamate 4-hydroxylase $(\mathrm{C} 4 \mathrm{H})$ and 4-coumarate CoA ligase (4CL) into 4-coumaroyl-CoA. Then chalcone synthase (CHS), chalcone isomerase (CHI), flavanone hydroxylase $(\mathrm{F} 3 \mathrm{H})$, flavonoid 3'-hydroxylase (F3'H), flavonoid 3', 5'-hydroxylase (F3'5'H), dihydroflavonol 4-re- 
ductase (DFR) and anthocyanidin synthase (ANS) transform 4-coumaroyl-CoA to anthocyanidins, which are finally modified by diverse transferases to individual anthocyanins. Tissue specific accumulation of anthocyanins is controlled by regulatory genes encoding transcription factors with the bHLH, R2R3-MYB regulatory domains and WD40 repeats, which are combined into the MYB-bHLH-WD40 (MBW) complex and activate transcription of the structural genes encoding enzymes of the biosynthesis.

In wheat grain, anthocyanins can be accumulated in pericarp and aleurone tissues. The most abundant anthocyanin in purple wheat is cyanidin 3-glucoside, while in blue one, it is delphinidin 3-glucoside (Abdel-Aal et al., 2006). The key structural genes were cloned in wheat unlike the genes for enzymes of final modifications that are represented by wide gene families and their identification is therefore hampered (Shoeva, Khlestkina, 2015). Two complementary genes Pp3/ $T a M y c l$ and $P p-1$ control anthocyanin synthesis in the wheat pericarp. $P p 3$ (mapped to chromosome 2A) encodes a bHLH transcription factor (Shoeva et al., 2014). The $P p-1$ genes (7A, 7B, 7D) encode R2R3-MYB-type transcription factors (Jiang et al., 2018). The $B a$ genes responsible for blue aleurone were transferred into cultivated wheat varieties from distant relatives such as Thinopyrum ponticum, Th. bessarabicum, T. boeoticum and T. monococcum (Zeven, 1991). The wheat grass ThMYC4E gene encoding the regulatory factor with the bHLH domain was identified as a candidate gene for $\mathrm{Bal}(\mathrm{Li}$ et al., 2017).

\section{Health benefit}

Anthocyanins consumed with food may have positive effects on human health. Due to suppression of genes involved in fatty acid synthesis and inhibition of pancreatic amylase and intestinal $\alpha$-glucosidase, anthocyanins may have a hypoglycemic effect (Tsuda et al., 2003; Tadera et al., 2006; Shobana et al., 2009). Anthocyanins and other flavonoids may be useful for the prevention of a variety of pathologies, including cardiovascular diseases (Howard, Kritchevsky, 1997; Lila, 2004). They demonstrate wide biological activities ranging from antioxidation, anti-inflammatory, anti-cancer, anti-ageing effects to lipid-profile regulation, obesity and diabetes prevention, hyperglycemia and retinal protections (Tsuda, 2012).

Some comparative studies were carried out to reveal effects of anthocyanin-rich wheat grain as a feed additive on growth characteristics of economically important animals. Inclusion of purple grains of a breeding line in the feed compound for high-yielding laying hens was demonstrated to improve lay-up parameters such as line egg weight, laying per hen and reduce feed compound consumption per unit of production. The yolk color of eggs laid by hens was not affected by the color of the grains eaten (Ruckschloss et al., 2010).

Feeding tests performed on fingerling carp showed the positive impact of purple grain of the wheat cultivar 'Konini' on the mass and length of carps compared with the control (Mareš et al., 2015).

The influence of wheat anthocyanins on antioxidant activity and liver functions was estimated in rats, chickens and fish (Mrkvicová et al., 2017). Significantly higher values of anti- oxidant status were determined in the liver of rats fed purple grains. The chickens fed 'Konini' wheat showed significantly different values obtained by distinct methods for antioxidant status measurement. No significant differences were detected in the hepatopancreases of fish. Animals fed 'Konini' wheat showed a tendency to lower liver enzyme activities in general, but a significant difference was found only in gamma-glutamyl transferase activity in the chicken's blood. The results suggested that feeding anthocyanin-rich grain can improve antioxidant activity and functions of liver tissue.

A comprehensive study of the effect of wheat genes associated with the level of anthocyanins in grain on the preventive effect of grain products in neurodegenerative disorders was carried out. The use of NILs having almost similar genomes with the exception of a small part of chromosome $2 \mathrm{~A}$, which contains the $P p 3$ gene, has allowed relating the observed differences precisely with anthocyanin biosynthesis (Shoeva et al., 2014; Gordeeva et al., 2015). Using mice as a model for neurodegenerative changes caused by Alzheimer's and Parkinson's diseases and natural aging, we revealed a beneficial effect of a grain diet with a high content of anthocyanins on the working memory and molecular processes of neuroregeneration (Tenditnik et al., 2017).

\section{Bread-making quality}

Anthocyanin-rich bakery products are, first of all, the products obtained from bran or with the addition of bran. The grains of the above-mentioned wheat NILs differing in anthocyanin content in the pericarp were used for evaluation of anthocyanin content in the end-use product, as well as in mixtures of flour and bran used for baking and separately in the bran (Khlestkina et al., 2017). As a result, significant differences were detected in samples obtained from anthocyanin-rich grains, compared with the control including the products that had passed a full processing cycle. The extraction of anthocyanins in the conditions most similar to those in the stomach has allowed assessing the amount of assimilable anthocyanins. The estimations have shown that one can get up to $1.03 \mathrm{mg}$ of anthocyanins with $100 \mathrm{~g}$ of whole-grained bread produced from anthocyanin-rich wheat (Khlestkina et al., 2017). It was shown that bread-making quality and the organoleptic properties of bakery products made from anthocyanin-rich grains did not concede, or in some cases were higher than the corresponding properties of products obtained from control NIL grains. In addition, it was found that the presence of anthocyanin increases the shelf life of bakery products and their resistance to molding in provocative conditions (Khlestkina et al., 2017).

Later, flour and wheat bran with anthocyanins and the control group were used for the production of flour confectionery products (Usenko et al., 2018). The share of anthocyanins in the products obtained from anthocyanin-rich wheat was 2.52.6 times higher than that in similar products obtained from control grains. The differences revealed between the grains of anthocyanin-rich and control wheat in the end-use products testify to the resistance of anthocyanins to technological processing. It has been estimated that when eating 100 grams of biscuit made from flour with the addition of anthocyanin-rich 
bran, the consumption of these beneficial substances will be up to $0.83 \mathrm{mg}$. Thus, a high content of anthocyanins in wheat bran allows producing enriched confectionery products with a high nutritional value (Usenko et al., 2018).

\section{Marker-assisted breeding}

Using DNA-markers for the $P p$ genes (Shoeva et al., 2014; Zong et al., 2017), we developed purple-grained breeding lines by crossing donor line producing anthocyanins in grain with elite wheat cultivars. The development of the breeding lines took 2 years (6 generations, including that in greenhouses) and required application of the DNA-markers twice. The markers linked to $P p-1$ and $P p 3$ were used first to select homozygouse plants carrying dominant alleles of these genes in $\mathrm{F}_{2}$ generation. After three backcrosses of the selected plats to the parental cultivars, the resulted final purple-grained breeding lines homozygous to the markers linked to $P p-1$ and $P p 3$ were selected among $\mathrm{BC}_{3} \mathrm{~F}_{2-3}$ progenies. The lines obtained according to this scheme are already used in field trials. Earlier, the marker-assisted backcrossing approach was used to develop a set of NILs carrying different combinations of the $P p$ alleles. The volume of plant material was reduced two-fold and the planting area was decreased $\sim 70$-fold due to the application of DNA-markers (Gordeeva et al., 2015).

\section{Conclusions}

The results of evaluation of end-use quality products combined with the data about the beneficial health effects of anthocyanins form wheat grain suggest that wheat bakery and confectionery products made from anthocyanin-rich grains can be included to the list for dietary food. In order to accelerate the breeding of wheat for dietary purposes, we have used data on molecular-genetic mechanisms underlying anthocyanin synthesis in the wheat pericarp and developed an optimal scheme for the accelerated creation of breeding lines needed for further selection and registration of anthocyaninrich wheat varieties.

\section{References}

Abdel-Aal E.S.M., Young J.C., Rabalski I. Anthocyanin composition in black, blue, pink, purple, and red cereal grains. J. Agri. Food Chem. 2006;54(13):4696-4704. DOI 10.1021/jf0606609.

Andersen O.M., Jordheim M. The anthocyanins. In: Andersen O.M., Markham K.R. (Eds). Flavonoids: Chemistry, Biochemistry and Applications. 2006. Boca Raton, FL: CRC Press. P. 452-471. DOI 10.1201/9781420039443.ch10.

Ficco D.B., De Simone V., Colecchia S.A., Pecorella I., Platani C., Nigro F., De Vita P. Genetic variability in anthocyanin composition and nutritional properties of blue, purple, and red bread (Triticum aestivum L.) and durum (Triticum turgidum L. ssp. turgidum convar. durum) wheats. J. Agri. Food Chem. 2014;62(34):8686-8695. DOI $10.1021 / \mathrm{jf5} 503683$.

Gordeeva E.I., Shoeva O.Y., Khlestkina E.K. Marker-assisted development of bread wheat near-isogenic lines carrying various combinations of purple pericarp (Pp) alleles. Euphytica. 2015;203(2): 469-476. DOI 10.1007/s10681-014-1317-8.

Howard B.V., Kritchevsky D. Phytochemicals and cardiovascular disease a statement for healthcare professionals from the American heart association. Circulation. 1997;95(11):2591-2593. DOI 10.1161/01.CIR.95.11.2591.
Jiang W., Liu T., Nan W., Jeewani D.C., Niu Y., Li C., Wang Y., Shi X., Wang C., Wang J., Li Y., Gao X., Wang Z. Two transcription factors TaPpm1 and TaPpb1 co-regulate anthocyanin biosynthesis in purple pericarps of wheat. J Exp Botany. 2018;69(10):2555-2567. DOI 10.1093/jxb/ery 101.

Khlestkina E.K., Shoeva O.Y., Gordeeva E.I. Flavonoid biosynthesis genes in wheat. Russ J Genet Appl Res. 2015;5(3):268-278. DOI 10.1134/S2079059715030077.

Khlestkina E.K., Usenko N.I., Gordeeva E.I., Stabrovskaya O.I., Sharfunova I.B., Otmakhova Y.S. Evaluation of wheat products with high flavonoid content: justification of importance of marker-assisted development and production of flavonoid-rich wheat cultivars. Vavilov J. Genet. Breed. 2017;21(5):545-553. DOI 10.18699/VJ17.25-o.

Landi M., Tattini M. Gould K.S. Multiple functional roles of anthocyanins in plant-environment interactions. Environ. Exp. Bot. 2015; 119:4-17. DOI 10.1016/j.envexpbot.2015.05.012.

Li N., Li S., Zhang K., Chen W., Zhang B., Wang D., Zhang H. ThMYC4E, candidate Blue aleurone 1 gene controlling the associated trait in Triticum aestivum. PloS ONE. 2017;12(7):e0181116. DOI 10.1371/journal.pone.0181116.

Lila M.A. Anthocyanins and human health: an in vitro investigative approach. J. Biomed. Biotechnol. 2004;2004(5):306-313. DOI 10.1155/S111072430440401X.

Mareš J., Brabec T., Vyhnánek T., Trojan V., Štiasna K., Presinszká M., Mrkvicová E., Hřivna L., Havel L. The effect of feeding wheat with purple pericarp on the growth of carp. Potravinarstvo. 2015;9(1):262-267. DOI 10.5219/477.

Mrkvicová E., Pavlata L., Karásek F., Št’astník O., Doležalová E., Trojan V., Brabec T. The influence of feeding purple wheat with higher content of anthocyanins on antioxidant status and selected enzyme activity of animals. Acta Veterinaria Brno. 2017;85(4):371-376. DOI 10.2754/avb201685040371.

Tadera K., Minami Y., Takamatsu K., Matsuoka T. Inhibition of $\alpha$-glucosidase and $\alpha$-amylase by flavonoids. J. Nutr. Sci. Vitaminol. 2006; 52(2):149-153. DOI 10.3177/jnsv.52.149.

Tenditnik M.V., Tikhonova M.A., Pavlov K.S., Amstislavskaya T.G., Khlestkina E.K. Evaluating the neuroprotective potential of wheat grain with high antocyanin content in correction of behavioral deficits induced by amyloid-beta neuro toxicity in mice. Abstracts of Belyaev Conference, 1-7August 2017, Novosibirsk. P. 165.

Tsuda T., Horio F., Uchida K., Aoki H., Osawa T. Dietary cyaniding 3-O- $\beta$-D-glucoside-rich purple corn color prevents obesity and ameliorates hyperglycemia in mice. J. Nutr. 2003;133(7):2125-2130. DOI 10.1093/jn/133.7.2125.

Tsuda T. Dietary anthocyanin-rich plants: biochemical basis and recent progress in health benefits studies. Mol. Nutr. Food Res. 2012; 56(1):159-170. DOI 10.1002/mnfr.201100526.

Rausher M.D. The evolution of flavonoids and their genes. In: Grotewold E. (Ed.). The Science of Flavonoids. 2006;175-211, Springer, New York, NY.

Ruckschloss L., Matúšková K., Hanková A., Jančík D. Influence of winter wheat with purple colour of the corn on laying hens' efficiency and eggs quality. Potranivarstvo. 2010:4(Suppl.):231-235.

Shobana S., Sreerama Y.N., Malleshi N.G. Composition and enzyme inhibitory properties of finger millet (Eleusine coracana L.) seed coat phenolics: Mode of inhibition of $\alpha$-glucosidase and pancreatic amylase. Food Chem. 2009;115(4):1268-1273. DOI 10.1016/j.foodchem.2009.01.042

Shoeva O., Gordeeva E., Khlestkina E. The regulation of anthocyanin synthesis in the wheat pericarp. Molecules. 2014;19(12):2026620279. DOI 10.3390/molecules191220266.

Shoeva O.Y., Khlestkina E.K. The specific features of anthocyanin biosynthesis regulation in wheat. Ogihara Y., Takumi S., Handa H. (Eds.). Advances in Wheat Fenetics: from Genome to Field. Japan: Springer, 2015. P. 147-157. DOI 10.1007/978-4-431-55675-6 16. 
Tsuda T. Dietary anthocyanin-rich plants: biochemical basis and recent progress in health benefits studies. Molecular Nutrition Food Res. 2012;56(1):159-170. doi.org/10.1002/mnfr.201100526.

Usenko N.I., Khlestkina E.K., Asavasanti S., Gordeeva E.I., Yudina R.S., Otmakhova Y.S. Possibilities of Enriching Food Products with Anthocyanins by Using New Forms of Cereals. Foods Raw Materials. 2018;6(1):128-135. DOI 10.21603/2308-4057-2018-1128-135.

Winkel-Shirley B. Flavonoid biosynthesis. A colorful model for genetics, biochemistry, cell biology and biotechnology. Plant Physiol. 2001;126:485-493. DOI 10.1104/pp.126.2.485.
Zeven A.C. Wheats with purple and blue grains: a review. Euphytica. 1991;56(3):243-258.

Zong Y., Xi X., Li S., Chen W., Zhang B., Liu D., Zhang H. Allelic variation and transcriptional isoforms of wheat TaMYC1 gene regulating anthocyanin synthesis in pericarp. Front. Plant Sci. 2017;8:1645. DOI 10.3389/fpls.2017.01645.

Acknowledgements. The study is supported by the Russian Science Foundation (Project No. 16-14-00086).

Conflict of interest. The authors declare no conflict of interest. 


\title{
Identification of wheat varieties with high grain protein and gluten content
}

\author{
D-r.F. Askhadullin ${ }^{1 *}$, D-1.F. Askhadullinn ${ }^{1}$, N.Z. Vasilova ${ }^{1}$, E.V. Zuev $^{2}$, I.I. Khusainova ${ }^{1}$, M.R. Tazutdinova ${ }^{1}$, E.Z. Bagavieva ${ }^{1}$ \\ 1 Tatar Scientific Research Institute of Agriculture, FRC Kazan Scientific Center RAS, Kazan, Russia \\ ${ }^{2}$ FRC N.I. Vavilov All-Russian Institute of Plant Genetic Resources (VIR), Saint-Petersburg, Russia
}

DOI 10.18699/ICG-PlantGen2019-03

(c) Autors, 2019

*e-mail: trulik@ya.ru

\begin{abstract}
Single examples of the creation of commercial varieties of soft wheat combining high potential productivity and grain quality indicate a strong conjugation of these systems. There is a limit to the increase in protein and gluten in soft wheat, the main elements of grain quality. One of the ways to solve this problem can be the search for and active involvement in the hybridization of samples characterized by high protein and gluten content. The paper reveals genotypes between Triticum species which are characterized by an increased content of these indicators over a number of years with different weather conditions.
\end{abstract}

Key words: Triticum; protein and gluten content in grain; productivity.

\section{Introduction}

Despite the creation of a number of varieties of soft wheat combining high grain productivity and high grain quality, there are limitations on increasing protein and gluten contents. The initial plant material plays a key role in the efficiency of selection for grain quality. Screening of the VIR wheat collection grown in the forest-steppe zone of the Republic of Tatarstan revealed varieties with the highest protein and gluten content. They can serve as a starting material for the selection of high-quality varieties of soft wheat.

\section{Materials and methods}

Cultivation of wheat varieties was preformed in 2016-2018 on TatSRIA's experimental fields in the north of the Middle Volga Region, in the Republic of Tatarstan, Russia. The soil was gray-forest, well cultivated. The weather conditions during research were typical of the forest-steppe zone, with frequent summer droughts every year except 2017, when the rainy and cold summer resulted in prolonged vegetation. Collection nurseries were established in accordance with classical methods of soft spring wheat selection. Wheat cultivation technology was traditional for the zone.

The protein and gluten contents in the grain were assessed using an Infratec 1275 infrared analyzer (FOSS). The NIR analyzer is not an absolutely accurate device, but it allows mass analysis. We have investigated the wheat varieties provided by the All-Russian Institute of Plant Genetic Resources (VIR) as well as genotypes received through institute exchange. Plant material consists of T. aestivum L. (278 varieties), T. durum Desf. (27 varieties), T. dicoccum (Schrank) Schuebl. (15 varieties), T. polonicum L. (3 varieties).

\section{Results and discussion}

The Middle Volga Region belongs to the areas where it is possible to guarantee the production of high quality wheat (Flaksberger, 1938; Vasilova, Askhadullin D-1., Askhadullin D-r., 2016). The genotype of the variety plays a key role in the gross production of high-quality wheat. The highyielding varieties of strong wheat created and recommended for cultivation in the Republic have limitations on increasing the protein and gluten content regardless of the cultivation technology. But there are reserves for increasing protein in grain in soft wheat while maintaining high productivity (Mitrofanova, Khakimova, 2016). Active use, in hybridization, of samples within the genus Triticum characterized by high protein content will increase the likelihood of creating highly productive varieties of spring wheat with protein content at the level of the best samples.

The samples of T. aestivum $\mathrm{L}$. available to us are diverse in protein and gluten content in grain. In high-protein samples. protein content in grain ranged from 14.7 to $18.7 \%$, gluten in grain from 32.8 to $38.1 \%$ (see Table 1). Collection of protein per unit area is the most important indicator of the effectiveness of breeding. Wheat cultivars Pamyati Maistrenko (K-65448, Russia, Omsk region) and Manu (K-66029, Finland) were the best samples on this indicator.

Protein and gluten levels of other tested species:

T. durum Desf. is widely used in hybridization with soft wheat and can be a source of high protein content. The maximum protein content was $16.4 \%$ in the sample of Bezenchukskaya 182 (K-59890, Russia, Samara region), while in other tested samples this measure did not exceed $15 \%$. The T. dicoccum (Schrank) Schuebl. species are high in protein. High-protein commercial varieties were created by hybridization with T. dicoccum (Lillian, Canada, etc.). Protein content in some samples reached $18.2 \%$, while the starch content was slightly lower than that of high-quality spring wheat. For protein content, K-7530 (Russia, Ulyanovsk region), K-10456 (Russia, Tatarstan), and K-21961 (Germany) stand out.

Noteworthy is the use of interspecific crosses with $T$. polonicum $\mathrm{L}$. The protein content of $T$. polonicum L. reached $17.8 \%$. The maximum protein and gluten content was in K-9277 (Israel) and Koko (K-62974, Syria) (see Table 2).

\section{Conclusions}

These data indicate a high level of protein and gluten in the species tested. Not a large set of samples can give a false result, but the use of samples of different origin levels it out. 
Table 1

Characteristics of the best T. aestivum samples by protein and gluten content in grain, 2016-2018

\begin{tabular}{lllll}
\hline № cat. VIR & Sample & Protein content in grain, $\%$ & Gluten content in grain, \% & Collecting $\mathrm{protein,} / \mathrm{m}^{2}$ \\
\hline 65478 & Krasnoufimskaya110, RUS: Sverdlovsk & 15.7 & 34.9 & 36.8 \\
65477 & Ekaterina, RUS: Sverdlovsk & 15.2 & 34.1 & 48.3 \\
65448 & Pamyati Maistrenko, RUS: Omsk & 15.0 & 33.7 & 60.0 \\
64856 & Polyushko, RUS: Novosibirsk & 14.7 & 33.3 & 47.9 \\
65473 & Long Fu 12, China & 15.9 & 35.0 & 40.4 \\
64977 & ACTaho, Canada & 15.9 & 34.2 & 45.0 \\
66203 & Lillian, Canada * & 18.7 & 37.5 & 25.8 \\
66204 & Lovitt, Canada * & 18 & 38.1 & 20.9 \\
66033 & Molera, Switzerland ** & 16.5 & 36.9 & 59.1 \\
66029 & Manu, Finland ** & 16 & 35.75 & 65.8 \\
65851 & Mayon 1, Syria ** & 15.9 & 36.15 & 30.8 \\
\hline
\end{tabular}

* tested only in 2018, ** tested in 2017-2018

Table 2

The limits of protein content and gluten in the samples tested, 2016-2018

\begin{tabular}{|c|c|c|}
\hline Species & Protein content of grain, \% & Gluten content in grain, $\%$ \\
\hline T. durum Desf. & $\begin{array}{l}\operatorname{Lim} \\
11.9-16.4\end{array}$ & $\begin{array}{l}\operatorname{Lim} \\
22.7-35.7\end{array}$ \\
\hline T. dicoccum (Schrank) Schuebl. & $\begin{array}{l}\operatorname{Lim} \\
13.2-18.2\end{array}$ & $\begin{array}{l}\operatorname{Lim} \\
24.9-29.8\end{array}$ \\
\hline T. polonicum L. & $\begin{array}{l}\operatorname{Lim} \\
14.2-17.8\end{array}$ & $\begin{array}{l}\operatorname{Lim} \\
31.2-37.8\end{array}$ \\
\hline
\end{tabular}

The source of high content continues to be T. aestivum L., but in crossing programs, despite some difficulties, you can use other high-protein species.

\section{References}

Flaksberger, C.A. Wheats, State agricultural publishing company, Moscow; Leningrad, 1938.

Vasilova N.Z., Askhadullin D1.F., Askhadullin Dr.F. et al. Formation of grain quality of spring soft wheat varieties. Achievements Science Technology AICis. 2016:30(11):42-44.
Mitrofanova O.P., Khakimova A.G. New genetic resources in wheat breeding for an increased grain protein content. Vavilovskii Zhurnal Genetiki $i$ Selektsii = Vavilov Journal of Genetics and Breeding. 2016;20(4):545-554. DOI 10.18699/VJ16.177 (in Russian).

Acknowledgements. This research was supported by FASO Russia project AAAA-A18-118031390148-1.

Conflict of interest. The authors declare no conflict of interest. 


\title{
Wheat genetic resources for breeding on adaptability
}

\author{
M.A. Yessimbekova*, M.Sh. Suleimenova, K.B. Mukin \\ Kazakh Research Institute of Agriculture and Plant Growing, Astana, Kazakhstan
}

DOI 10.18699/ICG-PlantGen2019-04

(c) Autors, 2019

* e-mail: minura.esimbekova@mail.ru

\begin{abstract}
High temperature can be one of the main factors limiting the productivity of all agricultural crops, including wheat. In this regard, understanding the physiological problems associated with stress caused by high temperature is of great importance. The aim of the studies was to phenotype wheat germplasm (Triticum aestivum L.) to assess the potential of using the NDVI (normalized difference vegetation index) and CTD (canopy temperature depression) measurements to identify wheat genotypes that show a high correlation of productivity with heat tolerance (CTD) and drought resistance (NDVI) cultures in the foothill and dry-steppe zones of the Trans-lli Alatau. A trend of increasing productivity with increasing CTD $(r=0.67)$ was revealed. Five winter wheat accessions were selected as sources of productivity and adaptability to high temperatures. Monitoring of the wheat gene pool using GreenSeeker, an optical sensor, showed a change in the plant biomass index (NDVI) value depending on the conditions of cultivation and the phase of development. An association ( $r=0.64)$ between NDVI and the yield of winter wheat was established. For spring wheat, a high degree of NDVI correlation $(r=0.51-0.54)$ with spike length, number of spikelets, kernels and weight of kernels per spike was noted.

Key words: winter and spring bread wheat; T. aestivum L.; yield productivity; biomass index.
\end{abstract}

\section{Introduction}

Worldwide, global climate change is objectively observed and projected. The Second National Communication on the UN Framework Convention on Climate Change of Kazakhstan indicates that the average temperature in the region has risen by more than $0.15^{\circ} \mathrm{C} / 10$ years (Eserkepova et al., 2009). High temperature can be one of the main factors limiting the productivity of all agricultural crops, including wheat. Understanding the physiological problems associated with stress caused by high temperature is of great importance. Various physiological mechanisms contribute to the heat tolerance of plants. The canopy temperature is a function of many environmental factors: soil water status, air temperature, relative humidity, and radiation (Amani et al., 1996). Canopy temperature depression (CTD) is a good indicator of the genotypes' relevance to a given environment. Experimental data showed a clear association of CTD with yield (Reynolds et al., 1998, 2001, 2007; Saint Pierre et al., 2010; Cossani, Reynolds, 2012; Pinto, Reynolds, 2015). Drought is a major factor limiting the yield of wheat throughout the world. The degree of modification depends on the variety, growth stage, duration and intensity of stress (Araus et al., 2002; Barnabas et al., 2008). The best option for increasing yields and crop stability is the development of drought-resistant crop varieties (Fischer, Maurer, 1978; Rajaram, 1996). It has recently become possible to perform indirect assessments of agronomic and physiological features using spectral reflection methods associated with photosynthetic activity and plant productivity (Verhulst, Govaerts, 2010). Among the most widely used simple methods is the normalized differential vegetation index (NDVI). NDVI is a non-destructive method for effective assessment of total dry matter (TDM), leaf area index (LAI) in wheat and barley. NDVI positively correlates with grain yield and can serve as an indirect criterion for the selection of productive forms. These indicators are very useful for assessing the photosynthetic ability of plants and yield (Sharma et al., 2011).

\section{Materials and methods}

Field experiments were conducted during the growing season of 2014/2016 on the experimental field plots of the gene pool department of Kazakh Research Institute of Agriculture and Plant Growing in 2 soil-climatic zones of the Trans-Ili Alatau $\left(48^{\circ} \mathrm{N}, 77^{\circ} \mathrm{E}\right): 1$ ) rain fed conditions of the foothill zone; 2) semi-arid conditions of the dry-steppe zone.

In the crop rotation system, wheat was placed annually after a three-year alfalfa. Fertilizers, applied according to the technology adopted in the zone, herbicides, fungicides and insecticides were used as needed to minimize the impact of weeds, diseases and insects. Material: The objects of the study were winter, facultative and spring bread wheat accessions from 3 International nurseries of CIMMYT 1) Winter Wheat Eastern European Regional Yield Trial (WWEERYT); 2) Facultative and Winter Wheat Observation Nursery (FAWWON); 3) Kazakhstan-Siberian Network on Wheat Improvement (KASIB). Methods: CTD was measured as the difference between air temperature and canopy temperature (Reynolds et al., 1998). NDVI measurements were conducted using GreenSeeker, a portable optical sensor unit (Trimble Navigation Limited, Sunnyvale, CA, USA). The stress susceptibility index (SSI) was calculated as follows: $\mathrm{SSI}=(\mathrm{Yp}-\mathrm{Ys}) / \mathrm{Yp} * 100$, where $\mathrm{Ys}$ is the yield of the genotype under stressful conditions; Yp is the yield of the genotype in non-stressful conditions. The data were analyzed using STATISTICA 10 (StatSoft).

\section{Results and discussion}

The international exchange of varieties and breeding materials is of great practical value for the creation of new varieties. 
For more than 20 years, Kazakhstan has been participating in the assessment of winter wheat nurseries formed by the International Program of CIMMYT. The meteorological conditions of the 2014/2016 research years were favorable both in thermal, water and energy terms. According to the CTD measurements, the detected genotypes of WWEERYT nurseries were divided into 3 groups: the warmest varieties were included in 1 and 2 groups $\left(\mathrm{CTD}=11.4-12.8^{\circ} \mathrm{C}\right)$ with the productivity scale from 225.0 to $610.0 \mathrm{~g} / \mathrm{m}^{2}$. The most numerous were the $3 \mathrm{rd}$ group $\left(69 \mathrm{pcs}, \mathrm{CTD}=13.0-14.20^{\circ} \mathrm{C}\right)$ with the yield from 460.0 to $910.0 \mathrm{~g} / \mathrm{m}^{2} .17$ high-yielding accessions $\left(\geq 650 \mathrm{~g} / \mathrm{m}^{2}\right)$ have been identified as promising. The coolest accession was KS89180B from the USA (CTD $=$ $=14.2{ }^{\circ} \mathrm{C}$, yielding $710.0 \mathrm{~g} / \mathrm{m}^{2}$ ).

The most productive in the group of cool accessions was a variety from Ukraine, 'Kharkovskaya-106' $\left(\mathrm{CTD}=13.6{ }^{\circ} \mathrm{C}\right.$, yielding $910.0 \mathrm{~g} / \mathrm{m}^{2}$ ). A trend to increase productivity with increasing CTD was revealed. A positive correlation is noted between CTD and average yield in 128 winter wheat varieties and lines $(r=0.67)$. Five accessions of the WWEERYT nursery with a high correlation between CTD and productivity were identified as sources of productivity and adaptability to high temperatures (heat tolerance). The yield of any plant organism, including winter wheat, is considered as the end product of the photosynthetic ability, which begins with the process of photosynthesis. The leaf area index (LAI) for Kazakhstan breeding productive varieties ranged from 48.2 to 71.2 thousand $\mathrm{m}^{2} /$ ha (the absorption energy $1.94-2.41 \%$ PAR). The total dry matter (TDM) ranged from 13.55 to $16.85 \mathrm{t} / \mathrm{ha}(\mathrm{St}=12.74 \mathrm{t} / \mathrm{ha})$, which ensured the grain yield from 5.12 to $7.41 \mathrm{t} / \mathrm{ha}$. The largest LAI ( 71.2 thousand $\mathrm{m}^{2} / \mathrm{ha}$ ) was with the variety 'Kazakhstanskaya-16', able to absorb and assimilate solar energy with a high efficiency (2.41\% PAR), which provided the formation of $16.85 \mathrm{t} / \mathrm{ha}$ of TDM and of $7.41 \mathrm{t} /$ ha of grain yield.

Normalized Differential Vegetation Index (NDVI) measures the amount of green vegetation in the area. In this regard NDVI was used as an indirect criterion for the selection of productive forms. The NDVI values for winter wheat accessions in rainfed conditions of the Trans-Ili Alatau foothill zone varied from 0.40 to 0.81 . The relationships between NDVI, physiological features and productivity of Kazakhstan winter wheat varieties are classified as average $(r=0.37-0.41)$. However, a high degree of correlation $(r=0.71)$ observed between NDVI and heading time (HT, the number of days from January 1) allowed us to reveal, within 6 HT groups of winter wheat accessions, a high degree of correlation $(r=0.64)$ between NDVI and productivity. NDVI measurements in the foothill zone on the spring bread wheat accessions from the KASIB international nursery showed the ability of the NDVI to differentiate wheat genotypes. High values of NDVI (0.70-0.75) were observed at the heading stage, which, as was established, can serve as an indicator of the good plant state before transition to the reproductive stage.

For spring wheat early maturing genotypes, there was a marked decrease in NDVI during transition from the heading stage to the grain filling period, Figure 1. It is hypothesized
(Sharma et al., 2011) that early maturing genotypes with high values of NDVI (0.70-0.75) are important for early sowing, for they will better tolerate early drought, which occurs in the prewinter and early spring months in many parts of Central Asia. Twenty-eight medium maturity genotypes with stable NDVI values (0.70) keep green leaves for long and better tolerate terminal heat stress, which often occurs in the foothill zone of the Trans-Ili Alatau in the third decade of June and July. A high degree of correlation between NDVI and spike length (SL), number of spikelets (NSS), number of kernels (NKS), and weight of kernels (WKS) per spike $(r=0.54 ; 0.51 ; 0.55$; 0.51 , respectively) were noted.

Gene expression is not the same in different environmental conditions. The water and heat stress of the dry-steppe zone caused a decrease in the photosynthetic ability and, as a result, a decreased NDVI (0.20-0.79) (Figure 2).

The stress susceptibility index (SSI) determined by a comparative analysis of the spring wheat productivity traits in the conditions of the foothill and dry-steppe zones allowed indicating five accessions - 'Lutescens 259', 'Erythrospermum 55/94', 'Stepnaya 17', 'Samgau', and 'Alpha-79' - with the lowest SSI for all analyzed traits. There are correlations of varying degrees between NDVI and PH (plant height), NSS, SL, WKS, NKS $(r=0.58 ; 0.50 ; 0.37 ; 0.30$; and 0.20 , respectively).

\section{Conclusions}

CTD is an integrated result of the environmental conditions affecting the absorption energy and the evaporation mechanism (Amani et al., 1996). The research results showed the possibility of using the CTD method as an indirect selection criterion for heat tolerance in the southeastern part of Kazakhstan: a high genetic correlation $(r=0.67)$ between CTD and productivity was established. Five accessions from the WWEERYT nursery, distinguished by a high correlation coefficient between the CTD index and productivity, have been transferred for use in breeding for productivity and heat tolerance. As a result of the research, the ability of NDVI to differentiate wheat varieties at different stages of growth and the ability to use NDVI values as predictors of wheat yield were established. In the foothill zone of the Trans-Ili Alatau, within six marked ripeness groups, a connection $(r=0.64)$ between the grain yield of winter wheat and the NDVI was established.

For spring wheat, a marked high degree correlation of NDVI with SL, NSS, NKS and WKS $(r=0.54 ; 0.51 ; 0.55$; 0.51 , respectively) was revealed. The results obtained in these experiments show that drought stress significantly reduced the NDVI. NDVI values varied from 0.20 to 0.79 . The correlations of varying degrees between NDVI and PH, NSS, SL, WKS, and NKS $(0.58 ; 0.50 ; 0.37 ; 0.30$; and 0.20 , respectively) are noted. The results show that the germplasm included in the study represents significant genotypic variations, which can be useful for programs to improve winter and spring wheat productivity and resistance to heat and drought. NDVI broadens the understanding of various management methods within an agro-ecological environment and shows how management affects and determines the efficiency of the resource use. 


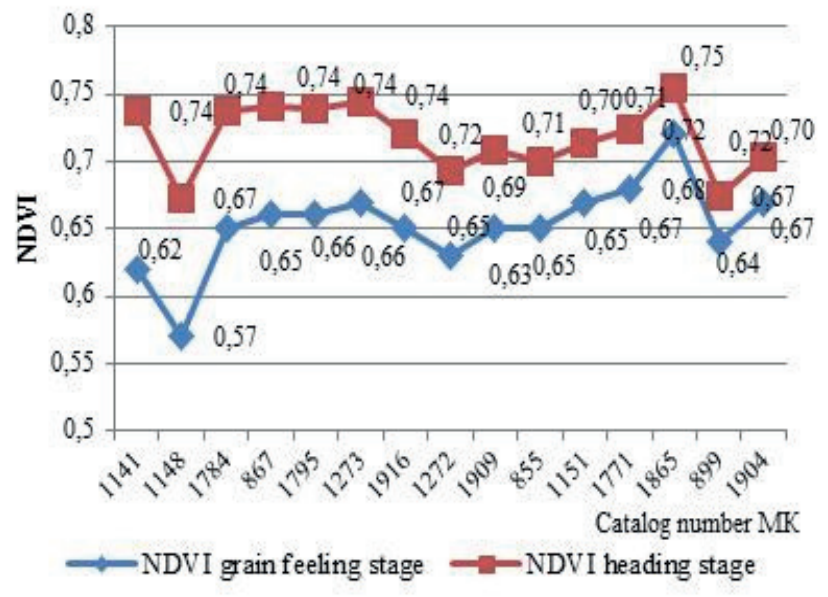

Figure 1. NDVI of spring bread wheat accessions from KASIB nursery under rainfed conditions at 2 growth stages (heading and grain filling stage), 2016.

\section{References}

Amani I., Fisher R.A., Reynolds M.P. Canopy Temperature Depression Association with Yield of Irrigated Spring Wheat Cultivars in a Hot Climate. J. Agron. Crop Sci. 1996;176(2):119-129. DOI 10.1111/j.1439-037X.1996.tb00454.x.

Araus J.L., Slafer G.A., Reynolds M., Royo C. Plant breeding and drought in C3 cereals: What should we breed for? Ann. Bot. 2002; 89:925-940. DOI 10.1093/aob/mcf049.

Barnabas B., Jager K., Feher A. The effect of drought and heat stress on reproductive processes in cereals. Plant Cell Environ. 2008;31(1): 11-38. DOI 10.1111/j.1365-3040.2007.01727.x.

Cossani C.M., Reynolds M.P. Physiological Traits for Improving Heat Tolerance in Wheat. Plant Physiol. 2012;160(4):1710-1718. DOI: 10.1104/pp.112.207753.

Eserkepova I., Kryukova V., Dolgikh S., Idrisova V., Cherednichenko A., Sergazina G. The Second National Communication of the Republic of Kazakhstan on the UN Framework Convention on Climate Change. 2009. Available at: https://unfccc.int/resource/docs/natc/ kaznc2r.pdf.

Fischer R.A., Maurer R. Drought resistance in spring wheat cultivars. I. Grain yield response. Aust. J. Agric. Res. 1978;29(5):897-907. DOI 10.1071/AR9780897.

Pinto R.S., Reynolds M.P. Common genetic basis for canopy temperature depression under heat and drought stress associated with optimized root distribution in bread wheat. Theoretical Applied Gen. 2015;128(4):575-585. DOI 10.1007/s00122-015-2453-9.

Rajaram S., Braun H.J., Ginkel M.V. CIMMYT's approach to breed for drought tolerance. Euphytica. 1996;92:147-153. DOI 10.1007/ BF00022840.

Reynolds M.P., Ortiz-Monastereo J.I., McNab A. Application of physiology in wheat breading. Mexico, D.F.: CIMMYT, 2001;1-240.

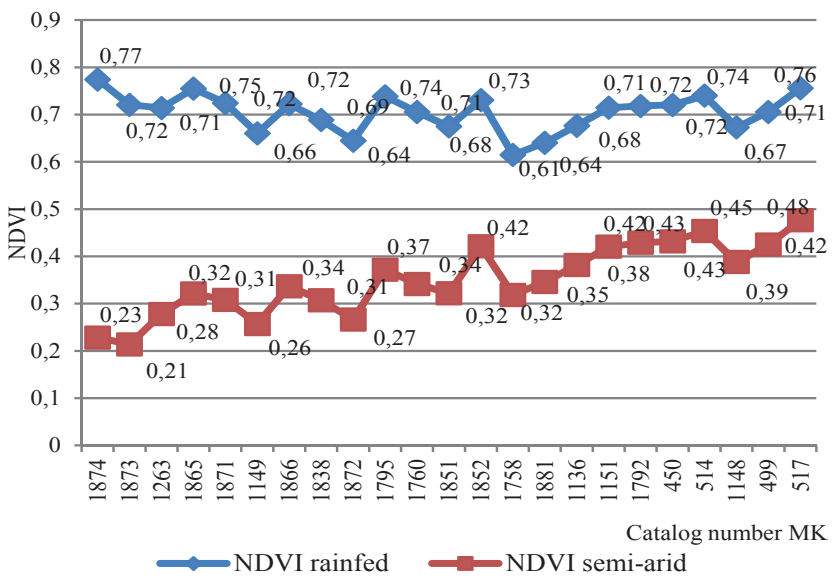

Figure 2. The values of the NDVI measurements of the KASIB spring wheat nursery in the conditions of the foothill and dry-steppe zones of the Trans-lli Alatau, 2016.

Reynolds M.P., Saint Pierre C., Abu S.I. Saad, Vargas M., Condon A.G. Evaluating potential genetic gains in wheat associated with stressadaptive trait expression in elite genetic resources under drought and heat stress. Crop Sci. 2007;47:172-189. DOI:10.2135/cropsci 2007.10.0022IPBS.

Reynolds M.P., Singh R.P., Ibrahim A., Ageeb O.A.A., Larque-Saavedra A., Quick J.S. Evaluating physiological traits to complement empirical selection for wheat in warm environments. Euphytica. 1998; 100:85-94. DOI:10.1023/A:1018355906553.

Saint Pierre C., Crossa J., Manes Y., Reynolds M.P. Gene action of canopy temperature in bread wheat under diverse environments. Theoretical Applied Gen. 2010;120(6):1107-1117. DOI 10.1007/ s00122-009-1238-4.

Sharma R.C., Islomov S., Yulshadev T., Khalikulov Z., Ziyadullaev Z. Diversity among winter wheat germplasm for NDVI (normalized difference vegetation index) under terminal heat stress in Central Asia. Proc. Int. Conf. "Diversity, Characterization and Utilization of Plant Genetic Resources for Enhanced Resilience to Climate Change". Baku, 3-4 October 2011. Baku, 2011;21-26.

Verhulst N., Govaerts B. The normalized difference vegetation index (NDVI) GreenSeekerTM handheld sensor: Toward the integrated evaluation of crop management. Part A: Concepts and case studies. Mexico, D.F.; CIMMYT, 2010;1-12.

Verhulst N., Govaerts B. The normalized difference vegetation index (NDVI) Green SeekerTM handheld sensor: Toward the integrated evaluation of crop management. Part B: User guide. Mexico, D.F.; CIMMYT, 2010;1-8.

Conflict of interest. The authors declare no conflict of interest. 


\title{
Development of new forms of spring and winter wheat with the involvement of the gene pool of wheatgrass and soybean and confirmation of the applicability of these methods in practical breeding
}

\author{
E.P. Razmakhnin*, T.M. Razmakhnina, N.I. Stepochkina, V.I. Ponomarenko, V.I. Kozlov, K.K. Musinov, A.A. Surnachev, \\ G.V. Artemova, I.E. Likhenko, G.Y. Galycin, N.P. Goncharov
}

Institute of Cytology and Genetics, SB RAS, Novosibirsk, Russia

DOI 10.18699/ICG-PlantGen2019-05

(c) Autors, 2019

*e-mail: eprazmakh@yandex.ru

\begin{abstract}
A technology has been developed for obtaining new forms of hybrid wheat by the method of remote hybridization with wheatgrass androgenic plants and an original leaf-nurse method. As the result of the application of this technology, 68 variety samples of hybrid winter wheat were obtained and brought to competitive tests. 30 promising genotypes exceeding in their characteristics the standard variety 'Novosibirskaya-40' were identified. 425 spring wheat-wheatgrass $F_{4}$ hybrids were obtained. 129 best varieties were selected and tested.
\end{abstract}

Key words: spring and winter breed wheat; wheatgrass; remote hybridization; leaf nurse.

\section{Introduction}

Producing commercial cultivars with significantly altered properties has always been the cherished desire of plant breeders. With intraspecific hybridization, significant changes are not achieved. Remote hybridization, genetic engineering methods, vaccinations, various types of mutagenesis, etc. are used to achieve this goal. Each of these methods has its advantages and disadvantages. Breeders widely use the method of remote hybridization of existing wheat cultivars with its wild relatives, in particular, with different species of wheatgrass to increase biodiversity and improve the quality of wheat. Wheatgrass has the following valuable characteristics: winter hardiness, salt and drought resistance, high content of protein and gluten in grains, strong root system, resistance to diseases, etc. (Tsitsin, 1981). It is desirable to transfer all these characteristics to the cultivated cereals. Work with wheatgrass has been going on for over 45 years in the Institute of Cytology and Genetics of the Siberian Branch of the RAS. The source material for the production of wheat-wheatgrass hybrids (WWHs) was the collection of seeds of wheatgrass Agropyron glaucum (syn. Elytrigia intermedium) collected in 1971 in East Kazakhstan in a wild-growing population, growing on a high and a low snow place. Such harsh growing conditions of wheatgrass plants caused, first of all, the presence of high frost resistance. Since 1985, we have been working on the creation of androgenic wheatgrass lines using the method of androgenesis in vitro and using these lines as donors of valuable traits for obtaining new forms of hybrid wheat. Using the haploid technology, we have created a collection of androgenic haploids, seed generation of doubled haploids as well as parental plants of wheatgrass, possessing high-quality androgenic characteristics and a number of other valuable features, among which the main ones can be distinguished: high cross-breeding with wheat and cold resistance (Razmakhnin, 2017). This made it possible to use - with high efficiency - the obtained lines in further work on the transfer of valuable traits from wheatgrass to wheat using the method of remote hybridization and an original method of leaf nurse (Razmakhnin et al., 2012).

\section{Materials and methods}

The main methods that we used for creation of new forms of wheat were intraspecific and interspecific hybridization and the method of leaf nurse (LN-mehod) (Razmakhnin et al., 2015). The winter wheat 'Filativka' and androgenic clones of wheatgrass were used for the development of WWHs. The winter wheat 'Bagrationovka' and leaves of soybean and frostresistant plants of wheatgrass were used for the development of LN-lines by the method of leaf nurse. Evaluation of frost resistance of wheatgrass and wheat plants was carried out by the laboratory express method (Razmakhnin et al., 2009). To reduce the height of the wheat lines developed and to improve their grain quality, we carried out their reciprocal crossing with the short-stem winter wheat variety 'Lars'. Spring forms of WWHs were obtained by backcrossing the WWHs obtained to spring introgression lines of wheat resistant to brown rust. The best spring WWH genotypes were crossed among themselves and with the spring wheat varieties 'Novosibirskaya-31' and 'Omskaya-37'. The selection process took place in the field and in the greenhouse.

\section{Results and discussion}

\subsection{The results of the research on the creation}

of new genotypes of winter wheat using wheatgrass and soybean as a donor of valuable traits

In 2017, we carried out at competitive test of 68 promising genotypes of WWHs and LN-lines. Most of the genotypes had higher rates of productivity and quality of grain than the standard variety 'Novosibirskaya-40'. Table 1 shows the results of the competitive test of 2017-2018 of the best varieties of WWHs and LN-lines. It is important to note that the root 
Table 1

Comparative assessment of winter breed wheat lines of the 2017-2018 competition test

\begin{tabular}{|c|c|c|c|c|c|c|c|c|c|c|c|}
\hline $\begin{array}{l}\text { Cultivar, } \\
\text { line }\end{array}$ & $\begin{array}{l}\text { Winter } \\
\text { hardiness, } \\
\%\end{array}$ & $\begin{array}{l}\text { Plant } \\
\text { height, } \\
\mathrm{cm}\end{array}$ & $\begin{array}{l}1000 \\
\text { kernel- } \\
\text { weight, g }\end{array}$ & $\begin{array}{l}\text { Nature, } \\
\text { g/l }\end{array}$ & Glassy, \% & Gluten, \% & $\begin{array}{l}\text { Power of } \\
\text { flour, e.a. }\end{array}$ & $\begin{array}{l}\text { Bread } \\
\text { volume, } \\
\mathrm{cm}^{3} / 100 \mathrm{~g}\end{array}$ & $\begin{array}{l}\text { Overall } \\
\text { baking } \\
\text { assessment }\end{array}$ & $\begin{array}{l}\text { Yield, t/h } \\
\text { average }\end{array}$ & $+/-$ to st \\
\hline $\begin{array}{l}\text { Novosibir- } \\
\text { skaya-40 }\end{array}$ & 63.5 & 109 & 37.3 & 790 & 50 & 37 & 228 & 680 & 4.1 & 5.29 & st \\
\hline LN 7b & 59.7 & 120 & 44.7 & 798 & 52 & 33.8 & 417 & 620 & 3.9 & 6.19 & +0.9 \\
\hline $\begin{array}{l}\text { WWH } \times \\
\text { Lars } 2\end{array}$ & 65.7 & 118 & 44.7 & 802 & 60 & 34.4 & 269 & 740 & 4.1 & 5.90 & +0.61 \\
\hline WWH 45c & 61.0 & 130 & 43.1 & 792 & 55 & 32.8 & 302 & 600 & 4.1 & 5.98 & +0.69 \\
\hline WWH 53 & 61.2 & 123 & 41.5 & 784 & 57 & 33.3 & 268 & 640 & 4.6 & 6.02 & +0.72 \\
\hline DS 2 & 59.2 & 118 & 48.3 & 800 & 55 & 30.8 & 332 & 620 & 4.5 & 6.52 & +1.22 \\
\hline $\begin{array}{l}\text { WWH } \times \\
\text { Lars } 9\end{array}$ & 64.2 & 121 & 39.1 & 774 & 52 & 27.9 & 193 & 720 & 4.4 & 6.56 & +1.27 \\
\hline $\begin{array}{l}\text { WWH } \times \\
\text { Lars } 19\end{array}$ & 66.0 & 126 & 43.6 & 800 & 57 & 25.8 & 258 & 600 & 4.3 & 7.04 & +1.75 \\
\hline $\begin{array}{l}\text { WWH } \times \\
\text { Lars } 18\end{array}$ & 60.5 & 96 & 37.9 & 768 & 54 & 23 & 205 & 600 & 4.4 & 6.29 & +1.0 \\
\hline LN 20 & 61.7 & 117 & 47.2 & 800 & 54 & 29.9 & 277 & 560 & 4.0 & 6.01 & +0.71 \\
\hline $\begin{array}{l}\text { WWH } \times \\
\text { Lars } 12\end{array}$ & 66.0 & 116 & 43.7 & 794 & 57 & 29.6 & 355 & 640 & 4.4 & 6.24 & +0.95 \\
\hline WWH 48a & 60.5 & 126 & 45.9 & 780 & 57 & 32.2 & 269 & 600 & 4.0 & 5.97 & +0.68 \\
\hline WWH 48b & 61.7 & 126 & 49.4 & 792 & 65 & 34.0 & 294 & 640 & 4.2 & 6.19 & +0.90 \\
\hline $\begin{array}{l}\text { WWH } \times \\
\text { Lars } 11\end{array}$ & 63.7 & 116 & 47.6 & 786 & 66 & 31.2 & 292 & 800 & 4.6 & 5.82 & +0.53 \\
\hline $\begin{array}{l}\text { WWH } \times \\
\text { Lars } 7\end{array}$ & 62.5 & 120 & 44.5 & 778 & 60 & 33.7 & 264 & 580 & 3.8 & 6.22 & +0.93 \\
\hline $\begin{array}{l}\text { WWH } \times \\
\text { Lars } 15\end{array}$ & 62.5 & 117 & 44.5 & 770 & 69 & 31.6 & 318 & 560 & 4.0 & 5.78 & +0.49 \\
\hline $\begin{array}{l}\text { WWH } \times \\
\text { Lars } 20\end{array}$ & 62.0 & 107 & 44 & 774 & 64 & 31.6 & 216 & 600 & 4.3 & 5.39 & +0.1 \\
\hline $\begin{array}{l}\text { LN ZS X } \\
\text { soybean } 1\end{array}$ & 61.5 & 110 & 47.8 & 782 & 64 & 33.0 & 284 & 700 & 4.4 & 5.7 & +0.45 \\
\hline $\begin{array}{l}\text { LN DS } \times \\
\text { soybean } 2\end{array}$ & 61.7 & 113 & 48.3 & 780 & 64 & 33.0 & 336 & 600 & 4.2 & 5.5 & +0.3 \\
\hline
\end{tabular}

Table 2

The average weight of roots of winter bread wheat

\begin{tabular}{llllllll}
\hline Cultivar, lines & Novosibirskaya-40 st & $\begin{array}{l}\text { WWH } \times \\
\text { Lars 11 }\end{array}$ & $\begin{array}{l}\text { WWH } \times \\
\text { Lars 12 }\end{array}$ & $\begin{array}{l}\text { WWH } \times \\
\text { Lars 19 }\end{array}$ & $\begin{array}{l}\text { LN ZS } \times \\
\text { soybean }\end{array}$ & $\begin{array}{l}\text { LN DS } \times \text { LN WWH 20× } \\
\text { soybean }\end{array}$ \\
\hline weight of roots, g & 0.49 & 0.88 & 1.38 & 1.43 & 1.0 & 0.93 & 1.2 \\
soybean
\end{tabular}



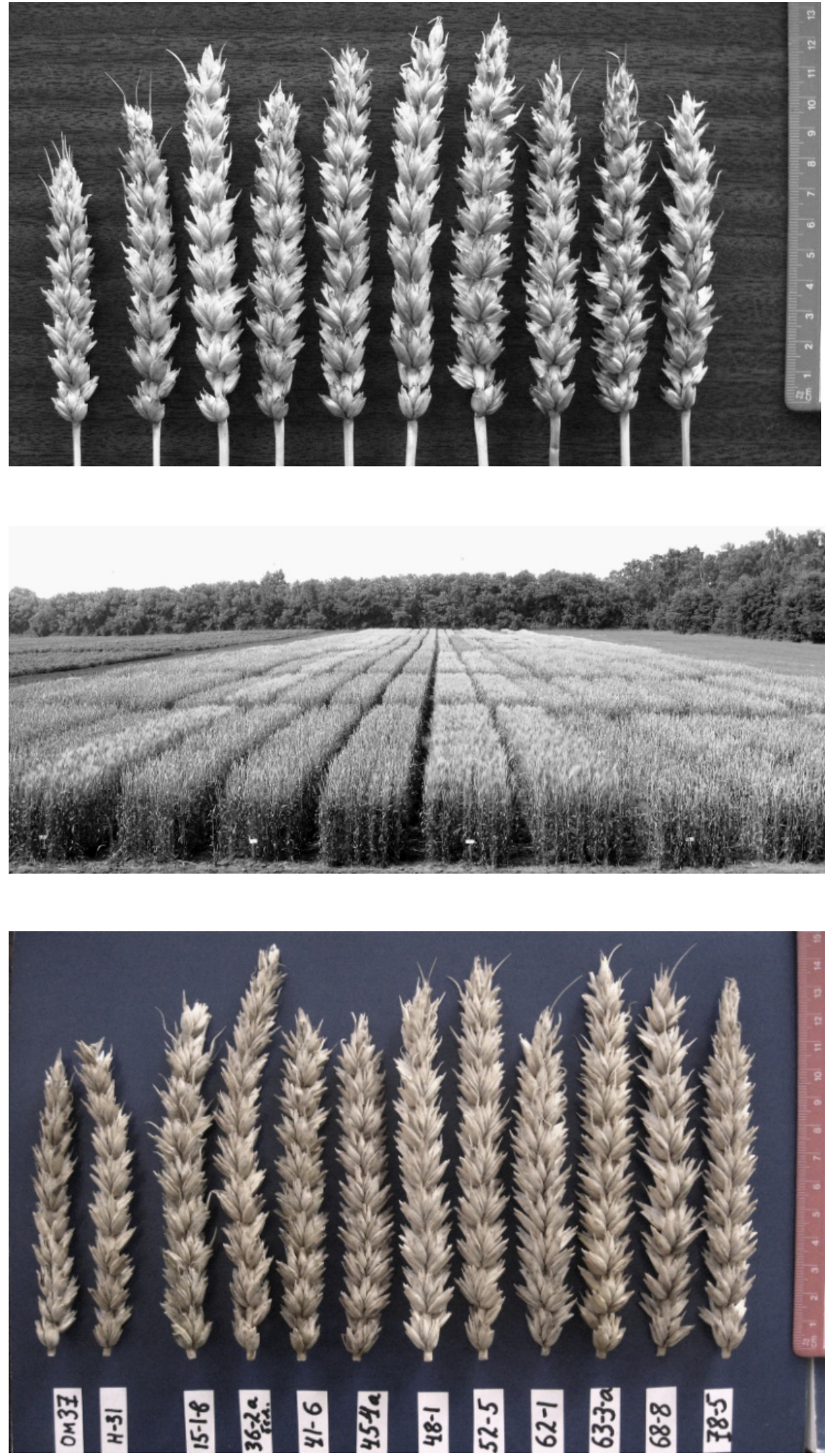

Figure 1. Spikes of the winter wheat

'Novosibirskaya-40' and lines of new forms of winter wheat.

Figure 2. Field competition test of developed WWHs and LN-lines.
Figure 3. Spikes of the spring wheat 'Omskaya-37', 'Novosibirskaya-31' and developed lines of new forms of spring wheat. 
system of the genotypes was significantly more developed (Table 2). This trait was clearly transmitted from wheatgrass, which has a powerful root system.

Figure 1 shows spikes of the winter wheat 'Novosibirskaya-40' and developed lines of new forms of winter wheat. Figure 2 shows the field competition test of the developed WWHs and LN-lines in 2018.

The results of the research on the creation of new genotypes of spring wheat using wheatgrass and soybean as donors of valuable traits

In 2017, 17 genotypes of spring WWHs and LN-lines out of 32 obtained in 2016 were tested. The spring wheat varieties 'Novosibirskaya-31' and 'Omskaya-37' were taken as standards. Productivity and 1000-kernel weight of the majority of the samples studied exceeded grades-standards. In order to expand the genetic diversity and improve the quality of grain, the best samples were crossed with each other and with two varieties of spring wheat, 'Novosibirskaya-31' and 'Omskaya-37'. As a result, 2563 grains of 91 reciprocal hybrids were developed. Selection, reproduction and structural analysis of these variants were carried out during the two vegetation periods of 2017-2018 in the greenhouse. Figure 3 shows spikes of the spring wheat varieties 'Omskaya-37', 'Novosibirskaya-31' and lines of new forms of spring wheat. In 2019, 5762 grains of 425 genotype variants were obtained. From these variants, 129 best genotypes were choose for breeding.

\section{Conclusion}

The results obtained prove the great prospects for the application of the method of remote hybridization and the method of leaf nurse to create new forms of hybrid wheat with the use of wheatgrass and soybean as donors of valuable traits. The created collection of androgenic plants of wheatgrass can serve as a good base for further breeding and genetic research.

\section{References}

Goncharov N.P., Goncharov P.L. Metodicheskie osnovy selektsii rastenii: Methodical Basics of Plant Breeding. Novosibirsk: Akad. Izd. Geo, 2009 (in Russian).

Razmakhnin E.P. Androgenesis in vitro in wheatgrass Elytrigia intermedium (Editor-in chief Acad. N.P. Goncharov). Novosibirsk: AO NIIsistem, 2017;144 p. (in Russian).

Razmakhnin E.P. Gene pool of wheatgrass (Agropyron glaucum) as a source of broadening wheat biodiversity. Inform. Vestnik VOGiS. 2008;12(4):701-709 (in Russian).

Razmakhnin E.P., Razmakhnina T.M., Chekurov V.M., Kozlov V.E. RF Patent No. 2370942. Byull. Izo bret. 2009;30. (in Russian)

Razmakhnin E.P., Razmakhnina T.M., Kozlov V.E., Gordeeva E.I., Galitsyn G.Y., Goncharov N.P., Veprev S.G. Obtaining new forms of wheat using distant hybridization and leaf-nurse method. Abstr. of International Conference "Plant Genetics, Genomics and Biotechnology", Novosibirsk, June 17-21. 2015;44-45.

Razmakhnin E.P., Razmakhnina T.M., Kozlov V.E., Gordeeva E.I., Goncharov N.P., Galitsyn G.Y., Veprev S.G., Chekurov V.M. Raising Highly Frost-Resistant Agropyron-Triticum Hybrids. Russian J Genetics: Applied Research. 2012;2(4):344-351.

Tsitsin N.V. Winter Wheat - Wheatgrass Hybrids, in Teoriya i praktika otdalennoi gibridizatsii (Distant Hybridization: Theory and Practice). Moscow: Nauka, 1981. (in Russian)

Acknowledgements. This work was supported by ICG SB RAS budget project No. 0324-2019-0039.

Conflict of interest. The authors declare no conflict of interest. 


\title{
Breeding of soft spring wheat in a changing climate
}

\author{
V.V. Novokhatin \\ Tyumen Scientific Center SB RAS, Tyumen, Russia
}

DOI 10.18699/ICG-PlantGen2019-06

(c) Autor, 2019

* e-mail: natalya_sharapov@bk.ru

\begin{abstract}
When creating the initial breeding material, the use of the family tree of parental varieties allows you to establish the geography of their origin and determine the dynamics of lim-factors of the environment at these geographic points. Hence a possibility to transfer endurance to hybrids to lim-factors of the environment of this zone. The hereditary increase in drought tolerance is due to the ecological-genetic organization of the quantitative traits of the family-defined genetic and physiological systems (GFS) that determine the crop, of which the main ones are: attraction, microdistribution, attracted plastic substances, adaptability, horizontal immunity, tolerance to thickening. Evaluation of the breeding material for these GFS allowed us to distinguish the early maturing line Lutescens 506-11, with their optimal manifestations and pronounced adaptability to the agroclimatic conditions of the Trans-Urals, which became the Grenada variety.

Key words: variety; family tree; lim-factor; environments; genetic-physiological system.
\end{abstract}

\section{Introduction}

Selection of soft spring wheat, in conditions with a pronounced aridity of the first half of the growing season, should be carried out taking into account the creation of the source material based on the expanded genealogical tree of the parental forms. This allows you to identify lim-factors at the geographic points of their origin and to combine in the created hybrids resistance to their negative manifestation. Evaluation of the created breeding material for seven genetic- physiological systems allows objectively selecting the genotypes that are most adaptive to local conditions, high-yielding, with a complex of economically valuable traits and properties.

\section{Material and methods}

Experimental work was carried out on the experimental field of the Research Institute of Agriculture of the Northern Zauralye (a branch of the Tyumen Scientific Center of the Siberian Branch of the Russian Academy of Sciences), in the conditions of the northern forest-steppe zone, on dark gray soil, fertilized with N30P45K30 kg/ha. As the source material, the material of the VIR collection was studied in the amount of 1200 samples of various ecological and geographical origin (Guidelines ..., 1985). Hybridization was carried out using the TV-method. F1, F2 and B1-B4 hybrids and breeding material were studied by the selection method (The program ..., 2011). The selection of elite plants is after a series of stabilizing transfers of hybrid populations against the background of typical dynamics of lim-factors of the environment. Competitive and environmental testing was carried out according to the method of GSI (Methods ..., 1989).

\section{Research results}

The genealogical tree of parental components allows us to establish the geography of their origin and to reveal the dynamics of lim-factors of the environment at various geographic points. The genealogical tree shows kinship in the dynamics of selection, which is ".. evolution directed by the will of man" (Vavilov, 1935). The pedigree of the created varieties allows one to theoretically substantiate the selection of pairs for crossing (Ushiyama et al., 2009; Witcombe, Virk, 2009; Novokhatin, 2016), to conduct a directed formative process and the selection of the necessary ecotypes (Novokhatin, 2016). So the family tree of the mid-season, intensive variety Icarus (var. pyrotrix) consists of 59 varieties, which cover eight secondary centers of the evolutionary development of culture. In the pedigree of the newly registered variety Grenada, the family tree includes 69 varieties of various genetic and ecological-geographical origin (Drahavtsev et al., 1984). In the conditions of climate warming, in the Northern Trans-Urals during the past forty years, the average air temperature has increased from 1.2 to $2.8^{\circ} \mathrm{C}$, and over the past 10 years it increased to $3.1{ }^{\circ} \mathrm{C}$. With an increase in positive active temperatures from 1847 to $2138^{\circ} \mathrm{C}(\mathrm{SCC}=1.31)$ (Novokhatin, 2015), the question of adapting the selection to dry conditions is urgent. The climate of the region has significant differences from those of the surrounding areas, since it is largely determined by the Scandinavian warm anticyclone and impoverished western cyclones. Analysis of the data of the Tyumen HMS for 103 years shows that in the Northern Trans-Urals there were $46 \%$ of years of droughts of varying degrees, of which 36 were significant, 11 years were dry and 8 were very dry, and 26 years were wet (Novokhatin, 2015). Productivity - as a complex indicator - is determined by the ecological-genetic organization of quantitative traits (Drahavtsev et al., 1984). Under climate warming conditions, a hereditary increase in drought resistance is required, one of the main factors of adaptability (Drahavtsev, 2019), which causes a change in the spectra of the products of the genes determining yield (Drahavtsev et al., 1984). At the same time, drought resistance is determined by 22 components, each of which has a share of additive dispersion in a particular set of varieties. Based on the fact that plants have seven genetic and physiological systems (GFS) determining yield, the attraction of the microdistribution of traced plastic substances, adaptability, horizontal immunity, payment for dry biomass of the lim-factor of soil nutrition, tolerance to thickening and variability of ontogenesis phases (Drahavtsev et al., 2017) should be taken into account in the breeding work. Among 
them, one of the determining factors is the GFS of adaptability to common lim-factors in the zone: drought resistance, cold resistance, heat resistance, resistance to salinity and acidic soils, to lodging and to germination of grain in the ear. The rate of adaptability depends on the genotype-environment interaction $(\mathrm{HCV})$, which varies with the productivity ranks of varieties. In the Northern Trans-Urals, out of $25 \%$ of the genetic component, in the formation of yields (from $100 \%$ phenotypic variability) about $20 \%$ are caused by genotypeenvironment interaction (HCV) (Novokhatin, Shelomentseva, 2014), which is an important factor in increasing productivity. Among the 22 components of drought tolerance included in the seven HFS, an important component is the root system that changes in ontogenesis. A large embryo has well-differentiated elements, which makes it possible to select genotypes with 5-6 actively growing germinal roots. At tillering, in rainfed conditions, the primary roots penetrate the soil by $50-70 \mathrm{~cm}$, at earing stage $-130-150 \mathrm{~cm}$ and at full ripeness stage $170-185 \mathrm{~cm}$, and on irrigation $-210-243 \mathrm{~cm}$, the maximum was shown for Kazakhstanskaya 10 cultivar. In dry conditions, the primary root system determines grain yield for early ripening varieties $-77-80 \%$, middle ripening $-67-69 \%$ and late ripening - 53-56\%. It was found that the morphological index associated with drought tolerance is the magnitude of the removal of the spike (Novokhatin, 2015). It should be borne in mind that spring wheat hybrids obtained with the participation of winter forms have a more developed and deeper penetrating secondary root system. Complex, often changing climatic conditions require the creation of well-adapted, plastic varieties. This is largely solvable when use in the breeding work all seven genetic-physiological systems (GFS) contributing to productivity. Evaluation of breeding lines on the main five GFS allowed identification, among them, of Lutescens 506-11 F5 [F1 (Kazakhstani early maturation $\times$ Tulunskaya 12) $\times$ Tulunskaya 12], which became the variety Grenada. In 'Grenada', the attraction is well pronounced: the recycling of plastic substances from the stem and leaves into an ear. This provides a full-bodied, well-ribbed ear. The new variety shows resistance to early summer drought due to a well-developed root system and dense cuticular wax coating. The variety is able to develop well and form high quality grain on slightly acidic soils and in cool conditions. The GFS of polygenic immunity (horizontal stability) of 'Grenada' is caused by a strong cuticular wax coating of leaves and stem, a gray-blue color, which prevents germination of fungal spores - septarios, rust, powdery mildew. Dense pubescence of leaves and leaf sheaths limits the accumulation of spores on them, protects them from damage by stealth and leaf-eating pests, and as albedo protects plants from overheating. GFS tolerance to thickening is one of the main criteria for the creation of varieties for intensive farming. A productive cenosis should provide from 510 to 560 productive tillers on $1 \mathrm{~m}^{2}$. With a grain mass from an ear of 1.1-1.2 (28-30 grains with a grain weight of $0.04 \mathrm{~g})$, the biological yield is from 5.5 to $6.4 \mathrm{t} / \mathrm{ha}$, which is typical of the new variety Grenada. Improving Drought tolerance should be improved with the help of wild species. An example of those is the variety Serebrina, a somatic hybrid of intensive 'Kazakhstanskaya 10' and non-extruded nuclear material of bluegrass meadowgrass, characterized by a combination of drought tolerance and resistance to pathogens and pests. Drought tolerance and adaptability of wheat are enhanced by transgenesis, by introducing amphidiploid genes by inserting foreign DNA into the recipient's genome. Breeding forms with triticale and sphaerococcum wheat were obtained. Newly created varieties should be resistant to lodging and to the preharvest germination of grain in the ear. This is possible only when evaluating the breeding material in provocative conditions. Thus, resistance to pre-harvest germination of grain in an ear is estimated by the activity of the $\alpha$-amylase complex and pre-harvest germination of grain in an ear in provocative laboratory conditions.

\section{Conclusions}

The use of the genealogical tree of parental forms allows you to identify lim-factors of the environment at geographical points of their origin. This allows to create hybrids resistant to environmens. Evaluation of breeding lines for seven genetic-physiological systems (GFS) allows to select productive genotypes, adaptive to local conditions, with a complex of agronomically valuable traits and properties. The analogue is the early ripe cultivar Grenada, created and registered in 2019, with horizontal resistance to pathogens.

\section{References}

Drahavtsev V.A. The solution of technological problems of breeding increase of yields arising from the theory of ecological organization of quantitative traits. East European Seientific J. 2019;2(42):11-26.

Drahavtsev V.A., Mikhaylenko I.M., Proskuryakov M.A. Non-conic approach to solving the problem of hereditary increase in drought resistance in plants (on the example of cereals). Agricultural Biol. 2017;52(3):487-500. DOI 10.15389/agrobiology. 2017.3.487.

Drahavtsev V.A., Tsilke R.A., Reiter B.G., Vorobyev V.A., Dubrovskaya A.G., Korobeinikov N.I., Novokhatin V.V., Maksimenko V.P., Babakishiyev A.G., Ilyushchenko V.G., Kalashnik N.A., Zuykov Yu.P., Fedotov A.M. Genetics of productivity signs of spring wheat in Western Siberia. Novosibirsk: Science, 1984:230.

Guidelines for the study of the world collection. Leningrad: VIR, 1985 $27 \mathrm{p}$.

Methods of State variety testing of agricultural crops (release of the second). Moscow, 1989;194.

Novokhatin V.V. Bioclimatic resources of the Northern Trans-Urals. Agrarian Bul. (Ekaterinburg). 2015;8:22-28.

Novokhatin V.V. Primary root system of spring soft wheat. Bulletin Russian Academy Agricultural Sci. (Moscow). 2015;1:35-39.

Novokhatin V.V. The effectiveness of various selection methods in plant breeding. Achievements Sci Technol. Agriculture. 2016;(3):42-45.

Novokhatin V.V., Shelomentseva T.V. Growth of spring soft wheat yield in the Northern Trans-Urals. Bul. RAAS. 2014;4:14-17.

The program of the integrated plant breeding and seed center for plant growing of the GNU Research Institute of Agriculture of the Northern Zauralye for the period from 2011-2030 / Novokhatina V.V. (Ed.). Tyumen, 2011;98.

Ushiyama T., Nakamura K., Anas Yoshida T. Pedigree analysis for breeding cultivars with higher performance. Plant Prod. Sci. 2009; 12(1):80-87. DOI 10.1626/pps.12.80.

Vavilov N.I. Scientific basis of wheat breeding. Moscow; Leningrad, $1935 ; 2: 158$.

Witcombe J.R., Virk D.S. Methodologies for generating variability. Part 2. Selection of parents and crossing strategies. Plant breeding and farmer participation. Ceccarelli S., Guinarres E.P., Weltizienm E. (Eds.). Rome, 2009;129-138.

Conflict of interest. The authors declare no conflict of interest. 


\title{
Spring common wheat breeding lines produced on the basis of distant hybridization: ecological strain testing in Bagan
}

\author{
B.F. Nemtsev ${ }^{1}$, A.B. Nemtsev², N.P. Goncharov ${ }^{2}$, S.V. Kurkova ${ }^{3}$ \\ ${ }^{1}$ Siberian Research Institute for Plant Industry and Breeding - Branch of the Institute of Cytology and Genetics, SB RAS, Krasnoobsk, Novosibirsk region, Russia \\ ${ }^{2}$ Institute of Cytology, RAS, St. Petersburg, Russia \\ ${ }^{3}$ North-Kulunda Department of Siberian Research Institute of Feed, Siberian Branch of the Russian Academy of Sciences
}

DOI 10.18699/ICG-PlantGen2019-07

(c) Autors, 2019

*e-mail: nembor@yandex.ru

\begin{abstract}
The article presents of studying--under the conditions of the agriculturally risky Kulunda steppe-the ecological homeostasis of spring common wheat breeding lines created using remote hybridization. The studies were carried out at the breeding and seed sector of grain and feed crops of the Siberian Research Institute of Feed North-Kulunda Department. One of the important indicators characterizing the resistance of plants to adverse environmental factors is homeostasis, a universal property in the system of the relationship between the genotype and the environment. Homeostasis is the ability of the genotype to minimize the effects of adverse external conditions. Statistical processing was performed using a package of Snedecor applications. We carried out the analysis of the homeostasis of the selection lines according to the algorithms developed by S.P. Martynov, the yield variance analysis of multiyear experience according to Tomilov, and multidimensional ranking of varieties on the main breeding traits, which was designed by I.A. Uzhakov. A breeding line (1459-E-06) of spring common wheat with high responsiveness to the environmental conditions and stable high yield was selected. This line was made by crossing spelt with durum wheat and further backcrossing with common wheat. This line is advisable for use as a source of high productivity of plants in the selection process, to obtain new genotypes with high adaptive properties and is recommended for transfer to the state strain testing.
\end{abstract}

Key words: spring wheat; interspecific hybridization; homeostasis; agronomic traits.

\section{Introduction}

Interspecific hybridization is currently one of the most effective breeding methods. The hybridization of common wheat with the hexaploid species Triticum compactum Host and T. sphaerococcum Perc. is easy as these species are genetically compatible. The use of wheat species in practical breeding is usually associated with the production of easily threshable forms.

Crossing of common wheat with T. sphaerococcum Perc. is promising, as it results in hybrids with high grain quality and early maturity. In addition to these properties, such hybridization allows plants with a solid straw, drought resistance and frost resistance to be obtained (Dorofeev, 1987).

When crossing spelt with common wheat, new varieties are resistant to diseases. In the world of wheat breeding, spelt played an important role as the initial form for interspecific crosses. N.I. Vavilov in 1911-1913 found hybrids with resistance to powdery mildew and brown rust. He considered promising the crossing of spelt with common and durum wheat cultivars (Vavilov, 1935). When inheriting signs of spelt, it dominates if it is taken as a mother plant.

\section{Materials and methods}

Modern breeding is based primarily on the use of the existing diversity of germplasm cultivated plants. And only carrying out distant hybridization with wild relatives allows makes it possible to increase it to an extent as well as to transfer it from some systematic units to other economically valuable traits or properties (Goncharov N.P., Goncharov P.L., 2018).
Through the use of distant hybridization, the breeder is looking for opportunities to expand the biodiversity of existing new economic plant species. In the Sector of Wheat Genetics, N.P. Goncharov produced common wheat hybrids with T. compactum, T. sphaerococcum, T. dicoccum, T. durum, Aegilops squarrosa (Table 1).

In these hybrid combinations, individual selection was carried out on the basis of signs of the main spike (length, number of spikelets, number of grains, mass of grain), with using of a selection criterion according Nemtsev (1989). The lines selected were tested according to the basic breeding scheme. Field experiments, observations and processing of the results of the experiment were carried out according to Armor (1985), and analyes and accounting according to VIR methods (Fedin, 1985). Statistical processing was performed using the Snedecor application package (Yuzhakov, Sorokin, 2000).

\section{Results and discussion}

As a result of the long selection of breeding lines, four lines have been allocated for environmental testing at the North Kulunda Department of Siberian Research Institute of Feed, During selection, it was taken into account that the lines should be adapted to unfavorable growing conditions. Attention was paid to the survival of plants. Only those lines that had a strong stem were selected, because of the humid continental climate. Soils are poor chernozems often with a loamy composition; salt licks; marsh soils. The weather conditions of the growing seasons of 2016 and 2017 were dry in Bagan, the amount of precipitation did not reach the average multi-year norm; in 
Table 1

The origin of the lines

\begin{tabular}{|c|c|c|c|c|}
\hline Breeding line & Origin & Generation (Progeny selection) & Selection type & Year \\
\hline 1459-E-06 & $\begin{array}{l}((\text { BS1E T. dicoccum x \# } 668 \text { T. durum }) \times \text { Novosibirsk 29) } \times \\
\text { Novosibirsk } 29\end{array}$ & $\mathrm{~F} 18(\mathrm{~F} 6)$ & individual & 2006 \\
\hline $1486-E-10$ & $\begin{array}{l}\text { [(Novosibirsk } 20 \times(\mathrm{k}-23790 \text { T. sphaerococcum India } \times \\
\text { Cl3090 T. compactum USA })) \times \text { Novosibirsk 29] } \times \\
\text { Novosibirsk } 29\end{array}$ & $\mathrm{~F} 16(\mathrm{~F} 6)$ & individual & 2008 \\
\hline 1488-E-09 & $\begin{array}{l}\text { (Bezostaya } 1 \times \text { Siberian 62) } \times \text { KU 221-24 (Vernal } \\
\text { T. dicoccum } \times \text { KU2074 Aegilops squarrosa) }) \times \\
(\text { Bezostaya } 1 \times \text { Siberian 62)] }\end{array}$ & F16(F7) & individual & 2009 \\
\hline 1436-E-03 & Novosibirsk $20 \times$ Astella (Czech winter variety) & $\mathrm{F} 18(\mathrm{~F} 3)$ & individual & 2003 \\
\hline
\end{tabular}

Table 2

Structure of the harvest (2016-2018)

\begin{tabular}{|c|c|c|c|c|c|c|c|c|c|c|c|c|}
\hline 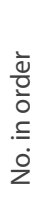 & 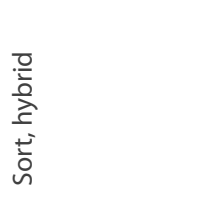 & 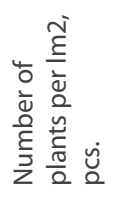 & 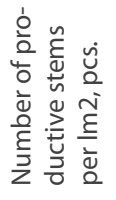 & 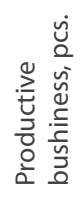 & 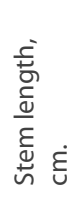 & 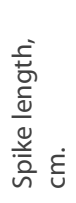 & 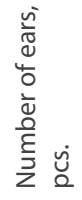 & 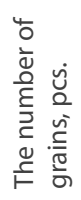 & 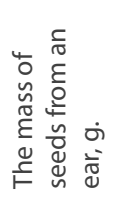 & 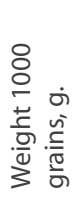 & 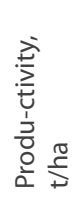 & 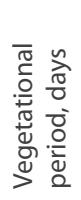 \\
\hline 1 & Omskaya 36 (st) & 191,5 & 250,8 & 1,3 & 73,7 & 6,5 & 9,5 & 24,1 & 0,90 & 35,0 & 2,33 & 75 \\
\hline 2 & 1459-E-06 & 264,7 & 338,5 & 1,3 & 67,1 & 6,0 & 9,0 & 23,5 & 0,78 & 32,7 & 2,64 & 76 \\
\hline 3 & 1486-E-10 & 277,6 & 314,0 & 1,2 & 64,4 & 5,1 & 9,0 & 20,6 & 0,60 & 29,0 & 1,97 & 75 \\
\hline 4 & 1488-E-09 & 260,8 & 330,0 & 1,3 & 63,2 & 4,9 & 9,0 & 22,3 & 0,60 & 27,2 & 1,97 & 75 \\
\hline \multirow[t]{2}{*}{5} & 1436-E-03 & 185,7 & 263,4 & 1,5 & 68,7 & 6,4 & 10,3 & 22,8 & 0,72 & 31,5 & 2,04 & 75 \\
\hline & NSR05 & 42,9 & 60,8 & 0,15 & 4,04 & 0,72 & 0,59 & 0,91 & 0,15 & 2,5 & 0,13 & 1,0 \\
\hline
\end{tabular}

Bakery evaluation showed that line 1459-E-06 is the best and belongs to the group of strong wheat (Table 3 ).

Table 3

Grain quality (2016-2018)

\begin{tabular}{|c|c|c|c|c|c|c|c|c|c|c|}
\hline \multirow[b]{2}{*}{$\begin{array}{l}\text { No. } \\
\text { in order }\end{array}$} & \multirow[b]{2}{*}{$\begin{array}{l}\text { Sort, } \\
\text { hybrid }\end{array}$} & \multirow[b]{2}{*}{$\begin{array}{l}\text { Natures, } \\
\text { g/l }\end{array}$} & \multirow[b]{2}{*}{$\begin{array}{l}\text { Vitreous- } \\
\text { ness (\%) }\end{array}$} & \multirow[b]{2}{*}{$\begin{array}{l}\text { Gluten } \\
\text { wine }\end{array}$} & \multirow[b]{2}{*}{$\begin{array}{l}\text { IDK-1, } \\
\text { units ap- } \\
\text { pliance }\end{array}$} & \multicolumn{3}{|c|}{ Aveogramma } & \multirow[b]{2}{*}{$\begin{array}{l}\text { Volume } \\
\text { of bread } \\
\mathrm{cm} 3 / 100 \mathrm{~g}\end{array}$} & \multirow[b]{2}{*}{$\begin{array}{l}\text { Total bak- } \\
\text { ery grade, } \\
\text { score }\end{array}$} \\
\hline & & & & & & $\begin{array}{l}\text { Flour } \\
\text { strength, } \\
\text { e.a. }\end{array}$ & $\begin{array}{l}\text { Dough } \\
\text { elasticity, } \\
\mathrm{mm}\end{array}$ & $\mathrm{P} / \mathrm{L}$ & & \\
\hline 1 & Omskaya 36 (st) & 759 & 50 & 28,2 & 60 & 511 & 103 & 1,28 & 760 & 4,1 \\
\hline 2 & 1459-E-06 & 762 & 50 & 29,3 & 62 & 589 & 107 & 1,32 & 760 & 4,3 \\
\hline 3 & 1486-E-10 & 702 & 50 & 36,6 & 74 & 277 & 46 & 0,22 & 660 & 3,8 \\
\hline 4 & 1488-E-09 & 718 & 50 & 29,2 & 62 & 400 & 65 & 0,26 & 720 & 4,3 \\
\hline \multirow[t]{4}{*}{5} & 1436-E-03 & 706 & 56 & 30,5 & 72 & 299 & 57 & 0,32 & 620 & 4,0 \\
\hline & The average & 729,4 & 51,2 & 30,8 & 66,0 & 415,2 & 75,6 & 0,680 & 704,0 & 4,10 \\
\hline & $\begin{array}{l}\text { Standart } \\
\text { deviation }\end{array}$ & 25,95 & 2,40 & 3,01 & 5,80 & 120,18 & 24,78 & 0,507 & 55,71 & 0,19 \\
\hline & Medium error & 11,61 & 1,07 & 1,35 & 2,59 & 53,75 & 11,08 & 0,227 & 24,92 & 0,08 \\
\hline
\end{tabular}


Table 4

Ranking of objects according a set of signs

\begin{tabular}{lllll}
\hline Place of the object & Sort, hybrid & Sum of ranks & Sum of weighted ranks & Euclidean distance \\
\hline 1 & $1459-\mathrm{E}-06$ & 79,0 & 79,0 & 1311,7 \\
2 & Omskaya 36 (st) & 69,5 & 64,5 & 1242,9 \\
3 & $1436-\mathrm{E}-03$ & 60,5 & 55,5 & 1049,1 \\
4 & $1488-\mathrm{E}-09$ & 48,0 & 43,0 & 1180,4 \\
5 & $1486-\mathrm{E}-10$ & 43,0 & 38,0 & 1097,0 \\
\hline
\end{tabular}

Table 5

Evaluation of homeostasis varieties

\begin{tabular}{|c|c|c|c|c|}
\hline No. in order & Sort, hybrid & Productivity, t/ha & Homeostatism & \\
\hline 1 & 1459-E-06 & 2,66 & 4,58 & above the average \\
\hline 2 & Omskaya 36 (st) & 2,33 & 1,45 & above the average \\
\hline 3 & 1436-E-03 & 2,04 & $-1,45$ & below the average \\
\hline 4 & $1486-E-10$ & 1,97 & $-2,17$ & below the average \\
\hline 5 & 1488-E-09 & 1,96 & $-2,41$ & below the average \\
\hline Medium index & & 2,189 & & \\
\hline NSR05 & & 0,079 & & \\
\hline
\end{tabular}

2018, $204.4 \%$ fell out during the growing season, and the average daily air temperature was $1.5^{\circ} \mathrm{C}$ below the multiyear average.

Univariate analysis of variance of plants showed that line 1459-E-06 was significantly superior to the standard: it had 73.2 more plants per square meter, 87.7 more productive stems per square meter, its yield was increased by $0.31 \mathrm{t} / \mathrm{ha}$, and the stems were $6.6 \mathrm{~cm}$ shorter. There were no significant differences in the rest of the signs (Table 2).Based on the above data, we carried out a multidimensional ranking of the varieties according to the main breeding characteristics developed by A.I. Yuzhakov. The program is designed for a multidimensional ranking of study objects (varieties of crops, animals, soil samples, etc.) according a set of features, the values of which, increasing from minimum to maximum, reflect their economic (or other) value. In fact, this is a method of an automatic classification of objects into three groups, according to the principle of increasing the distance of objects from the origin of coordinates, expressed by a generalized rank.

Since signs can have different degrees of utility, it is possible to specify a certain system of weights for each attribute, in the form of numbers from -10.0 to 10.0 (a negative weight value is for signs reflecting negative, undesirable properties of objects); if you do not specify the weight, the program assumes that all signs have an equal degree of utility (1.0). For the same data set, several rankings can be made by varying the weights system. According to the results of a comprehensive assessment of traits with weights $(+1.0)$ and only for the growing season (-1.0), line 1459-E-06 comes first (Table 4).

An important place in the selection of ecologically plastic varieties is occupied by the theory of homeostasis as the ability of plants to maintain internal balance and unleash the genetically determined potential of the variety at the phenotype level when conditions become abnormal (Yusufov, 1983). The state of homeostasis can be used as the main criterion for assessing the genotype. The measure of homeostasis of a variety is its ability to keep yield reductions to a minimum when conditions of cultivation deteriorate. The above is of great importance for obtaining not only maximum, but also stable yields in a wide range of growing conditions. Stable grain yield indicates high homeostasis. In contrast, large variability is indicative of a low homeostasis of the genotype with the same limiting environmental factors (Sapega, 1988). It has been established that high homeostatic genotypes in agrocenoses give less variation in plant productivity and slightly reduce yield with thick sowing or a combination of adverse factors with thickening (Hangildin, Litvinenko, 1981). Homeostasis is associated with tolerance to adverse environmental factors (Allard, Bradshaw, 1964).Analysis of the homeostasis of breeding lines according to the algorithm developed by S. S. Martynov was carried out. This program was designed to analyze the homeostasis of a certain set of varieties in an experiment performed in one of two ways: in growing conditions at several geographically dispersed points, or in different modes specially created in artificial growth chambers; for several years at one point, as in the present research.

\section{Conclusions}

Thus, the use of the existing set of techniques to identify potential productivity of agricultural crops makes it possible to establish the reliability of the observed differences and obtain the necessary information for the selection of valuable start- 
ing material in the selection for adaptability. A selection line (1459-E-06) of spring soft wheat with high responsiveness to environmental conditions and stable yield was selected. This line was produced by crossing spelt with durum wheat and further backcrossing with common wheat. The line gave an increase in yield due to better survival of plants. This line is advisable to use as a source of high productivity of plants in the breeding process, to obtain new genotypes with high adaptive properties and is recommended for transfer to state trials.

\section{References}

Allard R.W., Bradshaw A.D. Implication of genotype environmental interaction in applied plant breeding. Crop Sci. 1964;4:503-508.

Armor B.A. Methods of field experience (with the basics of statistical processing of research results). Moscow, 1985.

Fedin M.A. Methods of state variety testing of agricultural crops. Publisher: USSR Ministry of Agriculture. 1985.

Goncharov N.P., Goncharov P.L. Methodical bases of plant breeding. $3^{\text {nd }}$ ed. Novosibirsk: Acad. Publ. house "Geo", 2018
Hangildin V.V., Litvinenko N.A. Homeostaticity and adaptability of winter wheat varieties. Scientific Technical Bul. 1981;1:8-14.

Nemtsev B.F. Refinement of selection parameters by quantitative characteristics. Sat scientific tr. In: VASKhNIL. detachment SibNIIRS. RPO with the Academy of Agricultural Sciences, 1989;74-80.

Sapega V.A. Productivity and homeostasis of zoned varieties of spring wheat. Bul Agricultural Sci Kazakhstan. 1988;10:24-28.

Vavilov N.I. Scientific bases of wheat breeding. Moscow; Leningrad, 1935.

Dorofeev V.F. (Ed.). Wheat of the world; 2nd ed. Leningrad, 1987.

Yusufov A.G. Homeostasis and its significance in the ontogeny of plants. Agricultural Biol. 1983;1:25-35.

Yuzhakov A.I., Sorokin O.D. Software package applied "Snedecor V4" for processing data obtained in biological experiments. Information technologies, Information measuring systems and devices in research of agricultural processes, Materials of the regional scientificpractical conference. Novosibirsk, 2000.

Acknowledgements. The work is supported by the RSF grant 16-16-10021P.

Conflict of interest. The authors declare no conflict of interest. 


\title{
Creation and study of partial waxy wheat lines adapted for the Middle Volga region of Russia
}

\author{
D-l.F. Askhadullin ${ }^{1 *}$, D-r.F. Askhadullin ${ }^{1}$, N.Z. Vasilova ${ }^{1}$, R.R. Vafin ${ }^{2}$ \\ ${ }^{1}$ Tatar Scientific Research Institute of Agriculture, FRC Kazan Scientific Center RAS, Kazan, Russia \\ ${ }^{2}$ All-Russian Scientific Research Institute of the Brewing, Non-Alcoholic and Wine Industry, FRC for Food Systems RAS, Moscow, Russia
}

DOI 10.18699/ICG-PlantGen2019-08

(c) Autors, 2019

*e-mail: tatnii-rape@mail.ru

\begin{abstract}
From crossing the winter wheat variety Starshina (has the non-functional allele Wx-A1b) and spring wheat line 0-192-03-5 (has the non-functional allele Wx-B1b), we obtained two promising lines of partial waxy wheat, which combines the non-functional alleles $W x-A 1 b$ and $W x-B 1 b$. These lines are K-243-13Wx-2 and K-243-13Wx-6. Evaluation of these lines was conducted in the Tatar Research Institute of Agriculture in 2017-2018. The analysis of agronomically valuable traits of the obtained lines of partial Waxy wheat indicates prospects for their use as prebreeding material for the development of spring wheat varieties with a modified composition of grain starch.
\end{abstract}

Key words: wheat; waxy; non-functional alleles; disease resistance; productivity.

\section{Introduction}

One of the main parameters characterizing the functional properties of starch is the ratio of amylose / amylopectin. Biosynthesis of amylose is blocked partially or completely, if no GBSS enzyme is synthesized, for the production of which Waxy-genes are responsible. Non-functional alleles of Waxygenes cause synthesis disorders and changes in the localization of amylose in starch. Wheat samples carrying non-functional alleles at three loci are called 'Waxy wheat', and those carrying non-functional alleles at one or two loci are called 'partially Waxy wheat'. The creation of Waxy wheat varieties makes it possible to open new directions in the use of wheat grain. The search for non-functional alleles of Waxy-genes in Russian wheat varieties showed that these mutations are extremely rare (Klimushina et al., 2012; Abdulina et al., 2013; Boboshina, Boronnikova, 2013; Netsvetaev et al., 2015). The null allele $W x-D 1 b$ was not found in Russian varieties. The aim of our research was to assess the agronomically valuable traits of our two promising lines of partially Waxy wheat combining the non-functional alleles $W x-A 1 b$ and $W x-B 1 b$.

\section{Materials and methods}

We obtained two promising lines of partial waxy wheat, which combine the non-functional alleles $W x-A 1 b$ and $W x-B 1 b$. These lines were developed from hybridization of the winter wheat variety Starshina (has the non-functional allele $W x-A 1 b$ ) and spring wheat line O-192-03-5 (has the non-functional allele $W x-B 1 b)$ and were designated as K-243-13Wx-2 and K-243-13Wx-6.

The screening of wheat lines and varieties is performed with the molecular markers specific for the alleles of the analyzed gene loci (Table 1).

Nucleic acid extraction from wheat grains of milky-wax ripeness of the 2017 generation was performed using a commercial set of 'DNA-sorb C' (Central Scientific Research Institute of Epidemiology, Russia) in accordance to the manufacturer's instructions.

Evaluation of these lines was conducted in the Tatar Research Institute of Agriculture in 2017-2018. The Tatar RIA is located in the northern part of the Middle Volga region of Russia.

Table 1

List of the primers, protocols of PCR amplification for the identification of alleles of wheat Waxy genes

\begin{tabular}{|c|c|c|}
\hline Names and sequences of oligonucleotide primers & Alleles & Amplification protocols \\
\hline 4F: 5'-AAGAGCAACTACCAGT-3' & Wx-A1 & \multirow{3}{*}{$\begin{array}{l}\times 1: 94{ }^{\circ} \mathrm{C}, 4 \mathrm{~min} . \times 40: 94^{\circ} \mathrm{C}, 30 \mathrm{sec} ; 58^{\circ} \mathrm{C}, 30 \mathrm{sec} ; \\
72{ }^{\circ} \mathrm{C}, 30 \mathrm{sec} \times 1: 72{ }^{\circ} \mathrm{C}, 7 \mathrm{~min} .\end{array}$} \\
\hline 4R: 5'-TCGTACCCGTCGATGAAGTCGA-3' (Vanzetti et al., 2009; & Wx-B1 & \\
\hline McLauchlan et al., 2001) & Wx-D1 & \\
\hline 4F-c. $5^{\prime}-C C C C C A A G A G C A A C T A C C A G T-3^{\prime}$ & Wx-A1 & \multirow{3}{*}{$\begin{array}{l}\times 1: 94^{\circ} \mathrm{C}, 4 \mathrm{~min} \times 40: 94^{\circ} \mathrm{C}, 30 \mathrm{sec} ; 64^{\circ} \mathrm{C}, 30 \mathrm{sec} ; \\
72^{\circ} \mathrm{C} 30 \mathrm{sec} \times 1: 72^{\circ} \mathrm{C}, 7 \mathrm{~min} .\end{array}$} \\
\hline 4r-C. & Wx-B1 & \\
\hline 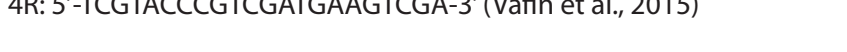 & Wx-D1 & \\
\hline 4F-c: 5'-CCCCCAAGAGCAACTACCAGT-3' & Wx-B1 & $\times 1: 94^{\circ} \mathrm{C}, 4 \mathrm{~min} . \times 40: 94^{\circ} \mathrm{C}, 15 \mathrm{sec} ; 65^{\circ} \mathrm{C}$, \\
\hline Wx-B2R: 5'-CGTTGACGATGCCGGTGTTG-3' (Vafin et al., 2015, 2018) & (B1b) & $15 \mathrm{sec} ; 72{ }^{\circ} \mathrm{C}, 15 \mathrm{sec} \times 1: 72^{\circ} \mathrm{C}, 7 \mathrm{~min}$. \\
\hline AFC: 5'-TCGTGTTCGTCGGCGCCGAGATGG-3' & Wx-A1 & $\times 1: 94{ }^{\circ} \mathrm{C}, 4 \mathrm{~min} . \times 40: 94^{\circ} \mathrm{C}, 30 \mathrm{sec} ; 65^{\circ} \mathrm{C}, 30 \mathrm{sec}$; \\
\hline AR2: 5'-CCGCGCTTGTAGCAGTGGAAGTACC-3' (Nakamura et al., 2002) & $(\mathrm{A} 1 \mathrm{~b})$ & $72{ }^{\circ} \mathrm{C}, 1 \mathrm{~min} \times 1: 72{ }^{\circ} \mathrm{C}, 7 \mathrm{~min}$. \\
\hline
\end{tabular}




\section{Results and discussion}

The average yield of line K-243-13Wx-6 was $276 \mathrm{~g} / \mathrm{m}^{2}$, which is much lower than that of the standard variety Yoldyz, $550 \mathrm{~g} / \mathrm{m}^{2}$. Line $\mathrm{K}-243-13 \mathrm{Wx}-2$ has an average yield of $534 \mathrm{~g} / \mathrm{m}^{2}$. The average weight of 1000 grains in K-243-13Wx-2 is $49.6 \mathrm{~g}$. In K-243-13Wx-2, the degree of lesion by leaf rust was $0-15 \%$, the degree of damage by stem rust was $15 \%$. This line is susceptible to powdery mildew, its resistance is 3 points ( 9 points is the maximum). Line $\mathrm{K}-243-13 \mathrm{Wx}-6$ is susceptible to leaf rust, the degree of damage was $15-50 \%$. Line K-43$13 \mathrm{Wx}-6$ is susceptible to stem rust, the degree of damage was $30-70 \%$. Resistance to powdery mildew of this line in epiphytotic 2017 was 4 points. In K-243-13Wx-2, the earing date is 1 day before that of O-192-03-5. In K-243-13Wx-6, the earing date is the same as in O-192-03-5. According to the analysis of the grain harvested in 2018, K-243-13Wx-2 and $\mathrm{K}-243-13 \mathrm{Wx}-6$ have a high protein content in the grain of 14.9 and $14.5 \%$, respectively, and have a high gluten content in the grain of 30.8 and $31.7 \%$, respectively.

\section{Conclusions}

The evaluation of agronomically valuable traits of the obtained lines of partial Waxy wheat (K-243-13Wx-2 and $\mathrm{K}-243-13 \mathrm{Wx}-6$ ) indicates prospects for their use as a starting prebreeding material for the development of spring wheat varieties with a modified composition of grain starch. In addition, the yield of line K-243-13Wx2 following two years of testing was not inferior or was higher than that of the sibs. The productivity of K-243-13Wx2 significantly exceeded the productivity of foreign varieties: Barunga, Ones 53 , Renee, Adisiba, Sonora 37, all carrying the $W x-B 1 b$ allele. Their yield was $35-51 \%$ of the yield of line K-243-13Wx2 carrying two Null-alleles. Whether line K-243-13Wx2 is suitable for industrial introduction will be shown by analysis of the the starch grain properties.

\section{References}

Abdulina I.R., Vafin R.R., Tyulkin S.V. et al. Detection of null WxB1b-allele of the Waxy-gene in spring wheat genotypes of Russian breeding. Modern Problems Science Education. 2013;2 (in Russian).

Boboshina I.V., Boronnikova S.V. Allelic variants of Waxy genes in Triticum aestivum L. cultivars grown in the Perm region and Bashkiria. Vavilov J. Gen. Breed. 2013;17(3):535-540.

Klimushina M.V., Gladkih N.I., Divashuk M.G. et al. Distribution of allelic variants of $W x$ genes in the common wheat collection made at the Krasnodar Lukyanenko research institute of agriculture. Vavilov J. Gen. Breed. 2012;16(1):187-192.

McLauchlan A., Ogbonnaya F.C., Hollingsworth B., Carter M., Gale K.R., Henry R.J., Holton T.A., Morell M.K., Rampling L.R., Sharp P.J., Shariflou M.R., Jones M.G.K., Appels R. Development of robust PCR-based DNA markers for each homeo-allele of granulebond starch synthase and their application in wheat breeding programs. Austral. J. Agricul. Res. 2001;52(11-12):1409-1416.

Nakamura T., Vrinten P., Saito M., Konda M. Rapid classification of partial waxy wheats using PCR-based markers. Genome. 2002;45: $1150-1156$.

Netsvetaev V.P., Ryzkova T.A., Tretyakov M.U. The quality of soft wheat. Belgorod, 2015. ISBN 978-5-85153-155-2 (in Russian).

Vafin R.R., Rzhanova I.V., Askhadullin D.F., Askhadullin D.F., Vasilova N.Z., Tagirov M.Sh., Tyulkin S.V., Abdulina I.R., Shagalieva G.I. Identification of Triticum aestivum L. genotype by allelic versions of waxy-genes and hmw glutenin subunits. Ecol., Envir. Conser. 2015;21:137-143.

Vafin R.R., Rzhanova I.V., Askhadullin D.F., Askhadullin D.F., Vasilova N.Z. Screening of the genotypes of bread wheat (Triticum aestivum L.) by the allelic variants of waxy genes and hmw glutenin subunits. Acta Agrobot. 2018;71(4):1746. DOI 10.5586/aa.1746

Vanzetti L.S., Pfluger L.A., Rodriguez-Quijano M., Carrill, J.M., Helguera M. Genetic variability for waxy genes in Argentinean bread wheat germplasm. Electr. J. Biotechnol. 2009;12(1):1-9.

Acknowledgements. This research was supported by FASO Russia project AAAA-A18-118031390148-1.

Conflict of interest. The authors declare no conflict of interest. 


\title{
Internal stem features of spring wheat varieties as factors determinig resistance to lodging
}

\author{
E.V. Ageeva ${ }^{1 *}$, I.N. Leonova ${ }^{2}$, E.A. Salina ${ }^{2}$, I.E. Likhenko ${ }^{1}$ \\ ' Siberian Research Institute for Plant Industry and Breeding - Branch of the Institute of Cytology and Genetics, SB RAS, Krasnoobsk, Novosibirsk region, Russia \\ ${ }^{2}$ Institute of Cytology and Genetics, SB RAS, Novosibirsk, Russia
}

DOI 10.18699/ICG-PlantGen2019-09

(c) Autors, 2019

* e-mail: elenakolomeec@mail.ru

\begin{abstract}
Using the anatomical method, the study of the main parameters of the internal stem structure of Russian spring bread wheat varieties was performed in order to assess their impact on resistance to lodging. An increase in the number of parenchyma vascular bundles from top to bottom was established. The decrease in the diameter of the vascular bundles is compensated for by an increase in their number. The diameter of vascular bundles in the internodes had a slight effect on resistance to lodging. The relationship between the numbers of bundles and stem diameter in both interstices was traced. Resistance to lodging correlated with the number of vascular bundles and the length of the internode EN1 and EN2. The number of vascular bundles, stem diameter and thickness of the primary cortex contribute to a high productivity of the ear. The study of anatomo-morphological traits allowed us to identify the cultivars 'Novosibirskaya 31,' 'Velut' and 'Bel', which may be of interest for breeding for resistance to lodging.

Key words: resistance to lodging; stem; vascular bundles; parenchyma; internode; wheat.
\end{abstract}

\section{Introduction}

Resistance to lodging is one of the important characteristics of modern varieties of bread wheat. Lodging results in a decline in yield and grain quality, and hampers mechanical harvesting. Resistance to lodging in plants is determined by anatomomorphological, physiological, and chemical parameters of stems (Packa et al., 2015). Anatomical characters usually include the length and diameter of the stem, the number and diameter of the vascular bundles, and the thickness of the primary cortex. However, now there is no consensus as to which parameters make the main contribution to lodging resistance. The aim of our study was to investigate the anatomo-morphological parameters of the stem in Russian varieties of bread wheat.

\section{Materials and methods}

Plant material incudes 11 Russian spring wheat varieties presented in Table 1. Plants were grown on the experimental field of Siberian Research Institute for Plant Industry and Breeding - Branch of the Institute of Cytology and Genetics SB RAS in 2018. For analysis of the stem anatomical structure, a technique developed at the All-Russian Research Institute of Grain Crops named after I.G. Kalinichenko (2009) for assessment of the conductive system of the ear's internode was used. Estimation of the internodes was carried out on the base of the method proposed by Lazarevich S.V. (1999), that is, from the internode under the ear to the internodes of the lower part of the stem. The internode under the ear was denoted 'EN1' (entre-noeud), the second from the top, 'EN2' and etc. Particular attention in the study of the internal structures of the stem of spring bread wheat in internodes EN1 and EN2 in the varieties was given to the stem diameter, the thickness of the primary cortex, the number and diameter of the vascular parenchyma bundles. Resistance to lodging was scored by a five-point standard technique. For statistical processing, an
ANOVA method were used (Dospekhov, 1985). Principal coordinate analysis of the total number of the traits was done with the use of the MRAN software Snedecor 5. The factor analysis was carried out using STATISTICA 8.

\section{Results and discussion}

The varieties 'Saratovskaya 29' and 'Novosibirskaya 18' were the most prone to lodging. Slightly sopping stems were observed in the 'Novosibirskaya 29', 'Chernyava 13' and 'Novosibirskaya 31' genotypes. The remaining samples of the set do not lodge. The number of bundles in EN1 among the studied samples varied from 14 to 24, but in EN2, from 16 to 33 (see Table 1). On average, an increase in their number from internode EN1 to internode EN2 was eight bundles. The varieties 'Bel' and 'Velut' stood out for these characters, in which 24 and 21 bundles were formed in the internode under the ear, but in the next internode, 33 and 29, respectively. The diameter of the vascular bundle in the upper internode did not exceed $260 \mu \mathrm{m}$, and in some genotypes it was below $225 \mu \mathrm{m}$. The decrease in the diameter of vascular bundles in EN1 was compensated for by the increase in their number in 'Novosibirskaya 18' (224 $\mu \mathrm{m}, 18$ bundles), 'Obskaya 2' (215 $\mu \mathrm{m}, 19$ bundles), 'Trizo' (228 $\mu \mathrm{m}, 18$ bundles) and 'Bel' (228 $\mu \mathrm{m}, 24$ bundles); in EN 2 in 'Novosibirskaya 29' (268 $\mu \mathrm{m}, 26$ bundles), 'Chernyava 13' (270 $\mu \mathrm{m}, 28$ bundles), 'Novosibirskaya 18' (262 $\mu \mathrm{m}, 28$ bundles) and 'Velut' (239 $\mu \mathrm{m}, 29$ bundles).

The varieties 'Bel' (176 and $239 \mu \mathrm{m}$ in EN1 and EN2, respectively), 'Velut' (217 and $239 \mu \mathrm{m})$ and 'Novosibirskaya 31' (219 and $237 \mu \mathrm{m}$ ) were distinguished by the thickness of the primary cortex. The diameter of the internode under the ear was more than $3 \mathrm{~mm}$. The largest diameter of EN1 was in 'Bel' (4.82 mm), 'Chernyava 13' (4.04 mm), and 'Novosibirskaya 31 ' $(4.07 \mathrm{~mm})$. The diameter of EN2 varied from 4.63 to $7.63 \mathrm{~mm}$, which was $2.36 \mathrm{~mm}$ larger than the aver- 
Table 1

Morphological stem indicators of spring bread wheat, 2018

\begin{tabular}{|c|c|c|c|c|c|c|c|c|}
\hline \multicolumn{5}{|c|}{ The internode under the ear (EN1) } & \multicolumn{4}{|c|}{ The second upper internode (EN2) } \\
\hline Variety & $\begin{array}{l}\text { Number of } \\
\text { bundles, pcs }\end{array}$ & $\begin{array}{l}\text { Diameter of } \\
\text { bundles, } \mu \mathrm{m}\end{array}$ & $\begin{array}{l}\text { Diameter of } \\
\text { stem, } \mathrm{mm}\end{array}$ & $\begin{array}{l}\text { Thickness of } \\
\text { the primary } \\
\text { cortex, } \mu \mathrm{m}\end{array}$ & $\begin{array}{l}\text { Number of } \\
\text { bundles, pcs }\end{array}$ & $\begin{array}{l}\text { Diameter of } \\
\text { bundles, } \mu \mathrm{m}\end{array}$ & $\begin{array}{l}\text { Diameter of } \\
\text { stem, } \mathrm{mm}\end{array}$ & $\begin{array}{l}\text { Thickness of } \\
\text { the primary } \\
\text { cortex, } \mu \mathrm{m}\end{array}$ \\
\hline Novosibirskaya 15 & 14 & 259 & 3.22 & 164 & 25 & 275 & 5.81 & 205 \\
\hline Novosibirskaya 29 & 16 & 234 & 3.60 & 128 & 26 & 268 & 5.29 & 188 \\
\hline Bel & 24 & 228 & 4.82 & 176 & 33 & 250 & 7.63 & 239 \\
\hline Chernyava 13 & 18 & 237 & 4.04 & 160 & 28 & 270 & 6.12 & 213 \\
\hline Saratovskaya 29 & 14 & 220 & 3.18 & 147 & 16 & 254 & 4.63 & 184 \\
\hline Obskaya 2 & 19 & 215 & 3.91 & 136 & 28 & 248 & 6.42 & 164 \\
\hline Novosibirskaya 18 & 18 & 224 & 3.61 & 169 & 28 & 262 & 6.01 & 206 \\
\hline Trizo & 18 & 228 & 3.60 & 176 & 23 & 258 & 5.32 & 199 \\
\hline Novosibirskaya 31 & 23 & 245 & 4.07 & 219 & 25 & 280 & 6.42 & 237 \\
\hline Novosibirskaya 16 & 16 & 234 & 3.76 & 127 & 28 & 271 & 6.18 & 198 \\
\hline Velut & 21 & 249 & 3.81 & 217 & 29 & 265 & 6.16 & 239 \\
\hline Mean & 18 & 234 & 3.83 & 169 & 26 & 261 & 6.17 & 205 \\
\hline $\operatorname{LSD}_{0,05}{ }^{*}$ & 1.4 & 9 & 0.2 & 10 & 2.4 & 8 & 0.6 & 12 \\
\hline
\end{tabular}

* Least Significant Difference

Table 2

Results of factor analysis of anatomo-morphological features

\begin{tabular}{|c|c|c|c|}
\hline Features & $\mathrm{PC} 1$ * & PC2 & PC3 \\
\hline $\begin{array}{l}\text { The numbers of bundles of } \\
\text { parenchyma EN1, pc. }\end{array}$ & -0.899 & 0.170 & -0.328 \\
\hline $\begin{array}{l}\text { The diameter of bundles of } \\
\text { parenchyma EN1, } \boldsymbol{\mu m}\end{array}$ & 0.308 & -0.870 & 0.336 \\
\hline The diameter stem EN1, mm & -0.862 & 0.407 & -0.076 \\
\hline $\begin{array}{l}\text { The thickness of the primary } \\
\text { cortex EN1, } \mu \mathrm{m}\end{array}$ & 0.619 & -0.504 & -0.467 \\
\hline $\begin{array}{l}\text { The numbers bundles of paren- } \\
\text { chyma EN2, pc. }\end{array}$ & -0.801 & 0.264 & 0.347 \\
\hline $\begin{array}{l}\text { The diameter bundles of paren- } \\
\text { chyma EN2, } \mu \mathrm{m}\end{array}$ & 0.081 & -0.864 & 0.194 \\
\hline The diameter stem EN2, mm & -0.901 & 0.289 & 0.145 \\
\hline $\begin{array}{l}\text { The thickness of the primary } \\
\text { cortex EN2, } \mu \mathrm{m}\end{array}$ & 0.804 & -0.451 & -0.268 \\
\hline Resistance to lodging & 0.469 & 0.080 & 0.718 \\
\hline
\end{tabular}

* PC, principal component

age diameter of the upper internode among the samples. The variety 'Bel' was characterized by the thickest stem from the whole set, the diameter of EN2 was $7.63 \mathrm{~mm}$. The thinnest stem was in 'Saratovskaya 29', $4.63 \mathrm{~mm}$.

In terms of all the features studied, the varieties 'Velut' (71.0), 'Novosibirskaya 31' (67.3) and 'Bel' (67.0) had the largest number of weighted ranks. The correlation analysis reflected the presence of significant correlations between the length of the stem and the length of the upper internode $(\mathrm{r}=0.91)$. A positive correlation of the average degree $(\mathrm{r}=0.59-0.37)$ was noted between the number of vascular parenchyma bundles and resistance to lodging. The correlation between the stem diameter in EN1, EN2 and resistance to lodging did not exceed 0.21 .
Estimation of the obtained data by the principal component analysis established that the first three components account for $93.65 \%$ of the total variance. Of these, $52.26 \%$ is explained by the first component, $28.87 \%$, by the second, and $11.52 \%$, by the third. The first component is related to the main parameters of the stem in the internodes studied: the number of vascular bundles of the parenchyma, the diameter of the internode and the thickness of the primary cortex (Table 2).

The relationship between the number of bundles and stem diameter in both internodes was established. At the same time, a decrease in the indices of these features results in an increase in the thickness of the primary cortex.

The leading role in the first component belonged to the stem diameter in EN2 $(-0.901)$ and the number of vascular 
parenchyma bundles in EN1 (-0.899). A number of authors claim that stem diameter and number of vascular bundles are related to the productivity of the ear (Skripka, 2012; Zakharov et al., 2014).

The second component is related to the diameter of the vascular bundles of the parenchyma in the internodes studied. The analysis of this factor showed that it has a significant negative correlation with the diameter of the vascular bundles in EN1 and EN2. It can be assumed that the selection of plants with a smaller diameter of the bundles of the parenchyma layer may be effective.

The greatest load of the third component is observed in resistance to lodging, in the thickness of the primary cortex in the upper internodes and in the number of vascular bundles in EN2, a significant positive relationship was noted only with resistance to lodging $(0.718)$. The feature of resistance to lodging is positively correlated with the number of bundles of parenchyma in EN2 and with the diameter of the bundles in EN1, while an increase in the thickness of the primary cortex and the number of bundles in the upper internode have a negative effect on the resistance to lodging.

Anatomo-morphological features have been identified, which correlate with wheat resistance to lodging (number of vascular bundles, length of internodes EN1 and EN2) and can cause the implementation of high ear productivity (number of vascular bundles, stem diameter and thickness of the primary cortex). It was found that the varieties 'Novosibirskaya 31', 'Velut' and 'Bel' are characterized by the most optimal com- bination of parameters such as stem diameter, number of vascular bundles and resistance to lodging which allows us to recommend them for breeding.

\section{References}

Packa D., Wiwart M, Suchowiska E., Bienkowska T. Morpho-anatomical traits of two lowest internodes related to lodging resistance in selected genotypes of Triticum. Int. Agrophys. 2015;29:475-483. DOI 10.1515/intag-2015-0053.

Ionova E.V. The method to assess the level of development of the conductive system of the ear's internode of winter wheat with different water availability. Grain Economy Russia. 2009;4:18-22 (in Russian).

Lazarevich S.V. The evolution of the anatomical structure of the stem of wheat. Minsk: Bel. ed. partnership "Hut", 1999. 295.

Dospehov B.A. The technique of field experience. Moscow: Agropromizdat, 1985;244-268.

Skripka L.F. Features of the anatomical structure of the stem of winter wheat against the background of making complex compost. Ecological Bulletin of the North Caucasus. 2012;3:79-87.

Zakharov V.G., Syukov V.V., Yakovleva O.D. Conjugation of anatomo-morphological features with resistance to lodging of spring soft wheat in the conditions of the Middle Volga region. Vavilov J. Genet. Breed. 2014;18(3):506-510 (in Russian).

Acknowledgments. Russian Science Foundation (project 16-16$00011-P$ ) supported this work. Plant cultivation was carried out in the framework of the IC\&G budget project No. 0324-2019-0039.

Conflict of interest. The authors declare no conflict of interest. 


\title{
Application of ISSR markers for study of genetic polymorphism of dark grain maize varieties
}

\author{
L.S. Valiyeva*, G.K. Rahimova, N.A. Nabiyeva \\ Genetic Resources Institute of the National Academy of Sciences of Azerbaijan, Baku, Azerbaijan
}

DOI 10.18699/ICG-PlantGen2019-10

(c) Autors, 2019

*e-mail: I.valiyeva@yandex.ru

\begin{abstract}
The grain of maize (Zea mays $L$.) can accumulate anthocyanins pigments belonging to the flavonoid groupings and possessing health benefits (antioxidant, antimicrobial, anti-carcinogenic). Numerous studies have found that regular consumption of food rich in anthocyanins leads to a significant decrease in the risk of diabetes, obesity, cardiovascular and oncological diseases. The combination of the nutritional and therapeutic values of the beneficial anthocyanins of maize is the main feature of the functional product. In this regard, breeding programs for increasing the content of anthocyanins in the grains become relevant. As a starting material, the genetic diversity of 38 maize samples with dark colored grains from the collection of the National Genbank of Azerbaijan was studied using 6 ISSR primers. On average, the level of polymorphism for all primers was $94.6 \%$, and the average value of the genetic diversity index was 0.92 . The high level of genetic variability of the dark grain maize varieties is a successful platform for the selection of promising genotypes in this direction of selection.
\end{abstract}

Key words: maize anthocyanins; functional product; genetic diversity; ISSR analysis.

\section{1. İntroduction}

Maize (Zea mays L.) is an important cultivated cereal, the most common in world agriculture. It is a valuable food and technical plant, from which more than 500 main products and by-products have been obtained (Tsikov, 2003). Among other useful matters are dark-colored pigments - anthocyanins - which give the corresponding color to plant organs and possess high antioxidant, antimicrobial and anticarcinogenic properties. They accumulate to a high degree in leaves, stem and grains of certain forms of maize (Tretyakov et al., 2012; Adzhieva et al., 2015). Numerous epidemiological studies from different countries have established that regular consumption of food plants rich in anthocyanins leads to a significant decrease in many chronic diseases, such as diabetes, obesity, cardiovascular and oncological diseases. The properties of beneficial anthocyanins that reduce the risk of developing diseases and promote human health have been scientifically substantiated and confirmed (Fukamachi et al., 2008; Tsuda, 2012; Lago et al., 2013; Khlestkina, 2013.) Thus, along with the nutritional value, the combination of therapeutic and preventive properties of the dark-grain forms of maize allows their use as a functional food (Rodriguez et al., 2013; Petroni et al., 2014; Dolmatova et al., 2016). In this connection, the directions of breeding for increasing the content of anthocyanins in the grains of maize are relevant. For the selection of valuable genotypes, their characterization and assessment using molecular technologies are important, which significantly reduces costs and time for developing hybrid combinations in breeding schemes (Khavkin, 2003). Highly informative ISSR markers have been successfully used to analyze the genetic diversity of maize (Sivolap et al., 2001; Barakat et al., 2009; Salah et al., 2016). The purpose of this study was to assess the genetic diversity of samples of dark grain maize, including self-pollinated lines and hybrids from the collection of the National Genebank of Azerbaijan, using ISSR markers.

\section{Materials and methods}

The studies were carried out in the Laboratory of Biotechnology of the Genetic Resources Institute (GRI of the National Academy of Sciences of Azerbaijan) in 2015-2019. The study object was seeds of 38 local dark-grain samples of maize from 3 varieties, 25 inbred lines, 10 interline, inter-variety and variety-linear hybrids. Total DNA was extracted from the leaves of maize using the modified CTAB method (Doyle et al., 1987). The concentration and quality of DNA was determined by a spectrophotometric method using a Nanodrop tester (Thermo Scientific, 2000). The concentration of DNA solutions for PCR was $50 \mathrm{ng} / \mathrm{mkl}$. As a result of preliminary studies, 6 primers were selected from 14 ISSR markers for the analysis, synthesizing clearly visible polymorphic allelesamplicons. The reaction mixture of ISSR-PCR with a volume of $20 \mathrm{mkl}$ included: DNA of the analyzed sample $(2 \mathrm{mkl})$, primer (Integrated DNA Technologies) $(0.2 \mu \mathrm{M})$, mixture of deoxyribonucleotides of 4 types (Bioline) $(0.2 \mu \mathrm{M}$ of each), 10x PCR buffer $(0.2 \mu \mathrm{M}), \mathrm{MgCI} 2(1.5 \mathrm{mM})$, Taq DNA polymerase (1 unit) (all reagents are from SinaClon Bioscience) and distilled water until the given volume was reached. PCR was performed in the following mode: initial denaturation at $94{ }^{\circ} \mathrm{C}$ for $5 \mathrm{~min} ; 35$ cycles: denaturation at $94{ }^{\circ} \mathrm{C}$ for $1 \mathrm{~min}$, hybridization at the melting temperature of the primer for 1 min, elongation at $72{ }^{\circ} \mathrm{C}$ for $2 \mathrm{~min}$, and final elongation at $72{ }^{\circ} \mathrm{C}$ for $7 \mathrm{~min}$. The detection of PCR products was carried out by electrophoresis in a $1.5 \%$ agarose gel with the addition of ethidium bromide ( $4 \mathrm{mkl} / 100 \mathrm{ml}$ of gel), in 1xTAE-buffer at $\mathrm{pH}-8.0$ for $50 \mathrm{~min}$ at a voltage of $120 \mathrm{~V}$. Amplicons after electrophoresis were visualized in a transilluminator (Bio-Rad) by irradiating gels in ultraviolet rays and analyzed by the intensity of the glow of the complexes of ethidium bromide with DNA.

The marker for determining the size of the amplified fragments was a 100-bp DNA ladder. For registration of the presence (1) or the absence (0) of fragments with the same molecular weight, we prepared binary matrices for each gel. 
Table 1

List of ISSR markers and their polymorphism

\begin{tabular}{|c|c|c|c|c|c|c|}
\hline \multirow{2}{*}{ Primer name } & \multirow{2}{*}{$\begin{array}{l}\text { Sequence } \\
5^{\prime} \rightarrow 3^{\prime}\end{array}$} & \multicolumn{2}{|c|}{ Number of bands } & \multirow{2}{*}{$\begin{array}{l}\text { Polymorphism } \\
\%\end{array}$} & \multirow{2}{*}{$\mathrm{H}$} & \multirow{2}{*}{$\mathrm{PIC}$} \\
\hline & & poly & mono & & & \\
\hline A1 & (AG)8T & 11 & 0 & 100 & 0.95 & 0.29 \\
\hline A5 & $(\mathrm{GAA}) 6$ & 16 & 2 & 88.8 & 0.91 & 0.37 \\
\hline UBC812 & (GA) $8 \mathrm{~A}$ & 8 & 1 & 88.8 & 0.90 & 0.35 \\
\hline UBC817 & (CA) $8 \mathrm{~A}$ & 7 & 0 & 100 & 0.93 & 0.38 \\
\hline UBC823 & $(\mathrm{TC}) 8$ & 9 & 1 & 90.0 & 0.86 & 0.27 \\
\hline UBC840 & (GA)8AT & 8 & 0 & 100 & 0.95 & 0.41 \\
\hline Average & & 9.8 & 0.6 & 94.6 & 0.92 & 0.35 \\
\hline
\end{tabular}

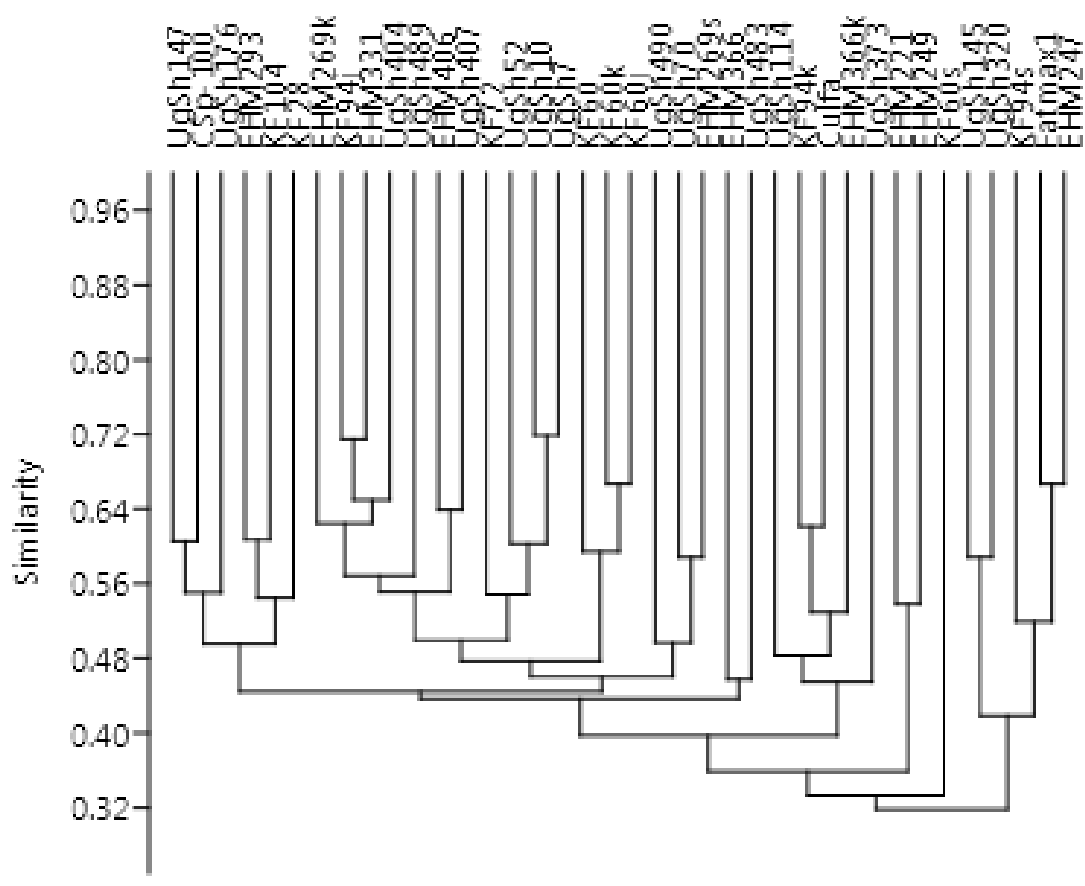

Figure 1. UPGMA dendrogram of 38 maize genotypes based on ISSR marker.

The number and proportion of polymorphic alleles were determined as indicators of genetic polymorphism. The genetic diversity index was calculated using Nei's formula: $\mathrm{H}=1-\sum \mathrm{Pi}^{2}$, where $\mathrm{Pi}$ is the frequency of the ith allele in relation to the total number of alleles (Nei et al., 1974). To establish the effectiveness of the selected marker system, the value of information polymorphism (polymorphism information content), PIC, was calculated (Chesnokov et al., 2015).

\section{Results and discussion}

The genetic diversity of 38 dark-grain maize genotypes was studied using 6 ISSR markers. In general, from among 63, 59 polymorphic alleles $(93.7 \%$ ) were amplified. On average, each locus has 9.8 polymorphic alleles (Table 1).

The length of the synthesized DNA fragments varied within 200-3000 base pairs, depending on the primer. Primer A1 generated an effective marker profile for all maize genotypes. Primer A5 consisting of 6 repeats of the GAA motif revealed the highest number of polymorphic alleles, 16; primers A1 and UBC-823 revealed 11 and 9 polymorphic alleles, respectively; and primer UBC-817 showed the lowest number, 7. All markers used revealed a high level of polymorphism in both hybrids and constant forms, with an average of $94.6 \%$. The genetic diversity index calculated for all primers ranged from 0.86 to 0.95 , with an average of 0.92 . These indicators showed a high level of variability in the genomes of the dark-grain maize samples. Primers A1, UBC-817 and UBC- 840 revealed the highest level (100\%) of genetic polymorphism of the collection studied, while the value of the genetic diversity index was also the highest, $0.95,0.93$ and 0.95 , respectively. For each polymorphic locus, information polymorphism content (PIC) values were calculated (averaged for each primer), 
which were within the range of $0.29-0.41,0.35$ on average. The highest PIC value, 0.41, was detected for primer UBC-840, and the minimum value, for $\mathrm{UBC}-823$. These data make it possible to note the high information content of UBC-840 for the detection of genomic differences and recommend its use in marker selection of maize. Our results of assessing the level of polymorphism generally agree with many studies on the molecular characterization of inbred lines and hybrids of maize using intermicrosatellite markers (Junior et al., 2011; Muhammad et al., 2016). According to the binary matrix of the presence or absence of amplicons with the same molecular weights, a genetic similarity matrix was constructed using the PAST computer program based on the Jaccard index. The coefficient of similarity between pairs of genotypes was in the range from 0.1315 to 0.7187 . The highest coefficient value was found between samples $\mathrm{UgSh} 7$ and $\mathrm{UgSh} 10$, and the lowest similarity was found between genotypes KF94s and UgSh373. These results demonstrate a significant genetic diversity of the studied genotypes of dark-grain forms of maize. Using the cluster analysis based on the UPGMA method, a dendrogram was compiled showing the genetic distances between the maize samples studied (Figure 1).

It shows that the maize samples were grouped in five main clusters. The largest of them - cluster №1 combines 25 genotypes, in turn, divided into 2 subclusters. The first one includes two inbred lines, and the second many-item subcluster combines both hybrids and constant forms. Clusters 2 and 5 included five samples from both categories. Two inbred lines, EHM221 and EHM249, formed Cluster 3. The complex hybrid KF60s has separated as an independent cluster, which indicates a difference in its genetic structure from those of the other forms. The knowledge of the cluster differentiation of the forms studied can be used for crossings in breeding programs. Samples belonging to the same cluster group or subgroup are genetically closer to each other; it is therefore advisable to involve them in crosses in pairs with samples from other clusters, but not among themselves. The distribution of the accessions in five cluster groups confirms significant genetic diversity.

\section{Conclusions}

Being a natural source of food, dark-grain corn with regular inclusion in the diet can contribute to the preservation and improvement of health, due to the presence of anthocyanins (Tsuda, 2012; Petroni et al., 2014; Dolmatova, 2016). In this regard, the selection for increasing the content of useful anthocyanins in the maize grain is relevant.

The study on molecular characterization revealed a significant genetic diversity of 38 inbred lines and dark-grain maize hybrids, adapted to local conditions, from the National Gene Bank of Azerbaijan. High polymorphism values (94.6\%) of PCR products synthesized using six ISSR markers were obtained. The genetic diversity index identified by markers A1, UBC-817 and UBC-840 (0.95, 0.93, and 0.95, respectively) suggests that they are most effective for studying the genetic diversity of maize. Cluster analysis revealed groups of geneti- cally similar and differing samples. For increasing the content of useful anthocyanins in the grain, we identified the forms to be used as a starting material for maize breeding.

\section{References}

Adzhieva V.F., Babak O.G., Shoeva O.Yu., Kilchevsky A.V., Khlestkina E.K. Molecular genetic mechanisms for the formation of the color of fruits and seeds of plants. Vavilovsky Journal Gen Breed. 2015;19(5):561-573. DOI 10.18699/VJ15.073.

Barakat M.N., El-Shafei A.A., Al-Doss A.A. Identification of molecular markers linked to northern corn leaf blight resistance in yellow population of maize genes, genomes and genomics. Global Science Books. 2009;89-95.

Chesnokov Yu.V., Artemeva A.M. Evaluation of the measure of informational polymorphism of genetic diversity. Agricultural Biol. 2015;50(5):571-578

Dolmatova I.A., Latypova S.Sh. Functional products in the diet of the population. Young Scientist. 2016;7:63-65. URL https://moluch.ru/ archive/111/27940/

Doyle J.J., Doyle J.L. A rapid DNA isolation procedure for small quantities of fresh leaf tissue. Phytochemical Bulletin. 1987;19:11-15.

Fukamachi K., Imada T., Ohshima Y., Xu J., Tsuda H. Purple corn color suppresses Ras protein level and inhibits 7,12-dimethylbenz [a] anthracene-induced mammary carcinogenesis in the rat. Cancer Sci. 2008;99:1841-1846. DOI 10.1111/j.1349-7006.2008.00895.x.

Júnior A.T.A., Oliveira E.C., Gonçalves L.S.A., Scapim C.A. et al. Assessment of genetic diversity among maize accessions using inter simple sequence repeats (ISSR) markers. Afr. J. Biotechnol. 2011; 10(69):15462-15469. DOI org/10.5897/AJB10.2624

Khavkin E.E. Molecular plant breeding: DNA technologies for creating new varieties of crops. Agricultural Biol. 2003;3:26-41.

Khlestkina E.K. The adaptive role of flavonoids: emphasis on cereals. Cereal Res. Commun. 2013;41:185-198.

Lago C., Cassani E., Zanzi C., Landoni M., Trovato R., Pilu R. Development of a maize cultivar rich in anthocyanins: colored polenta, a new 133:210-217. doi.org/10.1111/pbr.12153

Muhammad R.W., Qayyum A., Ahmad M.Q., Hamza A., Yousaf M. et al. Characterization of maize genotypes for genetic diversity on the basis of inter simple sequence repeats. Genetics Mol Research. 2017;16(1). DOI 10.4238/gmr16019438.

Nei M., Roychoudhury A.K. Sampling variances of heterozygosity and genetic distance. Genetics. 1974:76:379-390.

Petroni K., Pilu R., Tonelli C. Anthocyanins in corn: a wealth of genes for human health. Planta. 2014;240(5):901-911. DOI 10.1007/ s00425-014-2131-1.

Rodriguez V.M., Soengas P., Landa A., Ordas A., Revilla P. Effekts of selection for color intensity on antioxidant capacity of maize (Zea mays L.). Euphytica. 2013;193:339-345. doi.org/10.1007/s10681013-0924-0.

Salah N., Milad S.I., El-Rouby M.M., Barakat M.N. Identification of new molecular markers of stalk rotary resistance (Fusarium moniliforme) in maize. POJ. 2016;9(1):1836-3644.

Sivolap Yu.M., Trebelsky D.Yu. Identification of maize genotypes using PCR analysis. Cytol Gen. 2001;35(3):14-21.

Tretyakov M.Yu., Khoroshilov S.A., Sidorov A.N., Chulkov A.N., Deineka V.I., Deineka L.A. Corn as a source of anthocyanins. Achievements Sci Technol. 2012;9:30-32.

Tsikov V.S. Corn: technology, hybrids, seeds. Dnipropetrovsk: Dawn, 2003;196.

Tsuda T. Dietary anthocyanin-rich plants: Biochemical Basis Nutriol Food Res. 2012;56:159-170. DOI 10.1002/mnfr.201100526.

Conflict of interest. The authors declare no conflict of interest. 


\title{
Genetic structure of the ampelographic collection maintained in the Dagestan experimental station of VIR revealed by microsatellite analysis
}

\author{
M.M. Agakhanov ${ }^{1 *}$, V.A. Volkov² , E.K. Potokina ${ }^{1,2}$ \\ ${ }^{1}$ Vavilov Institute of Plant Genetic Resources (VIR), St. Petersburg, Russia \\ ${ }^{2}$ St. Petersburg State Forest Technical University, Russia
}

DOI 10.18699/ICG-PlantGen2019-11

(c) Autors, 2019

* e-mail: gt-06.01.2015@yandex.ru

\begin{abstract}
Dagestan Experimental Station of VIR (DOS VIR, the North Caucasus) were evaluated with eight microsatellite markers that have been previously recommended for grape varietal identification. 132 alleles of the eight SSR loci were detected, their PIC varied in the range $0.63-0.87$. Four genetic clusters $(K)$ were outlined in the assessed genetic diversity. Each of the first three clusters combined grape accessions of the same geographical origin and represents a distinct ecological-geographical group - convar. orientalis Negr., convar. occidentalis Negr. and convar. pontica Negr. The fourth cluster included mainly hybrids. Key words: grape germplasm collection; ex situ; microsatellites; genetic structure.
\end{abstract}

\section{Introduction}

The genome of Vitis vinifera L. contains a huge number of polymorphic microsatellite loci, the allelic diversity of which can be used to expose the genetic structure of grape germplasm collections maintained ex situ, as well as for detection of doublets and varietal identification (Dokupilová et al., 2013).

The objective of this study was to evaluate the genetic diversity of 72 grape accessions from the ampelographic collection of the Dagestan Experimental Station of VIR (DOS VIR), which was established in 1975 and currently maintains 320 cultivated grape varieties. For the ex situ collection, the genetic assessment of the accession diversity is important since so far only the traditional methods based on morphological trait evaluation were used to recognize grape varieties. In this study, the genetic diversity of the grape germplasm collection was explored by analysis of the polymorphism of eight microsatellite loci that have been previously recommended for the purpose of varietal identification.

\section{Materials and methods}

DNA was extracted from fresh leaves using the modified CTAB-method with 2-mercaptoethanol (Rahimah et al., 2006). Analysis of microsatellite loci was carried out on the basis of PCR with the primers that were previously reported. Sizes of the amplified alleles were estimated with the Genetic Analyzer Nanofor-05 (Syntol, Russia). Frequency-based analysis (F-statistics, heterozygosity, HWE) was performed using GenAlEx 6.2 (Peakall, Smouse, 2012). To investigate the genetic diversity and the population structure of the grape germplasm collection, the software Structure 2.3.4 was employed.

\section{Results and discussion}

72 grape accessions from the DOS VIR collection were analyzed with eight microsatellite loci: scu15vv, VVS 2, VVMD 27, VVMD 31, VVIH54, VVIP31, scu11vv, and VVIB01, which had previously been recommended for varietal identification of grapes (Thomas et al., 1993; Bowers et al.,

Table 1

Polymorphism of the microsatellite loci across 72 grape accessions of the DOS VIR collection

\begin{tabular}{|c|c|c|c|c|c|c|c|c|}
\hline Loci & scu15vv & VVS 2 & VVMD 27 & VVMD 31 & VVIH54 & VVIP31 & scu11vv & VVIB01 \\
\hline No. of alleles & 9 & 14 & 13 & 11 & 18 & 28 & 25 & 14 \\
\hline Size (bp) & $182-198$ & $121-153$ & $171-212$ & $198-250$ & $143-183$ & $164-197$ & $213-293$ & $284-324$ \\
\hline Heterozygosity & 0.760 & 0.863 & 0.841 & 0.762 & 0.844 & 0.945 & 0.874 & 0.755 \\
\hline PIC & 0.835 & 0.835 & 0.753 & 0.767 & 0.671 & 0.87 & 0.630 & 0.726 \\
\hline
\end{tabular}




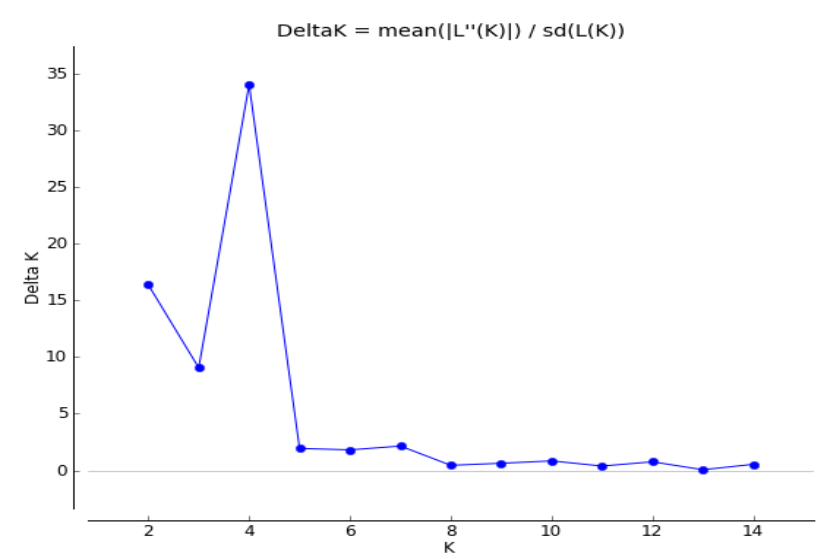

Figure 1. The most likely number of genetic clusters (K) detected within the grape genetic diversity studied.

1999). The number of detected alleles, heterozygosity (the percentage of identified heterozygotes out of the total number of plants analyzed), PIC (Polymorphic Information Content) for each microsatellite locus are presented in Table 1.

In total, 132 alleles of the eight SSR loci were detected, their PIC varied in the range $0.63-0.87$.

The probability of the number of genetic clusters $(\mathrm{K})$ among the studied accessions was estimated in the range from 1 to 5 . Ten repeats of the analysis were conducted for each $\mathrm{K}$ value. The most likely number of clusters $(\mathrm{K})$, that is, objectively isolated genetic groups in the representation studied, was determined according to the algorithm proposed by Evanno et al. (2005). Four genetic clusters (K) were outlined in the assessed genetic diversity of the grape accessions (Figure 1). Each of the first three clusters contains grape accessions of the same geographical origin and represents a distinct ecologicalgeographical group, the fourth cluster included mainly hybrids (Figure 2).

The first (red) cluster comprises 28 grape varieties that mostly belong to convar. orientalis Negr. and represent ancient Dagestan aborigine varieties. The second cluster (green) combines 18 varieties of the West-European ecogeographic group (convar. occidentalis Negr.). Among them, there were some famous grape varieties such as 'Riesling' and 'Aligoté'. The ancient autochthone grape varieties of the Black See basin (convar. pontica Negr.) were assigned to the third (blue) genetic cluster (see Figure 2).

In the ampelographic collection of the Dagestan Experimental Station of VIR, accessions of 25 grape ecotypes are maintained, including both ancient Dagestan varieties and

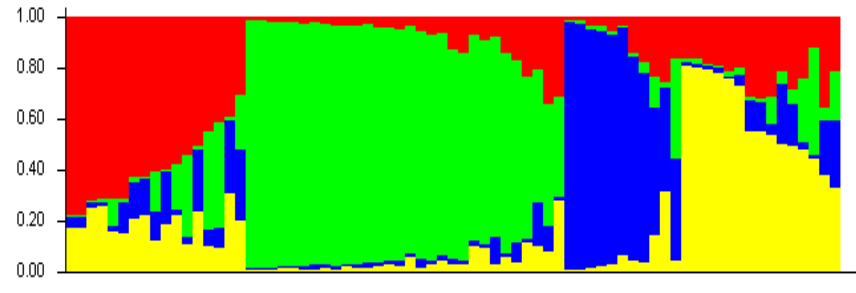

Figure 2. Structure of the genetic diversity of 72 grape accessions from the DOS VIR collection revealed with microsatellite loci.

varieties of Western European and Asian origin. The collection also contains several samples of wild-growing Vitis species which have been collected during the VIR expeditions to the Caucasus. To this day, no molecular studies have been conducted focusing on analysis of the genetic structure of this collection and its genetic diversity. Analysis of the allelic diversity of eight polymorphic microsatellite loci allowed us to evaluate the genetic structure and establish the relationship between the genotype of the grape accession and its origin.

\section{References}

Bowers J.E., Dangl G.S., Meredith C.P. Development and characterization of additional microsatellite DNA markers for grape. American Journal Enol. Viticulture. 1999;50(3);243-246.

Dokupilová I., Šturdík E., Mihálik D. Characterization of vine varieties by SSR markers. Acta Chimica Slovaca. 2013;6(2):227-234. DOI 10.2478/acs-2013-0035.

Peakall R., Smouse P.E. GenAlEx 6.5: genetic analysis in Excel. Population genetic software for teaching and research-an update. Bioinformatics. 2012:28;2537-2539. DOI 10.1093/bioinformatics/bts460.

Rahimah A.B., Cheah S.C., Rajinder S. Freeze-drying of oil palm (Elaeis guineensis) leaf and its effect on the quality of extractable DNA. J. Oil Palm Res. 2006;18:296-304.

Thomas M.R., Scott N.S. Microsatellite repeats in grapevine reveal DNA polymorphisms when analysed as sequence-tagged sites (STSs). Theoretical Applied Genetics. 1993;86(8):985-990.

Acknowledgements. The work is supported by the government program of the Ministry of Science and Education of Russian Federation, project No. AAAA-A19-119013090158-8.

Conflict of interest. The authors declare no conflict of interest. 


\title{
Genetic variation of water caltrop (Trapa L.) in several Russian populations
}

\author{
A.E. Artyukhin ${ }^{1}$, E.V. Mikhaylova ${ }^{2 *}$, B.R. Kuluev ${ }^{1,2}$ \\ ${ }^{1}$ Bashkir State University, Ufa, Russia \\ ${ }^{2}$ Institute of Biochemistry and Genetics UFRC RAS, Ufa, Russia
}

DOI 10.18699/ICG-PlantGen2019-12

(c) Autors, 2019

* e-mail: mikhele@list.ru

\begin{abstract}
Water caltrop (water chestnut) (Trapa L.) is a valuable aquatic plant. Its seeds are edible and rich in protein and starch. The plant has become very rare and is now included in the Red List of Threatened Species in 36 regions of Russia and protected in most of the EU countries. The diversity of Trapa species is questionable, however, it is important for the protection of this plant. We studied genetic polymorphism of Russian populations and one of the largest European populations of Trapa L. in Skadar lake using different RAPD and ISSR primers and the sequencing of the ITS region of nuclear ribosomal DNA. In spite of morphological differences, especially in seed shape, only samples from the Far East, distinguished as T. maximowiczii, were significantly polymorphic.

Key words: Trapa natans; Trapa maximowiczii; water caltrop; water chestnut; RAPD; ISSR; ITS.
\end{abstract}

\section{Introduction}

Water caltrop (water chestnut) (Trapa L.) is a valuable aquatic plant. Its seeds are edible and rich in protein and starch. Antimicrobial compounds are found in the seed coat and can be used in medicine. Water caltrop has been widely cultivated by people since the Neolithic; however, on the territory of Europe and Russia, its population has decreased dramatically over the last century. The plant has become very rare and is now included in the Red List of Threatened Species in 36 regions of Russia and protected in most of the EU countries. In the USSR, around 30 species of Trapa L. were distinguished on the basis of morphological characteristics (Kuluev et al., 2017), but now most of them are considered synonyms. Molecular genetic methods, including AFLP, RAPD, and DNA sequencing were used to study Asian populations of water caltrop, and several species were described. In Europe, there is most probably only one polymorphic species, T. natans. Several poorly studied populations of water caltrop still remain in regions with the severe continental climate (Southern Urals and Siberia). It is not clear why it has been preserved on these territories. The diversity of Trapa L. is higher in the Russian Far East (Pshennikova, 2007; Bolotova, 2014). The study of the genetic and morphological diversity of water caltrop is important for the survival and recovery of the unique populations.

\section{Materials and methods}

Plant material was collected from four lakes in the Southern Urals (lakes Upkankul, Bilgilyar, Lebyazh'ye and Medvezh'ye) and Skadar lake (Montenegro). Leaf samples from four lakes in the Russian Far East (Pshennikova, 2007; Bolotova, 2014) and lake Solnechnoye in Siberia (Chepinoga et al., 2013) were provided by our colleagues. DNA was extracted from dried leaves by the CTAB method. We used universal RAPD primers AFK1, AFK3, OPAI-04, OPAI-05, OPC-06 and ISSR primers 814, ISSR11, ISSR16, ISSR22, ISSR24. Primer GGAAGTAAAAGTCGTAACAAG was used for ITS sequencing. The phylogenetic tree was gener- ated using DNASTAR software and statistically analyzed by bootstrapping.

\section{Results and discussion}

There were morphological differences between the plants. For example, in lake Lebyazh'ye water caltrop was found at two points. At the first one, leaves were larger and thicker, just like those in lake Medvezh'ye; however, at the second point, leaf rosettes were smaller, just like those in lakes Upkankul and Bilgilyar. There were also some differences in fruit shape. In lake Upkankul, we found several seeds with bifurcated horns (Figure 1). These seeds were propagated in an aquarium for DNA analysis.

The greatest diversity of morphotypes was detected in the Far East. DNA samples of the putative species T. pseudoincisia, T. manshurica, T. maximowiczii, T. japonica and T. korshinskyi were compared with samples from Skadar lake, Southern Urals and Siberia using RAPD and ISSR analysis. ISSR analysis was never performed on water caltrop before. All primers described were applicable and stably gave at least eight bands. However, only the samples from two different lakes in the Far East, distinguished as $T$. maximowiczii, significantly differed from the other samples. This result was reproducible with all the primers. Genetic polymorphism between other samples was not detected (Figure 2).

DNA of the plants from each habitat (Europe, the Southern Urals, Siberia and the Far East) were picked for sequencing (Figure 3), which confirmed the result of RAPD and ISSR analyses. T. maximowiczii is significantly distant from the other samples on the phylogenetic tree, and relations between the other samples are rather complicated. Sequencing reveals genetic divergence between plants collected at two different points of the same lake (Lebyazh'ye) and between plants with normal and deformed seeds from the same lake (Upkankul). However, this question requires further study. Without regard for deformed and probably mutant seeds (Figure 3(5)), it can be supposed that water 

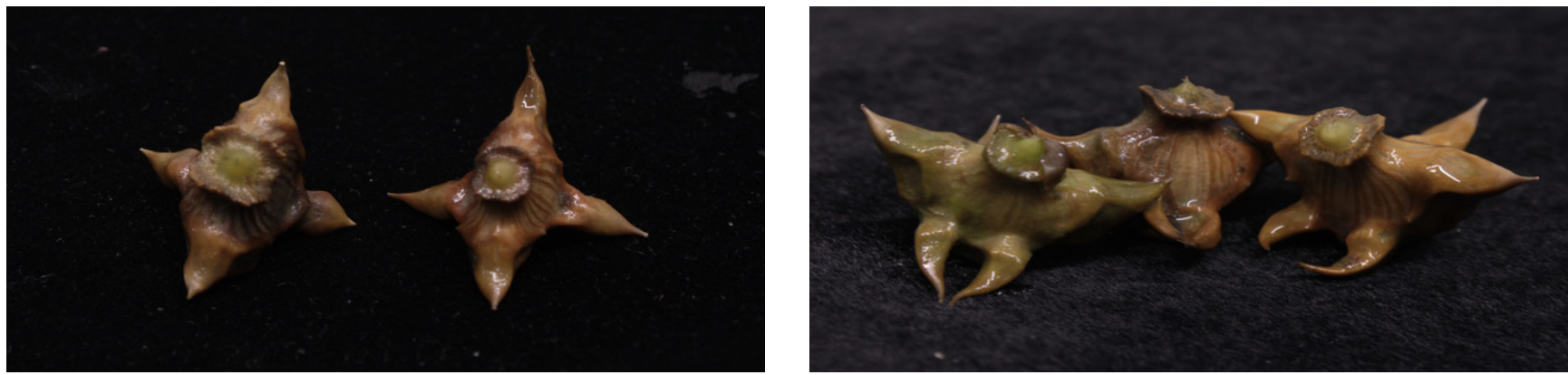

Figure 1. Normal and deformed seeds of water caltrop from lake Upkankul, Southern Urals.

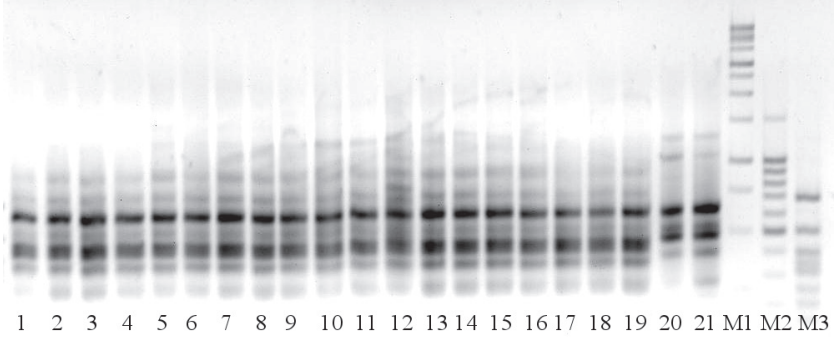

Figure 2. Results of DNA analysis with marker ISSR11. Sample 20: lake Lotos, Primorsky Krai, Russian Far East (T. maximowiczii); sample 21: noname lake, Amur oblast, Russian Far East (T. maximowiczii); 1-18: other samples. M1: 1-kb marker; M2: 100-bp marker; M3: 50-bp marker. caltrop from the Southern Urals is closer to the Siberian than to the European population. Noteworthy, during the isolation of the ITS region, T. maximowiczii demonstrated a double-band electrophoretic pattern, while the other samples gave one band. This is indirectly indicative of recombination events, and so these plants could be hybrids.

\section{Conclusions}

We obtained interesting results on genetic variation in several isolated Trapa L. populations. In general, samples from habitats with the severe continental climate (Southern Urals, Siberia) and samples from more favourable environments (Far East, Montenegro) demonstrate low levels of genetic polymorphism. The only exception is T. maximowiczii. It is possible that water caltrop has a great potential to adapt to different climatic conditions and can be reintroduced to its previous habitats from the South and be used as a food source again.

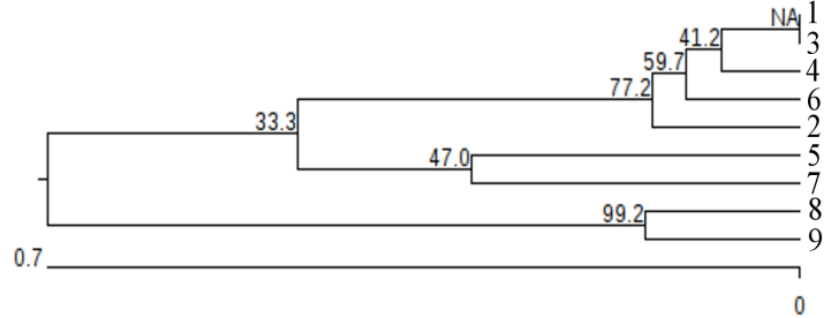

Figure 3. Phylogenetic tree of Trapa samples on the basis of ITS region sequencing:

1: lake Lebyazh'ye (point 1), Southern Urals, Russia; 2: lake Lebyazh'ye (point 2), Southern Urals, Russia; 3: lake Medvezh'ye, Southern Urals, Russia; 4: lake Upkankul (normal), Southern Urals, Russia; 5: lake Upkankul (mutant), Southern Urals, Russia; 6: lake Solonechnoye, Siberia, Russia; 7: lake Skadar, Montenegro; 8: lake Lotos, Primorsky Krai, Russian Far East (T. maximowiczii); 9: no-name lake, Amur oblast, Russian Far East (T. maximowiczii).

\section{References}

Kuluev B.R., Artyukhin A.E., Shevchenko A.M., Mikhaylova E.V. Water chestnut Trapa L.: biology, habitat and the study of its isolated populations in the lakes of Nurimanovsky district in the Republic of Bashkortostan. Biomics. 2017;9(2):101-118.

Pshennikova L.M. A new species of the genus Trapa (Trapaceae) from the Far East of Russia. Botanicheskii Zhurnal. 2007;92(1):159-160.

Bolotova Y.V. Distribution of Species of Genus Trapa L. (Trapaceae) in the Amur Region (Russian Far East). Vestnik of North-Eastern Federal University. 2014;11(2):22-28.

Chepinoga V.V., Bergmeier E., Rosbakh S.A., Fleckenstein K.M. Classification of aquatic vegetation (Potametea) in Baikal Siberia, Russia, and its diversity in a northern Eurasian context. Phytocoenologia. 2013;43(1-2):127-167.

Acknowledgements. The reported study was funded by Russian Science Foundation according to the research project No. 18-74-00056.

Conflict of interest. The authors declare no conflict of interest. 


\title{
Potato starch resistivity as an inheritable trait
}

\author{
L.M. Gvozdeva ${ }^{1 *}$, I.V. Rozanova ${ }^{1,2}$, V.K. Khlestkin ${ }^{1,3}$, E.K. Khlestkina ${ }^{1,2}$ \\ 1 Institute of Cytology and Genetics, SB RAS, Novosibirsk, Russia \\ ${ }^{2}$ N.I. Vavilov All-Russian Research Institute of Plant Genetic Resources (VIR), St. Petersburg, Russia \\ ${ }^{3}$ Russian Research Institute of Farm Animal Genetics and Breeding - Branch of the L.K. Ernst Federal Science Center for Animal Husbandry, \\ St. Petersburg, Russia
}

DOI 10.18699/ICG-PlantGen2019-13

(c) Autors, 2019

*e-mail: ungersy@mail.ru

\begin{abstract}
Potato is a significant crop in many countries. It is not only a source of vitamins, amino acids and fiber, but also of starch. Starch is an important source of energetic food for humans, as well as an important raw material of organic origin for biochemical industry. In terms of enzyme digestibility, starch is subdivided into 3 fractions: rapidly digestible (DS), slowly digestible, and resistant starches (RS). RS passes through the stomach and small intestine, remaining intact, and then enters the large intestine, where it is fermented into useful short-chain fatty acids (SCFA: acetate, propionate and butyrate) and serves as an excellent nutrient medium for intestinal microflora. Unlike normal starch, RS increases the body's sensitivity to insulin and lowers blood glucose levels. Thus, a diet enriched for RS can be used both for weight maintenance / stabilization and for the treatment of obesity, diabetes, Crohn's and Bechterew's disease. Identification of genomic regions associated with potato starch resistivity indicates this property to be an inheritable trait. Data on the genomic regions will facilitate potato breeding for diverse purposes in human diet as well as in processing industry.
\end{abstract}

Key words: diabetes; digestible starch; genome-wide association studies; obesity; potato starch; resistant starch.

\section{Introduction}

Potato (Solanum tuberosum L.) is one of the most popular carbohydrate foods in industrialized and some developing countries, with its production in 2017 having reached 440 million tons (according to FAOSTAT). In addition to vitamins, amino acids, microelements, and fiber, potato is a source of starch. Starch consists of polysaccharides, molecules that are composed of a number of monosaccharides (glucose) motives linked together with $\alpha-1,4$ and/or $\alpha-1,6$ linkages. There are two main structural types of starch polysaccharides: amylose, which is a linear $\alpha-1,4$ molecule and typically constitutes $15-20 \%$ of starch, and amylopectin, which is a larger branched molecule with $\alpha-1,4$ and $\alpha-1,6$ linkages, a major component of starch.

Potato and potato products yield variable glycemic responses. For example, the published glycemic index (GI) values for potato vary from very low (23 for an unspecified cultivar) to very high (144 for boiled Desiree) (Foster-Powell, 2002). The variation in the GI values of potato-products may be due to a number of factors such as potato genotype, maturity, starch structure, processing, and storage conditions (Lynch, 2007).

In terms of digestibility, starch is typically divided into 3 fractions: rapidly digesting starch (RDS), slowly digesting starch (SDS), and resistant starch (RS). According to Englyst and others, RDS and SDS are the starch fractions that hydrolyze to dextrins by $\alpha$-amylase and pullulanase enzymes within 20 to 120 min after ingestion, respectively. RS is the portion that is not hydrolyzed after $120 \mathrm{~min}$ and passes from the small to the large intestine (Englyst, 1992), where it is fermented by gut microflora (Nugent, 2005). Chemically RS is measured as the difference between total starch (TS) and the sum of RDS and SDS:

$\mathrm{RS}=\mathrm{TS}-(\mathrm{RDS}+\mathrm{SDS})$

$\mathrm{RDS}+\mathrm{SDS}=\mathrm{DS}$ (digestible starch)
Thus, RS is considered excellent dietary fiber, which would be expected to confer benefits to gut health, particularly in the large intestine, where RS is fermented and can result in the release of gases (methane, hydrogen, carbon dioxide), shortchain fatty acids, or SCFAs, (formate, acetate, propionate, butyrate and valerate) and smaller amounts of organic acids (lactate and succinate) and alcohols (methanol and ethanol). The SCFA butyrate is of particular interest given its role as fuel for the cells lining the colon (colonocytes) and there is growing interest in the potential influence of gut bacteria on health outcomes, both locally in the gut and systemically (Kataoka, 2016).

It should be noted that the amount of RS in a given food varies for different individuals, as the exact time of the transition from the small to the large intestine fluctuates depending on an individual's gastrointestinal functioning, the concentrations of endogenous carbohydrate digestion enzymes, viscosity of the gastric fluid, as well as the food matrix itself.

There are several factors described to affect starch resistivity:

- amylose/amylopectin ratio; a high amylose content of starch is known to lower starch digestibility (Chung, 2009);

- length and branching of amylopectin chains; long linear chains of amylopectin provide starch resistivity, and the branched chains of amylopectin, starch digestibility (Benmoussa, 2007);

- retrogradation of amylose; retrograded amylose in wheat, maize, peas, and potatoes was found to be highly resistant to digestion (Ring, 1988);

- ions; potato starch gels showed a decreased yield of RS in the presence of ions like calcium and potassium, which may be reflected to the prevention of hydrogen bond formation between amylopectin and amylose chains; 
- interaction of starch polysaccharides with proteins; a mixture of potato starch and albumin was autoclaved and then cooled to $-20{ }^{\circ} \mathrm{C}$; it was found that added albumin reduced RS content (Escarpa, 1997);

- enzyme inhibitors; enzyme inhibitors like phytic acid, polyphenols, and lectins present in leguminous seeds have been found to inhibit in vitro digestion and, consequently, the glycemic index of starch; since phytic acid inhibits amylolysis, an increase in phytate content decreases starch digestibility (Thompson, 1984);

- size, smoothness and intactness of the granules; large, smooth, undamaged starch granules are more protected from effects of enzymes, since they are difficult to attach to the granule and get inside (Blazek, 2010).

So, starch resistivity is caused by a complex of factors, which together influence the digestibility of starch.

RS values in raw, not cooked potato are very high (70\% on average). Thus, raw potato RS causes the following beneficial effects on health:

1) RS increases SCFAs production. The SCFA butyrate is the preferred fuel for colonocytes, increasing colonic blood flow, lowering luminal $\mathrm{pH}$ and helping prevent the development of abnormal colonic cell populations as well as facilitating the maintenance of epithelial integrity and regulating inflammation (Kataoka, 2016).

2) Raw potato starch dramatically induces changes in microbial composition and microbial metabolites. Coprococcus, Ruminococcus, and Turicibacter (bacteria important for degradation of starch and SCFA production) increased significantly, while Sarcina and Clostridium decreased in relative abundances in the hindgut of pigs fed raw potato starch. Thus, raw potato starch not only alters the composition of the gut microbial community but also modulates the metabolic pathway of microbial metabolism (Sun, 2016).

3) RS consumption has been shown to improve glycemic control in both animal and human studies. Eating a RS-rich diet substantially increased the mobilization and use of fat stores as a consequence of reduction in insulin secretion. SCFAs are reported to inhibit adipose tissue lipolysis, and in the liver and muscles, particularly acetate was proposed to inhibit glycogenolysis, with the result of sparing carbohydrate and increasing fat oxidation. Since RS almost does not split into glucose in the small intestine and improves insulin sensitivity, it can be useful in such serious diseases as type 2 diabetes and obesity (Tapsell, 2004; Canfora, 2015).

4) Consumption of RS is beneficial to cardiovascular diseases. Particularly, it has been shown that RS is associated with cardiovascular risk reduction (Bernstein, 2013).

5) Considerable evidence exists suggesting a protective role of high-fibre diets in colon cancer. Fibre is suggested to reduce colon cancer risk by increasing fecal bulk, reducing transit time and diluting fecal contents (Murphy, 2012). High butyrate production is reported to reduce colon cancer risk and butyrate treatment of cultured colon cancer cells can blunt the proliferation of the cancer cells and stimulate apoptosis (Macfarlane, 2003).

A number of studies revealed that RS could have a positive role in intestinal absorption of minerals. In humans, an RS-rich diet substantially increased the apparent absorption of calcium and iron compared with a completely DS diet (Morais, 1996). This is likely one of the reasons why supplementation with resistant starch can protect bone density during weight loss and positively affect the immune system.

\section{Materials and methods}

Starch and DNA were isolated from 90 potato varieties and hybrids from the ICG "GenAgro" collection. Starch was tested for resistance to enzymatic digestion by $\alpha$-amylase. Genotyping data were obtained on a $22 \mathrm{~K}$ Illumina Potato SNP-array. The association mapping was performed with the use of software products TASSEL, Structure, R.

\section{Results and discussion}

Schonhals et al. (2016) showed that SNPs in the candidate genes Pain-1, InvCD141 (invertases), SSIV (starch synthase), StCDF1 (transcription factor), LapN (leucine aminopeptidase), and cytoplasm type are associated with potato tuber yield, starch content and/or starch yield.

Khlestkin et al. (2019) found several SNPs associated with starch amylopectin phosphorylation.

It has been found that key genes for starch biosynthesis may affect factors, resulting in variations in starch resistivity. Thus, granule-bound starch synthase gene (GBSS) knockout drastically increases amylopectin content to up to $>98 \%$. When inhibited, the SBEI gene encoding the main starch branching enzyme does not increase amylose content in modified potato. But simultaneous inhibition of both SBEI and SBEII genes results in high (60-89\%) amylose starch with minor amylopectin content. Elevation of SBEII expression allows obtaining starch characterized by increased amylopectin branching with shorter end chains. In contrast, amylopectin from potato plants with inhibited $S B E$ synthesis has longer polysaccharide chains with lower branching. GWD gene knockout results in amylopectin with reduced phosphate content and, accordingly, reduced viscosity gels from the modified starch. Low phosphate starch demonstrates also a reduced rate of biocatalytic hydrolysis. Overexpression of SSIV results in increased tuber starch content in both greenhouse and field grown plants. Starch granule morphology and crystallinity may be corrected at the genetic level as well (Khlestkin, 2017).

We performed a genome-wide association study to search for SNPs responsible for potato starch resistivity. Samples of starch from 90 potato varieties and hybrids from the ICG "GenAgro" collection were tested for resistance to enzymatic digestion by $\alpha$-amylase. The average starch resistivity value found was about $75 \%$ of the total amount of starch. Contrasting forms with low (40-52\%) and high (up to 99\%) resistance of starch to digestion were identified. The association mapping performed with the use of genotyping data obtained on the 22K Illumina Potato SNP-array revealed significant region on chromosome 5.

\section{Conclusions}

In conclusion, the potato tuber starch set studied contains starch samples with both high and low RS content, which makes it possible to differentiate potato varieties according to this trait. Resistance towards amylases is a very important trait related to starch as a tunable nutrient, probably connected to 
several human diseases, and thus has to be carefully taken into account in diets for treatment and prophylactics of the diseases and comorbid states. Potato varieties with starch with the trait 'contrasting resistance' were identified. The SNP found on chromosome 5 is associated with the trait 'starch digestibility' and reflects the participation of this chromosome in the formation of resistance of potato starch towards amylase digestion. Further research is being conducted on the identified genomic region, aimed at identifying a candidate gene and developing a convenient PCR marker for accelerated breeding of potatoes with different digestibility of starch.

\section{References}

Benmoussa M., Moldenhauer K., Hamaker B. Rice Amylopectin Fine Structure Variability Affects Starch Digestion Properties. J. Agric. Food Chem. 2007;55:1475-1479.

Bernstein A.M., Titgemeier B., Kirkpatrick K., Golubic M., Roizen M.F. Major cereal grain fibers and psyllium in relation to cardiovascular health. Nutrients. 2013;5:1471-1487.

Blazek J., Gilbert E.P. Effect of enzymatic hydrolysis on native starch granule structure. Biomacromolecules. 2010;11:3275-3289.

Canfora E., Jocken J., Blaak E. Short-chain fatty acids in control of body weight and insulin sensitivity. Nat. Rev. Endocrinol. 2015; 11:577-591.

Chung H., Liu Q., Hoover R. Impact of annealing and heat-moisture treatment on rapidly digestible, slowly digestible and resistant starch levels in native and gelatinized corn, pea and lentil starches. Carbohydr. Polym. 2009;75:436-447.

Englyst H, Kingman S.M., Cummings J.H. Classification and measurement of nutritionally important starch fractions. Eur. J. Clin. Nutr. 1992;46(S2):33-50.

Escarpa A., Gonzalez M.C., Morales M.D., Saura-Calixto F. An approach to the influence of nutrients and other food constituents on resistant starch formation. Food Chem. 1997;60:527-536.

Foster-Powell K., Holt S.H.A., Brand-Miller J.C. International tables of glycemic index and glycemic load values. American Journal Clinical Nutrition. 2002;76:5-56.

Kataoka $\mathrm{K}$. The intestinal microbiota and its role in human health and disease. Journal Medical Investigation. 2016;63:27-37.

Khlestkin V.K., Peltek S.E., Kolchanov N.A. Target genes for development of potato (Solanum tuberosum L.) cultivars with desired starch properties (review). Sel'skokhozyaistvennaya Biologiya $=$ Agricultural Biology. 2017;52(1):25-36.
Khlestkin V.K., Rozanova I.V., Efimov V.M., Khlestkina E.K. Starch phosphorylation associated SNPs found by genome-wide association studies in the potato (Solanum tuberosum L.). BMC Genet. 2019;18:20-29.

Lynch D., Liu Q., Tarn T. R., Bizimungu B., Chen Q., Harris P. et al. Glycemic index - a review and implications for the potato industry. American Journal of Potato Research. 2007;84(2):179-190.

Macfarlane S., Macfarlane G.T. Regulation of short-chain fatty acid production. Proceedings Nutrition Society. 2003;62:67-72.

Morais M.B., Feste A., Miller R.G, Lifichitz C.H. Effect of resistant starch and digestible starch on intestinal absorption of calcium, iron and zinc in infant pigs. Paediatr. Res. 1996;39:872-876.

Mosquera T., Alvarez M.F., Jimenez-Gomez J.M., Muktar M.S., Paulo M.J., Steinemann S. et al. Targeted and untargeted approaches unravel novel candidate genes and diagnostic SNPs for quantitative resistance of the potato (Solanum tuberosum L.) to Phytophthora infestans causing the late blight disease. PLoS One. 2016; 11(6): 0156254.

Murphy N., Norat T., Ferrari P., Jenab M., Bueno-de-Mesquita B., Skeie G. et al. Dietary fibre intake and risks of cancers of the colon and rectum in the European prospective investigation into cancer and nutrition (EPIC). PLoS One. 2012;7:e39361.

Nugent A.P. Health properties of resistant starch. Nutr. Bull. 2005;30: $27-54$.

Ring S.G., Gee J.M., Whittam M., Orford P., Johnson I. Resistant Starch. Its chemical form in foodstuffs and effect on digestibility in vitro. Food Chem. 1998;28:97-109.

Schonhals E.M., Ortega F., Barandalla L., Aragones A., Ruiz de Galarreta J.I., Liao J.C. et al. Identification and reproducibility of diagnostic DNA markers for tuber starch and yield optimization in a novel association mapping population of potato (Solanum tuberosum L.). Theoretical Applied Genetics. 2016;129(4):767-785.

Sun Y., Su Y., Zhu W. Microbiome-metabolome responses in the cecum and colon of pig to a high resistant starch diet. Front Microbiol. 2016;7:779.

Tapsell L.C. Diet and metabolic syndrome: Where does resistant starch fit in? J. Association Analyt. Chem. Int. 2004;87:756-760.

Thompson L.U., Yoon J.H. Starch digestibility as affected by polyphenol and phytic acid. J Food Sci. 1984;49:1268-1269.

Acknowledgements. The work supported by a grant from the RFBR (No. 17-29-08006).

Conflict of interest. The authors declare no conflict of interest. 


\title{
Evaluation of genetic variability of buckwheat varieties (Fagopyrum esculentum) using ISSR-analysis
}

\author{
A.G. Klykov*, P.V. Fisenko, A.S. Chibizova, E.N. Barsukova \\ FSC of Agribiotechnology in the Far East named after A.K. Chaika, Ussurijsk, Russia
}

DOI 10.18699/ICG-PlantGen2019-14

(c) Autors, 2019

*e-mail: alex.klykov@mail.ru
Abstract: The article presents analysis of the genetic polymorphisim on ISSR primers of five varieties of buckwheat (Fagopyrum esculentum Moench) (Izumrud, Kitavase soba 1, Kitavase soba 2, Cheremshanka, Bashkirskaya krasnostebelnaya). The obtained results demonstrated the high level of polymorphism and the prevalence of intra- over intervarietal variability. There were defined genetic distances between the studied varieties and a dendrogram reflecting the genetic differences between vatieties was constructed. The most largest Nei's genetic distance $\left(D_{N}=0.2430\right)$ was found between 'Izumrud' and 'Bashkirskaya krasnostebelnaya'. The results of analysis of phylogenetic differences can be useful in buckwheat selection for developing new forms with high flavonoids contents.

Key words: Fagopyrum esculentum Moench; selection; variety; ISSR analysis; flavonoids.

\section{Introduction}

Fagopyrum esculentum Moench is an important cereal and nectar-bearing crop widely cultivated in many countries of the world. The genus Fagopyrum Mill. possesses valuable nutrient and medical qualities. Representatives of the genus Fagopyrum are promising sources of flavonoids, among which the main is 3-O-rutinoside quercetin (rutin or vitamin $\mathrm{P}$ ), which has antioxidant, angioprotective, antibacterial, and hepatoprotective properties (Klykov et al., 2018). The most important task of both foreign and Russian science is improvement of the existing varieties of $F$. esculentum and creation of new ones adapted to the growing conditions, diseases and pests and with high flavonoid content. A successful solution of the problem of this scale is possible on the basis of interdisciplinary research in the field of genetics, breeding, and biochemistry.

Buckwheat, despite its popularity, is not a mass object of genetic research. At the same time, the study of the intraspecific genetic diversity of $F$. esculentum is extremely relevant, due to the presence of a large number of varietal samples differing in the content of flavonoids. Inter-simple sequence (ISSR) repeat markers are widely used to detect intraspecific polymorphism, as well as variability in closely related genotypes of cultivated plants (Joshi et al., 2000; Sica et al., 2005).

The aim of this study was to evaluate the genetic polymorphism of Fagopyrum esculentum varieties of different origin with high flavonoid content using molecular marking.

\section{Materials and methods}

The plant material includes five varieties of $F$. esculentum Izumrud (Russia, Primorsky Krai), Kitavase soba 1 (Japan), Kitavase soba 2 (Japan), Cheremshanka (Russia, Republic of Tatarstan), and Bashkirskaya krasnostebelnaya (Russia, Republic of Bashkortostan) - isolated in the field conditions of Primorsky Krai for the flavonoid content in the aboveground mass, fruits and other agronomically valuable traits (Klykov et al., 2018).

Ten seeds of each buckwheat variety were germinated in the conditions of the culture room. DNA was isolated from the leaves by the method of Aljanabi et al. (1997) with additional purification using a chloroform/isoamyl alcohol mixture
(24/1). The amount of DNA in the sample was determined using a BioSpec-Nano spectrophotometer (Shimadzu). PCR was carried out 2-3 times using four ISSR primers. We used the ready-to-use reaction mix BioMaster HS-Taq PCR-Color (Biolabmics) with the addition of magnesium chloride to a final concentration of 2.5-3.0 mM, depending on the primer. To control contamination and nonspecific hybridization of primers, there was used a blank sample containing a complete reaction mixture without adding DNA.

Amplification was performed in the MJ Mini amplifier (BioRad) with preliminary denaturation for $5 \mathrm{~min}$ at $94^{\circ} \mathrm{C}$ followed by 40 cycles: $30 \mathrm{sec}$ at $94{ }^{\circ} \mathrm{C}$; $30 \mathrm{sec}$ at $49-60{ }^{\circ} \mathrm{C}$ (depending on the primer, the annealing temperature was selected individually); $1 \mathrm{~min}$ at $72^{\circ} \mathrm{C}$. The reaction products were separated by electrophoresis in $2 \%$ agarose gel, colored with ethidium bromide, in $0.5 \mathrm{X}$ TBE buffer. Visualization was performed by irradiation of the gel with ultraviolet light using a Gel Doc XR+ (BioRad).

For each primer, binary matrices were constructed where the presence or absence of a fragment was marked as 1 or 0 , respectively. Genetic distances and construction of dendrograms was carried out using the software package POPGENE and TFPGA.

\section{Results and discussion}

Studies have noted that the quantitative and qualitative yield of DNA from the tissues of buckwheat (freeze-dried leaves) is much lower than from the same number of tissues of other crops (soybeans, rice). When using green leaves, the situation improves, but the final concentration of total DNA is still lower. Perhaps this is due to the fact that buckwheat, compared with other crops, has the fewest chromosomes in the karyotype.

As a result, the PCR revealed 106 amplicons, 105 of which were polymorphic. Intravarietal polymorphism varied considerably, from a minimum of $\mathrm{P}=50 \%$ and $50.94 \%$ in 'Izumrud' and 'Bashkirskaya krasnostebelnaya', respectively, and to a maximum of $\mathrm{P}=75.47 \%$ in 'Cheremshanka'. The varieties Kitawase soba 1 and Kitawase soba 2 have similar level of polymorphism, $\mathrm{P}=65.09$ and $64.15 \%$, respectively. 
Table 1

Genetic distances $\left(D_{N}\right)$ between the of F. esculentum varieties

\begin{tabular}{|c|c|c|c|c|}
\hline Variety & Izumrud & Kitawase soba 1 & Kitawase soba 2 & Cheremshanka \\
\hline Izumrud & $* * *$ & & & \\
\hline Kitawase soba 1 & 0.1046 & $* * *$ & & \\
\hline Kitawase soba 2 & 0.1192 & 0.0372 & $* * *$ & \\
\hline Cheremshanka & 0.1196 & 0.0543 & 0.0577 & $* * *$ \\
\hline Bashkirskaya krasnostebelnaya & 0.2430 & 0.1833 & 0.1791 & 0.1872 \\
\hline
\end{tabular}
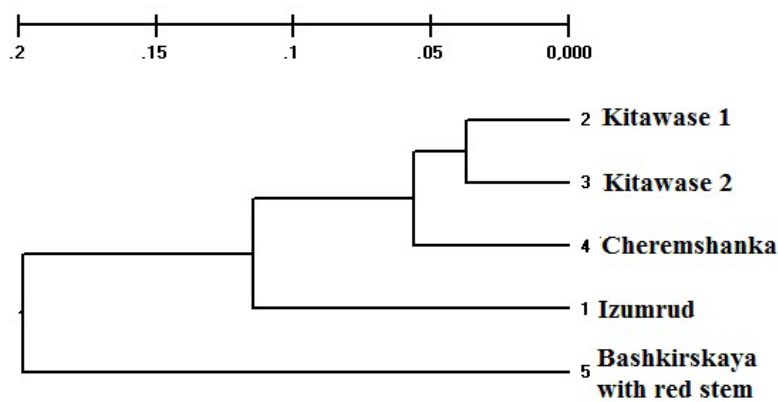

Figure 1. UPGMA dendrogram of phylogenetic relationships of buckwheat varieties constructed on the base of ISSR analysis.

Nei's genetic distances $\left(D_{N}\right)($ Nei M. 1972) were calculated on the basis of ISSR analysis. The highest value of $\mathrm{D}_{\mathrm{N}}=0.2430$ was found between 'Izumrud' and 'Bashkirskaya krasnostebelnaya', the lowest $\mathrm{D}_{\mathrm{N}}=0.0372$ was between 'Kitawase soba 1' and 'Kitawase soba 2' (Table 1).

To visualize genetic differences using the TFPGA software package, a phylogenetic relationship dendrogram was constructed using the pairwise intragroup unweighted (UPGMA) algorithm. The length of the branches reflects the level of genetic differences (Figure 1). 'Kitawase soba 1' and 'Kitawase soba 2' formed a cluster with the shortest branches, and 'Bashkirskaya krasnostebelnaya', having the highest value of genetic distances in relation to the other cultivars, formed a separate cluster with the longest branch.

We calculated the population differentiation index $\left(\mathrm{G}_{\mathrm{st}}\right)$, which shows the distribution of intra- and inter-population variability. The value of $\mathrm{G}_{\mathrm{st}}=0.3125$ indicates the predominance of intra-population variability over inter-population variability, which may be a consequence of the peculiarities of the biological features of the crop under study, namely, crosspollination, a large number of different biotypes in the variety population, leading to an increase in population variability compared to self-pollinating crops (Klykov, 2011). In our early studies, there was defined a diagnostic trait (anthocyanin color of stem, flowers, root system, nuclei) which is efficient for use in breeding in order to create new varieties of Fagopyrum esculentum with high rutine contents (Klykov et al., 2018).

\section{Conclusion}

Thus, according to the results of ISSR analysis, the varieties Izumrud, Krasnoznamennaya Bashkirskaya and Kitawase soba 1, which have the greatest genetic differences were recommended for breeding process in order to create new genotypes with high flavonoid contents. In breeding, as the initial forms of selection, the choice of high-grade varieties with the highest level of differences, can lead to heterosis in hybrids. The data from ISSR analysis can be used to select the best plants within the hybrid buckwheat population.

The work was done in the framework of the complex program of fundamental research of the FEB RAS "Far East" in 2018-2020 project No. 18-5-025.

\section{References}

Aljanabi S.M., Martinez I. Universal and rapid salt-extraction of high quality genomic DNA for PCR-based techniques. Nucleic Acid Research. 1997;25(22):4692-4693.

Joshi S.P., Gupta V.S., Aggarwal R.K., Ranjekar P.K., Brar D.S. Genetic diversity and phylogenetic relationship as revealed by inter simple sequence repeat (ISSR) polymorphism in the genus Oryza. Theor. Appl. Genet. 2000;100:1311-1320.

Nei M. Genetic distance between populations. American Naturalist. 1972;106(949):283-292.

Klykov A.G., Moiseenko L.M., Gorovoy P.G. Biological resources of species of the genus of buckwheat (Fagopyrum Miil.) in the Russian Far East. Monograph. Vladivostok, 2018;304.

Klykov A.G. Study of intravarietal variability and the possibility of its use in the selection of buckwheat biotypes with certain qualitative indicators. Reports of the Russian Academy of Agricultural Sciences. 2011;2:12-14.

Sica M., Gamba G., Montieri S., Gaudio L., Aceto S. SSR markers show differentiation among Italian population Asparagus acutifolius L. BMC Genetics. 2005;6:6-17.

Conflict of interest. The authors declare no conflict of interest. 


\section{Plant Resistance to Pathogens and Other Biotic Stresses}




\title{
Resistance to stem rust and a molecular marker analysis of $\mathrm{Sr}$ genes in spring bread wheat introgression lines
}

\author{
O.A. Baranova ${ }^{1 *}$, S.N. Sibikeev² , A.E. Druzhin ${ }^{2}$ \\ ${ }^{1}$ All-Russian Institute of Plant Protection (FSBSI VIZR), St. Petersburg-Pushkin, Russia \\ ${ }^{2}$ Agricultural Research Institute of the South-East Region (FSGFSI ARISER), Saratov, Russia
}

DOI 10.18699/ICG-PlantGen2019-15

(c) Autors, 2019

* e-mail: baranova_oa@mail.ru

\begin{abstract}
Agricultural Research Institute of the South-East Region and 11 cultivars cultivated in the Volga Region were analyzed for resistance to the Ug99 race group in Kenya (KARI). 10 immune lines (infection type 0 ) and 16 lines with moderate resistance (infection type MR) were identified. Cultivars and part of the lines (58 introgression lines) were assessed for resistance to Lysogorsk and Omsk stem rust pathogen populations and to stem rust isolates PgtZ1(TKSTF) and PgtF18.6 (TKSTF+Sr33) and also analyzed for the presence of the known Sr resistance genes ( $\mathrm{Sr} 22$, Sr25, Sr26, Sr31, Sr35, Sr36, Sr38, Sr39) using molecular markers. The Sr31/Lr26, Sr25/Lr19, $\operatorname{Sr} 22, \operatorname{Sr} 35$ and $\operatorname{Sr} 38 / L r 37$ genes were identified in the introgression lines. All lines carrying Sr31/Lr26 and Sr22 were resistant to all local pathogen populations taken into analysis. The Sr26, Sr36 and Sr39 genes were not detected in the wheat lines analyzed.
\end{abstract}

Key words: spring bread wheat; introgression lines; Puccinia graminis f. sp. tritici; Ug99; Srgenes.

\section{Introduction}

Stem rust of wheat, caused by Puccinia graminis Pers. f. sp. tritici Eriks. and E. Henn., is one of the most devastating diseases of wheat worldwide. The emergence of a new highly aggressive stem rust race in Uganda in 1999, Ug99 (TTKSK), infecting wheat cultivars which contain the $S r 31$ gene (Pretorius et al., 2000) caused great concern in world wheat producers, because the epiphytotic development of this pathogen on susceptible cultivars can result in yield losses reaching $100 \%$ (Hailu et al., 2015). On the other hand, new aggressive races of stem rust that differ from Ug99 have appeared in the world including Europe and the Russian Federation. In the Russian Federation, the epiphytotic development of the disease was noted in 2015, 2016, 2017 and 2018 in Western Siberia.

In the Lower Volga Region the strong epiphytotics of stem rust was observed in 2004 and 2006 (the severity of disease development was 50-60\%), in 2016 in the Saratov Region the degree of disease development reached $80 \%$, the yield losses were more than $50 \%$, and the weight of 1000 seeds was at the level of 18-19 grams (Sibikeev et al., 2017; Sibikeev, unpublished data). Furthermore, in 2016, the spread of stem rust on spring bread wheat cultivars during earing was noted throughout the Republic of Tatarstan (Vasilova et al., 2017).

It is a fact that as a result of breeding aimed at the productivity and quality of grain, there was a strong reduction in wheat genetic diversity in many aspects, including resistance to fungal diseases (Wulff, Moscou, 2014).

Thus, the expansion of the genetic basis of varieties, obtaining breeding material, diverse in resistance genes is extremely important. The problem of searching for new resistance genes is successfully solved by application in the breeding alien wheat species from such genera as Aegilops, Secale and Agropyron (Rahmatov et al., 2016; Lapochkina et al., 2017; Kishii, 2019).

In the framework of our project, these are 128 introgression lines with genetic material from Tritcum durum, $T$. dicoccum,
T. kihara, T. persicum, T. timopheevii, T. compactum, Aegilops squarrosa, Ae. speltoides, Agropyron elongatum, Secale cereale, Satu triticale, which gives a wide opportunity to identify known and search for new resistance genes. The Lower Volga region is one of the main bread wheat production zones.

Rust pathogen inoculum, in addition to the local population, is spread into the Lower Volga region from Western Europe, the North Caucasus, Central Asia, and North Africa through the Middle East (Iran) and the Caspian Sea, which greatly increases the likelihood of the spread of race Ug99 into the Russian Federation.Our study is devoted to evaluation of the genetic potential of wheat breeding material and the identification of resistance genes that are effective not only against local populations of the pathogen, but also against $\mathrm{Ug} 99$ and its biotype, as well as against the aggressive races of $P$. graminis f. sp. tritici outside the Ug99 lineage.

Therefore, the aims of this study were to (i) evaluate the resistance of introgression lines (128) and spring bread wheat cultivars to the stem rust race Ug99 lineage; (ii) evaluate resistance of introgression lines (58) and spring bread wheat cultivars (11) to the local population of stem rust and to identify $\mathrm{Sr}$ genes using available molecular markers.

\section{Materials and methods}

The breeding material from the FSGFSI ARI of the South-East Region (128 introgression lines) and 11 cultivars of spring bread wheat cultivated in the Volga Region and related to the analyzed lines were used in the work. The lines were obtained with the participation of CIMMYT synthetics, durum wheat cultivars, direct crossing with alien species such as Agropyron elongatum, Ag. intermedium, different species of the genus Triticum L., Secale cereale and Satu triticale.

The Omsk and Lysogorsk populations of the pathogen, collected in 2018 from the wheat cultivar Favorit, which carries the 6Agi (6D) substitution, were used for laboratory assessment of resistance at the seedling stage. Also in analy- 
ses we used two stem rust isolates. PgtZ1 (TKSTF) from the Zernograd pathogen population and F18.6 (TKSTF+Sr33) from Lysogorsk populations of $P$. graminis f. sp. tritici. The virulence of the pathogen isolates was evaluated using a set of 20 differentiators (North American differential set) (Cereal Disease Laboratory) and near isogenic lines (24 lines). The cultivars Avrora (Sr31) and Khakasskaya (susceptible control) were also used in the analysis. Inoculation of plants was carried out in accordance with the methods adopted in the world practice (Jin et al., 2007).

The reaction of seedlings to inoculation (IT) with the spore suspension of the stem rust pathogen was taken into account on the 12-14th day after infection on a standard scale (Stackman et al., 1962). Evaluation of the resistance of introgression lines to race Ug99 was conducted on the base of the Kenya Agricultural Research Institute (KARI) in 2018. The criteria for evaluation of adult plants' resistance were the ITs and the degree of plant damage on the scale recommended by CIMMYT (Roelfs et al., 1992).

DNA was isolated from five-day wheat seedlings using cetyltrimethylammonium bromide (CTAB) (Murray, Thompson, 1980). DNA markers recommended for marker-assisted selection (MAS https://maswheat.ucdavis.edu/) were used to identify resistance genes (Sr22, Sr25, Sr26, Sr31, Sr35, Sr36, $\mathrm{Sr} 38, \mathrm{Sr} 39$ ), separation of PCR products was carried out in $2 \%$ agarose gels. Near isogenic lines and cultivars with $\mathrm{Sr}$ genes served as the positive control, the susceptible cultivar Khakasskaya served as the negative control.

\section{Results and discussion}

3.1 Phytopathological analysis of resistance to Ug99 in Kenya The prospect of the analyzed introgression wheat lines for resistance breeding was confirmed by the results of the analysis conducted on the base of the Kenya Agricultural Research Institute (KARI). The analysis was conducted against the background of a strong disease development (up to $90 \mathrm{~S}$ on susceptible varieties). The racial composition of the pathogen population included races such as TTKSK (Ug99), TTKST (Ug99 + Sr24), TTTSK (Ug99 + Sr36), TTKTK (virulent to $S r T m p$ ), TTKTT (Sr24 and $S r T m p$ ). In the result, from the 128 introgression lines studied in Kenya, 10 lines were immune (reaction type 0 ).

Also, 16 lines showed reaction type 5MR, all the ten varieties tested (Saratovskaya 55, Saratovskaya 68, Saratovskaya 73, Albidum 32, Prokhorovka, Yugo-Vostochnaya 2, Dobrynya, Favorit, Voyevoda and Lebedushka) were not resistant to the Kenyan population of $P$. graminis. The lowest reaction types were $10 \mathrm{M}$ with 'Favorit' (Sr6Agi) and 20M with 'Dobrynya' (Sr25/Lr19).

\subsection{Phytopathological analysis of resistance to stem rust at the seedling stage}

At the next stage of work, 58 lines and 11 wheat cultivars were evaluated for resistance to the Saratov population of stem rust under field conditions and for resistance to the Omsk and Lysogorsk pathogen populations and to the two monopustule isolates (TKSTF, TKSTF+Sr33) at the seedling stage under laboratory conditions. All introgression lines were resistant to the Saratov population of stem rust in the field in 2018.

During evaluation at the seedling stage, 42 lines were resistant to the Omsk pathogen population and 32 lines were resistant to the Lysogorsk pathogen population. When evaluating resistance to isolates PgtZ1 (TKSTF avirulent to Sr11, Sr17, Sr24, Sr31) and PgtF18.6 (TKSTF+ virulent to Sr33), it was found that 15 lines were resistant and 7 were heterogeneous to PgtZ1, 15 lines were resistant and 5 were heterogeneous to PgtF18.6.

Only 11 lines were resistant to the Omsk and Lysogorsk pathogen populations and to both isolates of $P$. graminis used in analysis. During laboratory analysis of data on 11 cultivars, the following results were obtained: 'Prokhorovka', 'Yugo-Vostochnaya 2' and 'Dobrynya' were resistant to the Lysogorsk population of stem rust; 'Prokhorovka' and 'Yugo-Vostochnaya 2' were resistant to the Omsk pathogen population. Also, only 'Prokhorovka' (Sr31), 'YugoVostochnaya 2' (Sr31) and 'Lebyodushka' (Sr25+Sr6Agi) are resistant to PgtF18.6, while 'Prokhorovka' and 'YugoVostochnaya 2' are resistant to PgtZ1.

\subsection{Identification of resistance genes}

From the genes known to be ineffective against Ug99, but effective against local stem rust populations, the $\operatorname{Sr} 31$ gene in the introgression lines was identified. The Xscm 9 marker, developed for the 1BL.1RS rye translocation carrying the resistant genes to stem $(\mathrm{Sr} 31)$, leaf $(\operatorname{Lr} 26)$ and yellow $(\mathrm{Yr} 9)$ rust and powdery mildew $(P m 8)$, was used to identify it.

The 1BL.1RS translocation (gene Sr31) was identified in 15 lines out of 58. All samples carrying the 1BL.1RS translocation were resistant to the Saratov population of stem rust during the field evaluation and to all the rest of the analyzed pathogen populations during resistance evaluation at the seedling stage.

It was also concluded that the $S r 31$ gene still retains its effectiveness toward local stem rust populations.

The Sr25/Lr19 gene was identified in 40 lines (69\%) using the Gb marker recommended for the marker-assisted selection. The combination of the Sr31/Lr26 and Sr25/Lr19 genes was identified in 12 wheat lines. The $\operatorname{Sr} 38$ gene was detected in two lines using the VENTRIUP-LN2 primers; at this stage, the combination of the Sr25/Lr19+Sr38/Lr37 genes was identified in these lines. The $S r 22$ gene was introgressed from T. monococcum L. ssp. Aegilopoides to wheat.

Among the analyzed set of introgression lines there were three in the pedigree of which was line W3435 carrying Sr 22. For the identification of $\mathrm{Sr} 22$, three closely linked molecular markers, Xcfa2019, Xcfa2123 and Xwmc633, were used with the size of diagnostic fragments of 238, 234, and $117 \mathrm{bp}$, respectively.

In the analysis, line SWSR22TB containing the $S r 22$ gene and the parent line W3435 (Sr22) was used as a positive control. According to the results of PCR analysis, $\mathrm{Sr} 22$ can be postulated in two lines (L503 / W3534 // L503 / 3 / L503; L503 / W3534 // L503).

In both lines, a combination of the $S r 25 / L r 19+S r 22$ genes was identified and both of these lines were resistant to the Omsk and Lysogorsk pathogen populations and to P. graminis f. sp. tritici isolates PgtZ1 and PgtF18.6. The Sr35 gene using 
the Xcfa 2170 marker was identified in one line, 1230/2 (L503 / Sr 35 // L503 / 3 / L503), obtained from crossing lines L503 (Sr25) and Sr35. As the control, the parent line Sr35 and the line Marquis * 5 / G2919 (Sr35) were used. The Sr25/Lr19 and $\mathrm{Sr} 35$ genes were indentified in this line. Previously, line 1230-1 (L503 / Sr 35 // L503 / 3 / L503) with a possible presence of the $\operatorname{Sr} 35$ gene was immune to Ug99 in Kenya.

The assumption of the presence of the $S r 35$ gene in line 1230-1 was confirmed with the Xcfa2170 marker in the present work. Thus, a combination of the $S r 35+S r 25 / L r 19$ genes was identified in this line. No known stem rust resistance genes from Ae. speltoides were identified in the introgression lines, although the presence of introgressions from this species in the lines suggested that genes such as $\operatorname{Sr} 39 / \mathrm{Lr} 35$ could be present.

Thus, the $\operatorname{Sr} 31 / \operatorname{Lr} 26$ and $S r 25 / \operatorname{Lr} 19$ genes were mainly identified in the introgression lines. The combination of these genes $(\operatorname{Sr} 31+\operatorname{Sr} 25)$ was found in 15 lines $(26.3 \%)$. The $S r 26$, $\mathrm{Sr} 36$ and $\mathrm{Sr} 39$ genes were not detected in the analyzed wheat lines.

The strategy of anticipatory breeding for immunity is based, on the one hand, on studying the pathogen population, identifying dangerous pathotypes capable of overcoming resistance genes used in cultivated varieties, and, on the other hand, on finding effective resistance genes for them and then introducing these genes into the local, well-adapted germplasm. Such a strategy will make it possible to obtain a source material for breeding that is resistant to leaf and stem rust, including Ug99, and adapted for the zone of the Lower Volga region.

This work is an ongoing study, the goal of which is to obtain initial material for stem rust resistant breeding, including $\mathrm{Ug} 99$, and adapted for the zone of the Lower Volga region. Previously, we identified $S r$ genes in 57 introgression lines (Baranova et al., 2019), and now in 58 lines.

On the whole, in the lines studied, we identified mainly the $S r 31$ and $S r 25$ genes and their combination. In two lines, we identified $\mathrm{Sr} 22$. Its presence in them is indirectly confirmed by the fact that these lines were resistant to the local populations of the pathogen and to fungal isolates PgtZ1 and PgtF18.6, which are avirulent to $S r 22$.

These lines were not evaluated for resistance to Ug99, which will be done later. In some lines resistant to Ug99 in Kenya, resistance genes were identified. Thus, the new highperformance combinations are Sr25/Lr19+LrKuk/SrKuk, Sr25/Lr19 + Sr31/Lr26 + Sr28, Sr25/Lr19+Sr38/Lr37, and $\operatorname{Sr} 25 / \operatorname{Lr} 19+\operatorname{Sr} 35$. Of the 128 lines studied, 16 showed infection type 5MR.

Thus, the effectiveness of the above combinations has been confirmed, but line 11, apparently, still has unidentified $\mathrm{Sr}$ genes, since 'Lebedushka' with the identified $\mathrm{Sr} 25 / \mathrm{Lr} 19+$ Lr6Agi combination was at the level of 20MS. In addition, if the combinations coincide with infection types 0 and 5MR, it appears that the lines with infection type 0 have additional resistance genes, which will be tested in further studies.

\section{Conclusions}

From the 128 introgression lines studied in Kenya, 10 lines were found immune (infection type 0 ) and 16 lines showed reaction type 5MR. Gene combinations identified in these lines are Sr25 / Lr19 + LrKuk/SrKuk, Sr25/Lr19+Sr31/ $L r 26+\operatorname{Sr} 28, \operatorname{Sr} 25 / \operatorname{Lr} 19+\operatorname{Sr} 38 / L r 37$ and Sr25/Lr19 + Sr35 . The $S r 31 / L r 26$ and $S r 25 / L r 19$ genes were mainly identified in the analyzed 58 introgression lines. The combination of these genes - Sr31/Lr26 + Sr25/Lr19 - was identified in 15 lines $(26.3 \%)$ from 58 . The combination of the $\operatorname{Sr} 38 / \mathrm{Lr} 37+$ Sr25/Lr19 genes was identified in two lines; Sr25/Lr19+ $\mathrm{Sr} 35$, in two lines. A promising combination of genes, $\mathrm{Sr} 22+$ $\mathrm{Sr} 25 / \mathrm{Lr} 19$, was identified in two lines.

These lines were resistant to all analyzed populations of the pathogen, which makes them promising for further use in breeding. All lines carrying Sr31/Lr26 and Sr22 were resistant to all local pathogen populations taken into analysis. The $\mathrm{Sr} 26, \mathrm{Sr} 36$ and $\mathrm{Sr} 39$ genes were not detected in the analyzed wheat lines.

It is also necessary to note promise for the use of the triticale cultivar Satu, which carries the linkage genes $\mathrm{LrSatu} / \mathrm{SrS} \mathrm{Satu}$, in protection against stem rust pathogen (McIntosh et al., 1995). Two lines (Satu/C70//C74/3/C70/4/C70) and (Satu/ $\mathrm{C} 70 / / \mathrm{C} 74 / 3 / \mathrm{C} 74)$ were immune to $\mathrm{Ug} 99$ and its biotypes in Kenya.

\section{References}

Baranova O.A., Sibikeev S.N., Druzhin A.E. Molecular identification of the stem rust resistance genes in the introgression lines of spring bread wheat. Vavilovskii Zhurnal Genetiki $i$ Selektsii $=$ Vavilov Journal of Genetics and Breeding. 2019;23(2):296-303. DOI 10.18699/VJ19.494.

Hailu E., Woldaeb G., Denbel W., Wubishet Alemu, Tekelay Abebe, Agengehu Mekonnen. Distribution of stem rust (Puccinia graminis f. sp. tritici) races in Ethiopia. Plant. 2015;3(2):15-19. DOI 10.11648/j.plant.20150302.11.

Jin Y., Singh R.P., Ward R.W., Wanyera R., Kinyua M., Njau P., Fetch T., Pretorius Z.A., Yahyaoui A. Characterization of seedling infection types and adult plant infection responses of monogenic Sr gene lines to race TTKS of Puccinia graminis f. sp. tritici. Plant Dis. 2007;91:1096-1099.

Kishii M. An Update of Recent Use of Aegilops Species in Wheat Breeding. Front. Plant Sci. 2019;10:585. DOI 10.3389/fpls.2019. 00585 .

Lapochkina I.F., Baranova O.A., Shamanin V.P., Volkova G.V., Gainullin N.R., Lazareva E.N., Gladkova E.V., Anisimova A.V., Galinger D.N., Vaganova O.F. The development of the initial material of spring common wheat for selective breeding for resistance to stem rust (Puccinia graminis Pers. f. sp. tritici), including the Ug99 race in Russia. Russ. J. Genet.: Appl. Res. 2017;7(3):308-317. DOI $10.1134 / \mathrm{S} 207905971703008 \mathrm{X}$

McIntosh R.A., Wellings C.R., Park R.F. (Eds.). Wheat Rusts. An Atlas of Resistance Genes. CSIRO Australia, 1995.

Pretorius Z.A., Singh R.P., Wagoire W.W., Payne T.S. Detection of virulence to wheat stem rust resistance genes Sr31 in Puccinia graminis f. sp. tritici in Uganda. Plant Dis. 2000;84(2):203. DOI 10.1094/PDIS.2000.84.2.203B 
Rahmatov M., Rouse M.N., Steffenson B.J., Andersson S.C., Wanyera R., PretoriusZ.A., Houben A., KumarseN., Bhavani S., Johansson E. Sources o stem rust resistancein whea-alienintrigression lines. Plant Dis. 2016;100:1101-1109. DOI 10.1094/PDIS-12-151448-RE.

Roelfs A.P., Singh R.P., Saaru E.E. Rust Diseases of Wheat: Concepts and Methods of Disease Management. Mexico, D.F.: CIMMYT, 1992.

Murray M.G., Thompson W.F. Rapid isolation of high molecular weight plant DNA. Nucleic Acids Res. 1980;8(19):4321-4326. DOI 10.1093/nar/8.19.4321.

Sibikeev S.N., Druzhin A.E., Badaeva E.D., Shishkina A.A., Dragovich A.Y., Gultyaeva E.I., Kroupin P.Y., Karlov G.I., Khuat T.M.,

Divashuk M.G. Comparative analysis of Agropyron intermedium (Host) Beauv 6Agi and 6Agi2 chromosomes in bread wheat culti- vars and lines with wheat-wheatgrass substitutions. Russ. J. Genet. 2017;53(3):314-324. DOI 10.1134/S1022795417030115.

Stackman E.C., Stewart D.M., Loegering W.Q. Identification of Physiologic Races of Puccinia graminis var. tritici. US Department of Agriculture; Agric. Res. Service. 1962.

Vasilova N.Z., Askhadullin Dam.F., Askhadullin Dan.F. Stem rust epiphytotic on soft spring wheat in Tatarstan. Zashchita i Karantin Rasteniy = Plant Protection and Quarantine. 2017;2:27-28 (in Russian).

Wulf B.B.H., Moscou J.M. Strategies for transferring resistance into wheat: from wide crosses to GM cassettes. Front. Plant Sci. 2014; 5:692.

Acknowledgements. The work is supported by the RFBR grant No. 18-016-00170 a.

Conflict of interest. The authors declare no conflict of interest. 


\title{
Development of the panel of SSR markers to estimate the level of genetic diversity among the Siberian stem rust population
}

\author{
V.N. Kelbin ${ }^{1 *}$, E.S. Skolotneva ${ }^{1}$, S. Vidich ${ }^{2}$, M.A. Nesterov ${ }^{1}$, E.M. Sergeeva ${ }^{1}$, E.A. Salina ${ }^{1}$ \\ 1 Institute of Cytology and Genetics, SB RAS, Novosibirsk, Russia \\ ${ }^{2}$ University of Banja Luka, Banja Luka, Bosnia and Herzegovina
}

DOI 10.18699/ICG-PlantGen2019-16

(c) Autors, 2019

* e-mail: bak_anapiyayev@mail.ru

\begin{abstract}
Puccinia graminis f. sp. tritici is the causal agent of stem rust disease in wheat. The rust fungus has caused devastating epidemics of disease throughout history and is currently a potential threat to wheat production in some regions of Western Siberia. The samples were analyzed using 14 polymorphic simple sequence repeat (SSR) markers. The panels of specific SSR markers were suggested to distinguish the samples from different regions and single pustule isolates.
\end{abstract}

Key words: SSR markers; Stem Rust; Western Siberia.

\section{Introduction}

The genetic diversity of Puccinia graminis is extremely high. Within the species, there are several special forms (f. sp) virulent to different cereals, and there is a differentiation of P. graminis f. sp. tritici (Pgt) determined by the resistance of wheat varieties. Single sequence repeat (SSR) markers are developed to target highly unstable parts within an organism's genome. They present high levels of polymorphism due to high mutation rates e.g. caused by slippage during DNA replication. The advantage of using SSR markers in a dikaryotic organism like $P$. graminis is that they are co-dominant and alleles from both nuclei can be detected. By using SSR markers, many samples can be processed and differences within one species or closely related species may be detected. Tri-nucleotide repeat SSR markers have been developed for Pgt and have been shown to be useful in distinguishing between race groups (Zhong et al., 2009). The objective of this study was to develop a panel of SSR markers to estimate the level of genetic diversity among the Siberian stem rust population.

\section{Materials and methods}

Sample collection and storage. Infected stems of the susceptible wheat cv. 'Chernyava 13' were collected in the Novosibirsk region (test fields of ICG SB RAS and test fields of SibRIPPB - Branch of ICG SB RAS) and in the Omsk region (Omsk State Agrarian University) in 2018. Single pustule isolates of Pgt from heterogeneous samples were multiplied and stored in a freezer at $-80^{\circ} \mathrm{C}$ at the ICG SB RAS.

SSR marker analysis. Fourteen of the SSR markers used in international rust laboratories (Zhong 2009; Berlin 2012, 2017) were validated for Russian Pgt isolates. Genomic DNA was extracted from roughly $40 \mathrm{mg}$ of tissue from germinated or ungerminated urediniospores, teliospores and aeciospores of stem rust fungus. Spore material was pulverized by using liquid nitrogen. DNA isolation directly from urediniospores was carried out according to the method described by Justesen et al. (2002), and DNA extraction from infected plant material, according to the method described by Plaschke et al. (2002).
The PCR reaction was performed in a volume of $13 \mu \mathrm{l}$. The reaction mixture contained of $30 \mathrm{ng}$ DNA, $1.3 \mathrm{nmol}$ of the M13-tailed forward and $13 \mathrm{nmol}$ of the reverse primers, $0.54 \mathrm{mM}$ of each dNTP, $1 \mathrm{U} / \mu \mathrm{l}$ of HP-Taq DNA polymerase and buffer $(67 \mathrm{mM}$ Tris- $\mathrm{HCl} \mathrm{pH} 8.8 ; 18 \mathrm{mM} ; 1.7 \mathrm{mM} ; 0.01 \%$ Tween 20), $30 \mathrm{pmol}$ of each the M13-tailed primer labeled with FAM.

We used touchdown PCR to increase specificity and reduce background amplification, which is essential to correct allele calling and critical when pooling markers. PCR conditions were as follows: initial denaturation at $95^{\circ} \mathrm{C}$ followed by 12 cycles (ramp annealing temperature $0.5 \mathrm{gr} / \mathrm{cycle}$ ) of denaturation for $30 \mathrm{~s}$ at $95{ }^{\circ} \mathrm{C}$, annealing for $1 \mathrm{~min} 30 \mathrm{~s}$ at $63{ }^{\circ} \mathrm{C}$ and extension for $30 \mathrm{~s}$ at $72{ }^{\circ} \mathrm{C}$; and initial denaturation at $95^{\circ} \mathrm{C}$, followed by 23 cycles of denaturation for $30 \mathrm{~s}$ at $95^{\circ} \mathrm{C}$, annealing for $1 \mathrm{~min} 30 \mathrm{~s}$ at $57^{\circ} \mathrm{C}$ and extension for $30 \mathrm{~s}$ at $72^{\circ} \mathrm{C}$; and a final extension for $10 \mathrm{~min}$ of $72{ }^{\circ} \mathrm{C}$. The length of the amplicons was determined using an ABI 3130XL Genetic Analyzer (SB RAS Genomics Core Facility, Novosibirsk, Russia) and was scored using the Peak Scanner Software v1.0 (Applied Biosystems).

\section{Results and discussion}

To develop the panel of SSR markers effective for use on the Siberian population of stem rust, it was important to find out about the marker resolution.

The SSR-based profiles of Pgt samples from the same wheat cv. 'Chernyava 13', but collected in Omsk and Novosibirsk regions, showed difference when the following five markers were used: 109AGGF/R, 227AAGR/F, 293F/R, PgCAA8F1/ R1, CAA49F1/R1 (SSR panel\#1). These results indicate that (1) two distant Pgt populations exist in these regions of Western Siberia; (2) the SSR markers listed as panel\#1 are able to differentiate the geographical samples of the stem rust population.

Four SSR markers (SSR panel\#2: 109AGGF/R, CAA98F1/ R1, CAA53F1/R1, CAA49F1/R1) were enough to differentiate single-pustule isolates ( $\mathrm{sp}$ isolates) from the Novosibirsk population. By using SSR markers, stable marker fragments were obtained. By using 109AGGF/R, the following four 
Table 1

Primer sequences and characteristics of the 14 SSR makers used among Siberian stem rust

\begin{tabular}{lllllll}
\hline Locus & Primer name & Forward primer (5'-3') & Revers primer (5'-3') & $\begin{array}{l}\text { Size range, } \\
\text { bp }\end{array}$ & Motif & Reference \\
\hline Pgestssr021 & 21AAGF/R & GTTTGCCTGATGATGGATGA & CCGAATGCAGATTACCCTTG & $260-271$ & AAG & Stoxen S., 2012 \\
\hline Pgestrre024 & 24R/F & TCATCGACCAAGAGCATCAG & TTCGGGAGTGAGTCTCTGCT & $166-178$ & CAT & Stoxen S., 2012 \\
Pgestssr109 & 109AGGF/R & TCATCGACCAAGAGCATCAG & TTCGGGAGTGAGTCTCTGCT & $187-193$ & CCT & Zhong et al., 2009 \\
Pgestssr173 & 173R/F-ATC & TCCCTTGACCTTTCTCAACG & TCCATTGAGTTCCATCGTGA & $195-213$ & ATC & Zhong et al., 2009 \\
Pgestssr227 & 227AAGR/F & CACACGTCTCGAGGAACAGA & CTCGTGGGATGAAGTCCATT & $210-231$ & AAG & Zhong et al., 2009 \\
Pgestssr293 & 293F/R & GAACCTTGGCCTGAGTGCTA & GCAGCCTACAGCAAGAATCC & $258-270$ & GGT & Zhong et al., 2009 \\
Pgestssr341 & 341AACR/F & GATGTCGCACTCGGTTTCTT & GGCCTTGGTACCCAATTTCT & $232-235$ & TGG & Zhong et al., 2009 \\
Pgestssr353 & 353F/R & TCGAATCCCAAGGAACAGAG & ACGTCTTGGGTTTCTGTGGA & $253-259$ & AGG & Zhong et al., 2009 \\
PgtCAA49 & CAA49F1/R1 & TCGTCTGATCGTGAGAAACG & GACGATTGCTGAGGATTGCT & $128-164$ & CAA & Stoxen S., 2012 \\
PgtCAA53 & CAA53F1/R1 & AGGCTCAACACCACCCATAC & AGGAGGAGGTGAAGGGGATA & $204-240$ & CAA & Jin et al., 2009 \\
PgtCAA93 & CAA93F1/R1 & CACTCTCGCCAAACCTCATT & CGCCTGTGATGGTTGTATTG & $176-262$ & CAA & Jin et al., 2009 \\
PgtCAA98 & CAA98F1/R1 & ATTCGGATGGTCCGTTACTG & CCATCCCACTCAAATCATCC & $183-198$ & CAA & Jin et al., 2009 \\
PgtGAA8 & PgCAA8F1/R & GGATGATCGGTCAGTTGGTT & TGTCTGCCTGTCTGTCGAAC & $198-228$ & CAA & Stoxen S., 2012 \\
PgtCAT4.2 & PgCAT4F2/R1 & CCGTGTCGATCCCAATAATC & AGCAAGGTGAGAATCGGAAA & $141-150$ & CAT & Stoxen S., 2012 \\
\hline
\end{tabular}

marker fragments were obtained: 181, 187, 190, and $193 \mathrm{bp}$. One of them (190 bp) was polymorphic between single-pustule isolates. By using CAA98F1/R1, the following five marker fragments were obtained: 183, 189, 192, 195, and $198 \mathrm{bp}$. Two of them (189 and $195 \mathrm{bp}$ ) were polymorphic between single-pustule isolates. By using CAA53F1/R1, the following five marker fragments were obtained: 229, 231, 234, 237, and $246 \mathrm{bp}$. One of them (246 bp) was polymorphic between single-pustule isolates. By using CAA49F1/R1, the following six marker fragments were obtained: $128,131,134,146,149$, and $158 \mathrm{bp}$. Four of them $(128,146,149$, and $158 \mathrm{bp})$ were polymorphic between single-pustule isolates.

\section{Conclusions}

Validation of 14 SSR markers on the Siberian stem rust population allowed us to propose two SSR panels efficient for differentiation:

1) SSR panel\#1: the geographical samples of the stem rust population (from Omsk and Novosibirsk regions);

2) SSR panel\#2: single-pustule isolates of Pgt.

\section{References}

Berlin A., Berit S., Björn A. Multiple genotypes within aecial clusters in Puccinia graminis and Puccinia coronata: improved understanding of the biology of cereal rust fungi. Fungal biology and biotechnology. 2017;4(1):3.

Berlin A. et al. Genetic variation in Puccinia graminis collected from oats, rye, and barberry. Phytopathol. 2012;102(10):1006-1012.

Berlin A. Population biology of Puccinia graminis. 2012;2012(79).

Jin Y., Szabo L.J., Rouse M.N., Fetch T., Pretorious Z.A., Wanyera R., Njau P. Detection of virulence to resistance gene Sr36 within the TTKS race lineage of Puccinia graminis f. sp. tritici. Plant Disease. 2009;93:367-370.

Stoxen S. Population structure of Puccinia graminis f. sp. tritici in the United States. 2012.

Zhong S., Leng Y., Friesen T.L., Faris J.D., Szabo L.J. Development and characterization of expressed sequence tag-derived microsatellite markers for the wheat stem rust fungus Puccinia graminis f. sp. tritici. Phytopathol. 2009;99:282-289.

Acknowledgements. This work was supported by the Russian Foundation for Basic Research No. 17-29-08018 and budget project No. 0259-2019-0001.

Conflict of interest. The authors declare no conflict of interest. 


\title{
Study of introgression lines of common wheat Triticum aestivum/Triticum miguschovae for resistance to leaf rust
}

\author{
R.O. Davoyan*, I.V. Bebykina, E.R. Davoyan, D.S. Mikov, Y.S. Zubanova, D.M. Boldakov, A.N. Zinchenco
}

National Center of Grain named after P.P. Lukyanenko, Krasnodar, Russia

DOI 10.18699/ICG-PlantGen2019-17

(c) Autors, 2019

*e-mail: davoyanro@mail.ru

\begin{abstract}
The evaluation of resistance to leaf rust, the cytological and molecular analysis of 106 introgression lines of common wheat obtained on the basis of the synthetic form Triticum miguschovae Zhir were performed. Cytological stability of lines was established. 53 lines with high and 23 with medium resistance to leaf rust were selected. Two lines with the Lr39 gene and 26 lines with the Lr50 gene were identified with the use of molecular markers. Other resistant lines can presumably carry genes for resistance to leaf rust other than Lr39 or Lr50.

Key words: T. aestivum; T. miguschovae; introgression lines; resistance to leaf rust; cytological analysis; molecular markers.
\end{abstract}

\section{Introduction}

Leaf rust (Puccinia recondita Rob. ex Desm. f. sp. tritici Erikss.et Henn) is one of the most widespread and harmful diseases of wheat. The most effective way to control the infestation is by breeding resistant varieties. This work assumes the presence of a sufficient diversification of effective genes for resistance, including new ones. Of great interest are the species Triticum timopheevii Zhuk. (GGAA) and its natural mutant T. militinae Zhuk. et Migush., and Aegilops tauschii Coss. (DD) as sources of resistance to diseases (Friebe et al., 1996; McIntosh et al., 2005). The synthetic form T. miguschovae (GGA t $\left.A^{t} \mathrm{DD}\right)$ was used as a "genetic bridge' to transfer leaf rust resistance from these species to common wheat, where the D genome from Ae. tauschii was added to the AG genomes from T. militinae (Zhirov, 1980). To date, a large number of introgression lines and six varieties of winter common wheat have been obtained with the use of this form (Davoyan et al., 2012).

This article presents the results of the evaluation of 106 T. aestivum/T. miguschovae introgression lines of common wheat for resistance to leaf rust, cytological stability and the identification of previously transferred effective genes, Lr39 and $\operatorname{Lr} 50$.

\section{Materials and methods}

$106 \mathrm{BC}_{2} \mathrm{~F}_{22}-\mathrm{BC}_{4} \mathrm{~F}_{16}$ introgression lines of common wheat, obtained from crossing T. miguschovae with the varieties 'Bezostaya1', 'Kavkaz' and 'Skiphyanka' (MB, MK and $\mathrm{MKC}$ lines) susceptible to leaf rust were used as objects of research.

The cytological analysis was performed by studying chromosome paring in metaphase I of meiosis.

The reaction of plants to leaf rust infestation was evaluated using the international scale by Maines and Jackson in the field (Mains, Jackson, 1926). The plants with reaction types from 0 to 2 were classified as resistant. Plants with intermediate reaction types, between 0 and 1 , were designated as 01 . Plants with reaction types 3 and 4 were considered susceptible.

DNA of wheat was extracted from 5-7-day-old bleachedout sprouts using a method by Plaschke with the coauthors
(1995). Identification of genes was done with the use of molecular marker GDM-35 for Lr39 gene (Huang et al., 2001) and the GDM87 and WMS382 markers for the Lr50 gene (Brown-Guedira et al., 2003). Wheat lines KS86WGRC02 and KS96WGRC36 with genes for resistance to leaf rust, Lr39 and Lr50, respectively, were used as positive controls for identification of known genes.

\section{Results and discussion}

As the main aim of the work was to transfer resistance to diseases from T. miguschovae to common wheat, the lines were evaluated for resistance to one of the most widespread and harmful of them, leaf rust. The characteristics of the population of lines assessed for resistance to this pathogen in 20162018 is presented in Table 1 . The assessment of the lines revealed their difference in resistance to leaf rust in all combinations.

Highly resistant lines with reaction types 01 and 1 , medium resistant (reaction type 2), medium susceptible (reaction type 3 ) and highly susceptible (reaction type 4) lines were identified.

Fifty-three lines showed high resistance to leaf rust. 23 lines were medium resistant and 22 lines were susceptible to a local population of leaf rust. Also, 8 lines with a heterogeneous reaction type were revealed, where single pustules with treaction type 3 appeared on the background of high resistance (reaction type 1). Wide polymorphism of lines in resistance to leaf rust can indicate different introgressions of genetic material from T. miguschovae to the common wheat genome.

One of the basic conditions for the use of introgression lines as donors is their cytological stability, because it is closely connected with normal plant ontogenesis. Based on the fact that the lines analyzed were obtained by means of backcrosses from a large number of self-pollinating generations, it is very likely that they are meiotically stable. To acknowledge this, a cytological analysis of 20 resistant lines with reaction types 01,1 and 2 was performed. For the establishment of cytological stability, chromosome pairing in metaphase I of meiosis in 3-4 plants from every line was studied. The number of the cells studied in each line varied from 100 to 140 . The lines 
Table 1

Characteristics of the population of T. aestivum/T. miguschovae introgression lines for resistance to leaf rust in 2016-2018

\begin{tabular}{llllll}
\hline Cross combination & \multicolumn{5}{c}{ Number of lines with reaction type to leaf rust } \\
& 01 & 1 & 2 & $3-4$ & $1 / 3$ \\
\hline MB & 5 & 6 & 6 & 4 & 3 \\
MK & 15 & 11 & 12 & 6 & 2 \\
MKS & 10 & 6 & 5 & 12 & 3 \\
Total & 30 & 23 & 23 & 22 & 8 \\
\hline
\end{tabular}
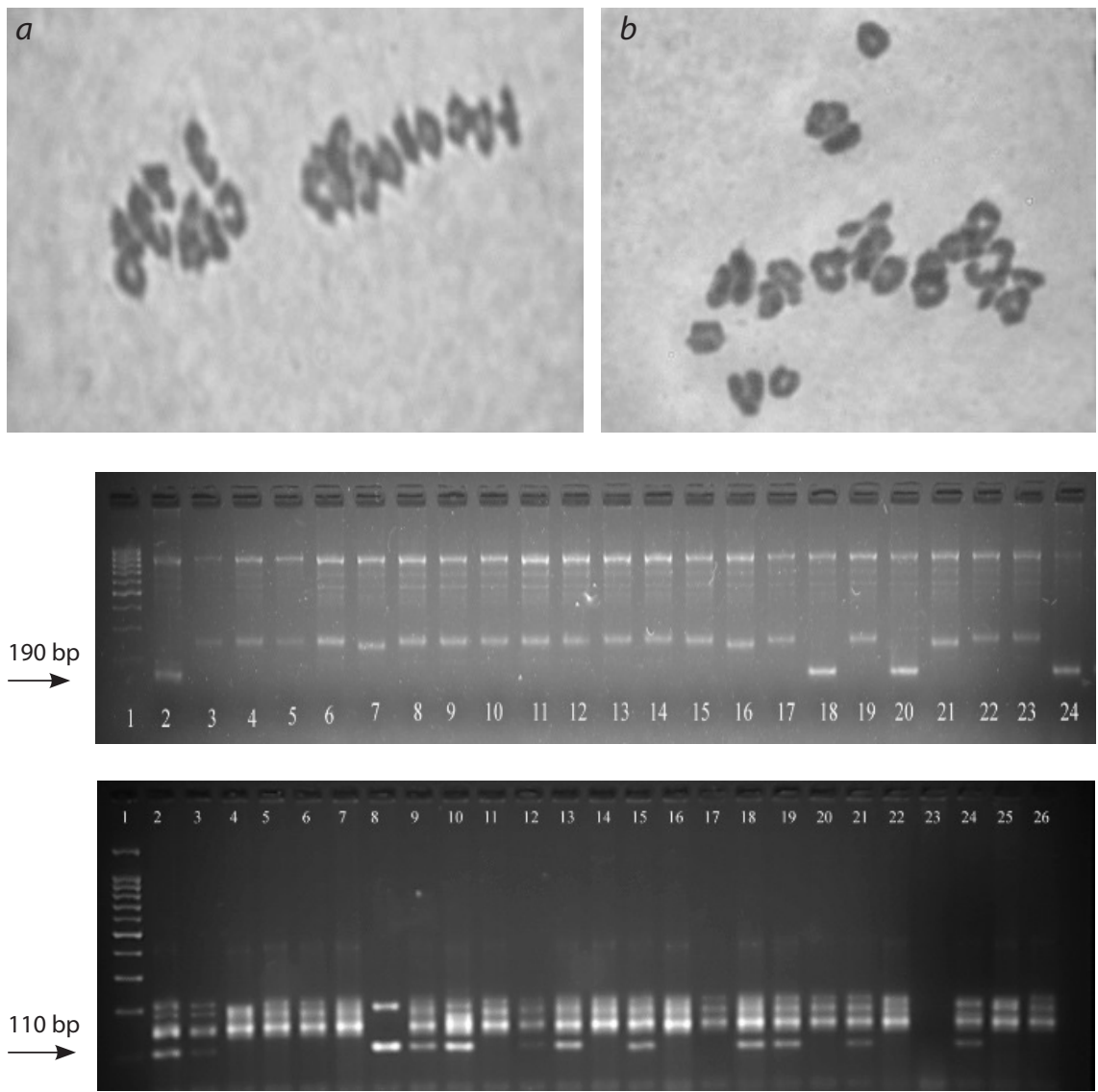

Figure 1. Association of chromosomes in metaphase I of meiosis in lines MK509-21" (a) and MB1801-21" (b)

Figure 2. Products of amplification with the use of the GDM35-R and GDM35-L primer pairs to the diagnostic marker linked to $L r 39$, a gene for resistance to leaf rust. 1, marker of length; $2, T C L r 39$ 3, variety 'Avrora'; 4-23, lines; 24, T. miguschovae; 18, line MK452; 20, line MKC985.

Figure 3. Products of amplification with the use of the GDM87-L/R primer pair to the diagnostic marker linked to the leaf rust resistance gene Lr50. 1, marker of length; 2, T. miguschovae; 3, KS96WGRC36 (Lr50); 4, variety 'Bezostaya 1 ; $; 5-26$, the lines obtained on the basis of T. miguschovae. were cytologically stable where they had more than $90 \%$ of cells with the bivalent $\left(21^{\mathrm{II}}\right)$ configuration of chromosomes (Figure 1).

All lines analyzed formed the $21^{\mathrm{II}}$ bivalent and were cytologically stable regardless of their origin and degree of resistance. The efficiency of selection for resistance to diseases depends on the presence of information about identification of genes. The genes the resistance to leaf rust $\operatorname{Lr} 18$ and $\operatorname{Lr} 50$ were transferred from $T$. timopheevii to common wheat, and Lr21, Lr32, Lr39, Lr41, Lr42, Lr43 were transferred from Ae. tauschii (McIntosh, 2005). It is possible that T. miguschovae and the lines obtained on its basis carry these genes. Of these resistance genes, $L r 39$ and $L r 41$ are effective and $L r 50$ is partially effective in various regions of Russia nowadays (Zhemchuzina, Kurkova, 2010). At the same time, the identity of genes $L r 39$ and $L r 41$ was established (Singh, 2004). In this connection, a screening of 76 resistance lines with genetic material from $T$. miguschovae for the presence of molecular markers linked to the Lr39 and Lr50 genes was performed. For identification of $\operatorname{Lr} 39$, a gene for resistance to leaf rust, the microsatellite marker GDM35 was used. GDM35 is widely used for screening varieties and lines in the USA (Sun et al., 2009). Specific fragments of amplification $190 \mathrm{bp}$ to the diagnostic marker GDM35, linked to the $L r 39$ gene were detected in the positive control line KS86WGRC02, the synthetic form T. miguschovae, and two highly resistant lines, MK452 and MKC985 (Figure 2).

Identification of the leaf rust resistance gene $L r 50$ was done with two microsatellite markers, $\mathrm{Xgwm} 382$ and $\mathrm{Xgdm} 87$, which outflank the $L r 50$ locus at a distance of 6.7 and $9.4 \mathrm{cM}$, respectively. The 110-bp fragment was determined after amplification with the use of the GDM87-L/R primers, and the 139-bp fragment appeared after amplification with the use of the $W M S 382-L / R$ primers. The presence of the $L r 50$ gene in the diagnosed sample was established upon revealing fragments of amplification of both markers. 
The $110 \mathrm{bp}$ fragment of amplification using the diagnostic marker GDM87 linked to the resistance gene $\operatorname{Lr} 50$ was identified in the positive control KS96WGRC36, the form T. miguschovae and in 32 resistance lines. The products of amplification of 22 lines are presented in Figure 3. The fragment specific to a marker linked to the $\operatorname{Lr} 50$ gene was revealed in lines MK295, MK425, MK538, MKS627, MB1681, MK1795, MB1885, MB2305, MK2497, and MB2519 (Nos. 8, $9,10,12,13,15,18,19,21$, and 24 , respectively).

\section{Conclusions}

The results obtained indicate the value of the studied lines for breeding for resistance to leaf rust. They are meiotically stable, different in resistance and can probably carry genes for resistance to leaf rust other than the effective genes $\operatorname{Lr} 39$ and Lr50. Genetic material from T. miguschovae was identified in introgression lines with the use of C-banding and FISH methods.

\section{References}

Brown-Guedira G., Singh S., Fritz A.K. Performance and mapping of leaf rust transferred to wheat from Triticum timopheevii subsp. armeniacum. Phytopathol. 2003;93:784-789.

Davoyan R.O., Bebyakina I.V., Davoyan O.R., Zinchenko A.N., Davoyan E.R., Kravchenko A.M., Zubanova Y.S. The use of synthe- tic forms in preservation and exploitation of the gene pool of wild common wheat relatives. Russian Journal of Genetics: Applied Research. 2012;2(6):480-485.

Friebe B., Jiang J., Raupp W.J. Characterization of wheat-alien translocations conferring resistance to diseases and pests: current status. Euphytica. 1996; 91:59-87.

Huang L. An RGA-like marker detects all known $L r 21$ leaf rust-resistance gene family members in Aegilops tauschii and wheat. Theor. Appl. Genet.2001;103(6-7):1007-1013.

Mains E.B. Fhysiologic specialization in leaf rust of wheat, Puccinia triticiana Erikss. Phytopatol. 1926;16:89-120.

McIntosh R.A. Catalogue of gene symbols for wheat: 2005 supplement. Ann. Wheat Newslet. 2005;51:272-285.

Plaschke J., Ganal M.W., Röder M.S. Detection of genetic diversity in closely related bread wheat using microsatellite markers. Theor. Appl. Genet. 1995;91:1001-1007.

Singh S. Lr41, Lr39, and a leaf rust resistance gene from Aegilops cylindrical may be allelic and are located on wheat chromosome 2DS. Theor. Appl. Genet. 2004;108:586-591.

Sun X., Bai G., Carver B.F. Molecular markers for wheat leaf rust resistance gene Lr41. Mol. Breedingm. 2009;23:311-321.

Zhemchuzina A., Kurkova N. Structure of population of Puccinia triticina in various regions of Russia in 2006-2008. Proc. of the BGRI Technical Workshop. St. Petersburg, Russia. May 30-31, 2010:27.

Zhirov E.G. Synthesis of a new hexaploid wheat. Trudi po prikladnoi botanike, genetike, selektsii. 1980;68:14-16 (in Russian).

Conflict of interest. The authors declare no conflict of interest. 


\title{
Development and study of new spring wheat lines containing alien genetic material from Th. intermedium and Ae. speltoides
}

\author{
I.N. Leonova*, V.V. Piskarev, N.I. Boiko, A.I. Stasyuk, I.G. Adonina, E.A. Salina
}

Institute of Cytology and Genetics, SB RAS, Novosibirsk, Russia

DOI 10.18699/ICG-PlantGen2019-18

(c) Autors, 2019

* e-mail: leonova@bionet.nsc.ru

\begin{abstract}
This paper presents the results of the introduction of leaf rust resistance genes inherited from Th. intermedium and Ae. speltoides into the genome of spring wheat cultivars differing in the length of the vegetation period. A total of $409 \mathrm{~F}_{4}$ families from cross combinations with the early ripening cultivar Novosibirskaya 15, mid-early 'Novosibirskaya 31', mid-ripening 'Udacha' and mid-late 'Sibirskaya 17' and the donors of $L r$ resistance genes 'Tulaikovskaya $10^{\prime}$ ' and 'Chelyaba 75 ' were studied for leaf rust resistance and the duration of vegetation period. A significant reduction in heading date was revealed in the $F_{4}$ lines obtained on the base of the mid-late variety Sibirskaya 17 . In contrast, the lines originating from of the 'Udacha' $\times$ 'Chelyaba $75^{\prime}$ and 'Novosibirskaya $15^{\prime} \times$ 'Tulaikovskaya $10^{\prime}$ crosses were characterized by an elongated period from germination to ear emergence. According to the results of molecular and phytopathological testing, breeding lines were selected that differ in pathogen resistance, length of vegetation period and productivity.

Key words: leaf rust; Lr gene; wheat varieties; heading date; Th. intermedium; Ae. speltoides.
\end{abstract}

\section{Introduction}

One of the important problems of modern breeding is the creation of new wheat cultivars carrying a complex of agronomically important traits. Wild wheat relatives such as wheatgrass (Thinopyrum ssp.) and goatgrass (Aegilops ssp.) are an inexhaustible source of widening the genetic diversity of bread wheat by genetic loci that determine resistance to biotic stress factors and adaptability. However, the alien genetic material of these species is transferred to the genome of common wheat in the form of extended translocations, or substitutions of whole chromosomes or their arms (Friebe et al., 1996; Petrash et al., 2016). Introgression of a large amount of foreign chromatin can lead to disruption of the functioning of the gene networks responsible for the formation of the traits. Therefore, when introducing disease resistance genes into commercial wheat cultivars, it is important to take into account the effects of alien translocations on such characters as heading date and yield. The purpose of this work was to create new resistant lines of bread wheat, differing in heading date and ripening. The selection of genotypes was carried out with the help of molecular markers that detect alien genetic material.

\section{Materials and methods}

For hybridization, we used four spring wheat varieties, Udacha, Novosibirskaya 15 (N15), Novosibirskaya 31 (N31) and Sibirskaya 17 , highly susceptible to leaf rust and belonging to different groups of ripeness (Piskarev et al., 2017). The wheat cultivars Tulaikovskaya 10 (T10, the $L r 6 A i=2$ gene from Th. intermedium) and Chelyaba 75 (the $\mathrm{LrSp} 2$ gene from Ae. speltoides) were used as donors of leaf rust resistance genes. $\mathrm{F}_{0}$ and $\mathrm{F}_{1}$ hybrids were multiplicated under greenhouse conditions to produce $\mathrm{F}_{2}$ plants; $\mathrm{F}_{2-4}$ progeny were estimated in field condition on the experimental plots of the Institute of Cytology and Genetics, SB RAS, in 2016-2018. The evaluation of resistance to leaf rust was carried out at the adult plant stage under local population of pathogen. The degree of susceptibility was assessed using a modified Cobb's scale (Peterson et al., 1948). Screening of genotypes for the presence of the $L r 6 A i=2$ and $\operatorname{LrSp} 2$ genes was performed using the $X i c g 6 A i=2$ and Xksum 73 markers as previously described (Leonova et al., 2017; Adonina et al., 2018). Separation of PCR products was performed in $2 \%$ agarose gel or on an ABI3130XL automatic sequencer in a $6 \%$ denaturing polyacrylamide gel.

\section{Results and discussion}

A total of 409 recombinant $\mathrm{F}_{2}$ plants was studied, 110 of them from cross combinations with the early ripening cv. N15, 102 plants with the mid-early cv. N31, 99 with the mid-ripening cv. Udacha and 98 with the mid-late cv. Sibirskaya 17. According to the results of the genotyping of the $\mathrm{F}_{2}$ progeny with primers to the $L r 6 A i=2$ and $L r S p 2$ genes, samples containing and not containing alien genetic material were selected.

The evaluation of $\mathrm{F}_{4}$ families for the response to the leaf rust pathogen showed that the donors of resistance genes, 'T10' and 'Chelyaba 75', exhibited from immune to medium-resistant (0R-10MR) reaction type, respectively. The parental varieties of bread wheat were highly susceptible to the pathogen (70-90S). Among the $\mathrm{F}_{4}$ offspring, 312 lines were resistant to leaf rust (0R-20MR), including 116 obtained on the base of 'T10', 196 lines with 'Chelyaba 75'. The susceptible response was shown by 75 families from ' $\mathrm{T} 10$ ' cross combinations. It should be noted that among the offspring originating from 'Chelyaba $75^{\prime}$ ', plants susceptible to leaf rust were not detected. As was shown previously, this effect may be associated with the gametocidal action of the Ae. speltoides translocation containing the $\mathrm{LrSp} 2$ gene (Adonina et al., 2018).

Genotyping of $\mathrm{F}_{4}$ offspring using the Xksum 73 marker, showed that in all samples obtained with the participation of 'Chelyaba 75', a fragment of 194 bp, specific to Ae. speltoides, was amplified (Figure 1). When using the Xicg6Ai=2 marker developed for the $6 \mathrm{DL} / 6 \mathrm{Ai}$ translocation in ' $\mathrm{T} 10$ ', a fragment 


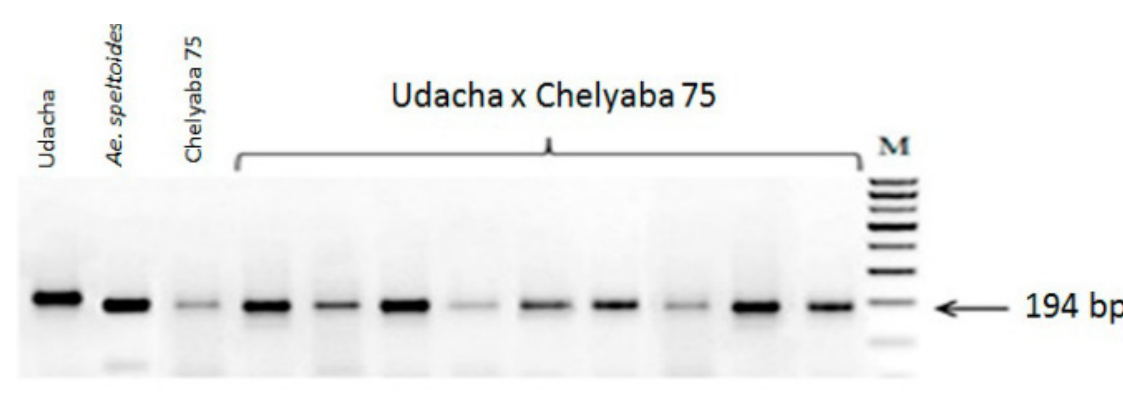

specific to Th. intermedium chromatin was amplified in all resistant plants. The results indicate the effectiveness of the primers for screening plant material for the presence of translocations inherited from the varieties Chelyaba 75 and T10.

A significant reduction was revealed in the length of heading date of the $\mathrm{F}_{4}$ lines obtained on the base of the mid-late variety Sibirskaya 17 compared with all the paternal donor cultivars. Resistant and susceptible lines based on the early cultivar N15 moved to flowering 2.0 ('N15' $\times$ 'T10') and 4.1 days ('N15' $\times$ 'Chelyaba $75^{\prime}$ ') later than the maternal wheat cultivars. The heading date of the lines from the 'N31' $\times$ ' $\mathrm{T} 10$ ' cross combination was overall shorter than in 'N15', and a similar reaction was observed with the lines from the 'Udacha' $\times$ 'T10' cross. In contrast, the lines of the 'Udacha' $\times$ 'Chelyaba 75 ' cross combination were characterized by an elongated period from germination to ear emergence in comparison with the maternal form.

A significant increase in the period from germination to maturation' from 3.6 days (resistant lines Sibirskaya $17 \times$ Chelyaba 75) to 16.7 days (resistant lines N31 × T10) was found. In general, the length of the vegetation period of resistant lines selected from combinations involving cultivars of the early and mid-early groups increased by 5.6 days ('N31' $\times$ 'Chelyaba $75^{\prime}$ ') and 15.8 days ('N31' $\times$ 'T10') in comparison with the maternal wheat cultivars. The results also indicate that the susceptible $\mathrm{F}_{4}$ lines obtained in cross combinations with ' $\mathrm{T} 10$ ' are characterized by shortened periods 'germination - ear emergence' and 'germination - maturation' compared with the resistant ones.

We have previously shown in cross combinations of winter wheats with spring donors of resistance genes that the use of the cv. T10 as a donor of the $L r 6 A i=2$ gene increases heading date of spring progenies (Stasyuk et al., 2017). However, this effect was not associated with the presence of fragments introgressed from an alien genome.

ANOVA analysis of heading date in resistant and susceptible wheat lines obtained on the base of ' $\mathrm{T} 10$ ' indicates that the variance of the factors «genotypes of maternal wheat cultivar» (A), «resistance to leaf rust» $(\mathrm{B})$ and «environments» $(\mathrm{C})$ is reliable at the $1 \%$ significance level. The effect of the environmental factor was $43.9 \%$ in comparison with the factors «genotypes of maternal wheat cultivar» $(31.4 \%)$ and «resistance to leaf rust» (14.6\%) (Figure 2). Analysis of factors affecting the period from germination to ripening indicates that the main contribution is made by the genotype of the maternal wheat (46.1\%).
Figure 1. PCR products obtained by amplification of genomic DNA of $\mathrm{F}_{4}$ progeny and the parental forms Chelyaba 75 and Udacha with ksud73 primers. Lane $M$ is a DNA ladder; the arrow indicates the diagnostic fragment.

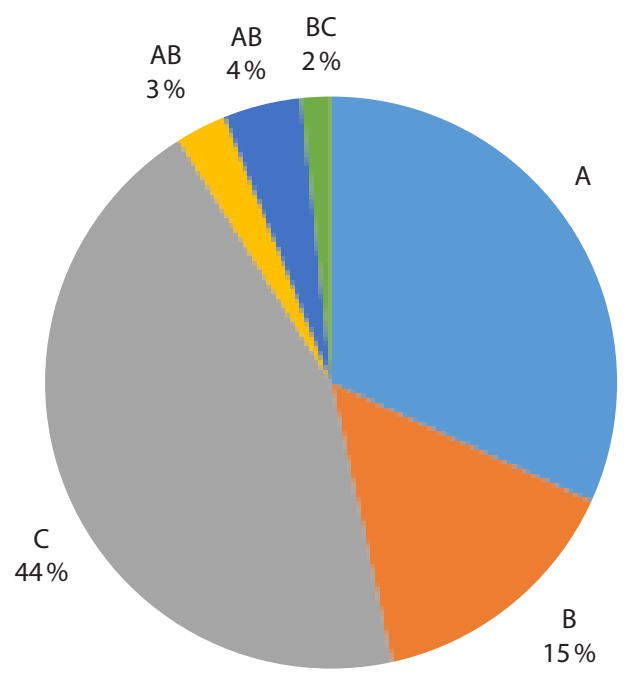

Figure 2. Effects of the genotypes of the maternal wheat cultivars (A), resistance to leaf rust (B) and environments (C), and their interaction on heading date in wheat lines derived from crosses between the varieties N15, N31, Udacha and Sibirskaya 17 with T10.

\section{Conclusions}

Thus, our study have shown that the use of donors of leaf rust resistance genes, originating from $T h$. intermedium and Ae. speltoides, in most cases leads to a prolongation of the developmental stages. It has been established that changes in the heading date is not always associated with the presence of alien translocations. The genotype of the maternal wheat variety makes a major contribution to the phenotypic manifestation of the trait "time from germination to ripening". The results also indicated the effectiveness of the use of molecular markers specific for alien translocations to select genotypes for target loci at the early stages of breeding.

\section{References}

Adonina I.G., Bukatich E.Yu., Piskarev V.V., Tyunin V.A., Shreider E.R., Salina E.A. Inheritance of the translocation in chromosome 2D of common wheat from Aegilops speltoides Tausch with leaf rust resistance genes. Rus. J. Genet. 2018;54:989-993. DOI 10.1134/ S1022795418080021. 
Friebe B., Jiang J., Raupp W.J., VcIntosh R.A., Gill B.S. Characterization of wheat-alien translocation conferring resistance to diseases and pests: current status. Euphytica. 1996;91:59-87. DOI 10.1007/ BF00035277.

Leonova I.N., Stasyuk A.I., Skolotneva E.S., Salina E.A. Enhancement of leaf rust resistance of Siberian winter wheat varieties by markerassested selection. Cereal research Commun. 2017;45:621-632. DOI 10.1556/0806.45.2017.048.

Peterson R.F., Campbell A.B., Hannah A.E. A diagrammatic scale for estimating rust intensity of leabes and stems of cerials. Can. Res. Sec. C. 1948;26:496-500.

Petrash N.V., Leonova I.N., Adonina I.G., Salina E.A. Effect of translocation from Aegilops speltoides. Tausch on resistance to fungal diseases and productivity in common wheat. 2016;52:1253-1262. DOI 1134/S1022795416120097.
Piskarev V.V., Boylo N.I., Kondratieva I.V. Sources of agronomically important traits for breeding soft spring wheat (Triticum aestivum L.) in the Forest steppe of Novosibirsk region. Rus. J. Genet.: Applied Research. 2017;7:281-289. DOI 10.1134/S2079057717030133.

Stasyuk A.I., Leonova I.N., Salina E.A. Variability of agronomically important traits in spring wheat hybrids obtained by marker-assisted selection from crosses of winter wheat with spring wheat donors of resisyance genes. Agricultural Biol. 2017;52:526-534. DOI 10.15389/agrobiology.2017.3.526.eng.

Acknowledgements. The work is supported by the Russian Science Foundation (project No. 16-16-00011-P). Multiplication of F0-F2 progeny was carried out in the framework of the project of the Ministry of Education and Science of the Russian Federation No. 0324-2019-0039.

Conflict of interest. The authors declare no conflict of interest. 


\title{
Interaction of the Tsn1 and Tsc2 sensitivity genes with the ToxA and ToxB effector genes in Triticum L. species
}

\author{
N.V. Mironenko ${ }^{1 *}$, O.A. Baranova ${ }^{1}$, N.M. Kovalenko ${ }^{1}$, O.P. Mitrofanova ${ }^{2}$ \\ ${ }^{1}$ The All-Russian Institute of Plant Protection, St. Petersburg, Russia \\ ${ }^{2}$ The N.I. Vavilov All-Russian Institute of Plant Genetic Resources
}

DOI 10.18699/ICG-PlantGen2019-19

(c) Autors, 2019

* e-mail: nina2601mir@mail.ru

\begin{abstract}
The present study was aimed at determining the presence of the $\operatorname{Tsn} 1$ (5BL) and Tsc2 (2BL) sensitivity genes in Triticum L. species and at assessing the response of wheat accessions to infection with Pyrenophora tritici-repentis isolates with the complementary effector genes ToxA and ToxB. It was shown that the diploid species T. urartu, T. boeoticum and $T$. monococcum ( $2 n=2 x=14$, A genome) had no Tsn1 and Tsc2 genes and showed no susceptibility reaction. The gene-for-gene interaction of Tsc2-ToxB was observed for the tetraploid species T. aethiopicum and T. turgidum $(2 n=4 x=28, A B)$. Despite the presence of the $T s c 2$ gene, the accessions of T. dicoccoides and T. dicoccum were resistant to the ToxB⿱ $B^{+}$ isolate. Different types of Tsc2-ToxB and Tsn 1-ToxA interactions were detected for accessions of other tetraploid and hexaploid wheat species $(2 n=6 x=42, A B D)$. The paper discusses possible causes of discrepancies between the observed and expected plant phenotypic reactions, which were determined by the interaction of the $T s n 1$ and $T s c 2$ sensitivity genes with the isolates containing the ToxA and ToxB effector genes.

Key words: wheat species; tan spot; effectors; Tsn1 and Tsc2 sensitivity genes; gene-forgene interactions.
\end{abstract}

\section{Introduction}

Tan spot caused by Pyrenophora tritici-repentis is a harmful disease spread worldwide. The three known genes of sensitivity to PtrToxA, PtrToxB, and PtrToxC toxins in P. triticirepentis are $T_{s n} 1, T s c 2$ and $T s c 1$, respectively. The Tsn1-Ptr ToxA, Tsc2-Ptr ToxB, and Tsc1-Ptr ToxC interactions have all been shown to play a significant role in the development of tan spot in common wheat (Triticum aestivum L.) (Faris et al., 2013; Kariyawasam et al., 2016).

The wheat sensitivity genes $T s n 1$ and $T s c 2$, as well as the Tox $A$ and ToxB effector genes encoding PtrToxA and PtrToxB toxins, have been cloned and used for developing gene-specific primers (Faris et al., 2010; Abeysekara et al., 2010; Andrie et al., 2007).

The purpose of the present study was to identify the presence of the $T s n 1$ (5BL) and $T s c 2$ (2BL) sensitivity genes in Triticum L. species and to reveal their response to infection with isolates possessing the Tox $A$ and ToxB complementary effector genes.

\section{Materials and methods}

All the 72 accessions representing 16 Triticum L. species from the VIR wheat collection were assessed for resistance to two isolates with ToxA $\left(\mathrm{ToxA}^{+}\right)$originating from Kazakhstan and Russia, and one ToxB ${ }^{+}$from Greece. Pathogen specific primers were used for PCR detection of $P$. tritici-repentis isolates (Antoni et al., 2010). ToxA and ToxB identification in fungal isolates was performed using gene-specific primers (Andrie et al., 2007). The Tsn 1 sensitivity gene was identified using functional allele-specific primers (Faris et al., 2010), and $T s c 2$, by using the XBE444541 marker (Abeysekara et al., 2010).

The procedure of resistance determination was based on determining the size of necrotic and chlorotic spots that formed after inoculation of seedling leaves with a conidial suspension. The detached leaf assays in benzimidazole $(40 \mathrm{mg} / \mathrm{l})$ were used. In the present work, the reaction of wheat accessions to the inoculation with $\mathrm{ToxA}^{+}$isolates (necrosis) and to the ToxB $^{+}$isolate (chlorosis) below 2 points were considered as resistance.

\section{Results and discussion}

According to the gene-for-gene model, necrosis and/or chlorosis are observed on wheat leaves when both the plant and pathogen have the dominant genes Tsn1/ToxA and/or Tsc2/ ToxB , respectively. Neither Tsn1 nor Tsc2 genes nor sensitivity reactions have been detected in all accessions of the diploid species T. urartu, T. boeoticum and T. monococcum. The gene-for-gene Tsc2-ToxB interaction was observed in the tetraploid wheats T. aethiopicum and T. turgidum, as well as in most accessions of the hexaploid wheats T. sphaerococcum and $T$. compactum, which had $T s c 2$ and were sensitive to the ToxB $^{+}$isolate.

Out of $14 T$. dicoccoides and $T$. dicoccum accessions, 12 were resistant to the $\mathrm{ToxB}^{+}$isolate despite the presence of the $T s c 2$ gene. Such a 'gene/plant reaction' link can be explained either by a mutation in the gene that disrupted its expression or by the presence in accessions of other gene(s) homologous to Tsc2.

When evaluating the Tsn1-Tox $A$ interaction, 8 accessions of different tetra- and hexaploid wheats (T. aethiopicum, T. durum, T. sphaerococcum) aroused particular interest. The dominant allele $T_{s n} 1$ was not detected in these accessions, but strong necrosis was observed after infection with the ToxA $^{+}$isolate, which is possibly due to the existence of other unknown susceptibility and effector genes. A number of accessions, in constrast, displayed the presence of $T_{s n} 1$ and the absence of susceptibility reactions. The reasons may be the same as in the case with Tsc2/ToxB interaction in T. dicoccoides and $T$. dicoccum. The studied accessions of T. macha and T. spelta were resistant to the Tox $\mathrm{A}^{+}$and ToxB ${ }^{+}$isolates, 
while no $T s n 1$ or $T s c 2$ genes were identified in them, with one exception.

Deviations from the expected gene-for-gene relationships in common wheat, which were observed among the cultivars of T. aestivum (Mironenko, Kovalenko, 2018), can have an explanation that the Tsn1-ToxA interaction may be epistatic to the production of other necrotrophic effectors, depending on the genetic background of the sensitive host (Manning, Ciuffetti, 2015). The authors believe that perhaps some wheat genotypes possess factors that lead to altered expression levels of the ToxA gene through epistasis, or in some way inhibit the recognition of ToxA by $T s n 1$ in plants inoculated with fungal spores.

The Tsc2-ToxB interaction is known to play a significant role in conferring susceptibility in tetraploid (Virdi et al., 2016) and hexaploid wheats (Abeysekara et al., 2010), while the Tsn1ToxA interaction is not a significant factor for the development of tan spot in durum cultivars (Virdi et al., 2016). According to some researchers, the Tsn1-ToxA interaction can play a major or a minor role, or have no effect at all for common wheat, depending on the genetic background (Faris et al., 2013).

The analyzed accessions of T. timopheevii and T. araraticum ( $2 n=4 x=28$, GA genome) have $T s c 2$, but not $T s n 1$; they were found to be resistant to the Tox $\mathrm{A}^{+}$and $\mathrm{ToxB}^{+}$isolates, which suggests the presence of a gene (genes) homologous to $T s c 2$ in these accessions.

\section{Conclusions}

It is believed that the ToxA gene appeared in P. tritici-repentis as a result of horizontal transfer from another wheat pathogen, Stagonospora nodorum (Friesen et al., 2006). Therefore, Tsn 1 is the major determinant for sensitivity to both $S$. nodorum blotch (SNB) and tan spot. The ToxA gene in P. tritici-repentis is less expressed than the identical gene SnToxA in $S$. nodorum during wheat infection (Virdi et al., 2016). The high role of the Tsn1-ToxA interaction was shown for the SNB manifestation in both hexaploid and tetraploid wheat (Liu et al., 2006).

According to our data, the Tsn1-ToxA interaction does not always play a significant role in conferring susceptibility to tan spot in hexaploid wheats in the wheat- $P$. tritici-repentis pathosystem, and has no effect on this disease manifestation in durum wheat, in contrast to the Tsn1-ToxA interaction in the wheat-S. nodorum pathosystem. We believe that one of the reasons for these differences may be the low expression of the ToxA gene in P. tritici-repentis, which was introduced into this pathogen as part of the alien translocation from another wheat pathogen, S. nodorum (Friesen et al., 2006).

\section{References}

Abeysekara N.S., Friesen T.L., Liu Z., McClean P.E., Faris J.D. Marker development and saturation mapping of the Tan Spot PtrToxB sensitivity locus Tsc2 in hexaploid wheat.Plant Genome. 2010;3(3): 179-189. DOI 10.3835/plantgenome2010.07.0017.

Andrie R.M., Pandelova I., Ciuffetti L.M. A combination of phenotypic and genotypic characterization strengthens Pyrenophora triticirepentis race identification. Phytopathol. 2007;97:694-670. DOI 10.1094/PHYTO-97-6-0694.

Antoni E.A., Rybak K., Tucker M.P. et al. Ubiquity of ToxA and absence of ToxB in Australian populations of Pyrenophora tritici-repentis. Austral. Plant. Pathol. 2010;39:63-68. www.publish.csiro. au/journals/app.

Faris J.D., Liu Zh., Xu S.S. Genetics of tan spot resistance in wheat. Theor. Appl. Genet. 2013;126:2197-2217. DOI 10.1007/s00122013-2157-y.

Faris J.D., Zhang Z., Lu H.J., Lu S.W., Reddy L. et al. A unique wheat disease resistance-like gene governs effector-triggered susceptibility to necrotrophic pathogens. Proc. Natl. Acad. Sci. USA. 2010;107: 13544-13549. Doi.org/10.1073/pnas.1004090107.

Friesen T.L., Stukenbrock E.H., Liu Z., Meinhardt S., Ling H. et al. Emergence of a new disease as a result of interspecific virulence gene transfer. Nature Genetics. 2006;38(8):953-956. Doi.org/10.1038/ ng1839.

Kariyawasam G.K., Carter A.H., Rasmussen J.B., Faris J., Xu S.S., Mergoum M., Liu Z. Genetic relationships between race-nonspecific and race-specific interactions in the wheat - Pyrenophora triticirepentis pathosystem. Theor Appl Gen. 2016;129:897-908. DOI 10.1007/s00122-016-2670-x.

Lamari L., Strelkov S.E., Yahyaoui A., Orabi J., Smith R.B. The identification of two new races of Pyrenophora tritici-repentis from the host centre of diversity confirms a one-to-one relationship in tan spot of wheat. Phytopathol. 2003;93:391-396.

Liu Z., Friesen T.L., Ling H., Meinhardt S.W., Oliver R.P., Rasmussen J.B., Faris J.D. The Tsn1-ToxA interaction in the wheat-Stagonospora nodorum pathosystem parallels that of the wheat-tan spot system. Genome. 2006;49(10):1265-73. DOI 10.1139/g06-088.

Manning V.A., Ciuffetti L.M. Necrotrophic effector epistasis in the $P y$ renophora tritici-repentis-wheat interaction. PLOS ONE. 2015;10(4): e0123548. DOI 10.1371/journal.pone.0123548.

Mironenko N.V., Kovalenko N.M. Peculiarities of interaction of Tsn 1 and ToxA genes in Triticuma estivum - Pyrenophora tritici-repentis pathosystem. PlantProtectionNews. 2018;2(96):12-16. (in Russian)

Virdi S.K., Liu Z., Overlander M.E. New insights into the roles of host gene-necrotrophic effector interactions in governing susceptibility of durum wheat to tan spot and Septoria nodorum blotch. G3. 2016; 6:4139-4150. DOI 10.1534/g3.116.036525/-/DC1.

Acknowledgements. The work is supported by the RFBR grant 1804-00128a and Comprehensive Program of Scientific Research “Development of selection and processing of grain crops"

Conflict of interest. The authors declare no conflict of interest. 


\title{
Molecular screening of wheat entries for resistance to the toxins Ptr ToxA and Ptr ToxB from the tan spot pathogen Pyrenophora tritici-repentis
}

\author{
A.M. Kokhmetova ${ }^{1 *}$, S. Ali $^{2}$, M.N. Atishova ${ }^{1}$ \\ ${ }^{1}$ Institute of Plant Biology and Biotechnology, Almaty, Kazakhstan \\ ${ }^{2}$ South Dakota State University, Brookings, USA
}

DOI 10.18699/ICG-PlantGen2019-20

(c) Autors, 2019

*e-mail:gen_kalma@mail.ru

\begin{abstract}
Tan spot caused by Pyrenophora tritici-repentis is a serious wheat disease. The aim of this study was the identification of genotypes resistant to $P$. tritici-repentis race 1 and 5 and their host-selective effectors Ptr ToxA and Ptr ToxB. 41 wheat accessions where characterized using molecular markers, diagnostic for the Tsn1 and Tsc2 genes. The accuracy of the marker XBE444541 was $92.11 \%$ with race 5 and $97.37 \%$ with Ptr ToxB. Genotyping results demonstrate the reliability of the marker $X f c p 623$ for identifying genotypes insensitive to Ptr ToxA. $78 \%$ of genotypes exhibited resistance to both race 1 and race 5 and to the toxins Ptr ToxA and ToxB. The results are of interest for efficient breeding based on the elimination of the genotypes with the dominant alleles Tsn1 and Tsc2, sensitive to Ptr ToxA and ToxB.
\end{abstract}

Key words: wheat; Pyrenophora tritici-repentis; tan spot; Tsn 1; Tsc2; ToxA; ToxB.

\section{Introduction}

Pyrenophora tritici-repentis (Died.) Drechsler is the causal agent of tan spot, a major foliar blight disease in wheatgrowing areas throughout the world (Duveiller et al., 1998). Yield losses can rise beyond $50 \%$. P. tritici-repentis produces multiple Host Selective Effectors (toxins) acting as pathogenicity/virulence factors. Five toxins (Ptr ToxA, B, C, and two toxins collectively known as Ptr ToxD) have been identified. The Tsn1-Ptr ToxA, Tsc2-Ptr ToxB, and Tsc1-Ptr ToxC interactions have all been shown to play significant roles in the development of tan spot in wheat (Faris et al., 2013). Molecular markers accelerated the characterization of wheat cultivars with superior resistance by rapid identification of related genes. Breeding for resistance to tan spot could be enhanced if additional resistance sources effective against multiple Ptr races were identified. The aim of this study was the identification of wheat genotypes resistant to P. triticirepentis race 1 and race 5 and their host-selective effectors (toxins) Ptr ToxA and Ptr ToxB.

\section{Materials and methods}

A common wheat collection of 41 accessions was assayed in the greenhouse at the two-leaf seedlings stage. The plants were rated for disease, using the scale based on lesion type (Lamari, Bernier, 1989). Toxin infiltration using purified toxins Ptr ToxA and Ptr ToxB was performed at the stage of two leaves (Xu et al., 2004). DNA was extracted from leaf powder following the protocol described by Riede and Anderson (1996). The wheat accessions were characterized using the molecular markers $X f c p 623$ and XBE4444541 diagnostic for the $T s n 1$ and $T s c 2$ genes conferring the sensitivity to fungal toxins. PCR was performed according to literature conditions (Zhang et al., 2009; Abeysekara et al., 2010). The amplification products were visualized by electrophoresis in $2 \%$ agarose gels in the TBE buffer with subsequent staining with ethidium bromide and the use of the GelDoc BIO-PRINT MEGA for documentation of allele types in cultivars. Wheat entries 6B662 and Glenlea served as positive and negative controls, respectively.

\section{Results and discussion}

Genotyping of wheat accessions using molecular markers was aimed at identifying the carriers of genes conferring sensitivity and resistance to HST Ptr ToxA and ToxB. The frequency of entries resistant to race 1 and race 5 in the wheat collection amounted to $78.95 \%$. Of greatest interest are 8 cultivars: Kokbiday, 428g / MK-122A, Lutescens 90, Lazzat, Omskaya 28, Omskaya 36, SOMO / SORA / ACTS5, BR14 / CEP847-1 and BR14 / CEP847-2, which showed high resistance both to the two races (race 1 and race 5), and to the two toxins (Ptr ToxA and ToxB), and also confirmed insensitivity to the HST during molecular screening. A moderate degree of resistance to the $P$. tritici-repentis races and toxins was observed in 21 wheat entries.

As an example, the results of the PCR amplification products, when the $X f c p 623$ primers were tested on 19 wheat genotypes, are shown in Figure 1. The molecular marker Xfcp623 linked the recessive $t s n 1$ allele conferring insensitivity to Ptr ToxA. As shown in Figure 1, 12 out of 19 entries each had a polymorphic band identical to $X f c p 623$. The marker $X f c p 623$ amplified a 380-bp fragment associated with the Tsn1 gene sensitive to Ptr ToxA in 8 wheat entries.

In summary, the results of genotyping presented in this study indicate that the marker Xfcp 623 had a null allele associated with insensitivity to the toxin in 30 out of 41 wheat accessions. The presence / absence of the marker Xfcp623 absolutely (100\%) coincided with the sensitivity / resistance to race 1 and Ptr ToxA. It demonstrates the reliability of $X f c p 623$ 


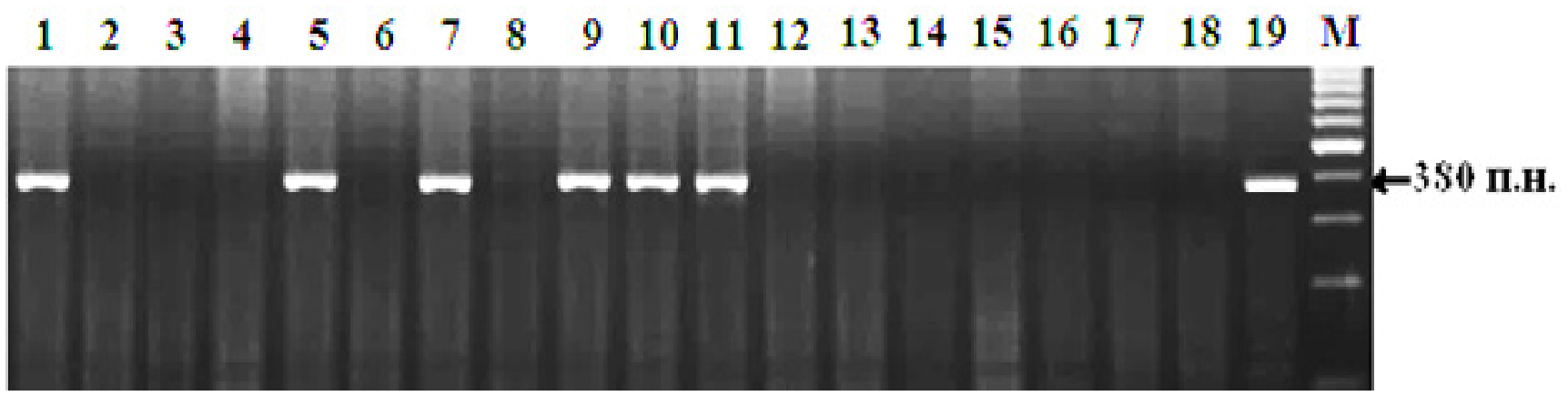

Figure 1. DNA amplification products of wheat accessions using primers to the diagnostic marker Xfcp623 linked to the Tsn 1 gene, controlling sensitivity to Ptr ToxA. Resolved in $2 \%$ agarose gel.

Note: 1, 428/Umanka-17; 2, 428g/MK-122A; 3, Kokbiday; 4, Lazzat; 5, 428/Umanka-18; 6, Omskaya 28; 7, KR11-20; 8, Omskaya 36; 9, JAS58/JAS55//ALD/3/MRNG/4/ ALD; 10, Koksu; 11, ZM23524; 12, SOMO/SORO/ACTS5; 13, BR14/CEP847; 14, Astana; 15, Kazakhstanskaya 25; 16, Kazakhstanskaya Rannespelaya; 17, Keremet; 18, Salamouni; 19, Glenlea, M, molecular weight marker (Gene-RulerTM; 100 bp DNA Ladder (Ferments, Lihuania)).

as a diagnostic marker for identifying wheat genotypes with resistance to the fungus and insensitivity to Ptr ToxA.

The marker XBE444541 amplified a 340-bp fragment associated with the $T s c 2$ gene, which is sensitive to Ptr ToxB in 8 wheat samples. Five of these entries were also sensitive to race 5. This marker amplified a 505-bp fragment associated with insensitivity to Ptr ToxB in 30 wheat entries. The coincidence of the marker XBE444541 was $92.11 \%$ with resistance to race 5 and $97.37 \%$ with resistance to Ptr ToxB.

The study of the reaction of wheat germplasm to fungal inoculation and toxin infiltration showed that 30 genotypes (78\%) exhibited resistance to both race 1 and race 5, and insensitivity to Ptr ToxA and ToxB. Sensitivity to Ptr ToxB is not always correlated with susceptibility to race 5 and depends on the host's genetic background of the wheat genotype, i. e. on the particular wheat genotype.

Despite the fact that tan spot is one of the most important diseases of wheat, there are still insufficient publications on resistance to the prevailing $P$. tritici-repentis races of wheat varieties cultivated in Kazakhstan. Our study is one of the first in this region, including comprehensive screening using races and purified toxins, as well as molecular analysis for the presence of target disease resistance genes. Recently, studies aimed at assessing the resistance of wheat germplasm to tan spot have been conducted (Singh et al., 2016; Kokhmetova et al., 2017, 2018). Many studies have shown statistically significant relationships between sensitivity to NE and susceptibility to $P$. tritici-repentis (Friesen, Faris, 2004; Abeysekara et al., 2010). The problem of identifying sources of resistance to P. tritici-repentis in our study was solved by using isolates of races and the toxins Ptr ToxA and Ptr ToxB. Our data are consistent with the results of a number of studies, where it has been shown that sensitivity to NE does not always determine sensitivity to $P$. tritici-repentis, and the involvement of interactions in the development of the disease depends on the host's genetic background (Kariyawasam et al., 2016). The results of the study are of interest for increasing the efficiency of breeding based on the elimination of the genotypes with the dominant alleles $T s n 1$ and $T s c 2$ sensitive to the toxins Ptr
ToxA and ToxB. The genotypes will be used in breeding for resistance to tan spot.

\section{Conclusions}

The results of genotyping and screening using necrotrophic effectors are of interest for increasing the efficiency of breeding on the basis of elimination of the carriers of the dominant alleles $T s n 1$ and $T s c 2$ controlling sensitivity to the toxins Ptr ToxA and ToxB from breeding material. All these data allow assuming that the carriers of the $t s n 1$ and $t s c 2$ genes conferring insensitivity to Ptr ToxA and ToxB can be used in breeding programs for the pyramiding of disease resistance genes. International collaboration with the CIMMYT is of great importance for successful breeding for tan spot resistance. Sources from different countries with broad-spectrum resistance to tan spot may contribute to resistance observed in our study and can be utilized to develop cultivars with durable resistance to tan spot. Our study generally creates opportunities for transferring the breeding process in Kazakhstan to a new scientific level due to the application of molecular and pathological methods. The results are used in wheat breeding programs for tan spot resistance with the Marker Assisted Selection.

\section{References}

Abeysekara N.S., Friesen T.L., Liu Z., McClean P.E., Faris J.D. Marker development and saturation mapping of the tan spot Ptr ToxB sensitivity locus Tsc2 in hexaploid wheat. Plant Gen. 2010;3:179-189. DOI 10.3835/plantgenome2010.07.0017.

Duveiller E., Dubin H.J., Reeves J., McNab A. Helminthosporium Blights of Wheat: Spot Blotch and Tan Spot. CIMMYT, 1998. El Batán, Mexico.

Faris J.D., Liu Z., Xu S.S. Genetics of tan spot resistance in wheat. Theor. Appl. Genet. 2013;126(9):2197-2217. DOI 10.1007/s00122013-2157-y.

Friesen T.L., Faris J.D. Molecular mapping of resistance to Pyrenophora tritici-repentis race 5 and sensitivity to $P \operatorname{tr} T o x B$ in wheat. Theor. Appl. Genet. 2004;109:464-471. DOI 10.1007/s00122-004-1678-9.

Kariyawasam G.K., Carter A.H., Rasmussen J.B., Faris J.D., Xu S.S., Mergoum M., Liu Z. Genetic relationships between race-nonspecific and race specific interactions in the wheat-Pyrenophora tritici-re- 
pentis pathosystem. Theor. Appl. Genet. 2016;129:897-908. DOI org/10.1007/s00122-016-2670-x.

Kokhmetova A., Kremneva O., Volkova G., Atishova M., Sapakhova Z. Evaluation of wheat cultivars growing in Kazakhstan and Russia for resistance to tan spot. J. Plant Pathol. 2017;99(1):161-167. DOI 10.4454/jpp.v99i1.3812.

Kokhmetova A.M., Ali S., Sapakhova Z., Atishova M.N. Identifcation of genotypes - carriers of resistance to tan spot Ptr ToxA and Ptr ToxB of Pyrenophora tritici-repentis in common wheat collection. Vavilov J. Genet. Breed. 2018;22(8):978-986. DOI 10.18699/ VJ18.440 (In Russian).

Lamari L., Bernier C.C. Evalution of wheat lines and cultivars to tan spot [Pyrenophora tritici-repentis] based on lesion type. Can. J. Plant Sci. 1989;11(1):49-56.

Riede C.R., Anderson J.A. Linkage of RFLP markers to an aluminum tolerance gene in wheat. Crop Sci. 1996;36(4):905-909.
Singh P.K., Crossa J., Duveiller E., Singh R., Djurle A. Association mapping for resistance to tan spot induced by $P$. tritici-repentis race 1 in a CIMMYTs historical bread wheat set. Euphytica. 2016; 207(3):515-525. DOI 10.1007/s10681-015-1528-7.

Xu S.S., Friesen T.L., Mujeeb-Kazi A. Seedling resistance to tan spot and Stagonospora nodorum blotch in synthetic hexaploid wheats. Crop Sci. 2004:44:2238-2245.

Zhang Z., Friesen T.L., Simons K.J., Xu S.S., Faris J.D. Development, identification, and validation of markers for marker assisted selection against the Stagonospora nodorum toxin sensitivity genes Tsn1 and Snn2 in wheat. Mol. Breed. 2009; 23:35-49. DOI 10.1007/ s11032-008-9211-5.

Acknowledgements. The work is supported by the granting project No. AP05132540 of the Ministry of Education and Science of the Republic of Kazakhstan.

Conflict of interest. The authors declare no conflict of interest. 


\title{
Functional characterization of Stagonospora nodorum necrotrophic effectors
}

\author{
S.V. Veselova*, G.F. Burkhanova, T.V. Nuzhnaya, I.V. Maksimov \\ Institute of Biochemistry and Genetics of the Ufa Federal Research Centre of the Russian Academy of Sciences, Ufa, Russia
}

DOI 10.18699/ICG-PlantGen2019-21

(c) Autors, 2019

* e-mail: veselova75@rambler.ru

\begin{abstract}
For many years pathogen causal agent of wheat leaf blotch such as Stagonospora nodorum have remained poorly understood, because the genetics of host resistance to S. nodorum in seedlings and adult plants is complex. The most important factor of virulence of the S. nodorum is multiple fungal necrotrophic effectors (NEs) encoded by SnTox genes that interact with the matching products of host susceptibility genes (Snn). In this mini-review, SnToxA-Tsn1, SnTox1-Snn1, and SnTox3-Snn3 interactions were described, including progress in the discovery of additional functions for effectors. The disclosure of the molecular mechanisms of action of necrotrophic effectors fundamentally changed our understanding of wheat leaf diseases.
\end{abstract}

Key words: Stagonospora nodorum; Triticum aestivum; necrotrophic effectors; wheat leaf diseases.

\section{Introduction}

The fungus Stagonospora nodorum is the causal agent of Septoria nodorum blotch (SNB) of wheat. SNB is a major disease of durum and common wheat in many parts of the world. Resistance to SNB has been shown to be a complex quantitatively inherited trait and, until recently, the underlying mechanism of virulence and resistance was not understood (Oliver et al., 2012; Faris et al., 2013; McDonald, Solomon, 2018). However, numerous recent studies to analyze wheat$S$. nodorum interactions have explained the genetic basis of this system at the classical and molecular levels. SNB is largely governed by a series of proteinaceous fungal necrotrophic effectors (NEs) (formerly referred to as host-specific (selective) toxins named SnToxN encoded by SnToxN genes), each of which interacts with a wheat susceptibility gene, SnnN. These interactions lead to the formation of necrosis and/or chlorosis on wheat (McDonald, Solomon, 2018). In contrast to the classical gene-for-gene hypothesis, where the interaction of effectors with host resistance (R)-gene complexes leads to resistance, necrotrophic effectors function in an 'inverse' manner. An interaction between a necrotrophic effector and the product of a host dominant sensitivity gene instead leads to disease. The lack of NE recognition by the host leads to resistance. Therefore, these host-pathogen interactions operate in an inverse gene-for-gene manner and the dominant alleles of the host NE recognition genes are considered susceptibility genes (Oliver et al., 2012; Faris et al., 2013).

\section{Necrotrophic effectors of Stagonospora nodorum}

The wheat-S. nodorum pathosystem is mediated by multiple fungal necrotrophic effector-host sensitivity gene interactions that include SnToxA-Tsn1, SnTox1-Snn1, SnTox3-Snn3 and others. SnToxA encodes a 13.2-kDa mature protein that causes necrosis on wheat varieties that contain Tsn1 (Oliver et al., 2012; Shi et al., 2016). SnTox1 encodes a 10.3-kDa mature cysteine-rich protein with a chitin-like binding motif at the C-terminus. Sensitivity to SnTox 1 is defined by the Snn 1 gene located on wheat chromosome 1BS (Liu et al., 2012; Phan et al., 2016). Both Tsn1 and Snn1 have been cloned and encode a serine/threonine protein kinase, nucleotide binding site leucine rich repeat protein (NB-LRR) and a wall-associated kinase protein (WAK), respectively (Shi et al., 2016; McDonald, Solomon, 2018). SnTox3 is an intron-free gene that codes for a $18-\mathrm{kDa}$ mature protein with six cysteine residues. SnTox3 is synthesized as a prepropeptide and cleavage of the signal peptide and the prosequence leads to maturation of a small, 17.5-kDa-long effector (Phan et al., 2016). Three disulfide bridges formed by six cysteine residues in SnTox 3 are essential for the structure and function of the effector protein (Winterberg et al., 2014; Phan et al., 2016). Sensitivity to SnTox3 is conferred by Snn3-B1 and Snn3-D1 located on wheat chromosomes 5BS and 5DS, respectively (Phan et al., 2016). In addition, QTL analyses have revealed that the S. nodorum-wheat interaction includes multiple effector-host sensitivity gene interactions such as SnTox2-Snn2, SnTox4 Snn4 and SnTox5-Snn5, SnTox6-Snn6 and SnTox7-Snn7 (Oliver et al., 2012; Phan et al., 2016). Genes that code for these fungal effectors and host dominant susceptibility genes remained unidentified.

\section{SnTox1-Snn1}

The SnTox1-Snn1 interaction was the first interaction to be characterized. This interaction accounts for as much as $58 \%$ of the disease variation (Oliver et al., 2012). The mode of action of SnTox1 is still under study. The SnTox1-Snn1 interaction is light-dependent. Light is necessary for the penetration and proliferation of the pathogen (Shi et al., 2016). Recently, chitin binding activity for SnTox 1 has been visualized in vivo using a GFP-tagged version of the protein (Lui et al., 2012). It has been shown that SnTox1 binds to the surface of the hyphae particularly near the points of hyphal branching or plant penetration. Thus, chitin binding activity of SnTox 1 was associated with the prevention of plant chitinases from binding with hyphae and degradation of the fungal cell wall and the release of chitin fragments into the apoplast. Consequently, the development of plant defense reactions was suppressed (Lui 
et al., 2012). In addition, it was shown that the SnTox1-Snn1 interaction caused the production of $\mathrm{H}_{2} \mathrm{O}_{2}$ and up-regulated transcription of genes of PR-protein and TaMAPK3 (Oliver et al., 2012; Shi et al., 2016).

\section{SnToxA-Tsn 1}

The SnToxA-Tsn1 interaction leading to necrosis was associated with photosynthesis. Expression of $T s n 1$ was regulated by the circadian clock and light, and the SnToxA-Tsn1 interaction was light-dependent (Oliver et al., 2012; McDonald, Solomon, 2018). Penetrating into the plant cell, SnToxA was located within the chloroplast and has been reported to bind to plastocyanin, a component of photosystem II, and a protein known as Tox-ABP1 (Oliver et al., 2012). The SnToxA-Tsn1 interaction results in photosystem perturbations leading to disruption of photosynthesis and cell death. Moreover, after SnToxA infiltration, a strong induction of secondary metabolism was observed, including tryptophan and monoamine serotonin. SnToxA strongly induced the tryptophan pathway as evident from microarray analysis.

Metabolome analysis detected significant increases in tryptophan, serotonin, two serotonin derivatives and the benzoxazinoid 6-methoxy-2-benzoxazolinone (MBOA) synthesized from the tryptophan precursor indole-3-glycerolphosphate (Fall et al., 2013). Recently. a novel role of serotonin as a phytoalexin in wheat has been established and it has been demonstrated that serotonin strongly inhibited sporulation of S. nodorum (Fall et al., 2013). Microscopy revealed that serotonin interferes with spore formation and maturation within pycnidial structures of the fungus. Subsequent analysis of $S$. nodorum exposed to serotonin revealed metabolite changes previously associated with sporulation, including trehalose and alternariol (Fall et al., 2013).

\section{SnTox3-Snn3}

The SnTox3-Snn3 interaction as well as the SnToxA-Tsn1 interaction led to the collapse of photosynthesis (Winterberg et al., 2014). It was interesting that they did so through different means. Thus, the SnTox3-Snn3 interaction did not depend on light. SnTox3 leads to down-regulation of the light reaction (particularly, photosystem I, ATP synthase) (Winterberg et al., 2014). In addition, SnTox3-infiltrated wheat leaves also showed a strong induction of enzymes involved in primary metabolism consistent with increases in hexoses, amino acids and organic acids as determined by primary metabolite profiling.

Careful scrutiny of both the microarray and proteomics data revealed impact on the secondary metabolism upon infiltration with SnTox3. Methionine and homocysteine metabolism was strongly induced upon exposure to SnTox3. Homocysteine S-methyltransferase, which catalyses synthesis of two methionine molecules from homocysteine and S-methyl methionine, was highly induced at the transcriptional level. Adenosylmethionine synthase, which catalyses the reaction from methionine to S-adenosyl methionine (SAM), responded positively at the transcriptional and the translational level upon SnTox 3 exposure. Genes encoding aminocyclopropane (ACC) synthase and ACC oxidase, both involved in the synthesis of ethylene from SAM, were up-regulated in SnTox3-infiltrated plants (Winterberg et al., 2014). SAM is a direct precursor for ethylene biosynthesis and primary methyl donor for a variety of defense-related metabolites.

Recently, by applying inhibitory analysis to different wheat genotypes and using $S$. nodorum isolates expressing SnTox3 (SnB) and not expressing SnTox3 (Sn4VD), we have shown that SnTox3 up-regulates the ethylene biosynthesis genes TaACS1, TaACO and genes for the primary response to ethylene, TaEIL1, TaPIE1 (TaERF1), through activation of genes of MPK3/MPK6 cascade and a significant increase of TaWRKY53b gene expression for regulating of redox-status of infected plants (Veselova et al., 2017; 2018a).

Furthermore, an inhibitory analysis showed that the ethylene signalling pathway activated by SnTox3 negatively affected the reactive oxygen species (ROS) generation in infected wheat plants at the initial stage of pathogen development (24 hour) (Veselova et al., 2018b). As a result of the ethylene influence on the enzymes of the pro- and antioxidant system, $\mathrm{O}_{2}{ }^{--}$content was reduced, and $\mathrm{H}_{2} \mathrm{O}_{2}$ generation was suppressed. Microscopy revealed that ethylene suppressing the oxidative burst at the pathogen penetration site provided appropriate conditions for the development of the pathogen in the wheat tissues (Veselova et al., 2018b).

\section{New functions of necrotrophic effectors}

The members of the pathogenesis-related protein 1 (PR-1) family are among the most abundantly produced proteins in plants on pathogen attack, and $P R-1$ gene expression has long been used as a marker for salicylic acid (SA)- dependent disease resistance. However, despite significant interest shown to them over several decades, their role in plant defense remains poorly understood. Recently, it has been shown that PR-1 proteins own sterol-binding activity, contain an embedded defense signaling peptide, CAPE1, and are targeted by effectors of plant pathogens during host infection (Breen et al., 2017). It has been shown that SnToxA and SnTox3 directly interact with the PR-1 protein (Breen et al., 2017).

SnToxA was shown to interact with wheat's PR-1-5, while SnTox3 was shown to interact with PR-1-1 as well as six other members from the PR-1 family (Breen et al., 2017). It has been identified that PR-1-derived defense signaling peptide from the C-terminus of TaPR-1-1, known as CAPE1, falls within the proposed SnTox3-TaPR-1 interaction surface and enhances the infection of wheat by S. nodorum in an SnTox3-dependent manner, but plays no role in SnToxA-mediated disease (Breen et al., 2017). This result indicates that CAPE1 may play an important role in the signal transduction pathway leading to disease for SnTox3 but not SnToxA. Nevertheless, it remains unknown how SnTox3 uses TaCAPE1 for this function and what role $\operatorname{Snn} 3$ plays in the interaction.

Certainly, many more questions await answers. How is CAPE1 cleaved from PR-1 proteins? Could SnTox3 induce the cleavage of the TaCAPE1 peptide? What pathways act downstream of CAPE1 detection and/or accumulation? It is clear that both PR-1 proteins and CAPE1 peptides are important host defense molecules.

Our results showed that suppression of defense responses and development of large lesions in susceptible wheat genotypes was associated with inhibition of the marker genes for transcription of the SA-signaling pathway, $P R-1$ and $P R-2$, at 
the initial stage of infection (Veselova et al., 2016). In addition, it was proved that it was ethylene that suppressed the induction of SA-dependent defense response (Veselova et al., 2016).

\section{Conclusions}

Much progress has been made in describing and understanding the wheat-S. nodorum system over the past two decades. It is known that the fungus produces NEs, which, when recognized by specific host sensitivity genes, induce disease, and that these host-NEs relationships follow an inverse gene-for-gene model. However, the mechanisms of the interaction of wheat and $S$. nodorum is very complicated, race specific interaction explaining only $40 \%$ of phenotypic expression (Faris et al., 2013; Shi et al., 2016; McDonald, Solomon, 2018). It is known that race non-specific QTLs that confer broad-spectrum - and potentially durable - resistance exist. The genetic basis of host resistance to $S$. nodorum in seedlings and adult plants is complex. SNB resistance has been reported to be quantitatively inherited in some instances (race-nonspecific resistance) and qualitatively inherited in others (race-specific gene-for-gene resistance). Resistance to this pathogen is controlled by a variety of mechanisms and, accordingly, a variety of genes. Therefore, the wheat- $S$. nodorum system is much more complex than currently described in the literature, and much additional work is needed to characterize this pathosystem.

Furthermore, relatively recently, over the past four years, the interaction of SnTox-Snn causing susceptibility has been shown to be targeted to manipulation of non-specific pathways of plant protection associated with redox-metabolism, secondary metabolites and pathogenesis-related proteins (Liu et al., 2012; Winterberg et al., 2014; McDonald, Solomon, 2018; Veselova et al., 2018a; b).

More work to identify and characterize race non-specific resistance QTLs will also be useful. The molecular cloning of more NE sensitivity genes and race non-specific resistance QTLs will allow further characterization of wheat-S. nodorum interactions, and shed light on the relationship between hostNEs interactions and race non-specific resistance mechanisms at the molecular level. It will also provide the tools necessary for the development of functional markers, which can be used to conduct highly efficient MAS for the pyramiding of NE insensitivity genes together with race non-specific resistance loci leading to the development of wheat with superior SNB resistance.

\section{References}

Breen S., Williams S.J., Outram M., Kobe B., Solomon P.S. Emerging insights into the functions of Pathogenesis-Related Protein 1. Trends Plant Sci. 2017;22(10):872-879. doi.org/10.1016/j.tplants. 2017.06.013.
Fall L.A., Solomon P.S. The necrotrophic effector SnToxA induces the synthesis of a novel phytoalexin in wheat. New Phytologist. 2013;200:185-200. DOI 10.1111/nph.12356.

Faris J.D. Liu Z., Xu S.S. Genetics of tan spot resistance in wheat. Theor Appl Genet. 2013;126:2197-2217. DOI 10.1007/s00122-0132157-y.

Liu Z., Zhang Z., Faris J.D., Oliver R.P., Syme R., McDonald M.C., McDonald B.A., Solomon P.S., Lu S., Shelver W.L., Xu S., Friesen T.L. The cysteine rich necrotrophic effector SnTox 1 produced by Stagonospora nodorum triggers susceptibility of wheat lines harboring Snn1. PLoS Pathog. 2012;8(1):e1002467. DOI 10.1371/journal. ppat.1002467.

McDonald M.C., Solomon P.S. Just the surface: advances in the discovery and characterization of necrotrophic wheat effectors. Current Opinion Microbiol. 2018;46:14-18. doi.org/10.1016/j.mib.2018. 01.019

Oliver R.P., Friesen T.L., Faris J.D., Solomon P.S. Stagonospora nodorum : from pathology to genomics and host resistance. Annu. Rev. Phytopathol. 2012;50:23-43. DOI 10.1146/annurev-phyto-081211173019.

Phan H.T.T., Rybak K., Furuki E., Breen S., Solomon P.S., Oliver R.P., Tan K.-C. Differential effector gene expression underpins epistasis in a plant fungal disease. Plant Journal. 2016;87:343-354.

Shi G., Zhang Z., Friesen T.L., Raats D., Fahima T., Brueggeman R.S., Lu S., Trick H.N., Liu Z., Chao W., Frenkel Z., Xu S.S., Rasmussen J.B., Faris J.D., The hijacking of a receptor kinase-driven pathway by a wheat fungal pathogen leads to disease. Sci. $A d v .2016$; 2(10):e1600822. DOI 10.1126/sciadv.1600822.

Veselova S.V., Burkhanova G.F. Ethylene and mitogenactivated protein kinases in regulation of redoxstatus in common wheat infected with Stagonospora nodorum. Ecobiotech. J. 2018a;1(4):201-215. DOI 10.31163/2618-964X-2018-1-4-201-215. (in Russian)

Veselova S.V., Burkhanova G.F., Maksimov I.V. Effect of phytopathogenic fungus Septoria nodorum Tox3 effector on the pro-/antioxidant status of wheat plants. Materials of the international symposium molecular aspects of plant redox metabolism. 2017;87-92 (in Russian)

Veselova S.V., Burkhanova G.F., Nuzhnaya T.V., Maksimov I.V. Roles of ethylene and cytokinins in development of defense responses in Triticum aestivum plants infected with Septoria nodorum. Russian J Plant Physiol. 2016;63(5):609-619. DOI 10.1134/ S1021443716050150

Veselova S.V., Burkhanova G.F., Nuzhnaya T.V., Rumyantsev S.D., Maksimov I.V. Influence of ethylene and reactive oxygen species on the growth of the pathogen Stagonospora nodorum Berk. in wheat plant tissue. Biomics. 2018b;10(4):387-399. DOI 10.31301/22216197.bmcs.2018-50. (in Russian)

Winterberg B., Du Fall L.A., Song X., Pascovici D., Care N., Molloy M., Ohms S., Solomon P.S. The necrotrophic effector protein SnTox3 re-programs metabolism and elicits a strong defence response in susceptible wheat leaves. BMC Plant Biol. 2014;14:215. DOI 10.1186/s12870-014-0215-5.

Acknowledgements: The work was supported by the Russian Foundation for Basic Research (project no. 18-04-00978).

Conflict of interest. The authors declare no conflict of interest. 


\title{
Septoria blight of spring wheat in West Siberia
}

\author{
E.Yu. Toropova ${ }^{1,2 *}$, O.A.Kazakova ${ }^{1,2}$, V.V. Piskarev ${ }^{3}$ \\ ${ }^{1}$ Novosibirsk State Agrarian University, Novosibirsk, Russia \\ ${ }^{2}$ All-Russian Research Institute of Phytopathology, Bolshie Vyazemy, Moscow region, Russia \\ ${ }^{3}$ Institute of Cytology and Genetics, SB RAS, Novosibirsk, Russia
}

DOI 10.18699/ICG-PlantGen2019-22

(c) Autors, 2019

* e-mail: 89139148962@yandex.ru

\begin{abstract}
Septoria blight of spring wheat leaves and ears is widespread in West Siberia, causing a decrease in yield by up to $50 \%$ or more with the deterioration in grain quality. The immunological assessment of a collection of 23 spring wheat varieties of different origin has shown no samples immune to Septoria. A differentiated manifestation of resistance to Septoria disease of leaves and ear has been established. Some varieties ('Orenburgskaya 23' and 'Vyatchanka' (Russia) as well as 'Long Chun 7 Hao' (China)) combine reduced susceptibility to Septoria disease of the leaves and ear. A study of a collection of varieties from three regions of Siberia in an epiphytotic year reveals the following trend: As compared with that in the Omsk and Kurgan regions, the transmission of the Septoria blotch causative agent is the most active with seeds of the Novosibirsk breeding lines.

Key words: Septoria; spring wheat; variety.
\end{abstract}

\section{Introduction}

For a long time the Septoria infection of leaves and ears has been one of the most common and harmful diseases of spring wheat in all areas of its cultivation (Eyal, 1999; Robert et al., 2004). With the wheat infection by Septoria, the leaves dry up prematurely, and the grain is formed only due to the stem and ear green parts. The grain is shriveled, with a low grain unit and a low 1000-grain weight. The spring wheat grain production falls by $25-60 \%$. The germination ability and germination energy of seeds are reduced by $7-12 \%$ (Parker et al., 2004; Robert et al., 2004). The causative agents of the disease are the fungi Parastagonospora nodorum (Berk.) Quaedvl. (teleomorph: genus Leptosphaeria), syn. Septoria nodorum (Berk.), and Septoria tritici Desm., syn. Mycosphaerella graminicola (Fuckel) J. Schröt. Of the two fungi on wheat, $P$. nodorum has a predominant distribution, differing in faster (8-10 times) germination of pycnospores and faster colonization of the host plant tissue compared to $S$. tritici (Eyal, 1999). Also, the plant pathogen Phaeosphaeria avenaria f.sp. triticae Shoem. \& C.E. Babc., syn. Septoria avenae f.sp. triticea, is observed on spring wheat in Siberia (Toropova et al., 2018). With the introduction of resource-saving tillage technologies, the frequency of Septoria epiphytotics in the West Siberian forest-steppe over the past 10 years has increased by 2.0-2.5 times (Toropova et al., 2018). In the last decade, the transmission of $P$. nodorum with spring and winter wheat seeds has intensified, which creates prerequisites for the early formation of foci of the disease, causing an increase in the multiplicity of fungicide application (Nolan et al., 1999; Simón et al., 2003). In the systems of control of the Septoria disease of spring wheat leaves and ears, resistant varieties are an important element; they are designed to slow down the reproduction rate of Septoria causative agents and to slow down or stop the epiphytotic process.

\section{Materials and methods}

The studies were carried out in 2016-2018 in the West Siberian forest-steppe zone. The investigation of Septoria leaf and ear blight was conducted using a collection of spring wheat varieties from the Institute of Cytology and Genetics of the Siberian Branch of the Russian Academy of Sciences. We used a standard international scale to detect Septoria blight and spot. The area under each variety (variety sample) ranged from 3 to $10 \mathrm{~m}^{2}$ in triplicate. In the northern forest-steppe of the Novosibirsk region, the year 2016 was dry, while 2017 and 2018 were wet, which significantly affected the intensity of the natural infection background.

\section{Results and discussion}

The monitoring of Septoria blight in 59 spring wheat cenoses in the Novosibirsk, Tomsk, Kemerovo, Kurgan, and Tyumen regions and the Altai Territory established a ubiquitous distribution of Septoria diseases in spring wheat varieties. The development of the disease was from 5 to $35 \%$, and the prevalence reached $90 \%$. The factors contributing to the development of Septoria were susceptible varieties; abundant precipitation during the critical period (spike formationflowering); high, close to $100 \%$, air humidity; the presence of infected plant debris in the field; and grass weeds (Nolan et al., 1999). The first Septoria foci on the lower leaves of susceptible spring wheat varieties were observed in 2016 and 2017, in third decade of June, and in 2018, due to late sowing, in the first two decades of July. First, P. nodorum appeared (June-early July), and then, S. tritici (end of July-August). Septoria epiphytotics of moderate and significant intensity occurred when precipitation was from 76 to $111 \mathrm{~mm}$ and the air temperature was an average of $16.7^{\circ} \mathrm{C}$. The causative agents of the disease were $P$. nodorum, $S$. tritici, and $S$. avenae f.sp. triticea, and the species ratio varied with region, spring wheat variety, and plant organs. The obvious predominance of $P$. nodorum was revealed in the Novosibirsk region. In the Tyumen region, with the predominance of $P$. nodorum, the second position was taken by $S$. avenae f.sp. triticea, not $S$. tritici, as in the Novosibirsk region. In Altai, the predominance of $P$. nodorum was less significant, $15.3 \%$ lower than in the Novosibirsk region. Also, $S$. tritici was encountered at 
all points of reference, but the frequency of its occurrence was 2 times higher than that in the Novosibirsk region. S. avenae f.sp. triticea was found in Altai 11.3 times more often than in the Novosibirsk region.

Additionally, differences were observed in the species composition of the causative agents of Septoria leaf blight in a collection of spring wheat varieties from the Novosibirsk district of the Novosibirsk region. The main causative agent of Septoria leaf and ear blight on all the wheat varieties was $P$. nodorum, which in two varieties made up $100 \%$ of the pathogenic complex. Its average proportion on the leaves of the varieties studied was significant, $88.9 \%$. The second position in the distribution on the leaves was taken by $S$. tritici, $10.4 \%$, which reached a maximum of $20 \%$ on the variety 'Altaiskaya 105'. S. avenae f.sp. triticea was detected only in two varieties, 'Altaiskaya Stepnaya' and 'Novosibirskaya 15'.

An immunological evaluation of spring wheat varieties showed no plant forms immune to the causative agents of Septoria disease. A plant pathological analysis of a collection of 23 spring wheat varieties in 2017 and 2018 showed that, at the beginning of the filling stage, ears of susceptible varieties had already been affected by Septoria. All the studied varieties of Novosibirsk selection, in which the spike was affected more than the leaves, were classified as the most susceptible. This creates a prerequisite for the transmission of $P$. nodorum with seeds and the early onset of the Septoria epiphytotic (Toropova et al., 2018). Eleven of 23 varieties (47.8\%) at the start of grain formation did not show spike damage. The best phytosanitary condition of all the considered wheat organs during the discussed phase was demonstrated by the varieties 'Orenburgskaya 23' and 'Tyumenochka', which showed an insignificant flag leaf loss with completely healthy spikes. The remaining varieties were in a satisfactory phytosanitary condition: complete dying-off of the subflag leaves, moderate (below the threshold) damage to the flag leaves, and healthy or sporadically affected spikes.

At the milky ripeness stage, the prevalence of Septoria reached $100 \%$ in all the varieties. Relative resistance to Septoria leaf blight was shown by the varieties 'Novosibirskaya 31', 'Sibirskaya 17', and 'Obskaya 2' with a strong development of Septoria spike spot. The domestic varieties 'Tyumenochka' and 'Zauralochka', as well as the NILs 'Thatcher Lr2c' (Canada), 'UI Pettit' (United States), 'Kaiyr' and 'Dostyk' (Kazakhstan), and 'KWS Akvilon' (Germany) showed relative resistance to Septoria blight. Reduced susceptibility was shown by the varieties 'Orenburgskaya 23' and 'Vyatchanka' as well as 'Long Chun 7 Hao' (China). They suffered moderate (threshold level) damage of both the leaves and the spike.

\section{Conclusions}

Monitoring has revealed significant differences in the presence of Septoria pathogens in the regions. In the Novosibirsk region, the predominance of $P$. nodorum is observed. In the Tyumen region, the predominance of $P$. nodorum is not always the case, because at some geographical points $S$. tritici and $S$. avenae f.sp. triticea show a higher prevalence in the pathogenic complex of the Septoria disease of spring wheat. In Altai, $P$. nodorum predominates at all survey points, but to a smaller extent than in the Novosibirsk region, and coexists with widespread $S$. tritici. The average contribution of $S$. avenae f.sp. triticea to the pathogenic complex of Septoria leaf blight in Altai is similar to that in the Tyumen region. The immunological assessment of the collection of spring wheat varieties has shown no forms completely immune to Septoria. A differentiated manifestation of resistance to Septoria leaf and ear disease has been established: Some varieties show resistance to the Septoria leaf blight with a strong ear spot incidence, while others, by contrast, are resistant to Septoria ear spot with strong damage to the leaf apparatus. Reduced susceptibility has been shown by the varieties 'Orenburgskaya 23' and 'Vyatchanka' as well as 'Long Chun 7 Hao' (China), which combined both positive qualities.

\section{References}

Eyal Z. The Septoria tritici and Stagonospora nodorum blotch diseases of wheat. European J Plant Pathol. 1999;105(7):629-641.

Nolan S. Studies on the interaction between Septoria tritici and Stagonospora nodorum in wheat / Nolan S., Cooke B.M., Monahan F.J. European J Plant Pathol. 1999;105(9):917-925.

Parker S.R., Welham S., Paveley N.D., Foulkes J., Scott R.K. Tolerance of Septoria leaf blotch in winter wheat. Plant Pathology. 2004; 53(1): $1-10$

Robert C. Analysis and modelling of effects of leaf rust and Septoria tritici blotch on wheat growth / Robert C., Bancal M.-O., Nicolas P., Lannou Ch., Ney B. J Experimental Bot. 2004;55(399):1079-1094.

Simón M.R. Influence of nitrogen supply on the susceptibility of wheat to Septoria tritici / Simón M.R., Cordo C.A., Perelló A.E., Struik P.C. J Phytopathol. 2003;151(5):283-289.

Toropova E.Yu., Kazakova O.A., Selyuk M.P., Insebaeva M.K., Kirichenko A.A., Filipchuk O.D., Kvitko A.V. Contamination of Wheat Seeds with Parastagonospora nodorum Berk. Achievements Sci Technol Agro-Industrial Complex. 2018;32(12):15-19 (in Russian).

Conflict of interest. The authors declare no conflict of interest. 


\title{
Race composition of the loose smut (Ustilago tritici) in Western Siberia
}

\author{
E.A. Orlova, N.P. Bechtold \\ Siberian Research Institute for Plant Industry and Breeding - Branch of the Institute of Cytology and Genetics, SB RAS, Krasnoobsk, \\ Novosibirsk region, Russia
}

DOI 10.18699/ICG-PlantGen2019-23

() Autors, 2019

*e-mail: Orlova.Lena10@yandex.ru

\begin{abstract}
The development of rational genetic protection for new varieties depends on data on the race composition of the wheat smut pathogen caused by Ustilago tritici, as well as on intrapopulation variability of fungus. The virulence of the isolates was estimated using a differential host series of varieties. Isolates of $U$. tritici were collected on the fields of the Novosibirsk and Omsk regions, as well as the Altai Krai in 2015-2018. Two sets of a differential host series were used for inoculation. The first one was developed in Russia by V. I. Krivchenko (1987) for identification of loose smut. This set consists of 9 wheat varieties: durum wheat (three entries) and bread wheat (six entries). The another set is Canadian and it's used in foreign studies. It was made by J.J. Nielsen, P. Thomas. (1996) for identification of loose smut and consists of 19 wheat varieties, three of them are durum wheat (TD-1, TD-11, TD-19). A total of 15 isolates collected from different varieties of spring bread wheat were assessed for virulence. As an isolate, one smut spike per plant was taken. The isolate was considered as virulent to the differential host line if more than $10 \%$ of the plants were infected. The races were identified by the key proposed by V.I. Krivchenko and J.J. Nielsen and P. Thomas. In the Novosibirsk region, the race 66 identified on the Russian set dominated. In the Canadian set, it is registered as T-8. The same race was noted in the Altai Krai. Also in these regions, the race 23 was identified. On the Canadian set, it is registered as $\mathrm{T}-18$. The race 12 was identified in the Novosibirsk and Omsk regions. In addition, the race 78 was identified in the Novosibirsk region, the race 58 was identified in the Altai Krai, and the race 1 was identified in the Omsk region. All races were specific for T. aestivum varieties and were not able to infect durum wheat varieties.
\end{abstract}

Key words: spring bred wheat; loose smut; pathogen races and population.

\section{Introduction}

The development of resistant wheat varieties for production crops is one of the effective measures to wheat smut pathogen caused by Ustilago tritici (Pers.) Jens. This depends on data on the race composition of the wheat smut pathogen, as well as on intrapopulation variability of fungus. The physiological race of smut pathogens is a sample or collection of chlamydospores, which has relatively the same virulence in certain set of differential host varieties. Such a concept of "race" was introduced in accordance with the biological features of the order Ustilaginales and selection requirements, at the $6^{\text {th }} \mathrm{In}$ ternational Botanical Congress in Amsterdam in 1935 (quote from Krivchenko, 1984). Loose smut pathogen races were first postulated by Grevel (1930). He identified 4 races. Later, Hanna and Popp (1932), using a self-selected differential host lines set, isolated races in the $U$. tritici population that differ in virulence on the test varieties. In Russia, V.I. Krivchenko (1987) carried out extensive work on the study and identification of physiological races of the loose smut. He compiled a differential host series of varieties, which was used in many research institutions of the USSR. This set contains 78 races of the loose smut (Druzhin, Krupnov, 2008). The Canadian set, created by J.J. Nielsen, P. Thomas, includes 19 wheat varieties. This set contains 44 races of the loose smut (Nielsen, Thomas, 1996).

For smut pathogens, the selective effect of genotypes is an important factor influencing the race variability. Based on this, we can assume the specific structure of the pathogen population in each zone sowing wheat. In this regard, we made an attempt to study and compare the race composition of the Novosibirsk, Omsk and Altai populations of the pathogen. This information may be of interest to both breeders and phytopathologists.

\section{Materials and methods}

The virulence of the isolates was estimated by infection types on differential set. Isolates were collected on the fields of the Novosibirsk and Omsk regions, as well as the Altai Krai in 2015-2018. As an isolate, one smut spike per plant was taken. A total of 15 isolates collected from different varieties of spring bread wheat were assessed for virulence.

Inoculation of plants was carried out during the most susceptible phase - the beginning of flowering, when single stamens appear on the ear, emerging from 1-2 spikelets. An aqueous suspension of smut spores was used to inoculate wheat ears. The suspension is prepared at the rate of 1 gram of spores per 1 liter of water. It is prepared immediately before infection of the plants. Inoculation of ears is carried out by the syringe method. In this case, approximately $0.05 \mathrm{ml}$ of suspension is placed into each flower. A separate syringe is used for each isolate. Infected ears were marked with paper labels. Inoculated seeds were sown the following year.

Two sets of differential host series of lines were used for inoculation. One of them was from Russia (Table 1). It was 
Table 1

The Russian differential host series of varieties for determining the physiological races of loose smut of spring wheat

\begin{tabular}{lll}
\hline Differential designation & Cultivar & Variety type \\
\hline D-1 & Moscovka & Graecum \\
D-2 & Kota & Erythrospermum \\
D-3 & Preston & Erythrospermum \\
D-4 & Rümkers Dickkopf & Lutescens \\
D-5 & Reward & Velutinum \\
D-6 & Diamant & Milturum \\
D-7 & Akmolinka 5 & Hordeiforme \\
D-8 & Mindum & Hordeiforme \\
D-9 & Narodnay & Hordeiforme \\
\hline
\end{tabular}

Table 2

The Canadian set of differential host lines for determining the physiological races of loose smut of spring wheat

\begin{tabular}{ll}
\hline Differential designation & Variety or breeding line \\
\hline TD -1 & Mindum \\
TD -2 & Renfrew \\
TD -3 & Florence/Aurore \\
TD -4 & Kota \\
TD-5 & Little Club \\
TD-6 & PJ 69282 \\
TD-7 & Reward \\
TD-8 & Carma \\
TD-9 & Kearney \\
TD-10 & Red Bobs \\
TD-11 & Pentad \\
TD-12 & Thatcher/Regent \\
TD-13 & PI 29854/ Cl 7795 \\
TD-14 & Sonop \\
TD-15 & H44/ Marquis \\
TD-16 & Marroqui 588 \\
TD-17 & Marquillo/Waratah \\
TD-18 & Manitau 2/Giza 144 \\
TD-19 & Wakooma \\
\hline
\end{tabular}

Table 3

Races of Ustilago tritici identified on the Russian set of differentiating varieties

\begin{tabular}{llllllllll}
\hline \multirow{2}{*}{ Race } & \multicolumn{2}{l}{ The reaction of varieties-differentiators } & & & \\
\cline { 2 - 9 } & D-1 & D-2 & D-3 & D-4 & D-5 & D-6 & D-7 & D-8 & D-9 \\
\hline 1 & 0 & 1 & 0 & 0 & 1 & 2 & 0 & 0 & 0 \\
12 & 0 & 1 & 0 & $1-2$ & 2 & $1-2$ & 0 & 0 & 0 \\
23 & 1 & 2 & 1 & 1 & 2 & 2 & 0 & 0 & 0 \\
58 & 2 & 2 & 1 & 1 & 2 & 1 & 0 & 0 & 0 \\
66 & 0 & 2 & 0 & 2 & 2 & 2 & 0 & 0 & 0 \\
78 & 0 & 2 & 0 & 0 & 2 & 2 & 0 & 0 & 0 \\
\hline
\end{tabular}


developed by V.I. Krivchenko (1987) for identification of loose smut. It consists of 9 wheat varieties, three of them are durum wheat (Mindum, Akmolinka 5 and Narodnaya). Differentiation of resistance reactions was carried out on a scale of: 0 - no affection; 1 - affected up to $10 \%, 2$ - affected over $10 \%$. The results were compared with a key to determine physiological races.

Since 2016, isolates of $U$. tritici have been inoculated with an additional differential host lines set - Canadian, created by Nielson, Thomas (1996) (Table 2). It uses for foreign studies and consists of 19 wheat varieties, three of them are durum wheat (TD-1, TD-11, TD-19). An isolate was considered virulent to the differential host line if more than $10 \%$ of the line plants were affected.

\section{Results and discussion}

In the Russian set of test varieties from 15 isolates studied, 6 varieties $(40 \%)$ were identified as race 66,3 varieties $(20 \%)$ - as race 23,2 varieties each $(13.3 \%)$ - as races 12 and 58, 1 variety each - as races 1 and 78 (Table 3 ). The race 66 was distinguished both among isolates collected in the Novosibirsk region and in the Altai Krai. It affected the varieties Kota, Rümkers Dikkopf, Reward, Diamant. On the Canadian set, the race was detected as T- 8 and it virulent on the TD-4, TD-5, TD-7, TD-8, TD-9, TD-13, TD-15 lines.

Races 12 and 23 were found among isolates collected in breeding plots of Novosibirsk and Omsk. On the Russian set of differentiating varieties, they did not affect the varieties Moskovka (D-1), Preston (D-3). The varieties Reward (D-5) and Diamant (D-6) were susceptible to them. On the Canadian set, the both races were detected as T-18 and they were virulent on the TD-4, TD-5, TD-7, TD-8, TD-9, TD-13 lines. In addition, the race 78 was identified on the Russian set of differentiating varieties in the Novosibirsk region. According to the compatibility reaction, this race was similar to the race 23, which made it possible to combine them under one name. Race 58 was identified in a population of $U$. tritici collected from spring bread wheat in Altai Krai. Unlike the tested isolates, it is virulent for the Moskovka variety (D-1). Race 1 was found among isolates of the Omsk region. It had low virulence and the only the variety Diamant (D-7) from Russian differential set was affected. All isolated races were specific for T. aestivum varieties and were not able to infect durum wheat varieties.

\section{References}

Druzhin A.E., Krupnov V.A. Wheat and the loose smut. Saratov, 2008. Krivchenko V.I. the Resistance of cereals to the agents of smut diseases. Moscow, 1984.

Krivchenko V.I., Myagkova D.V., Zhukova A.N., Khokhlova A.P. Guidelines for the study of resistance to smut cereal crops. Leningrad, 1987.

Menzies J.G., Knox R.E., Nielsen J., Thomas P.L. Virulence of Canadian isolates of Ustilago tritici: 1964-1998, and the use of the geometric rule in understanding host differential complexity. Canadian J Plant Pathol. 2003;25:62-72.

Nielsen J., Thomas P. Loose smut. Bunt and smut diseases of wheat: Concepts and methods of disease management. Mexico, D.F.CIMMYT, 1996.

Acknowledgements. This work was supported by ICG SB RAS budget project No. 0324-2019-0039.

Conflict of interest. The authors declare no conflict of interest. 


\title{
Potential of ribonuclease-sinthesizing plant growth promoting rhizobacteria in plant defence against viruses
}

\author{
G.F. Burkhanova*, A.V. Sorokan, V.U. Alekseev, A.A. Mazitova, I.V. Maksimov \\ Institute of Biochemistry and Genetics - Subdivision of the Ufa Federal Research Centre of the Russian Academy of Sciences, Ufa, Russia
}

DOI 10.18699/ICG-PlantGen2019-24

(c) Autors, 2019

*e-mail: guzel_mur@mail.ru

\begin{abstract}
Viruses cause epiphytotics on all major cultures of agronomic importance, representing a serious danger to global food security. As strictly intracellular pathogens, they cannot be controlled chemically and prophylactic measures consist mainly in the destruction of infected plants and excessive pesticide applications to limit the population of vector organisms. An alternative antiviral strategy is associated with the use of microbial enzymes, which are less toxic and are readily decomposed without accumulation of harmful substances. Plant-growth promoting microorganisms (PGPR), especially endophytic strains, or their communities can promote plant defence against viral diseases via producing ribonucleases, which are capable of degrading viral RNA.
\end{abstract}

Key words: plant virus; PGPR; endophyte; ribonuclease; resistance.
Viruses cause epidemics in all major crops, threatening global food security. The development of efficient and durable resistance able to withstand viral attacks represents a major challenge for agrobiology. Currently, viruses cannot be controlled with chemical pesticides, since known antiviral compounds are hazardous to people's health, such as teratogenic ribaverine (1, beta-D-ribofuranosyl-1,2,4-triazole3-carboxamide), which significantly reduced TSWV content in tomato and tobacco plants, via blocking RNA-replication. At present, practical control measures include monitoring and chemical control of the vector causing the viral disease to reduce yield losses. In addition, viral resistance breeding is limited by the absence of resistance genes. Transformationbased genetic engineering is restricted due to a large amount of time required for crossing in the field and environmental safety issues in many countries (Paudel, Sanfaçon, 2018). The application of systemic acquired resistance with non-specific elicitors or PGPR to manage viral diseases was recognized as a promising tool (Lee, Rui, 2016).

Hypersensitive response (HR), systemic acquired resistance (SAR), and elaboration of the gene-for-gene resistance response are contemporary immune response paradigms that were discovered more than 50 years ago (Mandadi, Scholthof, 2013). Accumulation of PR proteins is an integral component of innate immune responses in plants during viral attack. The PR-10 family, plant RNAses, are ubiquitous proteins that have been identified in a number of dicot and monocot plant species. They are small, slightly acidic and resistant to proteases. PR-10 proteins are classified as intracellular PR (IPR) proteins and are present in the cytoplasm because they lack signal peptide (Jain, Kumar, 2015). Thus, phosphorylation leads to enhanced ribonucleolytic activity against viral RNAs upon Tobacco mosaic virus (TMV) infection showing direct involvement of ribonucleolytic activity in plant defense (Park et al., 2004). For buckwheat varieties with different resistance to the Buckwheat burn virus (BBV), a positive correlation between resistance to virus and RNase activity was shown, the authors have analyzed two varieties, Roksolana and KaraDag (Sindarovska et al., 2014). Trifonova et al. (2018) have proposed to use of the level of RNase activity in potato leaves as a selective marker for resistance to viruses.

Interestingly, Loring (1941) has shown, for the first time, the reversible inactivation of TMV by exogenous crystalline ribonuclease and a decrease in the number of lesions on Nicotiana glutinosa and Phaseolus vulgaris leaves infected with RNAse-treated TMV. However, there is not a single preparation based on this technology, probably due to the lack of a "delivery agent". Transformation-based genetic engineering was the first step towards solving this problem. Thus, approximately one third of tobacco transgenic lines containing betasatellite DNA associated with cotton leaf curl disease and barnase of $B$. amiloliquefaciens gene constructs were shown to be completely resistant to Tomato leaf curl virus (TLCV) infection. There was no expression of barnase in the absence of TLCV, but upon infection of the cell with the virus, release of the betasatellite/split barnase cassette as a replicating molecule results in the reconstitution and expression of an active barnase gene and the destruction of the infected cell (Pakniat-Jahromy et al., 2010).

Thus, transgenic soybean lines constitutively expressing the double-strand RNA specific ribonuclease gene PAC1 from Schizosaccharomyces pombe exhibited less severe symptoms and enhanced resistance to Soybean mosaic virus (SC3 SC7, SC15, SC18 and SMV-R strains), and three isolates of Bean common mosaic virus (BCMV), Watermelon mosaic virus (WMV), and Bean pod mottle virus (BPMV) relative to WT plants (Yang et al., 2019).

Ribonuclease Cas13a was shown to provide immunity to a bacteriophage in Escherichia coli by interfering with the MS2 lytic ssRNA phage (Qi et al., 2013). CRISPR/Cas13a showed interference against green fluorescent protein (GFP)expressing TuMV in lines of Nicotiana benthamiana. Northern blots showed a clear reduction in the accumulation of the TuMV-GFP RNA genome using the crRNAs targeting HC-Pro or GFP2, indicative of targeted degradation of the TuMV-GFP genomic RNA via CRISPR/pCas13a (Aman et al., 2018).

Sugawara et al. (2016) generated transgenic Nicotiana tabacum plants expressing heterologous bovine pancreatic RNase. 
Higher RNase levels in the apoplast resulted in increased resistance to both CMV (Bromoviridae, Cucumovirus) and TMV (Virgaviridae, Tobamovirus), indicating a role of RNAhydrolyzing enzymes in non-specific plant antiviral response.

Research over the past decades provided substantial advances in the field of plant-miccrobe and plant-virus interactions. Remarkably, the advent of studies of plant interactions with plant-growth promoting rhizobacteria (PGPR), in particular, endophytic strains, has recently offered new strategies exploitable in the field.

So, it suggests the need for a search for biocontrol agents that combine the follow properties: a) integrated biocidal activities to spreading harmful organisms; b) the ability to induce plant immune reactions; c) environmental safety. Therefore, plant growth-promoting bacteria (PGPB), in particular, endophytic PGPB, which belong to a beneficial and heterogeneous group of microorganisms, are of great interest (Khalaf et al., 2018; Abdalla et al., 2017).

Endophytic microorganisms live within the tissues of plants without causing any symptoms of disease. Endophytes should be a treasured biological resource for plant protection against pathogens and pests. Bacterial endophytes have an advantage over bacteria inhabiting the rhizo- or phyllosphere, since living within a plant's tissues represents an opportunity to always be in "contact" with the plant's cells and, therefore, to more readily exert a direct beneficial effect on plant hosts, and to reduce the influence of the environmental conditions on PGPB. It was shown (Araújo et al., 2015) that a number of Bacillus strains have fungicidal, insecticidal, aphycidal (Araújo et al., 2015; Yang et al., 2017) and growth-promoting activities (Pieterse et al., 2014), synthesize antibiotics and biosurfactants (De Vleesschauwer, Höfte 2009), promote induced systemic resistance (ISR) against pathogens and pests (Rashid, Chung 2017). There is a wealth of data on endophyte influence on plant viability, and the most recent are investigations of the problem of artificial plant microbial community on the basis of growth-promoting bacteria (Moronta-Barrios et al., 2018).

The PGPR Bacillus polymixa and Pseudomonas fluorescens mix with chitosan application delayed symptom development and reduced disease severity as well as the titer of Squash mosaic virus (SqMV) at the generative phase of cucumber plants (Firmansyah et al., 2017). The mixture containing B. amyloliquefaciens IN937a, B. pumilus SE34 and B. pumilus T4 promotes tomato and papaya plants' resistance to Tomato chlorotic spot virus (TCSV) and Papaya ringspot virus (PRSV-W), respectively (Abdalla et al., 2017).

For instance, Piriformospora indica (Hymenomycetes: Basidiomycota), an endophytic root-colonizing fungal species, has been shown to repress Pepino mosaic virus (PMV), which is found widely in tomato greenhouses in many parts of the world, especially at high light intensities (Fakhro et al., 2010). Replication of Iris yellow spot virus (IYSV) was significantly reduced in endophytic fungus Hypocrea lixiicolonized onion plants as compared to endophyte free plants (Muvea et al., 2018). Arabidopsis thaliana ecotype columbia plants (Col-0) treated with S. marcescens 90-66 and B. pumilis strain SE-34 significantly reduced the symptom severity caused by Cucumber mosaic virus (CMV) (Ryu et al., 2004).
In a study by Harish et al. (2008), two endophytic bacterial strains belonging to Bacillus spp. (EPB22) and Pseudomonas spp. (EPB5) promoted banana resistance against Banana bunchy top virus (BBTV).

Bacteria, fungi and their metabolites can bind and destruct viral particles directly, through the synthesis of proteases, nucleases and lipopeptides. To date, 20 extracellular nucleases which have been characterized for Bacillus spp. B. amyloliquefaciens, B. pumilus and B. licheniformis produce extracellular RNAses, called 'barnase', 'binase' and 'balifase', respectively (Ulyanova et al., 2011, 2016; Ilinskaya et al., 2018). Among endophytic bacteria which were isolated from plants of the family Cucurbitacea, $73 \%$ of Bacillus spp., $27 \%$ of Paenibacillus spp., $30 \%$ of Enterobacteriaceae, all isolates of Cronobacter, Pantoea, Microbacterium and Staphylococcus showed RNAse activity (Khalaf, Raizada, 2018).

Bacillus pumilus ribonuclease possesses antiviral activity against plant RNA-viruses RCMV (Red clover mottle virus), PVX (Potato virus X) and AMV (Alfalfa mosaic virus). The maximum inhibitory effect against actively replicating viruses is observed when plants are treated with the enzyme at a concentration of $100 \mathrm{ug} / \mathrm{ml}$ prior to infection (Sharipova et al., 2015).

Bacillus cereus ZH14, which was isolated from Chinese Anxi oolong tea, secreted antiviral substances having 94.2\% virus inhibition when the bacterial culture filtrate and TMV extract were mixed at a ratio of 1:1 and had the ability to degrade ribonucleic acid (Zhou et al., 2008).

Thus, the search for endophytic microorganisms that can produce RNAses directly in plant tissues is a promising area of the development of the set of activities required to for defending plants against viral diseases.

\section{References}

Abdalla O., Shagufta B., Shouan Z. Application of plant growth-promoting rhizobacteria to control Papaya ringspot virus and Tomato chlorotic spot virus. Arc. Phytopathol. Plant Protect. 2017;50:1. DOI 10.1080/03235408.2017.1352248.

Araújo E.O. Rhizobacteria in the control of pest insects in agriculture. Afr. J. Plant Sci. 2015;9(9):368. DOI 10.5897/AJPS2015.1318.

De Vleesschauwer D., Höfte M. Rhizobacteria-induced systemic resistance. Adv. Bot. Res. 2009:51;223. DOI 10.3389/fpls.2017.01816.

Fakhro A., Andrade-Linares D.R., von Bargen S., Bandte M., Büttner C., Grosch R. et al. Impact of Piriformospora indica on tomato growth and on interaction with fungal and viral pathogens. Mycorrhiza. 2010;3:191. DOI 10.1007/s00572-009-0279-5.

Firmansyah D., Widodo W., Hendrastuti Hidayat S. Chitosan and Plant Growth Promoting Rhizobacteria Application to Control Squash mosaic virus on Cucumber Plants. Asian J. Plant Pathol. 2017;11:148. DOI 10.3923/ajppaj.2017.148.155.

Harish S., Kavino M., Kumar N., Saravanakumar D., Soorianathasundaram K., Samiyappan R. Biohardening with plant growth promoting rhizosphere and endophytic bacteria induces systemic resistance against Banana bunchy top virus. Appl. Soil Ecol. 2008;39:187. DOI 10.1016/j.apsoil.2007.12.006.

Khalaf E.M., Raizada M.N. Bacterial Seed Endophytes of Domesticated Cucurbits Antagonize Fungal and Oomycete Pathogens Including Powdery Mildew. Front Microbiol. 2018;9:42. DOI 10.3389/fmicb.2018.00042

Lee G.H., Ryu C.-M. Spraying of leaf-colonizing Bacillus amyloliquefaciens protects pepper from Cucumber mosaic virus. Plant Disease. 2016;10:2099. DOI 10.1094/PDIS-03-16-0314-RE. 
Mandadi K.K., Scholthof K.-B.G. Plant Immune Responses Against Viruses: How Does a Virus Cause Disease? Plant Cell. 2013;25:1489. DOI 10.1105/tpc.113.111658.

Moronta-Barrios F., Gionechetti F., Pallavicini A., Marys E., Venturi V. Bacterial Microbiota of Rice Roots: 16S-Based Taxonomic Profiling of Endophytic and Rhizospheric Diversity, Endophytes Isolation and Simplified Endophytic Community. Microorganisms. 2018;6:14.

Muvea A.M., Subramanian S., Maniania N.K., Poehling H.-M., Ekesi S., Meyhöfer R. Endophytic colonization of onions induces resistance against viruliferous thrips and virus replication. front. Plant Sci. 2018;34:73. DOI 10.3389/fpls.2018.01785.

Pakniat-Jahromy A., Behjatnia S.A., Dry I.B., Izadpanah K., Rezaian M.A. A new strategy for generating geminivirus resistant plants using a DNA betasatellite/split barnase construct. Epub 2010;1-2:57. DOI 10.1016/j.jviromet.2010.08.019.

Park C.J., Kim K.J., Shin R., Park J.M., Shin Y.C., Paek K.H. Pathogenesis-related protein 10 isolated from hot pepper functions as a ribonuclease in an antiviral pathway. Plant J. 2004;2:186. DOI 10.1046/j.1365-313X.2003.01951.x.

Paudel D.B., Sanfaçon H. Exploring the Diversity of Mechanisms Associated With Plant Tolerance to Virus Infection. Front. Plant Sci. 2008;9:1575. DOI 10.3389/fpls.2018.01575.

Qi L.S., Larson M.H., Gilbert L.A., Doudna J.A., Weissman J.S., Arkin A.P. et al. Repurposing CRISPR as an RNA-guided platform for sequence-specific control of gene expression. Cell. 2013;5:1173. DOI 10.1016/j.cell.2013.02.022.

Rashid M.H., Chung Y.R. Induction of systemic resistance against insect herbivores in plants by beneficial soil microbes. Front. Plant Sci. 2017:8;1816. DOI 10.3389/fpls.2017.01816.

Ryu C.M., Murphy J.F., Mysore K.S., Kloepper J.W. Plant growthpromoting rhizobacteria systemically protect Arabidopsis thaliana against Cucumber mosaic virus by a salicylic acid and NPR1-independent and jasmonic acid-dependent signaling pathway. Plant $J$. 2004;3:381. DOI 10.1111/j.1365-313X.2004.02142.x.

Sharipova M., Rockstroh A., Balaban N., Mardanova A., Toymentseva A., Tikhonova A., Vologin S., Stashevsky Z. Antiviral Effect of Ribonuclease from Bacillus pumilus against phytopatho- genic RNA-Viruses. Agricultural Sci. 2015;6:1357. DOI 10.4236 as.2015.611130.

Sindarovska Y.R., Guzyk O.I., Yuzvenko L.V., Demchenko O.A., Didenko L.F., Grynevych O.I., Spivak M.Y. Ribonuclease activity of buckwheat plant (Fagopyrum esculentum) cultivars with different sensitivities to buckwheat burn virus. Ukr. Biochem. J. 2014;86:33. PMID: 25033552.

Sugawara T., Trifonova E., Kochetov A., Kanayama Y. Expression of an extracellular ribonuclease gene increases resistance to Cucumber mosaic virus in tobacco. BMC Plant Biol. 2016;3:147. DOI 10.1186/ s12870-016-0928-8.

Trifonova E.A., Ibragimova S.M., Volkova O.A., Shumny V.K., Kochetov A.V. Ribonuclease activity as a new prospective disease resistance marker in potato. Vavilovskii Zhurnal Genetiki i Selektsii $=$ Vavilov Journal of Genetics and Breeding. 2018;8:987. DOI 10.18699/VJ18.441.

Yang S.Y., Lim D.J., Noh M.Y., Kim J.Ch., Kim Y.Ch., Kim I.S. Characterization of biosurfactants as insecticidal metabolites produced by Bacillus subtilis Y9. Entomol. Res. 2017;47:55. DOI 10.1111/1748-5967.12200.

Yang X., Niu L., Zhang W., He H., Yang J., Xing G., Guo D., Zhao Q., Zhong X., Li H., Li Q., Dong Y. Increased multiple virus resistance in transgenic soybean overexpressing the double-strand RNA-specific ribonuclease gene PAC1. Transgenic Res. 2019;28:129. DOI 10.1007/s11248-018-0108-8.

Zhou W., Zhang L., Zhang B., Wang F., Liang Z., Niu T. Isolation and characterization of ZH14 with antiviral activity against Tobacco mosaic virus. Canadian J. Microbiol. 2008;6:441. DOI 10.1139/ W08-026.

Acknowledgements. The work is supported by the joint international granting program of Russian science Fond (RCF) and Department of science and technology (DST) of the Government of India № 19-46-02004.

Conflict of interest. The authors declare no conflict of interest. 


\title{
Studying the infection rate of seeds of various genotypes of sweet sorghum (Sorghum bicolor L.) by fungus and bacterial microflora
}

\author{
K.M. Iskakova ${ }^{1}$, B.B. Anapiyayev ${ }^{1 *}$, E.B. Beisenbek ${ }^{1}$, A.B. Akhmetova ${ }^{2}$, A.M. Sagimbayeva ${ }^{1}$, A.S. Omarova ${ }^{3}$ \\ ${ }^{1}$ Kazakh National Research Technical University named after K.I. Satpaev, Almaty, Kazakhstan \\ ${ }^{2}$ Kazakh National Agrarian University, Almaty, Kazakhstan \\ ${ }^{3}$ Institute of Agriculture, Almalybak, Almaty region, Kazakhstan
}

DOI 10.18699/ICG-PlantGen2019-25

(c) Autors, 2019

* e-mail: bak_anapiyayev@mail.ru

\begin{abstract}
It was revealed that the sowing material of sweet sorghum (Sorghum bicolor L.) was injured with fungus and bacterial microflora. Studying the seed material of sweet sorghum demonstrated that it was injured with microflora, belonging to the genera Fusarium, Alternaria, Penicillium, Aspergillus, Mucor and Helminthosporium causing seed moulding and rotting. The genotypes and seed material of sweet sorghum most injured with fungus and bacterial microflora were determined. The germination energy and seed viability of various genotypes of sweet sorghum were determined. The infection rate of seed material considerably influenced the germination energy and seed viability of sweet sorghum. The injury of seeds by fungus and bacterial microflora is an important indicator defining the field viability of seeds and affecting the productivity of sweet sorghum.
\end{abstract}

Key words: swet sorghum; Sorghum bicolor L.; fungus and bacterial microflora; Fusarium; Alternaria; Penicillium; Aspergillus; Mucor; Helminthosporium.

\section{Introduction}

Sorghum is a valuable thermophilic spring-planted cereal culture, which resembles in appearance corn and is not inferior to it in terms of nutritious properties. Four main sorghum species are distinguished: grainy, sweet, grassy and broomy. The homeland to sorghum is Northeast Africa and Equatorial Africa, particularly Ethiopia and Sudan; it has also been cultivated in China and India since long time ago. Therefore sweet sorghum (Sorghum saccharatum Pers.) is the most drought-resistant culture. Sweet sorghum is characterized by the fact that, unlike grainy and broomy sorghum, the juice of its stem contains more than $10-20 \%$ of soluble sugars. In the nature, there is no other plant which could synthesize sucrose so quickly as sweet sorghum does. As it can be cultivated in southern droughty areas, where growing sugar beet is unprofitable or impossible, interest to sweet sorghum is very high. Sweet sorghum is a perspective crop for multi-purpose use. Sweet sorghum is used in bread baking and in production of forages and cardboard. Nowadays the biotechnological aspects of cultivation of sweet sorghum cells in vitro for the extension of genetic diversity are being studied (Baskaran et al., 2005; Dora et al., 2014; Teingham, Borde, 2017; Omer et al., 2018). Research in the genetic engineering of sorghum is intensive (Guel et al., 2009).

Factors affecting the quality of cellular juice and the power value of sweet sorghum depending on terms of sowing, depth of seed embedding and the use of nitrogen fertilizers were studied (Maw et al., 2016). Special attention was given to studying the cultivars and hybrids of sweet sorghum with a high content of sugar for bioethanol production. Molecular mechanisms of the resistance of sweet sorghum to biotic and abiotic stressful environmental factors were studied (Anami et al., 2015). At the same time, for cultivation of sweet sorghum, it is necessary to study factors that ffect the viability of seeds and productivity. One of the limiting factors affecting the viability of seeds in sweet sorghum is the injury of seed material with fungus and bacterial microflora. In this regard, the level of injury of seeds of sweet sorghum (Sorghum bicolor L.) cultivated in the conditions of the southeastern part of Kazakhstan were studied by us.

\section{Materials and methods}

The sweet sorghum genotypes SAB-1, SAB-2, SAB-3, SAB-4, SAB- 5, SAB-6, SAB-8, SAB-9, B-10, SAB-11 and SAB-12 were used as material for our research. During the analysis of seeds of different genotypes of sweet sorghum, their sowing qualities, such as germination energy on the $4^{\text {th }}$ day and the laboratory germination viability on the $8^{\text {th }}$ day, were estimated against state standard specifications. Fifty seeds of each genotype in 3-fold repetition were taken to determine their sowing qualities in the conditions of the moisture chambers. The number of infected seeds and sprouts was also noticed. Microflora was placed on the nutrient medium made of potato agar (PA). During this analysis, the lack of microflora was designated as (-), weak growth, as $(+)$, the average growth, as $(++)$, and intensive growth, as $(+++)$. The identification of fungus and bacterial microflora was carried out by morphological and cultural features of colonies of fungi and bacteria and their pure cultures. Morphological features of fungi were investigated by microscopy according to their spore forming. Bacterial microflora was selected into a pure culture and checked for pathogenicity using test objects such as a room geranium and tubers of potatoes. It was noted that pathogenic species of bacteria on geranium leaves caused a reaction of supersensitivity in the form of necrosis; on tubers of potatoes, it caused tissue maceration (rotting). Statistical analysis of the results obtained was carried out using the standard technique.

\section{Results and discussion}

Before sowing the various genotypes of sorghum in field conditions, the seed viability of sweet sorghum in vitro was studied. The seed viability of sorghum was affected by such 
Table 1

Sowing qualities of seeds of sweet sorghum, laboratory experiment, the moisture chamber

\begin{tabular}{lllll}
\hline \multirow{2}{*}{$\begin{array}{l}\text { Crop, } \\
\text { cultivar } \\
\text { (genotype) }\end{array}$} & $\begin{array}{l}\text { Germination } \\
\text { energy, } \%\end{array}$ & $\begin{array}{l}\text { Laboratory } \\
\text { germination } \\
\text { energy, } \%\end{array}$ & $\begin{array}{l}\text { Number of } \\
\text { infected seeds } \\
\text { and sprouts, }\end{array}$ \\
\cline { 3 - 4 } & & \multicolumn{2}{c}{ days of observation } & \\
\cline { 3 - 4 } & & $4^{\text {th }}$ & $8^{\text {th }}$ \\
\hline 1 & SAB-1 & 78.0 & 78.0 & 100 \\
2 & SAB-2 & 76.0 & 79.3 & 78.6 \\
3 & SAB-3 & 2.0 & 2.6 & 93.3 \\
4 & SAB-4 & 88.6 & 90.6 & 14.0 \\
5 & SAB-5 & 45.3 & 53.3 & 14.0 \\
6 & SAB-6 & 45.0 & 43.5 & 56.4 \\
7 & SAB-7 & 36.6 & 40.6 & 73.3 \\
8 & SAB-8 & 81.3 & 88.0 & 3.3 \\
9 & SAB-9 & 100 & 100 & 30.6 \\
10 & SAB-10 & 96.6 & 98.0 & 25.3 \\
11 & SAB-11 & 32.0 & 32.0 & 100 \\
12 & SAB-12 & 98.0 & 98.6 & 88.0 \\
\hline
\end{tabular}

factors as the initial cultivar genotype, periods of seed storage and the recontamination of sorghum grains by various microorganisms.

It was revealed that on the $4^{\text {th }}$ day amicable and full-fledged sprouts were noted in genotypes SAB-1, 2, 4, 8, 9, 10 and 11 (78; 76; 88.6; 81.3; 100; 96.6 and $98 \%$, respectively). The germination energy of genotypes SAB-5, 6, 7 and 11 was $45.3,45.0,36.6$, and $32.0 \%$, respectively; genotype SAB-3 possessed weak viability, only $2.0 \%$ (Table 1 ).

According to data from Table 1 , on the $4^{\text {th }}$ day amicable and full-fledged shoots were noted in genotypes SAB-1, 2, 4, 8, 9, 10 and 12 . They were $78 ; 76 ; 88.6 ; 81.3 ; 100 ; 96.6$ and $98 \%$, respectively. The germination energy in genotypes SAB-5, 6 , 7 and 11 was $45.3,45.0,36.6$ and $32.0 \%$, respectively, and genotype SAB-3 possessed weak viability, about $2.0 \%$.

Germination on the $8^{\text {th }}$ day in genotypes SAB-8, 9, 10 and 12 corresponded to the standards of the original and elite cultivars. The viability of genotypes SAB-1 and SAB-2 corresponded to the standards of reproductive cultivars for production: 78 and $79.3 \%$, respectively. Other seeds showed a very low germination: $32.0-53.3 \%$. The viability of genotype SAB-3 was only $2.6 \%$.

Strong damage to seeds and sprouts caused by diseases was also noted (Figure 1). The greatest number of infected seeds and sprouts in genotypes SAB-1, 2, 3, 7, 11 and 12 reached $100,78.6,93.3,73.3,100$ and $88 \%$, respectively. In other variants, infection varied from 3.3 to $56.4 \%$.

Studying the level of injury of sweet sorghum seeds by fungus and bacterial microflora was carried out on potato agar. The results of these studies are presented in Table 2. According to data from the Table 2, in all tests of seeds after surface sterilization on the nutrient medium fungus and bacterial infections were revealed (Figure 2). The highest rates of
Table 2

Phytoexamination of sweet sorghum seeds,

laboratory experiment, nutrient medium, 2018

\begin{tabular}{|c|c|c|c|c|c|c|}
\hline \multirow[t]{4}{*}{ № } & \multirow{4}{*}{$\begin{array}{l}\text { Crops, } \\
\text { cultivar }\end{array}$} & \multirow{4}{*}{$\begin{array}{l}\text { Number of } \\
\text { the infected } \\
\text { seeds and } \\
\text { sprouts, \% }\end{array}$} & \multicolumn{4}{|c|}{ Infection by microflora } \\
\hline & & & \multicolumn{2}{|c|}{ fungus } & \multicolumn{2}{|c|}{ bacterial } \\
\hline & & & \multicolumn{4}{|c|}{ days of observation } \\
\hline & & & $3^{\text {rd }}$ & $5^{\text {th }}$ & $3^{\text {rd }}$ & $5^{\text {th }}$ \\
\hline 1 & SAB-1 & 100.0 & +++ & +++ & +++ & +++ \\
\hline 2 & SAB-2 & 100.0 & ++ & ++ & +++ & +++ \\
\hline 3 & SAB-3 & 92.8 & + & ++ & ++ & +++ \\
\hline 4 & SAB-4 & 100.0 & - & ++ & ++ & ++ \\
\hline 5 & SAB-5 & 100.0 & + & + & ++ & ++ \\
\hline 6 & SAB-6 & 100.0 & + & + & ++ & + \\
\hline 7 & SAB-7 & 100.0 & + & + & ++ & ++ \\
\hline 8 & SAB-8 & 100.0 & + & ++ & + & +++ \\
\hline 9 & SAB-9 & 100.0 & - & ++ & ++ & +++ \\
\hline 10 & SAB-10 & 92.8 & + & ++ & ++ & +++ \\
\hline 11 & SAB-11 & 100.0 & +++ & +++ & +++ & +++ \\
\hline 12 & SAB-12 & 98.6 & + & + & ++ & + \\
\hline
\end{tabular}

injury by fungus and bacterial microflora were found in two sorghum genotypes, SAB-1 and SAB-11. Two other sweet sorghum genotypes, SAB-6 and SAB-12, demonstrated weak infection by fungus and bacterial microflora.

Based on the morphological features of their colonies and according to a microscopic analysis of their spore formation, the fungi revealed were in the species Fusarium, Alternaria, Penicillium, Aspergillus, Mucor and Helminthosporium causing seed moulding and rotting and also causing the rot of the root system.

Results of identification of bacteria on the basis of morphological features of their colonies on the nutrient medium and checking their pathogenic features on the test objects, a room geranium and tubers of potatoes, demonstrated their identity with phytopathogenic bacteria in the genera Erwinia and Pseudomonas causing different types of bacterioses.

On the basis of the phytoexamination carried out on sweet sorghum seeds, it was established that not every sample of seed material of the genotypes of this crop conformed to the State standard requirements in terms of sowing qualities. Additionally, their affection by a wide range of saprotrophic and pathogenic microflora was revealed.

\section{Conclusions}

As a result of the laboratory and field studies carried out, it was established that not all studied samples of seed material of sweet sorghum (Sorghum bicolor L.) conformed to the State standard requirements in terms of sowing qualities. Additionally, their affection by a wide range of saprotrophic and pathogenic microflora was revealed.

During the study of seed germination of sorghum of original and elite cultivars, it was revealed that not all the genotypes of sugar sorghum demonstrated a high level of viability. It was 


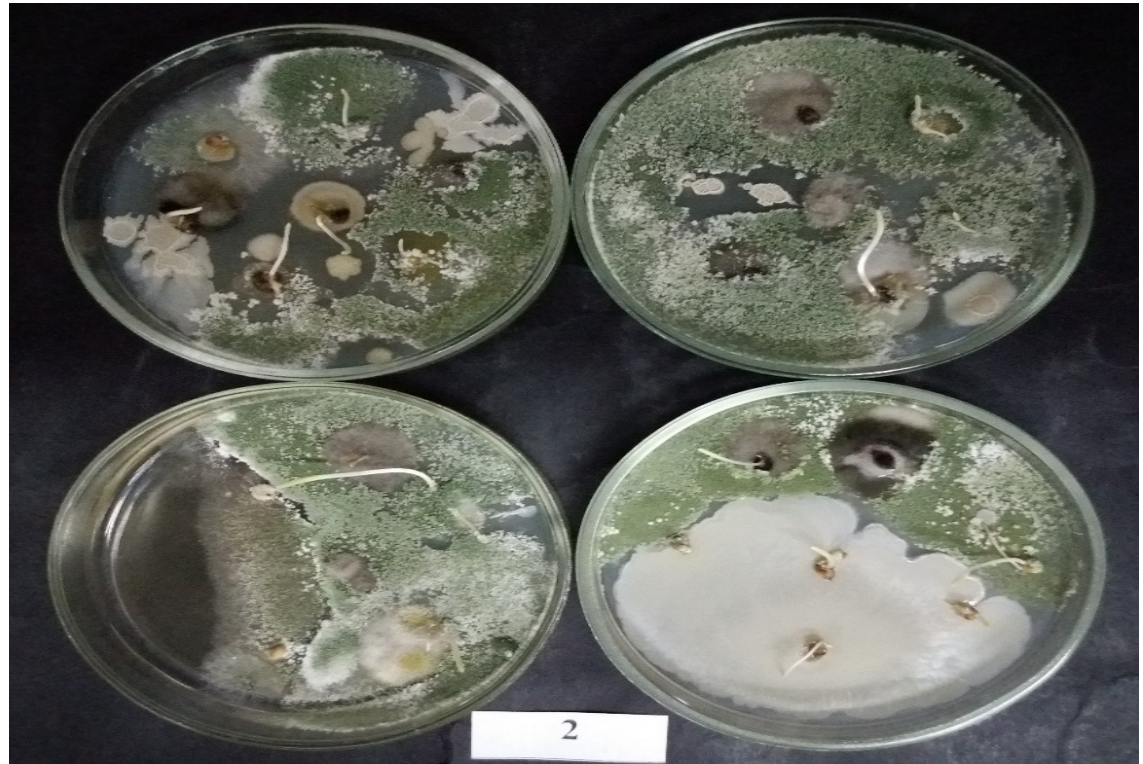

Figure 1. The seeds of sweet sorghum injured with fungus and bacterial microflora, laboratory experiment, 2018; genotypes SAB-2 and SAB-3. revealed that the laboratory viability of tgenotypes SAB-8, 9, 10 and 12 were consistent with the standards of the original and elite cultivars. The respective viabilities of genotype SAB-1 was $78 \%$ and SAB- 2 was $79.3 \%$ consistent with the standards of reproductive cultivars for production. Other seed material demonstrated a very low laboratory viability, 32.0-53.3\%. The viability of genotype SAB-3 was only $2.6 \%$.

Strong injury of seeds and sprouts by diseases was also noted. The greatest number of infected seeds and sprouts was revealed in genotypes SAB-1, 2, 3, 7, 11 and 12 (100, 78.6, $93.3,73.3,100$ and $88 \%$, respectively). In other experimental variants, the infection level varied from 3.3 to $56.4 \%$.

Studies the seeds of sweet sorghum for fungal and bacterial infection rates were carried out on potato agar. At the same time, in all test samples of seeds after surface sterilization on the nutrient medium fungus and bacterial infections were revealed. Based on the morphological features of their colonies and according to a microscopic analysis of their spore formation, the fungi revealed were in the species Fusarium, Alternaria, Penicillium, Aspergillus, Mucor and Helminthosporium, which are able to cause seed molding and rotting and also root rots.

In the result of the study conducted, the genotypes and seed material of sweet sorghum most infected with fungus and bacterial microflora were determined. The energy of germination and viability of seeds of the various genotypes of sweet sorghum were also determined. The germination energy and seed viability of sweet sorghum were considerably affected by the infection rate of seed material. Studying the infection rate of seeds by fungus and bacterial microflora is an important indicator of the field viability of seeds and productivity of sweet sorghum (Sorghum bicolor L.).

\section{References}

Anami S.E., Zhang L.M., Xia Y. et al. Sweet sorghum ideotypes: genetic improvement of stress tolerance. Food Energy Security. 2015; 4(1):3-24

Baskaran P., Rajevari B.R., Jayabalan N. A simple approach to improve plant regeneration from callus culture of Sorghum bicolor for crop improvement. J. Agriculture Technol. 2005;1(1):179-192.

Dora S.V., Sharma P., Sandra M.N. Efficient callus induction protocol for Sorghum bicolor. Asian J. Plant Sci. Res. 2014;4(3):14-21.

Gurel S., Gurel E., Kaur R. et al. Efficient, reproducible Agrobacterium-mediated transformation of sorghum using heat treatment of immature embryos. Plant Cell Rep. 2009;28:429-444.

Maw M.J.W., Houx III J.H., Fritschi F.B. Sweet sorghum ethanol yield component response to nitrogen fertilization. Industrial Crops Products. 2016;84:43-49.

Omer A.R., Asami P., Birungi J. Callus induction and plant regeneration from immature embryos of sweet sorghum (Sorghum bicolor Moench). Biotechnology. 2018;17(1):12-18.

Teingtham K., La Borde N.D. Is double haploid production in sorghum impossible? Int. J. Appl. Sci. Technol. 2017;10:4:247-256.

Acknowledgments. This study was supported in the framework of the Target Financing Program of the Science Committee of the Ministry of Education and Science of the Republic of Kazakhstan by project no. BR05236302.

Conflict of interest. The authors declare no conflict of interest. 


\title{
Role of genes involved in lignin biosynthesis in flax response to Fusarium oxysporum
}

\author{
R.O. Novakovskiy ${ }^{1 *}$, G.S. Krasnov ${ }^{1}$, T.A. Rozhmina ${ }^{1,2}$, L.P. Kudryavtseva ${ }^{2}$, A.A. Zhuchenko ${ }^{2,3}$, E.N. Pushkova ${ }^{1}$, L.V. Povkhova ${ }^{1,4}$, \\ P. Kezimana ${ }^{1,5}$, A.A. Dmitriev ${ }^{1}$, N.V. Melnikova ${ }^{1}$
}

\author{
${ }^{1}$ Engelhardt Institute of Molecular Biology, Russian Academy of Sciences, Moscow, Russia \\ ${ }^{2}$ Federal Research Center for Bast Fiber Crops, Torzhok, Russia \\ ${ }^{3}$ All-Russian Horticultural Institute for Breeding, Agrotechnology and Nursery, Moscow, Russia \\ ${ }^{4}$ Moscow Institute of Physics and Technology, Dolgoprudny, Russia \\ ${ }^{5}$ Peoples' Friendship University of Russia (RUDN University), Moscow, Russia
}

DOI 10.18699/ICG-PlantGen2019-26

(c) Autors, 2019

* e-mail: Olegovich46@mail.ru

\begin{abstract}
Flax (Linum usitatissimum L.) is an important crop used in various industries. Fusarium oxysporum is the causative agent of Fusarium wilt, and this disease is the most harmful for flax. The most effective way to control this pathogen is to develop resistant varieties. The mechanisms of flax resistance to $F$. oxysporum are still unclear. In our work, we analyzed the data obtained by transcriptome sequencing of resistant and susceptible flax varieties grown under control conditions and after inoculation with $F$. oxysporum. We evaluated expression alterations of $C C R, C C O A O M T, C O M T$, and $4 C L$ gene families, which are involved in lignin biosynthesis, and revealed their significant upregulation in flax varieties in response to F. oxysporum.
\end{abstract}

Key words: flax; Linum usitatissimum; resistant cultivars; Fusarium oxysporum; RNA-Seq; transcriptome; CCR; CCOAOMT; COMT; $4 \mathrm{CL}$.

\section{Introduction}

Flax (Linum usitatissimum L.) is a crop that is a source of fiber and flaxseed (Singh et al., 2011; Goyal et al., 2014). Fusarium oxysporum f. sp. lini is the most harmful pathogen that decreases the quality of flax products (Rashid, 2003). The molecular mechanisms of the resistance of L. usitatissimum to $F$. oxysporum are still unclear, and the search for genes involved in the response of flax to the pathogen is the main purpose of the study. The involvement of proteins associated with pathogenesis in the flax response to $F$. oxysporum infection was revealed (Wrobel-Kwiatkowska et al., 2004; Wojtasik et al., 2014; Galindo-Gonzalez, Deyholos, 2016).

In response to the infection with the fungus Fusarium oxysporum, cell walls are lignified. Many genes are involved in the process of lignin biosynthesis, including cinnamoyl CoA reductase $(C C R)$, caffeoyl-CoA O-methyltransferase (CCoAOMT), catechol-O-methyltransferase (COMT), 4-coumaric acid: coenzyme A ligase $(4 C L)$. Each of these genes has homologs located on different chromosomes (Wojtasik et al., 2015; Boba et al., 2016; Wojtasik et al., 2016).

Plants with reduced regulation of these genes were less likely to tolerate the disease caused by F. oxysporum (Hano et al., 2006). In the present work, we evaluated expression alterations of $C C R, C C O A O M T, C O M T$, and $4 C L$ gene families under $F$. oxysporum infection using RNA-Seq data for resistant and susceptible flax varieties. This made it possible to determine the general trends in the response of Linum usitatissimum to the pathogen and genotype-specific changes in expression.

\section{Materials and methods}

As the experimental material, resistant (3896 and 'Dakota') and susceptible (TOST and AP5) flax varieties were used, as well as their stable $\mathrm{BC}_{2} \mathrm{~F}_{5}$ hybrids $(3896 \times \mathrm{AP5}$, recurrent parent AP5, and 'Dakota' $\times$ AP5, recurrent parent AP5). Seed material was provided by the Institute for Flax (Torzhok, Russia). For seed sterilization, rinsing with $70 \%$ ethanol for 1 minute and $1 \%$ sodium hypochlorite for 20 minutes were used. For growing flax plants from seeds, Murashige-Skoog medium poured into $15-\mathrm{ml}$ glass tubes was used.

The tubes with the medium and seeds were incubated at $22{ }^{\circ} \mathrm{C}$ with a photoperiod of 16-hour day/8-hour night for seven days. After a week, half of the samples were infected with the most pathogenic isolate, $F$. oxysporum isolate \#39, from the phytopathogen collection of the Institute for Flax. The second half of the non-infected plants acted as the control. After 48 hours, 240 plants were removed from the tubes and the tips of the roots were collected followed by freezing in liquid nitrogen. RNA was then extracted from plant pools of 10-12 plants using the RNeasy Plant Mini Kit (Qiagen, USA).

As a result, we obtained 24 samples of RNA: TOST, AP5, 3896, 'Dakota', $3896 \times$ AP5, 'Dakota' $\times$ AP5 under control and experimental conditions in duplicate. Using an Agilent 2100 bioanalyzer (Agilent Technologies, USA) and a Qubit 2.0 fluorometer (Life Technologies, USA), we evaluated the quality and quantity of the RNA obtained. To obtain a cDNA library, a TruSeq Stranded Total RNA Sample Prep Kit (Illumina, USA) was used. Sequencing was performed on NextSeq500 (Illumina) with 80-nucleotide paired-end reads. The Trimmomatic program (Bolger et al., 2014) was used for trimming reads. Then, filtration was carried out with the Fusarium oxysporum reference genome and the rest reads were mapped to the L. usitatissimum reference genome (GenBank assembly GCA_000224295.2) using STAR (Dobin et al., 2013) and quantified using BEDTools (Quinlan and Hall, 2010).

The CPM values were determined for each gene for each variety under control and infection conditions. After that, the $\log$ (CPM Fusarium / CPM control) value was calculated for each variety and the $\mathrm{BC}_{2} \mathrm{~F}_{5}$ population. This work was done 
Table 1

Expression alterations of $C C R, C C O A O M T, C O M T, 4 C L$ genes in flax cultivars and populations with diverse resistance to $F$. oxysporum

\begin{tabular}{|c|c|c|c|c|c|c|}
\hline \multirow{3}{*}{ Gene } & \multicolumn{6}{|c|}{$\log (C P M$ Fusarium/CPM control) } \\
\hline & \multicolumn{2}{|c|}{ Susceptible genotypes } & \multicolumn{4}{|c|}{ Resistant genotypes } \\
\hline & TOST & AP5 & 3896 & Dakota & $3896 \times$ AP5 & Dakota $\times$ AP5 \\
\hline$C C R(\mathrm{Lu} 4)$ & 0.12 & 0.17 & 0.31 & 0.36 & 0.09 & 0.36 \\
\hline CCR (Lu5) & 0.47 & 0.45 & 1.01 & 0.60 & 0.50 & 0.70 \\
\hline CCoAOMT (Lu6) & 0.50 & 0.53 & 1.27 & 0.40 & 0.46 & 0.77 \\
\hline CCOAOMT (Lu8) & 1.03 & 1.28 & 1.74 & 1.42 & 0.90 & 1.39 \\
\hline COMT (Lu1) & 1.41 & 1.41 & 1.81 & 1.36 & 0.69 & 1.35 \\
\hline COMT(Lu14) & 1.17 & 1.36 & 1.44 & 1.18 & 0.61 & 1.42 \\
\hline $4 C L(\mathrm{Lu} 2)$ & 0.28 & 1.04 & 0.78 & 1.11 & 0.38 & 0.82 \\
\hline $4 C L(\mathrm{Lu} 4)$ & 0.06 & -0.17 & 0.20 & 0.21 & -0.06 & -0.28 \\
\hline $4 C L$ (Lu5) & 0.09 & 0.23 & 0.92 & 0.19 & 0.32 & 0.63 \\
\hline $4 C L(\operatorname{Lu} 13)$ & 0.99 & 0.92 & 1.38 & 1.24 & 0.49 & 1.21 \\
\hline
\end{tabular}

using the equipment of the Genome Center of the Engelhardt Institute of Molecular Biology (http://www.eimb.ru/rus/ckp/ ccu_genome_c.php).

\section{Results and discussion}

To identify genes in the CCR, CCOAOMT, COMT, and $4 C L$ families, we took the sequences of these genes and used NCBI BLAST to find homologous sequences in the reference Linum usitatissimum genome. As a result, we identified the numbers of homologs of the genes on different chromosomes: 2 for $C C R, 2$ for CCOAOMT, 2 for COMT, and 4 for $4 C L$. To denote the chromosome number, we used the designation "(Lu\#)", where "\#" is the number of the chromosome according to the reference assembly.

For each gene, the expression was evaluated on the basis of RNA-Seq data obtained for six varieties and populations of flax that were grown under control conditions or with $\mathrm{Fu}$ sarium oxysporum isolate \#39 (Dmitriev et al., 2017). Results are shown in Table 1, where log (CPM Fusarium/CPM control) values for each gene studied are presented for resistant (3896, 'Dakota', $3896 \times$ AP5, 'Dakota' × AP5) and susceptible (TOST and AP5) genotypes under control conditions and 48 hours after inoculation with Fusarium oxysporum.

A statistically significant increase in expression in flax varieties under $F$. oxysporum infection compared to the control conditions was observed for all studied genes except $4 C L$ (Lu4) ( $p<0.05$, Mann-Whitney test). The most significant increase in expression was detected for CCOAOMT (Lu8), COMT (Lu1), COMT (Lu14), and 4CL (Lu13) genes - more than 2-fold upregulation on average. There were no statistically significant differences in expression alterations between resistant and susceptible genotypes.

\section{Conclusions}

The search for genes with diverse expression changes in resistant and susceptible genotypes under Fusarium oxysporum infection is important for identifying resistance genes. In the present work, we used our RNA-Seq data for flax genotypes resistant (3896, 'Dakota', $3896 \times$ AP5, 'Dakota' $\times$ AP5) and susceptible (TOST and AP5) to F. oxysporum in control conditions or 48 hours after inoculation with $F$. oxysporum to evaluate the expression of 10 homologs of the CCR, CCOAOMT, $C O M T$, and $4 C L$ genes involved in lignin biosynthesis. We revealed that 9 of these genes were characterized by upregulation upon infection with the pathogen in all the genotypes studied. However, no genotype-specific changes were observed. The results of this work indicate the involvement of the $C C R$, $C C O A O M T, C O M T$, and $4 C L$ gene families in the response to Fusarium oxysporum infection. Our data also contribute to the understanding of the role of the CCR, CCOAOMT, COMT, and $4 C L$ genes in the stress response and resistance.

\section{References}

Boba A., Kostyn K., Kostyn A. et al. Methyl Salicylate Level Increase in Flax after Fusarium oxysporum Infection Is Associated with Phenylpropanoid Pathway Activation. Front Plant Sci. 2016;7:1951. DOI 10.3389/fpls.2016.01951.

Bolger A.M., Lohse M., Usadel B. Trimmomatic: a flexible trimmer for Illumina sequence data. Bioinformatics. 2014;30(15):2114-2120. DOI 10.1093/bioinformatics/btu170.

Dmitriev A.A., Krasnov G.S., Rozhmina T.A. et al. Differential gene expression in response to Fusarium oxysporum infection in resistant and susceptible genotypes of flax (Linum usitatissimum L.). BMC Plant Biol. 2017;17(Suppl 2):253. DOI 10.1186/s12870-017-1192-2.

Dobin A., Davis C.A., Schlesinger F. et al. STAR: ultrafast universal RNA-seq aligner. Bioinformatics. 2013;29(1):15-21. DOI 10.1093/ bioinformatics/bts635.

Galindo-Gonzalez L., Deyholos M.K. RNA-seq Transcriptome Response of Flax (Linum usitatissimum L.) to the Pathogenic Fungus Fusarium oxysporum f. sp. lini. Front Plant Sci. 2016;7:1766. DOI $10.3389 /$ fpls.2016.01766.

Goyal A., Sharma V., Upadhyay N. et al. Flax and flaxseed oil: an ancient medicine \& modern functional food. J Food Sci Technol. 2014;51(9):1633-1653. DOI 10.1007/s13197-013-1247-9.

Hano C., Addi M., Bensaddek L. et al. Differential accumulation of monolignol-derived compounds in elicited flax (Linum usitatissi- 
mum) cell suspension cultures. Planta. 2006;223(5):975-989. DOI 10.1007/s00425-005-0156-1.

Quinlan A.R., Hall I.M. BEDTools: a flexible suite of utilities for comparing genomic features. Bioinformatics. 2010;26(6):841-842. DOI 10.1093/bioinformatics/btq033.

Rashid K. Principal diseases of flax. Flax, CRC Press: 2003;92-123.

Singh K.K., Mridula D., Rehal J. et al. Flaxseed: a potential source of food, feed and fiber. Crit Rev Food Sci Nutr. 2011;51(3):210-222. DOI 10.1080/10408390903537241.

Wojtasik W., Kulma A., Boba A. et al. Oligonucleotide treatment causes flax beta-glucanase up-regulation via changes in gene-body methylation. BMC Plant Biol. 2014;14:261. DOI 10.1186/s12870-0140261-z.

Wojtasik W., Kulma A., Dyminska L. et al. Evaluation of the significance of cell wall polymers in flax infected with a pathogenic strain of Fusarium oxysporum. BMC Plant Biol. 2016;16:75. DOI 10.1186/s12870-016-0762-z.

Wojtasik W., Kulma A., Namysl K., et al. Polyamine metabolism in flax in response to treatment with pathogenic and non-pathogenic Fusarium strains. Front Plant Sci. 2015;6:291. DOI 10.3389/fpls. 2015.00291 .

Wrobel-Kwiatkowska M., Lorenc-Kukula K., Starzycki M. et al. Expression of beta-1,3-glucanase in flax causes increased resistance to fungi. Physiological Mol. Plant Pathol. 2004;65(5):245-256. DOI 10.1016/j.pmpp.2005.02.008.

Acknowledgements. This work was financially supported by the Russian Science Foundation, grant 16-16-00114.

Conflict of interest. The authors declare no conflict of interest. 


\section{Genetic and Epigenetic Mechanisms of Plant \\ Resistance to Abiotic Stresses}




\title{
Epigenetic mechanisms of the karyogenomic system of mature wheat germ derived under conditions of cold stress
}

\author{
E.A. Ivanova*, G.Kh. Vafina \\ Ufa Institute of Biology UFIC RAS, Ufa, Russia
}

DOI 10.18699/ICG-PlantGen2019-27

(c) Autors, 2019

*e-mail: fiona_belobor@mail.ru

\begin{abstract}
In the present work, it was shown that in the process of initiating the growth morphogenesis of mature wheat germ spring (Artyomovka) and the winter derived from it, (Mironovskaya 808), the mechanisms of spatial-temporal reorganization of chromatin structures with the participation of the $A r g-X$ proteolysis function. The features of the proteomic dynamics of bioheteropolymer structures (nucleoplasm, chromatin, nuclear matrix) of interphase nuclei in periods $\mathrm{G}_{1}(\mathrm{Oh} \rightarrow 3 \mathrm{~h} \rightarrow 6 \mathrm{~h}$ ) revealed a change in the localization of the $A r g-X$ zones of proteolytic activity in histones and nonhistones, which can to be associated with changes in the density of tension and changes in the structure of chromatin and to represent the epigenetic mechanisms of the karyogenic system of mature wheat germ, derived under conditions of cold stress.

Key words: Triticum aestivum L.; cold stress; cell nucleus; nucleoplasm; chromatin; nuclear matrix; non-histones; histones; Arg- $X$ (arginine-protein)-processing.
\end{abstract}

\section{Introduction}

According to the priority directions in the study of agricultural plants put forward in 2011 by EPIC, an international consortium of plant epigenetics for the next decade, included a paragraph of the need to understand the molecular basis of the interaction of genotype and environment, change the characteristics of plants in different conditions (Epic Planning Committee, 2012). It is believed that "the chromatin matrix is a physiologically important substrate on which remodeling and the transcription mechanism are deployed" (Allis et al., 2007). The most significant discoveries currently include finding out the location of chromosomes in interphase nuclei and that their structure is controlled by both genetic and environmental factors (Pawlowski, 2010; Tiang, et al., 2012). In order to understand the basic features of these patterns, effective information and computing technologies are being developed. In some of these works, their block-modular arrangement is virtually distinguished, where the blocks of gene networks interconnected by signaling molecules form a hierarchical structure. Currently, methodological progress has greatly advanced the understanding of the molecular-genetic organization of the interphase nucleus. It becomes obvious that the functional dynamics of the domain topology of interphase chromatin is involved in controlling the regulation of various interrelated basic processes in certain regions of the nucleus. We assumed that one of the mechanisms in the reorganization of the chromatin matrix can perform $A r g-X$ protease processing. This assumption is based on the fact that the chromatin of the nucleus is rich in arginine, and, of all the amino acids, only it is able to bind to certain purine and pyrimidine bases of DNA. The purpose of this work was to examine the karyogenomic analysis of the localization of $\operatorname{Arg}-X$ processing in topologically associated super-blocks of the hexaploid system of interphase chromatin in mature wheat germ adapted to cold stress.

\section{Mateials and methods}

The object of the study was the seeds of wheat superelite (Triticum aestivum L.) varieties: Artemovka (spring) and derived from it, Mironovskaya 808 (winter), obtained from the collection of the All-Russian Institute of Plant Industry named. N.I. Vavilova. Experimental work was carried out on the basis of our own patents: 1) on the assessment of the morphophysiological state of the nucleated embryos, 2) cell nuclei isolated from them and 3) supramolecular structures, and 4) non-histone ( $\mathrm{Ngb}$ ) and histone proteins, in which, 5) lacalization of $A r g-X$ protease processing was revealed. The methodical part of the work is presented in detail in the articles (Ivanova et al., 2014; 2015; Ivanova, 2017). The condition of air-dry seed and embryo (in a state of biological rest), we conditionally took for $0 \mathrm{~h}$. Seed soaking was carried out for 3 hours. The end of this period is marked as $3 \mathrm{~h}$. From air-dried seeds $(0 \mathrm{~h})$, swollen $(3 \mathrm{~h})$ and germinated for $6 \mathrm{~h}$ initiated to grow, separated from the endosperm, cell nuclei were isolated from which supramolecular structures were fractionated into a "labile chromatin" nucleoplasm (Np), chromatin fragile (Chr-I) and firmly (Chr-II) associated with the nuclear matrix (NM) and the NM itself. The $A r g-X$ protease activity in the suprastructures of cell nuclei was assessed by the cleavage of the $\operatorname{Arg}-X$ bonds in the arginine-enriched protein, protamine Salmine-A-I ("Merk").

\section{Results and discussion}

Currently, some progress has been made in the study of chromatin structure on the scale of a whole nucleus. In this paper, the study of the features of the structural reorganization of the interphase chromatin $\mathrm{G}_{1}$ phase of the cell cycle of spring and winter wheat was conducted against the background of the formed physiological features of the seeds of their mature embryos. It is known that the winter variety Mironovskaya 808 was derived by the method of multiple-group selection 
of highly productive, morphologically aligned homogeneous plants from the Artemovka variety (with exact indication of the best families, minimum temperature on the soil surface during wintering over 7 years). The result was that, up to the present, the Mironovskaya 808 is considered a masterpiece of world selection.

There are three regulatory levels in eukaryotic chromatin or genome. The first presents three classes of genetic elements that regulate gene blocks: 1) LCR (locus control regions); 2 ) enhancers, promoters; 3 ) insulators. The second level is chromatin, where regulation is carried out by modifying the crustal histones. At this level, the ATP-dependent chromatin remodeling system and the corresponding enzymes are involved. The first and second levels are interrelated. The third is the level of organization of the interphase core - 3D. It is proved that the nuclear level chromosomes are not randomly located inside the nucleus, each of them occupies a certain territory. It is noteworthy that unstructured amino-terminal tails that carry the guanidine group of arginine-enriched $(\mathrm{H} 3+\mathrm{H} 4)$ and moderately lysine-enriched $(\mathrm{H} 2 \mathrm{~A}+\mathrm{H} 2 \mathrm{~B})$ histones that make up the nucleosome protrude from the nucleosome core. These tails undergo active modification and internucleosomal interactions.

In space-time intervals, heteropolymer blocks were selected on the protein surface of which the interphase chromatin reorganization occurred and the chromatin matrix conformation changed, with the participation of the $\operatorname{Arg}-X$ protease system responsible for protein folding. It is possible that the foregoing is associated with epigenetic mechanisms under the influence of environmental factors.

The $\operatorname{Arg}-X$ protease system of Ngb and histone blocks of supramolecular structures is silent in the suprablocks of the total karyogenomic chromatin matrix of winter wheat mature germ nuclei during $0 \mathrm{~h}$ physiological state.However, in the process of seed swelling (3h), $A r g-X$ of protease-sensitive zones in the linker histone- $\mathrm{HI}$ is exposed at the level of the nuclear matrix and in the Ngb chromatin of unbroken (Chr-I) with NM.

During the period of morphogenetic processes activation in total chromatin suprablocks (6h), Ngb exhibits enhanced exposure at the NM, Chr-I, Chr-II level, as well as in the core histones $\mathrm{H} 2 \mathrm{~A}+\mathrm{H} 2 \mathrm{~B}$ of the nuclear matrix; in contrast to the spring variety Artyomovka, where the relatively uniform exposure of $\mathrm{Arg}-\mathrm{X}$ activity of the $\mathrm{H} 3+\mathrm{H} 4$ histone core occurs only in the Hn nucleoplasm $(0 \mathrm{~h} \rightarrow 3 \mathrm{~h} \rightarrow 6 \mathrm{~h})$. Nucleoplasm performs active nuclear-cytoplasmic relations (due to signaling systems entering the nucleus) and is rich in chaperones that participate in the assembly of nucleosomes. It is possible that the labile chromatin system is the physiological basis of functioning in the spring wheat variety. $A r g-X$ manifestation of nuclear activity at the NM level is explained by the fact that the nuclear matrix is considered as an active dynamic structure that participates in the formation of large enzymatic and regulatory complexes controlling the topology and DNA function.

Not only purely cognitive, but also practical results for biotechnology are expected from progress in understanding morphogenesis. Perhaps the molecular-genetic mechanisms of adaptation of winter wheat are associated with the organization of the nuclear matrix, where $A r g-X$ and hypersensitive sites are formed. Maybe this: LCR - locus control regions. As it is known, an organism is an integrated network of biochemical processes that are in constant dynamics and change as a result of exposure to internal and external conditions. In this regard, supramolecular descriptions of morphogenetic processes are valuable because they already integrate the interactions of many macromolecules and the mechanisms of epigenetic regulation.

\section{Conclusions}

In the present work, it was shown that in the process of initiating the growth morphogenesis of the mature wheat germs of the spring Artyomovka and the winter derived from it, Mironovskaya 808, the mechanisms of spatial-temporal reorganization of chromatin structures with the participation of the $A r g-X$ proteolysis function. Features of the proteomic dynamics of bioheteropolymer structures (nucleoplasm-labile chromatin, fragile and strongly bonded with NM, and also NM itself) interphase nuclei, in periods $\mathrm{G}_{1}(0 \mathrm{~h} \rightarrow 3 \mathrm{~h} \rightarrow 6 \mathrm{~h})$ of the cell cycle phase, revealed a change in the localization of the $\operatorname{Arg}-X$ zones of proteolytic activity in histones and nonhistones, which may be associated with changes in the density of tension and changes in the structure of chromatin and represent the epigenetic mechanisms of the karyogenomic system of mature wheat germ, derived under conditions of cold stress.

\section{References}

Allis C.D., Jenuwein T., Reinberg D. Epigenetics. 2007. Cold Spring Harbor, New York, USA.

Ivanova E.A. $\operatorname{Arg}-X$ proteo-processing as model system for organization of karyogenomics Interphase chromatin of mature germs of wheats, formed in the conditions of cold stress. J. Stress Physiol Biochemistry. 2017;13(4);65-73 (In Russian).

Ivanova E.A., Vafina G.H., Ivanov R.S. Analysis of $A r g-X$ proteasesensitive sites localization in the dynamics of suprastructures of interphase chromatin during induction of mature spring and winter wheat growth morphogenesis. Physiol Plant Genet (Kiev). 2014; 46(3):202-211.

Ivanova E.A., Vafina G.H., Ivanov R.S. Initial morphogenetic features of proteome of suprastructures of interphase chromatin for germination of mature germs in conditions of adapting to winter in wheat. J. Stress Physiol Biochemistry. 2015;11(4):29-42. (In Russian).

Pawlowski W.P. Chromosome organization and dynamics in plants. Plant Biol. 2010;13:640-645. DOI 10.1016/j.pbi.2010.09.015.

The EPIC Planning Committee. Reading the Second Code: Mapping Epigenomes to Understand Plant Growth, Development, and Adaptation to the Environment. The Plant Cell. 2012;24:2257-2261. DOI 10.1105/tpc.112.100636.

Tiang C.L., He Y., Pawlowski W.P. Chromosome organization and dynamics during interphase, mitosis, and meiosis in plants. Plant Physiol. 2012;158:26-34. DOI 10.1104/pp.111.187161.

Acknowledgements. The work is supported and performed as part of the state assignment of the Ministry of Education and Science of Russia No. 075-00326-19-00 on the topic No. R \& D of AAAA-A18-118022190104-7.

Conflict of interest. Authors declare no conflict. 


\title{
Comparative characteristic of near-isogenic lines differing by the $B l p$ locus in respect to abiotic stress resistance
}

\author{
A.Y. Glagoleva ${ }^{1 *}$, O.Y. Shoeva ${ }^{1}$, E.K. Khlestkina ${ }^{1,2}$ \\ ${ }^{1}$ Institute of Cytology and Genetics, SB RAS, Novosibirsk, Russia \\ ${ }^{2}$ N.I. Vavilov All-Russian Research Institute of Plant Genetic Resources (VIR), St. Petersburg, Russia
}

DOI 10.18699/ICG-PlantGen2019-28

(c) Autors, 2019

* e-mail: glagoleva@bionet.nsc.ru

\begin{abstract}
The black color of seeds is a ubiquitous trait among plants. Black pigments are caused by polyphenolic polymeric compounds called melanins. The study of plant melanin is hampered because of its complex structure and chemical inertness. At the same time, an adaptive role of black pigments in unfavorable environments has been previously demonstrated. The aim of the current work was to compare near-isogenic barley lines carrying different alleles of the Blp locus controlling accumulation of melanins in the hull and grain pericarp under salinity, drought and cadmium toxicity. It was demonstrated that the lines did not differ in germination rate while they responded differently to stress exposures at the seedling stage. The pronounced decline in root and shoot length in the black-spiked line compared with the yellow-spiked one was observed under drought stress conditions, while under salinity and cadmium toxicity, slightly increased values of the relative shoot length of the black- and yellow-spiked lines were observed, respectively. The data obtained demonstrated that neither the Blp gene nor black pigmentation controlled by this gene confer any advantages on barley plants at the seedling stage under stress conditions tested.
\end{abstract}

Key words: melanin; grain; seedlings; germination; salinity; drought; cadmium toxicity.

\section{Introduction}

The black color of seeds associated with melanins has been described in many plant species (Britton, 1983). These pigments are formed by oxidation of phenolic compounds to quinones by polyphenol oxidases followed by their polymerization to black high molecular-weight polymers (Nicolas et al., 1994). Melanins accumulating in covering grain tissues reportedly strengthen seed envelopes and protect in this way the developing embryo against mechanical injury, affecting seeds' longevity and germination rate as well as confer an increased resistance on plants under pathogen invasions and unfavorable conditions (Rogers, Kreitner 1983; Duran, Retamal, 1989; Debeaujon et al., 2002; Downie et al., 2003; Loskutov et al., 2016).

In barley (Hordeum vulgare L.), the black-spiked genotypes with melanins accumulated in hull and grain pericarp were described (Harlan, 1914). The trait is under the control of the Blp locus, which was mapped on chromosome $1 \mathrm{H}$ (Costa et al., 2001). To date, the locus has been narrowed down to 21 genes, but the candidate gene has not been identified yet (Long et al., 2019).

Black-seeded barleys are considered to be more drought and cold tolerant, more vigorous at the early stages of growth, more prostrate, taller, earlier in maturity than yellow-seeded types (Ceccarelli et al., 1987) as well as more resistant to Fusarium diseases (Choo et al., 2005, 2015). Although the trait has agricultural importance, the precise chemical structure of plant melanins is far from being clear (Jana, 2014), as well as the genes associated with the biosynthesis of black pigments are still remain unknown. To determine the specific genes for melanin biosynthesis, it is important to fully understand features of the trait.

In the current study, a comparative analysis of near-isogenic lines (NILs) carrying different alleles of the Blp locus was performed to determine role of the Blp locus in grain germination as well as in the plant response to abiotic stresses at the seedlings stage.

\section{Materials and methods}

\subsection{Plant material}

The barley NILs i:BwBlp (NGB20470) with the black color of seeds and their parental cultivar 'Bowman' (NGB22812) characterized by uncolored seeds were used in the study. The lines were provided by the Nordic Gene Bank (NGB, www. nordgen.org) and previously genotyped by microsatellite markers. The only chromosome segment in $1 \mathrm{HL}$ was different in the lines (Druka et al. 2011; Shoeva et al., 2016).

\subsection{Germination test}

To compare the melanins impact on germination, the seeds were placed on filter paper moistened with distilled water and kept for $48 \mathrm{~h}$ at $4{ }^{\circ} \mathrm{C}$ without light to synchronize germination. Thereafter the seeds were transferred to a RUMED ${ }^{\circledR}$ climate chamber (Rubarth Apparate $\mathrm{GmbH}$ ) at $20^{\circ} \mathrm{C}$ and $12 \mathrm{~h} \mathrm{light} / 12 \mathrm{~h}$ darkness daily cycle. The start of germination, appearance of roots and shoots were observed. The experiment was performed in three replicates for each genotype, with one hundred seeds per replica. The seeds were harvested after the field vegetation season of 2016 and stored for two years at room temperature until tested.

\subsection{Stress exposure}

The comparative study of the NILs was performed at the seedling stage under laboratory conditions modeling salinity, drought and cadmium toxicity. Salt stress was induced by $\mathrm{NaCl}$ at eight different concentrations varying from 10 to $150 \mathrm{mM}$. To model the drought stress, the $15,20,30$, 
and $40 \%$ solutions of PEG6000 were used. Six concentrations of $\mathrm{CdCl}_{2}$ varying from 0.3 to $20 \mathrm{mM}$ were used in the experiment with cadmium stress. The seeds were placed on filter paper moistened with distilled water and kept for $48 \mathrm{~h}$ at $4{ }^{\circ} \mathrm{C}$ without light to synchronize germination. Thereafter the seeds were transferred to a RUMED ${ }^{\circ}$ climate chamber at $20^{\circ} \mathrm{C}$ and $12 \mathrm{~h} \mathrm{light} / 12 \mathrm{~h}$ darkness daily cycle. After $24 \mathrm{~h}$, the seeds were exposed to the corresponding stress treatment. Distilled water was added to the control. The experiment was performed in three replicates for each concentration and each genotype, with fifteen seeds per replica. The root and shoot lengths of each seedling were measured at the fifth day after germination. The significance of differences between the treated and control samples of the NILs was assessed using Student's $t$-test, taking $p \leq 0.05$ as significant. Changes in root and shoot lengths were calculated as follows: length under stress condition/length in control*100\%.

\section{Results and discussion}

\subsection{Germination test}

We have observed an earlier germination start in the $\mathrm{i}: \mathrm{Bw} B l p$ line compared to 'Bowman' $(p \leq 0.05)$. However, there were no significant differences between NILs in root and shoot appearance $(p>0.05)$, and subsequently differences in germination rate between the lines were not observed.

An effect of black pigments on seed germination had been reported previously. For instance, although the seed coat structure (epidermis, macrosclereid cells, pigmented cells and aleurone-like cells) did not differ significantly between red and black seeds of wild mustard, the germination of red seeds was higher than that of black seeds (Duran, Retamal, 1989). Tomato mutants accumulating melanins in testa displayed poor germination rates on both water and gibberellin compared with the wild-type seeds without the pigments (Downie et al., 2003). Although tests for germination rates performed on two-year-old grains did not reveal any differences between yellow and black grains of barley, the results did not deny the possibility that some differences could be detected after a longer period of dormancy. A similar germination rate of black and yellow grains allows using them in comparative studies under stress conditions.

\subsection{Stress exposure}

Osmotic stress was induced by different concentrations of $\mathrm{NaCl}$ and PEG6000. From among the concentrations tested, the ones that caused a significant reduction in root and shoot lengths compared with the control and were low enough to reveal differences between the NILs were selected for further experiments. The following concentrations were chosen: 50, 100 and $150 \mathrm{mM} \mathrm{NaCl}$ and 20, 30 and $40 \%$ PEG6000.

In the salt stress experiment, we observed that treatment by $\mathrm{NaCl}$ mostly affected the development of roots rather than shoots in both NILs (Figure 1, $a$ ). The root length varied from $40 \%$ to $70 \%$ relative to the control, while the shoot length did not fall below $70 \%$ relative to the control. We have revealed slight differences between the NILs in shoot length with an increased values in the $\mathrm{i}: \mathrm{Bw} B l p$ line at all salt concentrations tested, but not in root length.
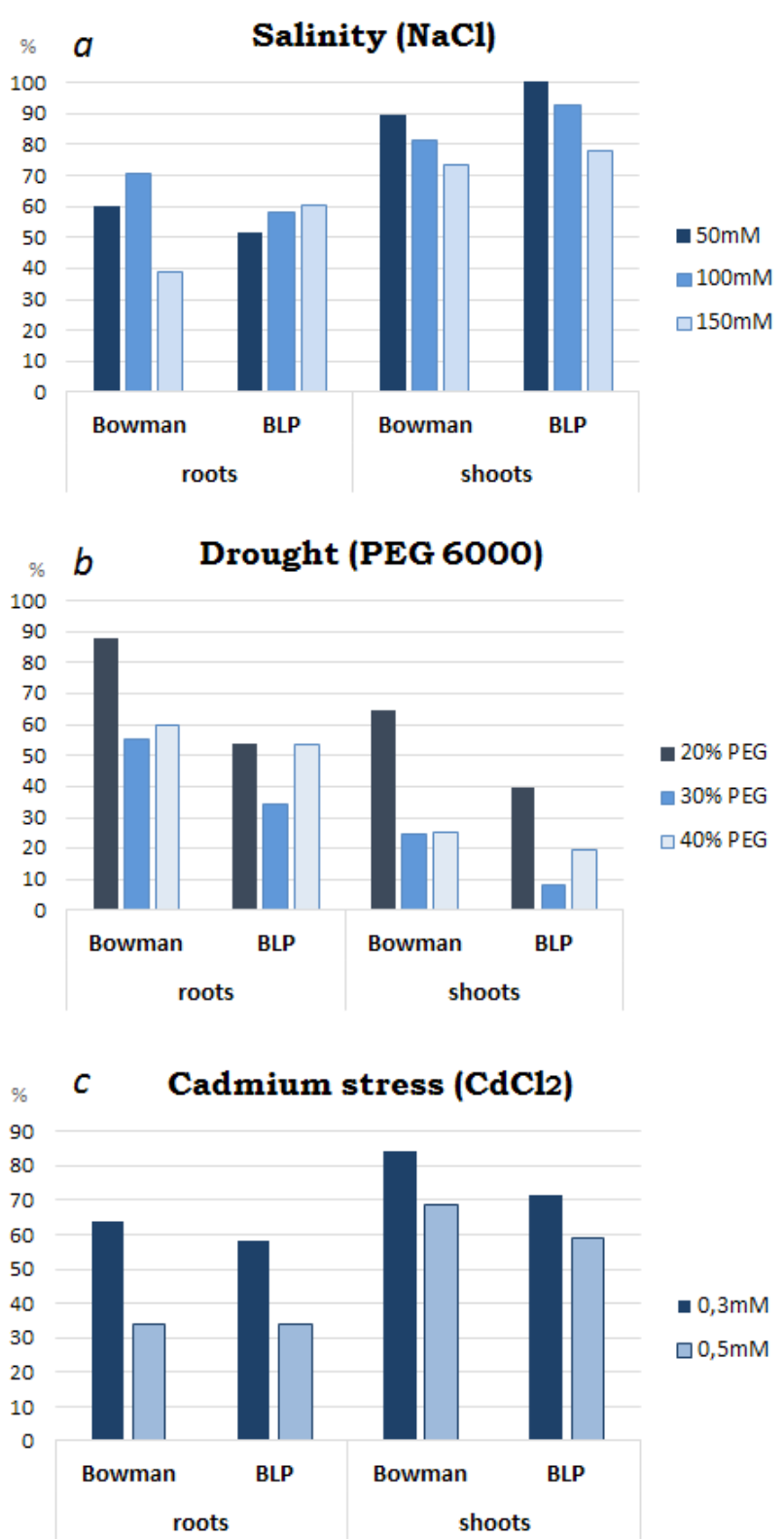

Figure 1. Changes in shoot and root length of 'Bowman' and $\mathrm{i} ; \mathrm{Bw} B / p$ (BLP) line under salinity (a), drought (b) and cadmium (c) relative to the control (\%).

In contrast to osmotic stress caused by $\mathrm{NaCl}$, PEG treatments affected mostly shoot growth in both NILs rather than roots (Figure 1,b). At 30 and $40 \%$ PEG concentrations, the shoot length was only $10-30 \%$ of the control, while the root length reached about $50 \%$ of the control in both 'Bowman' and i:BwBlp. Probably, there are different osmotic stress responsive mechanisms in the different parts of seedlings. A pronounced decline in seedling length in the i:BwBlp line compared with 'Bowman' was observed at all concentrations of PEG6000 tested with more drastic differences at $20 \%$ and $30 \%$ PEG, while under $40 \%$ they were not so strong.

To test the involvement of the Blp locus in cadmium stress resistance, 0.3 and $0.5 \mathrm{mM} \mathrm{CdCl}$ solutions were selected from among all the concentrations tested. Cadmium, similar 
to $\mathrm{NaCl}$, mostly affected root length rather than shoots under the same treatment conditions (Figure $1, c$ ). We observed a slight increment in relative root and shoot length in 'Bowman' compared to $\mathrm{i}: \mathrm{BwBlp}$. However, there were no significant differences between the NILs in absolute values.

The pigments present in seed envelopes can reportedly grant some advantages to plants under stress conditions. For instance, in comparative studies of the wheat NILs developed for grain anthocyanin pigmentation, it was demonstrated that at the seedling stage anthocyanins present in wheat grain positively affected roots elongation under drought conditions in comparison with non-pigmented line (Shoeva et al., 2017). The data obtained here demonstrated that neither the Blp gene nor black pigmentation controlled by this gene confer any advantages on barley plants at the seedling stage under stress conditions tested. Moreover, a pronounced decline in seedling length in the black-spiked line compared with the yellow-spiked one under PEG treatment was detected. Similar, susceptibility to water deficiency during germination and emergence was observed in Iraqi local barley cultivar 'Black' compared to yellow-grained cultivars, but it developed resistance during vegetation growth and yield formation (Yassen, Al-Omary, 1994). The data allows assuming the presence of a gene linked to Blp conferring drought resistance on 'Bowman' plants as well as Iraqi local barley cultivar mentioned.

\section{Conclusions}

Substances present in grain tissue not only can affect their germination but can also confer increased resistance under biotic and abiotic stress conditions. Using a precise genetic model of near-isogenic lines, we did not detect any significant positive effect of the dominant allele of the Blp gene on barley seedling growth or development under salinity, drought and heavy metal toxicity. These findings allow us to suggest that the $B l p$ locus affects specifically the pigmentation of barley spike, while it has no effect on plant development at the seedling stage even under stress conditions. This feature of the $B l p$ locus should be taken into account in further studies aimed at revealing a potential candidate gene for $B l p$.

\section{References}

Britton G. The biochemistry of natural pigments. Cambridge University Press. Cambridge. 1983.

Ceccarelli S., Grando S., van Leur J.A.G. Genetic diversity in barley landraces from Syria and Jordan. Euphytica. 1987;36:389-405. DOI 10.1007/BF00041482.

Choo T.M., Vigier B., Ho K.M., Ceccarelli S., Grando S., Franckowiak J.D. Comparison of black, purple, and yellow barleys. Genet. Resour. Crop. Evol. 2005;52(2):121-126. DOI 10.1007/s10722-0033086-4.

Choo T.-M., Vigier B.J., Savard M.E., Blackwell B.A., Martin R.A., Wang J.M., Yang J., Abdel-Aal E.-S.M. Black barley as a means of mitigating deoxynivalenol contamination. Crop Sci. 2015;55:10961103. DOI 10.2135/cropsci2014.05.0405.
Costa J.M., Corey A., Hayes P.M., Jobet C., Kleinhofs A., KopischObusch A., Kramer S.F., Kudrna D., Li M., Riera-Lizarazu O., Sato K., Szucs P., Toojinda T., Vales M.I., Wolfe R.I. Molecular mapping of the Oregon Wolfe Barleys: a phenotypically polymorphic doubled-haploid population. Theor. Appl. Genet. 2001; 103(2-3):415-424. DOI 10.1007/s001220100.

Debeaujon I., Léon-Kloosterziel K.M., Koornneef M. Influence of the testa on seed dormancy, germination, and longevity in Arabidopsis. Plant Physiol. 2000;122:403-414. DOI 10.1104/pp.122.2.403.

Downie A.B., Zhang D., Dirk L.M., Thacker R.R., Pfeiffer J.A., Drake J.L., Levy A.A., Butterfield D.A., Buxton J.W., Snyder J.C. Communication between the maternal testa and the embryo and/ or endosperm affect testa attributes in tomato. Plant Physiol. 2003; 133:145-160. DOI 10.1104/pp.103.022632.

Druka A., Franckowiak J., Lundqvist U., Bonar N., Alexander J., Houston K., Radovic S., Shahinnia F., Vendramin V., Morgante M., Stein N., Waugh R. Genetic dissection of barley morphology and development. Plant Physiol. 2011;155:617-627. DOI 10.1104/pp. 110.166249.

Duran J.M., Retamal N. Coat structure and regulation of dormancy in Sinapis arvensis L. seeds. J Plant Physiol. 1989;135:218-222. DOI 10.1016/S0176-1617(89)80180-4.

Harlan H.V. Some distinctions in our cultivated barleys with reference to their use in plant breeding. US Dept. of Agriculture. 1914;137:38.

Jana B.K., Mukherjee S.K. Notes on the distribution of phytomelanin layer in higher plants - a short communication. J. Pharmaceutical Biol. 2014;4(3):131-132.

Long Z., Jia Y., Tan C., Zhang X.-Q., Angessa T., Broughton S., Westcott S., Dai F., Zhang G., Sun D., Xu Y., Li C. Genetic Mapping and Evolutionary Analyses of the Black Grain Trait in Barley. Front. Plant Sci. 2019;9:1921. DOI 10.3389/fpls.2018.01921.

Loskutov I.G., Blinova E.V., Gavrilova O.P., Gagkaeva T.Yu. The valuable characteristics of oats genotypes and resistance to Fusarium disease. Vavilov J. Genet. Breed. 2016;20(3):286-294. DOI 10.18699/ VJ16.151.

Nicolas J.J., Richard-Forget F.C., Goupy P.M., Amiot M.J., Aubert S.Y. Enzymatic browning reactions in apple and apple products. Crit. Rev. Food Sci. Nutr. 1994;34(2):109-57. DOI 10.1080/1040839940 9527653

Rogers C.E., Kreitner G.L. Phytomelanin of sunflower achenes: a mechanism for pericarp resistance to abrasion by larvae of the sunflower moth (Lepidoptera: Pyralidae). Environ Entomol. 1983;12: 277-285. DOI 10.1093/ee/12.2.277.

Shoeva O.Y., Mock H.P., Kukoeva T.V., Börner A., Khlestkina E.K. Regulation of the flavonoid biosynthesis pathway genes in purple and black grains of Hordeum vulgare. PloS ONE. 2016;11(10):e0163782. DOI 10.1371/journal.pone.0163782.

Shoeva O.Yu., Gordeeva E.I., Abuzova V.S., Khlestkina E.K. Anthocyanins participate in protection of wheat seedlings from osmotic stress. Cereal Res. Commun. 2017;45:47-56. DOI 10.1556/0806. 44.2016.044

Yassen B.T., Al-Omary S.S. Analysis of the effects of water stress on leaf growth and yield of three barley cultivars. Irrig. Sci. 1994;14: 157-162. DOI 10.1007/BF00193138.

Acknowledgements. The study is supported by the Russian Science Foundation (Project No. 16-14-00086).

Conflict of interest. The authors declare no conflict of interest. 


\title{
Creation of mutant populations of barley (Hordeum vulgare L.) and flax (Linum ussitatissimum L.) induced by the chemical mutagen of the phosphemide
}

\author{
N.A. Bome ${ }^{1 *}$, K.P. Korolev ${ }^{1}$, N.V. Tetyannikov ${ }^{1}$, L.I. Weisfeld ${ }^{2}$, N.N. Kolokolova ${ }^{1}$ \\ ${ }^{1}$ Tyumen State University, Tyumen, Russia \\ ${ }^{2}$ N.M. Emmanuel Institute of Biochemical Physics, Moscow, Russia
}

Dol 10.18699/ICG-PlantGen2019-29

(C) Autors, 2019

* e-mail: bomena@mail.ru

\begin{abstract}
The effectiveness of barley and flax seed treatment with the chemical mutagen Phosphemidum has been studied for sensitivity in the first generation $\left(M_{1}\right)$ and for the mutability in the second $\left(M_{2}\right)$ and third generations $\left(M_{3}\right)$. Optimal concentrations of the mutagen for treatment of barley $(0.002,0.01 \%)$ and flax $(0.005,0.01 \%)$ seeds for obtaining mutant populations were determined. The change in chlorophyll content in leaves measured by a SPAD 502 optical meter (Minolta Camera Co., Ltd., Tokyo, Japan) during different phenological phases was the informative criterion for evaluating the response of the species studied to the effect of the mutagenic factor. It has been shown that chlorophyll accumulation in the leaves of plants in the control and experimental variants is similar and continues until the stage of milky ripeness in barley and flowering phase in flax. Chlorophyll degradation is accelerated by Phosphemidum.

Key words: barley; flax; mutant population; mutagen concentration; sensitivity; mutability.
\end{abstract}

\section{Introduction}

Genetic erosion of plants leads to a reduction in the number of cultivars and, therefore, to a decrease in the productivity of agrocenoses in changing environmental conditions (Aleksanyan, 2007; Mark van de Wouw, 2009). In this regard, the key role is given to the genetic diversity of plants, for widening of which creation of induced mutants are promising in breeding programs. Cultivars increase biodiversity, provide the source material for selection, which contributes to the conservation and an efficient use of plant genetic resources. The use of induced mutants in selection programs led to the creation of 3222 cultivars of 170 plant species in more than 60 countries of the world (FAO, 2015). High results were achieved using well-known chemical mutagens (DMS, HMM, HEM, EI, etc.). The significance of research in this area considerably increases with the induction of mutations by means of a new or an insufficiently studied mutagenic factor. This is especially important for the northern regions characterized by harsh (often extreme) soil and climatic conditions and limited resources of cultivated plant species.

The aim of our research is to develop the scientific basis for the use of the Phosphemidum chemical mutagen in the treatment of barley (Hordeum vulgare L.) and flax (Linum usitatissimum L.) seeds.

\section{Materials and methods}

The objects of the study are three barley samples: Zernogradsky 813 (k-30453, Russia, var. erectum), Dz02-129 (k-22934, Ethiopia, var. nigripallidum), C.I. 10995 (k-30630, Peru, var. sinicum), and three varieties of flax: Yarok (k-8282, Belarus), Ottava 770 B See (k-4035, Canada), Velizhzhsky Kriazh (k-5398, Russia), differing in origin, morphological characters and biological properties. Dry seeds were treated with an aqueous solution of Phosphemidum (diethylenimide 2-amidopyrimidyl phosphoric acid) at the following concen- trations: barley, $0.002 \%\left(2 \cdot 10^{-3} M\right)$ and $0.01 \%\left(1 \cdot 10^{-2} M\right)$; flax, $0.005 \%\left(5 \cdot 10^{-3} M\right), 0.01 \%\left(1 \cdot 10^{-2} M\right)$ and $0.1 \%\left(1 \cdot 10^{-1} M\right)$, with exposure for 3 hours. Then the seeds were washed in running tap water for 40 minutes (Weisfeld, 2010, 2016). 300 seeds of each barley sample and 200 seeds of each flax sample were treated by the mutagen. Seeds kept in distilled water were used as the control. Sowing in the field to obtain the first generation $\left(\mathrm{M}_{1}\right)$ was carried out in blocks for each variant of seeds in four repeats. $M_{1}$ plants were harvested individually. Sowing of the second generation $\left(\mathrm{M}_{2}\right)$ was carried out by families (the offspring of inflorescences from $M_{1}$ plants). The modified forms according to morphological characters and biological properties were selected from the control and mutagen-treated populations by means of visual observations and descriptions of $\mathrm{M}_{2}$ plants during the growing season. In the third generation $\left(\mathrm{M}_{3}\right)$, seeds collected from plants with phenotypic deviations from the initial sample in $\mathrm{M}_{2}$ were sown by families, and the percentage of families, in which the altered character was inherited, was calculated.

Statistical processing of experimental data was performed using STATGRAPHICS, STATISTICA 7 (StatSoft) software. The standard error of means $\left(\mathrm{S}_{\mathrm{x}}\right)$ and the significance of differences according to Student's criterion were calculated. The "box-whiskers" diagrams were constructed according to the method of John Tukey (Field et al., 2012).

\section{Results and discussion}

The effectiveness of the mutagenic factor was determined according to the sensitivity of barley and flax to the effects of Phosphemidum in seed treatment in the first generation $\left(\mathrm{M}_{1}\right)$, the mutation frequency and spectrum in the second $\left(\mathrm{M}_{2}\right)$ and third $\left(\mathrm{M}_{3}\right)$ mutant generations in controlled laboratory conditions (thermostat, climate chamber, vegetation shelves) and in the field experiment. Although new molecular methods for detecting mutant forms have been developed (e.g., the TILL- 


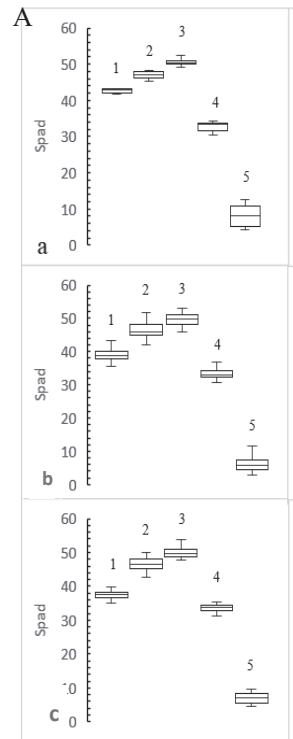

Zernogradsky 813

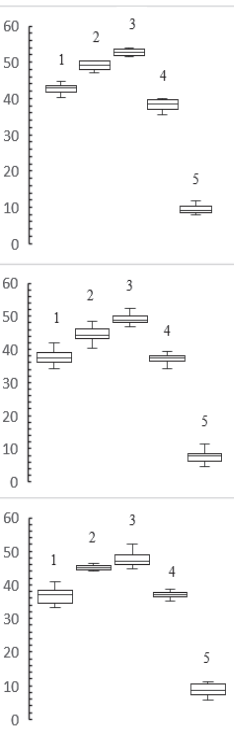

Dz02-129

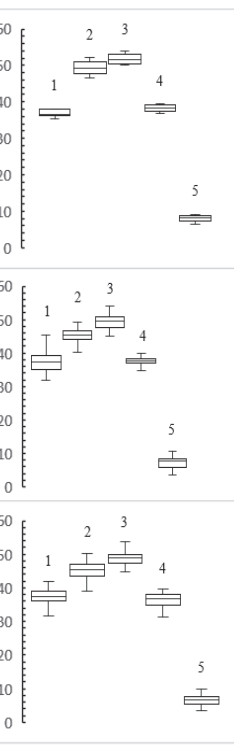

C.I.10995

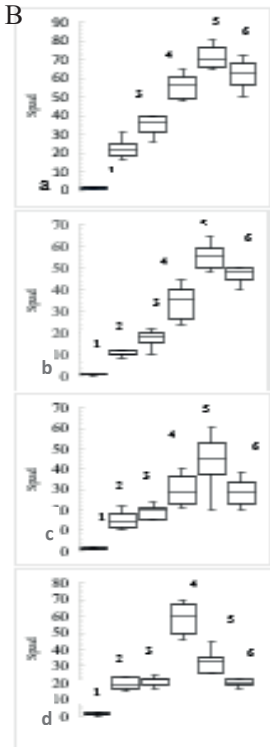

Yarok

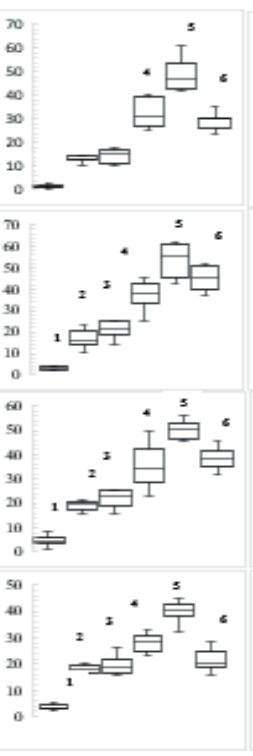

Velizhzhsky Kriazh

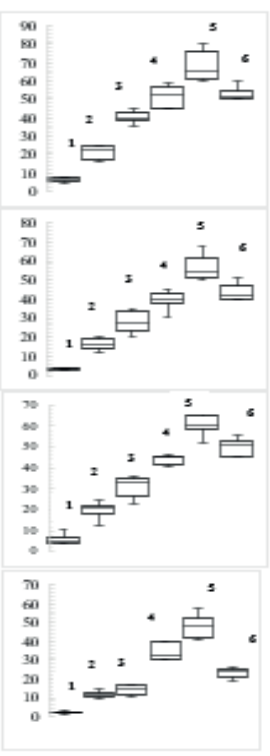

Ottava 770 B See

Figure1. Accumulation and degradation of chlorophyll in barley (A) and flax (B) leaves in control and mutant populations.

Stages of barley plant development: 1 , tillering; 2 , stem elongation; 3 , milky ripeness; 4 , wax ripeness; 5 , full ripeness.

$a$, control; $b, 0.002 \% ; c, 0.01 \%$.

Stages of flax plant development: 1 , germs; 2 , start of leaf spiral; 3 , quick growth; 4 , budding; 5 , flowering; 6 , green ripening.

$a$, control; $b, 0.005 \% ; c, 0.01 \% ; d, 0.1 \%$.

Notation: " - ", arithmetic mean; " $\square$ " is the standard error, \pm ; " ${ }^{\prime \prime}$ is the minimum value of the attribute ( $\min$ ); "1" is the maximum value of the attribute (max).

ING method) (Till et al., 2003, 2006), a prerequisite for their use is the presence of a mutant population, the size of which depends on the type of mutagen, its concentration, time and conditions of explant treatment.

The analysis of field germination of seeds and plant survival of barley and flax of the $M_{1}$ generation allowed us to determine the concentrations of Phosphemidum optimal for the growth and development of barley (C.I. 10995), 0.002 and $0.01 \%$, and of flax (Yarok, Velizhzhsky Kriazh), 0.005 and $0.01 \%$. Semi-lethal concentrations include: $0.01 \%$ for barley samples (Dz02-129, Zernogradsky 813) and $0.1 \%$ for flax varieties (Ottava 770 B See), since seed germination after treatment with Phosphemidum was below $50 \%$.

The physiological status of seeds and the variability of plant morphometric parameters in ontogenesis are found to be the informative criteria. The express diagnostics of chlorophyll content in the leaves of plants at different stages of ontogenesis was tested. Based on the readings of the SPAD 502 chlorophyll optical counter (Minolta Camera Co., Ltd., Tokyo, Japan), significant differences were found in the accumulation and degradation of chlorophyll in the control and variants with Phosphemidum (Figure 1).

Positive correlations of chlorophyll content in leaves with other selection-valuable characters (plant height, leaf area, yield, biological properties of seeds) provide more complete information about the interaction of the factors 'genotype' and 'environment' and their contribution to the overall phenotypic variability. The genetic activity of a mutagen is determined by the frequency and spectrum of mutations. In our study, mutational changes that occur under the effect of
Phosphemidum were diverse in their display and affected the stem, leaves, ear, physiological parameters of plant growth and development; system mutations were encountered as well. In the studied species, induction of plants with early ripening, large inflorescence, and an increase in the length of the stem were most frequently observed. The specificity of mutational changes was noticed. For example, only in barley sample C.I. 10995 the mutagen treatment led to the emergence of a new variety. In variants with a mutagen concentration of $0.01 \%$, stunted forms of plants with high resistance to lodging were obtained (9 points). In flax cultivars in variants with the mutagen, plants with a stem mass substantially exceeding the control were found. Using Phosphemidum allowed us to obtain plant forms with an increased number of seeds in a capsule. We consider mutational changes in the color of flowers (from white to shades of pink and blue), the seed coat (from yellow with different shades to dark brown), the shape and degree of opening of the box as a promising starting material for flax selection.

\section{Conclusion}

Reducing plant genetic diversity decreases the possibilities of the population supply with a variety of high-quality food products (McCouch et al., 2013). Therefore, the identification of new resources to increase the genetic diversity of cultivated plants and reduce their vulnerability to changing environmental conditions is extremely important. It is evident that the further development of mutation selection is largely determined by the search for new mutagens and the development of the technology for their application in plants. The 
task of selecting the optimal concentrations of the mutagen solution, providing the maximum possible yield of mutant forms with selection-valuable characters remains difficult to solve. The damaging action of the mutagen, leading to loss of seed viability, death of seedlings or mature plants, is often the obstacle to solve this task. This may be due to differences in the chromosome set (Hordeum vulgare L., $2 \mathrm{n}=14$; Linum usitatissimum L., $2 \mathrm{n}=30$ ), which should be taken into account in experimental studies.

Phosphemidum contains two Ethyleneimine groups, and is a derivative of Ethyleneimine, a known and widely used mutagen. Our results suggest that Phosphemidum is an effective chemical mutagen for producing plants with new or improved characters (Bome et al., 2017; Korolyov, Bome, 2018; Korolyov et al., 2019). The created mutant forms are a valuable source material for selection and genetic programs and for enriching the genetic diversity of agricultural plants. Identification of barley sample C.I. 10995 plants with a complex of new morphological characters that determine their belonging to another variety, the breadth of variation in flower color and the structure of the capsule in flax confirm the hypothesis by I.A. Rapoport (1993) on a high efficiency of chemical mutagens, especially alkylation compounds (Ethyleneimine and its derivatives), in the creation of rare mutations.

\section{References}

Aleksayan S.M. Interaction srategy of genbank world interaction in the context of globalization. Works Applied Bot., Gen. Selection. 2007; 164:11-33.

Bome N., Weisfeld L., Babaev E., Bome A., Kolokolova N. Influence of Phosphemidum, of chemical mutagen, on agrobiological charac- ters of soft spring wheat Triticum aestivum L. Agricultural Biology, 2017:52(3):570-579 DOI 10.15389/agrobiology.2017.3.570rus.

FAO/IAEA Mutant variety database. 2015. https://mvd.iaea.org/\#! Search.

Field A. Mieles J., Field Z. Discovering statistics using R. London, SAGE Publication LTD, 2012.

Korolyov K.P., Bome N.A., Weisfeld L.I. Study of reaction of flax (Linum usitayissumum L.) genotypes on mutagene stressor in the modeled and natural environmental conditions. Zemdirbyste-Agriculture. 2019;1:29-36. DOI 10.13080/z-a.2019.106.004.

Korolyov K.P., Bome N.A. Application of morpho-physiological makers in the study of the intraspecific polymorphism of Linum usitatissimum L. Agricultural Biol. 2018;53(5):927-937. DOI 10.15389/ agrobiology.2018.5.927rus.

McCouch S., Baute G.J., Bradeen J., Bramel P., Bretting P.K., Buckler E. et al. Agriculture: feeding the future. Nature. 2013;499 (I. 7456): 23-24 DOI 10.1038/499023a.

Rapoport I.A. Selected Works. Discovered of Chemical Mutagenesis. Moscow: Sciences, 1993.

Till B.J., Reynolds S.H., Greene E.A., Codomo C.A., Enns L.C., Johnson J.E., Burtner C., Odden A.R., Young K., Taylor N.E. Largescale discovery of induced point mutations with high-throughput TILLING. Genome Res. 2003;13(3):524-530. DOI 10.1101/gr. 977903.

Till B.J., Zerr T., Comai L., Henikoff S.A. Protocol for TILLING and Ecotilling in plants and animals. Nat Protoc. 2006;1(5):2465-2477. DOI 10.1038/nprot.2006.329.

Weisfeld L.I. Cytogenetic action of antitumor drug Phosphemidum. Fundamental Sciences and Practice. 2010;1(3):3-6.

Bome N.A., Bekusarova S.A. The mechanism of action of the chemical mutagen Phosphemidum. Prospects for the development of agroindustrial complex in modern conditions. 2016:36-39.

Conflict of interest. The authors declare no conflict of interest. 


\title{
Functional characterization of drought resistance in peach (Prunus petsica (L.) Batsch) cultivars damaged with Sharka disease
}

\author{
V.A. Brailko ${ }^{1 *}$, I.V. Mitrofanova ${ }^{1}$, N.V. Mesyats $^{1}$, O.V. Mitrofanova ${ }^{1}$, S.V. Chirkov ${ }^{1,2}$ \\ 1 Federal State Funded Institution of Science "The Labor Red Banner Order Nikita Botanical Gardens - National Scientific Center of the RAS", Yalta, Russia \\ ${ }^{2}$ Faculty of Biology, Lomonosov Moscow State University, Moscow, Russia
}

DOI 10.18699/ICG-PlantGen2019-30

(c) Autors, 2019

*e-mail: valentina.brailko@yandex.ru

\begin{abstract}
The article presents a comparative analysis of resistance to air and soil drought on the South Coast of the Crimea in healthy Prunus persica (L.) Batsch plants and ones infected with Plum pox virus. The degree of damage to tree crowns varied from $10 \%$ to $80 \%$. Structural differences in virus-free and infected plants were revealed: a decrease in leaf thickness and palisade index, the formation of large intercellular spaces in spongy tissue, necrotization in palisade chlorenchyma and a greater number of crystalline inclusions in the cell cytoplasm. Under optimal conditions, the cultivars with the water-holding capacity of leaf tissues changing at infection were determined. The summer drought caused a decrease in the total water content in the leaf tissues; the total water content in asymptomatic plants was $59-70 \%$; in those affected, it decreased to $55 \%$, while the water deficit increased to $31 \%$. Thus, PPV damages significantly reduced plant resistance to abiotic stress of the summer period in the cultivars 'Karnavalniy', 'Pushistiy Ranniy', 'Demerdzhinskiy'.

Key words: drought tolerance; Prunus persica L.; Sharka disease; virus resistance; peach.
\end{abstract}

\section{Introduction}

Peach is one of the economically most valuable fruits, the world production of which is more than 24 tons per year. A major with growing Prunus L. cultivars is that they are damaged by Sharka disease (Plum pox virus, PPV) (Mitrofanova et al., 2000; Garcia and Cambra, 2007; Chirkov and Prikhod'ko, 2015; Mitrofanova et al., 2017; Shevchenko et al., 2017). The infected plants were characterized by disturbed metabolic and growth processes that affected their fruiting (Mitrofanova et al., 2014; Brailko et al., 2015; Buntsevich et al., 2016). PPVinfected plants were more affected by adverse environmental conditions. The disease was a cause of yield losses of up to $85-100 \%$ due to fruit quality deterioration and their premature fall (Mitrofanova et al., 2014; Clente-Moreno et al., 2015).

The aim of our study was to identify structural and physiological changes in the peach leaf tissues under $P P V$ infection. To achieve the goal, histological and physiological analyses of the leaf blades from healthy and damaged peach trees in the open-field collection of the Nikita Botanical Gardens - National Scientific Center (NBG-NSC) were performed.

\section{Materials and methods}

Twelve peach cultivars were studied: 'Demerdzhinskiy', 'Krymskiy Shedevr', 'Lakomiy', 'Mechta', 'Podarok Neveste', 'Pushistiy Ranniy', 'Strelets', 'Karnavalniy' (NBGNSC breeding), 'Ambergold', 'Dixired', 'Tulip', 'Cardinal' (introduced cultivars). The particular value of these genotypes is in their early maturity (fruits of the cultivars 'Krymskiy Shedevr', 'Podarok Neveste' ripen in the second decade of July), their better transportability ('Cardinal'), high flavour qualities ('Demerdzhinskiy', 'Lakomiy') and frost resistance (characteristic of the cultivars 'Demerdzhinskiy' and 'Pushistiy Ranniy'). Anatomical studies were performed on temporary slides (Pausheva, 1990), which were analyzed using an AxioScope A.1 microscope (Zeiss, Germany) and AxioVisionRel 4.8.2. software. Micrographs were taken with an AxioCamERc5s digital camera.

Changes in the water regime were assessed by the following parameters: total water content, water deficiency, waterholding capacity of leaf tissues (Lishchuk, 1991).

Statistical analysis of the data was made with STATISTICA 6.0.

\section{Results and discussion}

Due to the monitoring of peach collection plots, cultivars and hybrid forms with Sharka disease (PPV) symptoms were identified. On the leaf blades of the damaged plants, patterns of narrow, blurred stripes were observed, more rarely lightyellow or yellow rings, which were clearly visible in the light. Among the symptoms, wrinkled leaves should also be noted. The degrees of tree crown damage were different: less than $10 \%$ leaf damage was observed in 'Podarok Neveste'; from 10 to $40 \%$, in 'Demerdzhinskiy', 'Strelets', 'Karnavalniy', 'Krymskiy Shedevr', 'Dixired', 'Ambergold', 'Tulip', and 'Cardinal'; and from 40 to $80 \%$ of leaves were infected in 'Lakomiy', 'Pushistiy Ranniy', and 'Mechta'. During fruit ripening, color necrotic spots appeared on the leaves.

The leaf blades of these cultivars have a complex of common anatomical and morphological characteristics which are typical of the peach culture in general (Sokolova, Schoferistov, 1991). The leaves are bifacial, hypostomatic, their thickness is from 145 to $192 \mu \mathrm{m}$ (Figure 1, b), covered with a thick cuticle on both adaxial and abaxial surfaces (cuticle thickness from 6 to $18 \mu \mathrm{m}$ ). The mesophyll is dense, consisting of 5-8 layers, sometimes isopalisade. The leaf petiole on the cross section has a rounded-triangular shape; the vascular bundle is collateral closed, has the shape of a regular arc (Figure 1,a). The 


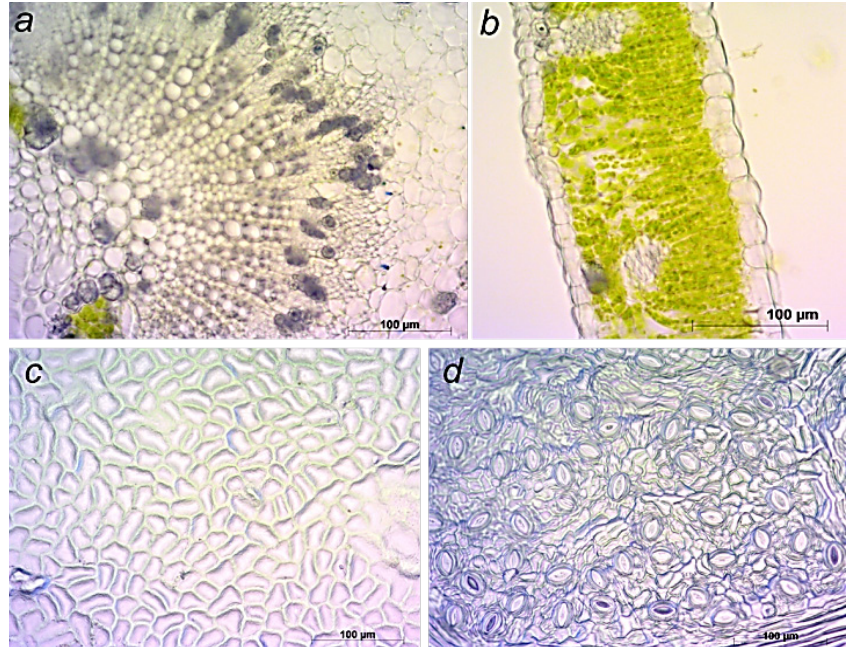

Figure 1. Leaf blade structure of asymptomatic $P$. persica trees, cultivar 'Pushistiy Ranniy': midvein (a), cross-section (b), casts of adaxial (c) and abaxial epidermis $(d)$.

epidermis is one cell layer thick; cell thickness is $31-48 \mu \mathrm{m}$ on the adaxial side and $12-16 \mu \mathrm{m}$ on the abaxial side. In terms of form, they are 5-7 angular, large on the adaxial leaf surface and small, elongated on the abaxial one (Figure 1, $c, d$ ). The stomatal apparatus of the anomocytic type, their number varies from 73 to 192 stomata/ $\mathrm{mm}^{2}$. The length of the stomatal pore is $25-32 \mu \mathrm{m}$.

The leaf blades of the damaged trees had a number of structural differences, compared with asymptomatic ones (see Figure 2, $a, b$ ), such as: a decrease in leaf thickness (by 8-12\%, noted in 'Lakomiy' and 'Krymskiy Shedevr'); a decrease in palisade index (in 'Lakomiy'), large intercellular spaces appeared in the spongy tissue; in most of the damaged leaves, no matter what cultivar, chloroplasts destruction began in the mesophyll layers adjacent to cover tissues and further through the mesophyll; necrosis began in palisade chlorenchyma; in the cell cytoplasm, a number of crystalline inclusions (calcium oxalate druses) significantly increased; the number of stomata in PPV-infected leaves significantly increased (1.2-2-fold) in 'Tulip' and 'Podarok Neveste'. Many authors who have studied the anatomical structure of leaves in various fruit crops note that drought-resistant plants are characterized by an isolateral small cell structure with tightly closed mesophyll cells (Sokolova, Shoferistov, 1991; Golubkova, 2014) Thus, the structural changes revealed can reduce the xerophytic properties of peach leaves in damaged cultivars.

Some authors (Elmanova, Opanasenko, 2010; Smykov et al., 2013; Drahavtseva et al., 2014) noticed a high drought tolerance of peach trees. In order to determine its degree, we assessed the water regime during the conditionally optimal and extreme vegetation periods of 2017 and 2018 (the weather conditions in summer 2017 did not have significant differences from the average long-term meteorological data, while in 2018 there were two peaks of hydrothermal stress: the maximum air temperature was $34^{\circ} \mathrm{C}$, relative humidity decreased to $23 \%$, the non-rainfall period before sampling lasted from 21 to 26 days during the extreme period). In optimal moisture condi-

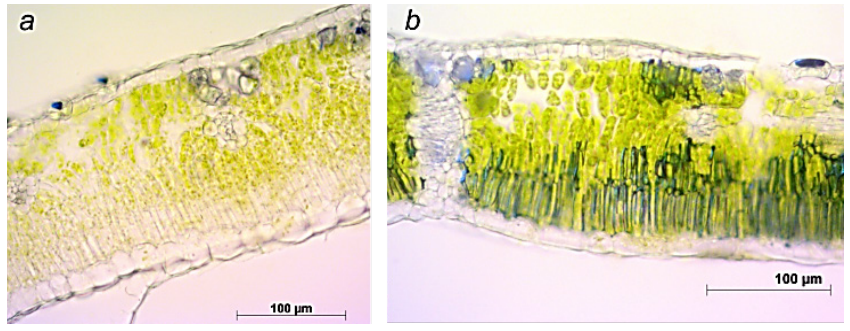

Figure 2. Leaf blade structure in PPV-infected $P$. persica trees, cultivars 'Lakomiy' (a) and 'Krymskiy Shedevr' (b). Original.

tions, the leaves were characterized with high water content $(69-76 \%)$. It should be noted that the value of the total water content in the leaves in May-June correlated with the amount of precipitation $(r=0.41 \ldots 0.52)$. Water deficit at that time ranged from $4 \%$ ('Podarok Neveste', 'Krymskiy Shedevr', 'Ambergold') to $15 \%$ (damaged leaves in 'Karnavalniy', 'Mechta'). With the presented cultivar difference, in the optimal conditions of the growing season beginning, cultivars demonstrated changes in water regime when infection were revealed: 'Mechta', 'Pushistiy Ranniy', 'Cardinal'. Their water holding capacity decreased by $18-30 \%$ compared to asymptomatic leaves. Summer drought resulted in a decrease in the total water content in the leaf tissues; in asymptomatic plants, the water content was 59-70\%; in those affected, it decreased to $55 \%$ ('Karnavalniy', 'Pushistiy Ranniy', 'Ambergold'). A direct correlation of water content with relative air humidity $(\mathrm{r}=0.59 \ldots 0.83)$ was noted. Water deficit was $12-26 \%$ in healthy plants and $20-31 \%$ in affected ones (the maximum was in 'Karnavalniy', 'Ambergold' and 'Cardinal'). The correlation of water deficiency with average daily air temperature $(r=0.59 \ldots 0.78)$ and relative air humidity $(r=-0.47 \ldots-0.71)$ was revealed. In the infected plants of the cultivars 'Mechta', 'Karnavalniy', 'Ambergold' and 'Cardinal' sublethal water deficit was reached.

\section{Conclusions}

Thus, our research demonstrated that high drought tolerance is generally characteristic of the cultivars 'Krymskiy Shedevr', 'Dixired', 'Tulip' and 'Podarok Neveste'. PPV damage resulted in structural and functional changes that reduce resistance to abiotic stress (drought) in the cultivars 'Karnavalniy', 'Pushistiy Ranniy' and 'Demerdzhinskiy'.

\section{References}

Brailko V.A, Grebennikova O.A., Mitrofanova I.V., Mitrofanova O.V. Structural, functional and biochemical features in Canna $\times$ hybrida hort. plants with viral diseases. Subtropical and decorative gardening. 2015;55:139-145.

Buntsevich L.L., Kpstyuk M.A., Nenko N.I. Physiological and biochemical characteristics of the leaves of plum and decrease in the quality of its fruits during infection pox (PPV). Technologies of food and processing industries AIC-healthy food. 2016;5:38-42.

Chirkov S.N., Prikhod'ko Yu.N. Genetic diversity and population structure of Plum pox virus in Russia (review). Agricultural Biology. 2015;50(5):529-539.DOI 10.15389/agrobiology.2015.5.529eng 
Clemente-Moreno M.J., Hernandez J.A., Diaz-Vivancos P. Sharka: how do plants respond to Plum poxvirus infection? J. Exp. Bot. 2015;66: 25-35. https://doi.org/10.1093/jxb/eru428

Dragavtseva I.A., Savin I.Yu., Domozhirova V.V., Morenets A.S., Akhmatova Z.P., Zagirov N.G. Adaptation of the peach crop to the conditions of cultivation in the south of Russia. Horticulture and viticulture. 2014;6:35-40.

Elmanova T.S., Opanasenko N.E. Ecological and physiological features of peach. Kiev: Agrarian science, 2010. 152 pp.

Garcia J.A., Cambra M. Plum Pox Virus and Sharka Disease. Plant Viruses. 2007;1:69-79.

Golubkova I.M. Micromorphological structure of the leaf blades in the representatives of the genus Persica Mill. in the M.M. Gryshko National Botanical Garden. Bulletin of Biology and Medicine Problems. 2016;1(127):38-41.

Lischuk A.I. Method for determining the water-holding capacity for dehydration in the leaves of fruit crops. Physiological and biophysical methods in the selection of fruit crops: guidelines. Moscow: GNBS, $1991.68 \mathrm{pp}$.

Mitrofanova I.V., Mitrofanova O.V., Chirkov S.N., Lesnikova-Sedoshenko N.P. Methodological approaches to Sharka (Plum pox vi$r u s)$ detection and identification on the different species of genus Prunus. Works of the State Nikitsky Botanical Gardens. 2014;138: 137-161.

Mitrofanova I.V., Mitrofanova O.V., Lesnikova-Sedoshenko N.P., Ivanov P.A., Sheveleva A.A., Chirkov S.N. Three highly divergent groups of Plum pox virus strain D isolates coexist in stone-fruit plantings of Nikita Botanical Gardens, Crimea. Acta Hortic. 2017; 1163:117-122. https://doi.org/10.17660/ActaHortic.2017.1163.17.

Mitrofanova O.V., Slavgorodskaya-Kurpieva L.E., Mitrofanova I.V., Lukicheva L.A. Diagnostics of viral diseases and biotechnological ways of virus-free planting material of stone fruits obtaining. Yalta: Krympress, 2000. 45 pp.

Pausheva Z.P. Practicum in plant cytology. Moscow: Kolos. 1990. 283 pp.

Shevchenko S., Gorina V., Mitrofanova I. The influence of viral status on pollen Characteristics of some apricot cultivars. Agriculture \& Forestry. 2017;63(1):87-93. DOI 10.17707/Agricult Forest.63.1.10.

Smykov A.V., Fedorova O.S., Suchkova J.E. Drought resistance and susceptibility of fungal diseases in hybrid forms of peach (Prunus persica (L.). Variety study and protection of plant variety rights. 2013;4:30-35.

Sokolova E.A., Shoferistov E.P. Anatomical structure of peach and nectarine species and cultivars. Scientific and Technical. bull All Union. Order of Lenin and the Order of Friendship of Peoples of the Research Institute of Plant Production them. N.I. Vavilov (Leningrad). 1991;212:33-37.

Acknowledgements. This work was supported by the Russian Science Foundation, project no. 19-16-00091.

Conflict of interest.The authors declare no conflict of interest. 


\title{
Response of the antioxidant system of two varieties of potatoes to salt stress
}

\author{
O.K. Murgan*, L.V. Kolomeichuk, I.S. Kovtun, M.V. Efimova
}

Tomsk State University, Tomsk, Russia

DOI 10.18699/ICG-PlantGen2019-31

(c) Autors, 2019

*e-mail: reborn_rinni@mail.ru

\begin{abstract}
The mechanisms of potato (Solanum tuberosum L.) plants' tolerance to chloride salinity were investigated in the early-season cv. 'Zhukovsky' and the mid-season cv. 'Lugovskoy'. At an age of 6 weeks, the plants were exposed to $100 \mathrm{mM} \mathrm{NaCl}$ stress for 7 days. Plant response to salt stress was estimated by physiological parameters (content of proline and activity of antioxidant enzymes) and the gene expression level for enzymatic and nonenzymatic antioxidant system. Early- and mid-ripening varieties of potato, in response to potato salinity, have differences in activity of guaiacol-dependent peroxidase, levels of gene expression of ascorbate peroxidase, and also accumulate toxic ions in leaves and roots, which has for the first time been shown in this study.
\end{abstract}

Key words: Solanum tuberosum L.; salt tolerance; antioxidant system.

\section{Introduction}

The growing season duration for potato plants is one of the key criteria for their regionalization in a certain climate zone. For the Siberian region characterized by a short summer season, early-maturing varieties are most preferred. However, the increase in saline areas sets priority on salt tolerance varieties. Salinization negatively affects the implementation of many physiological processes in plants, largely due to the generation of reactive oxygen species and the development of oxidative stress, which leads to disruption of the photosynthetic apparatus, a decrease in the intensity of photosynthesis and, as a consequence, a decrease in the productivity of plants; induction of aging or premature death of the plant. In response to the oxidative stress progress and metabolic disturbances, the plant responds by activating the cellular antioxidant system, which includes antioxidant enzymes (catalases, peroxidases, superoxide dismutases (SOD), etc.) and low-molecular-weight organic compounds with antioxidant properties (proline, phenolic compounds, carotenoids). In this article, the functioning of the antioxidant system for early- and mid-season varieties potato plants based on the proline content and antioxidant enzymes activity was studied. Also, gene expression levels of the enzymatic (APX1, APX3) and the non-enzymatic (P5CS1, $\mathrm{P} 5 \mathrm{CR}, \mathrm{PDH}$ ) plant protection systems under chloride salinity were discussed.

\section{Materials and methods}

The study was carried out on Solanum tuberosum L. plants of the early-season cv. 'Zhukovsky' and the mid-season cv. 'Lugovskoy'. Virus-free in vitro potato regenerants were cultivated for 21 days on the half-strength Murashige and Skoog $(1 / 2 \mathrm{MS})$ agar medium, after that the roots of the plants were washed from the agar medium and grown for three weeks on a $1 / 2$ MS liquid medium. To model salt stress, the plants were transferred for 7 days to $1 / 2$ MS with the addition of $100 \mathrm{mM}$ $\mathrm{NaCl}$. Half-strength MS medium without $\mathrm{NaCl}$ was used as a reference. Evaluation of physiological characteristics was performed according to the methods described previously (Efimova et al., 2018). Total RNA from leaf tissue was iso- lated using Manickavelu`s method (Manickavelu et al., 2007). Cyclofilin and elongation factor 1- $\alpha$ were used as reference genes. Levels of gene transcript contents were determined by real-time PCR (SYBRGreen I dye) using the LightCycler 96 System (Roche, Switzerland).

Our experiments were carried out in three biological replicates. The figures present the mean values and their standard errors (SE). The means were compared using ANOVA on Ranks (Kruskal-Wallis criterion).

\section{Results and discussion}

Plant adaptation to a disturbance of water status and a toxic effect of salinity mostly depends on compatible osmolytes acting as chemical chaperones. We revealed that accumulation of the universal compatible osmolyte proline in potato plants is species specific. Figure $1 a$ shows that the content of this osmoprotector in the leaves 'Zhukovsky' is two times higher than in 'Lugovskoy'.

In response to salinity (100 $\mathrm{MM} \mathrm{NaCl})$, plants showed a six- and sevenfold increase in proline content in the leaves of the early- and the mid-season variety, respectively.

To determine the mechanisms of proline accumulation in the leaves of plants, the expression of genes for proline synthesis (P5CS1 and P5CR) and proline degradation (PDH) was analyzed (Figure 1, $b, c, d$ ). In the absence of a stressor, the level of transcripts for proline synthesis genes was the same for both varieties, while the level of PDH gene expression in 'Zhukovsky' was two times higher than in 'Lugovskoy'. The variability of proline metabolism transcription genes under salinity was noted. 'Zhukovsky' plants responded to the stressor by inhibiting proline synthesis gene expression, while in 'Lugovskoy', an increase in P5CS1 and PDH expression was observed (see Figure 1, $b, c, d$ ).

To reduce the negative effects of oxidative stress triggered by $\mathrm{NaCl}$, the enzymatic antioxidant defense systems in plants can be activated. The superoxide radical is known to be a primary product of one-electron reduction of molecular oxygen and a precursor of other, frequently more aggressive ROS. Therefore, superoxide dismutase-catalyzed conversion of 

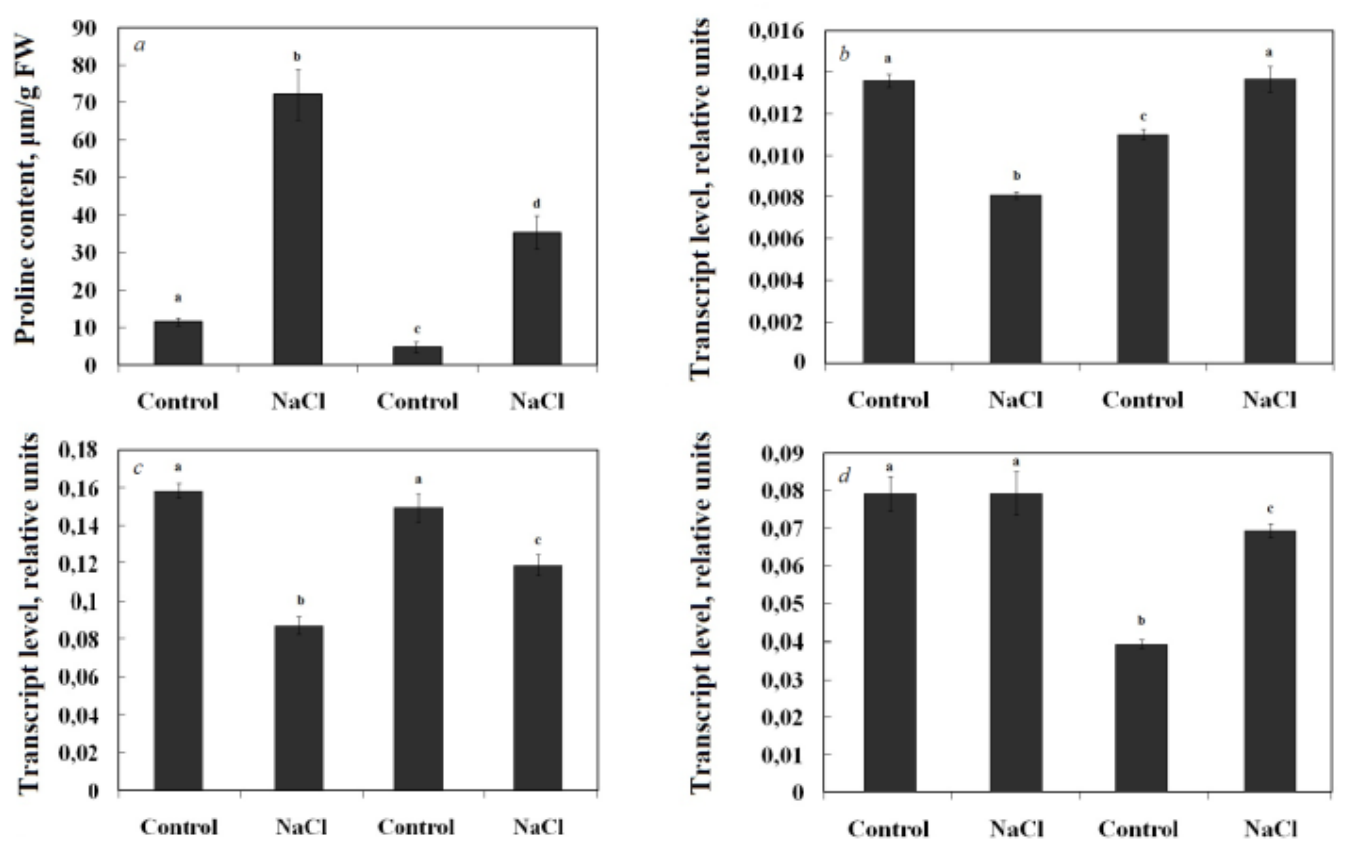

Zhukovsky

Lugovskoy

Zhukovsky

Lugovskoy

Figure 1. Effect of $100 \mathrm{mM} \mathrm{NaCl}$ on proline content (a) and transcript levels of P5CS1 (b), P5CR (c) and PDH (d) genes in S. tuberosum leaves. Letters indicate significant differences $(p<0.05)$ between the experiment variants.
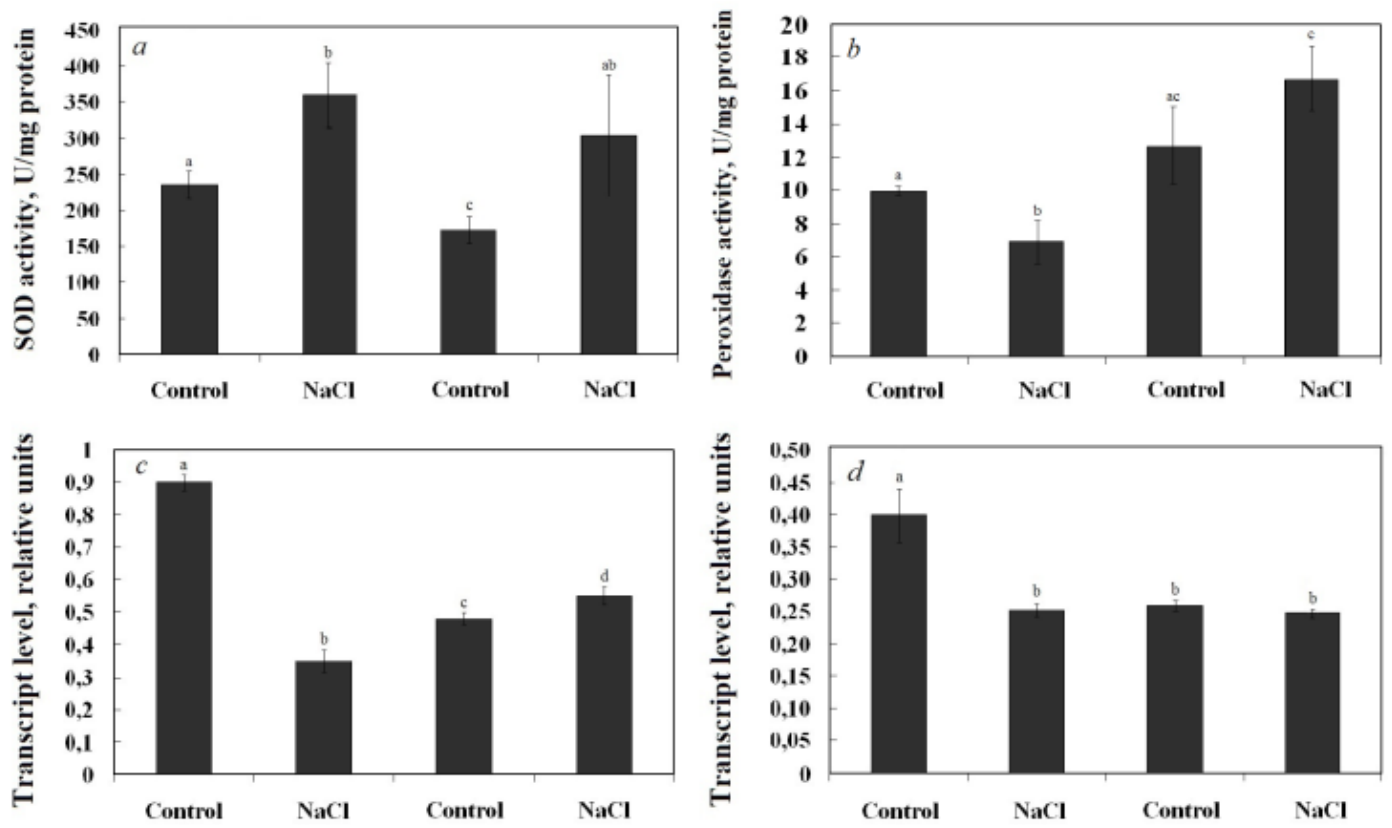

Zhukovsky

Lugovskoy

Zhukovsky

Lugovskoy

Figure 2. Effect of $100 \mathrm{mM} \mathrm{NaCl}$ on superoxide dismutase (a) and peroxidase activity (b), transcript levels of APX1 (c) and APX3 $(d)$ in S. tuberosum leaves. Letters indicate significant differences $(p<0.05)$ between the experiment variants. 
$\mathrm{O}_{2}^{-}$into $\mathrm{H}_{2} \mathrm{O}_{2}$ plays a key role in plant cell protection against oxidative destruction (Kartashov et al., 2008).

Guaiacol-dependent peroxidase catalyses the conversion of hydrogen peroxide into water. The activity of superoxide dismutase and peroxidase in the leaves of plants of the earlyand the mid-season potato variety was evaluated (Figure 2, $a, b)$. It has been shown that, under optimal conditions, 'Zhukovsky' had higher SOD activity and lower peroxidase activity compared with 'Lugovskoy'. During salinity, SOD and peroxidase activity increased 1.8 and 1.3 times, respectively, in 'Lugovskoy' leaves; while the plants of the earlyripening variety responded to stress by a 1.5 -fold increase in SOD activity and a 1.4-fold decrease in peroxidase activity (see Figure 2, $a, b$ ).

An important role in the regulation of the level of hydrogen peroxide in plant cells is played by ascorbate peroxidase (APX), which catalyzes the conversion of hydrogen peroxide into water with the participation of ascorbic acid. Ascorbic acid is dehydrolized to dehydroascorbate and acts as a substrate of reactions involving guaiacol-dependent peroxidase (Yang et al., 2018). We studied the expression level of the cytosolic ascorbate peroxidase gene APX1 and the peroxisomal ascorbate peroxidase gene APX3 (see Figure 2, c, d). The transcript level of the two APX genes was 1.5-1.9 times higher in 'Zhukovsky' than 'Lugovskoy' leaves. Transcript levels of the APX1 and APX3 genes in 'Zhukovsky' in stress condition decreased 1.6-2.6 times compared to the control variant, while 'Lugovskoy' plants kept the transcript levels for both genes at the control level (see Figure 2,c,d). Assay of the weight content of sodium and chlorine ions during salinization by the method of energy dispersive analysis on the Quanta 200 3D EDAX scanning electron microscope (Netherlands) showed that the mid-ripening potato variety 'Lugovskoy' response to $\mathrm{NaCl}$ was characterized by a smaller accumulation of toxic sodium and chlorine ions in the leaves and roots than the 'Zhukovsky' response, which indicates a higher salt tolerance of the mid-ripening variety (data not shown).

\section{Conclusions}

For the first time, the causes of potato plant resistance to $\mathrm{NaCl}$ action for the varieties analyzed were identified and a detailed comparison of the functioning of the protective systems of potato plants depending on the maturation period was made. We have shown that, in the case of chloride saliniza- tion, the early- and middle-ripening varieties regulated the functioning of the antioxidant system of plants by different ways. Thus, the early-ripening variety 'Zhukovsky' under the action of $\mathrm{NaCl}$ accumulates proline in the leaves and increases the activity of superoxide dismutase; at the same time, peroxidase activity decreases and the levels of the APX1 and APX3 genes are reduced. 'Lugovskoy' plants respond to the action of the stressor by a greater accumulation of proline, an increase in SOD and guaiacol-dependent peroxidase activities. It is considered that the activity of guaiacol-dependent peroxidase was to a much greater degree correlated with the plant capability of adaptation than proline accumulation and SOD activity (Kartashov et al., 2008). These data indicate a higher antioxidant activity for 'Lugovskoy' plants. In addition, plants of this variety accumulate less toxic ions of sodium and chlorine in the leaves and roots under stress condition than 'Zhukovsky' plants. The high salt tolerance of 'Lugovskoy' plants can be caused not only by increased antioxidant activity, but also by the reduced salt-absorbing capacity of root cells, as well as by controlled selective transport of ions to the aboveground organs.

\section{References}

Efimova M.V., Kolomeichuk L.V., Boyko E.V., Malofii M.K., Vidershpun A.N., Plusnin I.N., Golovatskaya, I.F., Murgan O.K., Kuznetsov V.V. Physiological Mechanisms of Solanum tuberosum L. Plants' Tolerance to Chloride Salinity. Russian J Plant Physiol. 2018;65(3):394-403. DOI 10.1134/S1021443718030020.

Manickavelu A. et al. Colloids and Surfaces B: Biointerfaces. 2007; $54: 254-258$

Nicot N., Hausman J.F., Hoffmann L., Evers D. Housekeeping gene selection for real-time RT-PCR normalization in potato during biotic and abiotic stress. J Experimental Bot. 2005;56(42):2907-2914. https://doi.org/10.1093/jxb/eri285.

Kartashov A.V., Radyukina N.L., Ivanov Yu.V., Pashkovskii P.P., Shevyakova N.I., Kuznetsov V.V. Role of antioxidant systems in wild plant adaptation to salt stress. Russian Journal of Plant Physiology. 2008;55(4):463-468. DOI 10.1134/S1021443708040055.

Yang Y., Guo Y. Elucidating the molecular mechanisms mediating plant salt-stress responses. New Phytol. 2018;217(2):523-539.DOI 10.1111/nph.14920

Acknowledgements. The work is supported by the granting program of Russian Foundation for Basic Research project No. 17-54-61017Egypt_a.

Conflict of interest. The authors declare no conflict of interest. 


\title{
Mechanism of plant adaptation to changing illumination by rearrangements of their photosynthetic apparatus
}

\author{
V.I. Belkov*, E.Yu. Garnik, Yu.M. Konstantinov \\ Siberian Institute of Plant Physiology and Biochemistry, Siberian Branch of the Russian Academy of Sciences, Irkutsk, Russia
}

DOI 10.18699/ICG-PlantGen2019-32

(c) Autors, 2019

* e-mail: anvad.irk@rambler.ru

\begin{abstract}
In this review, the mechanism and the physiology of the state transition process are overviewed. This mechanism allows plants to adapt their photosynthetic apparatus to changes in light conditions. State transitions are possible due to the specific structure of the photosystem II external light-harvesting antenna, which is able to move between photosystems II and I. As a result, the electron flow rate in the electron-transport chain of chloroplasts changes. The structure of photosystems II and I and the composition of photosystem II supercomplexes are described.

Key words: plant photosystems; PSI; PSII; chloroplast proteins; illuminance.
\end{abstract}

\section{Introduction}

Light is the most important environmental factor for photosynthetic organisms. This is a variable and unstable factor. For this reason, plants have developed appropriate adaptation mechanisms. There are short-term and long-term responses occurring in plants under shifts of illuminance quality and intensity (Dietzel et al., 2008). Short-term responses (a few seconds or minutes) induce lumen protonation and phosphorylation of various chloroplast proteins. These responses lead to non-photochemical quenching and the state transitions process. Long-term responses emerge after relatively long periods of time (hours or days, or during seasonal changes) and lead to sustainable changes in the content of chloroplast components (chlorophyll $a / b$ ratio, photosystem proteins and light-harvesting complexes) through changes in the expression of the corresponding genes (Dietzel et al., 2015).

Light reactions in plant chloroplasts are provided by four major complexes located in the thylakoid membrane: photosystem I (PSI), photosystem II (PSII), cytb6/f complex and ATP synthase. The understanding of the state transition mechanism is related to the study of the structure of the external antenna of PSII, which is represented by proteins of light-harvesting complex II (LHCII). A part of the external PSII antenna is mobile and can move between two photosystems. This mobility is the basis of the state transitions process. Thus, the state transitions process is one of ways to adapt to light fluctuations (Caffarri et al., 2015).

\section{Structure of photosystems in plants}

PSII is mostly located in grana stacks, whereas PSI is located in stroma lamellae (Albertsson, 2001; Dekker, Boekema, 2005). Both photosystems have similar structures and consist of two parts, a core protein complex and a light-harvesting antenna (light-harvesting complex I (LHCI) for PSI and lightharvesting complex II (LHCII) for PSII, respectively). The core complex is mostly represented by conservative proteins, which are largely similar in prokaryotes and eukaryotes except for small differences - the sites of photochemical reactions. In contrast, the structure of light-harvesting antennas (especially external antennas) in different photosynthetic organisms is not the same. External antenna proteins are responsible for light absorption and regulation of the photosynthetic processes (Horton et al., 1996).

The reaction center (RC) of PSII is a heterodimer, composed of the PsbA (D1), PsbD (D2) proteins and associated with 6 chlorophyll $a$ and two pheophytins (Umena et al., 2011). There are many small protein subunits of the Psb family, which are associated with the RC. The core proteins of PSII are linked to the internal antenna (represented by the CP47 (PsbB) and CP43 (PsbC) proteins, which are associated with 16 and 13 chlorophyll $a$ molecules, respectively) and a number of small subunits (Shi et al., 2012). The association of the PsbA, PsbD, $\mathrm{PsbB}$ and PsbC proteins in higher plants is called the Core of PSII (C). This core is connected with a system of external antennas, which consists of light-harvesting complex proteins associated with chlorophylls $a / b$ and are represented by the Lhcb1-6 subunits. This external antenna complex consists of trimers of Lhcb1-3 subunits, which are associated with the core complex by the minor subunits of Lhcb4-6 (Gao et al., 2018). The union of the core with the external LHC antenna is called the 'PSII supercomplex'.

It should be noted that the qualitative composition of the PSII supercomplex is not constant, and depends on the lightharvesting antenna size. The PSII supercomplex includes $\mathrm{C}$ and strongly (S), moderately (M) and loosely (L) bound LHCII trimers. LHCII-S connection is provided by association of LHCII proteins with PsbC and Lhcb5; LHCII-M connection, by the Lhcb6 and Lhcb4 proteins, which are located on a part of the PsbB protein. There are different variations of supercomplexes formed in thylakoid membranes $\left(\mathrm{C}_{2} \mathrm{~S}, \mathrm{C}_{2} \mathrm{M}\right.$, $\mathrm{C}_{2} \mathrm{~S}_{2}, \mathrm{C}_{2} \mathrm{SM}, \mathrm{C}_{2} \mathrm{~S} 2 \mathrm{M}, \mathrm{C}_{2} \mathrm{~S}_{2} \mathrm{M}_{2}$ and the $\mathrm{C}_{2} \mathrm{~S}_{2} \mathrm{M}_{2} \mathrm{~L}_{2}$ megacomplex) (Nosek et al., 2017). $\mathrm{C}_{2} \mathrm{~S}$ is the smallest supercomplex, which contains the core dimer of PSII, the Lhcb4 and Lhcb5 proteins and one LHCII trimer (Rantala et al., 2017). $\mathrm{C}_{2} \mathrm{~S}_{2} \mathrm{M}_{2}$ is the most common type of supercomplexes. In addition, the formation of $\mathrm{C}$ and CS complexes was also observed (Bielcznski et al., 2016). It was established that the external antenna of LHCII can migrate in the thylakoid membrane.

PSI consists of about 15 subunits. The RC of PSI is represented by the PsaA and PsaB proteins. The external antenna 
of PSI consists of four Lhca1-4 proteins, each of which is associated with $\sim 100$ molecules of chlorophylls $a / b$ and xanthophylls. The proteins of the external antenna extend around the RC of PSI. The structure of PSI included minor proteins (PsaC, PsaD, PsaE, PsaG, PsaK, PsaO, PsaH), which are involved in the docking with plastocyanine and ferredoxin, and also stabilize the LHCI antenna and the formation of a binding site with the LHCII protein. It is believed that the external antenna of LHCI is not able to move in the thylakoid membrane. In addition, PSI can be associated with the NADH dehydrogenase-like complex (NDH) resulting in the formation of a specific supercomplex involved in the cyclic electron flow (Yadav et al., 2017).

\section{The mechanism of state transitions}

State transitions is a mechanism of an absorbed light energy redistribution between two photosystems based on the reversible movement of LHCII trimers from PSII to PSI (Goldschmidt-Clermont, Bassi, 2015). According to this model, the excess of chlorophyll fluorescence is reduced (Bonaventura et al., 1969) and the electron flux of the electron-transport chain is stabilized (Dietzel et al., 2008). When PSII is overexcited, phosphorylation of LHCII (P-LHCII) occurs. These P-LHCII are dissociated from PSII and move from the stacks of thylakoids to lamellae where PSI is localized (State 2). As a result, the formation of state transitions supercomplex PSI-LHCI-LHCII occurs (Caffarri et al., 2014). When PSI is overexcited, P-LHCII is dephosphorylated by Protein Phosphatase1/Thylakoid-Associated Phosphatase PPH1/TAP38 and migrates back to PSII (State 1) (Kono et al., 2014). It was found that the LHCII proteins are phosphorylated in the N-terminal part. Hence, conformational changes of LHCII proteins occur and their affinity to PSII disappears (Nilson et al., 1997). Analysis of various mutants showed that the PsaH subunit of PSI is responsible for the physical placement of LHCII in PSI, and the PsaL, PsaO and PsaP subunits of PSI provide these interactions (Caffarri, 2015).

About $20 \%$ of LHCII proteins are involved in the transfer form PSII to PSI in Arabidopsis thaliana (Allen, 1992), while the figure for algae and cyanobacteria is up to $80 \%$, since this process is associated with switching between cyclic and linear electron transport (Goldschmidt-Clermont, Bass, 2015).

\section{Regulation of state transitions}

The state transition process is regulated through changes in the redox state of the plastoquinone pool. When PSII is excited, lastoquinone (PQ) reduces to plastoquinol (PQH2). $\mathrm{PQH} 2$ associates with a complex of cytb6/f and this interaction leads to activation of the protein kinase State Transition 7 (STN7). STN7 phosphorylates LHCII proteins (mostly Lhcb2 isoforms) and initiates state transition from State 1 to State 2 (Bellafiore et al., 2005; Longoni et al., 2017). This kinase functions as a dimer associated with the cytb6/f complex (Wunder et al., 2013). STN7 kinase has a transmembrane domain, which is located in the N-terminal part (on the lumen side), and a catalytic domain located on the stroma side of the thylakoid membrane.

In 2011, a model of STN7 regulation by ferredoxin/thioredoxin was proposed (Puthiyveetil, 2011). According to this model, when PSII is excited, $\mathrm{PQH} 2$ restores the disulfide bond in STN7 cysteines located on the lumen side and activates STN7. In high-light conditions, STN7 is inhibited by ferredoxin/thioredoxin signals.

\section{Conclusion}

At present, the structure of the PSII supercomplexes, the composition and location of their subunits are under study. The formation of these supercomplexes leads to the efficient usage of absorbed light energy. State transitions lead to the reversible movement of LHCII proteins between both photosystems. It is a subtle adaptation mechanism that allows plants to respond to changes in light conditions. In the evolutionary context, this mechanism was formed in cyanobacteria, algae and higher plants. It was established that the regulation of this process depends on the rate of electron flow in the electrontransport chain as well as protein kinases and phosphatases activity. Thus, the study of the processes of regulation of protein kinases and phosphatases can contribute to the further study of plant adaptation mechanisms.

\section{References}

Umena Y., Kawakami K., Shen J.-R., Kamiya N. Crystal structure of oxygen-evolving photosystem II at a resolution of $1.9 \AA$. Nature. 2011;473:55-60.

Horton P., Ruban A.V., Walters R.G. Regulation of Light harvesting in Green Plants. Annu. Rev. Plant Physiol. Plant Mol. Biol. 1996; 47:655-684.

Nosek L., Semchonok D., Boekema E.J., Ilik P., Kouril R. Structural variability of plant photosystem II megacomplexes in thylakoid membranes. Plant Journal. 2017;89:104-111.

Gao J., Wang H., Yuan Q., Feng Y. Structure and Function of the Photosystem Supercomplexes. Frontiers Plant Sci. 2018;9 (Article 357): $1-7$.

Allen J.F. Protein phosphorylation in regulation of photosynthesis. Biochim. Biophys. Acta-Bioenerg. 1992;1098:275-335.

Albertsson P. A quantitative model of the domain structure of the photosynthetic membrane. Trends Plant Sci. 2001;6:349-354. DOI 10.1016/S1360-1385(01)02021-0.

Dekke J.P., Boekema E.J. Supramolecular organization of thylakoid membrane proteins in green plants. Biochim. Biophys. Acta. 2005; 1706:12-39. DOI 10.1016/j.bbabio.2004.09.009.

Bellafiore S., Barneche F., Peltier G., Rochaix J.D. State transitions and light adaptation require chloroplast thylakoid protein kinase STN7. Nature. 2005;433:892-895. DOI 10.1038/nature03286.

Longoni P., Douchi D., Cariti F., Fucile G., Goldschmidt-Clermont M. Phosphorylation of the Light-Harvesting Complex II Isoform Lhcb2 Is Central to State Transitions. Plant Physiol. 2015;169:2874-288.

Wunder T., Liu Q., Aseeva E., Bonardi V., Leister D., Pribil M. Control of STN7 transcript abundance and transient STN7 dimerisation are involved in the regulation of STN7 activity. Planta. 2013;237: $541-558$.

Puthiyaveetil S. A mechanism for regulation of chloroplast LHC II kinase by plastoquinol and thioredoxin. FEBS Lett. 2011;585:17171721.

Dietzel L., Brautigam K., Pfannschmidt T. Photosynthetic acclimation: state transitions and adjustment of photosystem stoichiometry-functional relationships between short-term and long-term light quality acclimation in plants. FEBS J. 2008;275:1080-1088.

Dietzel L., Glaber C., Liebers M., Hiekel S., Courtois F., Czarnecki O., Schlicke H., Zubo Y., Borner T., Mayer K., Grimm B., Pfannschmidt $\mathrm{T}$. Identification of early nuclear target genes of plastidial redox signals that trigger the long-term response of Arabidopsis to light quality shifts. Mol. Plant. 2015;8:1237-1252. 
Eberhard S., Finazzi G., Wollman F.A. The dynamics of photosynthesis. Annu. Rev. Genet. 2008;42:463-515.

Caffarri S., Tibiletti T., Jennings R.C., Santabarbara S. A Comparison Between Plant Photosystem I and Photosystem II Architecture and Functioning. Current Protein Peptide Sci. 2014;15:296-331.

Shi L.-X., Hall M., Funk C., Schrцder W.P. Photosystem II, a growing complex: updates on newly discovered components and low molecular mass proteins. Biochim. Biophys. Acta. 2012;1817:13-25. DOI 10.1016/j.bbabio.2011.08.008.

Rantala M., Tikkanen M., Aro E.-M. Proteomic characterization of hierarchical megacomplex formation in Arabidopsis thylakoid membrane. Plant Journal. 2017;92:951-962.

Bielczynski L.W., Schansker G., Croce R. Effect of Light Acclimation on the Organization of Photosystem II Super- and Sub-Complexes in Arabidopsis thaliana. Frontiers Plant Sci. 2016;7. Article 105.

Yadav K.N., Semchonok D.A., Nosek L., Kouřil R., Fucile G., Boekema E.J., Eichacke L.A. Supercomplexes of plant photosystem I with cytochrome b6f, light-harvesting complex II and NDH. Biochim. Biophys. Acta. 2017;1858:12-20.

Bonaventura C., Myers J. Fluorescence and oxygen evolution from Chlorella pyrenoidosa. Biochim. Biophys. Acta 1969;189:366-383.

Goldschmidt-Clermont M., Bassi R. Sharing light between two photosystems: mechanism of state transitions. Current Opinion Plant Biol. 2015;25:71-78.

Kono M., Terashima I. Long-term and short-term responses of the photosynthetic electron transport to fluctuating light. J. Photochemistry Photobiol. 2014;137:89-99.

Nilsson A., Stys D., Drakenberg T., Spangfort M.D., Forsen S., Allen J.F. Phosphorylation controls the three-dimensional structure of plant light harvesting complex II. J. Biol. Chem. 1997;272:18350-18357.

Anknowlegments. This work was supported by the RFBR No. 1834-00800.

Conflict of interest. The authors declare no conflict of interest. 


\title{
Features of the interaction of miRNAs with genes of the rice MYB family under stress
}

\author{
A.T. Ivashchenko*, A.K. Rakhmetullina, A.U. Pyrkova \\ Al-Farabi Kazakh National University, Almaty, Kazakhstan
}

DOI 10.18699/ICG-PlantGen2019-33

(c) Autors, 2019

* e-mail: a.iavashchenko@gmail.com

\begin{abstract}
Data on the involvement of miRNA in the plant response to stress factors are considered. The MYB family of transcription factors plays a great role in the plant development, metabolism and responses to biotic and abiotic stress. The free energy of miRNA binding, the value of free energy of interaction, the position and schemes of potential binding sites were calculated using the MirTarget program. To identify miRNAs whose targets are genes in the MYB family, a search for binding sites of 738 miRNAs in mRNAs of 124 MYB family genes of Oryza sativa was performed. 16 genes were identified as targets for 11 miRNAs. The results show that miRNA can regulate the expression of most MYB genes and thus affect productivity and sustainability.

Key words: miRNA; mRNA; genes; transcription factors; rice; stress.
\end{abstract}

\section{Introduction}

Rice is one of the main food crops. According to the Food and Agriculture Organization of the United Nations, rice is the staple food for more than half of the world's population. MYB proteins constitute one of the largest transcription factor families in the plant kingdom, members of which are key factors in regulatory networks controlling development, metabolism and responses to biotic and abiotic stresses in the plant genome (Shushi et al., 2015). In agricultural production, abiotic stresses are known as the main causes leading to lower yields (Hoang et al., 2017). The plants have developed complex mechanisms for overcoming various stresses (Jian et al., 2010). Recent evidence suggests that miRNAs are involved in the regulation of gene expression, which affects the post-transcriptional stage of gene expression and relates to biotic and abiotic stress reactions in plants (Bari et al., 2014). Stress in plants causes an increase or decrease in the expression of certain miRNAs or the synthesis of new miRNAs (Varsha et al., 2016). Several stress-regulated miRNAs have been found in plants under various biotic and abiotic stressful conditions, including nutrient deficiency (Fujii et al., 2005), drought (Zhao et al., 2007; Liu et al., 2008; Zhou et al., 2010), low temperatures (Zho et al., 2008), salinity (Sunkar et al., 2008), bacterial infection (Navarro et al., 2006), UV-B radiation (Zhou et al., 2007), and mechanical stress (Lu et al., 2005). These studies suggest that miRNA is regulated in various ways in response to stress. However, limited studies have reported an association of miRNA with the expression of plant MYB genes. In the present work, the task was set to identify, using bioinformatics approaches, miRNAs that can bind to mRNA genes of the MYB family of rice and regulate their expression.

\section{Materials and methods}

The object of the study was the completely sequenced $O$. sativa genome. The nucleotide sequences of the mRNA genes of the MYB family were obtained from PlantTFDB, a plant transcription factor database (planttfdb.cbi.pku.edu.cn/). The miRNA nucleotide sequences were borrowed from miRBase (http://www.mirbase.org/). The free energy $(\Delta \mathrm{G})$ of miRNA binding, the position and schemes of potential binding sites were calculated using the MirTarget program (Ivashchenko et al., 2016). $\Delta \mathrm{Gm}$ for miRNA was defined as the free energy of miRNA binding with its fully complementary nucleotide sequence. The miRNA binding sites with mRNA were selected with the $\Delta \mathrm{G} / \Delta \mathrm{Gm}$ ratio being more than $90 \%$. Unique features of the MirTarget program include the consideration of the nucleotide interaction in miRNA with the mRNA of target genes not only between adenine (A) and uracil (U), guanine $(\mathrm{G})$ and cytosine $(\mathrm{C}), \mathrm{G}-\mathrm{U}$, but also between $\mathrm{A}$ and $\mathrm{C}$ through a single hydrogen bond based on the fact that the distance between $\mathrm{A}$ and $\mathrm{C}$ is equal to the distance between the nucleotides G-C, A-U, G-U (Leontis et al., 2002; Kool et al., 2001).

\section{Results and discussion}

B The study of the binding of 738 miRNA to mRNA of 124 genes of the MYB $O$. sativa family revealed that only 16 genes were targets for 11 miRNA (Table 1).

Four miRNA of the miR159c,d,e,f-3p family had the largest number of binding sites which were associated with mRNA genes (LOC_Os06g40330.1, LOC_Os01g59660.1, LOC Os05g41166.1, LOC_Os03g38210.1, LOC_Os04g46384.1) of the MYB family with the $\Delta \mathrm{G} / \Delta \mathrm{Gm}$ value from 90 to $96 \%$. Therefore, miR159 involved in the response to stress (Varsha et al., 2016) can affect the expression of the rice genes studied. miR2102-5p was binding with mRNA genes (LOC Os03g26130.1, LOC_Os01g64360.1, LOC_Os01g62410.1, LOC_Os03g25550.1) with the energy from $-110 \mathrm{~kJ} / \mathrm{mole}$ to $-113 \mathrm{~kJ} /$ mole and the degree of complementarity $(\Delta \mathrm{G} / \Delta \mathrm{Gm})$ $91 \%$ and $93 \%$. miR5075-3p had two binding sites in the mRNA of MYB genes. miR171d-5p, miR172d-5p; miR5827$5 \mathrm{p}$ had only one target gene (LOC_Os03g27090.1, LOC Os04g42950.1, LOC_Os06g02250.1, LOC_Os06g46560.1, $\mathrm{LOC}$ Os01g18240.1) with the value of $\Delta \mathrm{G} / \bar{\Delta} \mathrm{Gm}$ from 91 to $93 \%$. The miRNA binding sites in the mRNA genes of the MYB $O$. sativa family were located in the protein coding region. 
Table 1

Characteristics of miRNA BSs in the coding region mRNA of MYB transcription factors genes of $O$. sativa

\begin{tabular}{lllll}
\hline Gene & miRNA & Start & $\Delta \mathrm{G}, \mathrm{kJ} / \mathrm{mole}$ & $\Delta \mathrm{G} / \Delta \mathrm{Gm}, \%$ \\
\hline LOC_Os06g40330.1 & miR159c-3p & 1418 & -102 & 92 \\
LOC_Os01g59660.1 & miR159c-3p & 1343 & -102 & 92 \\
LOC_Os05g41166.1 & miR159c-3p & 878 & -106 & 91 \\
LOC_Os03g38210.1 & miR159d-3p & 938 & -102 & 92 \\
LOC_Os05g41166.1 & miR159d-3p & 878 & -104 & 92 \\
LOC_Os05g41166.1 & miR159e-3p & 878 & -102 & 90 \\
LOC_Os06g40330.1 & miR159f-3p & 1418 & -100 & 90 \\
LOC_Os04g46384.1 & miR159f-3p & 199 & -100 & 94 \\
LOC_Os01g59660.1 & miR159f-3p & 1343 & -104 & 91 \\
LOC_Os03g27090.1 & miR171d-5p & 369 & -106 & 90 \\
LOC_Os04g42950.1 & miR172d-5p & 995 & -96 & 91 \\
LOC_Os03g26130.1 & miR2102-5p & 661 & -110 & 91 \\
LOC_Os01g64360.1 & miR2102-5p & 453 & -110 & 91 \\
LOC_Os01g62410.1 & miR2102-5p & 441 & -110 & 93 \\
LOC_Os03g25550.1 & miR2102-5p & 804 & -113 & 91 \\
LOC_Os04g38740.1 & miR5075-3p & 727 & -113 & 95 \\
LOC_Os08g34960.1 & miR5075-3p & 553 & -117 & 91 \\
LOC_Os06g02250.1 & miR528-5p & 523 & -106 & 93 \\
LOC_Os06g46560.1 & miR5819-5p & 777 & -115 & 92 \\
LOC_Os01g18240.1 & miR5827-5p & 604 & -98 & \\
\hline
\end{tabular}

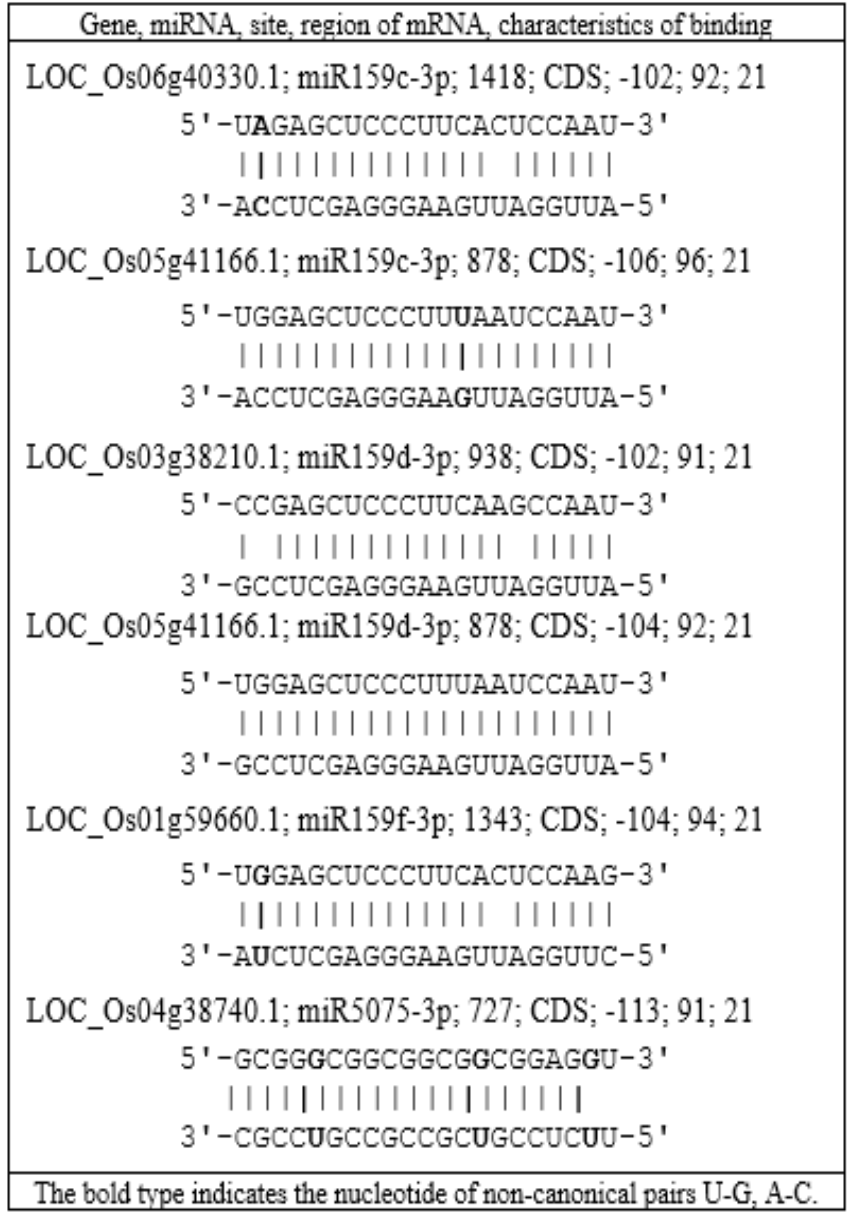

Figure 1. Schemes of miRNA interaction with mRNAs of MYB transcription factor genes in O. sativa.
Interaction schemes of miRNA with the MYB O. sativa mRNA genes (Figure 1), obtained using the miRTarget program, clearly show connections between their complementary nucleotides. Above each scheme is the name of the gene, the name of miRNA, the position of the beginning of the binding site (nt), the binding energy $(\mathrm{kJ} / \mathrm{mol})$, the value $\Delta \mathrm{G} / \Delta \mathrm{Gm}(\%)$ and the length of mRNA (nt). The upper and lower nucleotide sequences indicate mRNA and miRNA, respectively.

\section{Conclusions}

As a result of the research for each miRNA, groups of target genes of MYB transcription factors were established. The schemes of interaction of the nucleotide sequences of the studied miRNAs with the nucleotide sequences of the mRNA genes of the transcription factors of the MYB family were constructed. The associations found between miRNAs and genes can be used as markers of control of physiological processes in selection and regulation of growth of plant that are highly productive and resistant to abiotic and biotic stresses.

\section{References}

Bari A., Sagaidak I., Pinskii I., Orazova S., Ivashchenko A. Binding of miR396 to mRNA of Genes Encoding Growth-Regulating Transcription Factors Plants. 2014;61(6):807-810. DOI 10.1134/S102 1443714050033.

Fujii H., Chiou T.J., Lin S.I., Aung K., Zhu J.K. A miRNA involved in phosphate-starvation response in Arabidopsis. Curr. Biol. 2005; 15(22):2038-2043. DOI 10.1016/j.cub.2005.10.016.

Hoang X., Nhi D., Thu N., Thao N., Tran L. Transcription factors and their roles in signal transduction in plants under abiotic stresses. 2017;18(6):483-497. DOI 10.2174/1389202918666170227150057.

Ivashchenko A.T., Pyrkova A.Y., Niyazova R.Y., Alybayeva A., Baskakov K. Prediction of miRNA binding sites in mRNA. Bioinformation. 2016;12(4):237-240. 
Kool E.T. Hydrogen bonding, base stacking, and steric effects in DNA replication. Annu Rev Biophys Biomol Struct. 2001;30:1-22. DOI 10.1146/annurev.biophys.30.1.1.

Leontis N.B., Stombaugh J., Westhof E. The non-Watson-Crick base pairs and their associated isostericity matrices. Nucleic Acids Res. 2002;30(16):3497-3531. DOI 10.1093/nar/gkf481.

Liu H.H., Tian X., Li Y.J., Wu C.A., Zheng C.C. Microarray-based analysis of stress-regulated microRNAs in Arabidopsis thaliana. RNA. 2008;14(5):836-843. DOI 10.1261/rna.895308.

Lu S., Sun Y.H., Shi R., Clark C., Li L., Chiang V.L. Novel and mechanical stress-responsive micrornas in Populus trichocarpa that are absent from Arabidopsis. Plant Cell. 2005;17(8):2186-2203. DOI 10.1105/tpc. 105.033456 .

Navarro L., Dunoyer P., Jay F., Arnold B., Dharmasiri N., Estelle M., Voinnet O., Jones J.D. A plant miRNA contributes to antibacterial resistance by repressing auxin signaling. Sci. 2006;312(5772):436439. DOI 10.1126/science. 1126088.

Shushi S., Amit K., Viswanathan Ch., Dev M.P., Kailash C.B. Transcriptional Regulatory Network Analysis of MYB Transcription
Factor Family Genes in Rice. Front Plant Sci. 2015;6:1157. DOI 10.3389/fpls.2015.01157.

Sunkar R., Zhou X., Zheng Y., Zhang W., Zhu J.-K., Identification of novel and candidate miRNAs in rice by high throughput sequencing. BMC Plant Biol. 2008;29(8):25. DOI 10.1186/1471-2229-8-25.

Zhao B., Liang R., Ge L., Li W., Xiao H., Lin H., Ruan K., JinY. Identification of drought-induced microRNAs in rice. Biochem. Biophys. Res. Commun. 2007;354(2):585-590. DOI 10.1016/j.bbrc. 2007.01.022

Zhou L., Liu Y., Liu Z., Kong D., Duan M., Luo L. Genome-wide identification and analysis of drought-responsive microRNAs in Oryza sativa. J. Exp. Bot. 2010;61(15):4157-4168. DOI 10.1093/jxb/erq237.

Zhou X., Wang G., Zhang W. UV-B responsive microRNA genes in Arabidopsis thaliana. Mol. Syst. Biol. 2007;3:103. DOI 10.1038/ msb4100143.

Zhou X., Wang G., Sutoh K., Zhu J.-K., Zhang W. Identification of cold-inducible microRNAs in plants by transcriptome analysis. Biochim. Biophys. Acta. 2008;1779(11):780-788. DOI 10.1016/j. bbagrm.2008.04.005.

Conflict of interest. The authors declare no conflict of interest. 


\title{
Sensitive biomarker for assessing the effects of the environment on the population of plants
}

\author{
L.A. Minasbekyan ${ }^{1 *}$, G.S. Aidarkhanova ${ }^{2}$, I.A. Avagyan ${ }^{3}$ \\ ${ }^{1}$ YSU, Research Institute of Biology, Yerevan, Armenia \\ ${ }^{2}$ S. Seyfulin Kazakh AgroTechnical university, Nur-Sultan, Kazakhstan \\ ${ }^{3}$ SRC of V\&TC at AM of RA, Darakert, Armenia
}

DOI 10.18699/ICG-PlantGen2019-34

(c) Autors, 2019

* e-mail:minlia@ysu.am

\begin{abstract}
In the last few years, special importance has been given to the study of the population of pasture plants, since environmental pollution through animal food can be transmitted to humans. Due to these circumstances, it is imperative to regularly monitor pasture plants, both for relocating animals to more environmentally friendly meadows and as environmental protection measures aimed at improving damaged pastures. A great number of biotic and abiotic factors affect plant growth under natural growing conditions. No DNA sequence carries the complete information necessary to determine the phenotype of the organism. DNA methylation controls genomic integration, regulates genome expression and cell differentiation as well as the plant response to biotic and abiotic stresses. Epigenetic regulation involves various reversible chemical modifications occurring on both the DNA itself and the proteins interacting with it, affecting the chromatin structure and function without, however, altering the sequence of nucleic residues in the DNA. Epigenetics holds promise to explain at least a part of the influences the environment has on plants' phenotypes. Among pasture plants are widely distributed Bromus inermis, Medicago sativa, Onobrychis arenaria, Agropyron pectinoforme, etc. We have studied DNA methylation in esparcet (Onobrichis arenaria) and crested wheat grass (Agropyron cristatum) from the Kazakh Steppe and discuss the environmental factors that can led to changes in epigenetics marks. The data obtained on epigenetic changes in the plants studied will improve the methods of pasture monitoring, taking into account the ecological, climatic conditions of the regions and the agricultural sector of the countries' economies. Below is summarized literature data-based evidence about the sensitivity of DNA methylation and its use as a biomarker for ecological epigenetics. Data sets for model plants under different abiotic factors and non-model plants established for ecological epigenetics are provided. Key words: epigenetics; DNA methylation; biomarkers; abiotic stress factors.
\end{abstract}

\section{Introduction}

Plants growth under environmental conditions in the assessed climate and landscape is constantly subject to different environmental factors whcih, when rapid and extreme, can be recognized as stresses. Among the stresses the plants are constantly confronted with are both biotic (hormones, pests and insects) and abiotic (osmtic, temperature fluctuations, drought, radiofrequency, metal and microelemens) environmental impact factors, which seriously reduce crop productivity and the quality of pasture plants. Plant responses to the abiotic stresses, such as salt, drought, extreme temperatures, and human-made extremely high frequencies, are complex and involve numerous physiological, cellular and molecular adaptations.

\section{Epigenetic changes in model plants under some abiotic stresses}

Plants have a special system to adjust themselves to extreme external stressful conditions through instantly transmitting signals. Plant cells receiving signals from external stimuli through fluctuations in cytosolic concentrations decode them using their own machinery to the secondary messenger. $\mathrm{Ca}^{2+}$ is encoded in various stimuli of abiotic and biotic stresses. Recently, the Calcineurin B-like (CBL) protein-CBL-interacting protein kinase (CIPK) complex has been widely accepted as a
$\mathrm{Ca}^{2+}$ signaling mechanism, which is involved in the response to different external stress signals, including mm-wave impact (Manik et al., 2015; Pall, 2016). Exposure of 3-week tomato seeds to a high- frequency, low-amplitude electromagnetic field leads to altered expressions of at least five stress-related genes (Vian et al., 2016).

Under different abiotic and biotic stress factors, plant experience the alteration of many processes. It is known that at least four different regulons act in response to abiotic stresses. Dehydration-responsive element binding protein 1 (DREB1)/C-repeat binding factor (CBF) acts in response to cold stress. In response to heat stress, DREB2 regulons start to act influencing ABA-independent gene expression. The ABAresponsive element (ABRE) binding protein (AREB)/ABRE binding factor (ABF0 regulon functions in ABA-dependent gene expression under osmotic stress conditions (Ciarmiello et al., 2014).

In addition, there are NAC and MYB/MYC regulons involved in stress response gene expression. Expression profiling from 23 selected T. aestivum NAC genes at the developmental stages in field drought conditions identified seven with leafspecific expression and five with a grain-specific expression, the profiles of which depended on the genotype (Guerrin et al., 2019). 
Recent studies shows a positive effect of a combination of biotic and abiotic stresses on plant performance, reducing sensitivity to biotic stress. The interaction between both types of stress points to a crosstalk between their conformable signaling pathways. Such crosstalk may be synergistic and/or antagonistic and may include, among others, the involvement of phytohormones, transcription factors, kinase cascades and reactive oxygen species, which can lead to an enhancement in plant resistance against pathogens (Rejeb et al., 2014).

Multiple studies of model plants provide evidence that, in response to different abiotic and biotic stresses, epigenetic modifications in gene expression take place, which are heritable changes and are not encoded by a DNA sequence (Yong-Villalobos et al., 2015; Yong et al., 2016; Banerjee, Roychoudhury, 2018).

Although DNA methylation is only a minor chemical modification of cytosin residues, it is an important epigenetic modification, which carries valuable information for properly regulating gene expression and, therefore, a broad range of biological processes and diseases. DNA methylation is tissue-specific, dynamic, sequence-context-dependent and trans-generationally heritable, and these complex patterns of methylation highlight the significance of profiling DNA methylation to answer biological questions (Yong et al., 2016). Epigenetic modifications in the model plant characterized by genome-wide DNA methylation, histone modification, histone variant deposition, various classes of small RNAs, nucleosomal positioning, and chromatin modifications have a transgenerational adaptive response to biotic and abiotic environmental stresses (Dukowic-Shulz et al., 2018; Kumar et al., 2018; Wakeel et al., 2018; Weinhold, 2018).

\section{Epigenetic alterations in non-model plants}

The ecological and evolutionary significance of natural epigenetic variation commonly depends critically on whether epigenetic states are transmitted from parents to offspring. Although little is known about epigenetic inheritance in non-model plants, it has been shown that DNA methylation mediates the inherited genotype-specific effects of drought stress in P. persicaria (Herman, 2016).

The study showed that the genotype, epigenotype, and parental soil-moisture environment interact with systems, including drought, nutrient limitation, pathogen infection, high salinity, temperature shock, and UV radiation. Such DNA methylation changes have been associated with the induced expression of critical stress-response genes, thus implicating DNA methylation in the expression of adaptive phenotypic plasticity (Herman, 2016). The extensive transgenerational transmission of genome-wide global cytosine methylation and anonymous epigenetic markers in the non-model species L. latifollia was revealed (Herrera et al., 2017).

Analysis of methylation-sensitive amplification polymorphism (MSAP) has been often used to assess methyl-cytosine changes in response to stress treatment and, quite lately, in ecological studies of wild plant populations. The paper summarizes literature data on global DNA methylation in wild plants populations, analyzes the relationship between MSAP results and the percentage of global cytosine methylation in genomic DNA obtained by HPLC analysis (Alonso et al.,
2016). Notably, that environmentally induced epigenetic effects may be either transient or persistent across generations, and heritable changes may be either selected or linked to something that is selected. Future analyses should consider that part of the epigenetic variation is similar to phenotypic variation, and carefully designed experiments are necessary to characterize both genetic and environmental contributions to epigenetic variation (Richards et al., 2017).

\section{Conclusion}

The obtained data on epigenetic changes of the pasture plants will improve the methods of monitoring pastures used for agricultural purposes, taking into account the ecological, climatic conditions of the regions and the agricultural sector of the countries' economies.

The results of such studies will help to rank the populations of forage plants according to the rate of formation of microevolutions and will contribute to the improvement of traditional methods of agricultural technology. For natural pastures, one must also take into account the fact that the most important factor leading to the dynamical epigenetic changes in the populations of wild plants is climate change.

\section{References}

Alonso C., Perez R., Bazaga P., Medrano M., Herrera C.M. MSAP markers and global cytosine methylation in plants: a literature survey and comparative analysis for a wild-growing species. Mol. Ecol. Resources. 2016;16:80-90.

Banerjee A., Raychoudhary A. The gymnastics of epigenomics in rice. Plant Cell Rep. 2018;37:25-49. https://doi.org/10.107/s00299-0172192-2.

Ciarmiello L.F., Woodrow P., Piccirillo P., De Luca A., Carillo P.Ch. 3 "Transcription Factors and Environmental Stresses in Plants". In: Emerging Technologies and Management of Crop Stress Tolerance. 2014;57-78. ISBN: 9780128008768, https://doi.org/10.1016/b9780-12-800876-8.00003-5.

Dukowic-Schulze S., Liu C., Chen C. Not just expression: 3D implications of chromatin modifications during sexual plant reproduction. Plant Cell Rep. 2018;37:11-16. DOI 10.1007/s00299-017-2222-0.

Guerrin C., Roche J., Allard V., Ravel C., Mouzeyar S., Bouzidi M.F. Genome-wide analysis, expansion and expression of the NAC family under drought and heat stresses in bread wheat (T. aestivum L.). PLoS ONE. 2019;14(3):e0213390. https://doi.org/10.1371/journal. pone. 0213390

Herman J.J. Epigenetics of adaptive plasticity: an investigation of plant responses to environmental stress within and across generations. Diss. on PhD, Wesleyan University, 2016.

Herrera C.M., Alonso C., Medrano M., Perez R., Bazaga P. Transgenerational epigenetics: inheritance of global cytosine methylation and methylation-related epigenetic markers in the shrub Lavandulalatifolia. American J. Bot. 2017;105(4):1-8. DOI 10.1002/ajb2. 1074.

Kumar V., Khare T., Shriram V., Wani S.H. Plant small RNAs: the essential epigenetic regulators of gene expression for salt-stress responses and tolerance. Plant Cell Rep. 2018;37:61-75 https://doi. org/10.1007/s00299-017-2210-4.

Manik N.S.M., Shi S., Mao J., Dong L., Su Y., Wang Q., Liu H. The calcium sensor CBL-CIPK is involved in plant's response to abiotic stresses. Int. J. Genomics. 2015; article ID 493191.

Pall M.L. Electromagnetic fields act similarity in plants as in animals: probable activation of calcium channels via thei. Current Chemical Biol. 2016;10(1):74-82. DOI 10.2174/ 22127968106661 60419160433 
Rejeb I.B., Pator V., Mauch-Mani B. Plant response to simultaneous biotic and abiotic stress: molecular mechanisms. Plants. 2014;458475. DOI 10.3390/plants3040458.

Richards C.L., Alonso C., Becker C., Bossdorf O. et al. Ecological plant epigenetics: evidence from model and non-model species, and the way forward. Ecol. Letters. 2017;20:1576-1590. DOI 10.1111/ele. 12858

Vian A., Davies E., Gendraud M., Bonnet P. Plant responses to high frequency electromagnetic fields. Bio Med Research International. 2016; Article ID 1830262.

Wakeel A., Ali I., Khan A.R., Wu M., Upretti S., Liu D, Liu B., Gan Y. Involvement of histone acetylation and deacetylation in regulating auxin responses and associated phenotypic changes in plants. Plant Cell Rep. 2018;37:51-59. https://doi.org/10.1007/s00299-0172205-1.
Weinhold A. Transgenerational stress-adaption: an opportunity for ecological epigenetics. Plant Cell Rep. 2018;37:3-9. DOI 10.1007/ s00299-017-2216-y.

Yong W.-Sh., Hsu F.-M., Chen P.-Y. Profiling genome-wide DNA methylation epigenetics chromatin. 2016;9:26. DOI 10.1186/s13072016-0075-3.

Yong-Villalobos L., González-Morales S.I., Wrobel K., Gutiérrez-Alanis D., Cervantes-Peréz S.A., Hayano-Kanashiro C., Oropeza-Aburto A., Cruz-Ramírez A., Martínez O., Herrera-Estrella L. Methylome analysis reveals an important role for epigenetic changes in the regulation of the Arabidopsis response to phosphate starvation. Proc Natl Acad Sci USA. 2015;29;112(52):E7293-302. DOI 10.1073/ pnas. 1522301112.

Conflict of interest. The authors declare no conflict of interest. 


\title{
Selenium nanocomposites as a protection agent from potato ring rot
}

\author{
O.A. Nozhkina ${ }^{1 *}$, A.I. Perfileva ${ }^{1}$, I.A. Graskova ${ }^{1,3}$, B.G. Sukhov ${ }^{2,3}$ \\ 1 Siberian Institute of Plant Physiology and Biochemistry, SB RAS, Irkutsk, Russia \\ ${ }^{2}$ Irkutsk Institute of Chemistry named after A.E. Favorsky, SB RAS, Irkutsk, Russia \\ ${ }^{3}$ Irkutsk Scientific Center, Irkutsk, Russia
}

DOI 10.18699/ICG-PlantGen2019-35

(c) Autors, 2019

* e-mail: smallolga@mail.ru

\begin{abstract}
Nanocomposite substances based on natural matrices - arabinogalactan, starch, carrageenan - were used in the work. Studies have been conducted on the effect of nanocomposites on the pathogen of ring rot of potatoes, as well as the growth and development of plants in vitro. The data obtained did not show a negative effect on plants, but showed an antibacterial effect on the growth and biofilm formation of bacteria.

Key words: nanocomposite substances; ring rot; plants in vitro.
\end{abstract}

\section{Introduction}

Potato plants are susceptible to various bacterial diseases that have a negative impact on yield (Anisimov et al., 2009). One such disease is ring rot caused by the bacterium Clavibacter michiganensis ssp. sepedonicus. The disease is characterized by withering of plants at the stage of vegetation, metabolic disorders. Bacteria have the ability to overwinter in the affected tubers and are not stored in the soil, but can be stored for several years in the form of dried mucus on the surface of the container, on the harvesting equipment and in storage facilities. All known measures to combat the disease are reduced to disinfection with aggressive reagents (Eichenlaub et al., 2011). Therefore, it became necessary to search for safe resources of control and such resources are nanocomposite substances in a polysaccharide matrix containing selenium.

\section{Materials and methods}

The paper used potato plants in vitro, variety Lukyanovsky, which is susceptible to ring rot of potatoes (Romanenko et al., 1999), nanocomposites with selenium (NC) in the natural polysaccharide matrices arabinogalactan (AG), starch (St), carrageenan (Car), as well as bacteria Clavibacter michiganensis ssp. sepedonicus (Cms) strain Ac-1405 obtained from the All-Russian Collection of Microorganisms, Pushchino, Moscow region. Plants were propagated by cuttings on microclonal apparitional nutrient Murashige-Skoog medium $(4.2 \mathrm{~g} / \mathrm{l})$ supplemented with $30 \mathrm{~g} / 1$ sucrose. The plants were cultivated for 20 days at $26^{\circ} \mathrm{C}$ and 5-6 KLC illumination. A liquid culture for $\mathrm{Cms}$ to investigate bacteriostatic activity with selenium nanocomposite against ring rot of potatoes was grown in the dark at $26{ }^{\circ} \mathrm{C}$ on a rocker $(80 \mathrm{rpm})$ in flasks containing a GPY nutrient medium, pH 7.2 (Roozen et al., 1991). When considering the effect of NC on the plants we investigated the following biometric indicators: the growth rate of plants, growth of leaves of plants, increase in root mass of plants, the growth of the ground part of the plant, the activity of the enzyme peroxidase in plant tissues, and the content of active forms of oxygen in the tissues of plant roots. The effect of $\mathrm{NC}$ on the causative agent of the disease was checked using the method of optical density measurement of bacterial suspension and biofilm formation.

For experiments, we used solutions of nanocomposites, in which the content of selenium was $0.000625 \%$. All nanocom- posites were synthesized at the Irkutsk Institute of Chemistry. All synthesized substances are highly soluble in water and easy to use their aqueous solutions. Synthesis of NC Se was performed by oxidation of readily available sodium with hydrogen peroxide. The synthesis process was described in detail previously (Rodionova et al., 2015).

\section{Results and discussion}

As a result of the experiments conducted on bacteria, bactericidal and bacteriostatic effects were found in $\mathrm{NC} \mathrm{Se/AG}$ $(6.4 \% \mathrm{Se})$, compared with other starch- and carrageenanbased nanocomposites. This nanocomposite inhibited the growth of bacterial suspension, reduced the formation of biofilms, one of the important abilities of bacteria (Figure 1).

Furthermore, when studying the effect of nanocomposites on potato plants, no negative effect was observed. During the observation it was found that there was no stretching of the plant. Next, we examined the effects of $\mathrm{NC}$ at the infection of plants by the pathogen. A closer examination of the indicators revealed a stimulating effect in all the studied nanocomposites, both in infection and without. NC Se/St and NC Se/Car had a more pronounced effect (Figure 2).

During incubation of plants with NC Se/AG and Cms a decrease was found in the activity of peroxidase in relation to control plants, which indicates a decrease in stress in plants during infection. The accumulation of Se in plant tissues a day after NC treatment by the method of x-ray energy dispersive microanalysis (ReDMA) was also investigated. The analysis showed the absence of selenium within the detection limits of the device (Table 1). The effect of NK on soil bacteria was also studied. A pronounced negative effect of the duration of the experiment was not revealed.

\section{Conclusions}

The experiments revealed bacteriostatic and bacteriological effects of the selected selenium-containing nanocomposites. Experiments have shown the effect on the important ability of bacteria to form biofilms. NC Se prevents the formation of biofilms. NC Se/AG has a pronounced effect. It was shown that selenium does not accumulate in plant tissues after treatment with nanocomposites and infection. It helps cope with the disease (reduces the biometric index of plant activity peroxidase, one of the indicators of stress). These experimental results 


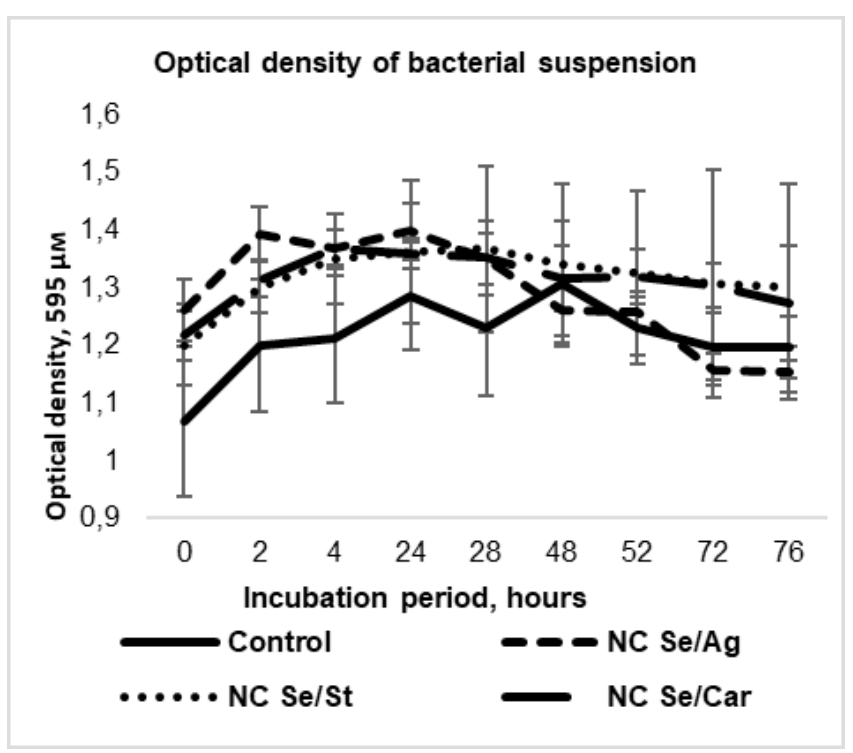

Figure 1. Effect of nanocomposites of selenium (NC Se) and arabinogalactan (AG), starch (St) and carrageenan (Car).

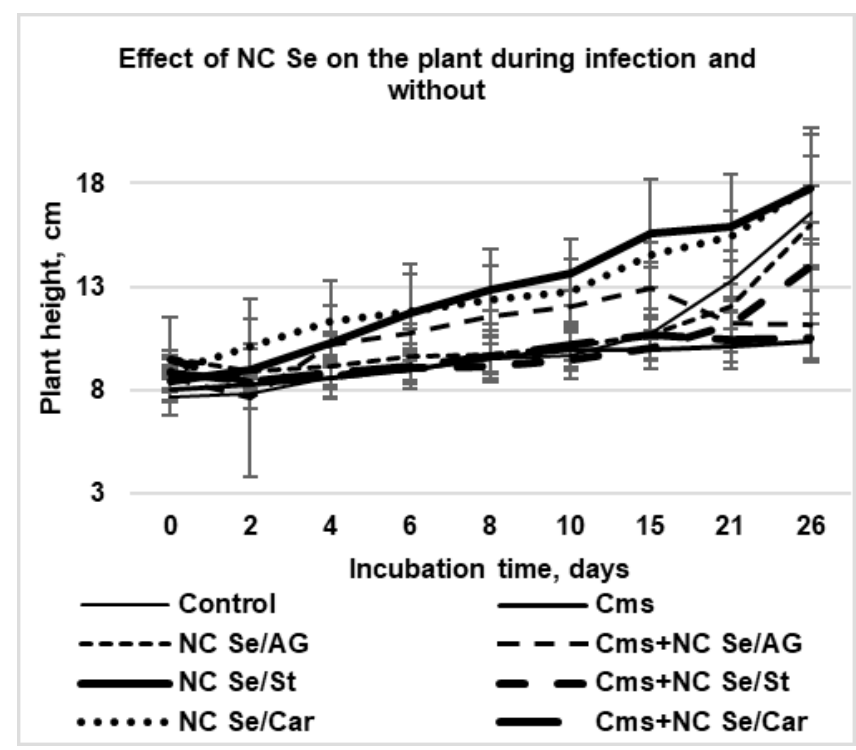

Figure 2. Effect of selenium nanocomposites (NC Se) in infection (Cms+NC Se) and without it (AG, arabinogalactan; St, starch; Car, carrageenan).

Table 1

The results of $\mathrm{x}$-ray energy-dispersive spectral microanalysis of potatoes plant tissue after processing on nanocomposites

\begin{tabular}{llll}
\hline Element & Norm. C [wt.\%] & Atom. C [at.\%] & Error [\%] \\
\hline Oxygen & 45.77 & 39.54 & 5.1 \\
Carbon & 45.36 & 52.19 & 5.0 \\
Nitrogen & 7.92 & 7.82 & 1.1 \\
Phosphorus & 0.69 & 0.31 & 0.1 \\
Magnesium & 0.26 & 0.15 & 0.0 \\
Sodium & 0.00 & 0.00 & 0.0 \\
Selenium & 0.00 & 0.00 & 0.0 \\
Total: & 100.0 & 100.0 & \\
\hline
\end{tabular}

allow us to consider these nanocomposite saline substances as an environmentally safe means to combat bacterial diseases of agricultural plants.

\section{References}

Anisimov B.V., Belov G.L., Varichev A.Yu., Elansky S.N., Zhuromsky G.K., Zavriev S.K., Zarouk V.N., Ivanyuk V.G., Kuznetsov M.A., Pliakhnevich M.P., Pshechenkov K.A., Simakov E.A., Sklyarova N.P., Staszewski Z., Uskov A.I., Yashin I. M. Protection of potato from diseases, pests and weeds. Moscow: Potato, 2009; 272 p.

Eichenlaub R., Gartemann K.H. The Clavibacter michiganensis subspecies: molecular investigation of grampositive bacterial plant pathogens. Ann. Rev. Phytopathol. 2011;49:445-464.

Romanenko A.S., Riffel A.A., Graskova I.A., Rachenko M.A. The role of extracellular pHhomeostasis in potato resistance to ring rot pathogen J. Phytopathol. 1999;147(11-12).
Roozen N.J.M., Van Vuurde J.W.L. Development of a semi-selective medium and an immunofluorescence colony-staining procedure for the detection of Clavibacter michiganensis subsp. sepedonicus in cattle manure slurry. Netherlands J. Plant Pathol. 1991;97(5): 321-334.

Rodionova L.V., Shurygina I.A., Sukhov B.G., Popova L.G., Shurygin M.G., Artemyev A.V., Pogodaeva N.N., Kuznetsov S.V., Gusarova N.K., Trofimov B.A. Nanobiocomposite of selenium and arabinogalactan: synthesis, structure and application. Journal General Chemistry. 2015;85(2);314-316.

Acknowledgements. The work was supported by grants of the President of the Russian Federation No. MK-1220.2019.11 and the Federal Property Fund of the Russian Federation and the Government of the Irkutsk region (project No. 17-416-380001).

Conflict of interest. The authors declare no conflict of interest. 


\section{Plant Biotechnology \\ in the Postgenomic Era}




\title{
Modern CRISPR/Cas9 biotechnology is a current challenge to create elite disease resistant crops cultivars
}

\author{
O.I. Kershanskaya, D.S. Nelidova, G.L. Esenbaeva, G.S. Mukiyanova, S.N. Nelidov
}

Institute Plant Biology and Biotechnology SC, MES RK, Almaty, Kazakhstan

DOI 10.18699/ICG-PlantGen2019-36

(c) Autors, 2019

* e-mail: gen_o.kersh@mail.ru

\begin{abstract}
The technology, a genome-editing tool called CRISPR-Cas9, revolutionized the life sciences when it appeared on the market in 2013. CRISPR (Clustered Regularly Interspaced Short Palindromic Repeats) associated with protein 9 (Cas9) is an RNA-regulated protection mechanism in bacteria and archaea. This is a new "crazy' popular technology of gene editing in humans, animals and higher plants. CRISPR/Cas9 gene-editing is allowing rapid scientific advances in many fields; now it has been shown that crop research can also benefit from this latest exciting technology. A new study of CRISPR-Cas9 technology shows potential to improve crop efficiency.
\end{abstract}

Key words: genome editing; CRISPR/Cas9; breeding perspective; barley.

\section{Introduction}

CRISPR/Cas9 is an RNA-regulated protection mechanism in bacteria and archaea. It is a new popular technology of gene editing in humans, animals and higher plants. The CRISPR/ Cas9 system is a simple, inexpensive and versatile tool for genome editing, resulting in a groundswell of research based on the technique, of which the popularity over the past 6 years has become known as the 'CRISPR craze' (Feng et al., 2013; Brooks et al., 2014; Doudna, Charpentier, 2014; Svitashev et al., 2015; Chandrasekaran et al., 2016; Khlestkina, Shumny, 2016; Gerasimova et al., 2017; Mushtaq et al., 2019). Unlike its predecessors, ZFNs or TALENs, the CRISPR/Cas9 system does not require any protein engineering steps, making it much more straightforward to test multiple gRNAs for each target gene. The CRISPR/Cas9 system consists of a single monomeric protein and a chimeric RNA. A 20-nt sequence in the gRNA confers sequence specificity and cleavage is mediated by the Cas 9 protein. Watson - Crick base pairing with the target DNA sequence is the basis for gRNA-based cleavage. CRISPR is now proving useful as a powerful tool for the improvement of agricultural crops. It is estimated that up to $40 \%$ of harvest is lost worldwide to pests/diseases threatening our food supply. The major crops-wheat, rice, barley-are susceptible to many viral and fungal diseases, which can result in a drastically reduced yield and poor quality grain. Crop cultivars with improved resistance to fungal or viral pathogens will benefit farmers and the local economy by increasing harvest yields and grain quality. The purpose of our research is: elaboration and establishment of a new breakthrough CRISPR/Cas9 biotechnology of genome editing for the creation of elite disease-resistant local barley varieties in Kazakhstan. In this review, some of the first steps in barley CRISPR/Cas9 genome editing for fungal and viral disease resistance are briefly discussed.

\section{Materials and methods}

Plant material: Five local cultivated Kazakhstan barley varieties, differing in yield and resistance to stress. Two of them are brewing barley, and three are feed barley.
Genetic material: target genes, constructs for transformation are: Ac-gene from Amaranthus caudatus, chitinase; CRISPR is a plant construction for barley genome editing by modification or knockout of eIF4E gene, the eukaryotic translation initiation factor that is required by many viruses for multiplication. eIF4E is a plant cellular translation factor essential for the Potyviridae life cycle, and natural point mutations in this gene can confer resistance to potyviruses.

Methods:

I. Gene molecular cloning techniques.

II. Procedure of CRISPR/Cas9 genome editing method:

1. Design sgRNA using the CRISPRdirect website. Requires the identification of target sites with specific sequence criteria, while also avoiding potential off-target effects.

2. Transcribe and screen sgRNA in vitro.

3. Design CRISPR-plant plasmid and constructs for target gene modification.

4. Preparation of Agrobacterium tumefaciens electro-competent cells.

5. Transformation of Agrobacterium tumefaciens competent cells with CRISPR-Cas9 plasmid.

6. Clone confirmation.

7. Deliver sgRNAs and Cas9 to the cell. There are several options for delivering sgRNAs and Cas9 to target cells.

We are developing a method for rapid genotype-independent delivery of genetic material using Agrobacterium pipetting, similar to a pollen-transfection method for other cereals and close to conventional cross-hybridization that requires no tissue culture steps. It is also effective to use bombardment, that is, bioballistic transformation using Bio-Rad' Gen Gun, USA. For S. pyogenes Cas9, the NGG PAM is required immediately downstream of the target site. The two strands of DNA are cut by the HNH and RuvC nuclease domains of Cas9. 8. Detection of Cas9 protein and confirmation of gene editing. Confirm that Cas9 protein is being expressed in target cells.

9. PCR screening. 10. Genotype determination. If there are indels on one or both copies of the target gene, Cas9/ sgRNA-mediated in vitro cleavage reaction can accurately determine the cell's genotype after gene editing. 


\section{Results}

The mechanism of genomic editing using CRISPR/Cas9 includes the next points. For genome editing purposes, generation of a targeted double-strand DNA break (DSB) is the key event that opens up multiple repair options both for the cell and the genome engineer. Such breaks are generally repaired by one of two pathways, homology-directed repair (HDR) or non-homologous end joining (NHEJ). Cells use NHEJ more frequently than HDR because the latter requires a template homologous to the regions flanking the break and to insertions or deletions (INDELs) at its position which can result in functional knock out of a gene.

In all phases of the cell cycle other than S phase, a homologous region of the chromosome is rarely in close enough proximity to act as this template, and thus NHEJ acts as a stop gap to quickly repair the break and maintain chromosomal integrity. NHEJ is an error-prone process that uses ligases, nucleases and polymerases to reseal a break, and generally results in nucleotides being inserted or deleted (indels) in an unpredictable process. If the break occurs in a protein-coding region, these indels will often result in a frame shift mutation and subsequent premature stop codon, abrogating the protein's function.

The magic of CRISPR is in its ability to force a DSB event. Cells must repair DSBs, otherwise there is a risk that cells will die. NHEJ typically leads to a knockout of the targeted genetic element's function. The process of monocots genomic editing includes the following stages: 1 ) selection of target sequences and design of sgRNA; 2) constructing of genetic vectors carrying the nuclease Cas9, sgRNA; 3 ) delivery of the "editing tools" to plant cells; 4) detection of changes in genomic DNA; 5) clean the expression cassette with foreign DNA.

To determine the nucleotide sequence of the target sgRNA, the following web resources in silico were used: CRISPRdirect, CRISPR-PLANT, CRISPR RGEN, etc. The best was CRISPRdirect. The sgRNA sequence for the eIF4E gene in barley (Hordeum vulgare mRNA for eukaryotic translation initiation factor 4E biomaterial PI 39500, Gene Bank accession no. FM244906.2) was selected as AAGGCAGGCCCGCCT. Cas9/sgRNA construct to target the barley eIF4E gene that was expected to disrupt the intact eIF4E protein had been designed. Other sgRNA2 that permit translation of two-thirds of the eIF4E gene protein products will be elaborated soon.

The sgRNA, Cas 9 nuclease, promoters, marker genes were used for constructing genetic vectors. Cassettes of expression of specific sgRNA included the promoter of ubiquitin 6 (U6) from Zea maize L. for sgRNA expression. The start for transcription initiation from the U6 promoter was $\mathrm{G}$ nucleotide. Cassettes for Cas 9 expression consisted of the $35 \mathrm{~S}$ promoter adapted to the Cas 9 coding sequence. The plant selection markers included the hygromycin B resistance gene and the neomycin phosphotransferase gene; the necessary sites of restriction of CRISPR/Cas9 constructs for use in barley is shown in Figure 1, $a$. The size of one sgRNA expression cassette was about $500 \mathrm{~kb}$. The total size of the plasmid was $13300 \mathrm{~kb}$.

As is known, Cas9 has been successfully used to edit the genomes of a number of plants, including barley (Khlestkina, Shumny, 2016; Gerasimova et al., 2017; Mushtaq et al., 2019).
Many genes of Gramineae family plants are characterized by an increased GC-content of the 5' region of the coding part. Cas9, according to the GC-content, corresponding to the structure of the cereal genes $(62.5 \%)$, with a total GC-content of $54.2 \%$, demonstrated a high efficiency of genome editing. In monocot plants, the promoters of ubiquitin genes of maize or rice have been successfully used for Cas9 expression.

Optimally composed expression cassettes made it possible to achieve $90 \%$ of the editing efficiency in T0. Genes of resistance to hygromycin (HPT), under the control of the $35 \mathrm{~S}$ promoter from Cauliflower mosaic virus, are often used as selective markers for editing the genomes of monocotyledonous plants. We have studied knock out and modification of epigenetic factor of virus eIF4E (eukaryotic factor of translation initiation), caused many virus translation initiation in barley. RNAi silencing of eIF $4 E$ has conferred resistance to multiple viruses in melon, broad spectrum resistance to potyviruses in tomato and cucumber (Chandrasekaran et al., 2016). More recently, Arabidopsis complete resistance to Turnip Mosaic Virus has been successfully engineered by editing eIF $4 E$ using the CRISPR/Cas9 tool.

For delivery of editing tools with an expression cassette into barley cells we have developed and patented a method of barley germ-line genetic transformation through pipetting with Agrobacterium tumefaciens, strain EHA105, the expression cassette carrying sgRNA and Cas9 nuclease, to stigma of barley flowers' pistils, exactly before anthesis. Pollen tubes were used as a delivery vector of the targeted construct into mature, but not divided yet, zygote. The method is genotype independent, simple, does not require the tissue culture step, effective at up to $20 \%$ of transformation frequency in the first generation of edited plants.

Confirmation of cloning CRISPR-plant construct and detection of edited events in barley were carried out by PCR, DNA sequencing with using Serial Cloner Program. For PCR screening of monocot CRISPR constructs, we have elaborated the forward primer 5'-GACCAAGCCCGTTATTCTGAC-3' and the reverse primer 5'-AAGTCTGATGCAGCAAGCGAG-3' to amplify the monocot fragment U6-sgRNA(305 bp) to confirm that the selected clones contain U6-sgRNA. The PCR amplification conditions were: $95^{\circ} \mathrm{C}$ for $2 \mathrm{~min}$ for initial denaturation; 30 cycles of $95^{\circ} \mathrm{C} / 30$ seconds, $60^{\circ} \mathrm{C} / 30 \mathrm{sec}$, and $72{ }^{\circ} \mathrm{C} / 30 \mathrm{sec} ; 1$ cycle of $72{ }^{\circ} \mathrm{C} / 5 \mathrm{~min}$.

Using CRISPR/Cas9 editing technology, we have developed $e I F 4 E$ non-transgenic barley mutants that exhibit resistance to three economically important viruses. In Agrobacterium-transformed T0 lines, we found deletions in the $e I F 4 E$ target gene in 8 lines out of 50 (see Figure 1, $b$ ). The same mutations were observed in the $\mathrm{T} 1$ generation, which implies a heterozygous mono-allellic T0 plant, as observed in tomato (Brooks et al., 2014) rice (Zhang et al., 2014) and cucumber (Chandrasekaran et al., 2016). In transgenic lines 4-6, progeny from the $\mathrm{T} 1$ generations showed partial cleavage activity of Cas9.

CRISPR/Cas9 tool editing of eIF4E gene has been successfully engineered in 5 local commercial Kazakhstan barley cultivars, not only in 'Golden Promise' cultivar which is widely popular around the world. 
$a$

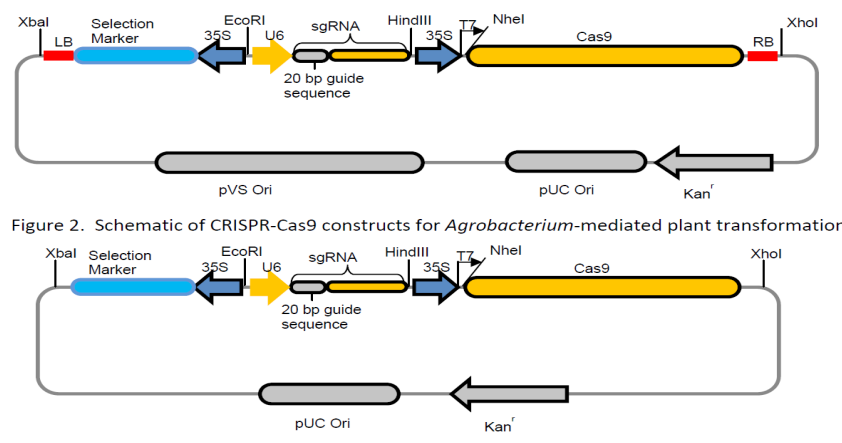

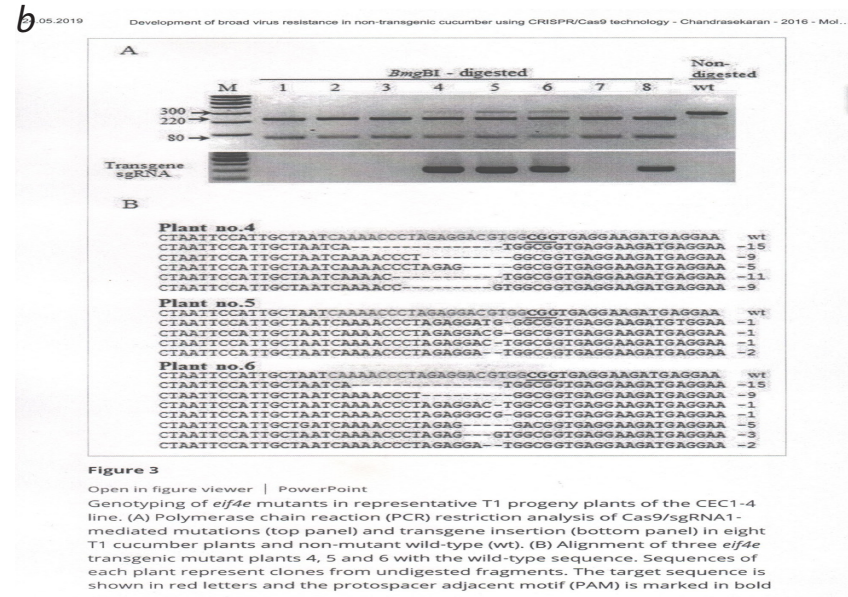

Figure 1. Schematic of the CRISPR-Cas9 construct for Agrobacterium-mediated plant transformation (a), PCR restriction analysis of Cas9/sgRNA elF4E barley mutants (top) and transgene insertion (bottom) in 8 out of 50 edited barley plants and wild-type controls (b).

\section{Discussion}

About 6 years ago the first results on genome editing were achieved on plants, thanks to the use of the relatively simple and convenient CRISPR/Cas9 system, there was a sharp increase in the number of published works reporting successful plant genome editing, including the directed modification of economically valuable genes of cultivated plants: potatoes, cabbage, tomato, maize, rice, wheat, barley, soybeans, sorghum (Feng et al., 2013; Brooks et al., 2014; Svitashev et al., 2015; Khlestkina, Shumny, 2016; Gerasimova et al., 2017). Published works demonstrate the possibility of obtaining nontransgenic plants using the CRISPR/Cas9 system with specific predetermined mutations stably inherited in generations.

The potential efficiency of CRISPR/Cas9 technology is much higher than that of traditional breeding approaches, and excludes the residual portion of the donor genome in editing crops. The average term for the creation of a stable genotype by CRISPR/Cas9 is 2 years, which is a third or a forth as long as the 10-12 years required by backcross methods of conventional breeding or half or a third as long as the time required by modern methods of marker-assisted selection $(\mathrm{MAS})+$ marker double haploid (MDG) + backcross $(\mathrm{BC})$ or obtaining double haploid hybrids. Studies of 145 target genes in 15 crops obtained for 5 years demonstrated the possibility of obtaining modified non-transgenic plants. Editing of 37 genes was accompanied with the improvement of crop yield and stress resistance (Brooks et al., 2014; Khlestkina, Shumny, 2016; Gerasimova et al., 2017). The practical advantage of CRISPR/Cas9 is the ease of multiplexing. The simultaneous introduction of DSBs at multiple sites can be used to edit several genes at once and can be particularly useful to knock out redundant genes or parallel pathways. The same strategy can be used to engineer large genomic deletions or inversions by targeting two widely spaced cleavage sites on the same chromosome (Khlestkina, Shumny, 2016). It is possible to edit several genes simultaneously by introducing multiple or long DNA breaks in the genome to embed a whole complex of useful genes that will be transmitted in the offspring as a single locus. Generally, the CRISPR/Cas9 system for plant genome editing is a breakthrough technology in breeding and a prospect for the creation of elite high yielding crops today and in the nearest future with great social and economic benefit. In the case of using CRISPR/Cas9, several methods are possible for creating of non-transgenic modified plants:

1) by using programmable nucleases, for example, by temporary expression of nuclease components using agroinfiltration or viral vectors, or by direct delivery of components in the form of functional gRNA and Cas9 protein;

2) by integrating the transgenes gRNA and Cas9 protein into a chromosome different from that of the edited gene, so as to get rid of transgenic structures due to independent inheritance in the offspring;

3) transient expression of structures carrying elements of the CRISPR/Cas9 system, without integrating them into genomic DNA. It is assumed that the temporary presence of nucleases and gRNA in the cell may be sufficient to introduce the necessary changes to the genome. It was shown that this principle can work on monocot plants.

Although the European regulatory framework for genetically modified crops focuses on the process and not the product (that is why two identical plants produced by conventional mutagenesis and genetic engineering would be regulated differently under the current guidelines), there is hope and confidence that plants altered by the excision of a few nucleotides using genome editing tools such as CRISPR/Cas9 would not be classified as genetically modified organisms. Removal of undesirable plasmid DNA including Cas9 and guide RNA achieved following segregation and screening of 'clean' plants in the next generation that carry only the edited event. The classification of genome edited plants is currently under review to decide whether new breeding technologies including CRISPR/Cas9 are exempt from GM classification. In the United States, a product-oriented concept has been adopted and it is established that CRISPR/Cas genome edited plants are not GMOs, as they contain no recombinant foreign DNA. Successful results of using CRISPR/Cas 9 technology in agriculture that have been achieved up to this day represent only the very first, initial uses of this exciting technology. Therefore, we can expect many more valuable opportunities for agriculture in the near future. 


\section{Conclusions}

CRISPR/Cas9 technology has revolutionized gene manipulation capabilities in many species including crops. The multiple functions that can be performed with CRISPR/Cas9 and its many derivatives make it a molecular tool that will open new opportunities in a complex world of plant-pathogen interactions and help design durable crop resistance to pathogens.

The CRISPR/Cas9 system for plant genome editing is a prospect for application of breakthrough technologies in breeding.

\section{References}

Doudna J.A., Charpentier E. The new frontier of genome engineering with CRISPR/Cas9. Sci. 2014;346(6213):12580-12596. DOI 10.1126/science. 1258096 .

Feng Z., Zhang B., Ding W., Liu X., Yang D.L., Yang D.L., Wei P., Cao F., Zhu S., Zhang F., Mao Y., Zhu J.K. Efficient genome editing in plants using CRISPR/Cas system. Cell Res. 2013;23:1229-1232. DOI 10.1038/cr.2013.114.

Brooks C., Nekrasov V., Lippman Z.B., Van Eck J. Efficient gene editing in tomato in the first generation using the clustered regularly interspaced short palindromic repeats/CRISPR-associated 9 system. Plant Physiol. 2014;166:1292-1297. DOI 10.1104/pp.114.247577.

Svitashev S., Young J.K., Schwartz C., Gao H., Falco S.C., Cigan A.M. Targeted mutagenesis, precise gene editing, and site-specific gene insertion in maize using Cas9 and guide RNA. Plant Physiol. 2015; 169:931-945. DOI 10.1104/pp.15.00793.

Khlestkina E.K., Shumny V.K. Prospects for application of breakthrough technologies in Breeding: the CRISPR/Cas9 system for plant genome editing. Genetics. 2016;52:774-787. DOI 10.7868/ S0016675816070055.

Chandrasekaran J., Brumin M., Wolf D., Leibman D., Klap C., Pearlsman M., Sherman A., Arazi T., Gal-On A. Development of broad virus resistance in non-transgenic cucumber using CRISPR/Cas9 technology. Mol. Plant Pathol. 2016;17:1140-1153. DOI 10.1111/ mpp. 12375 .

Gerasimova S.V., Khlestkina E.K., Kochetov A.V., Shumny V.K. CRISPR/Cas9 for genome editing and its specialty for monocot plants. Russian J. of Plant Physiol. 2017;64:92-108. DOI 10.1134/ S1021443717010071.

Mushtaq M., Sakina A., Wani S.H., Shikari A.B., Tripathi P., Zaid A., Galla A., Abdelrahman M., Sharma M., Singh A.K., Salgotra R.K. Harnessing genome editing techniques to engineer disease resistance in plants. Front. Plant Sci. 2019. Doi.org/10.3389/fpls.2019. 00550 .

Acknowledgements. The work is supported by the granting program of the Scientific Council of Ministry of Education and Sciences of Republic of Kazakhstan, Project IRN APO5132774, 2018-2020.

Conflict of interest. The authors declare no conflict of interest. 


\title{
Study of a region on wheat chromosome 5BS by targeted sequencing
}

\author{
M.K. Bragina ${ }^{1 *}$, D.A. Afonnikov ${ }^{1,2}$, G.V. Vasiliev ${ }^{1}$, E.A. Salina ${ }^{1}$ \\ ${ }^{1}$ Institute of Cytology and Genetics, SB RAS, Novosibirsk, Russia \\ ${ }^{2}$ Novosibirsk State University, Novosibirsk, Russia
}

DOI 10.18699/ICG-PlantGen2019-37

(c) Autors, 2019

* e-mail: koltunova@bionet.nsc.ru

\begin{abstract}
Despite the increasing use of high-throughput sequencing resulting from reduced cost and effort, large and complex genomes still pose a challenge in crop genomics. Bread wheat has a genome size of over $17 \mathrm{~Gb}$, which makes targeted capture an invaluable tool for a wide range of studies. To capture and sequence the $26.6-\mathrm{Mb}$ wheat chromosome $5 \mathrm{BS}$ region associated to leaf rust resistant genes, custom hybridization probes was created using information from the reference wheat genome ('Chinese Spring'). We show that this chromosomal region of leaf rust resistance and susceptible wheat lines were efficiently captured with sufficient coverage.

Key words: bread wheat genome; chromosome 5BS; leaf rust resistance genes; Lr52 gene; targeted sequencing.
\end{abstract}

\section{Introduction}

Despite the advances in and decreasing the cost of next-generation sequencing and bioinformatics tools, whole genome sequencing is not practical for most studies. The whole genome sequencing with high level of coverage and resolution is not enough to detect all changes in complex samples. To reduce the complexity of genomes in large or polyploid plants, the strategy of targeted enrichment is used. Targeted sequencing includes 3 stages: selection of the DNA fraction of interest (enrichment of samples), sequencing and analysis of the results obtained. The method starts with shearing total genomic DNA into fragments and hybridizing target-specific probes to the regions of interest. Then, the selected fragments are extracted and amplified by PCR before sequencing. As well-annotated genomes improve probe design, high-quality reference genomes reduce the risk of false-positive results or missing important variants in the generated data set (Chamala et al., 2015; Warr et al., 2015).

The wheat reference cultivar 'Chinese Spring' genome published by the International Wheat Genome Sequencing Consortium (IWGSC, 2018) and SNP markers associated with economically valuable genes in wheat varieties and lines will contribute to solving important problems in genetics and breeding. To date, more than 30 genes that control a number of morphological and quantitative traits, resistance to abiotic and biotic environmental factors have been mapped on wheat chromosome 5B. Of particular interest is the distal region of its short arm (5BS), in which genes for resistance against leaf rust (Lr52), septoria brown blotch (Snn3), rhizoctonia net blotch (QSe.jaas-5BS), yellow rust (Yr47), loose smut of wheat (UtBW278) and Hessian fly (H31) are presumably located. The mapping of DNA markers linked to the resistance genes on the 5BS reference pseudomolecule (RefSeq v1.0) allows the region where these genes reside to be identified. Our study was aimed to approbate targeted sequencing for analysis of chromosome 5BS region with a length of about $26.6 \mathrm{Mb}$ using lines with and without the Lr52 gene.

\section{Materials and methods}

\subsection{Plant material}

Mapping population F4 (lines from the cross $\operatorname{LrW}(52) \times$ hybrid_215) was developed for chosen plants which are differ to resistant genes against fungal diseases located on target region of 5BS. We selected 5 plants with $L r 52$ and 5 plants without Lr52 according to data of KASP and SSR genotyping together with screening for resistance (benzimidazole $(0.035 \% \mathrm{w} / \mathrm{v}))$.

\subsection{DNA extraction}

Genomic DNA was isolated from the young leaves of individual plants using the Kleargene plant 96-well plate DNA extraction kit (LGC Group), following the manufacturer's protocol. The isolated DNA was resuspended in $74 \mu \mathrm{l}$ of TE buffer. The measurement of DNA concentration was performed on a NanoDrop M2000 instrument (Thermo Scientific).

\subsection{Targeted sequencing}

To enrich a $26.6 \mathrm{Mb}$ of chromosome 5BS, a 1- $\mu \mathrm{g}$ portion of genomic DNA, in a total volume of $55 \mu \mathrm{l}$, was sheared for $2 \times$ 60 s using a Covaris M220 focused-ultrasonicator (an average fragment size of $600 \mathrm{bp}$ ). Genomic libraries were constructed with the KAPA HyperPlus Library Preparation Kit according to the manufacturer's instructions (KAPA Biosystems). Equal amounts of 10 libraries were pooled and subjected to in-solution target enrichment using the SeqCap EZ Target Enrichment System (Roche). Enrichment and hybridization of the samples were carried out according to the manufacturer's proposed protocol using Qubit 2.0 (Life Technologies) for DNA concentration measuring, SimpliAmp (Applied Biosystems) for the DNA library amplification and the Agilent 2100 Bioanalazer (Agilent Technologies) for quality control and the final library size determination. The 150-bp pairedend sequencing of the obtained library was performed on an Illumina NextSeq 550 platform (ICG SBRAS). 
Table 1

Characterization of probe designs developed by Roche to cover $26.2 \mathrm{Mb}$ of chromosome 5BS

\begin{tabular}{lll}
\hline Length of regions $(\mathrm{bp})$ & 26622901 & \\
\hline & Design 1 & Design 2 \\
Statistics & Probe_Coverage & Probe_Coverage \\
Target Bases Covered & 7065602 & 8095379 \\
\% Target Bases Covered & 26.5 & 30.4 \\
Targets with no coverage & 0 & 0 \\
Target Bases Not Covered & 19557299 & 18527522 \\
Due to N's & 873054 & 873054 \\
Due to repeats & 17525323 & 17096460 \\
\% Target Bases Not Covered & 73.5 & 69.6 \\
Due to N's & 3.3 & 3.3 \\
Due to repeats & 65.8 & 64.2 \\
Total capture targets & 17734 & 19923 \\
Total capture space (bp) & 7065602 & 8095379 \\
\hline
\end{tabular}

\section{Results and discussion}

Over the past few years, the efficiency of target enrichment has been proven for the study of the nucleotide diversity of polyploid species with a large, repetitive and heterozygous genome (Bragina et al., 2019). This method has been used in various crops, including in the study of ecological adaptation in barley (Russell et al., 2016), the identification of wheat disease resistance genes (Steuernagel et al., 2016), the cataloging of mutations in rice (Henry et al., 2014).

At present, two main technologies are used for hybridcapture applications for plants: solid-based and liquid-based hybridization (I. Terracciano et al., 2016). The most reliable commercial kits in studies on plant species were provided by Agilent Technologies (SureSelect), Roche NimbleGen (SeqCap EZ), MYcroarray (MYbaits) and Ion Torrent (TargetSeq).

For our study, Roche developed two types of probe design to cover $26.6 \mathrm{Mb}$ of chromosome 5BS (Table 1). Type 1 is a standard design in which probes can be mapped to target region of the genome up to 20 times. Moreover, the algorithm for probe selection has two stages. At the first stage, the most specific probes are selected (up to 3 coincidences per target region) and less specific probes are superimposed on this region to increase coverage. But our region of interest contains the vast majority of repetitive regions, and the developers have created a second design to increase the $\%$ of covered regions. Type 2 is a design in which probes can be mapped to target region of the genome up to 50 times. As a result, the maximum number of covered region with a length of $26.6 \mathrm{Mb}$ was about $8 \mathrm{Mb}$ mainly due to repeats as well as due to the incompleteness of the reference genome. For our study, the second type of probe design was chosen.

Although the probes were designed for 'Chinese Spring', the low specificity of the probes allows this method to be used for ours wheat lines as well. Probes with low specificity have been successfully utilized in studies on divergent taxa, but they usually produce fewer variants than the taxon-specific probes (Bragg et al., 2016; Chau et al., 2018).

The wheat lines of population F4 (lines from the cross LrW (52) $\times$ hybrid 215) were captured with probes developed by Roche to cover the region under study on the basis of the reference genome.

As a result of sequencing, an average of $4.28 \mathrm{~Gb}$ and $3.51 \mathrm{~Gb}$ of reads was obtained for the wheat lines with $\operatorname{Lr} 52$ and without Lr52, respectively. The total size of data obtained was about $39 \mathrm{~Gb}$. The proportions of sequences with $\mathrm{Q}>30$ were 78.95 and $78.52 \%$, and the mean quality score Q values were 31.44 and 31.35 for the wheat lines with $L r 52$ and samples without $L r 52$, respectively. The sequencing quality was estimated using the MAQ software (http://maq.sourceforge.net), a value of 30 and higher indicates a high quality of the sequences and unambiguous mapping with a small number of mismatches.

After preprocessing and quality control using the FASTXtoolkit utility (http://hannonlab.cshl.edu/fastx_toolkit/), the reads obtained were mapped onto the studied region of the wheat reference genome using the bwa-short algorithm in the short-read mapping software BWA (Li and Durbin, 2009). On average, $72.97 \%$ of the sequenced reads were not mapped, $7.50 \%$ were mapped one time and $19.53 \%$, more than once for samples with $\operatorname{Lr} 52$. For samples without Lr52, these parameters were $70.06,9.26$ and $20.69 \%$, respectively. The average alignment levels were $42 \%$ and $46 \%$ for resistant and susceptible samples, respectively. But in spite of the large number of unmapped sequences, the remaining reads allow us to study the region of interest.

Alignment of the reads to the wheat genome showed a high level of on-target enrichment efficiency. The 19923 baits designed correspond to a total of $8 \mathrm{Mb}$ of genomic regions, associated with the Lr52 gene. The number of baits per million base-pairs ranged from 505 to 1076, with an average of 749 . On average, 94.9 and $94.4 \%$ of base pairs in the bait 
regions of resistant and susceptible plants, respectively, were covered by uniquely mapped reads at $\geq 5 \times$ depth. Due to the variable length of sheared DNA fragments in the prepped library and because the median length of the sheared fragments was greater than the length of the baits, we acquired additional coverage in regions adjacent to the baits. In the target regions, 10 wheat plants had narrow mean coverage ranges, $40 \times$ and $48 \times$, for the leaf rust resistant and susceptible samples, respectively.

The data obtained are in a good agreement with the results of other groups. For example, in a work by Gardiner et al. (2016), a 110-MB NimbleGen capture probe set was used to enrich and sequence a doubled haploid mapping population of hexaploid wheat derived from the cross 'Avalon' $\times$ 'Cadenza'. An average depth of coverage of $45 \times$ was seen in the parental lines and $60 \times$ in the P1 bulk with an average of $98 \%$ of the reference sequence being mapped to uniquely. In 2019, two gold standard capture probe sets for a gene and a putative promoter capture of hexaploid bread wheat were presented and validated, which are designed using recently developed genome sequence and annotation resources. Researchers demonstrate that the capture probe sets effectively enrich the high-confidence genes and putative promoter regions that were identified in the genome alongside a large proportion of low-confidence genes and associated promoters (Gardiner et al., 2019).

Our results suggest that sequence capture is a reliable approach to study and annotate of the chromosome region in both the gene space and non-repetitive intergenic regions.

\section{Conclusions}

The goal of this study was to test in-solution sequence capture of a 26.6-Mb region of chromosome 5BS of leaf rust resistant and susceptible wheat plants. We have demonstrate that the capture probe sets that have been designed against the hexaploid wheat cv. 'Chinese Spring' to enrich the genic portion of a mapping population, F4 (lines from the cross_LrW(52) $\times$ hybrid_215), effectively enrich the region of interest, providing an average gain of $40 \times$ mapping coverage. Our results show that in-solution sequence capture is a reliable method to enrich the gene space in complex plant genomes. The approach used here is general and the developed probes provide large amounts of genomic data to be used in many downstream analyses.

\section{References}

Bragg J.G., Potter S., Moritz C. Exon capture phylogenomics: Efficacy across scales of divergence. Mol. Ecol. Resources. 2016;16:10591068.
Bragina M.K., Afonnikov D.A., Salina E.A. Progress in plant genome sequencing: research directions. Vavilovskii Zhurnal Genetiki i Selektsii = Vavilov Journal of Genetics and Breeding. 2019;23(1):38-48. DOI 10.18699/VJ19.459. (in Russian)

Chamala S., García N., Godden G.T., Krishnakumar V., JordonThaden I.E., De Smet R., Barbazuk W.B. et al. MarkerMiner 1.0: A new application for phylogenetic marker development using angiosperm transcriptomes. Applications Plant Sci. 2015;3:1400115.

Chau J.H., Rahfeldt W.A., Olmstead R.G. Comparison of taxon-specific versus general locus sets for targeted sequence capture in plant phylogenomics. Applications in Plant Sci. 2018;6(3):e1032.

Gardiner L.-J., Bansept-Basler P., Olohan L., Joynson R., Brenchley R., Hall N., O'Sullivan D.M., Hall A. Mapping-by-sequencing in complex polyploid genomes using genic sequence capture: a case study to map yellow rust resistance in hexaploid wheat. Plant J. 2016;87: 403-419.

Gardiner L.-J., Brabbs T., Akhunov A., Jordan K., Budak H., Richmond T., Singh S., Catchpole L., Akhunov E., Hall A. Integrating genomic resources to present full gene and putative promoter capture probe sets for bread wheat. GigaSci. 2019;8(4):giz018. DOI 1093/ gigascience/giz018.

Henry I.M., Nagalakshmi U., Lieberman M.C., Ngo K.J., Krasileva K.V., Vasquez-Gross H., Akhunova A. et al. Efficient genomewide detection and cataloging of EMS induced mutations using exome capture and next-generation sequencing. Plant Cell. 2014;26: $1382-1397$.

Li H., Durbin R. Fast and accurate short read alignment with BurrowsWheeler transform. Bioinformatics. 2009;25(14):1754-1760. DOI 10.1093/bioinformatics/btp324

Russell J., Mascher M., Dawson I.K., Kyriakidis S., Calixto C., Freund F., Bayer M. et al. Exome sequencing of geographically diverse barley landraces and wild relatives gives insights into environmental adaptation. Nature Gen. 2016;48:1024-1033.

Steuernagel B., Periyannan S.K., Hernández-Pinzón I., Witek K., Rouse M.N., Yu G., Hatta A. et al. Rapid cloning of disease-resistance genes in plants using mutagenesis and sequence capture. $\mathrm{Na}$ ture Biotechnol. 2016;34:652-655.

Terracciano I., Cantarella C., D'Agostino N. Hybridization-Based Enrichment and Next Generation Sequencing to Explore Genetic Diversity in Plants. In: Rogato A., Zazzu V., Guarracino M. (eds) Dynamics Mathematical Models Biol. Springer, Cham. 2016. DOI 10.1007/978-3-319-45723-9_10.

The International Wheat Genome Sequencing Consortium. Shifting the limits in wheat research and breeding using a fully annotated reference genome. Sci. 2018;361(6403). DOI 10.1126/science.aar7191.

Warr A., Robert C., Hume D., Archibald A., Deeb N., Watson M. Exome sequencing: Current and future perspectives. Genes Genomes Genetics. 2015;5:1543-1550.

Acknowledgements. The work is supported by the Ministry of Education and Science of the Russian Federation No. 0324-2019-0039 and by the Russian Foundation for Basic Research No. 17-04-00507.

Conflict of interest. The authors declare no conflict of interest. 


\title{
Intergenomic substitutions and translocations in wheat-alien lines and their use in studying the characteristics that determine adaptation and stress resistance
}

\author{
T.T. Efremova*, E.V. Chumanova \\ Institute of Cytology and Genetics, SB RAS, Novosibirsk, Russia
}

DOI 10.18699/ICG-PlantGen2019-38

(c) Autors, 2019

* e-mail: efremova@bionet.nsc.ru

\begin{abstract}
The authors have created new genetic models of common wheat with different types of intergenomic chromosome substitution or translocation that include genetic materials of taxonomically unrelated species (S. cereale, Ag. elongatum, Ag. intermedium, H. marinum) for the introgression of genes that control adaptation and resistance to biotic and abiotic stress factors, along with the studying of homology between chromosomes. For the identification of rye, barley and wheatgrass chromosomes in the genome of common wheat, the authors used the molecular-cytological analysis of lines based on the genomic in situ hybridization and PCR analysis with the use of specific primers. The genetic relations have been studied in terms of the degree of substitution and compensation ability of particular chromosomes. To study the homology and homeology of chromosomes and control the peculiar features of alien chromosome transmission and elimination via gametes, the authors performed an analysis on chromosomes' synapsis and assortment in the offspring of wheat-alien substitution lines. Newly created models were examined to identify and localize the genes or gene alleles in chromosomes of different genomes and homeologous groups, which control such traits as the type of development and heading stage, and resistance to the impact of unfavorable weather conditions (winter- cold tolerance, stem and leaf rust and powdery mildew tolerance).

Key words: common wheat; rye; wild barley; precise genetic stocks; chromosome substitution; isogenic lines;introgression; in situ hybridization; PCR analysis; adaptation; biotic and abiotic stress.
\end{abstract}

\section{Introduction}

Polyploidy of Triticum aestivum L. provides new opportunities for cytogenetic research, which allows for targeted intravarietal and alien substitution of chromosomes or their parts and examination of the effects of these chromosomes on the manifestation of a complex of traits (Sears, 1952, 1972). Diploid and polyploid species of Triticeae relative to common wheat contain the genomes that are not homologous to the A, B or D genomes of wheat. The examples of such gene pools are diploid and polyploid species of Aegilops, Thinopyrum, Secale and Hordeum. The genomes of these species are homologous to the genomes of common wheat. An alien chromosome belonging to the same homeologous group can compensate for the corresponding chromosome of wheat as a result of a substitution or a translocation.

Chromosome engineering describes the technologies that allow for manipulating specific chromosomes or their segments and obtain new wheat genetic lines (Qi et al., 2007; Chan, 2010). A successful transfer of alien genes based on the homeologous recombination depends on the $P h$ system. There are two known base loci of the $P h$ system: $P h l$ is located on the long arm of chromosome 5B, and $P h 2$ is located on chromosome 3DS (Sears, 1972). The Phl gene of common wheat to a significant extent prevents homeologous pairing, thus, only homologous chromosomes pair up and recombine, which results in the formation of bivalents in Metaphase I of common wheat meiosis. Homeologous pairing of chromosomes may occur either due to the nullisomy or deletion of $P h 1$ or the recessive mutation of $\mathrm{ph} 1 \mathrm{~b}$.
Researchers have described several methods that allow for chromosome or chromosome segment transferring from related species to wheat: 1 ) the use of ionizing radiation (Sears, 1956); 2) the use of homeologous recombination between chromosomes based on chromosome 5B with $P h 1$ gene elimination or use of $p h 1 b$ mutation (Sears, 1972); 3) the use of the univalent chromosomes trend to misdivision (Sears, 1952); 4) the use of gametocidal chromosomes (Gc) (Endo, Gill, 1996).

The genetic models obtained and applied for the studying of common wheat can be divided into several types. First, there are various types of aneuploid lines, which were first obtained by E.R. Sears $(1952,1966)$ in the cv. 'Chinese Spring'. They include full sets of monosomic, nullisomic-tetrasomic, tetrasomic, ditelosomic and monotelosomic lines. He developed new cytogenetic methods of common wheat analysis with the use of different types of aneuploids.

Another group of genetic models is represented by the wheat-alien substitution and addition lines, as well as the lines with alien translocations. The cytogenetic research based on the common wheat aneuploids has shown that in most cases an alien chromosome replaces wheat chromosomes of only one homeologous group. In some cases the alien chromosome is capable of replacing chromosomes from different homeologous groups, which indicates the presence of chromosome structural changes of different character. At the same time, the higher the compensation effect in the intergenome substitution, the closer the genetic affinity of genomes. Those genetic models that include lines with chromosome substitution and 
translocation, introgressive lines and synthetic wheats with the participation of Triticeae species, provide for the enrichment of the common wheat gene pool and play an important role in selection concerning the biotic and abiotic stress resistance (Jiang et al., 1994); with their help, scientists study the homeology of wheat chromosomes and genomes with other species of grasses (Qi et al., 2007; Chan, 2010) and specificities of chromosome behavior during the meiosis in the process of selection. Therefore, the researchers' interest in obtaining new wheat-alien lines is still intense, and new species are used as a source of new genes (Jiang et al., 1994; Friebe et al., 2001; Qi et al., 2011).

We have created new genetic models represented by near isogenic, introgressive and substitution lines, which possess a set of unique combinations of alien genetic material of different origin, to identify the influence imposed by donor chromosomes on stress resistance and adaptation to new environmental conditions. The results of this study are presented in the article.

\section{Alien substitution lines}

For the first time we obtained wheat-barley substitution lines (T. aestivum-H. marinum ssp. gussoneanum Hudson $4 x$ ) for the chromosomes of homeologous group 7, in which common wheat chromosomes 7A, 7B and 7D are substituted by barley H. marinum telocentric chromosome $7 \mathrm{HL}^{\text {mar }}$ (Efremova et al., 2013,2018 ). The analysis of the meiosis Metaphase I (MI) has shown that the ditelosomic (DT) lines obtained are characterized by cytologically stable meiosis, and most plants in each line have the following chromosome configuration: 20 " $+\mathrm{t}$ ". The GISH-analysis of substitution lines has shown that they bear a pair of barley telocentric chromosomes. The ditelosomic analysis allowed us to define the lines as DT7HL ${ }^{\text {mar }}(7 \mathrm{~A})$ and $\mathrm{DT}_{7} \mathrm{H}^{\text {mar }}(7 \mathrm{~B})$. On the basis of the compensation test and studying of the substitution lines' meiotic stability, we determined that $H$. marinum chromosome $7 \mathrm{HL}^{\text {mar }}$ is homeologous to the common wheat chromosomes of the seventh group (Efremova et al., 2018).

In order to increase the adaptive potential of plants, we created the wheat-rye $5 \mathrm{R}(5 \mathrm{~A})$ substitution lines based on the winter wheat cv. 'Filatovka' and cv. 'Ul'ynovka' to identify the role of rye chromosome $5 \mathrm{R}$ in controlling the winter-coldresistance feature. It is important to point out that as of today there are almost no research papers referring to the influence of rye chromosome 5R on the plants' winter resistance. Field tests performed in winter of 2017/2018 have shown that 90-100\% of wheat-rye $5 \mathrm{R}(5 \mathrm{~A})$ substitution lines survive the winter in the conditions of the Novosibirsk Region.

\section{Introgression lines}

Modern biotechnological methods are aimed at reducing the share of alien material in the cultivated grasses' genomes; thus, the studying of methods of inducing the chromosome homeologous recombination for acquiring translocations with the genes responsible for valuable traits of wild species has great practical and theoretical value (Qi et al., 2011). In order to find the combinations of crossing that induce a high frequency of chromosomes with translocations, we studied monosomic wheat-rye $5 \mathrm{R}(5 \mathrm{~A})$ and $5 \mathrm{R}(5 \mathrm{D})$ substitution lines and their hybrids with line L2075. The cytologic analysis has shown that rye chromosome $5 \mathrm{R}$ rather frequently undergoes misdivision both at the self-fertilization of monosomic alien lines and in $\mathrm{F}_{1-4}$ hybrid offspring [5R(5A) $\times$ L2075] and [5R(5D) $\times$ L2075] at the self-fertilization of dimonosomics with the chromosome configuration of $20^{\prime \prime}+1{ }^{\prime}+1$ '. In the MI meiosis, as a rule, chromosomes in the wheat-rye dimonosomics $5 \mathrm{R}$ 5A and 5R-5D are represented as univalents. However, within each hybrid combination from 15 to $18 \%$ of plants with a telocentric chromosome were selected. We have also found that univalent chromosomes 5A and 5D differ in the frequency of telocentric chromosome formation. Univalent chromosome $5 \mathrm{~A}$ undergoes misdivision with high frequency $(19 \%)$ in comparison with chromosome $5 \mathrm{D}(0.46 \%)$. As a result, based on in situ hybridization, among $\mathrm{F}_{4}[5 \mathrm{R}(5 \mathrm{~A}) \times \mathrm{L} 2075]$ hybrid plants we selected plants with the 5AS.5RL translocation, and among [5R(5D) $\times$ L2075] hybrids we detected no such wheatrye translocation. This translocation might have appeared in the case of the simultaneous presence, in the hybrids, of two univalents and a spontaneous misdivision process in the rye and wheat chromosomes followed by telocentric fusion. Thus, the mechanism of Robertsonian translocation formation in the offspring of dimonosomics can be used for transferring an alien chromosome arm to the wheat genome.

We obtained two wheat-rye lines identified as T5AS.5RL + T1RS.1BL and 5R(5D) + T1RS.1BL. The rye chromosomes are of different origin: $5 \mathrm{R}$ originates from the spring rye $\mathrm{cV}$. 'Onohoskaya', and 1RS from the winter rye cv. 'Saratovskaya 5'. Based on in situ hybridization and C-banding, we found that one line had a Robertsonian translocation, so that the short arm of wheat chromosome $5 \mathrm{AS}$ had been transferred to the long arm of rye chromosome 5RL. We found no such translocation in the second line: the obtained lines have the 5R(5D) substitution. To identify chromosomes 1RS and 5RL, we used rye-specific markers. The field tests of adult plants and sprouts tolerance analysis have shown that the T5AS.5RL + T1RS.1BL and 5R(5D) + T1RS.1BL lines possess leaf rust and powdery mildew tolerance, as well as moderate stem rust tolerance in conditions of Western Siberia (Efremova et al., 2014).

We created the introgressive lines of common wheat that possess a complex of useful traits that were transferred from phylogenetically distant species (Ag. elongatum, Ag. intermedium, $S$. cereale) united in a single genotype. These new genetic models include several alien genes which control diseases tolerance (a pyramid of rye and wheatgrass genes: Lr26/Pm8/Sr31+Lr19/Sr25+Lr6Ai/Sr6Ai/Pm6Ai), various grain colors (a combination of wheatgrass and common wheat genes, $\mathrm{Ba} 1$ and $\mathrm{Pp}-1 / \mathrm{Pp} 3$ ), and winter development type (the rye gene $v r n-R 1$ ), for studying the peculiarities of development of traits under examination depending on the combination of alien chromosomes or their segments. A combination of two/ three complex genetic systems responsible for stability, adaptation and morphobiological traits in one genotype is a rather complicated issue. One of the most promising approaches to its solution is to combine classic cytogenetic methods and MAS selection methods. The selection of a homozygous form with the combination of genes that controls disease tolerance, grain color and winter type of development has been performed 
based on phenotypic markers and molecular analysis with the help of PCR with specific primers. We performed phenotypic tests on the introgressive lines for disease tolerance in a field test and selected the plants that are tolerant to leaf rust.

Among the genes under examination we also studied the $\mathrm{Bal}$ gene which controls blue grain color. Using the genetic models with colored grain, we create new lines with the combination of genes that control the blue color of the aleuron layer and complex disease tolerance. In parallel, we are working on obtaining lines with a combination of genes that control purple pericarp and blue aleuron layer color in the genotype of the cv. 'Saratovskaya 29' ('S29') to increase the amount of anthocyanin in grains.

As a result of kernel section analysis and visual estimation of grain color in $\mathrm{F}_{3}$ hybrids, we managed to select individual plants with brown grain, purple pericarp and blue aleuron layer. Among $\mathrm{F}_{4}$-hybrids we selected, as a result, homozygous S29 lines $P p-1 P p 3^{P F} / B a 1, \mathrm{~S} 29 B a 1 / P p-1 P p 3^{P F}$ and S29Bal/ $P p 1 P p 3^{P}$ which have shown no grain color splitting. Grains are dark-brown. Among $\mathrm{F}_{3-4}$-hybrids of $\mathrm{S} 29 P p-1 P p 3^{P} / B a 1$ we continued to select homozygous forms. It was shown that the strength of kernel color may be different, which probably depends on the presence of genes in the plant genotype and their status. We can assume that the combinations of different alleles of the $P p-1 / P p 3$ and $B a 1$ loci are expressed in different ways.

We tested three samples of flour for the anthocyanin content. The estimation of total content of anthocyanins in hydrolisates of three flour samples has shown that original isogenic lines differ in content of anthocyanins; for the line with blue grain $(\mathrm{S} 294 \mathrm{Ag}(4 \mathrm{~B}))$, this parameter exceeds the parameter of the purple-grain line (i:S29Pp-1Pp $3^{P F}$ ), $135.2 \mathrm{mg} / 100 \mathrm{~g}$ and $81.1 \mathrm{mg} / 100 \mathrm{~g}$ correspondingly. The content of anthocyanins in the new line, S29 Pp1Pp $3^{P F} / B a 1$, exceeds that in the isogenic lines $(166.2 \mathrm{mg} / 100 \mathrm{~g})$.

Thus, the 'S29' lines obtained possess the complementary genes $P p-1 / P p 3$ which control the purple color of the grain pericarp (the donors are the common wheat cv. 'Purple Feed' and cv. 'Purple') and the Bal gene, which is responsible for the blue color of the aleuron layer (the donor is the wheatgrass Ag. elongatum). These lines contain larger amounts of anthocyanins than red-grained and blue-grained samples.

\section{Near-isogenic lines}

The existing allele differences of $\mathrm{Vrn}$ genes are basic for the wide area of wheatgrass cultivation and the high level of adaptation to environmental conditions. Noteworthy, all studies of structural-functional regulation of the duration of the wheat vegetation period are connected with the determination and description of the new allelic variants of the $V R N-1$ gene, but do not refer to the influence of structural changes in the regulatory parts of the $V R N-1$ gene on earliness. We have created the near-isogenic lines of the common winter wheat cv. 'Bezostaya 1' with different alleles of the $V R N-1$ gene and with their help performed an experimental study of the role that $V R N-1$ allele polymorphism has in the regulation of the duration of the vegetation period and the duration of particular phases of development for the first time (Efremova et al., 2011; Emtseva et al., 2013). We found that the isogenic line with the $V r n-A l a$ allele has a shorter "tillering - first node" phase in comparison with the lines with the $V r n-B 1 c$ and $V r n-B 1 a$ alleles. This line approached the heading stage earlier than the other isogenic lines. The same result was obtained earlier during the study of these lines in greenhouse conditions. This fact testifies one more time that gene $\mathrm{Vrn}-\mathrm{Al}$ has the strongest effect on the duration of the tillering stage and controls the heading stage in plants. Under the conditions of the naturally long day in the Novosibirsk Region, we found no difference between the isogenic lines with the Vrn-BIC and Vrn-Bla alleles in the duration of the "tillering - first node" phase, and the difference in the duration of the heading stage was 2 days. However, under the conditions of a short day in a greenhouse, the difference in the duration of the tillering phase between the $V r n-B 1 c$ and $V r n-B 1 a$ alleles appeared to be 12 days, and the difference in heading stage duration was 35 days (Emtseva et al., 2013). Based on these results, we can assume that the winter wheat $\mathrm{cv}$. 'Bezostaya 1' has a weak response to the photoperiod. It is known that not only the effects of $\mathrm{Vrn}$ genes, but also the Ppd genes that control photoperiod response, impose a significant influence on the developmental phases. Thus, under short day conditions, the effect of the $V r n-B 1 c$ and $V r n-B 1 a$ gene alleles in the genetic background of $\mathrm{cv}$. 'Bezostaya 1' manifests in the increase of vegetation period duration, especially the "tillering - first node" phase between the lines. Under ong day conditions, we observed no differences between the $V r n-B 1 c$ and $V r n-B 1 a$ alleles.

\section{References}

Chan S.W.L. Chromosome engineering: Power tools for plant genetics. Trends Biotechnol. 2010;28(12):605-610. DOI 10.1016/j.tibtech. 2010.09.002.

Chumanova E.V., Efremova T.T., Trubacheeva N.V., Arbuzova V.S. Rosseeva L.P. Chromosome composition of wheat-rye lines and the influence of rye chromosomes on disease resistance and agronomic traits. Russian Journal Genetics. 2014;50(11):1169-1178. DOI 10.1134/S1022795414110039.

Efremova T.T., Arbuzova V.S., Leonova I.N., Makhmudova K. Multiple allelism in the $V r n-B 1$ locus of common wheat. Cereal Res. Com. 2011;39(1):12-21. DOI 10.1556/CRC.39.2011.1.2.

Efremova T., Arbuzova V., Trubacheeva N., Ocadchaya T., Chumanova E., Pershina L. Substitution of Hordeum marinum ssp. gussoneanum chromosome 7HL into wheat homoeologous group-7. Euphytica. 2013;192:251-257. DOI 10.1007/s10681-012-0854-5.

Efremova T., Trubacheeva N., Chumanova E., Badaeva E., Rosseeva L., Arbuzova V., Pershina L. Development and characterisation of wheat-rye lines combining T1RS $1 \mathrm{BL}$ translocation and $5 \mathrm{R}(5 \mathrm{D})$ chromosome substitution or T1RS·1BL and T5AS·5RL translocations. Cereal Res. Com. 2014;3-4:547-557. DOI 10.1556/CRC. 2014.0013.

Efremova T.T., Chumanova E.V., Trubacheeva N.V., Pershina L.A. Compensation ability between the chromosomes of homoeologous group 7 of Triticum aestivum L. and Hordeum marinum ssp. gussoneanum Hudson $(2 n=28)$ and analysis of the transmission frequency of alien $7 \mathrm{H}^{1} \mathrm{~L}^{\text {mar }}$ chromosome through gametes in the progeny of wheat-barley substitution lines. Russian J. Gen. 2018;54(9):10501058. DOI 10.1134/S1022795418090065.

Emtseva M.V., Efremova T.T., Arbuzova V.S. The influence of Vrn-B1a and $V r n-B 1 c$ alleles on the length of developmental phases of substitution and near-isogenic lines of common wheat. Russian J. Gen. 2013;49(5):545-552. DOI 10.1134/S1022795413050050. 
Endo T.R., Gill B.S. The deletion stocks of common wheat. J. Hered. 1996;87:295-307.

Friebe B., Raupp W.J., Gill B.S. Alien genes in wheat improvement. Wheat in a global environment. Z. Bedö and L. Láng (Eds). Proc. $6^{\text {th }}$ Inter. Wheat Conference. Budapest, Hungary. Dordrecht; Boston; London: Kluwer Acad. Publ., 2001:709-720.

Jiang J., Friebe B., Gill B.S. Recent advances in alien gene transfer in wheat. Euphytica. 1994;73:199-212.

Qi L.L., Friebe B., Zhang P., Gill B.S. Homoeologous recombination, chromosome engineering and crop improvement. Chromosome Res. 2007;15:3-19. DOI 10.1007/s10577-006-1108-8.

Qi L.L., Pumphrey M.O., Friebe B., Zhang P., Qian C., Bowden R.L., Rouse M.N., Jin Y., Gill B.S. A novel Robertsonian translocation event leads to transfer of a stem rust resistance gene ( $S r 52)$ effective against race Ug99 from Dasypyrum villosum into bread wheat.
Theor Appl Genet. 2011;123:159-167. DOI 10.1007/s00122-0111574-z.

Sears E.R. Homoeologous chromosomes in Triticum aestivum. Genetics. 1952;37:624.

Sears E.R. Nullisomic-tetrasomic combinations in hexaploid wheat. In: Riley R., Lewis K.R. (eds) Chromosome manipulations and plant genetics. Oliver and Boyd, Edinburgh, 1966:29-45.

Sears E.R. Chromosome engineering in wheat. Stadler Symposia. University of Missouri, Columbia, 1972;4:23-28.

Acknowledgements. This study was supported by the Russian Foundation for Basic Research (grant no. 17-04-00721) and budget project no. 0324-2019-0039.

Conflict of interest. The authors declare no conflict of interest. 


\title{
Copy number variation of the $V r n-A 1 b$ allele in emmer and spelt wheat
}

\author{
A. Muterko \\ Institute of Cytology and Genetics, SB RAS, Novosibirsk, Russia
}

DOI 10.18699/ICG-PlantGen2019-39

(c) Autor, 2019

* e-mail: muterko@gmail.com

\begin{abstract}
In the present study the copy number variation of VRN1 was analyzed in accessions of tetraploid wheat T. dicoccum and hexaploid wheat T. spelta. For this purpose, a PCR approach based on end-point quantification was developed and the results obtained were confirmed in a qPCR assay. The duplication of the vrn-Ab.3 and Vrn-A1b.2 alleles in T. dicoccum and $T$. spelta has been shown for the first time. Furthermore, in accessions of T. spelta the duplication of Vrn-A1b.2 was strongly associated with the awnless spikes and $V r n-B 1 C$ genotype, indicating a likely common origin of these accessions. Variation of the Vrn-A1b.2 haploid copy number can provide additional advantages in manipulation of flowering time of wheat.
\end{abstract}

Key words: wheat; emmer; spelt; flowering time; copy number variation; genetic diversity.

\section{Introduction}

The VRN1 genes are major determinants of such agronomically valuable traits of wheat as growth habit and flowering time. The dominant alleles of these genes contain mutations within the promoter region and in the first intron, determining spring growth habit and early flowering of wheat.

The hexaploid wheat of T. spelta belongs to the Triticum dicoccum lineage and was derived from hybridization events between the domesticated hulled tetraploid wheat $T$. dicoccum and free-threshing hexaploid wheat T. aestivum. The dominant $V r n-A 1 b .2$ allele is one of major determinants of the spring growth habit in T. dicoccum and T. spelta (Muterko et al., 2016).

Previously the copy number variation (CNV) of the recessive $v r n-A 1$ allele was shown for hexaploid wheat (Diaz et al., 2012, Würschum et al., 2015, Muterko and Salina 2017, Muterko and Salina 2018). However, this polymorphism was not analyzed in tetraploid wheat and hexaploid wheat with the dominant $V r n-A 1$ alleles. In the present study, the CNV of VRN1 genes was investigated in accessions of tetraploid wheat $T$. dicoccum and spring accessions of hexaploid wheat T. spelta.

\section{Materials and methods}

Total nucleic acids were extracted from seedlings and leaves using CTAB lysis buffer, chloroform extraction and isopropanol precipitation.

PCR was carried with the VRN1ex4F (agttgcagcaactggagcag) and VRN1ex6R (tattctcctcetgcagtgac) primer pair. Both primers are annealed on all three homeologous VRN1 genes, producing fragments of similar lengths (470, 476 and $468 \mathrm{bp}$ fragments for the $V R N-A 1, V R N-B 1$ and $V R N-D 1$ genes). However, since the polymorphism of these fragments is localized within the A-tract rich region this accompanied the modulation of curvature of the DNA molecules. The DNA template was fragmented by temperature and PCR was carried out only for 24 cycles to quantify target amplicons at the exponential phase of amplification.
The horizontal electrophoresis was carried out on half of microscopic glass slides at $6-8{ }^{\circ} \mathrm{C}$ in ultrathin $(0.5 \mathrm{~mm})$ non-denaturing polyacrylamide gels in discontinuous buffer system Tris- $\mathrm{HCl} /$ Tris-Borate. Gels were stained in ethidium bromide and visualized under UV light. The ratios of peak intensities of the $V R N-A 1$ (A1), $V R N-B 1$ (B1) and $V R N-D 1$ (D1) fragments were used to quantify the relative copy number of the corresponding genes. In this approach the principles of isotachophoresis are used to preconcentration of DNA fragments and obtain very thin bands, producing the sharpened peaks of fluorescence intensity, which are suitable for proper quantification.

Quantitative PCR was performed using TaqMan probes for the $V R N-A 1$ and CONSTANS genes (Würschum et al., 2015). Sanger sequencing was carried out using a BigDye Terminator v3.1 sequencing kit with subsequent analysis on an ABI 3130xl Genetic Analyzer (SB RAS Genomics Core Facility).

\section{Results and discussion}

The VRN1-ratio test optimized as described in the Methods section was applied to the accessions of $T$. dicoccum and $T$. spelta carrying the dominant $V r n-A 1$ allele and found variation in $V R N-A 1$ copy number, but not in $V R N-B 1$ or $V R N-D 1$.

The A1/B1 ratio for accessions of $T$. dicoccum with the recessive (intact) $v r n-A 1$ as well as the dominant $V r n-A 1 a$, $V r n-A 1 b .2, V r n-A 1 e$ and $V r n-A 1 k$ alleles was 0.8 , indicating a single haploiod copy of $V R N-A 1$. However, in two accessions from Israel and Palestine, the intensity ratio of the $V R N-A 1$ PCR fragments to $V R N-B 1$ results in an average value of 1.6 (1.5-1.7), suggesting a duplication of $V R N-A 1$. To confirm this assumption, the qPCR was carried out, where the $C O N$ STANS genes were used, as the endogenous control, instead of $V R N-B 1$. The results of both $V R N 1$-ratio test and qPCR were consistent (Figure 1). Sequence analysis of the $V R N-A 1$ promoter region showed that both of these T. dicoccum accessions carry $v r n-A 1 b .3$.

The VRN1-ratio test divided accessions of T. spelta with the $V r n-A 1 b$ allele into two groups. It one of them, the average 

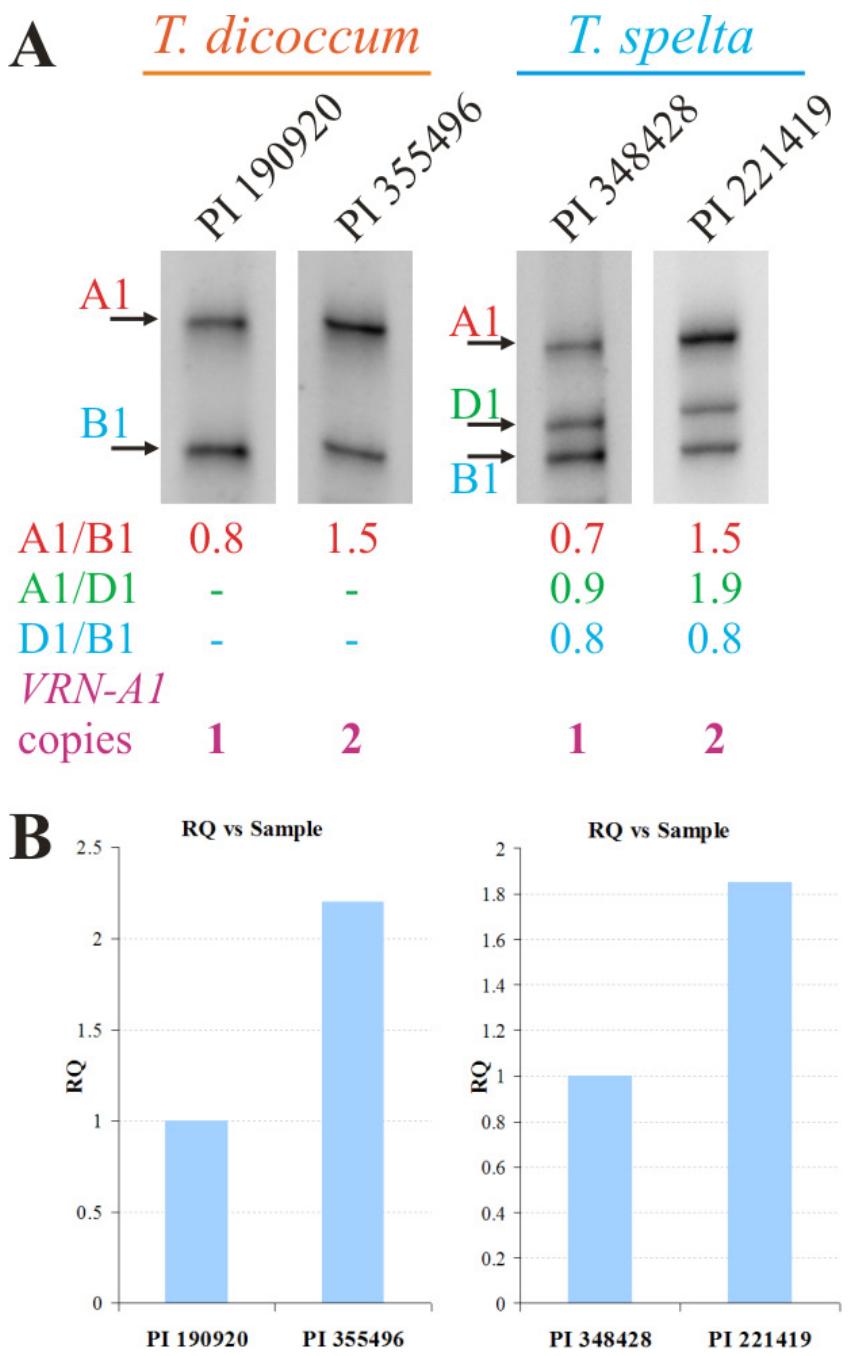

Figure 1. Quantification of the $V R N-A 1$ copies in accessions of $T$ dicoccum and T. spelta during the (A) VRN1-ratio test and (B) QPCR assays.

$\mathrm{A} 1 / \mathrm{B} 1$ and $\mathrm{A} 1 / \mathrm{D} 1$ ratios were 0.7 and 1 , respectively, while in the other, 1.4 and 2. The D1/B1 ratio for both groups was 0.8 . The results obtained assuming single and two haploid copies of $V R N-A 1$ for these groups, respectively, and the copy number of $V R N-A 1$ was confirmed using a qPCR assay (see Figure 1).

Interestingly, that duplication of $V r n-A 1 b .2$ in accessions of T. spelta was strongly associated with the $V r n-B 1 c$ genotype and awnless spikes, while accessions containing a single haploid copy of this allele were awned and carried recessive $v r n-B 1$ with the $V R N-B 1 s$ haplotype. These observations are likely related to the different origin of the $T$. spelta accessions analyzed. In fact, almost all accessions of $T$. spelta carrying a single haploid copy of $V r n-A 1 b .2$ originate from Italy (assumed Asturian spelt).

It is known that gene dosage of the dominant VRN1 alleles positively correlates with early flowering of polyploid wheat. On the other hand, multiplication of the recessive $v r n-A 1$ allele is associated with later flowering. In any case, the effect of the Vrn-A1b.2 duplication on phenotype provides additional advantages in the manipulation of flowering time of wheat.

\section{Conclusions}

Copy number variation of the VRN1 genes was investigated in accessions of tetraploid wheat $T$. dicoccum and hexaploid wheat $T$. spelta. The duplication of $v r n-A 1 b .3$ in $T$. dicoccum as well as vrn-A1b.3 and the Vrn-A1b.2 alleles in T. spelta was shown for the first time. In the European population of spring spelt wheat, the duplication of $V r n-A 1 b .2$ is associated with the awnless spikes and the $V r n-B 1 c$ genotype.

\section{References}

Diaz A., Zikhali M., Turner A., Isaac P., Laurie D. Copy number variation affecting the Photoperiod-B1 and Vernalization-A1 genes is associated with altered flowering time in wheat (Triticum aestivum). PLoS One. 2012;7(3):e33234. DOI 10.1371/journal.pone.0033234.

Muterko A., Kalendar R., Salina E. Novel alleles of the VERNALIZATION1 genes in wheat are associated with modulation of DNA curvature and flexibility in the promoter region. BMC Plant Biol. 2016;16(Suppl 1):9. DOI 10.1186/s12870-015-0691-2.

Muterko A.F., Salina E.A. Analysis of the VERNALIZATION-A1 exon-4 polymorphism in polyploid wheat. Vavilov Journal of Genetics and Breeding. 2017;21(3):323-333. DOI 10.18699/VJ16.19-o.

Muterko A., Salina E. Origin and distribution of the $V R N-A 1$ exon 4 and exon 7 haplotypes in domesticated wheat species. Agronomy. 2018;8(8):156. DOI 10.3390/agronomy8080156.

Würschum T., Boeven P.H., Langer S.M., Longin C.F., Leiser W.L. Multiply to conquer: Copy number variations at $P p d-B 1$ and $V r n-A 1$ facilitate global adaptation in wheat. BMC Genet. 2015;29:16-96. DOI 10.1186/s12863-015-0258-0.

Acknowledgements. This research was funded by the Russian Scientific Foundation grant No. 18-74-00080.

Conflict of interest. The authors declare no conflict of interest. 


\title{
Evaluation of in vitro plant regeneration efficiency in Siberian wheat cultivars
}

\author{
D.N. Miroshnichenko ${ }^{1 *}$, A.A. Klementyeva ${ }^{1}$, E.A. Salina² ${ }^{2}$ S.V. Dolgov ${ }^{1}$ \\ ${ }^{1}$ Branch of Shemyakin and Ovchinnikov Institute of Bioorganic Chemistry RAS, Pushchino, Moscow Region, Russia \\ 2 Institute of Cytology and Genetics, SB RAS, Novosibirsk, Russia
}

DOI 10.18699/ICG-PlantGen2019-40

(c) Autors, 2019

* e-mail: miroshnichenko@bibch.ru

\begin{abstract}
The regeneration ability of three Siberian bread wheat cultivars, 'Novosibirskaya-40', 'Novosibirskaya-61' and 'Velut', has been studied. Embryogenic callus formation and shoot regeneration were successfully achieved from the isolated immature zygotic embryos using a two-step regeneration protocol. Embryogenic calli were induced by culturing immature embryos on a medium supplemented with 2,4-dichlorophenoxyacetic acid $(2,4-D)$. During the first step of culture, all the cultivars were able to produce embryogenic calli with a high frequency varying from $87.1 \%$ ('Novosibirskaya-40') to $95.5 \%$ ('Novosibirskaya-61'). Upon withdrawal from auxin, differentiation of embryogenic structures into green plantlets was achieved. The ability to regenerate plants in vitro differed among the wheat cultivars tested, the highest was observed for 'Velut' (13.7 plantlets per morphogenic explant) and the lowest, for 'Novosibirskaya-40' (5.7 plantlets per morphogenic explant).

Key words: Triticum aestivum L.; immature embryos; somatic embryogenesis; plant regeneration.
\end{abstract}

\section{Introduction}

The complementing of the traditional breeding approaches with the modern biotechnologies opens the possibility to enhance genetic variation in wheat. Different new breeding technologies (NBTs) such as haploid production, genetic engineering, or plant genome editing strongly depend on the availability of cultivars demonstrating efficient in vitro plants regeneration. In last decades, the application of NBTs to genetically improve the diversity of the wheat genome was repeatedly reported (Shrawat, Armstrong, 2018; Borisjuk et al., 2019). However, most of the researches were mostly carried out using 'model' cultivars, while the application of NBTs to high-quality local cultivars has a more practical perspective.

In wheat, plant regeneration can be achieved through embryogenesis or organogenesis induced by the culturing of isolated immature zygotic embryos on a medium supplemented with auxins (Delporte et al., 2014). Our previous results showed that the 4-week culture of immature tissues on a media containing 2,4-D (2,4-dichlorophenoxyacetic acid) under darkness with the subsequent plant differentiation under light on media without phytohormones could be good starting practice for testing various wheat cultivars and species for regeneration abilities (Alikina et al., 2016). In this study, Siberian cultivars of bread wheat adapted to local environments were investigated for their ability to induce embryogenic calli and produce plants in vitro.

\section{Materials and methods}

Three different samples of bread wheat (Triticum aestivum L.) - cv. 'Novosibirskaya-40' (winter), cv. 'Novosibirskaya-61' (spring) and line 'Velut' (spring) - were tested. The wheat samples differ in genomic composition. In contrast to cv 'Novosibirskaya-40' the other two wheat samples have translocation from wild species: cv. Novosibirskaya-61 - from Agropyron and line 'Velut' - from rye and Aegilops speltodies (Salina, unpublished). The donor plants growing and the immature embryos isolation were performed as described (Alikina et al., 2016). To ensure a sufficient number (not less than 60 in general) of embryogenic calli formed and used to regenerate plants, 115-135 initial explants for each variety were placed on the induction medium.

Callus induction media used in this study consisted of MS macro- and microelements and vitamins (Murashige and Skoog, 1962), 2 mg/L 2,4-D, 150 mg/L L-asparagine, $3 \%$ $(\mathrm{w} / \mathrm{v})$ sucrose, and were solidified with $7 \mathrm{~g} / \mathrm{L}$ agar, $\mathrm{pH} 5.8$. The frequencies of embryogenic callus formation from immature embryos were calculated after 1 month of culture. For plant regeneration, embryogenic calli produced by immature embryos were transferred into culture flasks on a hormonefree medium containing MS mineral salts and vitamins, $20 \mathrm{~g} / \mathrm{L}$ sucrose, and $7 \mathrm{~g} / \mathrm{L}$ agar. At the end of culturing, the number of plantlets regenerated from embryogenic calli was calculated.

\section{Results and discussion}

An important prerequisite for the production of transgenic or genome-edited wheat plants is the availability of a target tissue competent for plant regeneration. In wheat, the most popular explants routinely used to induce plant regeneration are immature zygotic tissues (Shrawat, Armstrong, 2018). For many cultivars of polyploid wheat, it is usually sufficient to use the supplement of 2-3 mg/l of 2,4-D to induce somatic embryogenesis from isolated immature zygotic embryos (Delporte et al., 2014). In some cases, certain germplasms display significant recalcitrance in vitro, so optimization is required to achieve an appreciable level of morphogenic response with regard to the choice of auxin type and its proper concentration (Miroshnichenko et al., 2016, 2017). In the present study, we have made an attempt to study the morphogenic efficiency of three local wheat cultivars, 'Novosibirskaya-40', 'Novosibirskaya-61' and 'Velut'. Since the in vitro response of zygotic tissues in wheat strictly depends on the genotype, this research was aimed to clarify which of the cultivars could be 
Table 1

In vitro culture response of immature embryo tissue of three Siberian wheat cultivars

\begin{tabular}{llll}
\hline Cultivar & $\begin{array}{l}\text { Callus induction*, } \\
(\%)\end{array}$ & $\begin{array}{l}\text { Embryogenic callus induction**, } \\
(\%)\end{array}$ & No. of regenerated shoots*** \\
\hline Novosibirskaya-40 & $94.0 \pm 5.5$ & $87.1 \pm 9.6$ & $5.7 \pm 0.9$ \\
Novosibirskaya-61 & $99.3 \pm 1.8$ & $95.5 \pm 5.6$ & $8.0 \pm 1.2$ \\
Velut & $97.4 \pm 2.5$ & $93.9 \pm 8.7$ & $13.7 \pm 1.9$ \\
\hline
\end{tabular}

* Percentage of initial explants producing callus

** Percentage of initial explants producing embryogenic callus

*** Number of regenerated plantlets per embryogenic callus

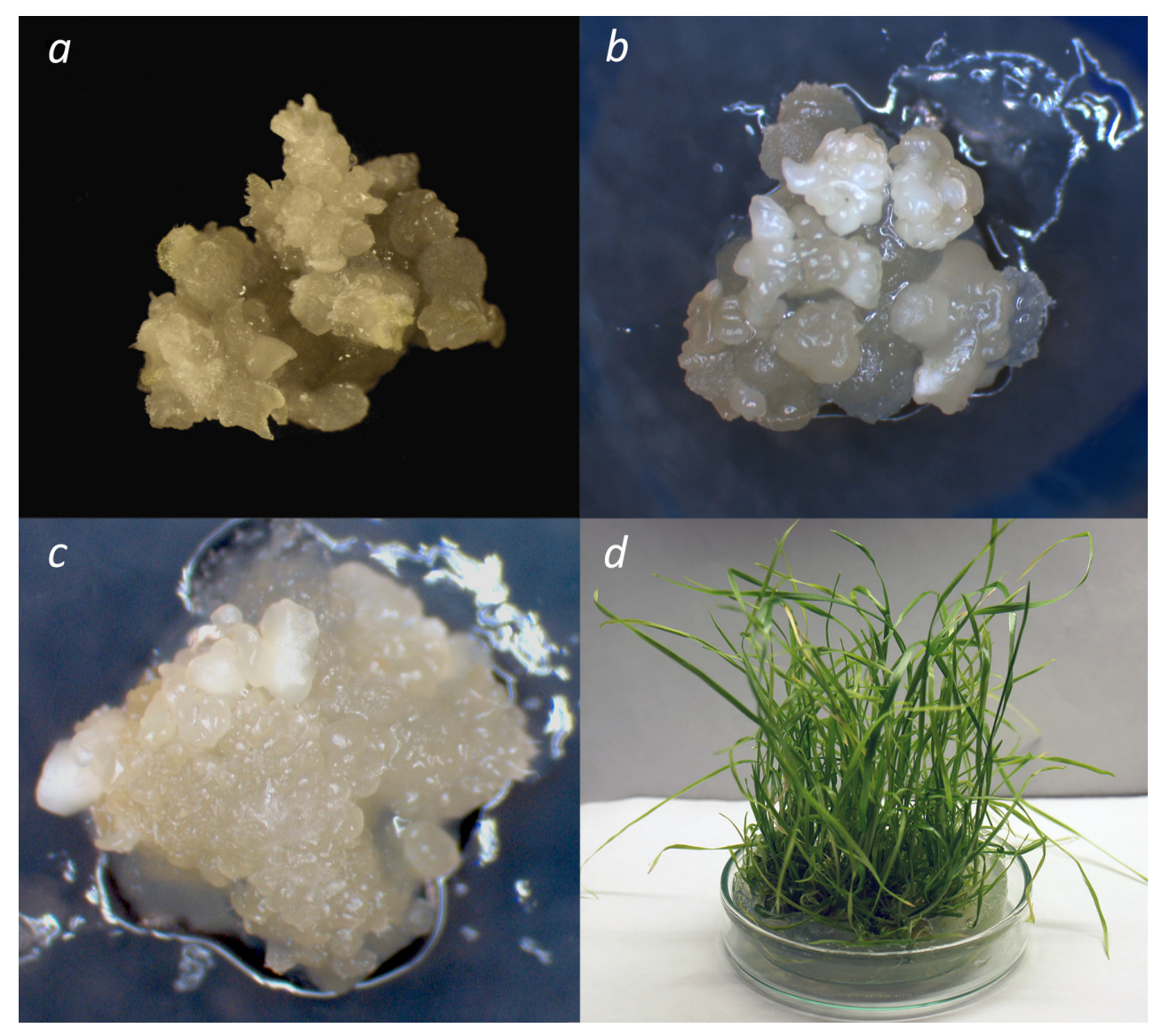

Figure 1. Embryogenic callus formation from immature embryo tissues of 'Novosibirskaya-61' (a), Novosibirskaya-40' (b), 'Velut' (c) on the medium supplemented with $2 \mathrm{mg} / \mathrm{L} \mathrm{2,4-D}$ after 4 weeks of culture, and regeneration of plants from embryogenic callus of 'Velut' $(d)$ after 30 days of culture on medium without growth regulators.

directly used for the NBT programs, and which require the further optimization of the in vitro morphogenesis protocol.

Within two weeks of cultivation, the formation of embryogenic callus surrounded by translucent non-embryogenic callus was observed in all cultivars. Taking into account the efficiency of callogenesis and embryogenesis (Table 1), no clear differences were found between cultivars. All the cultivars studied displayed a high ability to form embryogenic structures, varying from $87.1 \%$ ('Novosibirskaya-40') to $95.5 \%$ ('Novosibirskaya-61'). However, the pattern of the formation of the morphogenic structures differed in the cultivars studied.
'Novosibirskaya-61' and especially 'Novosibirskaya-40' explants formed mostly scattered embryogenic structures (Figure $1, a, b)$, while the entire explant surface of 'Velut' was usually covered with numerous embryogenic structures at the end of culture period on auxin-containing medium (see Figure 1,c).

The difference in the density of morphogenic structure formation significantly influenced the regeneration capacity of the cultivars. After transfer onto the medium lacking plant growth regulators, morphogenic explants of 'Velut' displayed high conversion into plantlets (Figure 1,d) - they reached the figure of 13.7 plantlets per explant (Table 1). In contrast, 
embryogenic callus of 'Novosibirskaya-40' and 'Novosibirskaya-61' generated only 5.7 and 8.0 plantlets, respectively. Despite the difference in the number of plants produced, none of the cultivars showed the formation of albino individuals among regenerated plants, a phenomenon previously reported for polyploid wheat germplasms belonging to T. kiharae, T. timopheevii, T. carthlicum and T. compactum (Alikina et al., 2016; Miroshnichenko et al., 2016).

Regenerated shoots of 'Novosibirskaya-40', 'Novosibirskaya-61' and 'Velut' with prominent roots were further transferred into the greenhouse. All plantlets that had been transferred to soil survived the greenhouse conditions and grew into morphologically normal and fertile plants.

\section{Conclusions}

The two-step protocol based on 2,4-D as the main exogenous inducer for the in vitro response of local Siberian cultivars of bread wheat can be successfully used to generate a sustainable supply of morphogenic material from immature embryos for the application in various NBT programs. All cultivars studied demonstrated an appreciable ability to produce embryogenic callus, which is the main target for delivering constructs encoding genome editing components or transgenic sequences. Some modifications of the protocol, however, should be recommended to control more efficiently the conversion of morphogenic structures into the whole plants in 'Novosibirskaya-40' and 'Novosibirskaya-61'. As an example, a combination of various plant growth regulators displaying distinctive biological activities (Miroshnichenko et al., 2017) could be simultaneously used for promoting a higher rate of morphogenesis in these wheat cultivars.

\section{References}

Alikina O., Chernobrovkina M., Dolgov S., Miroshnichenko D. Tissue culture efficiency of wheat species with different genomic formulas. Crop Breeding and Applied Biotechnology. 2016;16:307-314. DOI 10.1590/1984-70332016v16n4a46

Borisjuk N., Kishchenko O., Eliby S., Schramm C., Anderson P., Jatayev S., Kurishbayev A., Shavrukov Y. Genetic modification for wheat improvement: from transgenesis to genome editing. Biomed Res Int. 2019;2019:6216304. DOI 10.1155/2019/6216304.

Delporte F., Pretova A., du Jardin P., Watillon B. Morpho-histology and genotype dependence of in vitro morphogenesis in mature embryo cultures of wheat. Protoplasma. 2014;251(6):1455-1470. DOI 10.1007/s00709-014-0647-7.

Miroshnichenko D., Chaban I., Chernobrovkina M., Dolgov S. Protocol for efficient regulation of in vitro morphogenesis in einkorn (Triticum monococcum L.), a recalcitrant diploid wheat species. PLoS ONE. 2017;12(3):e0173533. DOI 10.1371/journal.pone.0173533.

Miroshnichenko D., Chernobrovkina M., Dolgov S. Somatic embryogenesis and plant regeneration from immature embryos of Triticum timopheevii Zhuk. and Triticum kiharae Dorof. et Migusch, wheat species with G genome. Plant Cell Tiss Organ Cult. 2016;125(3): 495-508. DOI 10.1007/s11240-016-0965-x.

Murashige T., Skoog F. A revised medium for rapid growth and bioassays with tobacco tissue cultures. Physiol Plant. 1962;15:473-497.

Shrawat A.K., Armstrong C.L. Development and application of genetic engineering for wheat improvement. Crit Rev Plant Sci. 2018; 37(5):335-421. DOI 10.1080/07352689.2018.1514718.

Conflict of interest. The authors declare no conflict of interest. 


\title{
Improvement of sorghum grain quality using modern genetic tools
}

\author{
L.A. Elkonin ${ }^{1 *}$, V.M. Panin ${ }^{1}$, G.A. Gerashchenkov², O.A. Kenzhegulov ${ }^{1}$ \\ ${ }^{1}$ Agricultural Research Institute of South-East Region, Saratov, Russia \\ ${ }^{2}$ Institute of Biochemistry and Genetics, Subdivision of the Ufa Federal Research Centre, RAS, Ufa, Russia
}

DOI 10.18699/ICG-PlantGen2019-41

(c) Autors, 2019

*e-mail: lelkonin@gmail.com

\begin{abstract}
A review of the studies on the improvement of the nutritional value of sorghum grain by genetic engineering tools is presented. These studies include biofortification of sorghum with amino acids and micronutrients and improving digestibility of seed storage proteins (kafirins) via RNA interference and genome editing. Transgenic sorghum harboring the genetic constructs inducing RNA silencing of kafirins are characterized by an increased in vitro digestibility of endosperm proteins, an increased proportion of lysine, and modification of endosperm texture, which becomes floury devoid of the vitreous layer. In some cases transgenic events with vitreous endosperm and a high digestibility of kafirins were obtained, which may be of interest for practical sorghum breeding. There are evidences that genetic constructs for RNA silencing may be unstable in the plant genome and their expression may be influenced by the environment. Induction of mutations that disrupt the functioning of the kafirin genes using genome editing may be a more effective approach for improving the digestibility of kafirins and increasing the nutritional value of sorghum grain.

Key words: kafirins; endosperm; in vitro protein digestibility; RNAi; CRISPR/Cas9; Sorghum bicolor.
\end{abstract}

\section{Introduction}

One of the promising areas of biotechnology is the improvement of the nutritional value of grain. This task is particularly important for sorghum, a high-yielding drought-tolerant cereal, which is a source of feed and food for millions of people in many countries around the world. However, compared to other cereals, the majority of sorghum cultivars are characterized by a number of nutritional constrains, such as a lower digestibility of seed storage proteins (kafirins) and starch, a poor nutritional value of kafirins, which have a low content of essential amino acids.

Among the factors that cause or may effect this phenomenon are the chemical structure of kafirins, which are abundant with sulphur-containing amino acids capable to form S-S bonds resistant to protease digestion; interactions of kafirins with non-kafirin proteins and non-protein components such as polyphenols and polysaccharides; the spatial organization of different kafirins in the protein bodies of endosperm cells (Belton et al., 2006). It is generally accepted that the peripheral disposition of $\gamma$-kafirin, which is considered as the most stable against protease digestion reduces digestibility of $\alpha$-kafirin, the major sorghum seed storage protein located centrally in protein bodies and comprising up to $80 \%$ of the total endosperm kafirins. In addition, $\gamma$-kafirin is characterized by the ability to form oligo- or polymers of high molecular weight, which are resistant to protease digestion.

In this paper, we summarized some experiments on biofortification of sorghum with amino acids and micronutrients and on improving digestibility of kafirins using genetic engineering approaches and outlined their importance for practical sorghum breeding.

\section{Sorghum biofortification with amino acids and micronutrients}

Numerous researches published up to date clearly demonstrate that genetic engineering techniques are quite promising for enrichment of cereal grain with essential amino acids, i. e. lysine, tryptophan, methionine, and micronutrients. By using endosperm-specific promoters, expression of the desired genes may be provided exactly in the kernels, rather than in somatic tissues. Sorghum grain has a low content of lysine and $\beta$-carotene (provitamin A), which are highly important for human health.

There are reports on obtaining transgenic sorghum plants with an increased content of lysine (up to 40-60\%) (Zhao et al., 2010) and $\beta$-carotene (up to $7.3-12.3 \mu \mathrm{g} / \mathrm{g}$ vs. $0.5 \mu \mathrm{g} / \mathrm{g}$ in non-transgenic control seeds). In order to increase $\beta$-carotene content in sorghum grain and ensure its stability during grain storage, the introduction of five genetic constructs encoding enzymes involved in the carotenoid biosynthesis pathway and preventing its oxidative degradation was performed (Che et al., 2016).

This research is a shining example of the effectiveness of the genetic engineering approach for modifying plant metabolism to meet human needs.

\section{Increase in seed storage protein digestibility using RNA-silencing technology}

In recent years, RNA interference technology has been intensively used to suppress the synthesis of seed storage proteins in different species of cereals including wheat, rice and maize. These experiments contributed to obtaining new information on the mechanisms of protein body formation, as well as the 
role of various classes of prolamins and glutenins in the development of endosperm and their effect on the technological properties of flour.

In sorghum, intensive studies on the induction of RNAsilencing of the kafirin genes have been undertaken by several research groups (DaSilva et al., 2011; Kumar et al., 2012; Grootboom et al., 2014). The main goal of these experiments was the improvement of in vitro protein digestibility as a result of suppressing synthesis of different kafirin sub-classes. In these experiments, RNAi-constructs differ in the number of targeted kafirin genes, the nature of intron separated inverted repeats of kafirin genes, and promoters driving these constructs.

In the experiments of each of these groups, lines of transgenic sorghum with suppressed synthesis of $\gamma$ - and/or $\alpha$-kafirins and a floury type of endosperm were obtained. Unfortunately, the presence of floury endosperm is a disadvantage of these lines, since the absence of a vitreous layer increases the fragility of the grain and reduces their resistance to damage by fungal diseases.

Remarkably, in our experiments with genetic constructs for the silencing of only the $\gamma$-kafirin gene (Elkonin et al., 2016) we have obtained transgenic plants, which had kernels with normal vitreous endosperm, as well as with a thin vitreous endosperm layer, with floury or modified endosperm types. In kernels with the modified endosperm type, the vitreous layer was significantly reduced and developed as sectors or patches surrounded by floury endosperm. These kernels resemble the kernels of recombinant sorghum lines obtained by hybridization of a highly digestible mutant with floury endosperm $(h d h l)$ with ordinary sorghum lines with vitreous endosperm (Tesso et al., 2006).

Previously, transgenic plants with patches of vitreous endosperm surrounded by floury endosperm were also observed in 'Tx 430' containing a genetic construct for silencing $\alpha$ - and $\gamma$-kafirins, while co-suppression of $\delta$-kafirin and $\gamma$-kafirin subclasses did not change the endosperm phenotype in this line (DaSilva, 2012). Apparently, the formation of different endosperm types results from peculiarities of expression of the genetic constructs in the genome of the recipient line.

The most important effect of kafirin silencing in transgenic plants was an increased protein digestibility in both cooked and raw sorghum flour. For example, transgenic plants of 'Tx430' carrying the genetic construct for silencing of $\alpha$ and $\gamma$-kafirin sub-classes were characterized by an improved in vitro protein digestibility of both raw and cooked grain flour: 78 and $61 \%$, respectively; while in the non-transgenic control these figures were 40-50 and 34-40\%, respectively (DaSilva et al., 2011).

The genetic construct for silencing only $\delta$ - and $\gamma$-kafirins also caused an improvement of in vitro protein digestibility of raw flour, but did not affect the digestibility of cooked flour (DaSilva, 2012). In experiments by Kumar et al. (2012), cooked flour obtained from transgenic plants carrying genetic constructs for silencing $\gamma$-kafirin did not differ from the nontransgenic control, while the silencing of $\alpha$-kafirin improved the protein digestibility of cooked flour.

Transgenic plants obtained in our experiments also had a significantly improved in vitro digestibility of endosperm pro- teins (Elkonin et al., 2016). A comparison of electrophoretic spectra before and after pepsin digestion revealed that the amount of undigested $\alpha$-kafirin monomers and total undigested protein was significantly lower (1.7-1.9 times, according to quantitative analysis of SDS-PAGE) in the transgenic plant than in the original non-transgenic line.

The digestibility value reached $85.4 \%$, while in original line this value was about $60 \%$. Remarkably, in the kernels of transgenic plant \#94-3-08 ( $\left.\mathrm{T}_{2}\right)$ with thick vitreous endosperm, the differences in kafirin digestion were more pronounced: the amount of undigested monomers was 17.5 as low, and the amount of total undigested protein was 4.7 as low as those in the original line. The digestibility value reached $92 \%$.

Plants from $\mathrm{T}_{3}$ generation inherited the improved digestibility of kafirins. In these plants, kernels had either floury or modified endosperm or endosperm with a vitreous layer. The level of digestibility of endosperm proteins in these plants was $83-90 \%$, significantly differing from the digestibility of proteins in the original non-transgenic line. Apparently, a decrease in $\gamma$-kafirin increases the digestibility of $\alpha$-kafirins. This increase may be due to chemical reasons (reduction of polymerization) and/or physical reasons (change in the spatial arrangement of $\alpha$-kafirins in the protein bodies that increase their availability to pepsin digestion).

The effect of increased protein digestibility was also observed in some plants from $\mathrm{T}_{4}$ generation, while in others it disappeared owing to the instability of the RNAi construct (see section 5).

\section{Rebalancing of the seed proteome and improvement of the nutritional value of sorghum grain by silencing kafirin genes}

An important consequence of silencing of prolamine genes in cereals is the enhancement of the synthesis of other proteins, including those that have a higher content of essential amino acids, lysine and threonine. Maize plants with silenced $\alpha$-zeins were characterized by a doubled content of the essential amino acids tryptophan and lysine (Huang et al., 2006).

In rice, it has been shown that gene silencing of a $13 \mathrm{kDa}$ prolamine increases the total lysine content up to $56 \%$ as a result of a compensatory rise in the synthesis of lysine-rich glutelins, globulins and chaperones (Kawakatsu et al., 2010). A significant increase in lysine content (up to $3.3 \mathrm{~g} / 100 \mathrm{~g}$ protein in comparison with $2.1 \mathrm{~g} / 100 \mathrm{~g}$ protein in the nontransgenic control) was found in transgenic sorghum plants carrying complex genetic constructs for RNAi silencing of the $\alpha-, \gamma-, \delta$-kafirin genes and lysine-ketoglutarate reductase gene, which control the catabolism of free lysine (DaSilva, 2012).

In our studies, in the kernels of transgenic plants from $\mathrm{T}_{2}$ generation with high in vitro protein digestibility, the total amino acid content was significantly reduced to $22.8-40.2 \%$, in comparison with the original non-transgenic line (Elkonin et al., 2016). At the same time, the relative content of two major essential amino acids, lysine and threonine, significantly increased. The lysine proportion increased 1.6-1.7 times: from $1.54 \%$ of the total amino acid content in the flour of the original non-transgenic line to $2.41-2.63 \%$ in the transgenic plants. Such an increase, coupled with a significant reduc- 
tion in the total level of amino acids, was presumably caused by a decrease in the content of $\alpha$-kafirins poor in lysine and threonine, while the synthesis of other proteins remained undisturbed. Consequently, the relative proportions of lysine and threonine increased. Perhaps, the suppression of the $\gamma$-kafirin synthesis prevents the accumulation of $\alpha$-kafirins, but does not affect the synthesis of other proteins richer in lysine and threonine.

Such a rebalancing of the seed proteome is a common phenomenon for transgenic plants with genetic constructs for RNA silencing of major seed storage proteins. For maize, it was suggested that developing kernels possess compensatory mechanisms that sense protein content when zein synthesis is interrupted, leading to translation of other mRNAs instead of zein mRNAs (Wu, Messing, 2014).

Remarkably, in knockdown mutant lines of soybean with suppressed synthesis of major storage proteins, the seeds maintained nearly identical levels of total protein compared to the untransformed soybean cultivars (Schmidt et al., 2011). These data suggest that proteome rebalancing in seeds might be a rather common event, providing a constant sink for reduced nitrogen during seed maturation.

\section{Instability of genetic constructs for RNA silencing of $\gamma$-kafirin gene}

In our experiments, we found that the progeny of transgenic plants with high in vitro protein digestibility sometimes lost this trait. Even different panicles of one and the same plant had different values of in vitro protein digestibility. PCR analysis of plants from the late generations $\left(\mathrm{T}_{4}, \mathrm{~T}_{5}\right)$ showed elimination of the construct for RNA silencing in the course of plant ontogenesis. Nevertheless, in some plants from the same progeny the construct was stable.

In addition, in some plants from $\mathrm{T}_{4}$ generations, we found elimination of the nos-promoter governing the marker bar gene from the transgenic construct for silencing the $\gamma$-kafirin gene. Therefore, these plants, in fact, turned to be functionally marker-free transgenic plants.

\section{Editing of nucleotide sequences of kafirin genes}

In above examples, suppressing the synthesis of kafirins is performed by small interfering RNAs (siRNAs) and subsequent mRNA cleavage and translational inhibition, which are important epigenetic mechanisms in plants. However, epigenetic mechanisms in plants are known to be sensitive to growing conditions and environmental factors (temperature, soil moisture and air, etc.). There are reports that temperature can have a major impact on the extent of gene silencing. Recently it has been shown that miRNA-mediated mRNA cleavage and translational inhibition are dependent on plant growth temperature (von Born et al., 2018). Therefore, the effectiveness of suppression of kafirin synthesis by RNAi constructs might be sensitive to plant growing conditions. In addition, genetic construct for RNA silencing may be unstable in the plant genome. In this regard, induction of mutations that disrupt the functioning of the kafirin genes at the genetic level may be a more effective approach for altering kafirin levels.
Recently, using the CRISPR/Cas9 gene editing tool Li et al. (2018) induced mutations in a conserved region encoding the endoplasmic reticulum signal peptide of $\alpha$-kafirins.

The target site mutations occurring in each $k l C$ gene include small deletions as well as a low frequency of small insertions. $\mathrm{T}_{1}$ and $\mathrm{T}_{2}$ seeds showed reduced $\alpha$-kafirin levels, an altered protein body microstructure, and selected $T_{2}$ events showed a significantly increased grain protein digestibility and lysine content. These data open new prospects for improving the nutritional value of sorghum grain using biotechnological approaches.

\section{References}

Belton P.S., Delgadillo I., Halford N.G., Shewry P.R. Kafirin structure and functionality. J. Cereal Sci. 2006;44:272-286. DOI 10.1016/j. jes.2006.05.004

Che P., Zhao Z.-Y., Glassman K., Dolde D., Hu T.X., Jones T.J., Gruis D.F., Obukosia S., Wambugu F., Albertsen M.C. Elevated vitamin E content improves all-trans beta-carotene accumulation and stability in biofortified sorghum. Proc. Natl. Acad. Sci. USA. 2016;113:11040-11045. DOI 10.1073/pnas.1605689113.

da Silva L.S. Transgenic sorghum: Effects of altered kafirin synthesis on kafirin polymerisation, protein quality, protein body structure and endosperm texture. PhD Thesis. Department of Food Science, Faculty of Natural and Agricultural Sciences, Univ. Pretoria, South Africa. 2012.

da Silva L.S., Taylor J., Taylor J.R. Transgenic sorghum with altered kafirin synthesis: kafirin solubility, polymerization, and protein digestion. J. Agric. Food Chem. 2011;59:9265-9270. DOI 10.1021/ jf201878p.

Elkonin L.A., Italianskaya J.V., Domanina I.V., Selivanov N.Y., Rakitin A.L., Ravin N.V. Transgenic sorghum with improved digestibility of storage proteins obtained by Agrobacterium-mediated transformation. Russ. J. Plant Physiol. 2016;63:678-689. DOI 10.1134/ S1021443716050046.

Grootboom A.W., Mkhonza N.L., Mbambo Z., O’Kennedy M.M., da Silva L.S., Taylor J., Taylor J.R.N., Chikwamba R., Mehlo L. Cosuppression of synthesis of major $\alpha$-kafirin sub-class together with $\gamma$-kafirin-1 and $\gamma$-kafirin-2 required for substantially improved protein digestibility in transgenic sorghum. Plant Cell Rep. 2014;33: 521-537. DOI 10.1007/s00299-013-1556-5.

Huang S., Frizzi A., Florida C.A., Kruger D.E., Luethy M.H. High lysine and high tryptophan transgenic maize resulting from the reduction of both 19- and 22-kD $\alpha$-zeins. Plant Mol. Biol. 2006;61:525535. DOI 10.1007/s11103-006-0027-6.

Kawakatsu T., Hirose S., Yasuda H., Takaiwa F. Reducing rice seed storage protein accumulation leads to changes in nutrient quality and storage organelle formation. Plant Physiol. 2010;154:1842-1854. DOI 10.1104/pp.110.164343.

Kumar T., Dweikat I., Sato S., Ge Z., Nersesian N., Chen H., Elthon T., Bean S., Ioerger B.P., Tilley M., Clemente T. Modulation of kernel storage proteins in grain sorghum (Sorghum bicolor (L.) Moench). Plant Biotechnol. J. 2012;10:533-544. DOI 10.1111/j.14677652.2012.00685.x.

Li A., Jia S., Yobi A., Ge Z., Sato S.J., Zhang C., Angelovici R., Clemente T.E., Holding D.R. Editing of an alpha-kafirin gene family increases digestibility and protein quality in sorghum. Plant Physiol. 2018;177(4):1425-1438. DOI 10.1104/pp.18.00200.

Schmidt M.A., Barbazuk W.B., Sandford M., May G., Song Z., Zhou W., Nikolau B.J., Herman E.M. Silencing of soybean seed storage proteins results in a rebalanced protein composition preserv- 
ing seed protein content without major collateral changes in the metabolome and transcriptome. Plant Physiol. 2011;156:330-345. DOI 10.1104/pp.111.173807.

Tesso T., Ejeta G., Chandrashekar A., Huang C.-P., Tandjung A., Lewamy M., Axtell J.D., Hamaker B.R. A novel modified endosperm texture in a mutant high-protein digestibility/high-lysine grain sorghum (Sorghum bicolor (L.) Moench). Cereal Chem. 2006;83:194-201. DOI 10.1094/CC-83-0194.

von Born P., Bernardo-Faura M., Rubio-Somoza I. An artificial miRNA system reveals that relative contribution of translational inhibition to miRNA-mediated regulation depends on environmental and developmental factors in Arabidopsis thaliana. PLoS ONE. 2018; 13(2):e0192984. DOI 10.1371/journal.pone.0192984
Wu Y., Messing J. Proteome balancing of the maize seed for higher nutritional value. Front. Plant Sci. 2014;5:240. DOI 10.3389/fpls. 2014.00240

Zhao Z.-Y., Glassman K., Sewalt V., Wang N., Miller M., Chang S., Thompson T., Catron S., Wu E., Bidney D., Kedebe Y., Jung R. Nutritionally improved transgenic sorghum. Plant Biotechnol. 2002 and Beyond. Vasil I.K. (Ed.). Springer, Dordrecht, 2003;413-416. DOI 10.1007/978-94-017-2679-5_85.

Acknowledgements. The work was partially supported by Russian Foundation for Basic Researches, grant no.19-016-00117.

Conflict of interest. The authors declare no conflict of interest. 


\title{
New efficient gene promoters from Stellaria media for plant genetic engineering
}

\author{
L.N. Efremova, S.R. Strelnikova, R.A. Komakhin \\ All-Russia Research Institute of Agricultural Biotechnology, Moscow, Russia
}

DOI 10.18699/ICG-PlantGen2019-42

(c) Autors, 2019

* e-mail: recombination@iab.ac.ru

\begin{abstract}
In a previous study we found that Stellaria media plants are the source of effective pro-SmAMP1 and pro-SmAMP2 promoters for plant biotechnology. A low level of polymorphism between nucleotide sequences of these promoters makes it possible to identify point mutations resulting in differences in their properties. A high degree of identity between pro-SmAMP1 and pro-SmAMP2 impedes the simultaneous employment of both promoters in one genetic construct for plant transformation. To create novel regulatory elements, we cloned the promoters of the $a$-harpinine gene and of the defensine gene from chickweed. These novel promoters do not have a homology with any other known promoter and have the same or a greater efficiency as the CaMV35S promoter in transient expression.

Key words: promoters; gene expression; reporter genes; transient expression.
\end{abstract}

\section{Introduction}

At the present time in plant biotechnology there is a deficit of regulatory elements for effective expression of recombinant genes due, first, to the lack of native promoters of plant genes with necessary parameters (Naqvi et al., 2010) and, secondly, to complexity in using available promoters for coordinated transcriptional control (Shrestha et al., 2018). We had previously found that hevein-like peptide genes from chickweed (Stellaria media) are a source of strong constitutive promoters for biotechnology of cultivated plants (Shukurov et al., 2012; Komakhin et al., 2016; Vysotskii et al., 2016; Vetchinkina et al., 2016). E. g., in transient expression experiments in Nicotiana benthamiana pro-SmAMP1 and pro-SmAMP2 promoters were 2-4 times more effective than the CaMV35S promoter; in rape (Brassica napus) and sugar beet (Beta vulgaris) plants pro-SmAMP1 and pro-SmAMP2 were comparable to CaMV35S (Madzharova et al., 2018). The functionality of the pro-SmAMP2 promoter was shown in the calluses of flax (Linum usitatissimum). In the homozygous lines of transgenic tobacco (Nicotiana tabacum), the proSmAMP1 and pro-SmAMP2 promoters are twice as strong as the CaMV35S promoter. The both promoters are at least as effective as the duplicated CaMV35S promoter for neomycin phosphotransferase II (nptII) gene control in the selection of transgenic tobacco and Arabidopsis plants on media with the antibiotic kanamycin at recommended concentrations. In the present research we focused on the fact that the proSmAMP1 and pro-SmAMP2 promoters are $94 \%$ identical, but differ significantly in their properties in plant cells. In transient expression in $N$. benthamiana the deletion variant (-442 bp) of the pro-SmAMP1 promoter was approximately 1.5 times stronger than the deletion variant $(-455 \mathrm{bp})$ of the pro-SmAMP2 promoter. At the same time, in the medium with excess kanamycin $(350 \mathrm{mg} / \mathrm{L})$, the effectiveness of selection of tobacco cells with the use of pro-SmAMP1 was a third as high as with pro-SmAMP2.

\section{Materials and methods}

Plants for experiments comprised tobaccos (N. benthamiana (Domin) and N. tabacum L. cultivar Samsun-NN). The plants were grown at $16 / 8$-h illumination and $18-22{ }^{\circ} \mathrm{C}$. Cells of Agrobacterium tumefaciens strain GV3101 were used for infiltration, and strain AGL0, for genetic transformation. Agrobacterial strain GV2260/C58C1 with genetic construct pLH7000 containing the gene of 19 tobusvirus suppressor protein was used for the agroinfiltration of $N$. benthamiana plants to suppress RNA interference. The strains were injected into leaves with a needle-free syringe. Agrobacterial transformation of plants was performed by the "lawn" method, which had been used earlier (Komakhin et al., 2016). Genetic constructs for transient expression containing the reporter gene gus controlled by the plant promoters were incorporated into plasmid pCambia1381Z (Cambia, Australia). Genetic constructs for plant transformation containing the nptII gene controlled by the plant promoters were incorporated into plasmid pCambia2300 (Cambia, Australia).

\section{Results and discussion}

Our results suggest that 25 point mutations between the sequences of the pro-SmAMP1 and pro-SmAMP2 promoters (amounting to only $6 \%$ of their length) account for their different effectiveness in plant cells. However, it is not clear which of them are functional in the -455- and -442- bp deletion variants. Thus, to clarify the principles of functioning of regulatory elements, we first found minimal promoters comprising only cis-elements essential for functioning.

The search for minimal promoters was carried out via consecutive deletion analysis starting from the $5^{\prime}$ end avoiding fractures within cis-acting elements found in silico. As a result, nine new deletion variants from -443 to $-76 \mathrm{bp}$ in size were prepared for each promoter. We established that the minimal nucleotide sequences of both promoters are nearly 120-bp long and comprise the identical transcription start sites (TSS) and cis-element TATA box, CAAT box, G box and ABRE. The presence of the CAAT box, G box and ABRE is necessary for activity of both core promoters including the TATA box and TSS. Nucleotide sequences were found to be $94 \%$ identical and having differences in their properties. On shortening the sequence down to the minimal size, the effectiveness of pro-SmAMP1 in the transient expression of 


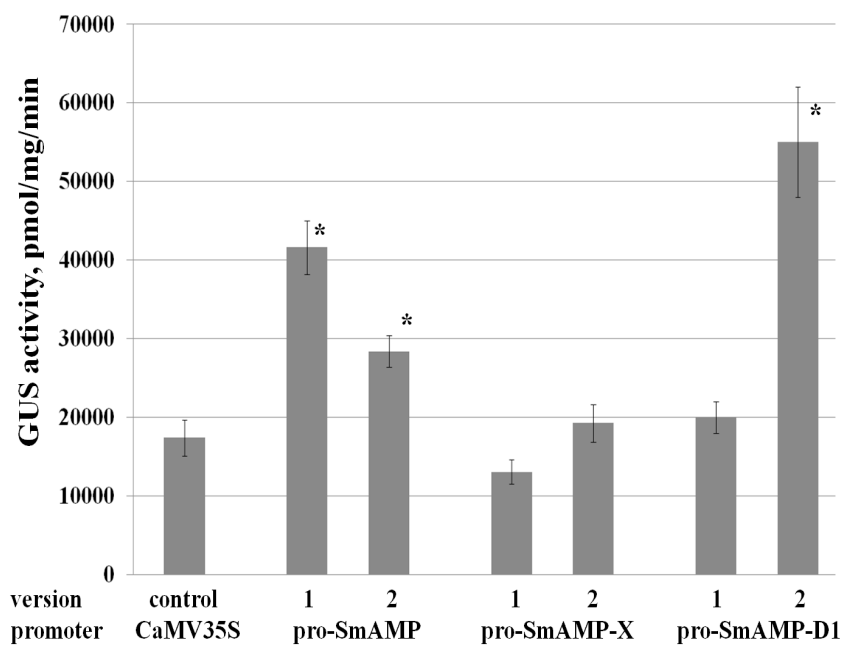

Figure 1. GUS activity in leaves of $N$. benthamiana plants at transient expression using plant promoters from S. media and virus CaMV35S promoter. Vertical lines indicate the standard error. Horizontal numbers show an individual version of plant promoters. ${ }^{*}$ values that are significantly different from the control at a $5 \%$ significance level. Gus activity was measured fluorimetrically, using 4-methylumbelliferyl-D-glucuronide (4-MU) as a substrate.

the gus gene in N. benthamiana plants somewhat increased, while in the case of pro-SmAMP2 it somewhat decreased, and the effectiveness ratio pro-SmAMP1 : pro-SmAMP2 reached 1.5-1.6. In the medium with excess kanamycin, the effectiveness of selection of transgenic tobacco cells with the use of nptII gene under control of pro-SmAMP1 was much lower than with pro-SmAMP2. In the case of minimal promoters, the differences in their properties are governed by only 7-9 point mutations; their functionality will be studied with a site-directed mutagenesis technique.

A significant similarity of nucleotide sequences in the promoters of hevein-like genes precludes their joint use within the same genetic construct to prevent recombination between the repeats. To create novel regulatory elements, we cloned the promoters of the $\alpha$-harpinine gene (pro-SmAMP-X) and defensine gene (pro-SmAMP-D1) from chickweed using the genome walking method (Pogorelko and Fursova, 2008). No homology of nucleotide sequences of the novel promoters, pro-SmAMP-X and pro-SmAMP-D1, with other known promoters was. In the chickweed genome, there are at least two versions of each new promoter, which are $83-93 \%$ identical. All new promoters are functional in the transient expression of the gus gene in $N$. benthamiana plants and are either as effective as virus promoter CaMV35S or substantially stronger than it (Figure 1).

As in the case with the promoters of the hevein-like peptide genes, point polymorphisms between two versions of the same promoter, pro-SmAMP-X and pro-SmAMP-D1, are functional and govern the difference in their effectiveness. In particular, one version of pro-SmAMP-D1 is approximately thrice stronger than the other one and the CaMV35S promoter.

\section{Conclusions}

Our results show that the gene promoters of various families of antimicrobial peptides from chickweed (S. media) are effective in transgenic plants for controling recombinant genes and may be successfully used in plant biotechnology. Lack of homology between different promoters provides the possibility of their simultaneous employment within a single genetic construct for plant transformation. Nucleotide polymorphism between the sequences of related promoters is functional and governs a different character of their activity in the cells of transgenic plants. Elucidation of the role of functional polymorphisms should pave the way for the production of new synthetic promoters featuring the best properties of native promoters.

\section{References}

Komakhin R.A., Vysotskii D.A., Shukurov R.R., Voblikova V.D., Komakhina V.V., Strelnikova S.R., Vetchinkina E.M., Babakov A.V. Novel strong promoter of antimicrobial peptides gene proSmAMP2 from chickweed (Stellaria media). BMC Biotechnology. 2016;16: 43. DOI 10.1186/s12896-016-0273-x.

Madzharova N.V., Kazakova K.A., Strelnikova S.R., Snycheva O.A., Vetchinkina E.M., Efremova L.N., Vysotskii D.A., Babakov A.V., Komakhin R.A. Promoters pro-SmAMP1 and pro-SmAMP2 from Wild Plant Stellaria media for the Biotechnology of Dicotyledons. Russ. J. Plant Physiol. 2018;65:750-761. DOI 10.1134/S1021443 718040040.

Naqvi S., Farre' G., Sanahuja G., Capell T., Zhu C., Christo P. When more is better: Multigene engineering in plants. Trends in Plant Science. 2010;15:48-56. https://doi.org/10.1016/j.tplants.2009.09.010

Shrestha A., Khan A., Dey N. cis-trans Engineering: Advances and Perspectives on Customized Transcriptional Regulation in Plants. Mol Plant. 2018;2;11(7):886-898. DOI 10.1016/j.molp.2018.05.008.

Shukurov R.R., Voblikova V.D., Nikonorova A.K., Komakhin R.A., Komakhina, V.V., Egorov, T.A., Grishin, E.V., Babakov A.V. Transformation of tobacco and Arabidopsis plants with Stellaria media genes encoding novel hevein-like peptides increases their resistance to fungal pathogens. Transgenic Res. 2012;21:313-325. https://doi. org/10.1007/s11248-011-9534-6.

Vetchinkina E.M., Komakhina V.V., Vysotskii D.A., Zaitsev D.V., Smirnov A.N., Babakov A.V., Komakhin R.A. Expression of plant antimicrobial peptide pro-SmAMP2 gene increases resistance of transgenic potato plants to Alternaria and Fusarium pathogens. Russ. J. Genet. 2016;52:939-951. https://doi.org/10.1134/S102279 5416080147.

Vysotskii D.A., Strel'nikova S.R., Efremova L.N., Vetchinkina E.M., Babakov A.V., Komakhin R.A. Structural and functional analysis of new plant promoter pro-SmAMP1 from Stellaria media. Russ. J. Plant Physiol. 2016;63:663-672. https://doi.org/10.1134/ S1021443716050174

Acknowledgements. The reported study was funded by RFBR according to the research project № 19-016-00067.

Conflict of interest. The authors declare no conflict of interest. 


\title{
Role of the expansin and xyloglucan endotransglycosylase genes in the regulation of tobacco growth under the influence of abiotic stress factors
}

\author{
B.R. Kuluev ${ }^{1,2 *}$, Kh.G. Musin ${ }^{1,2}$, Z.A. Berezhneva ${ }^{1}$, E.V. Mikhaylova ${ }^{1}$, E.A. Zaikina ${ }^{1}$ \\ 1 Institute of Biochemistry and Genetics - Subdivision of the Ufa Federal Research Centre of the Russian Academy of Sciences, Ufa, Russia \\ ${ }^{2}$ Bashkir State University, Ufa, Russia
}

DOI 10.18699/ICG-PlantGen2019-43

(c) Autors, 2019

* e-mail:kuluev@bk.ru

\begin{abstract}
The divergence of cellulose microfibrils during cell expansion is achieved by three basic mechanisms: hydrolysis of a part of binding glycans with endoglycanases, cutting and new crosslinking of glycans with xyloglucan endo-transglycosylases/hydrolases (XTHs), and the breaking of hydrogen bonds between the microfibrils of cellulose and glycan chains, which is carried out by expansins. We have created transgenic tobacco plants with the genes encoding tobacco expansins: NtEXPA1, NtEXPA4, NtEXPA5 and a gene that encodes tobacco xyloglucan endotransglycosylase, NtEXGT. Increased expression of the NtEXPA 1 and NtEXPA5 expansin genes led to an increase in growth rate and root length both under normal conditions and at $12{ }^{\circ} \mathrm{C}$ and $50 \mathrm{mM} \mathrm{NaCl}$. Increased expression of the expansin genes influenced changes in the fresh and dry mass of a shoot, leading to an increase in their exposure to hypothermia. Overexpression of the NtEXGT gene promoted tobacco root growth in a medium containing $50 \mathrm{mM} \mathrm{NaCl}$. In wild-type tobacco plants, transcript levels of the NtEXPA1, NtEXPA4, NtEXPA5, and NtEXGT genes were increased in response to abiotic stress treatment. Overall, data obtained may indicate the involvement of the NtEXPA1, NtEXPA4, NtEXPA5, and NtEXGT genes in the regulation of tobacco growth under hypothermia, drought, and salinity.
\end{abstract}

Key words: drought tolerance; expansin; xyloglucan; endotransglycosylase genes; N. tabacum

\section{Introduction}

Expansins are a group of proteins that are capable to modify the mechanical properties of plant cell walls by a nonenzymatic mechanism. These proteins are encoded by large multigene families and are widely distributed in plant species (Kuluev et al., 2016). Expansins are implicated in the growth responses of plants to adverse environments (Gao et al., 2010; Han et al., 2012; Lu et al., 2013). The enzymes of the xyloglucan endotransglycosylase family can potentially have two distinct catalytic activities, with radically different effects on xyloglucan: xyloglucan endo-transglycosylase (XET) activity results in the nonhydrolytic cleavage and ligation of xyloglucan chains, whereas xyloglucan endo-hydrolase (XEH) activity yields irreversible chain shortening (Rose et al., 2002). In angiosperms, XET/XTHs are typically encoded by large multigene families (Rose et al., 2002). There is information about the participation of XET/XTHs in providing tolerance to water deficit caused by drought and salinity (Choi et al., 2011). It has been shown that XET/XTHs expression has been induced by a broad spectrum of abiotic stresses, including drought, high salinity, and cold temperature (Kuluev et al., 2017). The aim of our study was to elucidate the molecular mechanisms of expression regulation of expansins and xyloglucan endotransglycosylases under changing environmental conditions and to determine the role of these proteins in ensuring growth and productivity, both under normal conditions and under the action of drought and hypothermia. Tobacco was chosen as a model object, including the transgenic lines of this plant expressing expansins and XTHs genes.

\section{Materials and methods}

Plants of the N. tabacum cv. 'Petit Havana SR1' were grown in 450-ml pots filled with universal soil substrate "Terra vita" in a greenhouse at $+27{ }^{\circ} \mathrm{C}$ under $140 \mathrm{mmol} \mathrm{m} \mathrm{m}^{-1}$ photon flux density and photoperiod of 16/8 hours (day/night) within 40 days (twelve leaves stage) and then subjected to stress treatments. Cadmium stress was induced by exposing plants to $100 \mu \mathrm{M}$ cadmium supplied as $\mathrm{Cd}\left(\mathrm{CH}_{3} \mathrm{COO}\right)_{2}$ for $16 \mathrm{~h}$. For freezing and cold treatments, plants were exposed to a temperature of 0 or $10{ }^{\circ} \mathrm{C}$ for $6 \mathrm{~h}$ and $8 \mathrm{~h}$, respectively. Heat stress treatment was performed by incubating tobacco plants at $42{ }^{\circ} \mathrm{C}$ for $6 \mathrm{~h}$. Drought stress was induced by withholding water supply for 2 days. For salt stress treatment, tobacco plants were germinated on universal soil for 40 days, then roots were carefully washed and plants were transferred for 5 days on hydroponics solution (10\% Hoagland-Arnon solution). After that, plants were incubated for $2 \mathrm{~h}$ at different concentrations of $\mathrm{NaCl}(20,80,170,250,350$, and $850 \mathrm{mM})$. After stress treatments, leaves were frozen in liquid nitrogen and used to isolate total RNA. Untreated plants served as controls. Expansin genes were used as target genes: NtEXPA1, NtEXPA4, NtEXPA5 and NtEXPA6 of tobacco, as well as the $N t E X G T$ gene encoding one of the xyloglucan endotransglycosylases of tobacco. When conducting our research, we also used $\mathrm{T}_{1}$ lines $35 S: \because N t E X P A 5, D M V:: N t E X P A 1, N t E X P A 4 i$ (NtEXPA4-silenced), XVE::NtEXPA1, 35S::NtEXGT of the previously created transgenic tobacco Nicotiana tabacum L. var. 'Petit Havana SR1'. 


\section{Results and discussion}

Transcript levels of the NtEXPA1, NtEXPA4, and NtEXPA5 genes were increased in response to $\mathrm{NaCl}$, drought, cold, heat, and $10 \mu \mathrm{M}$ abscisic acid (ABA) treatments but were reduced in response to more severe stresses, i. e. cadmium, freezing, and $100 \mu \mathrm{M}$ ABA. In contrast, no changes were found in NtEXPA6 transcript level after all stress treatments. The NtEXGT gene was also up-regulated by salinity, drought, cold, cadmium and $10 \mu \mathrm{M}$ abscisic acid treatments and down-regulated in response to $0{ }^{\circ} \mathrm{C}$ and $100 \mu \mathrm{M}$ abscisic acid. Based on the data obtained, it was possible to suggest that the genes studied are involved in the regulation and maintenance of growth under the action of abiotic stress factors. In addition, we examined the involvement of tobacco expansins and XTHs in the regulation of abiotic stress tolerance by transgenic approaches. Transgenic tobacco plants with constitutive expression of NtEXPA1 and NtEXPA5 exhibited improved tolerance to salt stress: these plants showed higher growth indices after $\mathrm{NaCl}$ treatment and minimized water loss by reducing stomatal density. In contrast, NtEXPA4-silenced plants were characterized by a considerable growth reduction under salinity and enhanced water loss. Root growth and stress tolerance of transgenic tobacco plants with constitutive expression of the NtEXPA1 and NtEXPA5 genes, as well as with reduced expression of the NtEXPA4 gene with prolonged cultivation under drought, salinity and low positive temperatures, were investigated. Increased expression of expansin genes led to an increase in the growth rate and the length of the roots, both under normal growing conditions and following exposure to a temperature of $+12^{\circ} \mathrm{C}$ and $50 \mathrm{mM} \mathrm{NaCl}$. Also, increased expression of expansin genes influenced the change in fresh and dry weight of the shoot, leading to their increase when they were exposed to hypothermia. Transgenic plants with a reduced level of expression of the expansin NtEXPA4 gene were characterized by a decrease in the fresh and dry weight of the shoot under the action of drought and low positive temperatures. $35 S: \because N t E X G T$ tobacco plants also showed higher rates of root growth under salt-stress conditions, greater frost and heat tolerance as compared with the wild-type tobacco plants.

\section{Conclusions}

Overall, data obtain may indicate the involvement of the NtEXPA1, NtEXPA4, NtEXPA5 and NtEXGT genes of tobacco in growth regulation under the action of hypothermia, drought and salinization. We suppose that genes can be used to improve root growth, as well as to increase the productivity of transgenic plants under the action of hypothermia and moderate salinity.

\section{References}

Choi J.Y., Seo Y.S., Kim S.J., Kim W.T., Shin J.S. Constitutive expression of CaXTH3, a hot pepper xyloglucan endotransglycosylase/hydrolase, enhanced tolerance to salt and drought stresses without phenotypic defects in tomato plants (Solanum lycopersicum cv. Dotaerang). Plant Cell Rep. 2011;30:867-877. DOI 10.1007/s00299-010-0989-3

Gao X., Liu K., Lu Y.T. Specific roles of AtEXPA1 in plant growth and stress adaptation. Russ. J. Plant Physiol. 2010;57:241-246. DOI 10.1134/ S1021443710020111.

Han Y., Li A., Li F., Zhao M., Wang W. Characterization of a wheat (Triticum aestivum) expansin gene, TaEXPB23, involved in the abiotic stress response and phytohormone regulation. Plant Physiol. Biochem. 2012;54:49-58. DOI 10.1016/j.plaphy.2012.02.007.

Kuluev B.R., Avalbaev A.M., Mikhaylova E.V., Nikonorov Y.M., Berezhneva Z.A., Chemeris A.V. Expression profiles and hormonal regulation of tobacco expansin genes and their involvement in abiotic stress response. J. Plant Physiol. 2016;206:1-12. DOI 10.1016/j.jplph.2016.09.001.

Kuluev B.R., Mikhaylova E.V., Berezhneva Z.A., Nikonorov Y.M., Postrigan B.N., Kudoyarova G.R., Chemeris A.V. Expression profiles and hormonal regulation of tobacco NtEXGT gene and its involvement in abiotic stress response. Plant Physiol. Biochem. 2017;111:203-215. DOI 10.1016/j.plaphy.2016.12.005.

Lu P., Kang M., Jiang X., Dai F., Gao J., Zhang C. RhEXPA4, a rose expansin gene, modulates leaf growth and confers drought and salt tolerance to Arabidopsis. Planta. 2013;237:1547-1559. DOI 10.1007/s00425-0131867-3.

Rose J.K.C., Braam J., Fry S.C., Nishitani K. The XTH family of enzymes involved in xyloglucan endotransglucosylation and endohydrolysis: current perspectives and a new unifying nomenclature. Plant Cell Physiol. 2002;43:1421-1435. DOI 10.1093/pcp/pcf171.

Acknowledgements. The study was performed within the framework of the State Assignment (project no. AAAA-A19-119021190011-0) and also supported by Russian Foundation for Basic Research grant No. 18-04-00118A.

Conflict of interest. The authors declare no conflict of interest. 


\title{
Reproduction and genetic accuracy during somatic embryogenesis in Larix sibirica
}

\author{
I.N. Tretyakova ${ }^{1 *}$, M.E. Park ${ }^{1}$, N.V.Oreshkova ${ }^{1,2}$, D.V. Kulagin ${ }^{3}$, A.V. Konstantinov ${ }^{3}$, V.E. Padutov ${ }^{3}$ \\ 1 Sukachev Institute of Forest, SB RAS, Krasnoyarsk, Russia \\ 2 Siberian Federal University, Krasnoyarsk, Russia \\ ${ }^{3}$ Institute of Forest, National Academy of Sciences of Belarus, Gomel, Belarus
}

DOI 10.18699/ICG-PlantGen2019-44

(c) Autors, 2019

* e-mail: culture@ksc.krasn.ru

\begin{abstract}
The quality of proliferative embryogenic cultures (ECs) and the genetic changes associated with somaclonal variations in the cell lines $(\mathrm{Cls})$ and cloned plants of Larix sibirica were studied. Cls were obtained from zygotic embryos on medium Al, supplemented by plant growth regulators: (2,4-D:6-BAP, 2:0,5 and 2:1). All Cls actively formed embryonalsuspensor mass (ESM), in which globular embryos propagated through cleavage, budding formation and proliferation of embryonic tubes of the suspensor. Cytogenetic studies of proliferating Cls of Siberian larch showed that the cells of young cell lines (aged 1-2 years) contained mainly cells with the normal number of chromosomes for this species $(2 n=24)$. Analysis of long-cultivated (7-9 years) Cls showed that their majority were genetically unstable and only one $(\mathrm{Cl} 6)$ was characterized as being stability. The genetic stability of this line was confirmed by a microsatellite analysis of nine microsatellite loci. Molecular genetic studies of proliferating $\mathrm{Cls}$, conducted using RAPD analysis, allowed us to obtain diversified line-specific PCR spectra that can be used as markers of ECs. Somatic embryos matured on the nutrient medium $\mathrm{Al}$ with $\mathrm{ABA}\left(32 \mathrm{mg} \mathrm{L}^{-1}\right)$. The number of mature somatic embryos in different cell lines varied from $9(\mathrm{Cl} 16.19)$ up to $1220(\mathrm{Cl} 4)$ per gram of fresh weight of ESM. Somatic embryos germinated on the medium Al without hormones and rooted (5-15\%). Stable maturation and germination of SEs was observed in Cl6. For 7 years, cloned trees have been growing at the station "Pogorelsky Bor" IF SB RAS successfully. Microsatellite analysis of clones showed their full compliance to Cl6.

Key words: molecular-genetic markers; somatic embryogenesis; Larix sibirica.
\end{abstract}

\section{Introduction}

To solve the problem of larch species propagation, a number of programmers for microcloning via somatic embryogenesis have been developed (Park, 2004, 2014). The genetic instability of larch species in vitro cultures as well as of other plant taxa is well known (von Aderkas, Anderson, 1993; Burg et al., 2007). Nevertheless, some studies indicate that during somatic embryogenesis in some Pinaceae species genetic variation was not detected and regenerant genetics was the same as in the original explant (Mo et al., 1989; Helmersson et al., 2004; Arrillaga et al., 2014; Cabezas et al., 2016; Ahn, Choi, 2017).

The aim of this paper is to study of the genetic variability of long-proliferating cell lines producing somatic embryos for decades and cloned trees.

\section{Materials and methods}

Larix sibirica cones were collected to mid-July 2008-2018 from open- and cross-pollinated mother tree A4 in the arboretum of the V.N. Sukachev Institute of Forests (Krasnoyarsk). Eight embryogenic cell lines were obtained from immature zygotic embryos at the pre-cotyledonary stages: Cl4 (2009), Cl6 (2011), Cl107 (2013), Cl16.28 (2015), Cl 18.3 (2018) by open pollination; Cl5 (2009), by cross-pollination between L. sibirica Ledeb. and L. sukaczewii; Cl 17.7 (2017), by crosspollination between $L$. sibirica and $L$. sibirica.

Explants were placed on the AI medium (Tretyakova, 2012) with sucrose $\left(30 \mathrm{~g} \mathrm{~L}^{-1}\right), 2 \mathrm{mg} \mathrm{L}^{-1}$ 2.4-D and $0.5 / 1 \mathrm{mg} \mathrm{L}^{-1}$
6-BAP. For proliferation of the obtained ESM, the basic AI nutrient medium, containing 2,4-D $\left(2 \mathrm{mg} \mathrm{L}^{-1}\right), 6-\mathrm{BAP}$ $\left(0.5 \mathrm{mg} \mathrm{L}^{-1}\right)$ and sucrose $\left(20 \mathrm{~g} \mathrm{~L}^{-1}\right)$ was used. The culture was incubated in the darkness at $24 \pm 1{ }^{\circ} \mathrm{C}$.

Experiments with maturating somatic embryos were carried out using the AI basic medium, containing $40 \mathrm{~g} \mathrm{~L}^{-1}$ sucrose, $32 \mathrm{mg} \mathrm{L}^{-1}$ abscisic acid (ABA), $0.2 \mathrm{mg} \mathrm{L}^{-1}$ indolebutyric acid (IBA) and $10 \%$ polyethyleneglycol (PEG 8000). Gelrite $\left(4 \mathrm{~g} \mathrm{~L}^{-1}\right)$ was used as a gelling agent. For germination of somatic embryos, hormone-free AI basic medium was used. Plantlets were transferred into glass flasks containing sterile soil substrate (sand/vermiculate/peat; 1:1:1; volume to volume), moistened with one-fourth strength AI media. Cultivation was carried out in the growth chamber.

Cytogenetic analyses were carried out using globular SEs at the proliferation stage. The material was treated with $0.2 \%$ colchicine, was fixed in ethanol-acetic acid mixture (3:1) and was stained in $1 \%$ aceto-hematoxylin solution. The cover glass was placed on the sample, avoiding the formation of bubbles and examined on a MIKMED-6 microscope (LOMO, Russia).

To genotype the microsatellite loci, DNA was isolated from needles of maternal trees A4, ESM and needles of 16 cloning trees. DNA was extracted using the CTAB method (Devey et al., 1996). The quality and quantity of the material obtained were checked using a Qubit 2 fluorimeter (Invitrogen, USA). The isolated DNA was used for PCR with 9 pairs of oligonucleotides designed previously for the microsatel- 


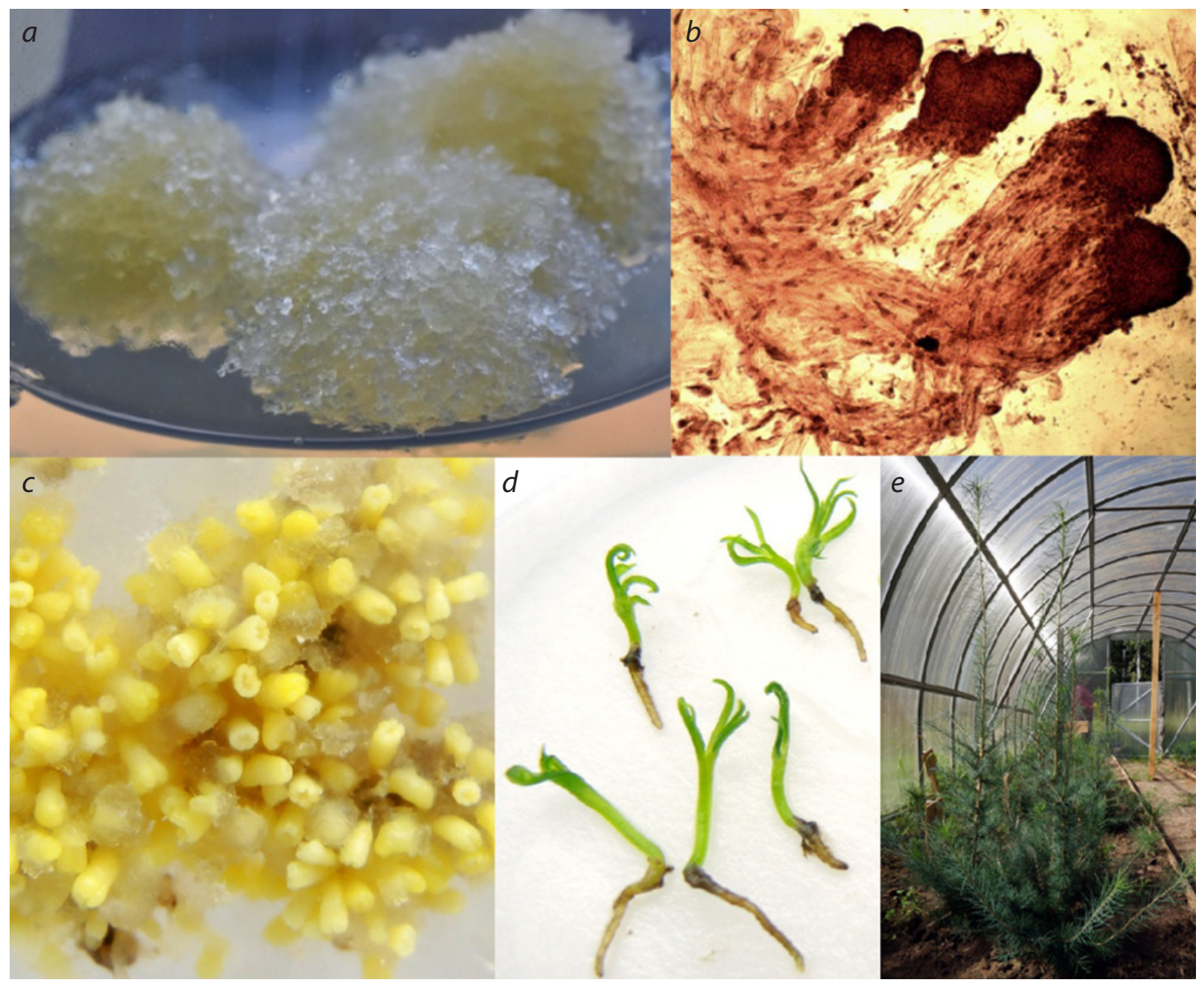

Figure 1. Larix sibirica Ledeb. plant regeneration via somatic embryogenesis: proliferating embryonal-suspensor mass (a), the multiplication of globular somatic embryos by cleavage (b), maturation of somatic embryos (c), plantlets derived via SE (d), cloned plants of $L$. sibirica in the greenhouse $(e)$

lite genotyping of different larch species (Krutovsky et al., 2014).

Statistical data analyses were carried out using standard techniques (Shmidt, 1984) by Microsoft Excel (Microsoft Corporation, USA) and STATISTICA 6.0 (Tulsa Scientific, USA). The reliability of the data obtained was assessed using one-way ANOVA test.

\section{Results and discussion}

Zygotic embryos of Larix sibirica from A4 genotypes obtained after open and cross-pollinations were introduced into the culture on the nutrient medium AI supplemented by growth regulators in 2009-2018. A cytological study demonstrated that ECs of larch included embryonal heads of globular somatic embryos and embryonal tubes (suspensors) (Figure $1, a, b)$. The number of globular SEs in the Cls tested in this study varied from 2040 (Cl6) to 4000 (Cl107) per gram fresh weight of ESM. Multiplication of somatic embryos has gone through the cleavage, budding of suspensor cells and suspensor protrusion.

Molecular genetic studies of proliferating Cls, conducted using RAPD analysis, allowed us to obtain diversified linespecific PCR spectra that can be used as markers of ECs.
Microsatellite analysis performed on nine loci showed a weak genetic variability of Cls. Cytogenetic studies showed that younger cell lines (C117.7 and Cl16.28) have the somatic chromosome number typical of Larix sibirica $(2 n=24)$. The analysis of long-cultivated $\mathrm{Cls}(\mathrm{Cl} 5, \mathrm{Cl} 4, \mathrm{Cl} 2$ and C1107) showed them cytogenetically instable and only $\mathrm{Cl} 6$ remained cytogenetically stable throughout 7 years of cultivation. Somatic embryos were allowed to mature on the AI media with ABA for 20-60 days.

After one week of maturation, somatic embryos of $\mathrm{Cls}$ separated from polyembryogenic complexes. Changes in anatomical structure were clearly visible after two to three weeks of maturation. Suspensors degenerated during maturation of somatic embryos at the cotyledonary stage of embryogenesis via the programmed cell death (PCD) mechanism. Somatic embryos having reached $1.1-1.5 \mathrm{~mm}$ in size and having a bipolar structure were considered mature (Figure 1,c). Different types of morphogenetic changes were observed during the maturation of somatic embryos. Well-developed somatic embryos were observed in Cl4; most of them (83.3\%) formed roots which stopped growing after 14 days. All embryos obtained from the maturation experiments have been used for germination tests. For 5 weeks, the regenerants elongated, 
formed cotyledons, hypocotyls and roots (Figure 1, $d$ ). Plantlets without developmental deviations ( 5 to $15 \%$ of total $\mathrm{Cls}$ ) were cultivated using a soil substrate in growth chambers. CL6 demonstrated stable maturation and germination of embryos (13 regenerants $1 \mathrm{~g}^{-1}, \mathrm{ESM}$ ).

CL6 cloned trees are growing successfully in the soil of the nursery of the Pogorelsky Bor of the Institute of Forest (Figure 1,e) during 7-years. These somatic plants are genetically stable and can be recommended as planting material for the plantation growing of larch in Siberia.

\section{Conclusions}

Our observations generally show that the obtained Cls of Siberian larch has been successfully proliferating on the AI medium for nine years. Microsatellite analysis of proliferating Cls showed their low variability. According to cytogenetic studies, only young (one- to two-year-old) cell lines were genetically stable. The genotyping of seven-year-old cloned larch trees showed full compliance with $\mathrm{Cl} 6$ from which they were obtained.

\section{References}

Ahn C.H., Choi Y.E. In vitro clonal propagation and stable cryopreservation system for Platycladus orientalis via somatic embryogenesis. Plant Cell Tissue Organ Cult. 2017;131(3):513-523. DOI 10.1007/s11240-017-1301-9.

Arrillaga I., Guevara M.A., Muñoz-Bertomeu J., Lázaro-Gimeno D., Sáez-Laguna E., Díaz L.M., Torralba L., Mendoza-Ponderous I., Segura I., Cervera M.T. Selection of haploid cell lines from megagametophyte cultures of maritime pine as a DNA source for massive sequencing of the species. Plant Cell Tissue Organ Cult. 2014; 118:147-155. DOI 10.1007/s11240-014-0470-z.

Burg K., Helmersson A., Bozhkov P., von Arnold S. Developmental and genetic variation in nuclear microsatellite stability during somatic embryogenesis in pine. $J$ Exp Bot. 2007;58:687-698. DOI $10.1093 / \mathrm{jxb} / \mathrm{erl} 241$.

Cabezas J.A., Morcillo M., Vélez M.D., Díaz L., Segura J., Cervera M.T., Arrillaga I. () Haploids in conifer species: characterization and chromosomal integrity of a maritime pine cell line. Forests. 2016;7:274. DOI 10.3390/f7110274.
Devey M.E., Bell J.C., Smith D.N., Neale D.B., Moran G.F. A genetic linkage map for Pinus radiate based on RFLP, RAPD, and microsatellite markers. Theor Appl Genet. 1996;92:673-679. DOI 10.1007/ BF00226088.

Helmersson A., von Arnold S., Burg K., Bozhkov P.V. High stability of nuclear microsatellite loci during the early stages of somatic embryogenesis in Norway spruce. Tree Physiol. 2004;24:1181-1186. DOI 10.1093/treephys/24.10.1181.

Krutovsky K.V., Tretyakova I.N., Oreshkova N.V., Pak M.E., Kvitko O.V., Vaganov E.A. Somaclonal variation of haploid in vitro tissue culture obtained from Siberian larch (Larix sibirica Ledeb.) megagametophytes for whole genome de novo sequencing. In $\mathrm{Vi}$ tro Cell Dev Biol - Plant. 2014;50:655-664. DOI 10.1007/s11627014-9619-z.

Mo L.M., von Arnold S., Lagererantz U. Morphogenic and genetic stability in long term embryogenic cultures and somatic embryos of Norway spruce (Picea abies [L.] Karst.). Plant Cell Rep. 1989;8: 375-378. DOI 10.1007/BF00270072.

Park Y.-S. Commercial implementation of multi-varietal forestry using conifer somatic embryogenesis. In: Proceedings of IUFRO joint Conference of Division 2, Forest Genetics and Tree Breeding in the Age of Genomics: Progress and Future, 1-5 November, 2004, Charleston, SC, USA, 2004. P. 139.

Park Y.-S. Conifer somatic embryogenesis and multi-varietal forestry. In: Fenning T. (Ed.). Challenges and Opportunities for the World's Forests in the 21 st Century. Forestry Sciences, Springer, Dordercht 2014;81:425-439. DOI 10.1007/978-94-007-7076-8_17.

Shmidt V.M. Matematicheskie metody v botanike (Mathematical Methods in Botany). Leningrad: Leningr. Univ., 1984.

Tretyakova I.N. Method of microclonal propagation of Siberian larch in in vitro culture via somatic embryogenesis for plantation growing [Sposob mikroklonal'nogo razmnozheniya listvennitsy sibirskoy $\mathrm{v}$ kul'ture in vitro cherez somaticheskiy embriogenez v srede i dlya plantatsionnogo lesovyrashchivaniya]. Patent of Russia No. 2456 344. 2012.

Von Aderkas P., Anderson P. Aneuploidy and polyploidization in haploid tissue cultures of Larix decidua. Physiol Plant. 1993;88:73-77. DOI 10.1111/j.1399-3054.1993.tb01762.x.

Acknowledgements. The work is supported by the RFBR according to the research project No.18-54-00010 Bel_a.

Conflict of interest. The authors declare no conflict of interest. 


\title{
Reactivation of VaSTS1 expression in Arabidopsis thaliana transgenic plants by retransformation with $2 b$ from the Cucumber Mosaic Virus isolate NK
}

\author{
N.N. Nityagovsky ${ }^{1,2 *}$, A.P. Tyunin ${ }^{1}$, K.V. Kiselev ${ }^{1,2}$ \\ 'Laboratory of Biotechnology, Federal Scientific Center of East Asia Terrestrial Biodiversity, Far Eastern Branch of Russian Academy of Sciences, \\ Vladivostok, Russia \\ ${ }^{2}$ Department of Biochemistry and Biotechnology, Far Eastern Federal University, Vladivostok, Russia
}

DOI 10.18699/ICG-PlantGen2019-45

(c) Autors, 2019

* e-mail: niknit1996@gmail.com

\begin{abstract}
Since transgene silencing in genetically transformed plants is a serious limitation for a wide application of genetic engineering techniques, studying mechanisms ensuring stability of transgene expression is vital. Multiple investigations concerning viral suppressors of gene silencing revealed that protein $2 \mathrm{~b}$ from Cucumovirus (CMV) effectively represses the RNA-induced silencing complex. The current study presents unique data on using the $2 \mathrm{~b}$ gene from the CMV isolate NK for a transgene silencing reduction in A. thaliana plants earlier transformed with VaSTS1 from Vitis amurensis Rupr. In our study, two VaSTS1 transgenic lines with decreased expression of VaSTS1 increased transgene expression up to 3.0-fold upon retransformation with $2 \mathrm{~b}$ from CMV NK. Thus, $2 \mathrm{~b}$ from CMV NK can reactivate a silenced transgene.

Key words: protein 2b; Cucumovirus; stilbenes; stilbene synthase; $t$-resveratrol; transgene silencing.
\end{abstract}

\section{Introduction}

Agrobacterium-mediated transformation is a common method to generate transgenic plants. However, transgene silencing is a serious restriction occurring in plants and plant cell cultures, frequently correlating with a high transgene copy number, the use of strong promoters, insertion locations of transgenes, occurring during integration (Butaye et al., 2005). Studies concerning the mechanisms leading to transgene silencing revealed that RNA interference is a key regulator of both endogenous and introduced gene sequences at transcriptional gene silencing (TGS) and post-transcriptional gene silencing levels (PTGS; Law, Jacobsen, 2010). This complex system involving short non-coding RNA to suppress exogenous sequences seems to be a result of a long co-evolution of plants and phytoviruses (Pumplin, Voinnet, 2013). Among the other phytoviruses, Cucumber mosaic virus (CMV) in the genus Cucumovirus of the family Bromoviridae has the broadest spectrum of known plant hosts, including more than 1200 species of herbaceous plants, shrubs, and trees referring to more than 100 different families (Rossinck, 2002). Multiple studies concerning the virulence of CMV strains assigned protein $2 \mathrm{~b}$ to be the key factor responsible for induction of symptoms, systemic necrosis, and synergic symptom induction by other viruses in the case of co-infection (Rossinck, 2002). Moreover, protein $2 \mathrm{~b}$ was shown to counter basal mechanisms of plant pathogen defense, including RNA silencing (Lewsey et al., 2010). Possessing two nuclear localization signals, CMV protein $2 \mathrm{~b}$ was shown to bind with double-stranded RNAs in the nucleus, which is required for a proper RNA-induced silencing complex (RISC) assembly and targeting. Moreover, $2 b$ of the CMV isolate Fny is able to block the PAZ domain of Argonaut 1 (AGO1), a RNA-slicing protein, a critical part of the plant RISC complex (Zhang et al., 2006).
Taking into consideration the fact that the suppression of transgenes introduced into plant genomes is associated with RNA silencing, the further development of genetic transformation techniques will overall benefit from the use of viral suppressors of silencing. Our recent study conducted on the rolB-transgenic cell culture VB2 of the wild-growing grape Vitis amurensis Rupr., which showed a significant reduction in $r o l B$ expression, revealed that transgene expression can be restored by retransformation with $2 b$ from the CMV isolate NK even after 10 years of continuous subcultivation (Dubrovina, Kiselev, 2012; Tyunin et al., 2019). Furthermore, retransformation with $2 b$ from CMV NK significantly enhanced the production level of pharmaceutically-valuable $t$-resveratrol in $2 b$-retransformed callus cell line VB2 by induction of stilbene synthase (VaSTS) genes encoding $t$-resveratrol biosynthesis enzymes.

In order to find an alternative biological model for the production of valuable $t$-resveratrol, Arabidopsis thaliana plants were transformed with the VaSTS1 gene responsible for $t$-resveratrol biosynthesis in $V$. amurensis (Tyunin et al., 2018). The derived homozygous $A$. thaliana transgenic lines, ST1-1 and ST1-3, demonstrated different levels of VaSTS1 transgene expression after several generations, suggesting transgene sequence silencing due to the RNAi mechanism. In the course of the current study, both ST1-1 and ST1-3 plants were retransformed with $2 b$ from CMV NK, and homozygous transformants were selected and analyzed for VaSTS1 transgene expression and the cytosine DNA methylation level within the VaSTS1 nucleotide sequence. Our data show a strong negative correlation between the transgene expression and the level of cytosine methylation within the VaSTS1 sequence. Furthermore, our data show the reactivation of VaSTS1 expression in response to retransformation with $2 b$ 
Table 1

$2 b$ and VaSTS1 expression and the average level of cytosine methylation of the VaSTS1 sequence in the $A$. thaliana lines

\begin{tabular}{llll}
\hline Line name & 2b expression, r.u. & VaSTS1 expression, r.u. & $\begin{array}{l}\text { Average level of cytosine methylation } \\
\text { within 3'-end of VaSTS1 sequence, \% }\end{array}$ \\
\hline KA-0 & $\mathrm{n} / \mathrm{a}$ & $\mathrm{n} / \mathrm{a}$ & $\mathrm{n} / \mathrm{a}$ \\
KA-0-2b-Ib-5p & $0.46 \pm 0.05$ & $\mathrm{n} / \mathrm{a}$ & $\mathrm{n} / \mathrm{a}$ \\
ST1-1 & $\mathrm{n} / \mathrm{a}$ & $0.43 \pm 0.06$ & 17.79 \\
ST1-1-2b-Ic-1p & $0.62 \pm 0.07$ & $0.20 \pm 0.04$ & 25.24 \\
ST1-1-2b-Ila-2p & $0.49 \pm 0.06$ & $0.53 \pm 0.05$ & 5.24 \\
ST1-1-2b-IId-2p & $0.46 \pm 0.03$ & $0.31 \pm 0.05$ & 2.44 \\
ST1-3 & $\mathrm{n} / \mathrm{a}$ & $0.13 \pm 0.04$ & 13.42 \\
ST1-3-2b-Ila-3p & $0.32 \pm 0.04$ & $0.11 \pm 0.02$ & 16.65 \\
ST1-3-2b-IIb-3p & $0.72 \pm 0.02$ & $0.36 \pm 0.08$ & 1.02 \\
ST1-3-2b-Ilb-5p & $0.77 \pm 0.03$ & $0.13 \pm 0.02$ & 29.38 \\
\hline
\end{tabular}

from CMV due to a decrease in the level of VaSTS1 cytosine methylation.

\section{Materials and methods}

A. thaliana transgenic lines ST1-1 and ST1-3 were obtained using the method of dipping inflorescences into the agrobacteria suspension as described previously (Dubrovina et al., 2017). Binary vector constructs contained the gene of interest and an antibiotic resistance gene on the double $35 \mathrm{~s}$ CaMV promoter.

A. thaliana transgenic lines KA-0 and VaSTS1 were transformed in the current study with Agrobacterium tumefaciens strain GV3101::pMP90 containing binary vector construct pZP-RCS2-2b-hpt. The selection of the obtained $2 b$ trangenic lines was performed on W0 media with kanamycin and hygromycin.

Transgenic lines KA-0, ST1-1 and ST1-3 were obtained by inoculation of wild-type $A$. thaliana (ecotype: Columbia) with $A$. tumefaciens strains GV3101::pMP90 containing binary vector constructs pZP-RCS2-nptII (empty vector) and pZP-RCS2-VaSTS1-nptII, respectively.

The $A$. thaliana transgenic plants were grown in planting pots using a commercially available universal potting mix in a climatic chamber (Panasonic MLR-352, Japan) at $22{ }^{\circ} \mathrm{C}$ under day $(16 \mathrm{~h})$ /night $(8 \mathrm{~h})$ conditions at an illumination of $\sim 120 \mu \mathrm{moL} \mathrm{m}^{-2} \mathrm{~s}^{-1}$.

DNA and RNA were extracted from the $2 b$ transgenic lines and cDNA was obtained from RNA as previously described (Tyunin et al., 2019). Expression analysis of the VaSTS1 and $2 b$ genes in $A$. thaliana was performed using real-time PCR (RT-PCR) according to the SYBR Green method.

Data on the level of cytosine methylation of the nucleotide sequence in the VaSTS1 transgenic lines were obtained by bisulfite sequencing as described previously (Kiselev et al., 2015).

\section{Results and discussion}

In the course of our study, A. thaliana transgenic plants ST1-1 and ST1-3 overexpressing VaSTS1 from $V$. amurensis were tested for the transgene expression level by qRT-PCR and compared to the control line KA-0 transformed with an empty vector (Table 1).

The data demonstrated a high level of VaSTS1 expression for ST1-1 plants, while in ST1-3 plants it was one-third as high. In order to test if retransformation with $2 b$ from CMV is able to restore VaSTS1 expression in ST1-3 transgenic plants, all lines mentioned were retransformed, and homozygous A. thaliana plants were analyzed (Table 1).

According to the data obtained, retransformation of ST1-1 plants had no significant effect on VaSTS1 expression, with the exception of line ST1-1-2b-Ic-1p, which showed a nonsignificant decrease in the level of VaSTS1 expression. However, retransformation of ST1-3 plants led to a strong increase in VaSTS1 expression in line ST1-3-2b-IIb-3p, reaching a level comparable with that of the high-expression line ST1-1.

According to the data on the level of cytosine methylation within the 3' end of the VaSTS1 transgene presented in Table 1 , both initial lines show comparable levels of methylated cytosines from 17.7 to $13.4 \%$ of the total amount of cytosine residues.

However, strong induction of VaSTS1 expression in ST1$3-2 b-I I b-3 p$ plants after retransformation with $2 b$ seems to be the result of the demethylation process within the 3 ' end of the transgene sequence, as the total level of methylated cytosines was reduced to $1.0 \%$.

\section{Conclusions}

Our data show that retransformation with $2 b$ from CMV can reactivate expression of a silenced transgene in model Arabidopsis thaliana plants. Reactivation of transgene expression is strongly connected to demethylation of cytosine residues within the nucleotide sequences of a reactivating transgene.

\section{References}

Butaye K.M.J., Cammue B.P.A., Delaure S.L., De Bolle M.F.C. Approaches to minimize variation of transgene expression in plants. Mol. Breed. 2005;16:79-91. DOI 10.1007/s11032-005-4929-9.

Dubrovina A.S., Kiselev K.V. Effect of long-term cultivation on resveratrol accumulation in a high-producing cell culture of Vitis amurensis. Acta Physiol. Plant. 2012;34:1101-1106. DOI 10.1007/s11738011-0907-5. 
Dubrovina A.S., Kiselev K.V., Khristenko V.S., Aleynova O.A. The calcium-dependent protein kinase gene $\mathrm{VaCPK} 29$ is involved in grapevine responses to heat and osmotic stresses. Plant Growth Regul. 2017;82:79-89. DOI 10.1007/s10725-016-0240-5.

Kiselev K.V., Tyunin A.P., Ogneva Z.V., Dubrovina A.S. Age-associated alterations in the somatic mutation level in Arabidopsis thaliana. Plant Growth Regul. 2015;75:493-501. DOI 10.1007/s10725-0140012-z.

Law J.A., Jacobsen S.E. Establishing, maintaining and modifying DNA methylation patterns in plants and animals. Nat. Rev. Genet. 2010; 11:204-220. DOI 10.1038/nrg2719.

Lewsey M.G., Murphy A.M., MacLean D., Dalchau N., Westwood J.H., Macaulay K., Bennett M.H., Moulin M., Hanke D.E., Powell G., Smith A.G., Carr J.P. Disruption of two defensive signaling pathways by a viral RNA silencing suppressor. Mol. Plant-Microbe Interact. 2010;23:835-845. DOI 10.1094/MPMI-23-7-0835.

Pumplin N., Voinnet O. RNA silencing suppression by plant pathogens: defence, counter-defence and counter-counter-defence. Nat. Rev. Microbiol. 2013;11:745-760. DOI 10.1038/nrmicro3120.

Roossinck M.J. Evolutionary history of Cucumber mosaic virus deduced by phylogenetic analyses. J. Virol. 2002;76:3382-3387. DOI 10.1128/JVI.76.7.3382-3387.2002.
Tyunin A.P., Nityagovsky N.N., Grigorchuk V.P., Kiselev K.V. Stilbene content and expression of stilbene synthase genes in cell cultures of Vitis amurensis treated with cinnamic and caffeic acids. Biotechnol. Appl. Biochem. 2018;65:150-155. DOI 10.1002/bab.1564.

Tyunin A.P., Nityagovsky N.N., Karetin Y.A., Kiselev K.V. Reactivation of rolB transgene expression in Vitis amurensis Rupr. cells upon retransformation with $2 b$ gene from Cucumovirus isolate NK. Biotechnol. Lett. 2019;41:443-445. DOI 10.1007/s10529-018-02642-6.

Tyunin A.P., Suprun A.R., Nityagovsky N.N., Manyakhin A.Y., Karetin Y.A., Dubrovina A.S., Kiselev K.V. The effect of explant origin and collection season on stilbene biosynthesis in cell cultures of Vitis amurensis Rupr. Plant Cell Tissue Organ Cult. 2019;136:189-196. DOI 10.1007/s11240-018-1490-x.

Zhang X., Yuan Y.R., Pei Y., Lin S.S., Tuschl T., Patel D.J., Chua N.H. Cucumber mosaic virus-encoded $2 \mathrm{~b}$ suppressor inhibits Arabidopsis Argonaute1 cleavage activity to counter plant defense. Genes Dev. 2006;20:3255-3268. DOI 10.1101/gad.1495506.

Acknowledgements. The work is supported by The Russian Foundation for Basic Research, grant number: 17-04-01381.

Conflict of interest. The authors declare no conflict of interest. 


\title{
Development of a new method for eradication of viruses by induction of posttranscriptional gene silencing in transgenic potato plants
}

\author{
A.M. Alexandrova*, O.V. Karpova, R.M. Nargilova, R.V. Kryldakov, B.K. Iskakov \\ M.A. Aitkhozhin Institute of Molecular Biology and Biochemistry, Almaty, Kazakhstan
}

DOI 10.18699/ICG-PlantGen2019-46

(c) Autors, 2019

* e-mail: alena_pisarenko@inbox.ru

\begin{abstract}
A new method of improving potato plants from a viral infection has been proposed. DNA fragments containing the full coding sequence of PVS $25 \mathrm{~K}$ protein in sense and antisense orientations were cloned from $5^{\prime}$ and $3^{\prime}$ ends of intron I of Ricinus communis catalase gene cat1 Ricinus communis into binary agrobacterial vector pCAMBIA2300 under control of $35 \mathrm{~S}$ CaMV promoter and terminator of nopalin synthase gene. Using the recombinant DNA as a transgene, transformation of six varieties of test-tube potato plants, which were infected with PVM, PVS and/or PVY individually or in complex, was carried out. Further field trials of 20172018 allowed us to select four promising transgenic lines that were free from viral infection. Key words: potato virus; PVS; PVM; PVY; RNA-interference; transgene; ELISA.
\end{abstract}

\section{Introduction}

The main focus of potato protection against viral diseases is on the creation of resistant varieties using traditional breeding methods, the recovery of seed material and the protection of planting against reinfection. The existing technologies for obtaining virus-free seed, both using the method of cultivation of apical meristem and using chemo- and heat therapy, as well as cryotherapy, are still expensive and time-consuming and, as a rule, do not eliminate the possibility of secondary infection of plants in the soil. In this regard, potato varieties with genetically fixed resistance to viral diseases are of particular importance. The creation of such varieties by traditional methods of breeding requires decades; moreover, donors of genes for resistance to viral diseases are mostly wild plant species that cannot always be crossed with cultivated varieties using classical methods of selection.

The resistance of transgenic plants to viral infections is considered as a separate type of specific plant resistance (pathogen-derived resistance, PDR). It is known that this kind of resistance is due to the mechanisms of RNA interference (or post-transcriptional gene silencing, PTGS or RNA silencing) and is characterized by highly specific degradation of viral RNA when interacting with transgenic RNA (Simon-Mateo and Garcia, 2011). For this aim, transgenes having a high degree of homology with the nucleotide sequences of the viral gRNA are used.

It was shown that transforming plants containing sense and antisense orientation of the transgene coding sequence, separated by an intron sequence, the so-called "hairpin" structure, is more resistant to viral infection than plants transformed with a vector that carries only a sense or an antisense sequence (Smith et al., 2000; Wesley et al., 2001). The introduction of such "hairpin" structures into cells leads to the formation of double-stranded RNA (dsRNA), which actually trigger the RNA interference mechanism in order to degrade foreign viral RNA in the event of a pathogen penetration (Moissiard and Voinnet, 2004).

Potato viruses $\mathrm{M}$ and S (PVM and PVS) are the most common viruses in Kazakhstan (Loebenstein and Manadilova,
2003; Khassanov, Vologin, 2018; Alexandrova et al., 2018). Until now, no resistance gene donors have been detected for viral diseases caused by these viruses. PVS is a representative of the group Carlaviruses of the family Betaflexiviridae (King et al. 2011). The virus is carried by aphids in a non-persistent manner and infects plants of the families Solanaceae and Chenopodiaceae. Genomic RNA (gRNA) of the virus is represented by positively charged single-stranded mRNA of about 8535 nucleotides in length and has a cap structure at the $5^{\prime}$ end and a poly (A) tail at the $3^{\prime}$ end (Monis et al., 1987; Mackenzie et al., 1989). Six reading frames were found inside the gRNA. ORF1 encodes a polypeptide of $223 \mathrm{~K}$ in size, inside of which are coding sequences of methyltransferase, peptidase, helicase, and RNA-dependent RNA polymerase. ORF2, ORF3 and ORF4 encode $25 \mathrm{~K}, 12 \mathrm{~K}$ and $7 \mathrm{~K}$ proteins that are included in the triple gene block (TGB), characteristic of all Carlaviruses (Morozov et al., 1989; Matoušek et al., 2005). These proteins are responsible for the spread of the virus from one cell to the next and have a region of significant homology with the sequences of the representatives of the potexvirus group. ORF5 encodes a $34 \mathrm{~K}$ coat protein $(\mathrm{CP})$, and ORF6 encodes a cysteine-rich $11 \mathrm{~K}$ protein, which has RNA-binding activity.

A method for the eradication of viral material was proposed in the framework of this study, based on the use of source material infected with one or more viruses to create transgenic potato plants capable of expressing a "hairpin" structure with the coding sequence of the PVS $25 \mathrm{~K}$ protein.

\section{Materials and methods}

The 35S CaMV promoter and terminator of the nopaline synthase gene (nos) were cloned from transient expression vector pBI221 (NCBI GenBank acc. No: AF501128) into binary agrobacterial vector pCAMBIA 2300 (NCBI GenBank acc. No: AF234315) between HindIII and BamHI, SacI and EcoRI, respectively.

The coding sequence of the PVS $25 \mathrm{~K}$ protein in two orientations (sense and antisense) was inserted into secondary plasmid vector pRAJ17 created on the basis of pBluescriptII 
$\mathrm{KS}+$ and containing intron 1 of the I catalase cat1 Ricinus communis catalase gene catl between the BamHI / NcoI and SalI / SacI restriction sites. The following primers were selected for cloning the coding sequence of $25 \mathrm{~K}$ protein in sense (\# 306 and \# 308) or into antisense orientation (\# 307 and \# 309) (the restriction sites are underlined, restrictase names are shown to the right):

\#306 5'- cgtaggatcc ttaggeggeg tgtaagtgg -3' NcoI

\#307 5'- cgtagagctc atgaggatat ttgatagctt $-3^{\prime} \quad$ SacI

\#308 5'- cgtaggatcc atgaggatat ttgatagctt $-3^{\prime} \quad$ Bam HI

\#309 5'- cgtagtcgac ttaggcggcg gtgtaagtgg -3' SalI

The sense or antisense sequences of the $25 \mathrm{~K}$ protein cloned into pRAJ17 using BamHI and NcoI (located on the 5' end of the intron) or SalI и SacI (on 3' end of the intron). Then the DNA fragment from Bam HI and $\mathrm{SacI}$ was recloned into pCAMBIA 2300 with the $35 \mathrm{~S}$ CaMV promoter and the nos-terminator. As a result, recombinant DNA with the [35S CaMV - 25K Sense - intron - 25K Asense - nos] cassette was created (Figure 1).

Potato plant transformation was carried out according to a standard method (Raldugina et al., 2011). DNA and RNA from transgenic plant leaves were isolated by a standard method using Trizol according to the manufacturer's recommendations (Sigma). Amplification of DNA fragments was performed using Pwo polymerase (Roche) according to the manufacturer's method. The program for amplification: stage 1: $5 \mathrm{~min}$ at $94{ }^{\circ} \mathrm{C}, 1$ cycle; stage 2: $30 \mathrm{sec}$ at $94{ }^{\circ} \mathrm{C}$, $30 \mathrm{sec}$ at $54^{\circ} \mathrm{C}, 1 \mathrm{~min} 30$ seconds at $72^{\circ} \mathrm{C}, 30$ cycles; stage 3 : 5 min at $72^{\circ} \mathrm{C}, 1$ cycle. The presence of PVS, PVM and PVY infection was determined by the standard DAS-ELISA method using commercial kits from BIOREBA as recommended by the manufacturer. The measurements were carried out on a Stat Fax 2100 photometer (Awareness) at $405 \mathrm{~nm}$.

\section{Results and discussion}

The presence of the $25 \mathrm{~K}$ protein is characteristic of all Carlaviruses, its coding sequence is known as part of the TGB. The property of the PVM $25 \mathrm{~K}$ protein is its ability to suppress RNA silencing (Senshu et al., 2011). In this study, DNA fragments containing the full coding sequence of the PVS $25 \mathrm{~K}$ protein were cloned from the 5' and 3' ends relative to the intron I of the Ricinus communis catalase gene cat 1 in the sense (Sense) and antisense (Asense) orientations into binary agrobacterial vector pCAMBIA 2300 under the control of the 35S CaMV promoter and the nos-terminator (Figure 1).

Potato plants of the varieties 'Dunyasha', 'Zeren', 'Kormilitsa', 'Albinka', 'Fortune', 'Picasso', 'Santa', 'Tien-Shansky' and 'Tokhtar' which were free from viral infection or infected with PVM, PVS and/or PVY alone or in complex were transformed by cocultivation with agrobacteria carrying the created recombinant DNA. The transformation efficiency for each variety was evaluated by the number of the regenerants containing the transgene (Table 1). Normal shoots were obtained only in 'Albinka', 'Dunyasha', 'Zeren' and 'Kormilitsa' after regeneration and transformation.

The plants were analyzed for the presence of recombinant DNA constructs, as well as RNA transcripts corresponding to the transgene. Transgenic plants that showed a positive response during these analyses were grown in soil and fur- ther tested for the presence of viruses using the DAS-ELISA method. According to our observations, a decrease in ELISA readings from a high value at the moment of planting into the soil to fewer readings during the first six months of observations was caused not only by the successful triggered RNA interference in cells during further plant development after transformation, but also by laboratory manipulations. The viruses did not have time to accumulate in the shoots of tubetest plants during grafting when the continuous intensive apical growth occurred. Therefore, there was a decrease in ELISA values even in untransformed plant regenerants which was observed, for example, for 'Zeren' and 'Dunyasha' infected with PVM. However, samples of these plants taken later again revealed the presence of viral infection after growing for two months in the soil in the greenhouse. That was the reason for the prolonged observation of the lines that had gone through the eradication procedure.

It was also noted that the original 'Zeren' plants which initially carried PVM + PVS + PVY infection had no more PVM during field trials, although this variety gave a positive response to the presence of this virus during the first six months after transformation. As a rule, several viruses in one plant can coexist if they belong to different groups. Moreover, if the titer of a more virulent pathogen remains at the same level, the titer of a less virulent pathogen grows during the growing season of the plant (Nyalugwe et al., 2012; Hameed et al., 2014). The results presented here are not consistent with the previous findings.

The enzyme immunoassay was performed every 30 days for 6 months after the transfer of transgenic plants to the soil in the greenhouse. Transgenic lines TL-59, TL-44, TL-62, TL-65 and all 'Albinka' lines had no changes and were infected by PVM and PVY as before transformation. As for the other varieties, there were lines that showed a decrease in ELISA value up to the complete absence of a positive response. As a result, the 4 transgenic lines were selected as being free of virus. TL-61 and TL-67 ('Dunyasha'), as well as TL-103 ('Kormilitsa') infected with PVM before transformation had a negative response. Moreover, complex infection with PVM + PVS + PVY was eliminated in TL-119 ('Zeren').

In 2017 and 2018, microtubers of 14 transgenic lines TL-39, TL-43, TL-46, TL-48, TL-74 and TL-159 ('Albinka'), TL-59 and TL-119 ('Zeren'), TL-44, TL-61, TL-62, TL-65, TL-67 ('Dunyasha') and TL-103 ('Kormilitsa') were planted in the field. Besides transgenic plants, the plants infected by different viruses (Table 1) and control virus-free plants of the same varieties were also grown to create a viral background and to check the rates of virus contamination. The presence of PVM, PVS and/or PVY had already been seen in virus-free control plants after the first ELISA in 2017.

During each season, leaf samples were collected from each plant three times for ELISA 1, 2 and 3 months after planting. Lines TL-103, TL-44, TL-61 and TL-67 remained free of PVM. PVM, PVS and PVY were eliminated in TL-119 plants.

Virus-free tubers were used for planting in 2018. After ELISA analysis, PVM and PVS were not detected in TL-103 and TL-119. PVM was not found in TL-61 and TL-67. TL-119 showed eradication of three viruses after the first six months 


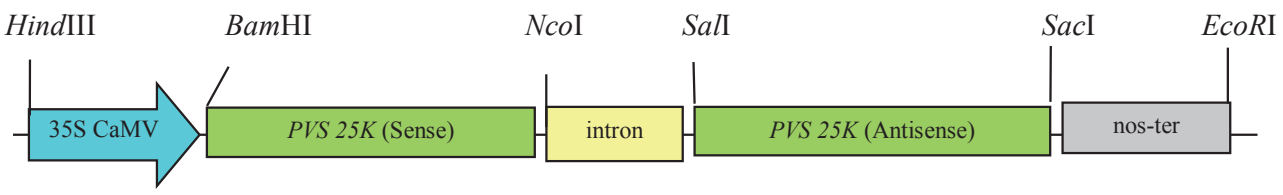

Figure 1. Scheme of the recombinant DNA cassette created as part of agrobacterial plasmid vector pCAMBIA2300 and used as a transgene for potato plant transformation.

\section{Table 1}

Transformation efficiency of various potato varieties

\begin{tabular}{lllll}
\hline Name of varieties & Virus infection & Number of regenerants (units) & Number of transgenic shoots (units) & Transformation efficiency, \% \\
\hline 'Albinka' & PVM, PVY & 18 & 8 & 44.4 \\
'Dunyasha' & PVM & 13 & 5 & 38.5 \\
'Zeren' & PVM, PVS, PVY & 15 & 4 & 26.7 \\
'Kormilitsa' & PVM & 5 & 1 & 20.0 \\
'Picasso' & PVM, PVY & 0 & 0 & 0 \\
'Santa' & PVM, PVY & 0 & 0 & 0 \\
'Tokhtar' & PVM & 0 & 0 & 0 \\
'Tien-Shansky' & PVM & 1 & 0 & 0 \\
'Fortune' & PVM, PVS & 0 & 0 & 0 \\
\hline
\end{tabular}

in the greenhouse. However, during field trials, a positive response to PVY was shown in 2017 by one out of five plants planted and in 2018 by seven out of 9 plants planted. PVY belongs to Potyvirus, PVS and PVM are Carlaviruses. The recombinant DNA construct developed was directed against PVS, but in the case of PVM it could be a trigger of RNA interference due to homology between genomic sequences. Although the amino acid sequences of the $25 \mathrm{~K}$ proteins of PVS, PVM and PVX have more differences than capsid proteins, conservative domains about 20 amino acids in size were found at the $\mathrm{N}$-terminus of these proteins.

\section{Conclusion}

The problem of multiple infections in potato fields in Kazakhstan still persists. A new methods of treatment of plants infected with related and unrelated viruses is proposed with the example of a transgene carrying the complete coding sequence of the PVS $25 \mathrm{~K}$ protein in two orientations and able to induce RNA interference in plant cells. As a result, four virus-free lines were obtained. Thus, it has been proven that the coding sequence of the PVS $25 \mathrm{~K}$ protein is a good target for the action of RNA interference.

\section{References}

Alexandrova A.M., Karpova O.V., Nargilova R.M., Kryldakov R.V., Nizkorodova A.S., Zhigaylov A.V., Yekaterinskaya E.M., Kushnarenko S.V., Akbergenov R.Zh., Iskakov B.K. Distribution of potato (Solanum tuberosum) viruses in Kazakhstan. Internetional Journal Biology Chemistry. 2018;11(1):33-40.

Hameed A., Iqbal Z., Asad S., Mansoor S. Detection of multiple potato viruses in field suggests synergistic interactions among potato viruses in Pakistan. Plant Pathol. J. 2014;30(4):407-415. DOI 10.5423/PPJ.OA.05.2014.0039.

Khassanov V.T., Vologin S.G. Occurrence of the Ordinary and the Andean Strains of Potato Virus S Infecting Potatoes in the Eastern Region of Kazakhstan. Plant Disease. 2018;102(10):2052. DOI 10.1094/PDIS-12-17-2000-PDN.

King A., Lefkowitz E., Adams M.J. Virus Taxonomy. Ninth Report of the Intern. Committee on Taxonomy of Viruses. Elsevier, 2011.
Loebenstein G. and Manadilova A. Virus and virus-like diseases of major crops in developing countries. Springer, Dordrecht, Netherlands. 2003:195-200. DOI 10.1007/978-94-007-0791-7 8.

Mackenzie D., Tremaine J., Stace-Smith R. Organisation and interviral homologies of 3'-terminal portion of potato virus RNA. J. Gen. Virol. 1989;70:1053-1063. DOI 10.1099/0022-1317-70-5-1053.

Matoušek J., Schubert J., Ptaček J., Kozlova P., Dedič P. Complete nucleotide sequence and molecular probing of potato virus $\mathrm{S}$ genome. Acta virologica. 2005;49:195-205.

Moissiard G., Voinnet O. Viral suppression of RNA silencing in plants. Molecular Plant Pathology. 2004;5:71-82.

Monis J., Daniels S., De Zoeten G., Slack S. Characterization of potato virus S (PVS) genomic RNA. Phytopathol. 1987;77:1742.

Morozov S., Dolja V., Atabekov J. Probable reassortment of genomic elements among elongated RNS-containing plant viruses. J. Mol. Evol. 1989;29:52-62.

Nyalugwe E., Wilson C., Coutts B., Jones R. Biological properties of Potato virus $\mathrm{X}$ in potato: effect of mixed infection with Potato virus $\mathrm{S}$ and resistance phenotypes in cultivars from three continents. Plant Disease. 2012;96(1):43-54. DOI 10.1094/PDIS-04-11-0305

Raldugina G., Danilova S., Yurjeva N. Molecular-genetic and biochemical methods of modern plant biology. Binom. Laboratory of knowledge. 2011;13-24. https://www.rfbr.ru/rffi/ru/books/o 1781847\#3

Senshu H., Yamaji Y., Minato N., Shiraishi T., Maejima K., Hashimoto M., Miura C., Nerya Y., Namba S. A dual strategy for the suppression of host antiviral silencing: two distinct suppressors for viral replication and viral movement encoded by Potato virus M. J. Virol. 2011;85(19):10269-10278. DOI 10.1128/JVI.05273-11.

Smith N.A., Singh S.P., Wang M.-B., Stoutjesdijk P.A., Green A.G., Waterhouse P.M. Total silencing by intron-spliced hairpin RNAs. Nature. 2000;407:319-320.

Simon-Mateo C., Garcia J.A. Antiviral strategies in plants based on RNA silencing. Biochim Biophys Acta. 2011;1809(11-12):722-731. DOI 10.1016/j.bbagrm.2011.05.011

Wesley S., Helliwell C., Smith N., Wang M., Rouse D., Liu Q., Gooding P., Singh S., Abbott D., Stoutjesdijk P., Robinson S., Gleave A., Green A, Waterhouse P. Construct design for efficient, effective and high-throughput gene silencing in plants. Plant J. 2001;462-469.

Acknowledgements. This research was supported by grant AP05131133 (2018-2020) of Ministry of Education and Science, Republic of Kazakhstan.

Conflict of interest. The authors declare no conflict of interest. 


\title{
Up-regulation of the vacuolar invertase TAI gene may contribute to the accumulation of carotenoids in tomato fruits
}

\author{
M.A. Slugina ${ }^{1 *}$, E.A. Dzhos ${ }^{1,2}$, A.V. Shchennikova ${ }^{1}$, E.Z. Kochieva ${ }^{1,3}$ \\ ${ }^{1}$ Institute of Bioengineering, Research Center of Biotechnology, RAS, Moscow, Russia \\ ${ }^{2}$ Lomonosov Moscow State University, Moscow, Russia \\ ${ }^{3}$ State Scientific Institution, All-Russian Research Institute for Selection and Seed Production of Vegetable Crops, RAS, Moscow, Russia
}

DOI 10.18699/ICG-PlantGen2019-47

(c) Autors, 2019

*e-mail: mashinmail@mail.ru

\begin{abstract}
Generally, fleshy fruit ripening is accompanied by its sweetening and color change caused by dramatic molecular, biochemical and physiological conversions. Species of the tomato clade differ in color of ripe fruits. Carotenoids accumulate in the fruit chromoplasts of red-fruited species, and the fruits of primitive green-fruited tomato species remain green due to the numerous blocks of carotenogenesis. In this study, the sugar and carotenoid content, as well as the expression patterns of the four genes encoding main fruit-specific sucrose cleavage enzymes TAl, SUS1, NI2 and LIN5, were characterized in immature green, mature green and ripe fruits of $S$. Iycopersicum cultivars and the wild green-fruited tomato species S. habrochaites and S. peruvianum. An analysis of the sugar and carotenoid content confirmed that carotenoids and hexoses accumulate in the ripe fruits of the red-fruited S. lycopersicum cultivars, while green-fruited tomatoes produce fruits enriched for sucrose and containing only trace amounts of carotenoids. The SUS1, LIN5 and NI2 expression showed no correlation with fruit color and hexose content. In fruits of green-fruited species, all analyzed genes were expressed in a similar way. TAl expression was extremely specific for cultivars, being maximal in ripe fruit, characterized by carotenoid and hexose accumulation in fruits. The findings suggest that vacuolar invertase TAI, rather than apoplastic invertase LIN5 or cytoplasmic sucrose synthase SUS1 and invertase $\mathrm{NI2}$, may specify sugar composition in ripe fruits.
\end{abstract}

Key words: sucrose hydrolysis genes; red- and green-fruited tomato species; carotenoid biosynthesis.

\section{Introduction}

Solanum section Lycopersicon includes the cultivated tomato S. lycopersicum and its 12 wild relatives that differ significantly in fruit physiology, biochemistry and morphology (Peralta et al., 2008). This makes tomato species an attractive model for studying the mechanism of fleshy fruit development from initiation to full maturity.

Ripening, converting mature fruit from inedible to edible form, is an irreversible process associated with perceptible organoleptic and visible alterations in texture, flavor, aroma, color, and size, due to dramatic molecular, metabolic, biochemical and physiological changes driven by internal and external signaling (Seymour et al., 2013). Ripening determines crop yield, shelf life, and fruit quality traits, including dry matter amount, content, and nutritional value (Li, Van Eck, 2007). The recently evolved so-called red-fruited tomato species (S. lycopersicum, S. pimpinellifolium, S. cheesmaniae, $S$. galapagense) have a yellow to red color of ripe fruits due to carotenoid synthesis (mainly beta-carotene and lycopene) and chlorophyll degradation (Llorente et al., 2016). Ripe fruits, formed by more ancient green-fruited tomato species, do not accumulate carotenoids and, as a result, stay green (Kilambi et al., 2017). The basic mechanisms of ripening are similar in both sets of tomato species and accompanied by high ethylene biosynthesis, fruit softening, and sugar content increment. However, they differ in sugar composition in ripening fruits: red-fruited species accumulate glucose and fructose, and green-fruited tomatoes contain sucrose (Beckles et al., 2012). The exact molecular mechanisms of mutual regulation of sugar metabolism and fruit pigmentation have not yet been fully understood. There is some evidence that sugars can act as signaling molecules to activate carotenoid biosynthesis and, as a result, the fruit acquires a different color. For example, changing the sugar concentration in mandarin (Citrus unshiu), watermelon (Citrullus lanatus) and tomato fruits alters their pigmentation (Iglesias et al., 2001; Telef et al., 2006; Zhang et al., 2017). Thus, a connection can be proposed between the sucrose-hexose ratio and the synthesis of carotenoids. In carbohydrate metabolism, glucose is the central molecule, sucrose is the most common form of translocated sugar, and sucrose-hexose interconversion is one of the main reactions (Winter, Huber, 2000). In plants, four sucrose cleavage enzymes are known: cytoplasmic sucrose synthase (SUS), and three invertases, acid vacuolar (TAI), acid apoplastic (LIN) and neutral cytoplasmic (NI) (Winter, Huber, 2000).

In this study, new data were obtained on the possible relationships between carbohydrate and carotenoid metabolism by analyzing fruit-specific expression patterns of SUS1, TAI, LIN5 and NI2 and fruit biochemical composition (sugars, carotenoids) during ripening in green- and red-fruited tomato species.

\section{Materials and methods}

Accessions of cultivated (S. lycopersicum cv. Silvestre Recordo, Red Cherry and Fioletovii) and wild (S. habrochaites and S. peruvianum) tomato species (Solanum section Lycopersicon) were provided by the N. I. Vavilov Institute of Plant Genetic Resources (St.-Petersburg, Russia) and grown in a greenhouse with a $16-\mathrm{h} / 8-\mathrm{h}\left(28{ }^{\circ} \mathrm{C} / 23^{\circ} \mathrm{C}\right)$ light-dark cycle (light intensity, 300-400 $\mu \mathrm{mol} \mathrm{m}^{-2} \mathrm{~s}^{-1}$ ). 
Total RNA was extracted from immature green (IF), mature green (MF) and fully ripe (RF) fruits using the RNeasy Plant Mini Kit (QIAGEN, Hilden, Germany) and analyzed by gel electrophoresis and fluorimetry (Qubit ${ }^{\circledR}$ Fluorometer, Thermo Fisher Scientific, Waltham, MA, USA). First-strand cDNA was synthesized using the Reverse Transcription System (Promega, Madison, WI, USA) and an oligo-dT primer and quantified by fluorimetry. Gene-specific primers separated by at least one big intron were designed to amplify fragments of coding sequences: SUSrtF (5'-GATTTCGAGCCTTTCACTGC-3')/SUSrtR (5'-AGGTATTCCTCTGCCTTCC-3') (for SUS1 gene), TAIrtF (5'-GAGGCTCCGGGAGTTGGTAA-3')/TAIrtR (5'-CC AAATCTTGACGGAGGCAG-3') (for TAI), LIN5rtF (5'-TGTCAAGAATGTTCATAGAACTC-3')/LIN5rtR (5'-TGAATGAGCCCAAATAATATTGC-3') (for LIN5) and NI2rtF (5'-ACTCTTGCTGCTAATGATCCTAA-3')/ NI2rtR (5'-ACTTCTTCATATTTGTTATCATCGAG-3') (for NI2). Quantitative real-time PCR (qPCR) was performed in two biological and three technical replicates using $2.5 \mathrm{ng}$ of cDNA, developed primers, and SYBR Green and ROX RT-PCR mixture (Syntol, Moscow, Russia) at the following conditions: denaturation at $95^{\circ} \mathrm{C}$ for $5 \mathrm{~min}$, and 40 cycles at $95^{\circ} \mathrm{C}$ for $15 \mathrm{~s}$ and $60^{\circ} \mathrm{C}$ for $40 \mathrm{~s}$. The expression levels were normalized to that of the tomato reference genes Expressed and Actin 2/7 (Expósito-Rodríguez et al., 2008; Bemer et al., 2012). Statistical analysis was performed using Graph Pad Prism version 7.02 (San Diego, CA, USA; https://www. graphpad.com/scientifc-software/prism/).

Biochemical analysis was performed in two biological replicates. To assess sucrose, glucose and fructose content, 1 $\mathrm{g}$ of fruit material was ground in liquid nitrogen, diluted with $10 \mathrm{ml}$ of $80 \%$ ethanol, centrifuged at 10,000 rpm for $15 \mathrm{~min}$, and analyzed by HPLC (Varian ProStar, VARIAN INC., Palo Alto, CA, USA) using an HPLC Refractive Index Detector 102M (Stayer, Moscow, Russia) and an Agilent Carbohydrate Analysis Column $(150 \mathrm{~mm} \times 4.6 \mathrm{~mm}, 5 \mu \mathrm{M})$; isocratic elution was performed with $75 \% \mathrm{v} / \mathrm{w}$ acetonitrile as a mobile phase; the flow rate was maintained at $1.5 \mathrm{ml} / \mathrm{min}$ and the temperature, at $30{ }^{\circ} \mathrm{C}$. Total carotenoids content was measured by Nagata and Yamashita equation (Nagata, Yamashita, 1992).

\section{Results and discussion}

Three $S$. lycopersicum cultivars and two wild tomato species, $S$. habrochaites and $S$. peruvianum, considered in this study represent two diverse groups varying in fruit pigmentation and sugar composition (Table 1). The same fruit samples of examined accessions were taken at three time points, including growth (IF), mature (MF) and ripe (RF) stages, both for biochemical and qPCR analyses.

An analysis of the sugar and carotenoid contents confirmed that carotenoids and hexoses accumulate in ripe fruits of the red-fruited $S$. lycopersicum cultivars, while green-fruited tomatoes produce fruits enriched for sucrose and containing trace amounts of carotenoids (see Table 1). The obtained data are fully consistent with the previously observed carbohydrate biochemistry of fruits in red- and green-fruited tomatoes (Peralta et al., 2008; Beckles et al., 2012) and suggest a negative correlation between the accumulation of monosaccharides and the presence of carotenoids.
To find out the possible factors influencing the difference in carbohydrate composition and, likely, in the implementation of the carotenoid biosynthesis in tomato fruits, SUS1, TAI, LIN5 and NI2 expression patterns were determined and compared in ripening fruits of red-fruited cultivars Silvestre Recordo, Red Cherry and Fioletovii and the green-fruited species $S$. habrochaites and S. peruvianum (Figure 1). These genes were selected for analysis among their paralogs because their products were shown to have fruit-specific activity (Winter, Huber, 2000; Baxter et al., 2005).

The transcription levels of the analyzed genes varied considerably relative to each other (see Figure 1). The SUS1, LIN5 and NI2 transcripts were found in fruits of both red- and green-fruited tomatoes, which indicates the absence of any correlation of their expression with fruit color.

In fruits of green-fruited species, all analyzed genes were expressed in a similar way. The LIN5 transcription level was the highest in mature green fruit and absent in ripe fruit. SUS1 transcription was maximal in immature green fruits and decreased during the transition from stage IF to stage RF.

Our observations suggest that primitive green-fruited species may have retained an ancestral expression pattern for each analyzed sucrose cleavage gene, as was also demonstrated for carotenoid metabolism genes (Kilambi et al., 2017).

In contrast, the SUS1 and LIN5 transcription varied between cultivars of the red-fruited species without correlation with the sugar and carotenoid content in ripe fruit.

Thus, S. lycopersicum cultivars, which, due to intensive tomato breeding, differ significantly in fruit color, sweetness and other related traits, may have diversified expression of sucrose catabolism genes with a unique pattern for each cultivar.

Unlike these genes, TAI expression was extremely specific to cultivars, being maximal in ripe fruit, characterized by carotenoid and hexose accumulation in fruits. Our observation is consistent with previous data on TAI expression in ripe fruits of other red-fruited tomato species (Slugina et al., 2017).

TAI activity in the vacuole may lead to accumulation of symplastic glucose in the cell, which may stimulate chromoplast formation, as shown for watermelon (Zhang et al., 2017).

Differences in fruit color in tomato species and cultivars may indicate the uniqueness of carotenoid biosynthesis regulation in each genotype.

Fruits of red-fruited species accumulate carotenoids at high levels in carotenoid sequestering substructures inside chromoplasts (Li, Van Eck, 2007). Fruit carotenogenesis coincides with the chloroplast into chromoplast transformation (Kilambi et al., 2017). In green-fruited species, fruits do not have orange/red color due to the numerous blocks of fruit-specific chromoplast formation and carotenoid synthesis (Kilambi et al., 2017).

\section{Conclusions}

The findings suggest that vacuolar invertase TAI, rather than apoplastic invertase LIN5 or cytoplasmic proteins, sucrose synthase SUS1 and invertase NI2, may be a key enzyme in determining sugar composition in ripe fruit. The role of cytoplasmic and apoplastic sucrose hydrolysis probably consists in maintaining the basic sucrose-hexose balance in the cells and in supplying dividing and expanding cells with energy 
Table 1

Sugar and carotenoid content in immature green (IF), mature green (MF) and ripe (RF) fruits of S. lycopersicum cultivars and two wild tomato species

\begin{tabular}{|c|c|c|c|c|c|}
\hline Accession & Fruit stage & $\begin{array}{l}\text { Glucose, } \mathrm{mg} / \mathrm{g} \text { fresh } \\
\text { weight }\end{array}$ & $\begin{array}{l}\text { Fructose, } \mathrm{mg} / \mathrm{g} \text { fresh } \\
\text { weight }\end{array}$ & $\begin{array}{l}\text { Sucrose, } \mathrm{mg} / \mathrm{g} \text { fresh } \\
\text { weight }\end{array}$ & $\begin{array}{l}\text { B-carotene, } \mathrm{mg} / \mathrm{g} \\
\text { fresh weight }\end{array}$ \\
\hline \multirow[t]{3}{*}{ S. habrochaites } & IF & 0.313 & 0.373 & 0.174 & \\
\hline & MF & 0.3865 & 0.493 & 0.4375 & \\
\hline & RF & 0.2285 & 0.339 & 1.5845 & $<0.001$ \\
\hline \multirow[t]{3}{*}{ S. peruvianum } & IF & 0.551 & 0.749 & 0.246 & \\
\hline & MF & 0.628 & 0.842 & 0.3125 & \\
\hline & RF & 0.024 & 0.399 & 1.328 & $<0.001$ \\
\hline \multirow{3}{*}{$\begin{array}{l}\text { S. lycopersicum cv. } \\
\text { Silvestre Recordo }\end{array}$} & IF & 0.837 & 0.812 & 0.181 & \\
\hline & MF & 0.9885 & 1.2075 & 0.149 & \\
\hline & RF & 1.3205 & 1.702 & 0.099 & 0.098 \\
\hline \multirow{3}{*}{$\begin{array}{l}\text { S. lycopersicum cv. } \\
\text { Red Cherry }\end{array}$} & IF & 0.916 & 0.952 & 0.172 & \\
\hline & MF & 0.818 & 0.917 & 0.201 & \\
\hline & RF & 0.893 & 1.203 & 0.055 & 0.08 \\
\hline \multirow{3}{*}{$\begin{array}{l}\text { S. lycopersicum cv. } \\
\text { Fioletovii }\end{array}$} & IF & 0.938 & 0.998 & 0.096 & \\
\hline & MF & 0.987 & 1.160 & 0.184 & \\
\hline & RF & 1.069 & 1.324 & 0.044 & 0.091 \\
\hline
\end{tabular}

a

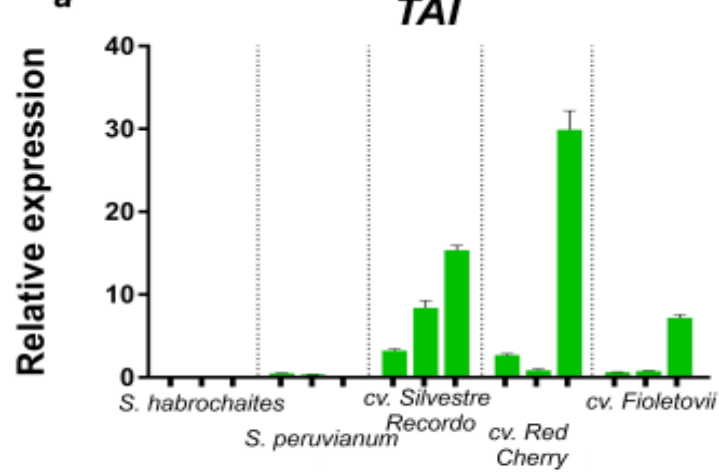

$c$

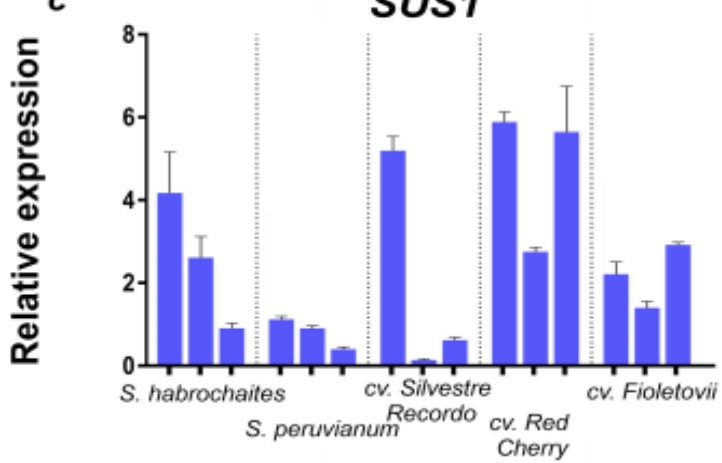

b

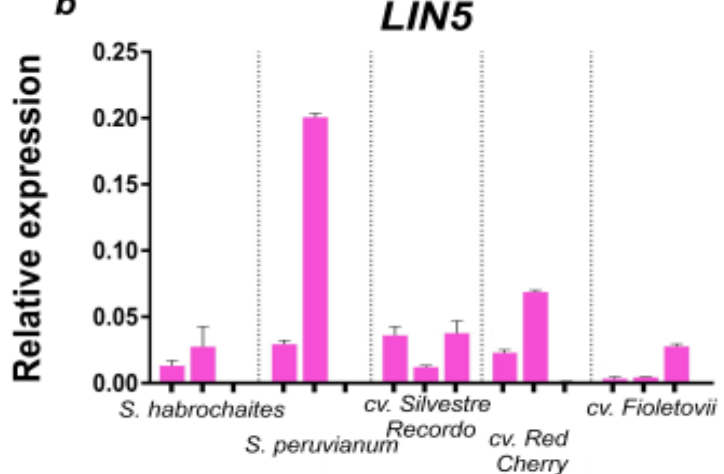

N/2

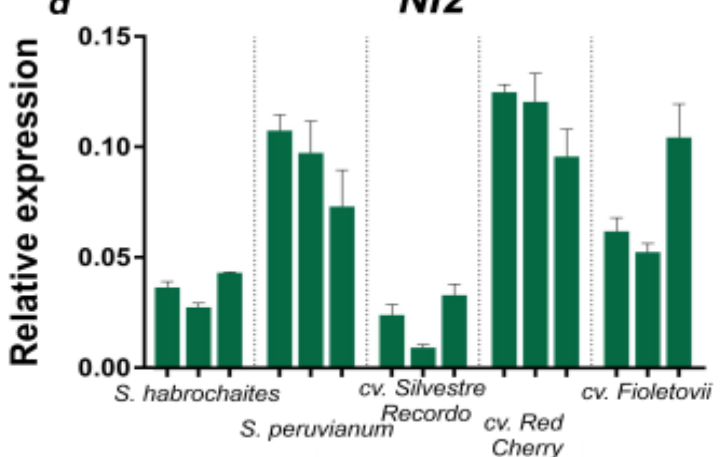

Figure 1. Expression patterns of TAI (a), LIN5 (b), SUS1 (c) and NI2 (d) in immature green, mature green and ripe fruits of S. lycopersicum cultivars and two wild tomato species. 
and carbon to synthesize the necessary compounds during fruit growth up to the stage of maturation.

Given the available evidence of a positive correlation between the sugar content and carotenoids in fruits, studying the genetic networks of fruit-specific carbohydrate metabolism may contribute to new alternative approaches to the manipulation of carotenoid levels in food crops.

\section{References}

Baxter C.J., Carrari F., Bauke A., Overy S., Hill S.A., Quick P.W., Fernie A.R., Sweetlove L.J. Fruit carbohydrate metabolism in an introgression line of tomato with increased fruit soluble solids. Plant Cell Physiol. 2005;46(3):425-437. DOI 10.1093/pcp/pci040.

Beckles D.M., Hong N., Stamova L., Luengwilai K. Biochemical factors contributing to tomato fruit sugar content: a review. Fruits. 2012;67:49-64. DOI 10.1051/fruits/2011066.

Bemer M., Karlova R., Ballester A.R., Tikunov Y.M., Bovy A.G., Wolters-Arts M., Rossetto P. de B., Angenent G.C., de Maagd R.A. The tomato FRUITFULL homologs TDR4/FUL1 and MBP7/FUL2 regulate ethylene-independent aspects of fruit ripening. Plant Cell. 2012;24(11):4437-4451. DOI 10.1105/tpc.112.103283.

Bolger A., Scossa F., Bolger M.E., Lanz C. et al. The genome of the stress-tolerant wild tomato species Solanum pennellii. Nature Gen. 2014;46:1034-1038. DOI 10.1038/ng.3046.

Expósito-Rodríguez M., Borges A., Borges-Pérez A., Pérez A. Selection of internal control genes for quantitative real-time RT-PCR studies during tomato development process. BMC Plant Biol. 2008;8:131. DOI 10.1186/1471-2229-8-131.

Iglesias D.J., Tadeo F.R., Legaz F., Primo-Millo E., Talon M. In vivo sucrose stimulation of colour change in citrus fruit epicarps: Interactions between nutritional and hormonal signals. Physiol. Plant. 2001;112(2):244-250. DOI 10.1034/j.1399-3054.2001.1120213.x.

Kilambi H.V., Manda K., Rai A., Charakana C., Bagri J., Sharma R., Sreelakshmi Y. Green-fruited Solanum habrochaites lacks fruit-specific carotenogenesis due to metabolic and structural blocks. $J$ Exp Bot. 2017;68(17):4803-4819. DOI 10.1093/jxb/erx288.

Li L., Van Eck J. Metabolic engineering of carotenoid accumulation by creating a metabolic sink. Transgen Res. 2007;16(5):581-585. DOI 10.1007/s11248-007-9111-1.
Llorente B., D'Andrea L., Ruiz-Sola M.A., Botterweg E., Pulido P., Andilla J., Loza-Alvarez P., Rodriguez-Concepcion M. Tomato fruit carotenoid biosynthesis is adjusted to actual ripening progression by a light-dependent mechanism. Plant J. 2016;85(1):107-119. DOI 10.1111/tpj.13094.

Nagata M., Yamashita I. Simple method for simultaneous determination of chlorophyll and carotenoids in tomato fruit. J. Japan. Soc. Food Sci. Technol. (Nippon Shokuhin Kogyo Gakkaishi). 1992; 39(10):925-928. DOI 10.3136/nskkk1962.39.925.

Peralta I.E., Spooner D.M., Knapp S. Taxonomy of Wild Tomatoes and their Relatives (Solanum sect. Lycopersicoides, sect. Juglandifolia, sect. Lycopersicon; Solanaceae. Systematic Bot Monographs. 2008; 84:1-186. ISBN 978-0-912861-84-5.

Seymour G.B., Østergaard L., Chapman N.H., Knapp S., Martin C. Fruit development and ripening. Ann Review Plant Biol. 2013;64: 219-241. DOI 10.1146/annurev-arplant-050312-120057.

Slugina M.A., Shchennikova A.V., Kochieva E.Z. TAI vacuolar invertase orthologs: the interspecific variability in tomato plants (Solanum section Lycopersicon). Mol. Gen. Genomics. 2017;292(5):11231138. DOI 10.1007/s00438-017-1336-y.

Télef N., Stammitti-Bert L., Mortain-Bertrand A., Maucourt M., Carde J.P., Rolin D., Gallusci P. Sucrose deficiency delays lycopene accumulation in tomato fruit pericarp discs. Plant Mol. Biol. 2006; 62:453-469. DOI 10.1007/s11103-006-9033-y.

Winter H., Huber S.C. Regulation of sucrose metabolism in higher plants: localization and regulation of activity of key enzymes. Crit. Rev. Biochem. Mol. Biol. 2000;35(4):253-289. DOI 10.1080/ 10409230008984165.

Zhang J., Guo S., Ren Y., Zhang H., Gong G., Zhou M., Wang G., Zong M., He H., Liu F., Xu Y. High-level expression of a novel chromoplast phosphate transporter CIPHT4;2 is required for flesh color development in watermelon. New Phytol. 2017;213(3):1208-1221. DOI 10.1111/nph.14257.

Acknowledgements. The work was supported by the Russian Science Foundation (grant No. 19-16-00016) and the Ministry of Science and Higher Education of the Russian Federation, and was performed using the experimental climate control facility (Institute of Bioengineering, Research Center of Biotechnology, Russian Academy of Sciences).

Conflict of interest. The authors declare no conflict of interest. 


\title{
Induction of in vitro propagation in mature embrios of maize
}

\author{
B.M.H. Humood*, O.I. Yudakova \\ Saratov State University, Saratov, Russia
}

DOI 10.18699/ICG-PlantGen2019-48

(c) Autors, 2019

*e-mail: bobogold18@gmail.com

\begin{abstract}
An efficient and reproducible regeneration protocol via direct organogenesis has been established using mature embryos as explants for three maize lines: BM (Brown marker), AT-TM (bm, wx, y) and AT-TM (lg, y). The seeds were sterilized by 'Domestos', $70 \%$ ethyl alcohol and $0.1 \%$ mercuric chloride. The different mediums for initiation, micropropagation and rooting were tested. The best results were obtained on MS medium supplemented with $2.0 \mathrm{mg} / \mathrm{l} \mathrm{BAP}$. The 3-5 axillary shoots developed in the basal parts of the explant after 3-4 weeks of cultivation. Microshoots were elongated on MS medium supplemented with $0.2 \mathrm{mg} / \mathrm{l}$ BAP. Microshoots in length were rooted on MS medium without hormones.

Key words: clonal micropropagation; in vitro cultivation; mature embryo culture; direct organogenesis; maize; Zea mays.
\end{abstract}

\section{Introduction}

Maize is one of the important food, feed and industrial plants. Breeding new varieties adapted to different environmental condition is necessary for practical use of maize and expanding its production. Particularly relevant is the breeding of new highly productive and environmentally plastic varieties and lines for growing in temperate latitudes, since their genetic diversity is limited.

Biotechnological and genetic engineering methods can significantly accelerate the selection process. Plant regeneration in vitro can occur both through direct organogenesis and through callus cultures with the subsequent development of de novo embryoids and shoots. Regeneration through callus cultures is often accompanied by somaclonal variability, which is undesirable when cloning unique genotypes and carrying out genetic engineering research. Plant regeneration through direct organogenesis, eliminating the stage of callus formation, can minimize the risk of somaclonal variability. Currently, considerable experience has been accumulated in the induction of somatic embryogenesis in maize when the explants are represented by immature and mature embryos (Huang, Wei, 2004; Rakshit et al., 2010; Joshi et al., 2014), unfertilized ovaries (Alatortseva, Tyrnov, 2003), fertilized ovules (Tang et al., 2006), anthers (Obert et al., 2004), seedling segments (Santos et al., 1984), leaves (Ahmadabadi et al., 2007), etc. However, induction of direct organogenesis was performed only for single genotypes (Mushke et al., 2016; Ahmad et al., 2017; Ovchinnikova et al., Humood et al., 2018; Olawuyi et al., 2019). It is known that the ability of regeneration in vitro largely depends on the plant genotype. It is believed that in maize only a small number of genotypes have regenerative capacities (Armstrong, Green, 1985). In this connection, the search for a new maize genotypes "responsive" to the in vitro culture and the induction of direct organogenesis in them is relevant.

The objective of the present study was to induce a direct organogenesis from mature embryos of maize.

\section{Materials and methods}

The materials of the present study are maize lines: BM (Brown marker), AT-TM (bm, wx, y) and AT-TM (lg, y). Lines AT-TM (bm, wx, y) and AT-TM (lg, y) were developed at the Saratov State University (Gutorova et al., 2016).

The mature embryos were used as primary explants. The seeds were soaked in distilled water for 24 hours and surface- sterilized with 'Domestos', $70 \%$ ethyl alcohol and $0.1 \%$ mercuric chloride for $5 \mathrm{~min}$ and rinsed four times with double distilled water. Embryos were isolated from the seeds and transferred onto nutrient medium for initiation of a sterile culture. The following media were tested: 1) starvation agar; 2) Murashige-Skuga (MS) (Murashige, Skoog, 1962) with the addition of vitamins according to the prescribed medium, $20 \mathrm{mg} / \mathrm{l}$ sucrose, $7 \mathrm{~g} / \mathrm{l}$ agar (PanReac), without the addition of hormones; 3) MS supplemented with $0.5 \mathrm{mg} / 1$ 6-benzylaminopurine (BAP). MS medium supplemented with different concentrations of BAP $(0.5$ and $2.0 \mathrm{mg} / \mathrm{l})$ were used for micropropagation. The medium was autoclaved for $20 \mathrm{~min}$ at $120^{\circ} \mathrm{C}$. The cultures were maintained at $24^{\circ} \mathrm{C}$ under a $16-\mathrm{h}$ photoperiod in the Sanyo MLR-352 climatic chamber.

Statistical processing of the results was carried out using Microsoft Office Excel 2010 and AGROS programs.

\section{Results and discussion}

Isolated embryos germinated with a frequency of about $90 \%$ in all approved variants of medium. However, vitrification of seedling tissues took place on starvation agar. Various morphoses (coleoptile underdevelopment, leaf curling and others) were observed on the medium supplemented with $0.5 \mathrm{mg} / \mathrm{l} \mathrm{BAP}$. Normal viable seedlings were obtained only on MS medium without hormones.

Seedlings after 7 days of cultivation were transferred to MS medium with 0.5 or $2.0 \mathrm{mg} / 1 \mathrm{BAP}$. The frequency of explant survival was 55.4, 40.6 and $92.0 \%$ in lines BM, ATTM (bm, $\mathrm{wx}, \mathrm{y})$ and AT-TM (lg, y), respectively. An effect of the genotype on the survival of the explants was revealed. 
$a$

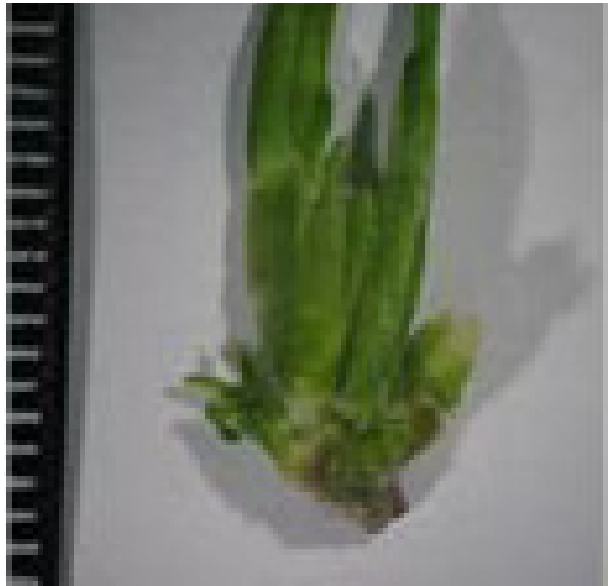

$c$

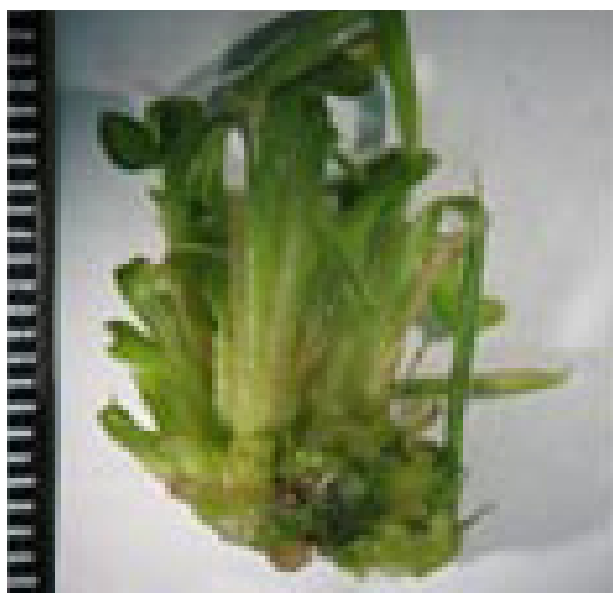

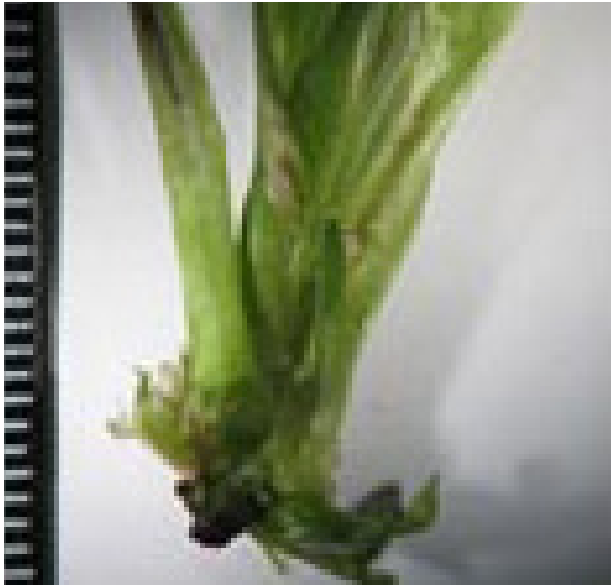

$d$

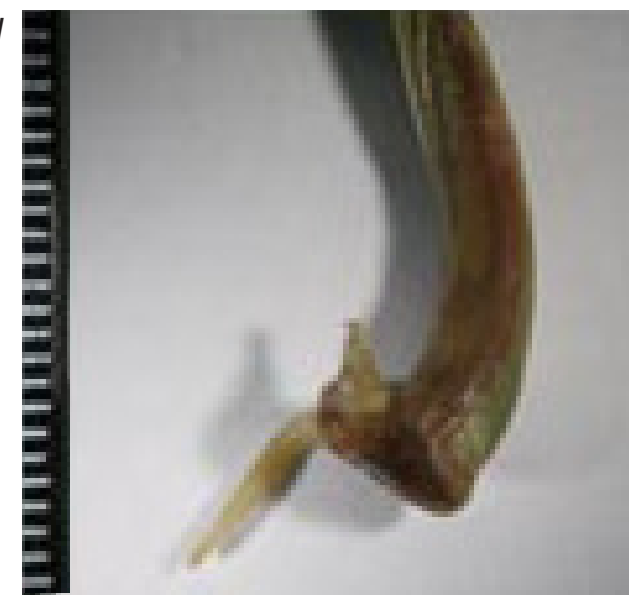

Figure 1. Regenerants of maize line AT-TM (bm, wx, y). a-c: on MS medium with $2.0 \mathrm{mg} / \mathrm{l} \mathrm{BAP}$ after $3(a), 4(b)$ and 5 (c) weeks of cultivation; $d$ : a shoot with spontaneously developed roots on MS medium with $0.2 \mathrm{mg} / \mathrm{l} \mathrm{BAP}$ after 10 days of cultivation.

Callus did not form both on medium supplemented with $0.5 \mathrm{mg} / \mathrm{l}$ and $2.0 \mathrm{mg} / \mathrm{l}$ BAP. Seedling after 3-4 weeks of cultivation on MS medium with $0.5 \mathrm{mg} / 1 \mathrm{BAP}$ consisted of several short internodes and 4-5 leaves. From 1 to 3 axillary buds were found in the node after the leaves were removed from the seedling. Axillary buds germinated in shoots after 5-7 weeks of cultivation. They had a length of 2-3 mm and were usually covered with a sheet vagina. In this regard, the explant visually looked like one primary shoot.

The process of axillary shoot formation was accelerated on MS medium with $2.0 \mathrm{mg} / \mathrm{l} \mathrm{BAP}$. The buds were formed in the first and second weeks of cultivation. Axillary shoots developed after 3-4 weeks of cultivation (Figure 1, $a, b$ ). Their number increased to 3-5. Regenerants looked like bundles of shortened shoots after 5 weeks of cultivation (Figure 1,c). The axillary shoot reached $10-15 \mathrm{~mm}$ in length.

The explants were transferred to MS medium without hormones or MS with $0.2 \mathrm{mg} / \mathrm{l} \mathrm{BAP}$ for elongation of axillary shoots. Microshoots did not lengthen and turned yellow on medium without hormones. The elongation of the shoots was observed only on MS medium with $0.2 \mathrm{mg} / \mathrm{l} \mathrm{BAP}$. This made it possible to separate shoots and transfer them on MS medium supplemented with auxins for rooting. It should be noted that some shoots spontaneously rooted on MS medium with $0.2 \mathrm{mg} / 1$ BAP (Figure 1, $d$ ).

\section{Conclusions}

Thus, we successfully carried out the induction of direct organogenesis for three maize genotypes. Previously successful induction of direct shoot organogenesis in some maize lines was carried out using BAP in combination with other hormones (IAA, $\mathrm{GA}_{3}$ ) (Ahmad et al., 2017). BAP is one of the most important cytokinins which play an important role in the multiplication and micropropagation of the plants. Only BAP was sufficient for shoot multiplication in the lines studied by us. The absence of the effect of the genotype on the number of developing axillary shoots and the influence of BAP concentration in the medium on this indicator were established.

The results obtained open up prospects for the use of the developed technology in gene engineering studies with the lines studied.

\section{References}

Ahmad M.Z., Hussain I., Ahmed S., Roomi S. Direct in vitro multiple shoot regeneration in maize (Zea mays) inbred lines. J. Innov BioRes. 2017;1(1):24-29. 
Ahmadabadi M., Ruf S., Bock R. A leaf-based regeneration and transformation system for maize (Zea mays L). Transgenic Res. 2007;16: 437-448. DOI 10.1007/s11248-006-9046-y.

Alatortseva T.A., Tyrnov V.S. Hormone-independent manifestation of in vitro embryogenesis in parthenogenetic maize lines. Bulletin Botanical Garden Saratov State University. 2003;2:207-211. (in Russian)

Armstrong C., Green C.E. Establishment and maintenance of frible, embryogenic maize callus and involvement of L-proline. Planta. 1985;164(2):207-214.

Gutorova O.V., Apanasova N.V., Yudakova O.I. Creation of genetically marked maize lines with inherited and induced types of parthenogenesis. Izv. Samara Scientific Center Russian Academy Sci. 2016;1(2-2):341-344. (in Russian)

Huang X.Q., Wei Z.M. High-frequency plant regeneration through callus initiation from mature embryos of maize (Zea mays L.). Plant Cell Rep. 2004;22:793-800. DOI 10.1007/s00299-003-0748-9.

Humood B.M.H., Apanasova N.V., Yudakova O.I. Introduction to culture in vitro of corn parthenogenetic lines. Izv. Saratov Univ. (N.S.), Ser. Chemistry. Biol. Ecol. 2018;18(3):320-324. DOI 10.18500/ 1816-9775-2018-18-3-320-324. (in Russian)

Joshi J.B., Yathish K.R., Amalraj J.J., Kumar K.K., Kokiladevi E., Arul L., Gnanam R., Balasubramanian P., Sudhakar D. A highthroughput regeneration protocol for recalcitrant tropical Indian maize (Zea mays L) inbreds. Maydica Electronic Publication. 2014; 59:211-216.

Murashige T., Skoog F. A revised medium for rapid growth and bioassays with tobacco tissue cultures. Physiol. Plant. 1962;1(15):473497. DOI 10.1111/J.1399-3054/1962.TB08052.X.

Mushke R., Yarra R., Bulle M. Efficient in vitro direct shoot organogenesis from seedling derived split node explants of maize (Zea mays L.). J. Genet. Engineering Biotechnol. 2016;14:49-53. DOI 10.1016j.jgeb.2016.03.001.

Obert B., Barnabas B. Colchicine induced embryogenesis in maize. Plant Cell Tiss. Org. Cult. 2004;77:283-285. DOI Doi.org/10.1023/ B:TICU.0000018399.60106.33.

Olawuyi O.J., Dalamu O., Olowe O.M. In vitro regeneration and proliferation of maize (Zea mays L.) genotypes through direct organogenesis. J. Natural Sci. Research. 2019;9(6):65-73.

Ovchinnikova V.N., Sotchenko V.S., Sotchenko Y.V. et al. Susceptibility of maize mesocotyl culture to agrobacterium transformation and its in vitro regeneration. Appl Biochem Microbiol. 2018;54(8): 808-815. DOI 10.1134/S0003683818080057.

Rakshit S., Rashid Z., Sekhar J. C., Fatma T., Dass S. Callus induction and whole plant regeneration in elite Indian maize (Zea mays L) inbreds. Plant Cell Tiss. Org. Cult. 2010;100(1):31-37. DOI 10.5897/ AJB10.500.

Santos M.A., Torne J.M., Blanco J.L. Methods of obtaining maize totipotent tissue. I. Seedling segments culture. Plant Sci Lett. 1984; 33:309-315.

Tang F., Tao Y., Zhao T., Wang G. In vitro production of haploid and doubled haploid plants from pollinated ovaries of maize (Zea mays). Plant Cell Tiss. Org. Cult. 2006;84:233-237. DOI 10.1007/s11240010-9874-6.

Acknowledgements. The work is supported by the Ministry of Education and Science of Russia within the framework of the basic part of the state task in the sphere of scientific activity on the assignment no. 6.8798.2017/BCh.

Conflict of interest. The authors declare no conflict of interest. 


\title{
Preparation of DNA libraries for sequencing of $S A D$ and FAD genes in flax
}

\author{
E.V. Romanova ${ }^{2}$, A.A. Dmitriev ${ }^{1}$, N.V. Melnikova ${ }^{1}$ \\ 'Engelhardt Institute of Molecular Biology, Russian Academy of Sciences, Moscow, Russia \\ 2 Peoples' Friendship University of Russia (RUDN University), Moscow, Russia \\ ${ }^{3}$ Federal Research Center for Bast Fiber Crops, Torzhok, Russia \\ ${ }^{4}$ Moscow Institute of Physics and Technology, Dolgoprudny, Russia \\ ${ }^{5}$ Agritec, Plant Research LTD, Sumperk, Czech Republik
}

P. Kezimana ${ }^{1,2 *}$, T.A. Rozhmina ${ }^{1,3}$, G.S. Krasnov ${ }^{1}$, R.O. Novakovskiy ${ }^{1}$, L.V. Povkhovaa ${ }^{1,4}$, E.N. Pushkova ${ }^{1}$, M. Pavelek ${ }^{5}$,

DOI 10.18699/ICG-PlantGen2019-49

(c) Autors, 2019

* e-mail: k1par@mail.ru

\begin{abstract}
Sequencing technologies such as targeted amplicon sequencing are highly effective approaches for studying genetic variation in specific genomic regions as they allow efficient variant identification and characterization. They are useful in studying specific biosynthetic pathways in plants that will allow the breeding of new cultivars with targeted composition. Given that flax seed is a major source of omega-3 fatty acids, we designed a study of the polymorphisms in genes involved in fatty acid biosynthesis. In this study, we report on the library preparation for the targeted amplicon sequencing of these genes.
\end{abstract}

Key words: targeted amplicon sequencing; SAD; FAD; DNA library preparation; fatty acids; flax.

\section{Introduction}

Sequencing technologies have become an ideal approach to study genetic variation in key genes in several metabolic pathways in plants. DNA polymorphisms are important markers in genetic analyses and can be detected by using genome resequencing. However, using polymorphisms in modern genetic applications requires low-error high-throughput analytical strategies that can be limited by the presence of repetitive sequences and structural variants that lead to false positive results in the identification of polymorphic alleles (Qi et al., 2014). Moreover, high-throughput sequencing technologies have become a powerful and informative tool for single nucleotide polymorphism (SNP) discovery that leads to the identification of genetic variations in particular genes. However, although the sequencing of individual cultivar may be cost-effective, the sequencing of many cultivars for the assessment of genetic variations is both expensive and difficult to achieve. To circumvent these issues, the targeted deep sequencing of amplicons can be used as a powerful approach for the rapid phylogenetic classification and characterization of several hundreds to thousands of plant cultivars. Here, we describe an analysis strategy that allows assessment of the polymorphism in key genes of the metabolic pathway that can be used in the development of new cultivars. For this study, we analyzed the biosynthetic pathway of fatty acids (FAs) in flax, as flax seed is a very rich source of omega-3 FAs, to which several health benefits have been attributed. The key enzymes involved in FA biosynthesis are fatty acid desaturases and elongases (Warude et al., 2006). The desaturation of FAs is an important step as it determines the saturated to unsaturated fatty acid ratio and, ultimately, the end-use of the oil as a food source or for industrial applications (Lee et al., 2016). Genes involved in the desaturation of FAs in flax have been identified (Green, 1986; Fofana et al., 2004, 2006; Vrinten et al., 2005; Banik et al., 2011). Stearoyl-ACP desaturases (SAD) introduce the first double bond at the $\Delta 9$ position (Ohlrogge and Browse, 1995; Post-Beittenmiller et al., 1992) and the fatty acid desaturases (FAD) introduce an additional double bond in the FAs. Two paralogous of SAD loci, SADI and $S A D 2$, have been identified in flax ( Singh et al., 1994; Fofana et al., 2004). Two closely related FAD2 genes, FAD2a and $F A D 2 b$, encoding the proteins responsible for desaturation of oleic acid into linoleic acid by addition of a double bond at the $\Delta 12$ position have been identified in flax ( Krasowska et al., 2007; Khadake et al., 2009). Other FAD genes (FAD3 genes) that encode proteins responsible for the desaturation of linoleic acid into linolenic acid by adding a double bond at the $\Delta 15$ position have also been identified. More specifically, three $F A D 3$ genes were identified in the flax genome: FAD 3a, FAD3b (Vrinten et al., 2005), and FAD3c (Banik et al., 2011). Given the advantages of amplicon sequencing, in this study, we describe the workflow for preparation of DNA libraries for targeted amplicon sequencing of $S A D, F A D 2$, and FAD3.

\section{Materials and methods}

A total of 288 flax cultivars with different FA compositions, obtained from the Institute for Flax (Torzhok, Russia), were grown in a Petri dish for 5-7 days. DNA was extracted from the pools of seedlings (about 50 plants from each cultivar) with a modified CTAB method, as cetyltrimethylammonium bromide (CTAB) is a surfactant useful for isolation of DNA from tissues containing high amounts of polysaccharides (Clarke, 2009). The quality and quantity of the extracted DNA were assessed using gel electrophoresis, fluorometric analysis using Qubit 2.0 (Life Technologies, USA), and PCR analysis. The extracted DNA was purified using CleanMag DNA (Evrogen, Russia). For the preparation of $S A D, F A D 2$, 
and FAD3 libraries, we modified the protocol for targeted amplicon sequencing on the Illumina platform (https://support. illumina.com/content/dam/illumina-support/documents/documentation/chemistry_documentation/16s/16s-metagenomiclibrary-prep-guide-15044223-b.pdf).

\section{Results and discussion}

For sample preparation, we used two-stage PCR, which allows adding the nucleotide sequences necessary for subsequent sequencing and sample barcoding to the target amplicons. This approach does not require the use of special kits but requires only specific primers and high-precision polymerase. Such sample preparation can significantly reduce the cost per sample. As recommended in the Illumina protocol, we defined forward and reverse primers that are complementary upstream and downstream of the region of interest, designed with overhang adapters, and used them to amplify templates from genomic DNA. For the regions of interest in this study (SAD, FAD2, FAD3 genes), we analyzed the sequences from GenBank, found conservative domains, and designed primers for overlapping amplicons (400-520 nt in length) covering the gene region and additional $500-1000 \mathrm{bp}$ in the promoter region and 100-200 bp at the end of the gene using NCBI Primer-BLAST and the MEGA software. As a result, we designed 12 primer pairs for $S A D$ genes, 10 for FAD2 genes, and 16 for FAD 3 genes. The primers were purchased from the Evrogen company.

The first-stage PCRs were carried out in a final volume of $10 \mu$ containing $5 \mathrm{ng}$ of total genomic DNA, $0.5 \mu \mathrm{M}$ of each primer (forward and reverse), 1x Tersus PCR buffer (Evrogen), $0.2 \mathrm{mM}$ dNTPs (Evrogen), and $1 \mathrm{x}$ Tersus polymerase (Evrogen). To increase the sensitivity, specificity, and yield, touchdown PCR was used, so the PCRs were performed on a GeneAmp PCR System 9700 (Applied Biosystems, USA) using the following conditions: an initial denaturation for 3 min at $95^{\circ} \mathrm{C}$ followed by 10 cycles at $95^{\circ} \mathrm{C}$ for $15 \mathrm{~s}, 65^{\circ} \mathrm{C}$ minus $1{ }^{\circ} \mathrm{C}$ after each step for $30 \mathrm{~s}, 72^{\circ} \mathrm{C}$ for $30 \mathrm{~s}$ and a subsequent run of 30 cycles at $95^{\circ} \mathrm{C}$ for $15 \mathrm{~s}, 55^{\circ} \mathrm{C}$ for $30 \mathrm{~s}$, $72{ }^{\circ} \mathrm{C}$ for $30 \mathrm{~s}$, and a final extension for $3 \mathrm{~min}$ at $72{ }^{\circ} \mathrm{C}$. The PCR products were purified using paramagnetic beads from a CleanMag DNA kit (Evrogen), which allowed us to remove primer dimers and other contaminations.

In the second-stage PCR, we used a unique combination of forward and reverse Nextera XT v2 index primers for each sample that allowed double indexing, thus reducing the cost of sample preparation of the various amplicons, as the index primers allow amplification of any amplicons containing the universal adapters. Thus, the set of index primers is the same for different applications. For each gene studied, the amplicons were combined for each flax cultivar by taking $4 \mu \mathrm{l}$ per sample before the second-stage PCR. The PCRs were carried out in a final volume of $30 \mu \mathrm{l}$ containing $3 \mu \mathrm{l}$ of the purified first-stage PCR product, $0.3 \mu \mathrm{M}$ of each primer, $1 \mathrm{x}$ Tersus PCR buffer (Evrogen), $0.2 \mathrm{mM}$ dNTPs (Evrogen), and 2x Tersus polymerase (Evrogen). The following conditions were used: an initial denaturation for $3 \mathrm{~min}$ at $95{ }^{\circ} \mathrm{C}$ followed by 10 cycles at $95^{\circ} \mathrm{C}$ for $30 \mathrm{~s}, 55^{\circ} \mathrm{C}$ for $30 \mathrm{~s}, 72^{\circ} \mathrm{C}$ for $1 \mathrm{~min}$, and a final extension for $3 \mathrm{~min}$ at $72^{\circ} \mathrm{C}$.
The second-stage PCR products were purified two times with CleanMag DNA (Evrogen) to remove short DNA fragments and any contaminations before sequencing. The quantity and quality were assessed by Qubit 2.0 (Life Technologies) and an Agilent 2100 bioanalyzer (Agilent, USA). The mean length of DNA libraries was about 550-600 bp, corresponding to the expected length. The DNA libraries were normalized to $4 \mathrm{nM}$ and pooled before sequencing on MiSeq Illumina (USA).

Briefly, the method used to prepare the DNA libraries for targeted amplicon sequencing makes the construction of DNA libraries possible with the introduction of adapter and index sequences to the locus-specific sequence being studied, thus allowing the sequencing of many samples simultaneously.

\section{Conclusions}

A simple and flexible method of library preparation is reported in this study that can accelerate genetic variation studies in target key genes involved in metabolic pathways. In this study, the genes examined are involved in FA biosynthesis in flaxseed, which is a major source of beneficial omega-3 FAs. The approaches reported in this study not only allow one to reduce the cost by sample with the two-step PCR with Nextera Illumina indexes but also allow flexibility for a wide range of experimental designs.

\section{References}

Banik M., Duguid S., Cloutier S. Transcript profiling and gene characterization of three fatty acid desaturase genes in high, moderate, and low linolenic acid genotypes of flax (Linum usitatissimum L.) and their role in linolenic acid accumulation. Genome. 2011;54:471483. DOI 10.1139/g11-013.

Clarke J.D. Cetyltrimethyl ammonium bromide (CTAB) DNA miniprep for plant DNA isolation. Cold Spring Harb. Protoc. 2009, pdb. prot5177. DOI 10.1101/pdb.prot5177.

Fofana B., Cloutier S., Duguid S., Ching J., Rampitsch C. Gene expression of stearoyl-ACP desaturase and $\Delta 12$ fatty acid desaturase 2 is modulated during seed development of flax (Linum usitatissimum). Lipids. 2006;41:705-712. DOI 10.1007/s11745-006-5021-x.

Fofana B., Duguid S., Cloutier S. Cloning of fatty acid biosynthetic genes $\beta$-ketoacyl CoA synthase, fatty acid elongase, stearoyl-ACP desaturase, and fatty acid desaturase and analysis of expression in the early developmental stages of flax (Linum usitatissimum L.) seeds. Plant Sci. 2004. DOI 10.1016/j.plantsci.2004.01.025.

Green A.G. Genetic control of polyunsaturated fatty acid biosynthesis in flax (Linum usitatissimum) seed oil. Theor Appl Genet. 1986;72:654-661. Available at: https://ink.springer.com/content/ pdf/10.1007\%2FBF00289004.pdf [Accessed June 5, 2018].

Khadake R.M., Ranjekar P.K., Harsulkar A.M. Cloning of a novel omega-6 desaturase from flax (Linum usitatissimum L.) and its functional analysis in Saccharomyces cerevisiae. Mol. Biotechnol. 2009; 42:168-174. DOI 10.1007/s12033-009-9150-3.

Krasowska A., Dziadkowiec D., Polinceusz A., Plonka A., Łukaszewicz M. Cloning of flax oleic fatty acid desaturase and its expression in yeast. J. Am. Oil Chem. Soc. 2007;84:809-816. DOI 10.1007/ s11746-007-1106-9.

Lee J.M., Lee H., Kang S.B., Park W.J. Fatty acid desaturases, polyunsaturated fatty acid regulation, and biotechnological advances. Nutrients. 2016. DOI 10.3390/nu8010023.

Ohlrogge J., Browse J. Lipid biosynthesis. Plant Cell. 1995;7:957-970. DOI 10.1105/tpc.7.7.957. 
Post-Beittenmiller D., Roughan G., Ohlrogge J.B. Regulation of plant Fatty Acid biosynthesis : analysis of acyl-coenzyme a and acyl-acyl carrier protein substrate pools in spinach and pea chloroplasts. Plant Physiol. 1992;100:923-930. Available at: http://www.ncbi.nlm.nih. gov/pubmed/16653077 [Accessed April 26, 2019].

Qi J., Chen Y., Copenhaver G.P., Ma H. Detection of genomic variations and DNA polymorphisms and impact on analysis of meiotic recombination and genetic mapping. Proc. Natl. Acad. Sci. U.S.A. 2014;111:10007-10012. DOI 10.1073/pnas.1321897111.

Singh S., McKinney S., Green A. Sequence of a cDNA from Linum usitatissimum encoding the stearoyl-acyl carrier protein desaturase. Plant Physiol. 1994;104:1075. DOI 10.1104/PP.104.3.1075.
Vrinten P., Hu Z., Munchinsky M.-A., Rowland G., Qiu X. Two FAD3 desaturase genes control the level of linolenic acid in flax seed. Plant Physiol. 2005;139:79-87. DOI 10.1104/pp.105.064451.

Warude D., Joshi K., Harsulkar A. Polyunsaturated fatty acids: Biotechnology. Crit. Rev. Biotechnol. 2006;26:83-93. DOI 10.1080/ 07388550600697479 .

Acknowledgements. This work was performed within the framework of the Program of fundamental research for state academies for 20132020 years (№ 01201363824 ) and was funded by RFBR according to the research project 17-29-08036.

Conflict of interest. The authors declare no conflict of interest. 


\title{
Rare species Iris scariosa and I. pumila in the Southern Urals
}

\author{
E.V. Mikhaylova ${ }^{1 *}$, A.N. Mustafina ${ }^{2}$, Y.M. Golovanov² ${ }^{2}$ A.V. Kryukova ${ }^{2}$ \\ 1 Institute of Biochemistry and Genetics UFRC RAS, Ufa, Russia \\ ${ }^{2}$ South Ural Botanical Garden UFRC RAS, Ufa, Russia
}

DOI 10.18699/ICG-PlantGen2019-50

(c) Autors, 2019

* e-mail: mikhele@list.ru

\begin{abstract}
Iris scariosa and I. pumila are two rare species of Iris found in the steppes of the Southern Urals. Both of them are included in the Red Data Book of the Russian Federation. The Southern Urals is the area where these two species coexist. Therefore, it is important to study these unique populations, their morphological and genetic diversity and possibilities of hybridization. We studied DNA samples using different RAPD and ISSR primers and observed not only phenotypical, but also genetic interspecific and interpopulation variability between plants from 29 populations of irises discovered in the Southern Urals. Moreover, several samples distinguished as I. scariosa on the basis of external features, genetically showed higher similarity to I. pumila and might be hybrids.

Key words: Iris scariosa; Iris pumila; RAPD; ISSR.
\end{abstract}

\section{Introduction}

Iris scariosa and I. pumila are two rare species of Iris found in the steppes of the Southern Urals. Both of them are included in the Red Data Book of the Russian Federation. I. pumila is an ancestor of many modern cultivars, and I. scariosa is known for its drought and salt tolerance and can also be used in breeding. I. pumila is reported to have 30,31 , or 32 chromosomes, and I. scariosa has a chromosome count of $2 n=24$ (Randolph, Mitra, 1961) and rarely $2 n=40$. The Republic of Bashkortostan and Orenburg Oblast are situated on the eastern border of the I. pumila habitat and the western border of the I. scariosa habitat, so the Southern Urals is the area where these two species coexist. Both species demonstrate phenotypical variability on this territory (Kryukova et al., 2018). Therefore, it is important to study these unique populations, their morphological and genetic diversity and possibilities of hybridization. RAPD analysis was successfully used on Siberian and Far Eastern Iris species and allowed inter- and intraspecific polymorphism to be detected (Makarevitch et al., 2003). However, molecular analysis was never performed on Iris species in the Southern Urals. Here we present the first attempt to study the genetic diversity of I. pumila and I. scari$o s a$ in the area of their coexistence.

\section{Materials and methods}

The survey was carried out in the Southern Urals on the territory of Orenburg Oblast and the Republic of Bashkortostan. Leaves were collected from plants of Iris and dried in silica gel. DNA was extracted from these leaves using the salt method. RAPD primers OPD-08 (GTGTGCCCCA), OPD-11 (AGCGCCATTG), OPD-13 (GGGGTGACGA) and OPB-12 (CCTTGACGCA) were used according to Makarevitch et al. (2003). In addition, there were chosen universal RAPD primers AFK1 (ACGGTGGACG), OPC-06 (GAACGGACTC) and OPAI-05 (GTCGTAGCGG) and two ISSR primers 814 (СТСТСТСТСТCTCTCTTG) and IS3 (GAGAGAGAGAGAGAGAC).

PCR was performed in a $30-\mu l$ mixture including $5 \mathrm{U}$ TaqDNA polymerase, $3 \mu \mathrm{l}$ of 10x Taq buffer, $250 \mu \mathrm{M}$ dNTP, $5 \mathrm{mM} \mathrm{MgCl}_{2}, 20 \mathrm{pmol}$ of primer and iris DNA. RAPD analysis was carried out using the following protocol: initial denaturation at $94{ }^{\circ} \mathrm{C}$ for 3 min followed by 35 cycles of denaturation each for $50 \mathrm{sec}$ at $94{ }^{\circ} \mathrm{C}$, annealing for $1 \mathrm{~min} 10 \mathrm{sec}$ at $30{ }^{\circ} \mathrm{C}$, and elongation for $1 \mathrm{~min} 40 \mathrm{sec}$ at $72{ }^{\circ} \mathrm{C}$. The final elongation step was for $7 \mathrm{~min}$ at $72{ }^{\circ} \mathrm{C}$. ISSR analysis was carried out using the following protocol: initial denaturation for $5 \mathrm{~min}$ at $94^{\circ} \mathrm{C}$ followed by 35 cycles of denaturation each for $50 \mathrm{sec}$ at $94^{\circ} \mathrm{C}$, annealing for $50 \mathrm{sec}$ at $50^{\circ} \mathrm{C}$, and elongation for $1 \mathrm{~min} 50 \mathrm{sec}$ at $72^{\circ} \mathrm{C}$. The final elongation step was for $7 \mathrm{~min}$ at $72{ }^{\circ} \mathrm{C}$. Results were analyzed using ImageLab software.

\section{Results and discussion}

29 populations of Iris were discovered in Orenburg Oblast and the Republic of Bashkortostan (Figure 1). Plants from 15 populations were distinguished as I. pumila, and plants from 14 populations were distinguished as I. scariosa on the basis of morphological characteristics. Leaves were collected from 19 populations and used for DNA analysis.

Noteworthy, both species were detected at location 24. Closely located populations 13 and 20 as well as 11 and 21 could also be hybridization zones. Primers OPD08, OPD11, OPD13 and OPB12 gave stable, well-reproducible, speciesspecific patterns for the Siberian and Far Eastern Iris species with no variation between individuals (Makarevitch et al., 2003). However, these primers were not just as representative for I. pumila and I. scariosa. OPD-08, OPD-11 and OPD-13 gave a small number of bands, and OPB-12 gave good bands with some variation within populations (Figure 2). However, there were clear patterns for each species, and it can be seen from the electropherogram that both of them are present at location 25 (Figure $2(6,7)$ ) and the sample from location 24 (Figure 2 (5)) cannot be clearly associated with either of these patterns.

Bands specific for either I. pumila or I. scariosa were also detected with other ISSR and RAPD primers we used. The best results were obtained with ISSR primer 814 (Figure 3), which averagely produced 13 amplicons from I. scariosa DNA and 9 from I. pumila DNA. Six of them were present in both species, the others were polymorphic. In the populations that 


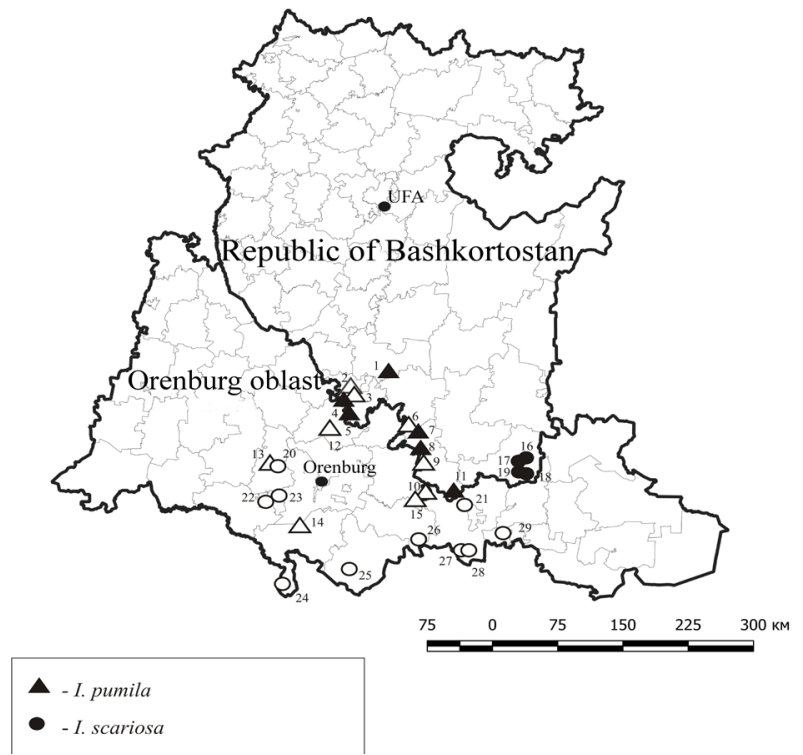

Figure 1. Location of the Iris populations studied (1-29) on the map of Orenburg Oblast and the Republic of Bashkortostan. Populations marked in white were chosen for DNA analysis.

were considered to be pure, variation between individuals was minimal.

Again, both patterns were present at location 25. Although plants from this population were distinguished as I. scariosa on the basis of morphological characteristics, some of them genetically were closer to I. pumila. They could either belong to this species or be hybrids. Bands specific for I. scariosa were detected in several samples from locations 13 and 14. The possibility of hybridization in these populations should also be considered. However, RAPD and ISSR are not accurate methods, though they can be used for primary screening of large numbers of samples. This approach has been successfully used to search for hybrids between Brassicaceae species several times (Mikhaylova, 2018). It may as well be applied to the species of Iris. However, our hypothesis must be confirmed by sequencing and chromosome analysis. After that our samples can also be compared with Siberian, Far Eastern and many other well studied Iris populations.

\section{Conclusions}

Both I. scariosa and I. pumila are reported to have unstable chromosome number, so the genetic diversity we observed in Southern Urals is understandable. Hybridization also can occur within the genus of Iris. I. pumila itself is considered to be a natural hybrid between I. pseudopumila and I. attica. Our investigation of unique populations of I. pumila and I. scariosa in the area of their coexistence in Southern Urals gave promising results. Hybrids between these species were never searched for and never found before. Such hybrids can be used in breeding of drought and salt tolerant cultivars of irises. Continuation of this research is important for the preservation of rare Iris species in the Southern Urals.

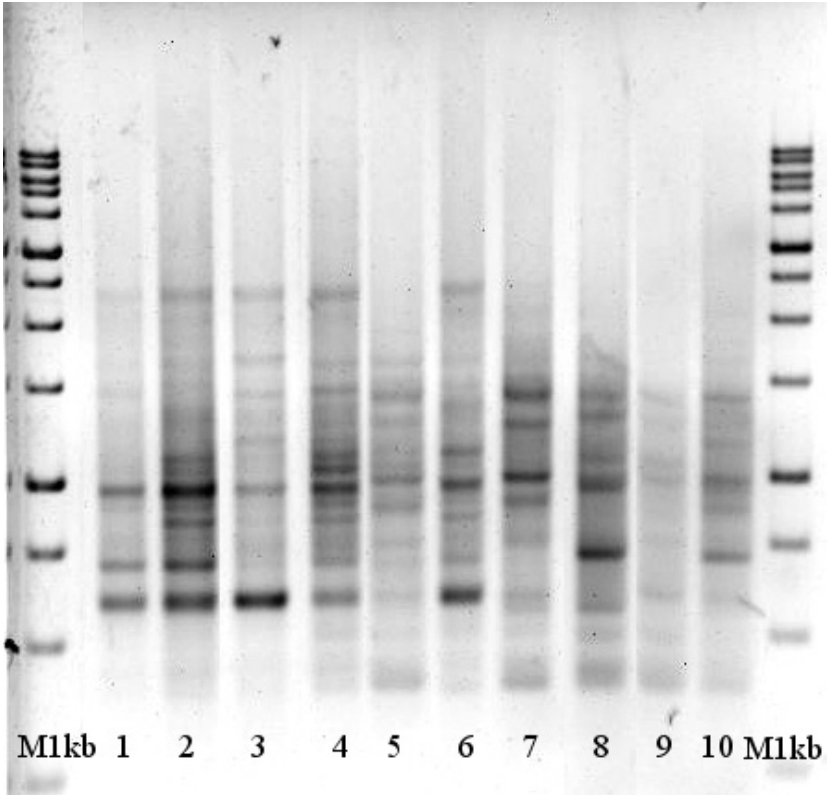

Figure 2. Results of DNA analysis using primer OPB-12 (1,2: location 3 ; 3: location 13; 4: location 14; 5 : location 24; 6,7: location 25; 8: location 29; 9, 10: location 28).

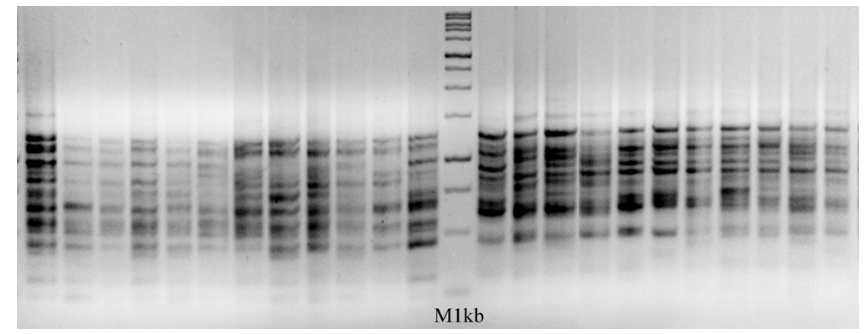

Figure 3. Results of DNA analysis using primer 814 (12 samples from location 29 (I. scariosa) on the left side of the 1-kb DNA marker, and 11 samples from location 6 (I. pumila) on the right side).

\section{References}

Randolph L.F., Mitra J. Karyotypes of Iris species indigenous to the USSR. American J. Botany. 1961;48(10):862-870.

Kryukova A.V., Abramova L.M., Mustafina A.N. To the biology and ecology of rare species of Iris genus in the steppe of South Urals. Samarskaya Luka: Problems Regional Global Ecol. 2018;27(4-1): 271-275.

Makarevitch I., Golovnina K., Scherbik S., Blinov A. Phylogenetic relationships of the Siberian Iris species inferred from noncoding chloroplast DNA sequences. International J. Plant Sci. 2003;164(2): 229-237.

Mikhaylova E.V., Kuluev B.R. Potential for gene flow from genetically modified Brassica napus on the territory of Russia. Environmental Monitoring Assessment. 2018;190:557. DOI 10.1007/s10661-0186946-2.

Acknowledgements. This work was supported by the RFBR grant mol_a 18-34-00022.

Conflict of interest. The authors declare no conflict of interest. 


\title{
Extraction of high-molecular-weight DNA from poplar plants for Nanopore sequencing
}

\author{
E.N. Pushkova*, A.D. Beniaminov, G.S. Krasnov, R.O. Novakovskiy, L.V. Povkhova, N.V. Melnikova, A.A. Dmitriev \\ Engelhardt Institute of Molecular Biology, Russian Academy of Sciences, Moscow, Russia
}

DOI 10.18699/ICG-PlantGen2019-51

(c) Autors, 2019

* e-mail: pushkova18@gmail.com

\begin{abstract}
Poplar (Populus trichocarpa) is a model object for genetic studies in trees. The extraction of pure high-molecular-weight DNA from plant cells is difficult because of a high level of storage substances that adversely affect Nanopore sequencing quality. We developed and optimized a methodology for isolation of pure genomic DNA from poplar plants using modified CTAB buffer, QIAGEN Genomic-tip 20/G, and AMPure XP beads. The developed method allowed us to isolate pure DNA samples with the $A_{260 / 280}$ ratio in the range of 1.8-1.9, the $A_{260 / 230}$ ratio in the range of 2.2-2.6, and a length of about $50 \mathrm{~kb}$. The obtained DNA can be used for sequencing on a Nanopore platform as well as for a wide range of molecular studies.
\end{abstract}

Key words: Populus; Nanopore sequencing; high-molecular-weight DNA.

\section{Introduction}

Genomic studies can be used to address problems both in applied and basic research. Plant genomes compared to the human genome and other animals' genomes are much more complex, which makes their analysis more problematic. Plants have the largest genomes compared to other living organisms from $61 \mathrm{Mb}$ (Genlisea tuberosa) (Fleischmann et al., 2014) to $152 \mathrm{~Gb}$ (Paris japonica) (Pellicer et al., 2010) - which is almost 50 times the size of the human genome. Moreover, plant genomes exhibit a wide range of ploidy (the presence of more than two genomes (genome duplication) per cell), contain regions with a high GC content and regions with transposable elements. These structural features of plant genomes represent a severe problem of a whole genome assembly using short reads produced by sequencing platforms generating reads with an average read length of 300-1000 bp. However, improvements in sequencing technology with the Nanopore platform have made it possible to obtain reads with a length of about 100 thousand nucleotides (van Dijk et al., 2014). This allows one not only to simplify and accelerate the assembly of previously unpublished genomes, but also to improve the already existing assemblies. Nanopore sequencing technology requires high-quality DNA. However, extracting pure highmolecular-weight DNA from plant cells is difficult because of a high level of storage substances, such as polysaccharides and secondary metabolites, for example, alkaloids, phenolics, terpenes, which not only interfere with DNA isolation, but also adversely affect its quality, as well as Nanopore sequencing quality. Moreover, these metabolites vary considerably, which makes it impossible to use a universal DNA isolation protocol. Our study was aimed to optimize the isolation protocol of pure high- molecular-weight genomic DNA from poplar plants for Nanopore sequencing. Poplar (Populus trichocarpa) is a model object for genetic studies in trees (Ellis et al., 2010). That was the first tree, whose genome was sequenced entirely in 2006 (Tuskan et al., 2006). At present, there is a reference genome assembly for $P$. trichocarpa; however, this assembly continues to be refined and changed. The complete genome assemblies of poplar species will help geneticists and breeders in developing tree cultivars with desired properties.

\section{Materials and methods}

\subsection{Plant material}

The material was obtained in the flowering period from the leaves of Populus $\times$ sibirica, the most common poplar in Moscow. We chose young, partially expanded leaves, which provide the highest quantity of DNA per unit of tissue volume.

\subsection{DNA extraction}

The leaf material was lysed in a modified Carlson buffer taken from the Nanopore protocol (100 mM Tris-HCl, $\mathrm{pH} 9.5 ; 2 \%$ CTAB; $1.4 \mathrm{M} \mathrm{NaCl} ; 1 \%$ PEG 8000; 20 mM EDTA) with the addition of $0.04 \mathrm{M} \beta$-mercaptoethanol (BioRad, USA), $1 \%$ PVP (BioChemica PanReac AppliChem, Germany). The homogenate was incubated in the Dwarf thermostat (DNA Technology, Russia).

For DNA purification, chloroform (Acros Organics, USA) was added to the homogenate and centrifuged in IEC Micro$\max$ (Thermo Fisher Scientific, USA); and the aqueous phase was collected. For further purification from polysaccharides, $5 \times$ CTAB buffer (5\% CTAB, $350 \mathrm{mM}$ EDTA) was added to the aqueous phase. For the precipitation of DNA, we used a precipitation buffer ( $1 \%$ CTAB, $50 \mathrm{mM}$ Tris- $\mathrm{HCl}, \mathrm{pH} 8.0$, $10 \mathrm{mM}$ EDTA). Purification of the obtained DNA was performed using QIAGEN Genomic-tip 20/G (Germany). DNA was dissolved in TE buffer (Evrogen, Russia) and further purified using AMPure XP beads (Beckman Coulter, UK). The purity and quality of the DNA were assessed using a NanoDrop 2000C spectrophotometer (Thermo Fisher Scientific, USA). The electrophoretic analysis was performed in an SE.1 electrophoretic tank (Helicon, Russia) with the Elf-4 power source (DNA Technology, Russia) using a $0.8 \%$ agarose (Helicon, Russia). The DNA concentration was measured on the Qubit 2.0 fluorometer (Invitrogen, USA) using a dsDNA high-sensitivity (HS) assay kit (Invitrogen, USA). 


\section{Results and discussion}

\subsection{Extraction of high-molecular-weight DNA from poplars}

The first step to obtain a high-quality pure DNA is to destroy the cell wall, which we performed by physical tissue destruction - grinding with a pestle in liquid nitrogen, which enables cell destruction thus inhibiting any biochemical and physical processes that could damage the DNA. We poured liquid nitrogen into the mortar and $0.2 \mathrm{~g}$ of leaf material was pounded with a pestle to a flour-like consistency. We concluded that plant material used for DNA extraction should be less than 200-300 mg in weght; otherwise, we would fail to avoid the adverse effects of polyphenols, polysaccharides, and others. Next, we chemically acted on the plant cells using one of the most widely used methods based on the CTAB buffer (Murray and Thompson, 1980). However, the standard method did not meet the requirements for the quality and purity of the DNA, so we modified and changed the composition of the Carlson buffer in order to obtain high-quality DNA. Cell lysis was performed in $5 \mathrm{ml}$ of Carlson buffer with $12.5 \mu \mathrm{l}$ $\beta$-mercaptoethanol and $1 \%$ PVP. The homogenate was incubated at $65{ }^{\circ} \mathrm{C}$ for 1 hour mixing the sample by inversion halfway through. The cationic surfactant, cetyltrimethylammonium bromide (CTAB) Included in the buffer lyses the cell wall. Mercaptoethanol destroys disulfide bridges, including those in proteins, breaking down their tertiary and quaternary structures, and also acts as a natural antioxidant inhibiting the oxidation processes that directly or indirectly damage the DNA. The chaotropic agents present in the extraction buffer, such as salts, denature macromolecules breaking hydrogen bonds, hydrophobic interactions, and van der Waals forces. High salt concentration, for example, precipitates polysaccharides, which otherwise may form a jelly complex with DNA. The presence of EDTA, a chelating agent binding metal ions $\left(\mathrm{Mg}^{2+}, \mathrm{Ca}^{2+}, \mathrm{Fe}^{3+}\right.$, etc. $)$ enables deactivation of metal-dependent enzymes located in plant extracts, including nucleases that destroy DNA. Polyvinylpyrrolidone (PVP), which is also present in the extraction buffer, binds with phenols preventing the formation of their complexes with DNA. We continued our DNA extraction with chloroform, which helps remove proteins, polysaccharides, and phenol residues. After incubation, we let the samples cool to room temperature and added 1 volume of chloroform. The sample was vortexed for two pulses of $5 \mathrm{~s}$ each and centrifuged at $5500 \mathrm{~g}$ for $10 \mathrm{~min}$ at room temperature. Then, we carefully transferred the top (aqueous) phase to a new tube without disturbing the interphase. However, even after modifying the stage of chemical cell lysis, we were unable to get rid of polysaccharides completely. To remove polysaccharide residues during the extraction step with chloroform, we collected the aqueous phase and added 0.2 volumes of $5 \times \mathrm{CTAB}$ buffer and incubated it at $65^{\circ} \mathrm{C}$ for 10 minutes. Then, we repeated the chloroform extraction. If the solution becomes distinctively cloudy, indicating the presence of polysaccharides, we recommend to repeat the chloroform extraction with the addition of 0.2 volumes of $5 \times$ CTAB buffer. Next, we added 2 volumes of precipitation buffer to the top phase and mixed it thoroughly by inverting the tube 10 times. Then, the samples were incubated for 1 hour at room temperature and centrifuged at $10000 \mathrm{~g}$ for 15 minutes at room temperature. We carefully discarded the supernatant without disturbing the pellet.

At this stage, the amount of isolated DNA was sufficient, approximately $5 \mu \mathrm{g}$; however, the DNA purity and the presence of proteins and RNA in the sample did not meet the requirements of sequencing on the Nanopore platform. We decided to carry out the post-treatment stage on the QIAGEN DNeasy Plant Mini Kit columns. Unfortunately, after testing this kit, we were faced with large losses of material and low-quality DNA. The length of high-molecular DNA after the columns was about $40 \mathrm{~kb}$, which was not that we wanted. We decided to try cleaning on QIAGEN Genomic-tip 20/G columns.

\subsection{Purification of high-molecular-weight DNA}

\section{from poplar plants with QIAGEN Genomic-tip 20/G}

The precipitate of the high-molecular-weight DNA obtained at the previous step was dissolved in $2 \mathrm{ml}$ of G lysis buffer supplemented with $4 \mu \mathrm{l}$ of RNase A $(100 \mathrm{mg} / \mathrm{ml})$, which contributed to RNA hydrolysis. RNA removal is a crucial stage in DNA isolation for sequencing with the Nanopore platform, since hairpin RNA structures significantly reduce the quality of sequencing and clog the protein pores in the flow cell. We incubated the sample at $37^{\circ} \mathrm{C}$ for 30 minutes and then added $100 \mu \mathrm{l}$ of alkaline protease $\mathrm{K}$ and incubated the sample at $50{ }^{\circ} \mathrm{C}$ for 30 minutes. Protease hydrolyzes proteins, including histones associated with the DNA, and effectively inactivates nucleases. DNA samples were then deposited to a column using the kit protocol. The method is based on ionexchange chromatography and is implemented by binding a positively charged resin in a column with negatively charged DNA. Elution from the matrix is carried out by decreasing salt concentration. Proteins and RNA at low salt concentrations are easily separated from the matrix, while DNA is more tightly bound to the support and is eluted at lower concentrations. After appropriate purification from RNA and proteins, the parameter $\mathrm{A}_{260 / 280}$ of dissolved DNA samples was about 1.8, and the concentration was about $400 \mathrm{ng} / \mu \mathrm{l}$. However, the concentration of the DNA assessed by Qubit 2.0 was about $250 \mathrm{ng} / \mu \mathrm{l}$. This discrepancy in values may indicate remaining contamination in the sample. We decided to add an additional stage of purification on magnetic beads.

\subsection{DNA purification after columns with AMPure XP beads}

The DNA sample obtained was diluted to a concentration of $60 \mathrm{ng} / \mu \mathrm{l}$ in a final volume of $50 \mu \mathrm{l}$ with TE buffer of $\mathrm{pH} 8$. Then, DNA was purified again using AMPure XP beads in a ratio of 1:0.7. We chose 1:0.7, for its provides the best selection for DNA fragments $>2 \mathrm{~kb}$. We incubated the sample for 10 minutes at room temperature, placed the tube on a magnetic stand, and discarded the supernatant. Keeping the tubes on the magnetic stand, we washed beads 2 times with $200 \mu$ of freshly prepared $70 \%$ ethanol without disturbing the pellet. Then, we air dried the sample for 30 seconds, removed the tubes from the magnetic stand and resuspended beads in $40 \mu 1$ of TE buffer. The sample was incubated for $3 \mathrm{~min}$ at $50{ }^{\circ} \mathrm{C}$ and then for $5 \mathrm{~min}$ at room temperature. At this stage, we increased the incubation time at $50{ }^{\circ} \mathrm{C}$ from 1 minute to $3 \mathrm{mi}-$ nutes. This contributed to a better DNA yield. The principle 
of this method is based on a reversible binding of DNA on the surface of magnetic particles, which are easily precipitated from the suspension using a magnetic stand. Thus, during the cleaning with beads, we remove various impurities, such as salts etc.

\subsection{Quality control of isolated genomic DNA}

The quantity and quality of the isolated DNA were evaluated by the $\mathrm{A}_{260 / 280}$ and $\mathrm{A}_{260 / 230}$ ratios used to assess the amount of protein and metabolite contamination left after the nucleic acid isolation process. The recommended $\mathrm{A}_{260 / 280}$ and $\mathrm{A}_{260 / 230}$ ratios before Nanopore sequencing are 1.80 and 2.0-2.2, respectively. Before measuring the absorbance of samples at 280, 260, and $230 \mathrm{~nm}$, it is necessary to calibrate the spectrophotometer using a solution (not containing DNA) in which the DNA is resuspended. Also, we do not recommend using samples with concentrations below $50 \mathrm{ng} / \mu \mathrm{l}$, as it may lead to incorrect values. The $\mathrm{A}_{260 / 280}$ ratio for the poplar high-molecular-weight genomic DNA samples was about 1.8, which corresponds to the recommended value. Its reduction indicates protein and phenol contamination, since these compounds have an absorption maximum at $280 \mathrm{~nm}$. The increased $\mathrm{A}_{260 / 280}$ ratio indicates the contamination of the DNA sample with RNA molecules. The $\mathrm{A}_{260 / 230}$ ratio for the DNA samples was about 2.4. Absorption at a wavelength of $230 \mathrm{~nm}$ can be caused by contamination with phenolates, thiocyanates, and other organic compounds. The concentration of the DNA samples was also assessed during the evaluation of the $\mathrm{A}_{260 / 280}$ and $\mathrm{A}_{260 / 230}$ ratios using a spectrophotometer. Next, we measured the DNA concentration using a fluorometer, which confirmed the concentration value obtained by the spectrophotometer. This suggests that the obtained high-molecular-weight DNA is of good quality and purity. This is an important step of DNA purity control because if the values from the two instruments were to diverge by more than 2-fold, it would indicate the presence of various contaminants (mentioned above). Therefore, we would recommend adding a purification step. To further assess the quality and size of the isolated DNA, an electrophoretic analysis was performed in a $0.8 \%$ agarose gel. As a control, pure high-molecular-weight DNA from phage $\lambda$ at different concentrations was used. The electropherogram showed a clear band whose length corresponded to the length of the control DNA, approximately $50 \mathrm{~kb}$, indicating that the isolated high-molecular-weight DNA was not degraded. In addition, we compared the isolated DNA with phage $\lambda$ DNA at varying concentrations regarding luminescence intensity determining the amount of the DNA in an aliquot. As a result of the work, we would like to especially emphasize the importance of the sample preparation stage for sequencing on the Nanopore platform. The key to success lies in optimizing the DNA isolation and purification protocol for each object individually, as well as a correct and accurate assessment of the purity, amount, and size of DNA. Using the DNA obtained with the protocol developed, we obtained $9 \mathrm{~Gb}$ of sequencing data per run of Nanopore MinION with R9.4.1 flow cell.

\section{Conclusion}

During this study, we developed and optimized a methodology of isolation of pure high-molecular- weight genomic DNA from poplar plants that can be sequenced using the Nanopore platform. We selected conditions for cell lysis and DNA purification using QIAGEN Genomic-tip 20/G and AMPure XP beads, which allowed us to dispose of main plant storage substances such as polysaccharides and secondary metabolites, for instance, alkaloids, phenolics, terpenes. The developed method of isolation and purification of DNA allowed us to isolate pure DNA samples with the $\mathrm{A}_{260 / 280}$ ratio in the range of 1.8-1.9, the $\mathrm{A}_{260 / 230}$ ratio in the range of 2.2-2.6, a concentration of about $300 \mathrm{ng} / \mu \mathrm{l}$, and a length of about $50 \mathrm{kbp}$. The obtained pure DNA can be used for sequencing on a Nanopore platform as well as for a wide range of molecular research.

\section{References}

Ellis B., Jansson S., Strauss S.H. et al. Why and How Populus Became a "Model Tree". New York, NY: Springer New York, 2010.

Fleischmann A., Michael T.P., Rivadavia F. et al. Evolution of genome size and chromosome number in the carnivorous plant genus Genlisea (Lentibulariaceae), with a new estimate of the minimum genome size in angiosperms. Ann Bot. 2014;114(8):1651-1663. DOI 10.1093/aob/mcu189.

Murray M.G., Thompson W.F. Rapid isolation of high molecular weight plant DNA. Nucleic Acids Res. 1980;8(19):4321-4325. DOI 10.1093/nar/8.19.4321.

Pellicer J., Fay M.F., Leitch I.J. The largest eukaryotic genome of them all? Botanical J. Linnean Society. 2010;164(1):10-15. DOI 10.1111/j.1095-8339.2010.01072.x.

Tuskan G.A., Difazio S., Jansson S. et al. The genome of black cottonwood, Populus trichocarpa (Torr. \& Gray). Sci. 2006;313(5793): 1596-1604. DOI 10.1126/science.1128691.

van Dijk E.L., Auger H., Jaszczyszyn Y., et al. Ten years of next-generation sequencing technology. Trends Genet. 2014;30(9):418-426. DOI 10.1016/j.tig.2014.07.001

Acknowledgements. The reported study was funded by RFBR according to the research project 18-34-20113 mol_a_ved.

Conflict of interest. The authors declare no conflict of interest. 


\section{Plant Systems Biology and Digital Technologies}




\title{
Novel genomic marker for the Alm locus in barley identified based on transcriptome analysis
}

\author{
N.A. Shmakov ${ }^{1 *}$, A.Yu. Glagoleva ${ }^{1}$, G.V. Vasiliev ${ }^{1}$, D.A. Afonnikov ${ }^{1}$, E.K. Khlestkina ${ }^{2}$ \\ 1 Institute of Cytology and Genetics, SB RAS, Novosibirsk, Russia \\ ${ }^{2}$ Vavilov Institute of Plant Genetic Resources, RAS, St. Petersburg, Russia
}

DOI 10.18699/ICG-PlantGen2019-52

(c) Autors, 2019

*e-mail: shmakov@bionet.nsc.ru

\begin{abstract}
Plastids are semi-autonomous organoids that give plant cells the ability to photosynthesize. They retain their own genome which works in tight coordination with the nuclear genome of the plant cells. Many aspects of such coordination are still unclear. A fitting model to study specifics of nucleus-plastid interactions are plants with partial albinism. The near-isogenic barley line i:BwAlm with partial albinism was studied using RNA-seq technology. De novo transcriptome reconstruction was performed, and transcriptomes of lines i:BwAlm and 'Bowman' were compared. A contig was identified that appears in i:BwAlm, but not in the isogenic line 'Bowman'.

Key words: plant albinism; transcriptome reconstruction; transcript annotation; transcript localization.
\end{abstract}

\section{Introduction}

Chlorophylls are green plant pigments that play a key part in photosynthesis. In plant cells, chlorophylls a and $b$ are located in plastids, on the membrane of thylakoids, where they form complex structures with a large number of so-called Chlorophyll Binding Proteins and other photosynthesis-related proteins. The plastid genome ('plastome') is highly reduced and usually contains 100-120 genes (Börner et al., 2015), while the proteome of plastids may contain around 3000 proteins (Zoschke, Bock, 2018). Thus, the majority of the proteins presented in the plastids are encoded by nuclear genes (Khan et al., 2013). This requires a precise coordination of nuclear and plastid genomes for the proper functioning of the photosynthetic machinery (Liebers et al., 2017). It is known that the plastid-to-nucleus communication is mediated by signaling molecules, for example, Mg-protoporphyrin IX (Chan et al., 2016). However, the details of plastid-to-nucleus crosstalk is poorly understood.

A promising model for studying specific aspects of such crosstalk are plants with partial albinism. They provide materials for studying signaling components and pathways between plastid and nucleus (Arisha et al., 2015). The near-isogenic line (NIL) i:BwAlm of barley (Hordeum vulgare L.) is a plant model of this kind. Plants of this line have chlorophylldeficient lemma and pericarp and nodes. i:BwAlm contains a recessive mutation in the Alm gene, which is located on chromosome 3HS (Costa et al., 2001). The Alm gene itself has not yet been identified, and its protein product, molecular function and mechanism of action are unknown.

Recently we performed an analysis of the transcriptome of the barley NILs i:BwAlm (NGB20419) with partial albinism of spike and stem nodes and its parental NIL 'Bowman' (NGB22812) with normal phenotype. Using an approach based on read alignment to the reference genome, we identified several genes encoded in the nuclear genome and related to photosynthesis with differential expression between the lines i:BwAlm and 'Bowman' (Shmakov et al., 2016). In this work, we extended our analysis to identify possible genes related to the plastid-to-nucleus communication us- ing de novo assembled transcripts from a previous RNA-seq experiment.

\section{Materials and methods}

\subsection{Plant material}

The barley NILs i:BwAlm (NGB20419) with partial albinism of spike and stem nodes and its parental cultivar 'Bowman' (NGB22812) were used in the RNA-seq analysis. The lines were provided by the Nordic Gene Bank (NGB, www.nordgen. org). These lines were previously genotyped by microsatellite markers. The only chromosome segment different between the NILs is a segment in chromosome 3HS that contains the Alm gene. To localize the contig of interest in the $H$. vulgare genome, a set of wheat-barley addition lines and the parental wheat 'Chinese Spring' and barley 'Betzes' cultivars were used.

\subsection{Bioinformatic analysis: libraries preprocessing}

Six short-read libraries were obtained by IonTorrent sequencing as described in Shmakov et al. (2016). The libraries were filtered using PrinSeq-lite v 0.20.4 (Schmieder, Edwards, 2011). Reads shorter than 50 nucleotides, longer than 270 nucleotides, and reads with mean quality below 20 were removed. Non-coding RNA contamination was identified using read alignment to non-coding RNA sequences of $H$. vulgare (Ensembl plants database, v. 42) by Bowtie2 v. 2.3.4 (Langmead, Salzberg, 2012): reads that successfully mapped to the ncRNA sequences were discarded. Clean libraries were mapped to the genome of $H$. vulgare (Ensembl plants database, v. 42) using Dart v. 1.3.2 (Lin, Hsu, 2018). These alignments were later used to perform genome-guided transcriptome assembly.

\subsection{Bioinformatic analysis: transcriptome assembly}

De novo assembly was performed for the libraries from two lines separately. Transcripts were assembled using three tools: rnaSpades v. 3.12.0 (Bushmanova et al., 2018) with default parameters, Trinity v. 2.2.0 (Grabherr et al., 2013) with default 
Table 1

Metrics of the six barley libraries before and after preprocessing and mapping

\begin{tabular}{llll}
\hline Library & Raw reads, millions & Clean reads, \% & Mapped, \% \\
\hline i:BwAlm1 & 4.6 & 84.3 & 98.7 \\
i:BwAlm2 & 3.0 & 86.6 & 98.8 \\
i:BwAlm3 & 5.8 & 92.6 & 98.9 \\
Bowman1 & 4.1 & 92.0 & 99.1 \\
Bowman2 & 4.0 & 59.6 & 97.8 \\
Bowman3 & 6.9 & 96.6 & 99.0 \\
\hline
\end{tabular}

Table 2

Metrics for line-specific and unified transcriptomes

\begin{tabular}{llll}
\hline & \multicolumn{2}{l}{ Metrics of assembled transcriptomes } & N50 \\
\cline { 2 - 4 } Assembly & No. of raw contigs & No. of nr contigs & 1026 \\
\hline i:BwAlm & 110,387 & 49,186 & 1050 \\
Bowman & 106,078 & 44,326 & 940 \\
Unified & 93,512 & 58,049 &
\end{tabular}

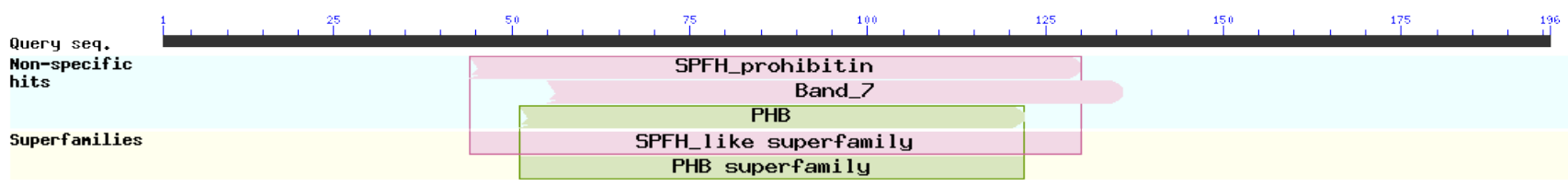

Figure 1. The domain structure of the putative protein encoded by contig DN5639c0g1t1 from line $\mathrm{i}: \mathrm{BwAlm}$. The ruler shows amino acid numbering. Domains are shown schematically on the yellow bar.

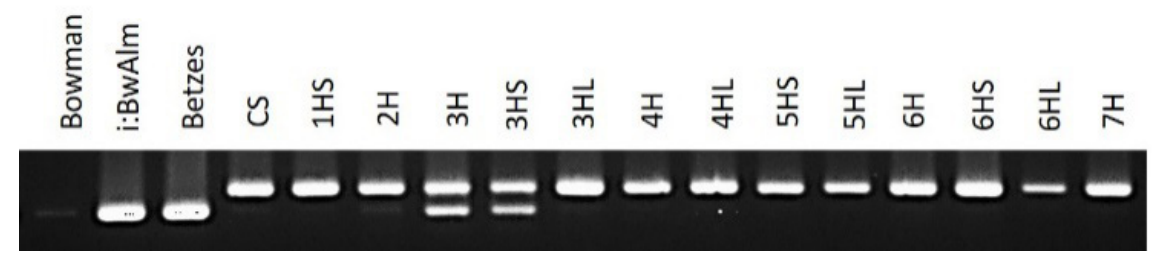

Figure 2. PCR profile of the DN contig in genomic DNA of barley NILs and wheat-barley addition lines.

parameters and trans-ABySS v. 2.0.1 (Robertson et al., 2010) with k-mer values set at 24, 48 and 64. Three assemblies obtained with trans-ABySS were then merged together using the transabyss-merge utility. Additionally, genome-guided assembly was performed using Trinity, and read alignments produced by Dart were used for assembly. The tr2aacds.pl tool of Evidential Gene pipeline v. '18may07' (Gilbert, 2013) was used to remove redundancy in the assemblies and to identify open reading frames and amino acid sequences encoded by the contigs. Contigs without ORFs or those encoding amino acid products less than 30 aa in length were excluded from further analysis.

Two barley line transcriptomes were obtained by merging transcripts from different assembling methods and removing redundancy. Finally, the unified transcriptome was built by merging line transcriptomes and removing redundant sequences. To evaluate the quality of the contigs, they were analyzed with BUSCO software (Simão et al., 2015) v. 3.0.2.

Kallisto software v. 0.45.0 (Bray et al., 2016) was used to quantify the expression values of contigs. The unified transcriptome was used as a reference. Contigs with expression values of less than 1 TPM (Transcripts Per Million reads, normalized measure of expression) were excluded from further analysis.

Two unified line-specific assemblies and a unified transcriptome assembly were analyzed using rnaQUAST v 1.5.1 software (Bushmanova et al., 2016) using H. vulgare genome v. 41 as a reference. This tool performs transcript to reference alignment by GMAP (Wu, Watanabe, 2005) and makes it possible to identify RNA sequences absent in the current version of the barley genome. Putative protein products of these contigs were then aligned to the NCBI nr protein database using the ublast tool from Usearch software (Edgar, 2010) v 8.1.1756 i86linux32. The e-value threshold for significant homology identification was set at $10^{-50}$. Contigs with the best hit to the sequences of other than plant species origins were removed as contaminants. The remaining contigs were analyzed more closely.

\subsection{Contig localization}

To localize the contig of interest on barley chromosomes, the set of wheat-barley addition lines (Islam et al., 1981) and the 
parental wheat cv. 'Chinese Spring' and barley cv. 'Betzes' were used. The primers (forward 5'GAGGACTTGGAT GAGAG3' and reverse 5'GCATTCCTGTTATCTTG3') were constructed using online service IDT PrimerQuest software (http://eu.idtdna.com/PrimerQuest/Home/).

\section{Results and discussion}

\subsection{Library preprocessing}

Filtering of the libraries removed $\sim 15 \%$ of all reads. Additionally, $\sim 8 \%$ of the remaining reads were removed as potential rRNA contamination. Of the remaining reads, $\sim 98.5 \%$ were successfully mapped to the $H$. vulgare genome. Table 1 contains metrics of library filtering and mapping.

After length and quality filtering and ncRNA contamination removal, a total of $24,913,867$ reads remained in the six libraries, of which 22,636,345 were mapped to the reference genome and were later used for genome-guided transcriptome assembly.

\subsection{Transcriptome reconstruction}

Assembly was performed for two lines in separate, then a unified assembly of the $H$. vulgare lemma transcriptome was obtained. Table 2 shows several metrics of assembled transcriptomes for both lines separately and for the unified transcriptome. BUSCO analysis demonstrated that all transcriptomes contain $43-47 \%$ of transcripts which have full-length alignment with BUSCO sequences, 25-27\% of them aligned partially and 26-30\% were not found among the BUSCO sequence set. Unified assembly has a greater percentage of full and fragmented BUSCO sequences than both line-specific assemblies.

54,875 contigs in the unified assembly have expression levels $>1$ TPM. rnaQuast analysis identified 508 contigs from the i:BwAlm assembly, 405 contigs from the 'Bowman' assembly and 788 contigs from the unified assembly which are absent in the barley reference genome. The search of homologs for the unaligned sequences from the unified assembly in the NCBI nr database yielded similar sequences for 15 contigs. One of them is a DN5639c0g1t1 contig, which originated from the $\mathrm{i}: \mathrm{Bw} A \operatorname{lm}$ transcriptome, and no significant homology to this transcript was found among the 'Bowman' transcripts. It has a length of 691 nucleotides, and an amino acid product 196 aa in length is predicted to be encoded by this contig; it has expression levels of $\sim 6$ TPM in the $\mathrm{i}: \mathrm{Bw}$ Alm libraries. The best hit for the putative protein sequence encoded by DN5639c0g1t1 in the NCBI nr database is sequence BAK08282.1 from $H$. vulgare (e-value 4e-77). This is a predicted protein with an unknown function. The domain structure of the putative protein product of DN5639c0g1t is shown in Figure 1 as identified by the CDD/SPARCLE NCBI online service (Marchler-Bauer et al., 2017). It contains the SPFH_prohibitin $(\mathrm{e}-\mathrm{value}=4.2 \mathrm{e}-13)$, Band_7 $(\mathrm{e}-\mathrm{value}=$ $9.8 \mathrm{e}-5)$ and PHB (e-value $=2 \mathrm{e}-3$ ) domains in the middle part of the amino acid sequence. The translated amino acid sequence of contig DN5639c0g1t1 also has a homology to the Solanum pennellii prohibitin-1, mitochondria-like protein (NCBI protein accession number XP_015060913.1). The e-value of this homology is $3 \cdot 10^{-20}$

\section{Contig localization in the barley genome}

The presence of length polymorphism between barley (amplicon length, $356 \mathrm{bp}$ ) and wheat (amplicon length, $400 \mathrm{bp}$ ) in the amplified region allows us to localize DN5639c0g1t1 in the barley genome on chromosome 3HS (Figure 2) using wheat-barley addition lines. Since the only genome fragment that differs between the 'Bowman' and $\mathrm{i}:$ BwAlm genomes is situated on the short arm of chromosome $3 \mathrm{H}$, it can be speculated that this gene is situated inside this genome fragment and, thus, close to the Alm gene.

Resequencing of the contig from genomic DNA of line $\mathrm{i}:$ BwAlm was performed. The sequenced fragment has a length of 311 nucleotides and contains an insert $102 \mathrm{nt}$ in length, which presumably is an intron. Aside from this insert, its sequence is identical to the sequence of contig DN5639c0g1t1. This implies that the designed pair of primers is specific to the transcript of interest.

\section{Conclusions}

A contig was identified through RNA-seq analysis that is present in the NIL $\mathrm{i}: \mathrm{Bw}$ Alm genome. At the same time, it either is absent in the genome of the isogenic line 'Bowman' or has a polymorphic region that forbids amplification of a fragment from the designed pair of primers. This contig is located on the short arm of barley chromosome $3 \mathrm{H}$. The translated amino acid sequence of the contig has a weak homology to S. pennellii prohibitin-1 protein. Since this contig is present in the 'Betzes' genome, it is unlikely that it has any effect on the formation of the specific Alm phenotype. However, this gene can still be used to further narrow down the Alm locus in future experiments with segregating populations.

\section{References}

Arisha M.H., Shah S.N.M., Gong Z.-H., Jing H., Li C., Zhang H.-X. (2015). Ethyl methane sulfonate induced mutations in M2 generation and physiological variations in M1 generation of peppers (Capsicum annuum L.). Frontiers Plant Sci. https://oi.org/10.3389/ fpls.2015.00399

Börner T., Aleynikova A.Y., Zubo Y.O., Kusnetsov V.V. (2015). Chloroplast RNA polymerases: Role in chloroplast biogenesis. Biochimica Biophysica Acta. https://doi.org/10.1016/j.bbabio.2015.02.004

Bray N.L., Pimentel H., Melsted P., Pachter L. (2016). Near-optimal probabilistic RNA-seq quantification. Nature Biotechnol. https://doi. org/10.1038/nbt.3519

Bushmanova E., Antipov D., Lapidus A., Przhibelskiy A.D. (2018). rnaSPAdes: a de novo transcriptome assembler and its application to RNA-Seq data. BioRxiv. https://doi.org/10.1101/420208

Bushmanova E., Antipov D., Lapidus A., Suvorov V., Prjibelski A.D. (2016). RnaQUAST: A quality assessment tool for de novo transcriptome assemblies. Bioinformatics. https://doi.org/10.1093/bioinformatics/btw218.

Chan K.X., Phua S.Y., Crisp P., McQuinn R., Pogson B.J. (2016). Learning the Languages of the Chloroplast: Retrograde Signaling and Beyond. Ann Review Plant Biol. https://doi.org/10.1146/annurev-arplant-043015-111854.

Costa J.M., Corey A., Hayes P.M., Jobet C., Kleinhofs A., KopischObusch A., ... Wolfe R.I. (2001). Molecular mapping of the Oregon Wolfe Barleys: A phenotypically polymorphic doubled-haploid population. Theoretical Applied Gen. https://doi.org/10.1007/s001 220100622.

Edgar R.C. (2010). Search and clustering orders of magnitude faster than BLAST. Bioinformatics. https://doi.org/10.1093/bioinformatics/btq461. 
Gilbert D.G. (2013). Gene-omes built from mRNA-seq not genome DNA. 7th Annual Arthropod Genomics Symposium. https://doi. org/10.7490/f1000research.1112594.1

Grabherr M.G. ., Haas B.J., Yassour M., Levin J.Z. ., Thompson D.A., Amit I., ... Regev A. Trinity: reconstructing a full-length transcriptome without a genome from RNA-Seq data. Nature Biotechnol. 2013;29(7):644-652. https://doi.org/10.1038/nbt.1883. Trinity

Islam A.K.M.R., Shepherd K.W., Sparrow D.H.B. (1981). Isolation and characterization of euplasmic wheat-barley chromosome addition lines. Heredity. https://doi.org/10.1038/hdy.1981.24.

Khan N.Z., Lindquist E., Aronsson H. New Putative Chloroplast Vesicle Transport Components and Cargo Proteins Revealed Using a Bioinformatics Approach: An Arabidopsis Model. PLoS ONE. 2013;8(4). https://doi.org/10.1371/journal.pone.0059898.

Langmead B., Salzberg S.L. (2012). Fast gapped-read alignment with Bowtie 2. Nature Methods. https://doi.org/10.1038/nmeth.1923.

Liebers M., Grübler B., Chevalier F., Lerbs-Mache S., Merendino L., Blanvillain R., Pfannschmidt T. (2017). Regulatory Shifts in Plastid Transcription Play a Key Role in Morphological Conversions of Plastids during Plant Development. Frontiers Plant Sci. 1-8. https:// doi.org/10.3389/fpls.2017.00023.

Lin H.N., Hsu W.L. DART: A fast and accurate RNA-seq mapper with a partitioning strategy. Bioinformatics. 2018;34(2):190-197. https:// doi.org/10.1093/bioinformatics/btx558.

Marchler-Bauer A., Bo Y., Han L., He J., Lanczycki C.J., Lu S., ... Bryant S.H. (2017). CDD/SPARCLE: Functional classification of proteins via subfamily domain architectures. Nucleic Acids Research. https://doi.org/10.1093/nar/gkw1129.
Robertson G., Schein J., Chiu R., Corbett R., Field M., Jackman S.D., .. . Birol I. (2010). De novo assembly and analysis of RNA-seq data Nature Methods. https://doi.org/10.1038/nmeth.1517.

Schmieder R., Edwards R. Quality control and preprocessing of metagenomic datasets. Bioinformatics. 2011;27(6):863-864. https:// doi.org/10.1093/bioinformatics/btr026.

Shmakov N.A., Vasiliev G.V., Shatskaya N.V., Doroshkov A.V., Gordeeva E.I., Afonnikov D.A., Khlestkina E.K. Identification of nuclear genes controlling chlorophyll synthesis in barley by RNA-seq. BMC Plant Biol. 2016;16(Suppl 3). https://doi.org/10.1186/s12870016-0926-x.

Simão F.A., Waterhouse R.M., Ioannidis P., Kriventseva E.V., Zdobnov E.M. (2015). BUSCO: Assessing genome assembly and annotation completeness with single-copy orthologs. Bioinformatics. https://doi.org/10.1093/bioinformatics/btv351.

Wu T.D., Watanabe C.K. (2005). GMAP: A genomic mapping and alignment program for mRNA and EST sequences. Bioinformatics. https://doi.org/10.1093/bioinformatics/bti310.

Zoschke R., Bock R. (2018). Chloroplast translation: structural and functional organization, operational control, and regulation. Plant Cell. https://doi.org/10.1105/tpc.18.00016.

Acknowledgements. This work was supported by RSF project No. 18-14-00293.

Conflict of interest. The authors declare no conflict of interest. 


\title{
Comparative transcriptome analysis of Syringa vulgaris vegetative apices in vivo and in vitro
}

\author{
A.A. Krinitsina ${ }^{1,4 *}$, A.S. Speranskaya ${ }^{1}$, O.A. Churikova ${ }^{1}$, M.D. Logacheva ${ }^{1}$, E.A. Konorov ${ }^{2,5}$, M.S. Belenikin ${ }^{3}$ \\ ${ }^{1}$ Lomonosov Moscow State University, Moscow, Russia \\ ${ }^{2}$ Vavilov Institute of General Genetics, Moscow, Russia \\ ${ }^{3}$ The Moscow Institute of Physics and Technology, Dolgoprudny, Russia \\ ${ }^{4}$ I.M. Sechenov First Moscow State Medical University, Pharmaceutical Natural Science Department, Moscow, Russia \\ ${ }^{5}$ V.M. Gorbatov Federal Research Center for Food Systems of Russian Academy of Sciences, Moscow, Russia
}

\section{DOI 10.18699/ICG-PlantGen2019-53}

(c) Autors, 2019

*e-mail:ankrina@gmail.com

\begin{abstract}
Long-term conservation of plants in vitro means setting up conditions in which plants slow down their growth, which reduces the frequency of subculture needed to keep the material alive. Fall of cultivation temperature is frequently used for preservation of ornamental plants' cultures and of lilac's cultivars as well. For a better understanding of processes in in vitro culture, a comparative transcriptome analysis of vegetative apices of Syringa vulgaris $L$. during dormancy or in the phase of active growth in vivo and in vitro was carried out. A pairwise comparison of samples showed that a decrease in the temperature of lilac's microshoot cultivation down to $+10^{\circ} \mathrm{C}$ leads to the formation of a response similar to the response to oxidative stress. The changes in gene expression similar to such stress response persist within active shoots growth in sterile culture after their transfer to standard cultivation conditions $\left(+22^{\circ} \mathrm{C}\right)$.

Key words: in vitro conservation; transcriptome; lilac; apex; ornamental plants.
\end{abstract}

\section{Introduction}

Long-term conservation of plants in vitro means setting up conditions in which plants slow down their growth, which reduces the frequency of subculture needed to keep the material alive. Such an effect can be achieved through different approaches. The most common is by decreasing the temperature of cultivation, which leads to a strong slowdown of plant growth (up to its complete stop) and thus makes it possible to reduce the frequency of subculture. This way is widely used for ornamental plants as well (Ozudogru et al., 2010). Different types of explants can be placed into slow growth storage: microshoots or their parts, for example single-noded grafts, buds encapsulated in alginate beads.

Lilac is a widespread ornamental shrub. Nowadays, according to the International Lilac Society, there are more than 2000 cultivars of this genus in the world. The methods of microclonal propagation are being developed and constantly improved for it (Molkanova et al., 2002; Gabryszewska, 2011). It was showed that at a temperature of $+15^{\circ} \mathrm{C}$ the growth of lilac microshoots in vitro is slowing down (Gabryszewska, 2011). While creating the meristem's alginate beads, it is possible to conserve them at a temperature of $+4{ }^{\circ} \mathrm{C}$ (Refouvelet et al., 1998). We showed that at a temperature of $10^{\circ} \mathrm{C}$ the growth of lilac microshoots practically stopped. For all that the reaction to low positive temperature turned out to be cultivar-specific (Churikova, Krinitsina, 2018). In nature, lilac buds pass by autumn to endodormancy. The decrease in temperature leads to this state when during further transfer to normal conditions active growth begins.

The understanding of peculiarities of lilac apexes' state in slow-growth culture is possible by comparison of the levels of expression of their genes in slow-growth conditions with those in conditions of natural (in vivo) dormancy and conditions of dormancy release. For this, it was necessary to assemble de novo the reference transriptome of Syringa vulgaris and to reveal possible differences in expression profiles in explants in vivo and in vitro.

\section{Materials and methods}

Two lilac cultivars were used for the experiment: 'P.P. Konchalovsky' and 'Velikaya Pobeda'. Both cultivars belong to D IV-III group (double, bluish), but 'P.P. Konchalovsky' has the corolla consisting of four petal circles, and 'Velikaya Pobeda', of two. Extraction of RNA for the reference transcriptome was carried out from 'P.P. Konchalovsky' apical complexes of vegetative shoots (apex with 2 leaf primordia) of this year when their active growth begins, and from the flowers at the stage of uncolored corolla. Samples (not less than 30 apexes for one sample) were fixed in RNA-later (Sigma). Also, data on the RNA sequence from apical complexes of vegetative buds during physiological dormancy were used.

For comparison of lilac's apexes in slow-growth culture (in vitro), during physiological dormancy (in vivo) and during active growth of plants on its end one-noded grafts of both cultivars were placed into slow-growth storage conditions $\left(+10^{\circ} \mathrm{C}\right)$ on MS medium with $1.5 \mathrm{mg} / 1$ 2-ip and $20 \mathrm{~g} / 1$ sucrose for 270 days.

For transcriptome analysis, apexes of one half of shoots were cut off and fixed in RNA-later. The remaining shoots were transferred to normal condition and allowed to grow for 28 days, after that active growth microshoot apexes were cut off and fixed in RNA-later, too. Likewise, the vegetative apices of adult $S$. vulgaris shrubs were collected under dormancy (in winter) and from active growth (in springtime).

The total RNA was purified with an RNeasy Plant Mini Kit (Qiagen) from $20 \mathrm{mg}$ of each fixed sample. The libraries 
were prepared using a NEBNext ${ }^{\circledR}$ Poly(A) mRNA Magnetic Isolation Module and a NEBNext ${ }^{\circledR U}$ Ultra RNA Library Prep Kit for Illumina (NEB) and sequenced using a HiSeq 2500 System. The reference transcriptome was assembled by Trinity (Haas et al., 2013), transcript quantification was made by Salmon. For annotation, transcripts were searched against the NCBI non-redundant (NR) protein database using BlastX, with a cut-off E-value of $10^{-5}$. Gene ontology (GO) terms were extracted from the annotation of high-score BLAST matches in the NCBI NR proteins database (E-value $\leq 1.0 \times 10^{-5}$ ) using Blast2GO (Conesa et al., 2005). Differential expression analyses were conducted using edgeR, a correction via false discovery rate (FDR) estimation was made.

\section{Results and discussion}

Using the Illumina RNA-seq technique, 263 million raw reads were obtained and $46.3 \%$ of them remained after adapter and quality filtering. The final de novo assemblies consisted of 281,159 transcripts. The length distribution of transcripts was as follows: 19 transcripts were longer than 1000 b.p. (3 of them are unique), 84,556 transcripts were in the range of 1000-9999 b.p. (10,429 of them are unique), 196,584 transcripts, in the range of 100-999 b.p. (28,308 of them are unique). 182,177 transcripts had blast hits, for 112,741 of them GO annotations were obtained.

Transcripts were categorized into 38 functional groups based on gene ontology categorization. Some of them belong to more than one group. Within this group, assignments to the molecular function category was highest with $80 \%$, followed by the biological process category $(69.5 \%)$ and the cellular component category $(58.3 \%)$. Under the molecular function category, binding $(59.78 \%)$ and catalytic activity $(64.77 \%)$ were the most common. A moderate number of transcripts $(10 \%)$ belong to the transporter activity group. A very small number of transcripts were associated with metallochaperone $(0.03 \%)$ and antioxidant $(0.02 \%)$ activity.

Among the biological process categories, metabolic process $(75.14 \%)$ and cellular process $(72.07 \%)$ were prominently represented. A moderate number of transcripts were also involved in the biological regulation (19.07\%), localization $(17.39 \%)$, regulation of biological process $(16.66 \%)$, response to stimulus (13.01\%), cellular component organization $(12.79 \%)$, cellular component biogenesis $(2.5 \%)$ and rhythmic process $(2 \%)$ categories, while only a limited number were associated with multi-organism process $(0.9 \%)$, development $(0.2 \%)$ biological adhesion $(0.1 \%)$, cell killing $(0.1 \%)$, growth $(0.08 \%)$, reproduction $(0.05 \%)$, locomotion $(0.05 \%)$, signaling $(0.05 \%)$ and reproductive process $(0.05 \%)$.

For the cellular component category, the majority of the transcripts were assigned to the cell $(60.09 \%)$, membrane $(58.52 \%)$ and organelle $(45.31 \%)$ categories. A moderate number of transcripts $(19.78 \%$ and $10 \%)$ belong to the protein-containing and macromolecular complexes.

A pairwise comparison of samples showed differences in the level of transcription of two $\beta$-glucosidase isoforms, five superoxide dismutase isoforms, four peroxidase isoforms and three xyloglucan xylo-glucosyltransferase isoforms in slowgrowth condition in vitro vs. endodormant lilac's plant apices in vivo. Differences in the level of transcription were identified for seven superoxide dismutase isoforms, three $\beta$-glucosidase isoforms and cytochrome p450 isoforms in lilac's shoot apices of active growth plants in vivo vs. in vitro.

$\beta$-glucosidase activity is connected with the response to abiotic stress through accumulation of antioxidant flavonols (Singh et al., 2015; Baba et al., 2017). Change in superoxide dismutase and peroxidase gene expression takes place during oxidative stress (Raychaudhur, Deng, 2000; Li et al., 2004). However, there were no differences in the expression of glutathione-S-transferases, other limitation oxidative stress proteins, which play a role in plant growth in vivo and shoot morphogenesis in vitro in Arabidopsis thaliana (Gong et al., 2005). Glutathione peroxidase was also absent among differentially expressed genes. They are considered to be important in plant growth and oxidative stress response (Bela et al., 2015). We think that differentially expressed thioredoxin in our case can compensate function of plant glutathione peroxidases due to similar molecular activities (Herbette et al., 2002).

\section{Conclusions}

Thus, a decrease in the temperature of lilac microshoot cultivation in sterile conditions down to $+10{ }^{\circ} \mathrm{C}$ leads to the same response as the response to oxidative stress. It keeps during active growth of shoots in sterile culture after transfer to standard conditions of cultivation $\left(+22^{\circ} \mathrm{C}\right)$.

\section{References}

Baba S.A., Vishwakarma R.A., Ashraf N. Functional characterization of CsBGlu12, a $\beta$-glucosidase from Crocus sativus provides insights into its role in abiotic stress through accumulation of antioxidant flavonols. J Biological Chemistry. 2017;292:4700-4713. DOI 10.1074/jbc.M116.762161.

Bela K., Horváth E., Gallé Á., Szabados L., Tari I., Csiszár J. Plant glutathione peroxidases: emerging role of the antioxidant enzymes in plant development and stress responses. J Plant Physiol. 2015;176:192-201. DOI 10.1016/j.jplph.2014.12.014.

Conesa A., Götz S., Garcia-Gomez J.M., Terol J., Talon M., Robles M. Blast2GO: a universal tool for annotation, visualization and analysis in functional genomics research. Bioinformatics. 2005;21:36743676. DOI 10.1093/bioinformatics/bti610.

Gabryszewska E. Effect of various levels of sucrose, nitrogen salts and temperature on the growth and development of Syringa vulgaris L. shoots in vitro. J Fruit Ornamental Plant Research. 2011; 19(2):133-148.

Gong H., Jiao Y., Hu W.W., Pua E.C. Expression of glutathione-Stransferase and its role in plant growth and development in vivo and shoot morphogenesis in vitro. Plant Mol Biol. 2005;57(1):53-66. DOI 10.1007/s11103-004-4516-1

Haas B.J., Papanicolaou A., Yassour M., Grabherr M., Blood P.D., Bowden J., Couger M.B., Eccles D., Li B., Lieber M., Macmanes M.D., Ott M., Orvis J., Pochet N., Strozzi F., Weeks N., Westerman R., William T., Dewey C.N., Henschel R., Leduc R.D., Friedman N., Regev A. De novo transcript sequence reconstruction from RNA-seq using the Trinity platform for reference generation and analysis. Nat Protoc. 2013;8(8):1494-512. DOI 10.1038/nprot.2013.084.

Herbette S., Lenne C., Leblanc N., Julien J.L., Drevet J.R., RoeckelDrevet P. Two GPX-like proteins from Lycopersicon esculentum and Helianthus annuus are antioxidant enzymes with phospholipid hydroperoxide glutathione peroxidase and thioredoxin peroxidase 
activities. European J Biochemistry. 2002;269(9):2414-2420. DOI 10.1046/j.1432-1033.2002.02905.x.

Li X.Q., Li S.H., Chen D.F., Meng F.R. Induced activity of superoxide dismutase and peroxidase of in vitro plants by low concentrations of ethanol. Plant Cell, Tissue Organ Culture. 2004;79:83-86. DOI 10.1023/B:TICU.0000049439.36866.4e.

Molkanova O.I., Churikova O.A., Konovalova L.N., Okuneva I.B. Clonal micropropagation of Syringa vulgaris L. introduced species. Vestnik Moskovskogo universiteta (Ser. Biol.). 2002;4:8-14. (in Russian)

Ozudogru E.A., Previati A., Lambardi M. In vitro conservation and cryopreservation of ornamental plants. In: Jain S., Ochatt S. (Eds.). Protocols for in vitro propagation of ornamental plants. Methods Mol Biol (Methods and Protocols). 2010;589. DOI 10.1007/978-160327-114-1_28.
Raychaudhur S.S., Deng X.W. The role of superoxide dismutase in combating oxidative stress in higher plants. Bot Review. 2000; 66(1):89-98 DOI 10.1007/BF02857783.

Refouvelet E., Le Nours S., Tallon C., Daguin F. A new method for in vitro propagation of lilac (Syringa vulgaris L.): Regrowth and storage conditions for axillary bud encapsulation in alginate beads, development of a preacclimatisation stage. Sci. Hortic. 1998;74:233241. DOI 10.1016/S0304-4238(98)00088-0.

Acknowledgements. The work is supported by the Scientific program AAAA-A16-116021660105-3 of the Department of Higher Plants, Lomonosov Moscow State University and by the Russian Academic Excellence Project 5-100 (Sechenov University).

Conflict of interest. The authors declare no conflict of interest. 


\title{
Overexpression of RPOTmp, an Arabidopsis RNA-polymerase with dual-targeting, influences plant growth and transcriptome
}

\author{
V.I. Tarasenko, A.I. Katyshev, I.V. Gorbenko*, V.I. Belkov, E.Yu. Garnik, Yu.M. Konstantinov, M.V. Koulintchenko \\ Siberian Institute of Plant Physiology and Biochemistry, Siberian Branch of the Russian Academy of Sciences, Irkutsk, Russia
}

DOI 10.18699/ICG-PlantGen2019-54

(c) Autors, 2019

* e-mail: gravov.chemistry@gmail.com

\begin{abstract}
In dicot plants, RPOTmp is a dual targeting protein, which is presumably involved in gene transcription in both mitochondria and chloroplasts. The Arabidopsis rpotmp knockout line has retarded growth and development, changed expression of mitochondrial genes and decreased activities of the mitochondrial respiratory complexes. However, the particular importance of RPOTmp as a part of the mitochondrial and plastid transcription machinery remains unclear. In the current study, we used RPOTmp overexpressor lines with changed enzyme targeting directing either into mitochondria or chloroplasts, to study the particular role of this RNA polymerase in organelle gene expression and its plausible involvement in retrograde regulation. We have shown that RPOTmp overexpression influences plant growth and development and leads to significant changes in transcriptome. Key words: Arabidopsis thaliana; RPOTmp; mitochondria; chloroplast; gene expression.
\end{abstract}

\section{Introduction}

In a number of dicotyledonous plants, including Arabidopsis, transcription of organellar genes is performed by three nuclearencoded RNA polymerases, RPOTm, RPOTmp, and RPOTp. RPOTm performs the main function in plant mitochondria; RPOTp, along with PEP, a plastid-encoded RNA polymerase, plays a similar role in plastids. RPOTmp is localized in mitochondria as well as in chloroplasts and presumably participates in the control of gene expression of both organelles. The role of RPOTmp in mitochondrial transcription is confirmed by many studies (Emanuel et al., 2006; Courtois et al., 2007; Kühn et al., 2009). The absence of RPOTmp in Arabidopsis leads to a decrease in the transcription of genes encoding the subunits of respiratory complexes I and IV. Despite the obvious, though not fully understood role of RPOTmp in mitochondrial transcription, the function of this NEP polymerase in dicotyledonous chloroplasts is still under discussion. Many genetic elements in plastids and mitochondria are regulated by different types of promoters, implying competing or cooperative transcription of genes by different types of enzymes. Transcription of the plastid genome of lower plants, including algae, with the possible exception of Physicomitrella, is carried out only by PEP. In contrast, the benefits of using phage-type NEP polymerase by angiosperms, and even two of them by eudicots, remain unknown.

Since the localization and activity of RPOTmp is associated with two organelles, very different in their functions and type of gene expression, elucidation of specific functions of this RNA polymerase in each of the organelles is of considerable interest. Earlier (Tarasenko et al., 2016) we obtained two genetic constructs in which the gene sequence of the catalytic part of the Arabidopsis rpot2 gene was combined with the sequence encoding the transit peptide of mitochondrial RNA polymerase (RPOTm) (mtTmp-pBI121) or with the sequence encoding the transit peptide of chloroplast RPOTp (ptTmp-pBI121) (Figure 1, $a$ and $b$ ). These genetic constructs were used for agrobacterial transformation of Arabidopsis inflorescences (Clough, Bent, 1998) of the wild type or of the rpotmp knockout line. The following variants of transgenic plants were obtained (Figure 1,c): wild-type plants expressing recombinant protein RPOTmp targeted (1) to mitochondria (Col-M) or (2) to chloroplasts (Col-P); plants of the rpotmp mutant line, expressing recombinant protein targeted (3) to mitochondria (Tmp-M) or (4) to chloroplasts (Tmp-P).

The aim of this study was to find out more detail about the role RPOTmp plays in the regulation of organelle transcription and possibly in retrograde regulation of organelle functions.

\section{Materials and methods}

\subsection{Plant material and growth conditions}

Wild-type Arabidopsis thaliana (L.) Heynh plants (Col-0) and mutant line GABI_286E07 from the collection of GABIKat insertion mutants (Rosso et al., 2003) were used. In the mutant line, a T-DNA insert is located in the first exon of the rpot 2 gene, preventing the formation of a functional RPOTmp protein (Kühn et al., 2009). After 3 days at $4{ }^{\circ} \mathrm{C}$, plants were grown in pots at $24^{\circ} \mathrm{C}$ day $/ 21^{\circ} \mathrm{C}$ night, a 16 -h photoperiod and irradiance of $150 \mu \mathrm{mol} \mathrm{m}^{-2} \mathrm{~s}^{-1}$ in a KBW 720 growth chamber (Binder, Germany). A mixture of compost and Vermiculite (1:1) was used as a substrate. At least 50 plants of each line were used to estimate growth characteristics.

\subsection{Microarray analysis}

Total RNA samples were extracted from rosette leaves of 12-day-old plants using a Qiagen RNeasy Plant Mini Kit (Qiagen). RNA samples were labeled with a Low Input Quick Amp Labeling Kit, two-color, (Agilent Technologies) and an Agilent RNA Spike-In Kit, two-color, (Agilent Technologies). The cRNAs samples of Col- 0 and transgenic lines were labeled with $\mathrm{Cy} 3$ and $\mathrm{Cy} 5$ fluorescent dyes, respectively. Microarray analysis was performed by hybridizing four arrays in a single Arabidopsis (V4) Gene Expression Microarray slide $(4 \times 44 \mathrm{~K}$; Agilent Technologies) with a mixture of the Cy3- and Cy5labeled cRNAs. After hybridization using a Gene Expression Hybridization Kit (Agilent Technologies), the microarray slide 
was scanned using a scanner model G2539A with scan control A.8.5.1 (Agilent Technologies). Data analysis was performed using Feature Extraction 10.10.1.1 (Agilent Technologies) and GeneSpring GX 12.6.1 (Agilent Technologies). The p-value of each gene was calculated by two-way ANOVA and corrected by the Benjamini and Hochberg false discovery rate (FDR) method. Differential expression between samples was considered to be statistically significant at $p<0.05$ and FDR $<0.1$.

\section{Results and discussion}

\subsection{Phenotypic characteristics of Arabidopsis RPOTmp overexpressor lines}

The seeds of several homozygous lines with overexpression of RNA polymerase RPOTmp (Col-M and Col-P) were planted on Phytagel and on soil. The rate of seed germination, growth and development, the appearance of plants of Col-M lines were similar to those of the wild-type plants (Figure 1, $d$ ). The Col-P lines showed some differences from the wild-type plants. One out of six Col-P lines studied, Col-P12, was characterized by somewhat accelerated growth on the solid medium and on the soil and by a significantly $(p<0.05)$ earlier onset of flowering compared to the wild-type line. In contrast, three lines, Col-P5, Col-P8, and Col-P18, had a tendency for slow growth. Delayed seed germination and growth were expressed to a much greater extent in one of the lines, Col-P5 (see Figure $1, d)$. Also, plants of this line showed a pronounced delay in flowering, demonstrating in this respect a similarity with the rpotmp mutant plants. In addition, it can be noted that the plants of this line had the yellowish color of the first pair of true leaves at the time of their formation (a unique feature, not marked in any of the other lines studied), increased leaf folding in mature rosettes, a more rounded and curled shape of the leaves. The latter features also resemble the phenotype of the rpotmp mutant plants with inactivated expression of RPOTmp.

\subsection{Transcriptome analysis of Arabidopsis RPOTmp overexpressor lines}

Using the DNA microarray method, we performed a genomewide analysis of changes in the level of nuclear, chloroplast and mitochondrial gene transcripts in rpotmp mutant lines, lines overexpressing RPOTmp with mitochondrial or chloroplast targeting (Col-M15, Col-M20, Col-5, Col-P12), and in lines with complementation of RPOTmp functions in mitochondria (Tmp-M3, Tmp-M11) or in chloroplasts (Tmp-P1), in comparison with the wild-type plants. Total RNA extracted from 12-day-old seedlings was used for the analysis. Three biological repeats of RNA preparations obtained from several independently grown plants were used for analysis. From the resulting dataset, the genes, the expression level of which was statistically significant $(p<0.05)$ and at least two-fold different from the expression level of the wild-type plants, were selected for analysis. For each of the lines studied, several hundred genes met these criteria, which indicates that either the absence of RPOTmp in both (the rpotmp mutant) or one (the Tmp-M and Tmp-P lines) cell compartment, or the overexpression of the RNA polymerase leads to a significant response at the transcriptome level. Remarkably, most of the genes with altered expression were nuclear ones, showing that the observed changes can be attributed to retrograde regulation, that is, being dependent on the changes occurring in the organelles.

From the obtained it was clear that the expression changes in the rpotmp knockout line were similar to a high degree to that observed in the Tmp-P1 line (Figure 2), indicating that RPOTmp targeting to chloroplasts does not lead to compensation of defects characteristic of the mutant. In Tmp-M3 and Tmp-M11 lines, the number of genes with altered expression is the lowest; in this respect, these lines are close to the Col-P12 line with RPOTmp overexpression in chloroplasts, but not to the Col-P5 line. The Col-M15 line transcriptome was enriched for genes with an increased level of expression, which stand out in a separate cluster (Figure 2).

In addition, genes encoded in chloroplast and mitochondrial genomes were analyzed. It is interesting to note that none of the chloroplast genes were represented among genes with significantly altered expression in eight lines studied, which also indicates against any significant role RPOTmp can play in the transcription of the chloroplast genome. In contrast, the expression level of a number of mitochondrial genes was significantly altered. The data obtained using DNA microchips confirmed a decrease in the expression in the rpotmp mutant for all mitochondrial genes (such as rps4, matR, cox1, nad1, nad5, nad4, nad6, ccb256) shown previously by Kühn et al. (2009). In addition, several mitochondrial genes whose transcript levels in the absence of RPOTmp either decrease (orf100c, orf106d, orf107f, orf109, orf143, orf153a, orf215a, orf313, orfFX) or increase (orf110b, orf107c, orf111b, orf139a, orf141, orf184, orf 240a) have been identified by our analysis for the first time.

\section{Conclusion}

Analysis of changes in the level of mitochondrial gene transcripts allows us to draw conclusions about the almost complete identity of expression changes in the rpotmp and Tmp-P1 lines, and, conversely, a significant degree of compensation for these changes in the lines with RPOTmp complementation in mitochondria (Tmp-M3, Tmp-M11). The expression analysis of the mitochondrial genes in plants with RPOTmp overexpression showed a somewhat surprising picture. While the content of the mitochondrial gene transcripts in the Col-P12 line was close to that in the wild-type plants (which was to be expected in the line overexpressing RPOTmp with chloroplast targeting), the other line, Col-P5, was very close in this respect to the rpotmp knockout line. This fact correlates well with the phenotypic appearance and the level of mitochondrial genome copy number of plants of this line (the data are not shown). Analysis of the level of mitochondrial transcripts in the lines overexpressing RPOTmp with mitochondrial targeting (ColM15, Col-M20) also showed significant differences between these lines. While the Col-M15 line was characterized by an increased level of most mitochondrial transcripts, the content of many transcripts in the Col-M20 line, in contrast, was reduced, and the character of the changes was similar to that of the rpotmp and Col-P5 lines. It is interesting to note that the phenotype of these plants did not differ significantly from the phenotype of the wild-type plants. 
A Structure of nuclear encoded organellar RNA-polymerases
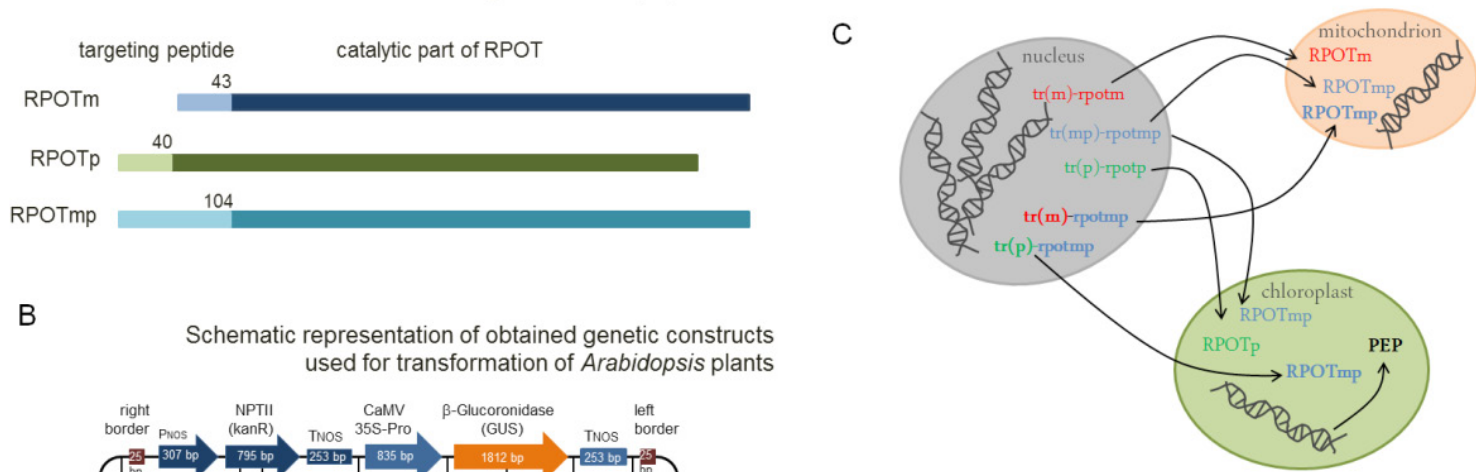

B

Schematic representation of obtained genetic constructs used for transformation of Arabidopsis plants

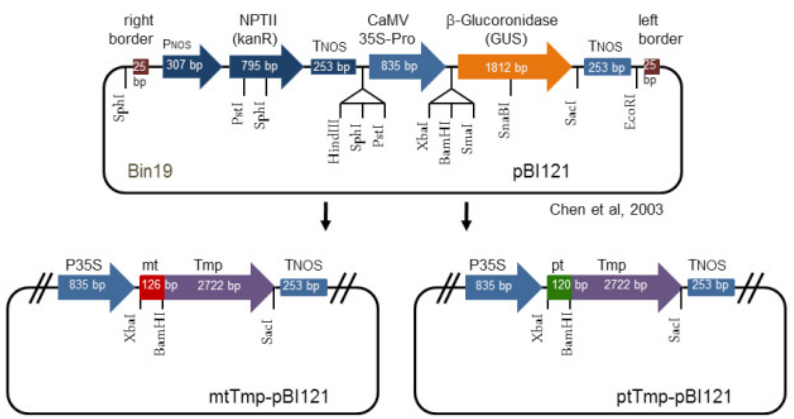

\section{D}
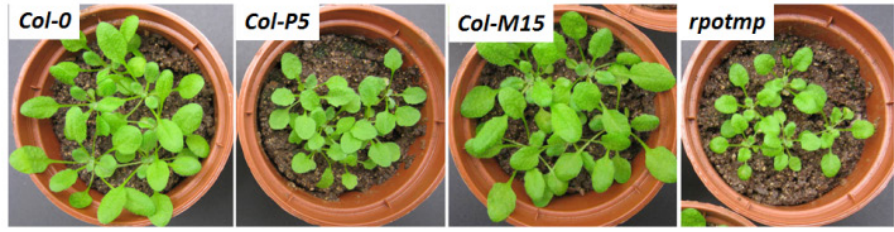

Figure 1. Transgenic Arabidopsis lines overexpressing RPOTmp with mitochondrial or chloroplast targeting. (a) Schematic representation of gene structures encoding three Arabidopsis RPOT polymerases. (b) Scheme of obtained genetic constructs (from Tarasenko et al., 2016). (c) Schematic representation of native and recombinant RPOTmp localization in cellular organelles. $\operatorname{tr}(m), \operatorname{tr}(p), \operatorname{tr}(m p)$ : sequences encoding transit peptides of the Arabidopsis rpotm, rpotp and rpotmp genes, respectively. (d) Appearance of Arabidopsis wild-type plants (Col-0), rpotmp mutant line and lines overexpressing RPOTmp with mitochondrial (Col-M15) or chloroplast (Col-P5) targeting.

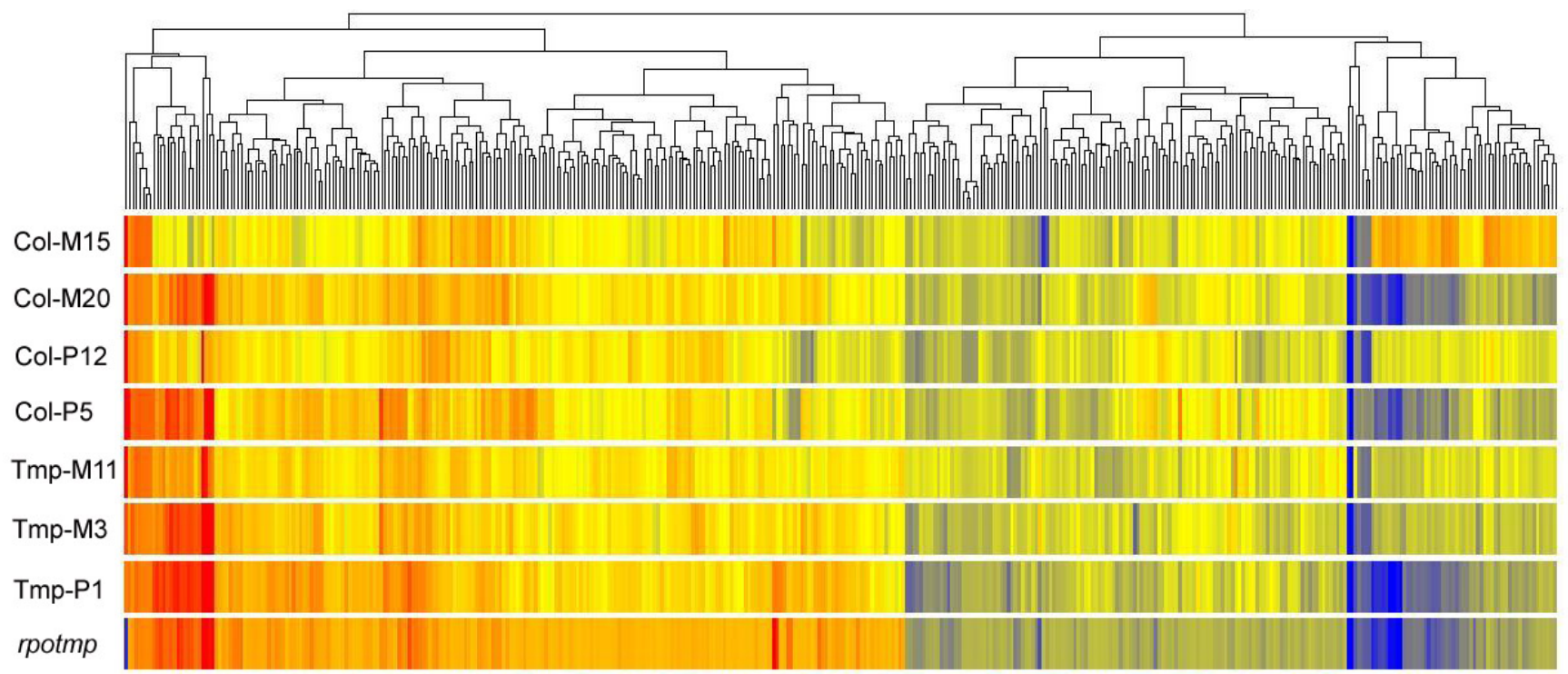

Figure 2. Dendrogram representing the clustering of genes differentially expressed in Arabidopsis lines overexpressing RPOTmp with mitochondrial or chloroplast targeting (Col-M, Col-P), in the rpotmp mutant line and in plants with RPOTmp complementation in mitochondria and chloroplasts (Tmp-M and Tmp-P). Red color means an increase in the level of gene expression compared to the level in the wild-type plants; blue represents a decrease. Genes whose expression levels differ at least two-fold from the level in wild-type plants $(p<0.05, n=3)$ are presented. 
It should also be noted that the increase in the expression of RPOTmp caused a change in the expression of many transcription factors belonging to certain classes (data not shown). Our task in subsequent studies will be to test the expression of selected genes encoding transcription factors of these potentially interesting classes.

Although we cannot, at the moment, make a definite conclusion about the reasons for the observed diversity of gene expression responses in the lines studied, it is obvious that the absence and increase in RPOTmp content produces different signals that lead to changes in expression in other cell compartments. At the same time, it seems that the change in the expression of the mitochondrial genome and/or the functional state of the mitochondria is one of the main sources and intermediaries in the transmission of this signal.

\section{References}

Chen P.Y., Wang C.K., Soong S.C., To K.Y. Complete sequence of the binary vector $\mathrm{pBI} 121$ and its application in cloning T-DNA insertion from transgenic plants. Mol. Breed. 2003;11:287-293.

Courtois F., Merendino L., Demarsy E., Mache R., Lerbs-Mache S. Phage-type RNA polymerase RPOTmp transcribes the rrn operon from the PC promoter at early developmental stages in Arabidopsis. Plant Physiol. 2007;145:712-21.
Emanuel C., von Groll U., Müller M., Börner T., Weihe A. Development- and tissue-specific expression of the RPOT gene family of Arabidopsis encoding mitochondrial and plastid RNA polymerases. Planta. 2006;223:998-1009.

Kühn K., Richter U., Meyer E., Delannoy E., de Longevialle A.F., O’Toole N., Börner T., Millar A., Small I., Whelan J. Phage-type RNA polymerase RPOTmp performs gene-specific transcription in mitochondria of Arabidopsis thaliana. Plant Cell. 2009;21:27622779.

Rosso M.G., Li Y., Strizhov N., Reiss B., Dekker K., Weisshaar B. An Arabidopsis thaliana T-DNA mutagenized population (GABI-Kat) for flanking sequence tag-based reverse genetics. Plant Mol. Biol. 2003;53:247-259.

Tarasenko V.I., Katyshev A.I., Yakovleva T.V., Garnik E.Y., Chernikova V.V., Konstantinov Y.M., Koulintchenko M. RPOTmp, an Arabidopsis RNA polymerase with dual targeting, plays an important role in mitochondria, but not in chloroplasts. J. Exp. Bot. 2016;67(19): 5657-5669. DOI 10.1093/jxb/erw327.

Acknowledgements. Equipment of the Bioanalitika Center for Collective Use, Siberian Institute of Plant Physiology and Biochemistry, Siberian Branch of the Russian Academy of Sciences, Irkutsk, was used in this study.

Conflict of interest. The authors declare no conflict of interest in financial or any other sphere. 


\title{
$N D H$ gene disruption - possible implication for adaptation of Allium species to different light conditions
}

\author{
A.S. Speranskaya ${ }^{1,8 *}$, M.S. Belenikin², E.A. Konorov ${ }^{3,4}$, S.V. Kuptsov ${ }^{1}$, M.I. Antipin ${ }^{1}$, M.D. Logacheva ${ }^{5}$, D.O. Omelchenko ${ }^{1,6}$, \\ A.A. Krinitsina ${ }^{1,7}$ \\ ${ }^{1}$ Lomonosov Moscow State University, Moscow, Russia \\ ${ }^{2}$ Moscow Institute of Physics and Technology, Dolgoprudny, Russia \\ ${ }^{3}$ Vavilov Institute of General Genetics of Russian Academy of Sciences, Moscow, Russia \\ ${ }^{4}$ V.M. Gorbatov Federal Research Center for Food Systems of Russian Academy of Sciences, Moscow, Russia \\ ${ }^{5}$ Skolkovo Institute of Science and Technology. Russia, Moscow Region \\ ${ }^{6}$ Institute for Information Transmission Problems, Moscow, Russia \\ ${ }^{7}$ All-Russia Research Institute of Agricultural Biotechnology, Moscow, Russia \\ ${ }^{8}$ I.M. Sechenov First Moscow State Medical University of the Russian Ministry of Health (Sechenov University), Department of Medical Genetics, Moscow, \\ Russia
}

DOI 10.18699/ICG-PlantGen2019-55

(c) Autors, 2019

* e-mail: hanna.s.939@gmail.com
Abstract: We have analyzed plastome sequences of twelve Allium species and found certain features reflecting evolutionary processes in the genus. The A. paradoxum plastome sequence differed markedly from other Allium species by a large 4,825 bp long inversion in the SSC region and pseudogenization of all genes encoding the NADH complex. The NADH complex is presumably required to optimize photosynthesis. In ndh defective plants the photosynthesis rate decreases under excess light. We assume that the natural distribution of $A$. paradoxum, restricted to shady forests, is linked to $n d h$ genes' impairment. No other analyzed Allium species demonstrated these features, not even the phylogenetically close shade-tolerant $A$. ursinum.

Key words: Allium; plastome; shaded environments; adaptation; NDH genes; gene loss; pseudogenization.
Finding genetic markers that reflect adaptation of plants to certain ecological niches is an important task with many possible practical outcomes. This field of plant molecular ecology is vast. Modern methods of genetic analysis applied to plants proved fruitful in solving many ecological problems: findings such as conditional expression and methylation changes led to insights into the genetic basis of adaptation to many stress factors: drought (Cortés et al., 2012; Shi et al., 2013; Rico et al., 2014), herbivorous insects (Smith, Clement, 2012; Eyres et al., 2016), cold hardiness (Gusta, Wisniewski, 2013), salinity (Hasegawa, 2013), soil acidity (Kochian et al., 2015) and others.

Light intensity is one of the most important abiotic factors in plant life. Plants mostly growing in shady habitats can be either shade-loving (sciophilous) or just shade-tolerant. Shadetolerant plants, or scioheliophytes, can cope with low light levels but are also able to grow in more or less open habitats with some degree of direct sunlight, while shade-loving plants stunt their growth or get sunburns if exposed to direct sun.

It is not yet fully known what genetic factors determine the development of shade tolerance, but certain data suggest that these traits may be inherited and are under natural selection. In the recently sequenced Panax ginseng genome, there is an amplification of chlorophyll $\mathrm{a} / \mathrm{b}$ proteins $(\mathrm{CAB})$, which is proposed to be a shade adaptation (Kim et al., 2018). There are also works that show some genetic basis for shade-loving and shade-tolerance predisposition in tomato (Sulistyowati et al., 2016; Ritonga et al., 2018).

Species in the genus Allium are adapted to habitats with a wide range of light intensity, from shady forests to open habitats like meadows, steppes and deserts. We have analyzed plastome sequences of twelve wild and cultivated Allium species. Ten of them, namely $A$. ursinum, A. paradoxum (MH053150), A. macleanii, A. nutans, A. platyspathum, A. schoenoprasum, A. pskemense, A. obliquum (MH157875), A. fistulosum, A. victorialis were sequenced, assembled and annotated in our lab. Sequences for A. cepa (KF728080) and A. sativum (KX683282) were obtained from works of von Kohn et al. (2013) and Filyushin et al. (2016).

A wealth of data regarding higher plants' plastide genomes is available at present. Full plastomes of more than 8000 plant species have been currently analyzed, of which more than 10 belong to the genus Allium (for several Allium species, no final annotations have been published yet and we are not analyzing them in this work). The plastomes of all studied Allium species contain the same number of tRNA genes (30 in total, of them 9 are represented by two copies in IR) and rRNA ( 8 genes, all 4 are represented by two copies in IR), 79 genes encode proteins. In general, the Allium plastomes analyzed had similar numbers, arrangement and orientation of genes (data not published). Yet some of the analyzed species proved to have deletions of certain genes, e.g. the small ribosome subunit gene rps16 (Belenikin et al., 2016).

The $A$. paradoxum plastome was quite distinct from other species in that all its $n d h$ genes were subject either to deletion or to pseudogenization. It also had a large (4825 kB) inversion in the SSC region. A number of other distinctions in the plastome structure of the species have been identified (Omelchenko et al., 2019, in press). All other analyzed Allium species did not have any alterations in the structure of the $n d h$ gene family. The NADH-dehydrogenase complex protects plants in stress conditions, preventing oxidative stress, partici- 
pating in electron cyclic transport and chloroplast respiration at night. It is divided into five subcomplexes, of which only one, the membrane subcomplex, is encoded by plastome genes only, while the others are encoded by nuclear or both nuclear and plastome genes. Genes of the NADH-dehydrogenase complex are also found in the mitochondrial genome, but they are of a different origin compared to plastome ones (according to Onoiko, Zolotareva, 2014). The proteins of the membrane NADH-dehydrogenase complex in the plastome are encoded by $11 n d h$ genes $(n d h A-K)$. Deletion of different plastome genes is sometimes accompanied by their transfer to the mitochondrial or nuclear genome (Logacheva et al., 2016; Lin et al., 2017). In some representatives of Pinaceae (Picea abies and Pinus massoniana), non-functioning fragments of $n d h$ genes were found in the nuclear genome (Ranade et al., 2016; Ni et al., 2017), and in several Orchidaceae, their copies were found in mitochondrial genomes (Lin et al., 2015). Deletion or pseudogenization of plastome $n d h$ genes is not always accompanied by their copies appearing elsewhere, e.g. in many orchids, despite the loss of $n d h$ plastome genes, they were not found in their nuclear genome either (Cai, 2015; Lin et al., 2017). Ruhlman et al. (2015) have analyzed transcriptomes of both flowering plants and gymnosperms (Pinaceae, Gnetales, Geraniaceae and Orchidaceae) that had lost plastome $n d h$ genes and did not found any functional copies of these genes.

In a considerable number of plant species belonging to unrelated taxonomic groups some $n d h$ genes are deleted, while the others had become pseudogenes (e.g. Pinaceae (Ranade et al., 2016; Ni et al., 2017), Gnetales (Ranade et al., 2016), Orchidaceae (Chang et al., 2005; Lin et al., 2017) and others). In all cases mentioned above, all $n d h$ plastome genes had lost their function. It is possible that this deletion is linked to operon organization of plastome genes (Sanderson, 2015). In particular, $n d h$ genes are also organized into an operon (Maier et al., 1995; del Campo et al., 2005). Loss of $n d h$ genes is considered to be an ancient trait, common to all Pinaceae (Lin et al., 2010; Wu et al., 2011). On the other hand, deletions of $n d h$ genes in Orchidaceae had most likely occurred independently in several taxonomic lines in the family (Lin et al., 2015).

Considering that many unrelated taxa had lost their plastome $n d h$ genes independently, we can speculate that this feature is a consequence of convergent evolution. An indirect confirmation of $n d h$ gene defunctionalization being an adaptive event can be found in the fact that it occurs in plants as primitive as Marchantiophyta (Wickett et al., 2008).

Mutant $n d h$ gene types are almost never affecting the phenotype if the plant is growing in its optimal conditions, but these plants are less stress tolerant. It is possible that electron cyclic transport is required for photosynthesis to be effective in stress conditions, such as drought, heat, high light intensity (Horvath et al., 2000; Wang et al., 2006; Sanderson et al., 2015; Yamori et al., 2015), and also in low light levels, as the NADH-dehydrogenase complex is known to mediate the minor pathway of electron cyclic transport in photosystem I. Analysis of ecological and trophic preferences of plants with $n d h$ deletions has shown that it is common in plants with some degree of heterotrophy (Wicke et al., 2011; Petersen et al., 2015; Silva et al., 2016, 2018; Shin, Lee, 2018). On the other hand, hemiparasitic plants do not always defunctionalize their $n d h$ genes. All $n d h$ genes are functional in the plastome of Aureolaria virginica belonging to Orobanchaceae, a family characterized by a different level of $n d h$ gene pseudogenization (Frailey et al., 2018).

Nevertheless, a full loss of all $n d h$ genes can be found not only in plants with various degrees of heterotrophy, but also in obligate autotrophic species. Besides Allium paradoxum it was found in some Pinaceae (Ni et al., 2017), in Erodium (Blazier et al., 2011), in the monotypic genera Circaeaster and Kingdonia (Circaeasteraceae), and even in Cactaceae in Carnegiea gigantea (Sanderson et al., 2015).

At least some events of $n d h$ pseudogenization may be possibly linked to light intensity adaptations. As was mentioned before, a properly functioning NADH-dehydrogenase complex allows plants to adapt flexibly to light intensities that are far from optimal, while defects in it may influence plant reactions to both high $\left(800 \mu \mathrm{mol}\right.$ photons $\left.\mathrm{m}^{-2} \mathrm{~s}^{-1}\right)$ and low $\left(200 \mu \mathrm{mol}\right.$ photons $\left.\mathrm{m}^{-2} \mathrm{~s}^{-1}\right)$ light intensity (Yamori et al., 2015; Ruhlman et al., 2015).

As the loss of $n d h$ genes makes intense light a stress factor, we suppose that $n d h$ gene defunctionalization and shade-loving habit are linked in Allium paradoxum. All the species in the study that are related to A. paradoxum had a full functioning set of $n d h$ genes. Its closest relative in the study, A. ursinum, is a representative of the same evolutionary line (first) and the same subgenus. On a phylogenetic tree, these species are in neighboring clades (Hanelt, 1996; Friesen, Fritsch, 2006). A. ursinum also prefers forest habitats, but it requires rather high light conditions, starting to grow before canopy closure, and its distribution is thought to be limited mostly by water availability, as it can grow successfully in open habitats if precipitation is high and evenly distributed or in the vicinity of rivers and streams (Oborny et al., 2011). Thus we can suppose that historically both understorey Allium species were shade-tolerant, but after the loss of functionality of its $n d h$ genes $A$. paradoxum became a shade-loving species and lost the ability to grow in open habitats.

Nevertheless, several species with the defunctionalization of $n d h$ genes grow in mesic or arid open habitats and do not suffer from intense light (Carnegiea, Pinus, Circaeaster and Kingdonia), and thus had supposedly developed a different mechanism of light stress tolerance than the NADH gene complex.

\section{References}

Belenikin M.S., Krinitsina A.A., Logacheva M.D., Kuptsov C.V., Speranskaya A.S. The quest for evolutionary changes in plants adapted to high-altitude habitats: the next-generation sequencing and comparative analysis of chloroplast genomes of some Allium species. Plant Protection News. 2016;3(89):23-24.

Blazier J.C., Guisinger M.M., Jansen R.K. Recent loss of plastid-encoded ndh genes within Erodium (Geraniaceae). Plant Mol. Biol. 2011;76(3-5):263-272. DOI 10.1007/s11103-011-9753-5.

Cai J., Liu X., Vanneste K., Proost S., Tsai W.C., Liu K.W., Chen L.J., He Y., Xu Q., Bian C., Zheng Z., Sun F., Liu W., Hsiao Y.Y., Pan Z.J., Hsu C.C., Yang Y.P., Hsu Y.C., Chuang Y.C., Dievart A., Dufayard J.F., Xu X., Wang J.Y., Wang J., Xiao X.J., Zhao X.M., Du R., Zhang G.Q., Wang M., Su Y.Y., Xie G.C., Liu G.H., Li L.Q., 
Huang L.Q., Luo Y.B., Chen H.H., de Peer Y.V., Liu Z.J. The genome sequence of the orchid Phalaenopsis equestris. Nat Gen. 2015; 47(1):65. DOI 10.1038/ng.3149.

Chang C.C., Lin H.C., Lin I.P., Chow T.Y., Chen H.H., Chen W.H., Cheng C.H., Lin C.Y., Liu S.M., Chang C.C., Chaw S.M. The chloroplast genome of Phalaenopsis aphrodite (Orchidaceae): comparative analysis of evolutionary rate with that of grasses and its phylogenetic implications. Mol. Biol. Evol. 2005;23(2):279-291. DOI 10.1093/molbev/msj029.

Cortés A.J., Chavarro M.C., Madriñán S., This D., Blair M.W. Molecular ecology and selection in the drought-related Asr gene polymorphisms in wild and cultivated common bean (Phaseolus vulgaris L.). BMC Gen. 2012;13(1):58. DOI 10.1186/1471-2156-13-58.

del Campo E.M., Sabater B., Martín M. Characterization of the 5'-and 3 '-ends of mRNAs of ndhH, ndhA and ndhI genes of the plastid ndhH-D operon. Biochimie. 2006;88(3-4):347-357. DOI 10.1016/j. biochi.2005.09.005.

Eyres I., Jaquiéry J., Sugio A., Duvaux L., Gharbi K., Zhou J.J., Legeai F., Nelson M., Simon J.-C., Smadja C.M., Butlin R., Ferrari J. Differential gene expression according to race and host plant in the pea aphid. Mol Ecol. 2016;25(17):4197-4215. DOI 10.1111/mec. 13771.

Filyushin M.A., Beletsky A.V., Mazur A.M., Kochieva E.Z. The complete plastid genome sequence of garlic Allium sativum L. Mitochondrial DNA. Part B. 2016;1(1):831-832. DOI 10.1080/23802359. 2016.1247669.

Frailey D.C., Chaluvadi S.R., Vaughn J.N., Coatney C.G., Bennetzen J.L. Gene loss and genome rearrangement in the plastids of five Hemiparasites in the family Orobanchaceae. BMC Plant Biol. 2018; 18(1):30.

Friesen N., Fritsch R.M., Blattner F.R. Phylogeny and new intrageneric classification of Allium (Alliaceae) based on nuclear ribosomal DNA ITS sequences. Aliso: A J Systematic Evolutionary Bot. 2006;22(1):372-395. DOI 10.5642/aliso.20062201.31.

Gusta L.V., Wisniewski M. Understanding plant cold hardiness: an opinion. Physiol Plantarum. 2013;147(1):4-14. DOI 10.1111/j.13993054.2012.01611.x.

Hanelt P. Taxonomic problems in Mediterranean Allium, and relationships with non-Mediterranean Allium groups. Bocconea. 1996;5(1): 259-265.

Hasegawa P.M. Sodium $(\mathrm{Na}+)$ homeostasis and salt tolerance of plants. Environmental Experimental Bot. 2013;92:19-31. DOI 10.1016/j. envexpbot.2013.03.001.

Horváth E.M., Peter S.O., Joët T., Rumeau D., Cournac L., Horváth G.V., Kavanagh T.A., Schäfer C., Peltier G., Medgyesy P. Targeted inactivation of the plastid ndhB gene in tobacco results in an enhanced sensitivity of photosynthesis to moderate stomatal closure. Plant Physiol. 2000;123(4):1337-1350. DOI 10.1104/pp.123. 4.1337.

Kim N.H., Jayakodi M., Lee S.C., Choi B.S., Jang W., Lee J., Kim H.H., Waminal N.E., Lakshmanan M., Nguyen B., Lee Y.S., Park H.S., Koo H.J., Park L.Y., Perumal S., Joh H.J., Lee H., Kim J., Kim I.S., Kim K., Koduru L., Kang K.B., Sung S.H., Yu Y., Park D.S., Choi D., Seo E., Kim S., Kim Y.C., Hyun D.Y., Park Y.I., Kim C., Lee T.H., Kim H.U., Soh M.S., Lee Y., In J.G., Kim H.S., Kim Y.M., Yang D.C., Wing R.A., Lee D.Y., Paterson A.H., Yang T.J. Genome and evolution of the shade-requiring medicinal herb Panax ginseng. Plant Biotechnol. J. 2018;16(11):1904-1917. DOI 10.1111/ pbi.12926.

Kochian L.V., Piñeros M.A., Liu J., Magalhaes J.V. Plant adaptation to acid soils: the molecular basis for crop aluminum resistance. $A n-$ nual Review Plant Biol. 2015;66:571-598. DOI 10.1146/annurevarplant-043014-114822.

Lin C.P., Huang J.P., Wu C.S., Hsu C.Y. Comparative chloroplast genomics reveals the evolution of Pinaceae genera and subfamilies. Gen Biol Evolution. 2010;2:504-517. DOI 10.1093/gbe/evq036.
Lin C.S., Chen J.J., Chiu C. C., Hsiao H.C., Yang C.J., Jin X.H., Leebens-Mack J., de Pamphilis C.W., Huang Y.T., Yang L.H., Chang W.J., Kui L., Wong G.K.S., Hu J.M., Wang W., Shih M.C. Concomitant loss of NDH complex-related genes within chloroplast and nuclear genomes in some orchids. Plant J. 2017;90(5):994 1006. DOI 10.1111/tpj.13525.

Lin C.S., Chen J.J., Huang Y.T., Chan M.T., Daniell H., Chang W.J., Hsu C.T., Liao D.C., Wu F.H., Lin S.Y., Liao C.F., Deyholos M.K., Wong G.K.S., Albert V.A., Chou M.L., Chen C.Y., Shih M.C. The location and translocation of ndh genes of chloroplast origin in the Orchidaceae family. Sci Reports. 2015;5:9040. DOI 10.1038/ srep09040.

Logacheva M.D., Schelkunov M.I., Shtratnikova V.Y., Matveeva M.V., Penin A.A. Comparative analysis of plastid genomes of non-photosynthetic Ericaceae and their photosynthetic relatives. Sci Reports. 2016;6:30042. DOI 10.1038/srep30042.

Maier R.M., Neckermann K., Igloi G.L., Kössel H. Complete sequence of the maize chloroplast genome: gene content, hotspots of divergence and fine tuning of genetic information by transcript editing. J Mol Boil. 1995;251(5):614-628. DOI 10.1006/jmbi.1995.0460.

Ni Z., Ye Y., Bai T., Xu M., Xu L.A. Complete chloroplast genome of Pinus massoniana (Pinaceae): Gene rearrangements, loss of ndh genes, and short inverted repeats contraction, expansion. Molecules. 2017;22(9):1528. DOI 10.3390/molecules22091528.

Oborny B., Botta-Dukat Z., Rudolf K., Morschhauser T. Population ecology of Allium ursinum a space-monopolizing clonal plant. Acta Botanica Hungarica. 2011;53:371-388. DOI 10.1556/ABot.53. 2011.3-4.18.

Onoiko E.B., Zolotareva E.K. The chloroplast NAD(p)H-dehydrogenase complex of the highest plants. Plant Physiol Gen (Kyiv) 2014; 46:371-384.

Petersen G., Cuenca A., Seberg O. Plastome evolution in hemiparasitic mistletoes. Genome Biol Evol. 2015;7(9):2520-2532. DOI 10.1093/ gbe/evv165.

Ranade S.S., García-Gil M.R., Rosselló J.A. Non-functional plastid ndh gene fragments are present in the nuclear genome of Norway spruce (Picea abies L. Karsch): insights from in silico analysis of nuclear and organellar genomes. Mol Gen Genom. 2016;291(2):935-941. DOI 10.1038/srep09040.

Rico L., Ogaya R., Barbeta A., Penuelas J. Changes in DNA methylation fingerprint of Quercus ilex trees in response to experimental field drought simulating projected climate change. Plant Biol. 2014; 16(2):419-427. DOI 10.1111/plb.12049.

Ritonga A.W., Chozin M.A., Syukur M., Maharijaya A., Sobir S. Genetic variability, heritability, correlation, and path analysis in tomato (Solanum lycopersicum) under shading condition. Biodiversitas J Biol Diversity. 2018;19(4):1527-1531. DOI 10.13057/biodiv/ d190445.

Ruhlman, T.A., Chang, W.J., Chen, J.J., Huang, Y.T., Chan, M.T., Zhang, J., Liao D.C., Blazier J.C., Jin X., Shih M.C., Jansen R.K., Lin C.S. NDH expression marks major transitions in plant evolution and reveals coordinate intracellular gene loss. BMC Plant Boil. 2015;15(1):100. DOI 10.1186/s12870-015-0484-7.

Sanderson M.J., Copetti D., Búrquez A., Bustamante E., Charboneau J.L., Eguiarte L.E., Kumar S., Lee H.O., Lee J., McMahon M., Steele K., Wing R., Yang T.J., Zwickl D., Wojciechowski M.F. Exceptional reduction of the plastid genome of saguaro cactus (Carnegiea gigantea): Loss of the ndh gene suite and inverted repeat. $\mathrm{Am}$ J Bot. 2015;102(7):1115-1127. DOI 10.3732/ajb.1500184.

Shi Y., Yan X., Zhao P., Yin H., Zhao X., Xiao H., Li X., Chen G., Ma X.F. Transcriptomic analysis of a tertiary relict plant, extreme xerophyte Reaumuria soongorica to identify genes related to drought adaptation. PLoS One. 2013;8(5):e63993. DOI 10.1371/journal. pone. 0063993.

Shin H.W., Lee N.S. Understanding plastome evolution in Hemiparasitic Santalales: Complete chloroplast genomes of three species, Den- 
drotrophe varians, Helixanthera parasitica, and Macrosolen cochinchinensis. PloS One. 2018;13(7):e0200293. DOI 10.1371/journal. pone.0200293.

Silva S.R., Diaz Y.C., Penha H.A., Pinheiro D.G., Fernandes C.C., Miranda V.F., Michael T.P. Varani A.M. The chloroplast genome of Utricularia reniformis sheds light on the evolution of the ndh gene complex of terrestrial carnivorous plants from the Lentibulariaceae family. PLoS One. 2016;11(10):e0165176. DOI 10.1371/journal. pone. 0165176 .

Silva S.R., Michael T.P., Meer E.J., Pinheiro D.G., Varani A.M., Miranda V.F. Comparative genomic analysis of Genlisea (corkscrew plants - Lentibulariaceae) chloroplast genomes reveals an increasing loss of the ndh genes. PLoS One. 201813(1):e0190321. DOI 10.1371/journal.pone. 0190321 .

Smith C.M., Clement S.L. Molecular bases of plant resistance to arthropods. Ann Rev Entomol. 2012;57:309-328. DOI 10.1146/annurevento-120710-100642.

Sulistyowati D., Chozin M.A., Syukur M., Melati M., Guntoro D. Selection of shade-tolerant tomato genotypes. J Applied Horticulture. 2016;18(2):154-159.

von Kohn C., Kiełkowska A., Havey M.J. Sequencing and annotation of the chloroplast DNAs and identification of polymorphisms distinguishing normal male-fertile and male-sterile cytoplasms of onion. Genome. 2013;56(12):737-742. DOI 10.1139/gen-2013-0182.

Wang P., Duan W., Takabayashi A., Endo T., Shikanai T., Ye J. Y., Mi H. Chloroplastic NAD (P) H dehydrogenase in tobacco leaves functions in alleviation of oxidative damage caused by temperature stress. Plant Physiol. 2006;141(2):465-474. DOI 10.1104/pp.105. 070490.

Wicke S., Schneeweiss G.M., Depamphilis C.W., Müller K.F., Quandt D. The evolution of the plastid chromosome in land plants: gene content, gene order, gene function. Plant Mol Biol. 2011; 76(3-5):273-297. DOI 10.1007/s11103-011-9762-4.

Wickett N.J., Fan Y., Lewis P.O., Goffinet B. Distribution and evolution of pseudogenes, gene losses, and a gene rearrangement in the plastid genome of the nonphotosynthetic liverwort, Aneura mirabilis (Metzgeriales, Jungermanniopsida). J Mol Evol. 2008;67(1):111-122. DOI 10.1007/s00239-008-9133-1.

Wu C.S., Lin C.P., Hsu C.Y., Wang R.J., Chaw S.M. Comparative chloroplast genomes of Pinaceae: insights into the mechanism of diversified genomic organizations. Gen Biol Evol. 2011;3:309-319. DOI 10.1093/gbe/evr026.

Yamori W., Shikanai T., Makino A. Photosystem I cyclic electron flow via chloroplast NADH dehydrogenase-like complex performs a physiological role for photosynthesis at low light. Sci Reports. 2015; 5:13908.

Acknowledgements. This work was supported by the RFBR grant No. 18-04-01203.

Conflict of interest. The authors declare no conflict of interest. 


\title{
Gene expression in Scots pine populations from the Chernobyl exclusion zone: transcriptomic approach
}

\author{
P.Yu. Volkova ${ }^{1 *}$, G.T. Duarte ${ }^{2}$, S.A. Geras'kin ${ }^{1}$ \\ ${ }^{1}$ Institute of Radiology and Agroecology, Obninsk, Russia \\ ${ }^{2}$ Institute Jean-Pierre Bourgin, Versailles, France
}

DOI 10.18699/ICG-PlantGen2019-56

(c) Autors, 2019

* e-mail: volkova.obninsk@gmail.com

\begin{abstract}
Radioactive contamination of natural areas is one of the most long-lasting anthropogenic impacts on the environment. Scots pine (Pinus sylvestris L.) is an important species for radiation protection of biota because of its high radiosensitivity. We conducted the de novo transcriptome analysis of Scots pine populations growing in the Chernobylaffected zone, which is still today contaminated with radionuclides. The transcriptional response involved modulation of the cellular redox system and ion balance, and enhanced expression of chaperones and histones. Our data suggest that the modulation of ROS level occurs mainly through the control of glutathione- and thioredoxin-related responses and most likely involves a fine-tuning of ROS-generating processes, which might be related to the control of gas exchanges via stomata. It is interesting to note that the stress response profile identified does not rely on the modulation of ABA biosynthesis or catabolism genes. These adaptive responses are triggered by radiation doses 30 times lower than the one accepted as safe for biota species by international regulations. These findings suggest that the environmental management in radiation protection should be reviewed.
\end{abstract}

Key words: radiation exposure; scot pine; Pinus sylvestris L.; transcriptome.

\section{Introduction}

The Chernobyl exclusion zone is a unique area for accessing the effects of ionizing radiation on the abundance, distribution, life history, and molecular changes caused on different plant species. Scots pine (Pinus sylvestris L.) is one of the most widespread tree species across Europe and Northern Asia, being a promising organism for radiation-related studies because of its high radiosensitivity (ICRP, 2008). Intending to gain insight into the ability of plants to withstand chronic radiation exposure, we evaluated the transcriptome profiles of Scots pine trees from four populations growing at clean and radioactively contaminated territories. This work has been recently accepted for publication (Duarte et al., 2019).

\section{Materials and methods}

The sample plots are located in the Bryansk region of Russian Federation and in the Gomel region of Belarus Republic. The reference plot (Ref) and the low-contaminated Zabor'e plot (Zab) are both located in the Bryansk region. The highly contaminated Kulazhin (Kul) and Masany (Mas) plots are situated in the Chernobyl exclusion zone. To perform the transcriptome analysis, we sampled pine needles from nine individual trees at each experimental plot. RNA of three pooled samples from a plot was sequenced using the Illumina HiSeq 2500 technology. The de novo transcriptome assembly was performed using BinPacker (Liu et al., 2016), SOAPdenovoTrans (Xie et al., 2014) and Trinity (Grabherr et al., 2011). The transcriptome annotation was conducted with Trinotate (Bryant et al., 2017) and InterProScan (Jones et al., 2014). The detailed description of the RNA sequencing procedures and bioinformatics analyses are available (Duarte et al., 2019; Duarte et al., forthcoming).

\section{Results and discussion}

The gene expression profile of the four studied populations correlated to the radiation levels at the sample plots. The clustering analysis of the expression profiles grouped the two highly contaminated populations (Mas and Kul); the low contaminated population (Zab) did not differ significantly from the reference. Nevertheless, the transcriptome profile of Zab population revealed the same regulation pattern of stress-related genes that were also identified for the high-dose irradiated populations, Mas and Kul. Only seven transcripts were commonly regulated among the three contaminated sample plots. Four of them were related to stress responses: a transcript for an anionic peroxidase related to cell death responses (WUN1_SOLTU), and three abscisic acid (ABA)responsive transcripts (CIPKK_ARATH, CIPKA_ARATH, and SLAC1_ARATH). Among the ABA-related genes, it is interesting to single out the down-regulation of the F-box protein PP2-B11 (P2B11_ARATH), which has been described as an attenuator of ABA responses (Cheng et al., 2017).

The functional analysis of the differentially expressed transcripts did not evidence a classical stress response signature (e.g. heat, hypoxia, cold, etc.). The response to chronic radiation exposure also did not resemble one to acute radiation, suggesting that the adaptation process to the former is rather unique. Those few genes that overlap between acute and chronic irradiation conditions showed inverse expression patterns. Short-term experiments also showed that the response pattern changes according to the radiation exposure duration (Kovalchuck et al., 2007).

The transcriptional profiles evaluated in our work suggest that the adaptation to chronic radiation exposure involves: (1) modulation of ROS accumulation through balancing of 
ROS-generating processes and antioxidant molecules; (2) control of cellular damage by enhanced expression of chaperones and histones, along with the modulation of ions balance, to counteract the damaging effects of a higher ROS basal level on proteins activity, DNA, and membranes; (3) control of the activity of transposable elements (TEs).

The production of ROS is an inherent consequence of the exposure to radiation (Szumiel, 2015). During oxidative stress, plants activate antioxidant mechanisms including enzymes (superoxide dismutase, catalases, peroxidases, and enzymes of ascorbate-glutathione cycle) and accumulate low molecular weight antioxidants for minimizing the damage (Sewelam et al., 2016). On the other hand, ROS are also central signalling molecules during stress responses (Sewelam et al., 2016). Apparently, organisms under chronic radiation exposure have to adapt to a different ROS threshold, which would allow them to balance the buffering of ROS without blocking their signalling function. Our data suggest that the ROS level modulation occurs mainly through the control of glutathioneand thioredoxin-related responses and most likely involves a fine-tuning of ROS-generating processes.

ROS-generating processes were repressed, while an enrichment of processes related to the control of gas exchanges via stomata was also observed. This observation suggests that the photosynthesis rate, which is a major ROS source, might be under a fine-tuning. It is interesting to note that the control of stomata movement seems not to involve the modulation of ABA levels. Conversely, the gene expression pattern suggests the control of the sensitivity of the pathway, for instance via the repression of PP2-B11, a SnRK2 negative regulator. A perspective for future work is the confirmation of ABA attenuation and of the control of photosynthesis rate on chronic irradiated plants.

Interestingly, the transcriptome analysis revealed the absence of activation of repair processes in the populations under chronic radiation exposure, responses that are known to occur during acute radiation stress condition (Culligan et al., 2006). This observation can be understood as another evidence of the adaptation of the evaluated populations to the chronic stress, being the expression of the repair machinery below the detection threshold. Nevertheless, the constant exposure to ionizing radiation imposes a permanent risk for the integrity of the molecules in the cells, including DNA single- and doublestrand breaks (Caplin and Willey, 2018). In this context, our analyses indicate that the strategy adopted by the evaluated populations is to increase the maintenance of the integrity of the molecules in the cell, which could be explained by the enhanced expression of chaperones and histones.

Finally, the control of TEs activity, which is also a source of DNA damage, is also evident in all chronically irradiated populations. However, the activity of the TEs was inversely correlated to the radiation dose exposure. While more active TE families were identified in the low-dose exposed individuals from Zab, the opposite trend was shown for Kul individuals.

\section{Conclusions}

Radioactive contamination of the natural areas is one of the most long-lasting anthropogenic impacts on the environment. Scots pine (Pinus sylvestris L.) is a promising organism for radiation-related research because of its high radiosensiti- vity, but the genome size of Pinacea species has imposed obstacles for high-throughput studies so far. In this work, we conducted the analysis of the de novo assembled transcriptome of Scots pine populations growing in the Chernobyl-affected zone, which is still today contaminated with radionuclides because of the accident at the nuclear power plant in 1986. The transcriptome profiles indicate a clear pattern of adaptive stress response, which seems to be dose-dependent. The transcriptional response indicates a continuous modulation of the cellular redox system, enhanced expression of chaperones and histones, along with the control of ion balance. Interestingly, the activity of transposable element families is inversely correlated to the exposure levels to radiation. These adaptive responses, which are triggered by radiation doses 30 times lower than the one accepted as safe for biota species by international regulations, suggest that the environmental management in radiation protection should be reviewed.

\section{References}

Bryant D.M., Johnson K., DiTommaso T. et al. A tissue-mapped axolotl de novo transcriptome rnables identification of limb regeneration factors. Cell Rep. 2017;18:762-776.

Caplin N., Willey N. Ionizing radiation, higher plants, and radioprotection: From acute high doses to chronic low doses. Front. Plant Sci. 2018;9:847.

Cheng C., Wang Z., Ren Z. et al. SCFAtPP2-B11 modulates ABA signaling by facilitating SnRK2.3 degradation in Arabidopsis thaliana. PLoS Genet. 2017;7:1006947.

Culligan K.M., Robertson C.E., Foreman J. et al. ATR and ATM play both distinct and additive roles in response to ionizing radiation. Plant J. 2006;48:947-961

Duarte G.T., Volkova P.Yu., Geras'kin S.A. The response profile to chronic radiation exposure based on the transcriptome analysis of Scots pine from Chernobyl affected zone. Environmental Pollution. 2019;250:618-626. DOI 10.1016/j.envpol.2019.04.064.

Duarte G.T., Volkova P.Y., Geras'kin S.A. A Pipeline for Transcriptome Assembly, Annotation, and Gene Ontology Analysis for Non-model Organisms: a Case Study with Scots Pine. MethodsX (forthcoming).

Grabherr M.G., Haas B.J., Yassour M. et al. Trinity: reconstructing a full-length transcriptome without a genome from RNA-Seq data. Nat. Biotechnol. 2011;29:644-652.

ICRP. 2008. Publication 108. Environmental protection - the concept and use of reference animals and plants. Ann. ICRP 38.

Jones P., Binns D., Chang H.Y. et al. . InterProScan 5: genome-scale protein function classification. Bioinformatics. 2014;30:1236-1240.

Kovalchuck I., Molinier J., Yao Y. et al. Transcriptome analysis reveals fundamental differences in plant response to acute and chronic exposure to ionizing radiation. Mutat. Res. 2007;624:101-113.

Liu J., Li G., Chang Z. et al. BinPacker: packing-based de novo transcriptome assembly from RNA-seq data. PLoS Comput. Biol. 2016; 12:e1004772.

Sewelam N., Kazan K., Schenk P.M. Global plant stress signaling: Reactive oxygen species at the cross-road. Front Plant Sci. 2016;7:187.

Szumiel I. Ionizing radiation-induced oxidative stress, epigenetic changes and genomic instability: the pivotal role of mitochondria. Int. J. Radiat. Biol. 2015;91:1-12.

UNSCEAR. 2008. Effects of ionizing radiation on non-human biota. In Sources and Effects of Ionizing Radiation, United Nations Scientific Committee on the Effects of Atomic Radiation (UNSCEAR) Report, Volume II, Annex E.

Xie Y., Wu G., Tang J. et al. SOAPdenovo-Trans: de novo transcriptome assembly with short RNA-Seq reads. Bioinformatics. 2014;30: 1660-1666.

Acknowledgements. The work is supported by the Russian Science Foundation, grant \# 14-14-00666, Russian Foundation for Basic Research, grant No. 18-34-20012.

Conflict of interest. The authors declare no conflict of interest. 


\title{
Use of deep sequencing to study the genetic diversity of flax pathogens
}

\author{
N.V. Melnikova ${ }^{1}$, A.A. Dmitriev ${ }^{1 *}$ \\ 'Engelhardt Institute of Molecular Biology, Russian Academy of Sciences, Moscow, Russia \\ ${ }^{2}$ Federal Research Center for Bast Fiber Crops, Torzhok, Russia \\ ${ }^{3}$ Peoples' Friendship University of Russia (RUDN University), Moscow, Russia \\ ${ }^{4}$ Moscow Institute of Physics and Technology, Dolgoprudny, Russia
}

R.O. Novakovskiy ${ }^{1}$, G.S. Krasnov ${ }^{1}$, E.N. Pushkova ${ }^{1}$, L.P. Kudryavtseva ${ }^{2}$, T.A. Rozhmina ${ }^{1,2}$, P. Kezimana ${ }^{1,3}$, L.V. Povkhova ${ }^{1,4}$,

DOI 10.18699/ICG-PlantGen2019-57

(C) Autors, 2019

* e-mail: Alex_245@mail.ru

\begin{abstract}
Pathogens decrease flax yield and reduce product quality. The development of molecular markers is necessary for fungus identification and application of proper defense actions. In our work, we present the method based on deep sequencing for studying the genetic diversity of fungal pathogens of flax. ITS regions of rRNA genes and regions of genes encoding beta-tubulin (tub2), translation elongation factor 1-alpha (tef1), and RNA polymerase II subunits (RPB1 and RPB2) were studied using deep sequencing in 100 pathogen strains of Fusarium, Colletotrichum, Melampsora, Aureobasidium, and Septoria. Our method can be used for the characterization of genetic diversity of pathogens and determination of DNA sequences that are the most suitable for identification of fungus using molecular markers.
\end{abstract}

Key words: deep sequencing; flax pathogens; genetic diversity.

\section{Introduction}

Flax is a valuable crop which has been attracting more and more attention in recent years. Flax fiber is used to produce high-quality fabrics and composite materials (Costa et al., 2018). Flax seed has a complex of useful properties and is used in the pharmaceutical and food industries, as well as in the production of feed, high-quality paints, and polymeric materials (Singh et al., 2011). Diseases, primarily caused by fungal pathogens, lead to significant crop losses and reduce product quality. The main pathogens of flax are Fusarium oxysporum, Melampsora lini, Colletotrichum lini, Septoria linicola, and Aureobasidium pullulans (Muir, Westcott, 2003).

To combat flax diseases, effective measures are necessary, among which the identification of pathogen for choosing plant protection actions is an important one. Molecular markers are an effective tool for identifying pathogens (Crous et al., 2015), but the choice of nucleotide sequences that will be used for genetic diagnosis of pathogens is crucial. In the present work, the method for assessment of polymorphism of particular genes in fungal pathogens of flax using deep sequencing was proposed.

\section{Materials and methods}

Strains of F. oxysporum, M. lini, C. lini, S. linicola, A. pullulans, Fusarium moniliforme, Fusarium solani, Fusarium culmorum, Fusarium gibbosum, Fusarium sporotrichiella, Fusarium avenaceum, and Fusarium semitectum were obtained from the Institute for Flax (Torzhok, Russia). To isolate the DNA, the fungal samples were ground using a MagNA Lyser homogenizer (Roche, Switzerland) in a CTAB buffer and phenol-chloroform purification was performed. One hundred DNA samples were isolated, the quality and concentration of which were determined by agarose gel electrophoresis and a Qubit 2.0 fluorometer (Life Technologies, USA). The internal transcribed spacer (ITS) regions of the rRNA genes and regions of genes encoding beta-tubulin (tub2), translation elongation factor 1-alpha (tef1), and RNA polymerase II subunits (RPB1 and RPB2) were chosen to study the genetic diversity of flax pathogens with. The analysis of the literature data was performed and the sequences of primers that allow amplification of selected sequences from various species and genera of pathogens causing fungal plant diseases and are actively used in phylogenetic studies were found (Raja et al., 2017). To prepare DNA libraries of selected genes for deep sequencing, universal adapters were added to the target-specific primers. This is necessary for sequencing and performing the second PCR, which is needed for indexing the samples and adding the sequences required for sequencing. The Illumina protocol was taken as a basis (support.illumina.com/downloads/16s metagenomic_sequencing_library_preparation.html).

For the second PCR, universal Nextera XT v2 primers were used. The PCR conditions were optimized with selected primer pairs. The best results were obtained with amplification in $20 \mu \mathrm{l}$ of the reaction mixture containing 2 units of highprecision Tersus polymerase (Evrogen, Russia), $1 \times$ Tersus polymerase buffer (Evrogen), $200 \mu \mathrm{M}$ dNTP (Thermo Fisher Scientific, USA), $0.5 \mu \mathrm{M}$ of each primer (Evrogen), and $20 \mathrm{ng}$ of DNA under the following conditions: $3 \mathrm{~min}$ at $95{ }^{\circ} \mathrm{C}$; 35 cycles for the first PCR and 12 cycles for the second PCR: $15 \mathrm{~s}$ at $95{ }^{\circ} \mathrm{C}, 30 \mathrm{~s}$ at $58{ }^{\circ} \mathrm{C}, 30 \mathrm{~s}$ at $72{ }^{\circ} \mathrm{C} ; 3 \mathrm{~min}$ at $72{ }^{\circ} \mathrm{C}$. After the first PCR and after the second PCR, purification of PCR products using CleanMag DNA (Evrogen) magnetic beads was performed. According to the developed method, ITS, tub2, tef1, RPB1, and RPB2 sequences were amplified for 100 samples of pathogens causing fungal flax diseases, and DNA libraries were prepared for deep sequencing. The quality and concentration of the obtained DNA libraries were evaluated on an Agilent 2100 bioanalyzer (Agilent, USA) and a Qubit 2.0 fluorometer. The described sample preparation 
allowed us to obtain high-quality DNA libraries, which were equimolarly mixed before sequencing.

Using the MiSeq sequencer (Illumina, USA), we performed sequencing of ITS and $t u b 2$, tef1, $R P B 1$, and $R P B 2$ genes for 100 samples of the fungal flax pathogens: F. oxysporum, F. avenaceum, F. culmorum, F. moniliforme, F. gibbosum, F. semitectum, F. sporotrichiella, F. solani, M. lini, C. lini, S. linicola, and $A$. pullulans. The read length was $300+300$ nucleotides. The pipeline was developed for the analysis of the sequencing data. This work was performed using the equipment of "Genome" Center of Engelhardt Institute of Molecular Biology (http://www.eimb.ru/rus/ckp/ccu_genome_ce.php).

\section{Results and discussion}

Although the use of ITS to determine the species of fungi is the most promising approach (Pryce et al., 2003; Schoch et al., 2012), sometimes the use of only these sequences has an insufficient resolution. In this case, it is advisable to use them in combination with protein-coding genes, such as $t u b 2$ and tef1, and to perform an additional analysis of RPB1 and $R P B 2$ also having a high interspecific diversity but poorly amplified for a number of fungi (Schoch et al., 2012; Crous et al., 2015; Raja et al., 2017).

Approaches for identifying fungal pathogens are being actively developed and used for different plant species (McCartney et al., 2003; Atkins, Clark, 2004; Divakara et al., 2014). However, for pathogens of flax, such work has not yet been performed. This is largely due to the lack of data on polymorphism of nucleotide sequences that are the most suitable for the identification of pathogens. The data on polymorphism of such genes on representative sample sets of strains of fungi of various species would allow molecular diagnostics of flax pathogens.

The proposed approach based on deep sequencing enables the analysis of up to 384 pathogen samples in one run of a high-throughput sequencer. The samples will be separated by bioinformatics analysis due to the presence of double indexes. The approach is especially effective when sequencing several amplicons for a large number of samples takes place (in our case, 5 amplicons for 100 samples). This allows one to reduce both financial and labor costs, as well as to obtain a high coverage (a thousand-fold or more) to accurately identify DNA polymorphism.

\section{Conclusions}

The approach based on deep sequencing makes it possible to effectively assess the genetic diversity of pathogens causing fungal flax diseases and to determine DNA sequences that are the most promising for use as genetic markers for identification of plant pathogens.

\section{References}

Atkins S.D., Clark I.M. Fungal molecular diagnostics: a mini review. $J$ Appl Genet. 2004;45(1):3-15.

Costa S.M., Ferreira D.P., Ferreira A. et al. Multifunctional flax fibres based on the combined effect of silver and zinc oxide $(\mathrm{Ag} / \mathrm{ZnO})$ Nanostructures. Nanomaterials (Basel). 2018;8(12). DOI 10.3390/ nano8121069.

Crous P.W., Hawksworth D.L., Wingfield M.J. Identifying and naming plant-pathogenic fungi: past, present, and future. Annu Rev Phytopathol. 2015;53:247-267. DOI 10.1146/annurev-phyto-080614120245.

Divakara S.T., Santosh P., Aiyaz M. et al. Molecular identification and characterization of Fusarium spp. associated with sorghum seeds. J Sci Food Agric. 2014;94(6):1132-1139. DOI 10.1002/jsfa.6380.

McCartney H.A., Foster S.J., Fraaije B.A. et al. Molecular diagnostics for fungal plant pathogens. Pest Manag Sci. 2003;59(2):129-142. DOI $10.1002 /$ ps.575.

Muir A.D., Westcott N.D. Flax: The genus Linum: CRC Press, 2003.

Pryce T.M., Palladino S., Kay I.D. et al. Rapid identification of fungi by sequencing the ITS1 and ITS2 regions using an automated capillary electrophoresis system. Med Mycol. 2003;41(5):369-381. DOI $10.1080 / 13693780310001600435$.

Raja H.A., Miller A.N., Pearce C.J. et al. Fungal identification using molecular tools: A primer for the natural products research community. J Nat Prod. 2017;80(3):756-770. DOI 10.1021/acs.jnatprod. $6 \mathrm{~b} 01085$.

Schoch C.L., Seifert K.A., Huhndorf S. et al. Nuclear ribosomal internal transcribed spacer (ITS) region as a universal DNA barcode marker for Fungi. Proc Natl Acad Sci USA. 2012;109(16):6241-6246. DOI 10.1073/pnas.1117018109.

Singh K.K., Mridula D., Rehal J. et al. Flaxseed: a potential source of food, feed and fiber. Crit Rev Food Sci Nutr. 2011;51(3):210-222. DOI 10.1080/10408390903537241.

Acknowledgements. This work was financially supported by the Russian President Grant MK-5828.2018.4.

Conflict of interest. The authors declare no conflict of interest. 


\title{
Computer program for construction of regression function for phenotype in agroclimatic models with interactions
}

\author{
K.N. Kozlov ${ }^{1 *}$, S.V. Nuzhdin ${ }^{1,2}$, M.G. Samsonova ${ }^{1}$ \\ ${ }^{1}$ Peter the Great St. Petersburg Polytechnic University, St. Petersburg, Russia \\ ${ }^{2}$ University of Southern California, Los Angeles, CA, USA
}

DOI 10.18699/ICG-PlantGen2019-58

(c) Autors, 2019

*e-mail: kozlov_kn@spbstu.ru

\begin{abstract}
Regression models that connect agronomic traits to climatic factors provide valuable insights into phenological characteristics of cultivars. The genotype-by-environment interactions are modeled by a weighted sum of pairwise products between a control functions and group indicator variables. In contrast to existing modeling frameworks in our approach the analytic form of a control function, regression coefficients and a set of predictors are inferred by stochastic minimization of the deviation of the model output from data. The approach was successfully applied to the three datasets for soybean and chickpea to predict time to flowering with coefficient of determination 0.45-0.97.

Key words: mathematical modeling; regression; agroclimatic factors.
\end{abstract}

\section{Introduction}

Plants react to climate change with changing phenotype integrating climate-biospheric interactions (Morisette et al., 2009). Though mathematical modeling is one of the most important tools for prediction of phenologiclal traits the accuracy remains a problem (Richardson et al., 2012). The duration of developmental stages must closely coincide with the available season for acceptable results. Widely used methods for prediction of phenological traits are calculation of the sum of temperatures above the temperature minimum and regression models (Major et al., 1975; Pedersen et al., 2004; Setiyono et al., 2007). Several successful crop simulation models like SSM (Soltani et al., 2006a, 2006b), DSSAT (Boote et al., 2013; Jones et al., 2003, 2017a), APSIM (Keating et al., 2003) and others (Battisti et al., 2018; Williams et al., 1989) have been developed for legumes. Biophysical and biochemical processes are described with differential equations problemspecific parameters for genotype, soil, weather and economic factors. Developed in the absence of genomic information, these models considered genotype influence at best as a set of given "genetic coefficients" that do not correspond to actual genes (Hwang et al., 2017). Consequently, the inability of these models to take gene-by-environment interactions into account restricts the prediction of phenological traits of cultivars across different geographical locations and genotypes (Vadez et al., 2013). We propose a more general approach implemented in the computer program called 'nlreg', in which the analytic form of a control function together with regression coefficients and a set of predictors are inferred automatically by stochastic minimization of the deviation of the model output from data.

\section{Materials and methods}

The interactions between factors and $K$ different geographical locations or genotypes is modeled by a weighted sum of pairwise products between the control functions $F_{n}$ and the group indicator variables $d_{i}^{k}$ such that $d_{i}^{k}=1$, for plant $i$ from group $\mathrm{k}$ and $=0$ otherwise. Thus, for a set of data records $\left(\mathrm{y}_{\mathrm{i}}\right.$, $\mathrm{X}_{\mathrm{i}}$ ), where $\mathrm{y}_{\mathrm{i}}$ is the phenotype and $\mathrm{X}_{\mathrm{i}}$ is the vector of climatic factors for plant $\mathrm{i}$, the computer program presented here constructs Model (1).

$y_{i}=\beta_{0}+\sum_{\mathrm{n}=0}^{N-1} \beta_{\mathrm{n}+1} F_{n}\left(X_{i}\right)+\sum_{n=0}^{N-1} \sum_{l=1}^{K} \zeta_{k \cdot \mathrm{N}+n}$. $F_{n}\left(X_{i}\right) \cdot d_{i}^{k}+\varepsilon_{i}(1)$,

where $\beta_{\mathrm{n}}$ and $\zeta_{\mathrm{k} \cdot \mathrm{N}+\mathrm{n}}$ are the regression coefficients, $\mathrm{N}$ is the number of functions $F_{n}$, and $\varepsilon_{i}$ is the standard error.

The analytic form of function $\mathrm{F}_{\mathrm{n}}$ is constructed from the vector of codons of length $\mathrm{M}$ using Grammatical Evolution (GE) (Noorian et al., 2016; O'Neill and Ryan, 2001) which utilizes a context-free grammar (CFG). The CFG is defined by the 4-tuple of a finite set of terminal symbols, non-terminal symbols, the production rule set and the start symbol (Aho et al., 2006). In our approach, non-terminal symbols are defined as arithmetic operations “+”, “_”, “*”, “/” or expressions $X$, $(X-$ Const $)$, or $1 /(X-$ Const $)$ where the members of terminals set $X$ and Const denote a name of the predictor and the constants, respectively.

The model is further built using the LASSO algorithm (Tibshirani, 1996) which minimizes the sum of squared differences between model output and data and penalizes the sum of absolute values of regression coefficients $\beta_{n}$, thus reducing non-important ones to 0 .

The vector of codons is determined by minimizing the approximation error using the stochastic optimization technique called the Differential Evolution Entirely Parallel (DEEP) method (Kozlov and Samsonov, 2011; Kozlov et al., 2016). Differential Evolution (DE) was proposed in 1995 (Storn, 1995, 1997). DEEP incorporates several recent enhancements (Fan and Lampinen, 2003; Kozlov et al., 2016; Zaharie, 2002). DEEP employs the pool of worker threads with an asynchronous queue of tasks to evaluate the individual solutions in parallel. The code is available on GitLab (https://gitlab.com/ mackoel/deepmethod).

Although a few GE implementations are freely available (Noorian et al., 2016; Peter Harrington, 2018), they either lack a specific set of expressions or show low performance in our tasks. We implemented GE in $\mathrm{C}++$ using Armadillo 


\section{Days to flowering}

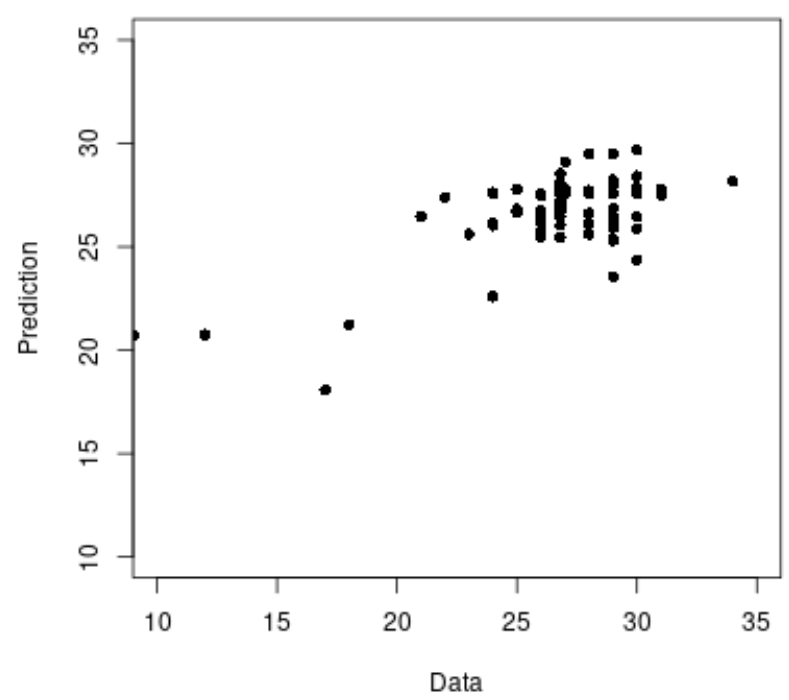

Figure 1. Comparison of model predictions with experimental data for models for chickpea VIR landraces from Turkey and Ethiopia.
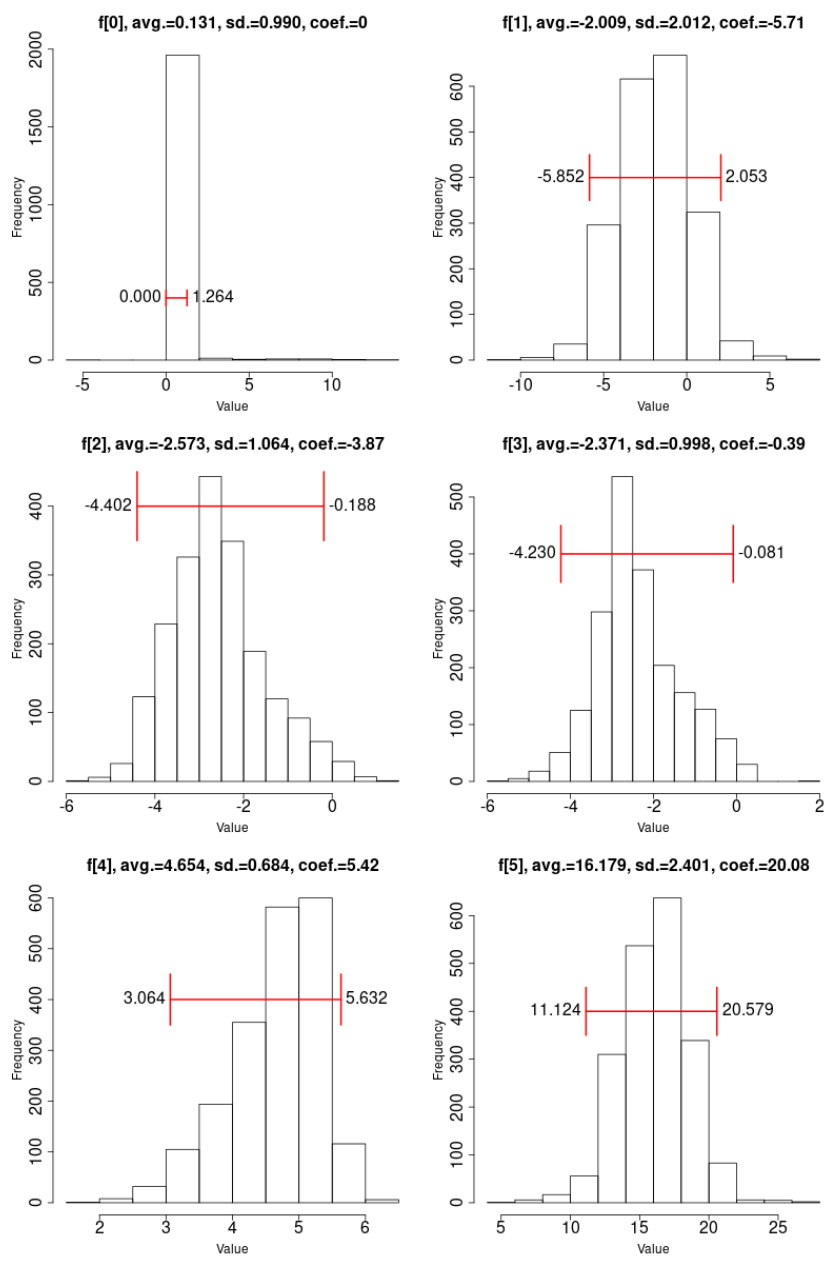

Figure 2. Confidence intervals for the $95 \%$ significance level for the intercept and 5 regression coefficients for functions $F_{n}$.
(Sanderson and Curtin, 2016), mlpack (Curtin et al., 2013), HDF5, HighFive (The Blue Brain Project, 2018) and Qt for efficient matrix operations, the LASSO method, data inputoutput and utility functions, respectively. The code is available on GitLab (https://gitlab.com/mackoel/nlreg) and can be compiled for GNULLinux or MS Windows 8.1 and 10 operating systems.

The program is accessed using a command line interface that accepts several options. Tabular data is read from a HDF5 file and parameters are supplied in a file in INI-format. To facilitate high-performance computing, the program can utilize OpenMP and MPI parallelization technologies.

\section{Results and discussion}

The approach was successfully applied to the three datasets for soybean and chickpea to predict time to flowering. For a dataset that comprises 379 plants of 9 different soybean accessions phenotyped at Pushkin VIR stations in 1999-2013, the method constructed a more accurate model (coefficient of determination $\mathrm{R}^{2}=0.60$ ) than the previous one in (Kozlov et al., 2018; Seferova and Novikova, 2015).

The models for chickpea VIR landraces from Turkey $\left(\mathrm{R}^{2}=0.45\right)$ and Ethiopia $\left(\mathrm{R}^{2}=0.52\right)$ were built in (Kozlov et al., 2019b). The comparison of model predictions with experimental data is presented in Figure 1. Modeling revealed the difference in the impacts of temperature and precipitation. The impact of temperature was 60 and $48 \%$ for Turkey and Ethiopia, respectively. The impact of precipitation was estimated at 86 and $89 \%$ for Turkey and Ethiopia, respectively.

The model for wild chickpea collected by von Wettberg et al. (2018) $\left(\mathrm{R}^{2}=0.97\right)$ showed that the genotype-by-environment interactions accounted for about $17.2 \%$ of variation in time to flowering (Kozlov et al., 2019a).

To access the practical identifiability of model parameters, we applied a bootstrap approach (Mudelsee, 2010) and performed 1999 runs with sampled datasets (Efron and Tibshirani, 1993). Confidence intervals for the $95 \%$ significance level for the intercept and 5 regression coefficients for functions $F_{n}$ are presented in Figure 2. Five out of six coefficients are considered identifiable as their confidence intervals do not contain zeroes. Genotype-by-environment interactions were significantly non-zero $(\mathrm{P}<0.05$ in t-test $)$ for 56 out 90 combinations of functions $\mathrm{F}_{\mathrm{n}}$ with allele combinations at 6 SNP positions.

\section{Conclusions}

In contrast to existing modeling frameworks, in our approach control functions are automatically composed in analytic form that allows a wider range of non-linear dependencies between the phenotype and climatic factors to be explored. The results of numerical experiments with the wild chickpea dataset showed that certain environmental variables differently affect the flowering time of different genotypes. The analysis revealed that the $95 \%$ confidence intervals for five out of six regression coefficients did not contain zeroes and thus represent a well-established influence of the climatic factor on time to flowering. 56 regression coefficients of genotype-by-environment interactions are significantly nonzero. Consequently, the computer program developed is a 
useful tool for mathematical modeling of phenological traits like flowering time and the investigation of genotype-byenvironment interactions.

\section{References}

Aho A.V., Lam M.S., Sethi R., Ullman J.D. Compilers: Principles, Techniques, and Tools (2Nd Edition). Boston, MA, USA: AddisonWesley Longman Publishing Co., Inc., 2006.

Battisti R., Sentelhas P.C., Boote K.J. Sensitivity and requirement of improvements of four soybean crop simulation models for climate change studies in Southern Brazil. International Journal of Biometeorology. 2018;62:823-832.

Boote K.J., Jones J.W., White J.W., Asseng S., Lizaso J.I. Putting Mechanisms into Crop Production Models. Plant Cell Environ. 2013.

Curtin R.R., Cline J.R., Slagle N.P., March W.B., Ram P., Mehta N.A., Gray A.G. mlpack: A Scalable C++ Machine Learning Library. Journal of Machine Learning Research. 2013;14:801-805.

Efron B., Tibshirani R. An introduction to the bootstrap. New York: Chapman \& Hall, 1993.

Fan H.-Y., Lampinen J. A Trigonometric Mutation Operation to Differential Evolution. Journal of Global Optimization. 2003;27:25.

Hwang C., Correll M.J., Gezan S.A., Zhang L., Bhakta M.S., Vallejos C.E., Boote K.J., Clavijo-Michelangeli J.A., Jones J.W. Next generation crop models: A modular approach to model early vegetative and reproductive development of the common bean (Phaseolus vulgaris L). Agricultural Systems. 2017;155:225-239.

Jones J.W., Hoogenboom G., Porter C.H., Boote K.J., Batchelor W.D., Hunt L.A., Wilkens P.W., Singh U., Gijsman A.J., Ritchie J.T. The DSSAT cropping system model. European Journal of Agronomy. 2003; 18:235-265.

Jones J.W., Antle J.M., Basso B., Boote K.J., Conant R.T., Foster I., Godfray H.C.J., Herrero M., Howitt R.E., Janssen S. et al. Brief history of agricultural systems modeling. Agricultural Systems. 2017a; 155:240-254.

Keating B., Carberry P.S., Hammer G., Probert M.E., Robertson M.J., Holzworth D., Huth N.I., Hargreaves J., Meinke H., Hochman Z. et al. An overview of APSIM, a model designed for farming systems simulation. European Journal of Agronomy. 2003;18:267-288.

Kozlov K., Samsonov A. DEEP -- Differential Evolution Entirely Parallel Method for Gene Regulatory Networks. Journal of Supercomputing. 2011;57:172-178.

Kozlov K., Samsonov A.M., Samsonova M. A software for parameter optimization with Differential Evolution Entirely Parallel method. PeerJ Computer Science. 2016;2:e74.

Kozlov K., Singh A., Berger J., Wettberg E.B., Kahraman A., Aydogan A., Cook D., Nuzhdin S., Samsonova M. Non-linear regression models for time to flowering in wild chickpea combine genetic and climatic factors. BMC Plant Biology. 2019a;19:94.

Kozlov K.N., Novikova L.Yu., Seferova I.V., Samsonova M.G. A Mathematical Model of the Effect of Climatic Factors on Soybean Development. Biophysics. 2018;63:136-137.

Kozlov K.N., Samsonova M.G., Nuzhdin S.V. Regression Model For Time To Flowering Of Chickpea Landraces. Russian Journal of Genetics. 2019b;55:1-5.

Major D.J., Johnson D.R., Tanner J.W., Anderson I.C. Effects of daylength and temperature on soybean development. Crop Science. 1975; 15:174-179.

Morisette J.T., Richardson A.D., Knapp A.K., Fisher J.I., Graham E.A., Abatzoglou J., Wilson B.E., Breshears D.D., Henebry G.M., Hanes J.M. et al. Tracking the rhythm of the seasons in the face of global change: phenological research in the 21st century. Frontiers in Ecology and the Environment. 2009;7:253-260.

Mudelsee M. Climate time series analysis: classical statistical and bootstrap methods. Dordrecht; New York: Springer, 2010.

Noorian F., de Silva A.M., Leong P.H.W. gramEvol : Grammatical Evolution in R. Journal of Statistical Software. 2016;71:1-26.

O'Neill M., Ryan C. Grammatical evolution. IEEE Transactions on Evolutionary Computation. 2001;5:349-358.

Pedersen P., Boote K.J., Jones J.W., Lauer J.G. (). Modifying the CROPGRO-Soybean Model to Improve Predictions for the Upper Midwest. AGRONOMY JOURNAL. 2004;96:556-564.

Harrington P. Genetic Programming C++ Code. 2018.

Richardson A.D., Anderson R.S., Arain M.A., Barr A.G., Bohrer G., Chen G., Chen J.M., Ciais P., Davis K.J., Desai A.R. et al. Terrestrial biosphere models need better representation of vegetation phenology: results from the North American Carbon Program Site Synthesis. Global Change Biology. 2012;18:566-584.

Sanderson C., Curtin R. Armadillo: a template-based C++ library for linear algebra. Journal of Open Source Software. 2016;1:26.

Seferova I.V., Novikova L.Yu. Climatic factors that impact the earlymaturing soybean accessions in North-West Russia. Works on Applied Botany, Genetics and Breeding. 2015;176:88-97.

Setiyono T.D., Weiss A., Specht J., Bastidas A.M., Cassman K.G., Dobermann A. Understanding and modeling the effect of temperature and daylength on soybean phenology under high-yield conditions. Field Crops Research. 2007;100:257-271.

Soltani A., Robertson M.J., Mohammad-Nejad Y., Rahemi-Karizaki A. Modeling chickpea growth and development: Leaf production and senescence. Field Crops Research. 2006a;99:14-23.

Soltani A., Hammer G.L., Torabi B., Robertson M.J., Zeinali E. Modeling chickpea growth and development: Phenological development. Field Crops Research. 2006b;99;1-13.

Storn R. Differential evolution - a simple and efficient adaptive scheme for global optimization. 1995.

Storn R. Differential Evolution - A Simple and Efficient Heuristic for Global Optimization over Continuous Spaces. DIFFERENTIAL EVOLUTION. 1997:19.

Tibshirani R. Regression shrinkage and selection via the lasso. J. of the Royal Statistical Society : Series B. 1996;58:267-288.

Vadez V., Soltani A., Sinclair T.R. Crop simulation analysis of phenological adaptation of chickpea to different latitudes of India. Field Crops Research. 2013;146:1-9.

von Wettberg E.J.B., Chang P.L., Başdemir F., Carrasquila-Garcia N., Korbu L.B., Moenga S.M., Bedada G., Greenlon A., Moriuchi K.S., Singh V. et al. Ecology and genomics of an important crop wild relative as a prelude to agricultural innovation. Nature Communications. 2018;9.

Williams J.R., Jones C.A., Kiniry J.R., Spanel D.A. The EPIC Crop Growth Model. TRANSACTIONS of the ASAE. 1989;32:497-511.

Zaharie D. Parameter Adaptation in Differential Evolution by Controlling the Population Diversity. In Proc. of 4th InternationalWorkshop on Symbolic and Numeric Algorithms for Scientific Computing. Petcu D. (Ed.). Timisoara, Romania: Analele Universitatii Timisoara, 2002. pp. 385-397.

Acknowledgements. The work is supported by the Federal Targeted Program (Agreement No. 14.575.21.0136 from 26.09.2017, RFMEFI57517X0136). Calculations were performed in Supercomputer Center of Peter the Great St.Petersburg Polytechnic University.

Conflict of interest. The authors declare no conflict of interest. 


\title{
Bioniformatics reserch of CRISPR/Cas-systems in the genomes of the phytopatogenic strain Agrobacterium fabrum C58
}

\author{
I.A. Portnaia ${ }^{1 *}$, A.Yu. Borisenkoํㅜ Yu.P. Dzhioev ${ }^{1}$, O.G. Karnoukhova ${ }^{1}$, Ju.A. Markova ${ }^{2}$, L.A. Stepanenko ${ }^{1}$, O.N. Reva ${ }^{3}$, \\ N.P. Peretolchina ${ }^{1}$, V.I. Zlobin ${ }^{1}$ \\ ${ }^{1}$ Irkutsk State Medical University, Irkutsk, Russia \\ ${ }^{2}$ Siberian Institute of Plant Physiology and Biochemistry, Irkutsk, Russia \\ ${ }^{3}$ Centre for Bioinformatics and Computational Biology, Department of Biochemistry, Genetics and Microbiology, University of Pretoria, Pretoria, \\ South Africa
}

DOI 10.18699/ICG-PlantGen2019-59

(c) Autors, 2019

* e-mail: portnaya.yana.1997@yandex.ru

\begin{abstract}
The phytopathogenic bacteria of the species Agrobacterium fabrum, which is one of the eleven species of the Agrobacterium tumefaciens complex, have become important plant pathogens in the recent years. They penetrate the crown, roots and stems of plants through wounds, causing tumors in the roots. They are also optional pathogens for humans and animals. Various chemical pesticides and biological preparations are used to combat these pathogens. However, due to their environmental hazards and multiple resistance to them, it becomes necessary to look for new methods and approaches to combat them. The research into bacterial CRISPR/Cas-systems has become one of the breakthrough trends in biology, agriculture and medicine today. Due to the large number of decoded bacterial genomes, as well as computer and software technologies, it becomes possible to conduct model studies on the search for and analysis of the diversity of all forms of bacterial activity. This study presents the results of a bioinformatics search for and analysis of loci and structures of CRISPR/Cas-systems in the genome of Agrobacterium fabrum str. C58 presented in the GenBank database. Here are presented some software and an algorithm for searching for CRISPR/Cas-systems and screening bacteriophages identical to the spacer sequences of CRISPR-arrays. The results were obtained on the structure of their CRISPRarrays, the diversity of CAS-proteins and phage strains detected through spacer sequences. Key words: phytopathogenic bacteria; bioinformatics analysis; CRISPR/CAS-systems; CRISPR-arrays; cas-protein; phage strains.
\end{abstract}

\section{Introduction}

Bacteria that cause plant diseases are called phytopathogenic. They have different degrees of pathogenicity and belong to different genera: Erwinia, Pseudomonas, Xanthomonas, Agrobacterium, Pectobacterium, Rhizobium, and others. Plant diseases caused by bacteria are called bacterioses, which are divided into 3 groups: general (vascular), local (parenchymal) or tumors. With a general lesion, the pathogen penetrates into the vascular system of the roots, the disease is accompanied by wilting of leaves and stems, and leads to the death of the plant. A typical example of vascular bacteriosis is potato ring rot. Tumor formations on plants are cancer and tuberculosis. In the case of cancer tumors, the growth of tissue is observed; in the case of tuberculosis, cavities are filled with bacterial mucus and then are formed in the expanding tissue. The virulence factors of phytopathogenic bacteria are toxins and enzymes. Toxins interact with plant cell enzymes, inactivate them, causing the cells to die. Under the action of a number of enzymes (pectolytic, proteolytic, cellulolytic), the plant cell wall substances are split and, as a result, the pathogens freely enter cells and destroy them (Bolotin et al., 2005).

Various chemical pesticides and biological preparations are used to combat these pathogens. However, due to the environmental hazards of these drugs and the growing resistance of bacteria to them, it becomes necessary to look for new methods and approaches to overcome them. The research of the CRISPR/Cas-systems of bacteria is one of the breakthrough trends in biology, agriculture, and medicine which effectively use it nowadays. The CRISPR/Cas-system (Clustered Regularly Interspaced Short Palindromic Repeats/ CRISPR-associated proteins, or short palindromic repeats, regularly arranged by groups with CRISPR-associated proteins) is a specific adaptive protective system of prokaryotes against foreign genetic material (Gasiunas et al., 2014). CRISPR-arrays are a set of short palindromic repeats of 21-47 nucleotide pairs (b.p.) separated by unique spacer sites. Spacers complementally correspond to the gene segments of bacteriophages and plasmids to which the bacterium demonstrates resistance and carry information about the meetings of the bacterium with them during the evolutionary process (Bolotin et al., 2005). There are cas-genes nearby, whose products ensure the functioning of the CRISPR loci. There are 3 types of CRISPR/Cas-systems, differing in cas-genes and the mechanism of action of the system (Kloepper et al., 1992; Makarova et al., 2006).

In recent years, the genes and genomes of many bacterial species have been decoded. Bioinformatics methods are widely used for processing the information related to a DNA. They allow the genomes to detect and to determine the structure of nucleotide repeats of CRISPR/Cas-systems (Makarova et al., 2011). A screening of spacers using these methods makes it possible to determine the degree of bacterial resistance to specific phages and plasmids. Research in this direction is relevant both for the study of intraspecific and interspecific evolutionary processes, and for solving practical problems in the treatment of human and plant infectious dis- 
eases (Abedon et al., 2011). The aim of this work is to search for and to analyze loci and structures of CRISPR/Cas-systems in the genome of Agrobacterium fabrum str. C58 present in the GenBank database through the developed bioinformatics algorithm of the programs, as well as screening phage strains through CRISPR-arrays.

\section{Materials and methods}

The object of the study is strain 58 of Agrobacterium fabrum (included in the Agrobacterium tumefaciens complex), present in the GenBank database (No. NC_003062.2). To search for CRISPR/Cas-systems, the methods of systems modeling MacSyFinder (Macromolecular System Finder, ver. 1.0.2) (Abby et al., 2014) were used. The search for structural and functional characteristics of cas-genes was carried out using auxiliary software packages makeblastdb (ver. 2.2.28) and HMMER (ver.3.0) (Biswas et al., 2014). To search for CRISPR-arrays in the genome of the strain, five bioinformatic software search algorithms were used:

1) PILER-CR: CRISPR repeats (http://www.drive5.com/ pilercr),

2) CRISPI: a CRISPR Interactive database (http://crispi. genouest),

3) CRISPRFinder (http://crispr.u-psud.fr/Server),

4) CRT: CRISPR recognition tool (http://www.room 220. com/crt),

5) CRISPRDetect(http://brownlabtools.Otago.ac.nz/ CRISPRDetect/predict_crispr_array.html).

Phage detection through the decoded spacers for the identified CRISPR-arrays was performed using BLASTn programs from the GenBank-Phage database, where the following programs were used: CRISPRTarget (http://bioanalysis. Otago.ac.nz/CRISPRTarget/crispr_analysis.html), Mycobacteriophage Database (http: //phagesdb.org/blast) and Phages database (http: //www.phantome. org /PhageSeed / Phage.cgi).

\section{Results and discussion}

To sum up, the result of our analysis is identification of cas3 (class I) and cas4 (class I-II) genes and their structural and functional characterization. Based on program matches for each site, two CRISPR-arrays were detected in the genome of $A$. fabrum str. C58. One CRISPR-array consists of three spacer sequences ranging in size from 28 to 44 nucleotide bases (b.p.) and separated by four repeats each 9 b.p. in length (CCTCCTCCC). The other CRISPR-array consists of two spacers ranging in size from 15 to 27 b.p. and separated by three repeats each 9 b.p. in length (TATCGCCAT). Using the structures of the spacers in the identified CRISPR-array, the phage strains identified, which are likely infected the $A$. $f a$ brum str. C58 strain during its evolution. The known phage strains were identified as representatives of the bacterial genera Mycobacterium, Streptomyces, Gordonia, and Arthrobacter.

\section{Conclusions}

Thus, the developed bioinformatical software algorithm used in our work makes it possible to search for loci and describe the structures of the CRISPR/Cas-system of bacteria, and also makes it possible to assess the degree of their resistance to phages and plasmids. Using A. fabrum str. C58 strain as an example, it was shown that it has two CRISPR-arrays and cas-genes in its genome and that this strain is highly resistant to various types of alien phages.

Also, the number of spacers and the degree of their identity to the phage protospacers indicate the level of their impact on the strain during evolution. Therefore, the development and selection of high-quality software methods and their algorithmic constructions make it possible to identify the specific features of the studied strain that could not be noticed by other methods. The obtained information, in a long term, will allow selecting target phages for carrying out strain-specific phage therapy of plant diseases caused by phytopathogens.

\section{References}

Abby S.S., Néron B., Ménager H., Touchon M., Rocha E.P.C. Mac SyFinder: A Program to Mine Genomes for Molecular Systems with an Application to CRISPR-Cas Systems. Torres N.V. (Ed.). PLoS ONE. 2014;9(10): e110726. DOI 10.1371/journal.pone.0110726.

Abedon S.T., Kuhl S.J., Blasdel B.G., Kutter E.M. Phage treatment of human infections. Bacteriophage. 2011;1(2):66-85. DOI 10.4161/ bact.1.2. 15845 .

Biswas A., Gagnon J.N., Brouns S.J.J., Fineran P.C., Brown C.M. CRISPR Target: Bioinformatic prediction and analysis of crRNA targets. RNA Biol. 2013;10(5):817-827. DOI 10.4161/rna.24046.

Bolotin A., Quinquis B., Sorokin A., Ehrlich S.D. Clustered regularly interspaced short palindrome repeats (CRISPRs) have spacers of extrachromosomal origin. Microbiol. 2005;151:2551-2561. DOI 10.1099/mic.0. 28048-0.

Borisenko A.Yu., Dzhioev Yu.P., Paramonov A.I. The use bioinformatics methods for researching of CRISPR/Cas systems in the genome of Staphylococcus aureus. Sibirskij medicinskij zhurnal (Irkutsk). 2015;2:71-74.

Gasiunas G., Sinkunas T., Siksnys V. Molecular mechanisms of CRISPR-mediated microbial immunity. Cellular Mol Life Sci. 2014;71(3):449-465. DOI 10.1007/s00018-013-1438-6.

Kloepper J.W. abd C.J. Beauchamp. A review of issues related to measuring colonization of plant roots by bacteria. Canad J Microbiol. 1992;38:1219-1232.

Makarova K.S., Grishin N.V., Shabalina S.A., Wolf Y.I., Koonin E.V. A putative RNA-interference-based immune system in prokaryotes: computational analysis of the predicted enzymatic machinery, functional analogies with eukaryotic RNAi, and hypothetical mechanisms of action. Biol Direct. 2006;1:7. DOI 10.1186/1745-6150-1-7.

Makarova K.S., Haft H.D., Barrangou R. et al. Evolution and classification of the CRISPR-Cas systems. Nature Reviews Microbiol. 2011;9(6):467-477. DOI 10.1038/nrmicro2577.

Conflict of interest. The authors declare no conflict of interest. 
Plant Breeding

in the $21^{\text {st }}$ Century 


\title{
Main directions of the spring bread wheat breeding in Western Siberia
}

\author{
I.A. Belan ${ }^{1 *}$, L.P. Rosseeva ${ }^{1}$, N.P. Blokhina ${ }^{1}$, L.F. Lozhnikova ${ }^{1}$, V.V. Nemchenko ${ }^{2}$, S.N. Abakumov ${ }^{3}$, R.K. Kadikov ${ }^{4}$, \\ N.V. Trubacheeva ${ }^{5}$, L.A. Pershina ${ }^{5}$
}

1 Omsk Agricultural Scientific Center, Omsk, Russia

2 "Agrocomplex Kurgansemena", Kurgan, Russia

"FSUE "Ishimskoe", Tobolovo, Russia

${ }^{4}$ Agrotechstroy, Ufa, Bashkortostan, Russia

${ }^{5}$ Institute of Cytology and Genetics, SB RAS, Novosibirsk, Russia

DOI 10.18699/ICG-PlantGen2019-60

(c) Autors, 2019

* e-mail: belan_skg@mail.ru

\begin{abstract}
This paper discusses the outcomes of a long-running plant breeding work that began in 1968 and was aimed at the development of spring bread wheat varieties. It is reported that over the 37-year period (1968-2005), 67 varieties have been developed and sent for the State Variety Testing; 30 varieties have at various times been included in the State Register and stayed listed for periods from 4 to 25 years. Currently, there are 19 varieties listed in the State Register; most of them (63\%) belong to strong wheat. The plant breeding programs aimed at the development of new varieties in West Siberia place high emphasis on breeding for resistance to leaf pathogens. The results of using alloplasmic genotypes (H. vulgare)-T. aestivum and $\mathrm{DH}$-lines with a fixed combination of fungal disease resistance genes are discussed.
\end{abstract}

Key words: variety; combination; introgressive line; resistance.

\section{Introduction}

Variety is not only one of the main factors of sustainable production of wheat grain, but it also accumulates and integrates achievements in various fields of science. The dynamic replacement of old varieties with new ones that are more productive and resistant to unfavorable biotic and abiotic environmental factors ensures increased yielding capacity and gross grain yields. No other section of crop production ensures such a substantial return as selective plant breeding does. According to Nettevich (2000), owing to selective breeding, wheat yields were increased by $32-52 \%$. In Western Siberia, due to the achievements of breeding and the development of new varieties, the yield of bread wheat increased by $45 \%$ (Suslyakov, 1994), and durum wheat - by $50 \%$ (Evdokimov, 2006).

\section{Materials and methods}

Work on the development and evaluation of breeding material is carried out according to the complete plant breeding scheme. The monitoring and counts were conducted in accordance with the "Methods of state variety testing of agricultural crops" (1985). All collection accessions, breeding lines and varieties were evaluated for their resistance to leaf pathogens both at the seedling stage and at the adult plant stage (Methods ..., 1988; Mikhaylova and Kvitko, 1970). In the field, the counts were conducted 3-4 times every 6-8 days after the onset of disease manifestation. For the varieties that retarded the development of pathogens, the resistance index (RI) was determined (Kovalenko et al., 2012). The breeding lines and varieties selected in the field were evaluated in the Grain Technology Laboratory for 18 indices of grain, flour and bread quality.

\section{Results and discussion}

The development of a new variety begins with the selection of parents and hybridization. At present, the varieties whose hybrid populations were obtained from 2000 through 2005 are included in the State Register and sent in for the State Variety Testing (SVT). The Table presents data for the period of the variety development since 1968 , which shows a significant progress in breeding work. Overall, 1,211,308 hybrid grains in 1688 combinations were obtained over 37 years. The Table shows that the number of varieties included in the State Register depends on the number of combinations but not on the number of hybrid grains obtained per 1 combination. Over this period, 66 varieties of various ripeness groups and purposes were sent for variety testing. Of those, 30 varieties were grown in the West Siberian region and stayed listed in the State Register within the period of 4 to 25 years. As of 2019, 19 varieties are included in the State Register of the Russian Federation, 12 varieties are grown in the Republic of Kazakhstan, and five varieties are under State Variety Testing. Of those 19, six were developed in the 1970s and 1980s, and 13, in the 1990s and 2000s (Table 1). The varieties developed are grown in five regions of the Russian Federation (from the Middle Volga to the Russian Far Eastern regions) and in four regions of Kazakhstan (Akmola, Kostanay, Pavlodar and North Kazakhstan).

In recent years (2015-2018), one of the main factors of wheat yield reduction has been a large-scale spread of brown and stem rust. Susceptible varieties had significantly lowered yields, but the absolute yield increase in new middle-early varieties with low resistance amounted to $0.46 \mathrm{t} / \mathrm{ha}$ and the growth coefficient made 1.18 . The mid-ripening varieties 'Omskaya 38', 'Sigma', 'Kazanskaya yubileynaya', 'Uralosibirskaya 2' characterized by a high resistance level (RL) $(\mathrm{RL}<0.35)$, had a yield increase from 0.58 to $1.01 \mathrm{t} / \mathrm{ha}$, i.e. they increased yields 1.32 times as compared to susceptible varieties. The new middle-late varieties 'Omskaya 37', 'Uralosibskaya' and 'Omskaya 42' are characterized by a high 
Table1

The outcomes of spring bread wheat variety development, FSBSI Omsk Agricultural Scientific Center, 1968-2005

\begin{tabular}{|c|c|c|c|c|c|}
\hline \multirow{2}{*}{ Year } & \multicolumn{2}{|c|}{ Average number, units } & \multirow{2}{*}{$\begin{array}{l}\text { Develo } \\
\text { ped varieties }\end{array}$} & \multicolumn{2}{|c|}{ Included in the State Register } \\
\hline & Combi nations & Hybrid grains & & Total & As of 2019 \\
\hline 1968-1970 & 129 & 20 & 8 & 4 & 1 \\
\hline $1971-1975$ & 235 & 173 & 7 & 2 & 1 \\
\hline $1976-1980$ & 301 & 203 & 6 & 2 & 1 \\
\hline $1981-1985$ & 310 & 158 & 2 & 1 & 1 \\
\hline 1986-1990 & 380 & 62 & 7 & 5 & 3 \\
\hline 1991-1995 & 457 & 57 & 13 & 6 & 4 \\
\hline $1996-2000$ & 481 & 32 & 10 & 7 & 6 \\
\hline $2001-2005$ & 475 & 33 & 13 & 3 & $2+5$ at SVT \\
\hline Total & 13587 & 1094929 & 66 & 30 & 19 \\
\hline
\end{tabular}

The scheme for development of spring bread wheat varieties using alloplasmic DH-17 line (H. vulgare) -T. aestivum

\author{
DH-17(H.vulgare)-T.aestivum $\times$ Com 37-1RS.1BL \\ Hybrid population L-311/00-22 - 1RS.1BL \\ Alloplasmic introgression lines - 1RS.1BL \\ $\downarrow$
}

Selection of lines for resistance to fungal pathogens, yield and grain quality

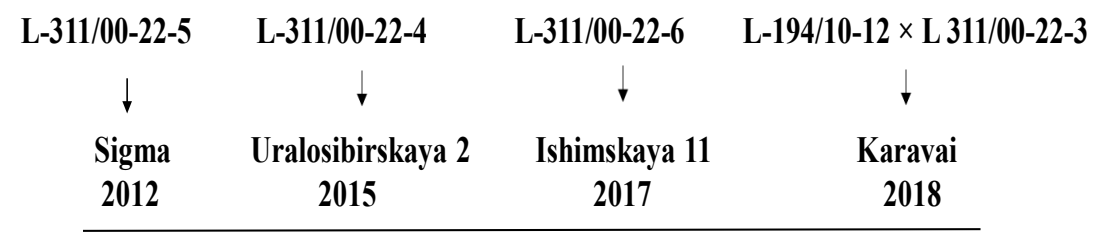

Varieties of spring bread wheat
Figure 1. The scheme for development of spring bread wheat varieties. resistance level. The absolute yield increase in these varieties ranged from 0.86 to $1.23 \mathrm{t} / \mathrm{ha}$, and the growth coefficient made 1.49 .

Grain quality tests are run at all stages of the breeding process beginning with early nurseries. Under laboratory conditions, complete tests for 18 indices of grain, flour and bread quality are performed. The tests in the competitive variety trial nurseries ensure strict selection regarding 7 indices of grain quality, such as grain-unit (at least $730 \mathrm{~g} / \mathrm{L}$ ), grain gluten content (no less than $25 \%$ ), flour strength (above 280 alveograph units), dough dilution (no more than 60 farinograph units), valorimetric evaluation (no less than 70 valorimeter units) and loaf volume (no less than 1100 points). The varieties defined as strong and valuable wheat are sent to the State Variety Testing. Of the 19 varieties included in the State Register, 12 varieties were classified as strong ones (63\%). According to the Grain
Quality Laboratory, to stabilize the production of strong and valuable grain under the conditions of the southern part of West Siberia, the varieties 'Omskaya 38' and 'Omskaya 37' may be promising ones as they form a strong grain at a frequency of $50 \ldots 70 \%$ (Pakhotina et al., 2018).

The main strategy of developing new varieties with multiple resistance to adverse biotic and abiotic factors is a broader use of wheat wild relatives and other cultivated cereals as the sources of new genes for spring bread wheat.

Due to a large-scale spread of fungal pathogens, the task before plant breeders is to develop highly productive and stress-resistant varieties. In our works, introgressive wheat lines and wheat relatives - T. durum, T. dicoccum, T. dicoccoides, Agr. elongatum, Agr. intermediate, T. timopheevii, $S$. cereale - are involved in hybridization as the carriers of genetic material to provide source material. Owing to inclusion 
of alien genetic material, the varieties that inhibit the development of leaf pathogens were obtained: 'Omskaya 37', 'Omskaya 38', 'Omskaya 41', 'Sigma 2', 'Pamyati Maystrenko', and 'Uralosibirskaya'. One of the directions of our work is the use of alloplasmic genotypes $(H$. vulgare $)-T$. aestivum and $\mathrm{DH}$-lines with a fixed combination of resistance genes of different origin (Figure 1).

For instance, the hybrid form 311/00-22 developed from the crossing of the alloplasmic line DH(1)-17 with line Com 37 (CIMMYT), and the 1RS.1BL translocation source proved to be promising for breeding. Lines L-311-22-1 through L-311-22-6 showed an advantage over the standard varieties regarding resistance to leaf and stem rust, yield and grain quality. As a result of breeding tests of the alloplasmic lines L-311-22-5, L-311-22-4, and L-311-22-6, the spring bread wheat varieties 'Sigma', 'Uralosibirskaya 2' and 'Ishimskaya 11' were obtained, respectively. L-311-22-3 became the parentage of the new variety Karavay. These results confirm the fact that the Sr31 gene remains effective for protection against stem rust in the Omsk, Kurgan and Tyumen Regions, and Bashkortostan. The DH-lines that combine the genes for resistance to powdery mildew, leaf and stem rust have been studied. The new lines are evaluated for resistance to Ug99 and yellow rust in Kenya (KARI).

Since 2000, within the framework of an international cooperation, the Laboratory has been participating in the Kazakhstan-Siberian Network (KASIB) on breeding improvement of spring wheat. The evaluation of the best lines in terms of yield and quality is carried out for resistance to stem and yellow rust against a specialized infectious background in Kenya.

The increased grain yield in 'Sigma' is determined by the density of the productive plant stand, ear length, and thousandkernel weight. When studying plants at 9 sites of the Republic of Kazakhstan and at 7 sites of the Russian Federation within the framework of the KASIB program (2015 and 2016), out of 49 varieties and lines studied, regarding productive plant stand, 'Sigma' was ranked $8^{\text {th }}$ for productive plant stand, $2^{\text {nd }}$ for ear length, $3^{\text {rd }}$ for spikelet number per ear, and was the best in terms of thousand-kernel weight. The yield of 'Sigma' was at the level of the mid-season standard. The maximum yield was obtained at the site Otar, $8.2 \mathrm{t} / \mathrm{ha}$, while the standard produced $4.2 \mathrm{t} / \mathrm{ha}$. The variety was successfully introduced into commercial production in West Siberia. Its commercial seed production was organized.

An important role in improving the efficiency of breeding belongs to the cooperation with the following institutions: Institute of Cytology and Genetics, N.I. Vavilov All-Russian Research Institute of Plant Industry, All-Russian Research Institute of Plant Protection, OOO "Kurgansemena", Bashkir State Agricultural University, Tatar Research Institute of Agriculture, Institute of Plant Industry named after V.Ya. Yuryev of Natl. Acad. of Agr. Sci. of Ukraine, and CIMMYT (International Maize and Wheat Improvement Center). The results of the team work are the jointly developed varieties 'Kazanskaya yubileynaya', 'Omskaya 35', 'Omskaya 36', 'Boyevchanka', 'Omskaya 38', 'Gerakl', 'Pamyati Maystrenko', 'Uralosibirskaya 2', 'Omskaya krasa', 'Sigma', 'Sigma 2', 'Ishimskaya 11 ' and 'Uralosibirskaya'.

\section{Conclusions}

Summarizing the data of analysis for the period from 1968 through 2018, the following may be concluded:

it has been shown that new varieties with high and medium levels of resistance during large-scale spreads of brown and stem rust produce yields $0.88-1.43$ times higher as compared to susceptible varieties;

the following varieties are of particular interest for plant breeders: the middle-early variety 'Boyevchanka', the mid-ripening varieties 'Sigma', 'Uralosibirskaya 2', and 'Kazanskaya yubileynaya'; and the middle-late varieties 'Uralosibirskaya' and 'Omskaya 42'.

\section{References}

Evdokimov M.G. Selection of spring durum wheat in Siberian Irtysh River area: monograph. Omsk, OOO IPTs "Sfera" Publ., 2006; 220 p. (in Russian)

Kovalenko E.D., Kolomiets TM, Kiseleva M.I., Zhemchuzhina A.I., Smirnova L.A., Scherbik A.A. Methods of evaluating and selecting the source material when developing wheat varieties resistant to leaf rust. Guidelines of All-Russian Research Institute of Phytopathology. Moscow, 2012;93 p. (in Russian)

Methods of state variety testing of agricultural crops: general part. Moscow, 1985;1:269 p. (in Russian)

Methods of breeding and evaluation of wheat and barley disease resistance in the CMEA member countries. Prague, 1988;321 p. (in Russian)

Mikhaylova L.A., Kvitko K.V. Laboratory methods of cultivation of the causative agent of brown rust of wheat. Mikologiya fitopatologiya $=$ Mycol Phytopathol. 1970;4(3):269-270. (in Russian)

Nettevich E.D. On the improvement of spring wheat varieties grown in the Central Region of Russia. Selektsiya $i$ semenovodstvo $=$ Selective Breeding Seed Production. 2000;4:10-14. (in Russian)

Pakhotina I.V., Ignateva E.Yu., Zelova L.A., Belan I.A., Rosseeva L.P., Blokhina N.P. Evaluation of spring soft wheat varieties for the stability of the formation of strong and valuable quality grain under the conditions of the south of West Siberia. Uspekhi sovremennogo estestvoznaniya $=$ Successes Modern Natural Science. 2018;9: 29-36. (in Russian)

Suslyakov V.S. Spring soft wheat varieties bred at the Siberian Research Institute of Agriculture and methods of their development. Novosibirsk, 1994;88 p. (in Russian).

Acknowledgements. This work was supported by ICG SB RAS budget project No. 0324-2019-0039.

Conflict of interest. The authors declare no conflict of interest. 


\title{
Improved marker for the Rht-B1p dwarfing allele in wheat
}

\author{
M.S. Bazhenov ${ }^{1 *}$, L.A. Nazarova ${ }^{1}$, A.G. Chernook ${ }^{1,2}$, M.G. Divashuk ${ }^{1,2}$ \\ ${ }^{1}$ Laboratory of Applied Genomics and Crop Breeding, All-Russia Research Institute of Agricultural Biotechnology, Moscow, Russia \\ ${ }^{2}$ Centre for Molecular Biotechnology, Russian State Agrarian University - Moscow Timiryazev Agricultural Academy, Moscow, Russia
}

DOI 10.18699/ICG-PlantGen2019-61

(c) Autors, 2019

* e-mail: mikhabazhenov@gmail.com
Abstract: Introduction of dwarfing genes into wheat varieties is a way for improvement of lodging resistance and increasing grain yield. Recently, the Rht-B1p allele (formerly designated as 'Rht17') associated with reduced plant height has been sequenced. However, the PCR markers developed previously for its detection were not perfect, and sometimes gave confusing results. In this work, we designed new primers for detection of the Rht-B1p allele and optimized PCR conditions for them. The new PCR marker can confidently detect the Rht-B1p allele in common wheat.

Key words: plant height; wheat; molecular markers; PCR; Rht17; Rht-B1p.

\section{Introduction}

Introduction of dwarfing genes into cereal crop varieties was crucial for increasing food production in the last 40 years of the XX century (Hedden, 2003). Irrigation and application of higher doses of fertilizers mainly increase yield. However, in the case of tall wheat varieties, these practices cause lodging, leading to heavy economic losses. Semi-dwarf wheat plants possessing shorter and stronger stalks are more resistant to lodging. Semi-dwarf wheat varieties make it possible to obtain higher yields under conditions of intensive agriculture.

The semi-dwarf plant height of contemporary wheat was achieved mainly due to the gibberellin-insensitive dwarfing genes Rht1 (the modern designation "Rht-Blb") and Rht2 ("Rht-Dlb"), which were introduced into American and European varieties from the Japanese variety 'Norin 10' (Borojevic, Borojevic, 2005). The advantage of the gibberellin-insensitive dwarfing genes is that they not only increase resistance to lodging, but also have a positive effect on the partitioning of the assimilates towards the developing ear, thereby further increasing grain yield. However, these genes have some disadvantages, for example, increased susceptibility to Fusarium head blight and shortening of the coleoptile of the seedlings, leading to a decrease in germination rate under conditions of deep sowing (Srinivasachary et al., 2008; Grover et al., 2018).

In addition to Rht-B1b and Rht-D1b, there are several other alleles of these genes that cause plant height reduction. At the same time, it is known that different alleles, despite the same molecular mechanism of their action, can affect the height and other economically valuable traits to slightly varying degrees. This can be caused by differences in their overall level of expression, and in expression patterns in different plant tissues. For example, it is known that the $R h t-D 1 b$ allele has a greater effect on susceptibility to Fusarium head blight than Rht-B1b (Srinivasachary et al., 2008), and the allele Rht-Ble (previously referred to as "Rht11") reduces plant height slightly stronger than Rht-B1b (Divashuk et al., 2012).

The effect of the Rht-Blp allele (previously designated as "Rht17") on the economically valuable traits of wheat has not yet been studied as sufficiently as those of other reducedheight alleles (Bazhenov et al., 2015). In this regard, reliable molecular markers for its identification are required. The dominant markers previously developed by us for identifica- tion of Rht-B1p in some cases give difficult-to-interpret results. Thus, we re-developed the primers and optimized the PCR conditions for reliable identification of the Rht-B1p allele (or its lack) in common wheat.

\section{Materials and Methods}

The following common wheat accessions with known reduced-height genes were used as a plant material: 'Novosibirskaya 67' (Rht-B1a), PI518620 (Rht-B1b), 'Karlik-1' (Rht-B1e), and 'Chris Mutant' (Rht-B1p). F3 lines of the 'Chris Mutant'/'Novosibirskaya 67' intercross were used for validation of the markers.

DNA samples were isolated from seedlings using the CTAB protocol (Doyle, 1991).

Primers for detection of the Rht-BIp allele were designed based on the known sequence (GenBank: KT013263.1) for combined use with the BF primer: 5'GGTAGGGAGG CGAGAGGCGAG3' (Ellis et al., 2002). The primer length was chosen based on its calculated melting temperature. The melting temperatures of the primers were calculated according to the method of Santa Lucia (Santa Lucia, 1998) using Primer-BLAST (NCBI).

For detection of the Rht-B1p allele, we designed the RhtB1p-R primer: 5'-CCATCTCCAGCTGCTCCAGCTTATA-3', and for detection of any of the other alleles, the Rht-B1a-R primer: 5'-CCATCTCCAGCTGCTCCAGCTTATG-3'. To enhance annealing specificity, we incorporated noncomplementary nucleotides (underlined) near the $3^{\prime}$ ends of the primers. The positions of the primers on the sequence of the gene are shown in Figure 1.

The PCR was performed using a GeneAmp PCR System 9700 (Applied Biosystems) in $25-\mu \mathrm{L}$ reaction volumes containing $70 \mathrm{mM}$ Tris- $\mathrm{HCl}$ buffer ( $\mathrm{pH} 8.6$ ), $16.6 \mathrm{mM}$ $\left(\mathrm{NH}_{4}\right)_{2} \mathrm{SO}_{4} 2.5$ or $1.5 \mathrm{mM} \mathrm{MgCl}, 0.2 \mathrm{mM}$ of each dNTP, $0.3 \mu \mathrm{M}$ of forward and reverse primers, $1.25 \mathrm{U}$ of Taq-polymerase (Sileks), and $100 \mathrm{ng}$ of template DNA.

During optimization of the PCR conditions, we tested two concentrations of $\mathrm{MgCl}_{2}(2.5$ and $1.5 \mathrm{mM})$, and a range of annealing temperatures, $56-64{ }^{\circ} \mathrm{C}$, in the main cycle.

The optimized PCR conditions were as follows: (1) $95^{\circ} \mathrm{C}$ for 10 minutes; (2) 5 cycles at $94{ }^{\circ} \mathrm{C}$ for 30 seconds, $67^{\circ} \mathrm{C}$ with a $1{ }^{\circ} \mathrm{C}$ drop every next cycle for $60 \mathrm{~s}, 72{ }^{\circ} \mathrm{C}$ for $80 \mathrm{~s}$; 


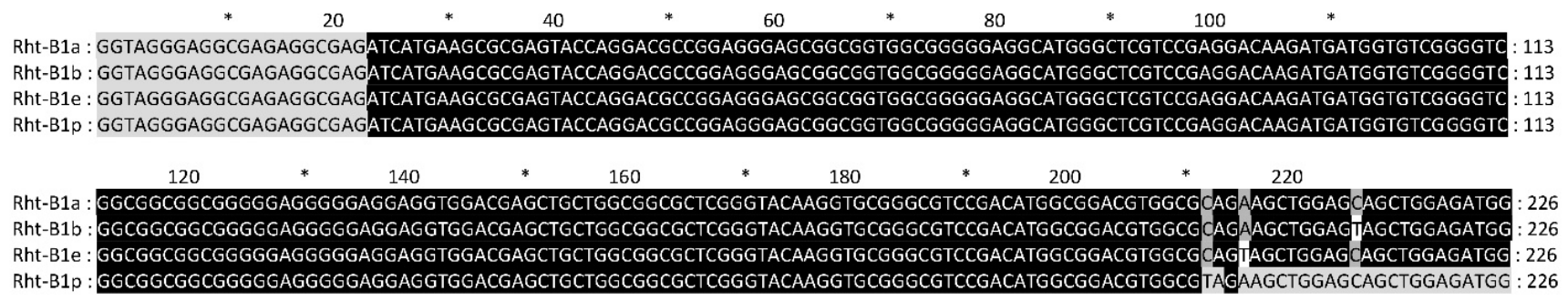

Figure 1. Alignment of the different Rht-B1 alleles $(a, b, e, p)$ and the positions of the primers BF and RhtB1pR (highlighted).

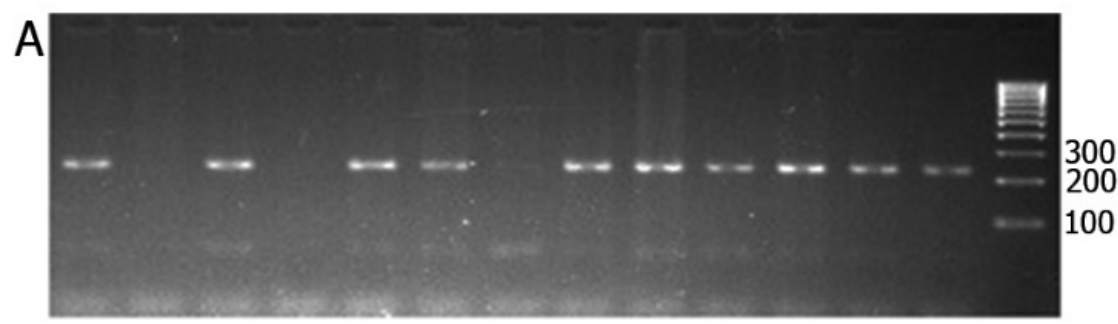

B

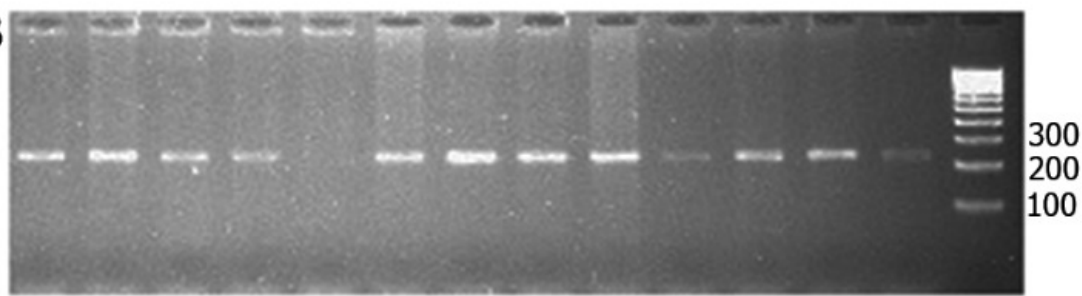

Figure 2. An example of the electrophoresis of the $P C R$ products obtained using the primers (A) BF/RhtB1pR and (B) BF/Rht-B1a-R and the DNA of the $F_{3}$ plants of the 'Chris Mutant'/'Novosibirskaya 67 ' intercross. The PCR product length is 226 base pairs. Plant 5 is a homozygote for Rht-B1p; plants 2, 4, and 7 are homozygotes for Rht-B1a; other plants are heterozygotes. M, DNA size standard M-100 (JSC Synthol).
(3) 30 cycles at $94{ }^{\circ} \mathrm{C}$ for 30 seconds, $62^{\circ} \mathrm{C}$ for $30 \mathrm{~s}, 72^{\circ} \mathrm{C}$ for $50 \mathrm{~s}$; (4) $72{ }^{\circ} \mathrm{C}$ for $10 \mathrm{~min}$.

The PCR products were subjected to electrophoresis in a $1.5 \%$ agarose gel run with TBE buffer with the addition of ethidium bromide. The gels were visualized using a Gel Doc $\mathrm{XR}+$ gel imaging system (Bio-Rad).

\section{Results and Discussion}

Introduction of 5 touchdown cycles at the beginning of the PCR allowed us, on the one hand, to enhance the specificity of the annealing of the primers and, on the other hand, to increase the amount of the resulting PCR product. As our experiments showed, further amplification could be conducted at a broad range of temperatures $\left(56\right.$ to $\left.63^{\circ} \mathrm{C}\right)$. We established the optimal annealing temperature in the main PCR cycles to be $62{ }^{\circ} \mathrm{C}$ for both primer pairs.

Separately, the markers obtained using each primer pair are dominant. However, the PCRs conducted with both primer pairs in combination can easily distinguish between the homozygous and heterozygous genotypes of the plants in the crosses of wheat accessions with the Rht-Bla and Rht-Blp alleles (Figure 2).

Compared to our previous primers for detection of $R h t-B 1 p$ (Bazhenov et al., 2015), our new ones being used under optimal conditions do not give any byproducts that can confuse the researcher. Testing our new primers on accessions with different $R h t-B 1$ alleles showed that the BF/Rht-B1p-R primer pair is perfectly specific for the Rht-B1p allele. However, the $\mathrm{BF} / \mathrm{Rht}-\mathrm{B}$ la-R primer pair gives only a faint PCR-product when the $R h t-B 1 b$ allele is present. Thus, in cannot perfectly detect the absence of the $R h t-B 1 p$ allele, if $R h t-B 1 b$ is present. To analyze the genotypes of the plants in the populations that segregate for $R h t-B 1 p$ and $R h t-B 1 b$ alleles, we recommend to use the $\mathrm{BF} / \mathrm{Rht}-\mathrm{B} 1 \mathrm{p}-\mathrm{R}$ primer pair for the $R h t-B 1 p$ allele, and the BF/MR1 primer pair proposed for detection of $R h t-B 1 b$ by Ellis et al. (2002).

\section{Conclusions}

Our new PCR markers, used under optimized conditions, can confidently detect the Rht-B1p allele in common wheat and discriminate its homozygous and heterozygous genotypes. Application of these markers will facilitate introduction of the $R h t-B 1 p$ dwarfing allele to new wheat varieties.

\section{References}

Bazhenov M.S., Divashuk M.G., Amagai Y., Watanabe N., Karlov G.I. Isolation of the dwarfing Rht-B1p (Rht17) gene from wheat and the development of an allele-specific PCR marker. Mol. Breed. 2015; 35(11). DOI 10.1007/s11032-015-0407-1.

Borojevic K., Borojevic K. The transfer and history of «reduced height genes» (Rht) in wheat from Japan to Europe. J. Hered. 2005;96(4): 455-459. DOI 10.1093/jhered/esi060.

Divashuk M.G., Vasilyev A.V., Bespalova L.A., Karlov G.I. Identity of the Rht-11 and Rht-B1e reduced plant height genes. Russ. J. Genet. 2012;48(7):761-763. DOI 10.1134/S1022795412050055. 
Doyle P.J. DNA Protocols for Plants. Molecular Techniques Taxonomy. 1991;57(1):283-293. DOI 10.1007/978-3-642-83962-7.

Ellis M., Spielmeyer W., Gale K., Rebetzke G., Richards R. «Perfect» markers for the Rht-B1b and Rht-D $1 \mathrm{~b}$ dwarfing genes in wheat. Theor. Appl. Genet. 2002;105(6-7):1038-1042. DOI 10.1007/s00122002-1048-4.

Grover G., Sharma A., Gill H.S., Srivastava P., Bains N.S. Rht8 gene as an alternate dwarfing gene in elite Indian spring wheat cultivars. PLOS ONE. 2018;13(6):e0199330. DOI 10.1371/journal.pone. 0199330.

Hedden P. The genes of the Green Revolution. Trends Genet. 2003; 19(1):5-9. DOI 10.1016/S0168-9525(02)00009-4.
SantaLucia J. A unified view of polymer, dumbbell, and oligonucleotide DNA nearest-neighbor thermodynamics. Proc. Natl. Acad. Sci. 1998;95(4):1460-1465. DOI 10.1073/pnas.95.4.1460.

Srinivasachary, Gosman N., Steed A., Hollins T.W., Bayles R., Jennings P., Nicholson P. Semi-dwarfing Rht-B1 and Rht-D1 loci of wheat differ significantly in their influence on resistance to Fusarium head blight. Theor. Appl. Genet. 2008;118(4):695-702. DOI 10.1007/s00122-008-0930-0.

Acknowledgements. This research was funded by Russian Science Foundation, grant number 17-76-20023.

Conflict of interest. The authors declare no conflict of interest. 


\title{
Marker-assisted selection and yield component assessment of spring wheat plants derived from crosses between spring and winter wheat cultivars
}

\author{
A.I. Stasyuk, I.N. Leonova, E.A. Salina \\ Institute of Cytology and Genetics, SB RAS, Novosibirsk, Russia
}

DOI 10.18699/ICG-PlantGen2019-62

(c) Autors, 2019

*e-mail: stasyuk@bionet.nsc.ru

\begin{abstract}
The effectiveness of the use of marker-assisted selection for identification of spring growth-habit genotypes derived from crosses between soft winter wheat cultivars and the spring wheat introgression line 21-4 carrying the Ae. speltoides LrAsp5 gene for resistance to leaf rust has been demonstrated. The duration of the period from sprouting to heading has been shown to vary across the hybrids in both directions relative to the parental line, even though the allelic compositions of the $V R N-1$ genes were identical. The presence of foreign genetic material has no effect on heading date. Plants with $\operatorname{LrAsp} 5$ are highly resistant to leaf rust. The expression of the quantitative traits follows an individual pattern in each line, irrespective of the presence of alien translocations.

Key words: spring soft wheat; $V R N-1$ genes; $L r$ genes; marker-assisted selection; yieldrelated traits.
\end{abstract}

\section{Introduction}

Spring soft wheat is the main crop in West Siberia, having more than $50 \%$ of the land area under crops and pulse crops. The first priority of spring soft wheat breeding is the development of high-yield cultivars with resistance to biotic and abiotic environmental factors. To this end, the breeders search for, find and use donors of important traits in crosses. The good choice is soft winter wheat, which has advantages over spring wheat in terms of yield. Identification of homozygous spring wheat plants resulting from crosses between winter and spring wheats requires large timescales. The use of molecular markers can make the search for genotypes of interest less time- and labor-consuming. In our study, the winter wheat cultivars 'Biyskaya ozimaya', 'Filatovka', 'Novosibirskaya 3' and 'Novosibirskaya 40' adapted to West Siberia were used as the maternal forms. The spring wheat introgression line 21-4 with a translocation on the long arm of Ae. Speltoides chromosome 5B carrying the LrAsp5 gene was used the pollinator. The aim of our work was to identify, using molecular markers, soft wheat plants with a spring growth habit in the hybrid population and to assess the quality of their agronomically important traits.

\section{Materials and methods}

The material used were hybrid plants derived from crosses between each of the soft winter wheat cultivars 'Biyskaya ozimaya', 'Filatovka', 'Novosibirskaya 3' and 'Novosibirskaya 40' and the spring wheat introgression line 21-4 (T. aestivum/Ae. speltoides) carrying the LrAsp 5 locus for resistance to leaf rust. We were searching the $\mathrm{F}_{2}$ population for spring and winter growth-habit plants using allele-specific markers for the Vrn-A1, Vrn-B1 and Vrn-D1 genes as described in a work by Likhenko et al. (2015). To identify plants carrying the LrAsp 5 gene from Ae. speltoides, the Pr1 and Pr5 primers were used, their structure and PCR conditions for them as described in a work by Leonova et al. (2017). Agriculturally important traits were assessed in $\mathrm{F}_{3}$ plants on an experimental field (Michurinskiy Settlement, Novosibirsk Region) in 2018. The parental spring wheat line 21-4 was used as the control. The traits assessed were: number of days from sprouting to heading, resistance to leaf rust, grain number per spike, grain weight per spike and 1000-grain weight. Resistance to leaf rust was assessed using the 0-4 scale by Mains and Jackson (Mains, Jackson, 1926). Differences between the mean values of two samples were tested for significance using Student's $t$-criterion.

\section{Results and discussion}

Crosses between each of the winter soft wheat cultivars 'Biyskaya ozimaya', 'Filatovka', 'Novosibirskaya 3' and 'Novosibirskaya 40' and wheat introgression line 21-4 resulted in 303 hybrid plants, from among which 90 homozygous spring-habit $\mathrm{F}_{2}$ plants were identified using molecular markers linked to the $V R N-1$ genes. Of them, 24 had translocations from Ae. speltoides, detected with the use of the molecular markers Pr1 and Pr5.

Agronomically valuable traits were analyzed in three 'Biyskaya ozimaya' $\times$ 21-4 hybrid plants, of which two had Ae. speltoides translocations, 18 'Filatovka' $\times 21-4$ hybrid plants, of which five had Ae. speltoides translocations, 15 'Novosibirskaya 3' $\times 21-4$ hybrid plants, of which four had Ae. speltoides translocations and 28 'Novosibirskaya 40' $\times$ 21-4 hybrid plants, of which ten had Ae. speltoides translocations. The parental spring wheat line 21-4 was used as the control.

Heading date was substantially influenced by the allelic composition of the $V R N-1$ genes controlling growth habit (Stelmakh, 1993; Trevaskis et al., 2007). Our analysis of these genes showed that all spring growth-habit progeny of the crosses between each of the soft winter wheat cultivars and the spring line had the same allelic combination as had the parental line 21-4 - Vrn-Ala, vrn-B1, and vrn-D1. In line 21-4, the number of days from sprouting to heading was 41.1 . In the 'Biyskaya ozimaya' $\times 21-4$ progeny, three out of 13 lines 
Table 1

Number of days from sprouting to heading and leaf rust resistance in lines with LrAsp5

\begin{tabular}{|c|c|c|c|c|}
\hline \multirow{2}{*}{ Cross } & \multirow{2}{*}{ Line } & \multirow{2}{*}{$\begin{array}{l}\text { Sprouting to heading, days } \\
x \pm s x\end{array}$} & \multicolumn{2}{|c|}{ Leaf rust resistance } \\
\hline & & & Infection type 1 & Percent leaf area infected \\
\hline Line 21-4 & Control & $41.1 \pm 0.2$ & 1 & 5 \\
\hline \multirow[t]{2}{*}{ Biyskaya ozimaya × 21-4 } & $77-7$ & $39.4 \pm 0.2^{*}$ & 1 & 10 \\
\hline & $77-10$ & $42.3 \pm 0.3^{*}$ & 0 & 0 \\
\hline \multirow[t]{5}{*}{ Filatovka $\times 21-4$} & $83-3$ & $39.4 \pm 0.2^{*}$ & 0 & 0 \\
\hline & $83-10$ & $41.4 \pm 0.2$ & 0 & 0 \\
\hline & $83-11$ & $41.4 \pm 0.2$ & 1 & 15 \\
\hline & $84-14$ & $41.1 \pm 0.3$ & 0 & 0 \\
\hline & $87-8$ & $40.1 \pm 0.4$ & 1 & 5 \\
\hline \multirow[t]{4}{*}{ Novosibirskaya $3 \times 21-4$} & $31-8$ & $38.5 \pm 0.1^{*}$ & 2 & 20 \\
\hline & $31-14$ & $38.2 \pm 0.3^{*}$ & 2 & 30 \\
\hline & $32-10$ & $39.3 \pm 0.3^{*}$ & 1 & 20 \\
\hline & $34-12$ & $40.3 \pm 0.2^{*}$ & 1 & 10 \\
\hline \multirow[t]{10}{*}{ Novosibirskaya $40 \times 21-4$} & $53-1$ & $41.2 \pm 0.3$ & 2 & 50 \\
\hline & $53-10$ & $37.8 \pm 0.3^{*}$ & 2 & 40 \\
\hline & $54-6$ & $42.7 \pm 0.4^{*}$ & 0 & 0 \\
\hline & $54-7$ & $41.0 \pm 0.2$ & 0 & 0 \\
\hline & $54-10$ & $39.8 \pm 0.3^{*}$ & 2 & 30 \\
\hline & $54-14$ & $42.3 \pm 0.2^{*}$ & 2 & 30 \\
\hline & $56-8$ & $43.3 \pm 0.4^{*}$ & 0 & 0 \\
\hline & $57-5$ & $40.4 \pm 0.4$ & 1 & 10 \\
\hline & $57-8$ & $39.9 \pm 0.3^{*}$ & 0 & 0 \\
\hline & $57-11$ & $39.4 \pm 0.2^{*}$ & 2 & 30 \\
\hline
\end{tabular}

* Differences between the hybrid lines and the parental line are significant at $p<0.05$.

${ }^{1}$ On the 0-4 scale after Mains and Jackson.

were later in ear emergence than line 21-4. Line 77-10 with an alien translocation was the latest - it was 1.2 days later than the control (Table 1). Other three lines were earlier than the control. Line 77-7 with a translocation was the earliest - it was 1.7 days earlier than the parental line. No other line was different from line 21-4. In the 'Filatovka' $\times$ 21-4 progeny, only line $85-1$ was later than the parental line -2.9 days later. Five lines were earlier than the control, with line 86-2 being the earliest - it was 2.8 days earlier. All the other lines, including those with translocations, in this hybrid population were similar to the control. In the 'Novosibirskaya 3' $\times 21-4$ hybrid population, only two lines, $31-12$ and $32-7$, had the same heading date as the parental line 21-4. All the other lines in this hybrid population were earlier than their spring growth-habit parent. Line 35-12 was the earliest - it was 4.3 days earlier than the control. In the 'Novosibirskaya 40' $\times 21-4$ progeny, four lines were later than, 12 were earlier than and 12 were not different from the parental line 21-4. Line 56-8 with a translocation was the latest - it was 2.2 days later than the control. Line 53-10 with a translocation was the earliest - it was 3.3 days earlier than the control.

Heading dates in the lines with foreign genetic material in their genomes were shown to be earlier than, equal to or later than that in the control line 21-4. The same was true of the lines without alien introgressions. It can therefore be concluded that the translocation from Ae. speltoides has no effect on heading date in soft wheat. It had previously been demonstrated that hybrid plants derived from crosses between winter and spring wheats were later in ear emergence than the spring growth-habit parent, even though the allelic compositions of the $V R N-1$ genes were identical (Stasyuk et al., 2017). The hybrid plants resulting from the crosses between each of the winter cultivars and line 21-4 had the same allelic composition of the $V R N-1$ genes as had the parental line, but their heading dates varied in both directions relative to the control. It is likely that the differences in heading date are explained by factors other than $V R N-1$.

Scoring the severity of leaf rust showed that all the lines that had translocations from Ae. speltoides were immune or slightly susceptible (Table 1). Lines without LrAsp5 were highly susceptible and had infection type 4 on the $0-4$ scale by Mains and Jackson, with pustules covering up to $100 \%$ of the leaf area.

Analysis of yield components showed that, in the 'Biyskaya ozimaya' $\times$ 21-4 progeny, grain number per main spike was similar to that in the parental line in almost all lines, except for 
line 74-8 without translocations and line 77-7 with a translocation from Ae. speltoides, which were inferior to the control. In the 'Filatovka' $\times 21-4$ progeny, ten lines were equal to line 21-4, and eight lines, including line 83-10 with a translocation, were inferior to the control. In the 'Novosibirskaya 3' $\times 21-4$ progeny, line 36-3 without translocations was superior and five lines, including two with translocations, were inferior to the control. In the 'Novosibirskaya $40^{\prime} \times 21-4$ progeny, five lines, of which two had foreign genetic material, were inferior to the control. No other line was different from the spring growth-habit parent.

Grain weight per spike in the 'Biyskaya ozimaya' $\times 21-4$ progeny was not significantly different from the control, except for line 74-8, which was inferior. An line with an Ae. speltoides introgression, 83-3, which was superior to the parental line, was identified among the 'Filatovka' $\times$ 21-4 hybrids. Seven lines, of which one had a translocation, were inferior to the control, while the others were similar to the spring growth-habit parent. Two 'Novosibirskaya 3' $\times$ 21-4 hybrid lines without translocations were significantly superior to the control, and four were inferior in terms of grain weight per spike. The other nine lines in that progeny were not different from the parent. In the 'Novosibirskaya 40' $\times 21-4$ progeny, seven lines, including three with translocations, were inferior to the parental line, while the others were not different from the control.

1000-grain weight in line 75-13 without translocations and line 77-7 with a translocation from cross 'Biyskaya ozimaya' $\times$ 21-4 was significantly higher than in the control, three lines were inferior and the other eight were similar to the control in terms of this measure. In the 'Filatovka' $\times 21-4$ progeny, four lines were superior and four were inferior to the control. In either case, one of the lines had a translocation. The other lines in that population were not significantly different from the control. In the 'Novosibirskaya 3' $\times 21-4$ progeny, five lines, including one with a translocation, were superior, three were inferior, and seven were similar to the control. In the 'Novosibirskaya 40' $\times 21-4$ progeny, four lines, of which two had translocations, were superior to the control. Three lines, of which one had a translocation, were significantly inferior and 21 were significantly similar to the control.

The assessment of the quantitative traits showed that the lines with translocations from Ae. speltoides were superior, equal or inferior to the control in terms of those traits. It can therefore be concluded that the expression of the quantitative traits in each line follows an individual pattern, irrespective of the presence of alien translocations. Based on the assessment of yield components, lines 75-13, 83-3, 84-10, 31-15, 35-3, $36-3,36-6,54-2,56-7,57-8$, and 57-11 were significantly superior to the parental line 21-4 in terms of 1000-grain weight or grain number per main stem spike and grain weight per main stem spike. These lines can be recommended for use in breeding work.

\section{Conclusions}

Our results show the effectiveness of marker-assisted selection, with which we identified among $\mathrm{F}_{2}$ plants those that had a spring growth habit and carried a translocation with the LrAsp5 gene from Ae. speltoides. A field experiment demonstrated that plants with translocations were highly resistant to the West Siberian population of Puccinia triticina Erikss., the causative agent of leaf rust. Variation in heading date is probably not only due to the $V R N-1$, genes, but also due to the genetic background of the winter wheat varieties used. The expression of the quantitative traits follows an individual pattern in each line, irrespective of the presence of alien translocations.

\section{References}

Likhenko I.E., Stasyuk A.I., Shcherban'A.B., Zyryanova A.F., Likhenko N.I., Salina E.A. Study of allelic composition of Vrn-1 and $P p d-1$ genes in early-ripening and middle-early varieties of spring soft wheat in Siberia. Rus. J. Genet.: Applied Research. 2015;5(3): 198-207.

Leonova I.N., Stasyuk A.I., Skolotneva E.S., Salina E.A. Enhancement of leaf rust resistance of Siberian winter wheat varieties by markerassisted selection. Cereal Research Communications. 2017;45(4): 621-632.

Mains E.B., Jackson H.S. Physiological specialization in the leaf rust of wheat, Puccinia triticina Erikss. Phytopathol. 1926;16:89-120.

Stelmakh A.F. Genetic effects of Vrn genes on heading date and agronomic traits in bread wheat. Euphytica. 1993;65:53-60.

Trevaskis B., Hemming M.N., Dennis E.S., Peacock W.J. The molecular basis of vernalization-induced flowering in cereals. Trends Plant Sci. 2007;12(8):352-357.

Stasyuk A.I., Leonova I.N., Salina E.A. Variability of agronomically important traits in spring wheat hybrids obtained by marker-assisted selection from crosses of winter wheat with spring wheat donors of resistance genes. Sel'skokhozyaistvennaya Biologiya $=$ Agricultural Biol. 2017;52(3):526-534.

Acknowledgements. This work was supported by grant No. 16-1600011 from the Russian Science Foundation.

Conflict of interest. The authors declare no conflict of interest. 


\title{
Transferability of barley EST markers used for analysis T. aestivum - H. marinum subsp. gussoneanum introgression lines
}

\author{
N.V.Trubacheeva ${ }^{1 *}$, E.D. Badaeva ${ }^{2}$, T.S. Osadchaya ${ }^{1}$, L.A. Pershina ${ }^{1}$ \\ ${ }^{1}$ Institute of Cytology and Genetics, SB RAS, Novosibirsk, Russia \\ ${ }^{2}$ Vavilov Institute of General Genetics, Moscow, Russia
}

DOI 10.18699/ICG-PlantGen2019-63

(c) Autors, 2019

* e-mail: ntr@ngs.ru

\begin{abstract}
We evaluated the applicability of seventy-eight $H$. vulgare EST markers for studying bread wheat- $H$. marinum subsp. gussoneanum substitution and addition lines. Of all the markers studied, thirty-six (46\%) were amplified in H. marinum ssp. gussoneanum and wheat introgression lines. The identification of wild barley chromosomes using EST markers confirmed the GISH and C-banding data. Thus, it was established that the H. vulgare EST markers can be successfully used to identify the chromosomes of $H$. marinum subsp. gussoneanum in introgression lines of wheat.
\end{abstract}

Key words: EST markers; introgression alloplasmic lines; wild barkey.

\section{Introduction}

Wild relatives have been employed successfully in common wheat breeding programmes to introgress agronomically important genes (Ceoloni et al., 2014). Sea barley (Hordeum marinum subsp. gussoneanum, $2 n=28$ ) has potentially useful traits such as resistance to abiotic stresses, including high salt tolerance (Garthwaite et al., 2005), waterlogging (Garthwaite et al., 2005), and tolerance to combined salinity and waterlogging resulting in low $\mathrm{O}_{2}$ concentrations (Malik et al., 2009). These resistance traits may have been transferred to wheat due to the crossability of wild barley with bread wheat. Chromosomes from $H$. marinum could be introduced into common wheat through wheat-barley hybrids and backcrossing to wheat (Pershina et al., 2009; Trubacheeva et al., 2009). Introgressed segments can be assessed by in situ hybridisation, which readily distinguishes $H$. marinum chromosomes from those of wheat (Trubacheeva et al., 2009). Molecular markers capable of detecting small segments of H. marinum chromatin in a wheat background would also enhance the use of this wild species to increase wheat genetic resources. The aim of this work was to study the amplification of EST markers of barley $H$. vulgare in the genome of the wild barley $H$. marinum ssp. gussoneanum and to assess their use for detecting barley chromatin segments in the alloplasmic bread wheat-H. marinum subsp. gussoneanum introgression lines.

\section{Materials and methods}

The accessions of the barley H. marinum ssp. gussoneanum Hudson $(2 n=4 x=28), H$. vulgare cv. 'Nepolegaushii' $(2 n=$ $2 x=14$ ), and bread wheat $T$. aestivum cv. 'Pyrotrix 28 ' were used for the initial transferability analysis of 78 EST markers. Alloplasmic (with the cytoplasm of $H$. marinum) wheat-barley introgression lines were studied using GISH, C-banding and EST analysis. A set of 78 EST-SSR markers developed by Hagras et al. (2005) and uniformly distributed across the $H$. vulgare chromosomes were tested for amplification of $H$. marinum ssp. gussoneanum DNA. PCR conditions followed a touch-down protocol as described by Hagras et al. (2005). Amplified products were separated in $1.5 \%$ agarose gels, stained with ethidium bromide and photographed in ultraviolet light.

\section{Results and discussion}

The transferability of $85 \mathrm{H}$. vulgare EST markers, which were from all the seven homoeologous groups of barley, to the chromosomes of $H$. marinum ssp. gussoneanum was examined. Forty-two markers, i. e., $49 \%$, did not amplify fragments in H. marinum ssp. gussoneanum. Two markers were not polymorphic between $H$. vulgare, $H$. marinum ssp. gussoneanum and T. aestivum and therefore could not be used. These 44 markers were not applicable for analysing lines with chromosomes of $H$. marinum ssp. gussoneanum. Forty-one EST markers, i.e., 48\%, showed a clear single band of the same size in $H$. vulgare and $H$. marinum ssp. gussoneanum but failed to amplify or amplified a fragment of different sizes in wheat. Thus, these 41 EST markers of $H$. vulgare were transferable to $H$. marinum ssp. gussoneanum and would be useful in identifying $H$. marinum ssp. gussoneanum chromosomes in bread wheat backgrounds.

The presence of barley chromosomes in the alloplasmic lines was detected using GISH analysis and C-banding of chromosomes. GISH was performed to reveal the chromosome configuration and the presence of $H$. marinum ssp. gussoneanum chromosomes in alloplasmic bread wheat- $H$. marinum subsp. gussoneanum lines. It was established that all the lines studied carry H. marinum ssp. gussoneanum chromosomes and are either substitution or addition lines. We found a disomic substitution line with $2 n=40 \mathrm{w}+2 \mathrm{H}^{\mathrm{mar}}$, a ditelosomic addition line with $2 n=42 \mathrm{w}+2 \mathrm{tH}^{\mathrm{mar}}$ and a disomic addition line with $2 n=42 \mathrm{w}+2 \mathrm{H}^{\operatorname{mar}}$ (Figure 1, a). In the line derived from incomplete amphiploid $(2 n=54), 12$ wild barley chromosomes were added to 42 wheat chromosomes $\left(42 \mathrm{w}+12 \mathrm{H}^{\mathrm{mar}}\right)$ (Figure 1, $b$ ). Two lines were multiple addition lines carrying two pairs of $H$. marinum ssp. gussoneanum chromosomes $\left(2 n=42 \mathrm{w}+4 \mathrm{H}^{\mathrm{mar}}\right)$ and one line was a multiple substitution line $\left(2 n=36 \mathrm{w}+6 \mathrm{H}^{\mathrm{mar}}\right)$. C-banding confirmed the number of chromosomes in the lines studied and determined the types of substitutions in the alloplasmic wheat-barley substitution lines. 

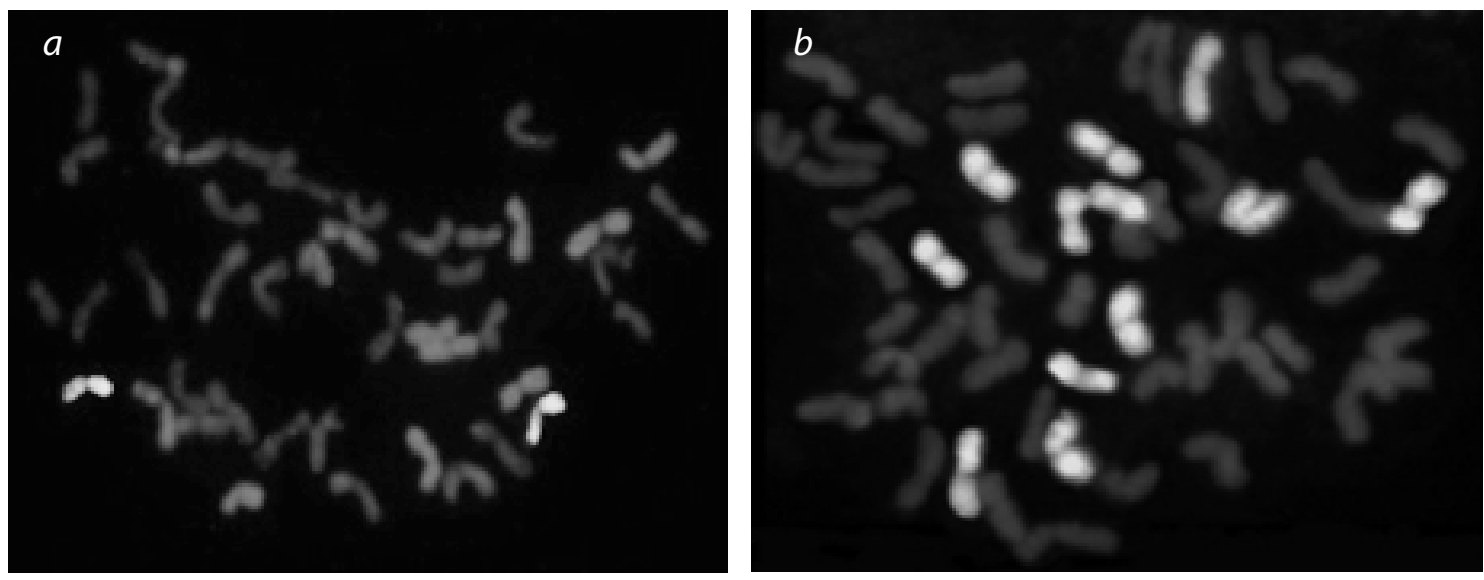

Figure 1. Genomic in situ hybridization with $H$. marinum ssp. gussoneanum genomic DNA (green) probes to mitotic metaphase chromosomes.

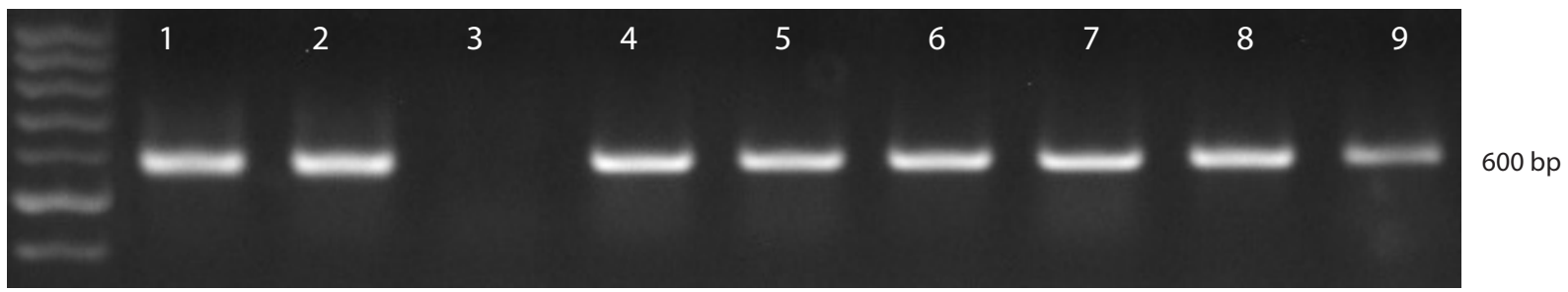

Figure 2. Example of a PCR amplification profile used for identifying chromosome $7 \mathrm{H}^{\text {mars }}$ with EST marker k4573. 1, $H$. vulgare; 2, H. marinum ssp. gussoneanum; 3, T. aestivum; 4, 7H $\mathrm{H}^{\operatorname{mar}}$ (7D) disomic substitution line; $5,7 \mathrm{H}^{\text {mar }}$ (7B) disomic substitution line; $6,1 \mathrm{H}^{\operatorname{mar}}(1 \mathrm{~B}), 5 \mathrm{H}^{\mathrm{mar}}(5 \mathrm{D}), 7 \mathrm{H}^{\operatorname{mar}}(7 \mathrm{D})$ multiple substitution line; $7,7 \mathrm{H}^{\operatorname{mar} S}$ ditelosomic addition line; $8,7 \mathrm{H}^{\mathrm{mar}}$ disomic addition line; 9, $1 \mathrm{H}^{\mathrm{mar}}+7 \mathrm{H}^{\text {mar }}$ multiple addition line.

The following types of substitutions have been identified: $7 \mathrm{H}^{\mathrm{mar}} \mathrm{L}(7 \mathrm{D}), 7 \mathrm{H}^{\mathrm{mar}}(7 \mathrm{D}), 7 \mathrm{H}^{\mathrm{mar}}(7 \mathrm{~B})$, and one line contained three chromosome substitutions, $1 \mathrm{H}^{\operatorname{mar}}(1 \mathrm{~B}), 5 \mathrm{H}^{\mathrm{mar}}(5 \mathrm{D})$ and $7 \mathrm{H}^{\mathrm{mar}}(7 \mathrm{D})$. We identified the addition lines with a pair of telocentric chromosomes for the long arm of chromosome $7 \mathrm{H}^{\mathrm{mar}}$, a pair of telocentric chromosomes for the short arm of $7 \mathrm{H}^{\mathrm{mar}}$ and the line with 42 chromosomes of wheat and a pair of chromosomes $7 \mathrm{H}^{\mathrm{mar}}$.

There is a lack of molecular markers for wild species such as H. marinum subsp. gussoneanum, and the transfer of markers to them from related crop species is a feasible method for genetic analysis (Hagras et al., 2005). Therefore, EST markers of $H$. vulgare were used because cultivated barley is a closely related species of wild barley. The transferable EST markers of all chromosomes were amplified, except for $5 \mathrm{H}^{\text {mar }}$, in the line with $42 \mathrm{w}+12 \mathrm{H}^{\text {mar }}$. All markers specific for $H$. vulgare chromosomes $1 \mathrm{H}, 5 \mathrm{H}$ and $7 \mathrm{H}$ were successfully amplified in the wheat-barley substitution line with three wild barley chromosomes, $1 \mathrm{H}^{\mathrm{mar}}, 5 \mathrm{H}^{\mathrm{mar}}$, and $7 \mathrm{H}^{\text {mar. }}$ In the lines that were disomic for the $7 \mathrm{H}^{\operatorname{mar}}(7 \mathrm{D})$ and $7 \mathrm{H}^{\operatorname{mar}}(7 \mathrm{~B})$ substitutions, as well as in the addition line for $7 \mathrm{H}^{\mathrm{mar}}$, five markers for $7 \mathrm{H}$ were amplified (Figure 2).

In the line with chromosomes $1 \mathrm{H}^{\mathrm{mar}}$ and $4 \mathrm{H}^{\text {mar }}$ and with chromosomes $1 \mathrm{H}^{\mathrm{mar}}$ and $7 \mathrm{H}^{\mathrm{mar}}$, markers located in the homoeologous chromosomes of $H$. vulgare were also amplified. Thus, according to the results of EST analysis, transferable markers of chromosomes $1 \mathrm{H}, 4 \mathrm{H}, 5 \mathrm{H}$ and $7 \mathrm{H}$ are localized on the homoeologous chromosomes of wild barley H. marinum. Localization of EST markers on homoeologous chromosomes in related species was also demonstrated in (Hagras, 2005), where it was found that $90 \%$ of the studied EST markers of cultivated barley are localized on homoeologous $H$. chilense chromosomes. The authors explain this by the fact that EST sequences have a unique character in the genome and are highly conserved. At the same time, the absence of amplification products in $H$. marinum ssp. gussoneanum with $54 \%$ of the $H$. vulgare markers used indicates that the genomes of the two barley species have undergone significant changes in evolution. These two species of barley are known to be phylogenetically distant and belong to different subgenera of the genus Hordeum (Blattner 2015).

\section{Conclusion}

In our work, a combination of cytogenetic and molecular genetic approaches were used for characterization of bread wheat-H. marinum ssp. gussoneanum introgression lines. The results showed that transferable $H$. vulgare EST markers can be successfully used to identify the chromosomes of $\mathrm{H}$. marinum ssp. gussoneanum.

\section{References}

Blattner F.R. Progress in phylogenetic analysis and a new infrageneric classification of the barley genus Hordeum (Poaceae: Triticeae). Breed Sci. 2009;59:471-480. 
Ceoloni C., Kuzmanovic L., Forte P., Gennaro A., Bitti A. Targeted exploitation of gene pools of alien Triticeae species for sustainable and multi-faceted improvement of the durum wheat crop. Crop Pasture Sci. 2014;65:96-111.

Garthwaite A.J., von Bothmer R., Colmer T.D. Salt tolerance in wild Hordeum species is associated with restricted entry of $\mathrm{Na}+$ and $\mathrm{Cl}-$ into the shoots. $J$ Exp Bot. 2005;56(419):2365-2378.

Hagras A.A., Kishii M., Sato K., Tanaka H., Tsujimoto H. Extended application of barley EST markers for the analysis of alien chromosomes added to wheat genetic background. Breed Sci. 2005;55: 335-341.

Malik A.I., English J.P., Colmer T.D. Tolerance of Hordeum marinum accessions to $\mathrm{O} 2$ deficiency, salinity and these stresses combined. Ann Bot. 2009;103(2):237-248. DOI 10.1093/aob/men142.
Pershina L.A., Devyatkina E.P., Belova L.I., Trubacheeva N.V., Arbuzova V.S., Kravtsova L.A. Features of alloplasmic wheat-barley substitution and addition lines (Hordeum marinum subsp. gussoneanum)-Triticum aestivum. Russian J Gen. 2009;45:1223-1229.

Trubacheeva N.V., Efremova T.T., Badaeva E.D., Kravtsova L.A., Belova L.I., Devyatkina E.P., Pershina L.A. Production of alloplasmic and euplasmic wheat-barley ditelosomic substitution lines $7 \mathrm{H}^{1} \operatorname{Lmar}(7 \mathrm{D})$ and analysis of the $18 \mathrm{~S} / 5 \mathrm{~S}$ mitochondrial repeat in these lines. Russ. J. Genet. 2009;45:1438-1443.

Acknowledgements. The work is supported by project No. 03242019-0039, RFBR grant No. 17-04-01738.

Conflict of interest. The authors declare no conflict of interest. 


\title{
Study of introgression lines of common wheat obtained with the participation of the synthetic forms T. miguschovae and Avrodes by allelic variants of the $W x$ genes
}

\author{
E.R. Davoyan ${ }^{1 *}$, R.O. Davoyan ${ }^{1}$, Yu.S. Zubanova ${ }^{1}$, D.S. Mikov ${ }^{1}$, D.M. Boldakov ${ }^{1}$, A.G. Chernook ${ }^{2}$, M.G. Divashuk ${ }^{2}$ \\ ${ }^{1}$ National Center of Grain of P.P. Lukyanenko, Krasnodar, Russia \\ ${ }^{2}$ St. All-Russia Research Institute of Agricultural Biotechnology, Moscow, Russia
}

DOI 10.18699/ICG-PlantGen2019-64

(c) Autors, 2019

* e-mail: davoyanro@mail.ru

\begin{abstract}
We studied the synthetic forms Triticum miguschovae (GGA $\left.{ }^{t} \mathrm{~A}^{\mathrm{D}} \mathrm{DD}\right)$ and Avrodes (BBAASS), as well as introgression lines of common wheat obtained with their participation from allelic variants of the $W x$ genes with the use of molecular markers. It was revealed that most of the lines carry wild-type alleles $W x-A 1 a, W x-B 1 a$ and $W x-D 1 a$, which were transferred from the recipient varieties. A fragment of amplification that is not typical of the $W x-B 1 a$ allele was found in line 393. The alleles of the $W x-A 1$ and $W x-B 1$ genes in the synthetic form of T. miguschovae are different from those in common wheat, and may have different phenotypic manifestations on the formation of starch. The lack of amplification from the $D$ genome in the synthetic form Avrodes is associated with the substitution of wheat chromosome 7D with its homoeologous chromosome from Ae. speltoides.

Key words: common wheat; synthetic forms; introgression lines; molecular markers; Wx-genes.
\end{abstract}

\section{Introduction}

The study of allelic variants of $W x$ genes is important for breeding aimed at creating varieties of bread wheat (Triticum aestivum L.) with a modified starch composition. The starch macromolecule consists of two types of glucose polymers: amylose and amylopectin. The ratio of amylose to amylopectin affects the properties of starch, which are the determining factors of its quality and end-use direction (Zeng et al., 1997). The enzyme responsible for the biosynthesis of amylose in wheat is the starch synthase GBSSI associated with granules encoded by the three homoeologous genes, $W x-A 1, W x-D 1$ and $W x-B 1$ (Nakamura et al., 1995). Each of these genes has several allelic variants. Wild-type alleles, $W x-A 1 a, W x-B 1 a$ and $W x-D 1 a$, do not carry mutations and actively express the GBSSI protein (Yamamori et al., 1994). Another type of allele is nonfunctional (null allele) and leads to a decrease in amylose content in starch. Polymorphism of allelic variants of $W x$ genes was studied for common and the hard wheat Triticum durum (Rodrígez-Quijano et al., 1998). As a result, it became possible to identify different alleles of the $W x$ genes, including null alleles, which were used as the basis for breeding programs aimed at producing wheat varieties with a modified starch composition (Nakamura et al., 1995). Recently, such studies have been carried out on wild relatives of common wheat (Guzman et al., 2011). In this regard, species of the genus Aegilops such as Aegilops tauschii Coss. (DD) and Aegilops speltoides Tausch. (SS) are of great interest, for they may be sources of new alleles of $W x$ genes with different enzymatic activity and have the potential to increase the genetic diversity of bread wheat for this trait. For transmission of common wheat valuable traits from wild relatives, the genome-substituted synthetic form Avrodes and the genome-added form T. miguschovae were used (Zhirov et al., 1984; Ivanov, 1984). When using these forms, introgression lines of common wheat were obtained, characterized by disease resistance, high protein content and other morphobiological features that are interesting for selection (Davoyan et al., 2012). Presumably, these lines can carry both known and new alleles of $W x$ genes.

\section{Materials and methods}

The objects of the study were the synthetic forms T. miguschovae and Avrodes, as well as 14 introgression lines of common wheat obtained with their participation. Commercial common wheat varieties Avrora, Mironovskaya 808, Echo, Bezostaya 1, Fisht, Grom, Vostorg, and Kavkaz were used as recipients. The synthetic forms and lines studied were obtained from the Department of Biotechnology of the National Center of Grain named after P.P. Lukyanenko. DNA isolation was performed by boiling in alkali. Evaluation of the lines for an allelic variant of $W x$ genes was performed with the use of PCR. Primers were selected on the basis of literature data, their names, sources and amplification conditions are presented in the Table 1.

\section{Results and discussion}

To study the samples for the allelic state of the $W x$ - $A 1$ gene, we used a code-marker created by Nakamura et al. (2002), which amplified fragments from all homeologous alleles of the $W x$ genes. In samples with wild-type alleles $W x-A 1 a$, amplification of two fragments, $410 \mathrm{bp}$ and $389 \mathrm{bp}$ in length, and in the presence of the null allele $W x-A 1 b, 410 \mathrm{bp}$ and $370 \mathrm{bp}$, is observed. In the majority of the lines studied, as well as in the synthetic form Avrodes, the wild-type allele $W x-A l a$ was identified (Figure 1). In line 393 obtained with the participation of T. miguschovae, heterogeneity was revealed, there is no amplification from the A genome in lane 8.2 (389-bp fragment). One bend was amplified with a different size from the 410-bp fragment in the synthetic form T. miguschovae, which is characteristic of common wheat, and also in line 393 there is no amplification from the $\mathrm{A}$ genome. 
Table 1

PCR conditions and primer names used to identify the corresponding alleles

\begin{tabular}{llll}
\hline Primers & Loci of genes (alleles) & Annealing temperature, ${ }^{\circ} \mathrm{C}$ & Source \\
\hline AFC/AR2 & $W x-A 1(A 1 b)$ & 65 & Nakamura et al., 2002 \\
4 F/4R & $W x-A 1, W x-B 1, W x-D 1$ & 58 & McLauchlan et al., 2001 \\
Wx-D1-2F/Wx-D1-2R & $W x-D 1(D 1 b)$ & 55 & Shariflou et al., 2001 \\
\hline
\end{tabular}

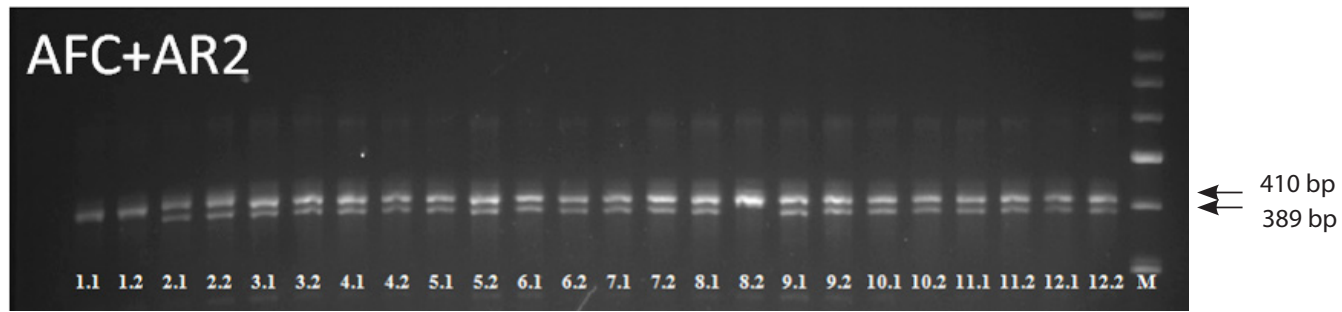

Figure 1. Electrophoregram of PCR products with primers AFC and AR2: 1: T. miguschovae; 2: Avrodes; 3: 241; 4: D16/1; 5: D16/2; 6: D16/4; 7: 1381; 8: 393; 9: 7; 10: 2269; 11: 1453; 12: variety 'Aurora'; M: marker length of DNA fragments.

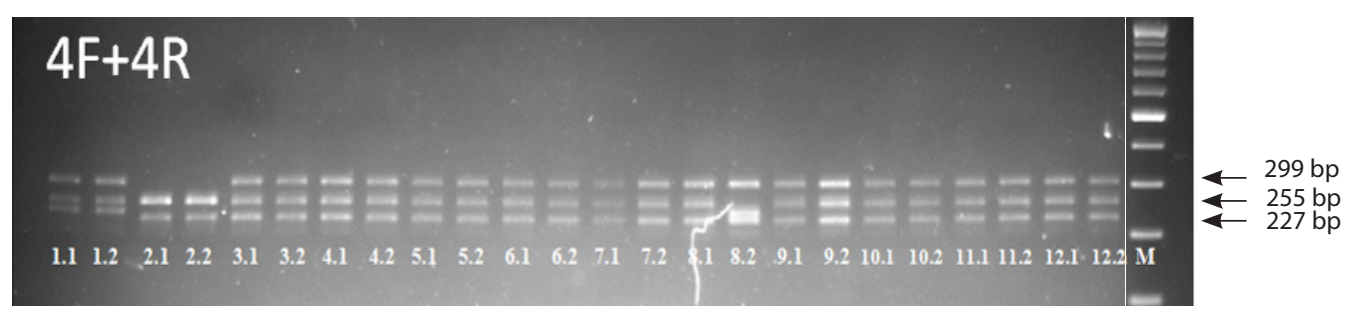

Figure 2. Electrophoregram of PCR products with primers $4 \mathrm{~F}$ and $4 \mathrm{R}$ 1: T. miguschovae; 2 : Avrodes; 3: 241; 4: D16/1; 5: D16/2; 6: D16/4; 7: 1381; 8: 393; 9: 7; 10:2269; 11: 1453; 12: variety Aurora; M: marker length of DNA fragments.

McLauchlan et al. (2001) developed a molecular labeling system for the $W x-B 1$ gene which amplify fragments from all three loci. Three DNA fragments $(299,255,227 \mathrm{bp})$ are amplified in samples with a wild-type allele. Two fragments (fragment of $227 \mathrm{bp}$ is absent) are synthesize in forms with a null allele (Figure 2). In the majority of the lines studied, the wild type allele $W x-B 1 a$ was detected. In the synthetic form T. miguschovae, the amplification fragment from the $\mathrm{B}$ genome differed in size from the 227-bp fragment characteristic of common wheat. Avrodes revealed no amplification from the D genome (299-bp amplification fragment). At the same time, the fragment characteristic of the genome B ( $257 \mathrm{bp}$ ) differed in intensity from the others. In the first case that was due to the replacement of the D genome of bread wheat with the $\mathrm{S}$ genome from Ae. speltoides and in the second, probably, due to double amplification from the B genome. Line 393 is heterogeneous, plants were identified with both amplification fragments typical of common wheat and different from it. So in Figure 2, in sample 8.2, there is no amplification from the A genome and an additional fragment is found which is similar in size to the fragment from the B genome (227 bp).

Identification of the allelic state of the $W x-D 1$ gene was carried out using a marker developed by Shariflou et al. (2001). This marker amplifies $279 \mathrm{bp}$ fragment in the case of null allele for the $W x-D 1$ gene; in the presence of the wildtype allele $-910 \mathrm{bp}$ fragment. A fragment specific for the wild-type allele $W x$-Dla was detected in the studied lines and in T. miguschovae. There was no amplification from the D genome in the synthetic form.

\section{Conclusions}

It was revealed that the majority of the lines studied present typical wild-type alleles for the common wheat genes $W x-A 1 a$, $W x-B 1 a$ and $W x-D 1 a$ as a result of the work carried out with the help of molecular markers. The wild-type alleles $W x-B 1 a$ and $W x-D 1 a$ were transmitted from the recipient varieties in the case of lines derived from Avrodes, and the Wx-Ala allele could be transmitted from both the recipient varieties and Avrodes. The $W x-A 1 a, W x-B 1 a$ alleles were transmitted from the recipient varieties in the lines obtained with the participation of T. miguschovae. Heterogeneity in line 393 is apparently related to the ongoing formative process. Probably, chromosome 7A from common wheat was replaced in this line by its homoeologous chromosome from T. miguschovae, hence no amplification from the A genome, and the reason why an additional fragment has been identified. The alleles of the $W x-A 1$ and $W x-B 1$ genes are different from those in common wheat in the synthetic form T. miguschovae, and may 
have a different phenotypic manifestation on the formation of starch. Thus, the selected molecular markers developed for identifying the null alleles of the $W x$ genes of bread wheat can also be used to identify the alleles of the $W x$ genes carried by T. miguschovae, Avrodes and the lines derived from them and for marker-assisted selection. The synthetic forms T. miguschovae and Avrodes, as well as line 393, carry alleles different from wild-type ones and are interesting for studying the polymorphism of allelic variants of $W x$ genes and their influence on the technological properties of wheat flour.

\section{References}

Davoyan R.O., Bebyakina I.V., Davoyan O.R., Zinchenko A.N., Davoyan E.R., Kravchenko A.M., Zubanova Yu.S. Synthetic forms as a basis for the preservation and use of the gene pool of wild relatives of common wheat. Vavilovsky Journal Genetics Breeding. 2012;16(1):44-51.

Zhirov E.G., Ternovskaya T.K. Genomic engineering in wheat. Vestnik Sel'skokhozyaistvennoi Nauki. 1984;10:58-66.

Ivanov G.I. New wheat amphidiploid with DDAbAb genomes. Scientific Techn. Bullet All-Russian Scientific-Research Institute Plant Industry. 1984;142:78-79.

Guzmán C., Caballero L., Alvarez J.B. Molecular characterization of the $W x-B 1$ allelic variants identified in cultivated emmer wheat and comparison with those of durum wheat. Mol. Breeding. 2011;28: 403-411.

McLauchlan A., Ogbonnaya F.C., Hollingsworth B. Development of robust PCR-based DNA markers for each homeoallele of granulebond starch synthase and their application in wheat breeding programs. Aust. J. Agric. Res. 2001;52:1409-1416.

Nakamura T., Jamamori M., Hirano H. Production of waxy (amylasefree) wheat. Mol. Gen. Genet. 1995;248:253-259.

Nakamura T., Vrinten P., Saito M., Konda M. Rapid classification of partial waxy wheats using PCR-based markers. Genome. 2002;45: $1150-1156$.

Rodriguez-Quijano M., Nieto-Taladriz M.T., Carrillo J.M. Polymorphism of waxy proteins in Iberian hexaploid wheats. Plant Breeding. 1998; 117:341-344.

Shariflou M.R., Hassani M.E., Sharp P.J. A PCR-based DNA marker for detection of mutant and normal alleles of the Wx-D1 gene of wheat. Plant Breeding. 2001;120(2):121-124.

Yamamori M., Nagamine T., Nakamura T., Endo T.R. Waxy protein deficiency and chromosomal location of coding genes in common wheat. Theoretical Applied Genetics. 1994;89(2-3):179-184.

Zeng M., Morris C.F., Batey I.I., Wrigley C.W. Sources of variation for starch gelatinization, pasting, and gelation properties in wheat. Cereal Chemistry. 1997;74:63-71.

Conflict of interest. The authors declare no conflict of interest. 


\title{
Non-brittle rachis 1-A (Btr1-A) gene in di- and hexaploid wheat species
}

\author{
V. Vavilova*, I. Konopatskaia, N.P. Goncharov \\ Institute of Cytology and Genetics, SB RAS, Novosibirsk, Russia
}

DOI 10.18699/ICG-PlantGen2019-65

(c) Autors, 2019

* e-mail: valeriya-vavilova@bionet.nsc.ru

\begin{abstract}
Spike brittleness is one of the key domestication traits in Triticum species. In the recent studies it was found that the Non-brittle rachis 1-A (Btr1-A) gene involved in the regulation of the brittle/non-brittle spike trait. Here we investigated the genetic variability of the Btr1-A gene from 13 accessions of Triticum monococcum L., T. urartu Thum. ex Gandil., T. boeoticum Boiss., T. macha Decapr. et Menabde, T. aestivum ssp. petropavlovskyi (Udacz. et Migusch.) N.P. Gontsch., T. spelta L., T. spelta ssp. yunnanense (King ex S.L. Chen) N.P. Gontsch., T. vavilovii (Thum.) Jakibz. and T. tibetanum Shao. The Btr1-A sequences for T. aestivum ssp. petropavlovskyi and T. vavilovii were obtained for the first time. Hexaploid wheat accessions analyzed were characterized by a 2-bp deletion in the Btr1-A coding region (positions 291-299). The presence of this deletion leads to the formation of a nonfunctional protein (97 instead of 196 amino acids). Additional investigations are required to establish the potential relationship between Btr1-A and other genes that regulate the brittle/non-brittle spike trait in Triticum species.

Key words: wheat; Triticum; spike morphology; brittle rachis; Btr1-A gene.
\end{abstract}

\section{Introduction}

Currently, wheat (Triticum L.) is an important cereal in the agriculture, one of the first that was domesticated (Purugganan, Fuller, 2009). Along with spike shape, threshability and spring growth habit, spike brittleness is one of the key domestication traits (Goncharov, 2012). It has been shown that the mutation of the Non-brittle rachis 1-A (Btr1-A) gene controls the brittle/non-brittle spike trait in Triticum species (Zhao et al., 2019). Pourkheirandish et al. (2018) found that the non-synonymous change at the coding region of $B \operatorname{tr} 1-A$ ( $\mathrm{G}$ to A, A119T) leads to non-brittle rachis formation in the diploid einkorn wheat Triticum monococcum, compared to its wild progenitor Triticum boeoticum with a brittle rachis spike. In cultivated polyploid wheat species, the Btr $1-A$ gene contains a 2-bp deletion in the coding region, forming a premature stop codon and resulting in a non-functional protein (Zhao et al., 2019). Moreover, the transgenic wheat lines created by Zhao et al. (2019) made it possible to establish that the Btr $1-A$ gene was associated with spike density, grain size and grain yield. In the present study we investigated the genetic variability of the $B \operatorname{tr} 1-A$ gene from di- and hexaploid wheat species including four endemics.

\section{Materials and methods}

The germplasm of di- and hexaploid wheat species was grown under standard greenhouse conditions. The brittle/non-brittle spike trait was determined visually. The list of wheat accessions analyzed in this study is presented in Table 1. Total DNA was isolated from $100 \mathrm{mg}$ of leaves using a DNeasy Plant Mini Kit (QIAGEN) according to the manufacturer's protocol. The Btrl-A sequences of T. monococcum and T. boeoticum (MG596311-MG596321) and whole genome sequences (WGS) of Triticum dicoccoides (LSYQ02000006), Triticum aestivum (OETA01178479) (B-genome), T. aestivum (OETA01219489) and Aegilops tauschii (NWVB01000003) (D-genome) were used to design genome-specific primers to amplify the Btr $1-A$ gene from di- and hexaploid wheat species. The primer pair Btr-A1-F/ Btr-A1-R 5'-CGAGCTTGACCT CATGTAAC-3'/ 5'-CTACTGCATCATCAGTCCATC-3' amplifies partial upstream and downstream parts and the coding region of Btr 1-A. PCR was performed in a $20-\mu \mathrm{l}$ volume containing $20 \mathrm{ng}$ of genomic DNA, $10 \mathrm{mM}$ Tris- $\mathrm{HCl}$ ( $\mathrm{pH} 8.9$ ), $1 \mathrm{mM}\left(\mathrm{NH}_{4}\right)_{2} \mathrm{SO}_{4}, 1.5 \mathrm{mM} \mathrm{MgCl}_{2}, 200 \mu \mathrm{M}$ dNTPs, $0.5 \mu \mathrm{M}$ primers, and $0.25 \mathrm{U}$ of Taq DNA polymerase. PCR products were separated by agarose gel electrophoresis and purified using a QIAquick Gel Extraction Kit (QIAGEN). For all wheat accessions purified PCR products were sequenced. Sequencing reactions were performed with $20 \mathrm{ng}$ of the PCR product and an ABI BigDye Terminator Kit on an ABI 3130XL Genetic Analyser (Applied Biosystems) in the SB RAS Genomics Core Facility (http://www.niboch.nsc.ru/doku.php/corefacility). Nucleotide and amino acid sequences were aligned using AliView v. 1.18.1.

\section{Results and discussion}

We obtained the Btr1-A gene sequences for three diploid and five hexaploid wheat species (Table 1). For diploid wheat accessions, the length of the Btr $1-A$ sequences obtained was $902 \mathrm{bp}$. In the case of all hexaploid wheat accessions investigated, the length of the gene sequences was $899 \mathrm{bp}$ (a 1-bp deletion in the upstream and a 2-bp deletion in the coding region of the Btrl-A gene compared with diploids).

Comparative analyses allowed us to determine that the Btrl-A gene sequences of T. monococcum (PI-266844) and T. boeoticum (K-18399) were identical with T. monococcum (MG596319, MG596320) and T. boeoticum (MG596311MG596313, MG596315, MG596317-MG596318), respectively. The T. urartu (Ig-110784) sequence contained an additional substitution at position 125 ( $\mathrm{T}$ to A, L42Q) compared to the data presented by Zhao et al. (2019) (Figure 1). The 2-bp deletion in the Btr1-A coding region of T. spelta and T. spelta ssp. yunnanense (non-brittle rachis), T. tibetanum and 
Table 1

Wheat species used in the study and their phenotypes

\begin{tabular}{lll}
\hline Species & Accession & Phenotype \\
\hline Triticum monococcum L. & $\mathrm{Pl}-266844$ & Non-brittle rachis \\
T. urartu Thum. ex Gandil. & $\mathrm{lg}-110784$ & Brittle rachis \\
T. boeoticum Boiss. & $\mathrm{K}-18399$ & Brittle rachis \\
T. macha Decapr. et Menabde & $\mathrm{K}-31689$ & Brittle rachis* \\
T. macha Decapr. et Menabde & $\mathrm{K}-58671$ & Brittle rachis* \\
T. aestivum ssp. petropavlovskyi (Udacz. et Migusch.) N.P. Gontsch. & $\mathrm{KU} 502$ & Non-brittle rachis \\
T. aestivum ssp. petropavlovskyi (Udacz. et Migusch.) N.P. Gontsch. & $\mathrm{K}-43351$ & Non-brittle rachis \\
T. spelta L. & $\mathrm{K}-53364$ & Non-brittle rachis \\
T. spelta ssp. yunnanense (King ex S.L. Chen) N.P. Gontsch. & KU506 & Non-brittle rachis \\
T. spelta ssp. yunnanense (King ex S.L. Chen) N.P. Gontsch. & KU509 & Non-brittle rachis \\
T. vavilovii (Thum.) Jakibz. & Tri9416 & Non-brittle rachis \\
T. tibetanum Shao & KU510 & Brittle rachis* \\
T. tibetanum Shao & KU515 & Brittle rachis*
\end{tabular}

* the spike is separated from the whole straw, rarely without breaking into spikelets (Dorofeev et al., 1979)

T. urartu (Ig-110784)
T. monococcum (PI-266844)
T. boeoticum (K-18399)
T. macha (K-31689, K-58671)
T. aestivum ssp. petropavlovskyi (KU502, K-43351)
T. spelta (K-53364)
T. spelta ssp. yumnanense (KU506, KU509)
T. tibetamum (KU510, KU515)
T. vavilovii (Tri9416)
T. urartu (Ig-110784)
T. monococcum (PI-266844)
T. boeoticum (K-18399)
T. macha (K-31689, K-58671)
T. aestivum ssp. petropavlovskyi (KU502, K-43351)
T. spelta (K-53364)
T. spelta ssp. yumnamense (KU506, KU509)
T. tibetamum (KU510, KU515)
T. vavilovii (Tri9416)
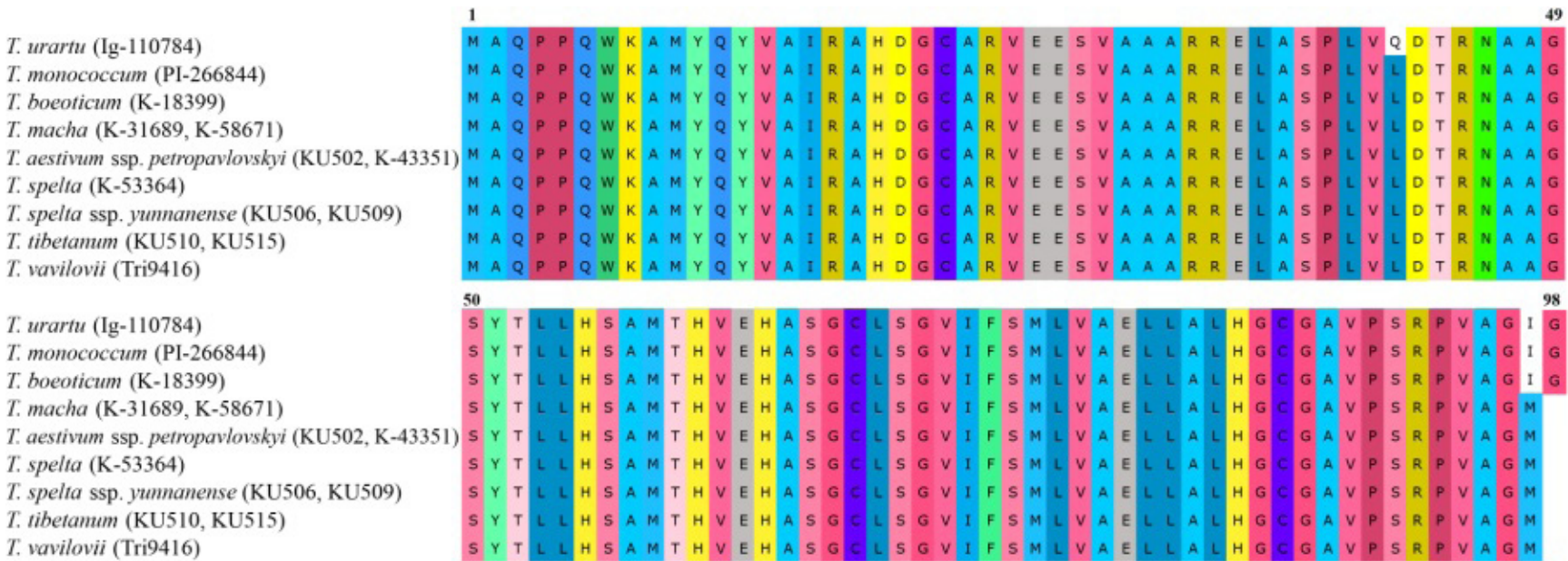

T. urartu (Ig-110784) T. monococcum (PI-266844) T. boeoticum (K-18399)
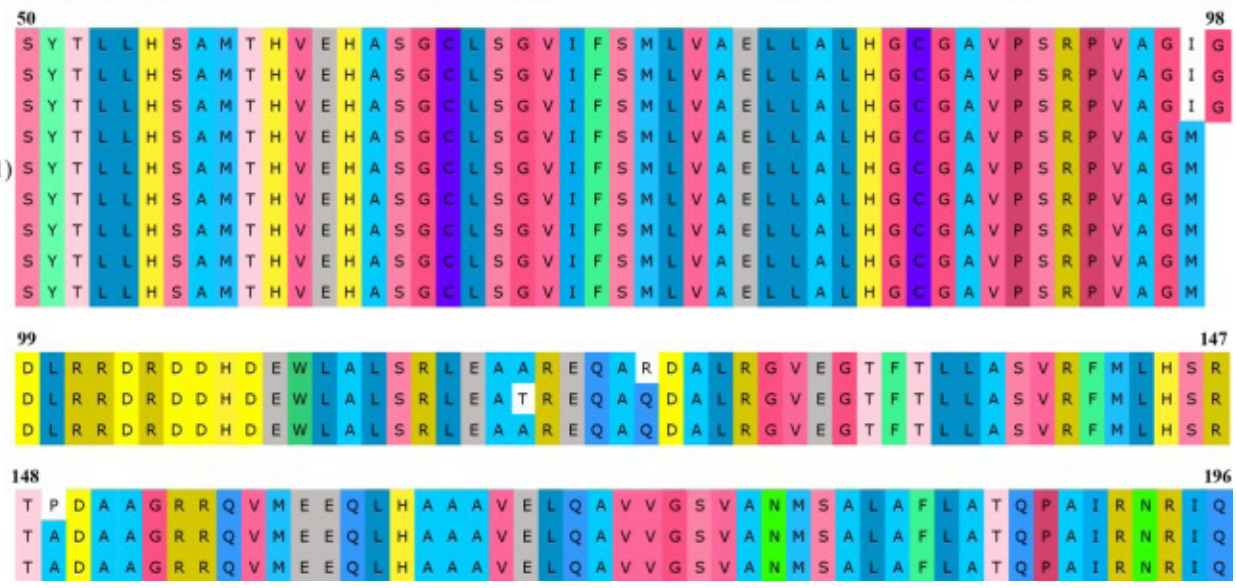

Figure 1. Alignment of the BTR1 protein of the di- and hexaploid wheat accessions analyzed in this study. The length of the BTR1 protein is 196 and 97 amino acids for the diploids and the hexaploids, respectively. 
T. macha (brittle rachis) was previously detected by Zhao et al. (2019). The T. aestivum ssp. petropavlovskyi and T. vavilovii accessions with non-brittle rachis that were investigated in this study also contain that deletion. This deletion formed a premature stop codon and resulted in a nonfunctional protein (Figure 1). The 1-bp deletion at position -97 from the start codon for all hexaploid wheat accessions was detected for the first time in the present study.

\section{Conclusions}

In the present study we investigated the genetic variability of the Btr1-A gene from several Triticum species including four endemics. All hexaploid wheat accessions were characterized by a 2-bp deletion in the Btr $1-A$ coding region, leading to the formation of a nonfunctional protein (97 amino acids instead of 196 in diploids). The Btr $1-A$ sequences for T. aestivum ssp. petropavlovskyi and T. vavilovii were established for the first time in this study. Nevertheless, further investigations are required to understand the potential relationship between the $B \operatorname{tr} l$ and $Q$ genes, regulating spike morphology traits such as spike density, brittleness and grain weight.

\section{References}

Dorofeev V.F., Filatenko A.A., Migushova E.F., Udachin R.A., Jakubtsiner M.M. Pshenitsa (Wheat). In: Dorofeev V.F., Korovina O.N. (Eds.). Cultivated flora of the USSR, vol 1. Leningrad: Kolos, 1979; $348 \mathrm{pp}$.

Goncharov N.P. Comparative genetics of wheats and their related species. Novosibirsk: Geo, 2012; 523 pp.

Pourkheirandish M., Dai F., Sakuma S., Kanamori H., Distelfeld A., Willcox G., Kawahara T., Matsumoto T., Kilian B., Komatsuda T. On the origin of the non-brittle rachis trait of domesticated einkorn wheat. Front Plant Sci. 2018;8:1-10. DOI 10.3389/fpls.2017.02031.

Purugganan M.D., Fuller D.Q. The nature of selection during plant domestication. Nature. 2009;457:843-848. DOI 10.1007/978-94-007$7572-5$ - 18.

Zhao Y., Xie P., Guan P., Wang Y., Li Y., Yu K., Xin M., Hu Z., Yao Y., Ni Z., Sun Q., Xie C., Peng H. Btrl-A induces grain shattering and affects spike morphology and yield-related traits in wheat. Plant Cell Physiol. 2019;60:1342-1353. DOI 10.1093/pcp/pcz050.

Acknowledgements. This study was supported by the Russian Science Foundation (grant No. 16-16-10021-P).

Conflict of interest. The authors declare no conflict of interest. 


\title{
Development of androgenic polyembrioids in the anther culture of alloplasmic introgression lines of (H. vulgare) - T. aestivum and (H. marinum ssp. gussoneanum) $-T$. aestivum
}

\author{
L.A. Pershina ${ }^{1 *}$, N.V. Trubacheeva ${ }^{1}$, T.S. Osadchaya ${ }^{1}$, I.A. Belan ${ }^{2}$, L.P. Rosseeva ${ }^{2}$ \\ 1 Institute of Cytology and Genetics, SB RAS, Novosibirsk, Russia \\ ${ }^{2}$ Omsk Agricultural Scientific Center, Omsk, Russia
}

DOI 10.18699/ICG-PlantGen2019-66

(c) Autors, 2019

* e-mail: pershina@bionet.nsc.ru

\begin{abstract}
The peculiarities of the development of embryo-like structures and regenerants in anther culture of introgression alloplasmic lines of common wheat carrying the cytoplasm of barley were compared with euplasmic lines. In all genotypes, the predominant formation of polyembryoids was found, out of which seedling families developed. According to a study of phenotypic traits and the level of fertility in androgenic regenerants with a spontaneously doubled number of chromosomes and restored fertility, about $80 \%$ of families contained clones. Sister DH lines formed from clones and included in breeding are simultaneously tested in different ecological zones.

Key words: alloplasmic lines; androgenesis; doubled haploid; clones.
\end{abstract}

\section{Introduction}

Introgressive hybridization is the basic method for increasing the genetic diversity of cultivated plants (Gill et al., 2011). An additional source of biodiversity can also be alloplasmic lines (allo-lines) with restored fertility (Liu et al., 2016), which are formed as a result of the replacement of the cytoplasm with an alien one. New intergenomic interactions in these lines may cause epigenetic modification of nuclear genes (Soltani et al., 2016) and changes in the manifestation of signs (Liu et al., 2002). We have developed an approach to obtain introgressive doubled haploid (DH) allo-lines of bread wheat which are used in genetic studies (Trubacheeva et al., 2012) and in breeding (Pershina et al., 2018). It was shown that one of the limitations in obtaining the genetic diversity of DH lines of triticale via anther culture is the development of a large number of clones among androgenic regenerants (Oleszczuk et al., 2014). How often clones are formed as a result of the cultivation of anthers of other genotypes is not known, since the works where this problem has been studied are few. In this report, the results of studying this phenomenon in anther culture of introgression allo-lines of bread wheat with the cytoplasm of $H$. vulgare and $H$. marinum ssp. gussoneanum $(2 n=28)$ are presented.

\section{Materials and methods}

The formation of single seedlings and their families was studied in anther culture of nine introgression allo-lines with the cytoplasm of $H$. vulgare and three introgression euplasmic lines of bread wheat. All these lines have different combinations of genes for resistance to fungal pathogens, introgressed into wheat from its wild relatives. In addition, two allo-lines with the cytoplasm of $\mathrm{H}$. marinum and chromosome $7 \mathrm{H}^{\text {mar }}$ were used. Anther culture was performed according to previously used methods (Osadchaya et al., 2017). The frequency of individual embryo-like structures which are sources for regeneration of individual seedlings and their families was analyzed.

\section{Results and discussion}

In the anther culture of all studied lines, embryo-like structures were formed from microspores (Figure 1,a). Separate embryo-like structures are formed into polyembryos. The family of seedlings developed from one polyembryoid (see Figure $1, b$ ). The family of albinos and the family of green seedlings are presented in Figure 1, $c$ and $d$. The formation of androgenic polyembryos was described for certain varieties of bread wheat (Seldimirova et al., 2016). In our work, it has been shown that in the studied introgressive allo-lines and euplasmic lines polyembryoids are formed predominantly.

In total, in all the lines 208 androgenic embryo-like structures have shown the ability to regenerate green seedlings. Of these, $174(83.6 \%)$ embryo-like structures resulted in seedling families. In allo-lines with the cytoplasm of $H$. vulgare the frequency of embryo-like structures, from which the family of green seedlings developed, was $81.8 \%$ with the variation of this indicator in different lines from 63.6 to $100 \%$. In allo-lines with the cytoplasm of H. marinum $90.4 \%$ of the embryo-like structures gave the families of regenerants. In euplasmic lines, the value of this indicator is $87.5 \%$.

Thus, regardless of the origin of alloplasmic and euplasmic introgressive lines via anther culture polyembryoids mainly formed, of which families involving from two to 22 seedlings were developed. Among the 34 single androgenic plants that reached heading, $24(70.5 \%)$ were completely sterile, three plants set single seeds and seven plants were fertile with a seed set between 15 and 35 per ear. Phenotypic traits and fertility levels were studied in plants of 121 families of allo-lines. Within 99 families, the plants were phenotypically identical and did not differ from each other in fertility. Plants within these families can be assigned to clones. Most families, 68 out of $90(75.5 \%)$, had either completely sterile plants (53 families), or besides completely sterile plants, included plants with single grains (from 1 to 3) (15 families). Plants from these families are of lower growth than the original plants, anther donors, and they can be assigned to haploids. 

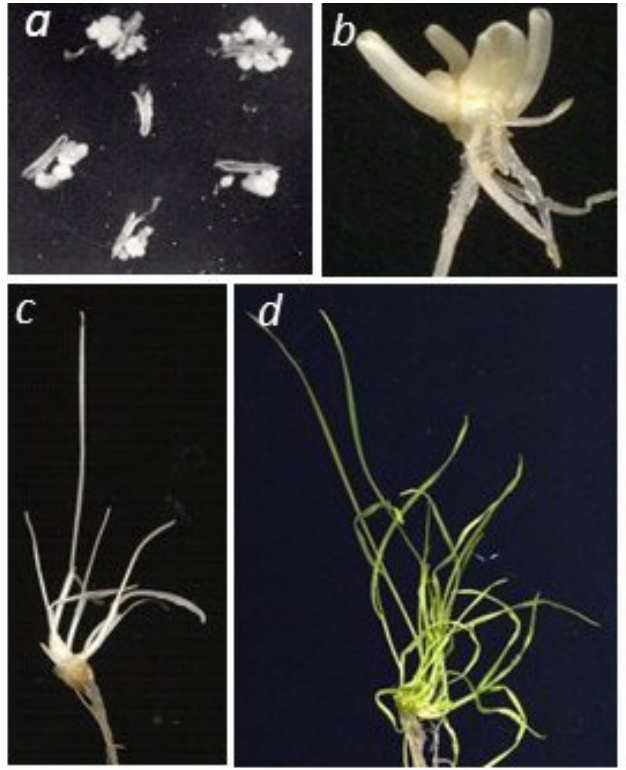
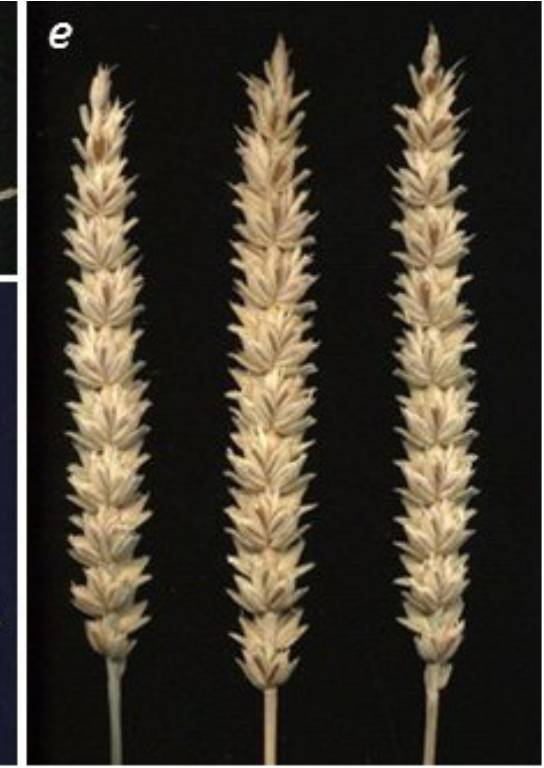

Figure 1. The embryo-like structures in anther culture $(a)$; the regeneration of the seedlings from a polyembryoids (b); the family of albino $(c)$ and green $(d)$ seedlings; ears of sister regenerants from the same family with restored fertility $(e)$.
Of these, 53 families ( $53.5 \%$ ) had only sterile plants and 15 families, in addition to completely sterile plants, included separate plants with single grains (from 1 to 3 ). Sterile plants in these families are identical in phenotype, and they can be assigned to haploids compared to taller and fertile donor plants. Due to the spontaneous doubling of the number of chromosomes via androgenesis, plants of 31 families were fertile. In four families, the plants set from 5 to 10 grains per ear; in five families, from 10 to 20 grains per ear. Plants in 22 families contained from 20 to more than 30 grains per ear (see Figure 1,e).

The remaining 22 families out of 121 studied included plants that differed in fertility and phenotypic traits. These families included completely sterile plants, plants with low and high levels of fertility. Based on a comparison of fertility and phenotypic traits, it can be assumed that in 99 families out of 121 studied clones were formed, the frequency being $81.8 \%$. From the seeds of individual fertile plants and plants from families, DH lines are formed, which are included in cytogenetic and molecular analysis for a more detailed study of the putative clones and families with plants of different fertility.

\section{Conclusions}

Our results showed that, regardless of the origin of the cytoplasm, introgression lines of common wheat in the anther culture of individual microspores form not individual androgenic embryoids, but polyembryoids from which plant families (clusters) develop. According to phenotypic characteristics and fertility levels, families of regenerants, which are considered as clones, have been previously isolated. A more detailed analysis of these families will determine how effective the selection of clones by phenotype and level of fertility is. The sister DH lines included in breeding are simultaneously tested for resistance to fungal pathogens and agronomically valuable traits in different ecological zones. The results of such tests will determine the expediency of the practical use of clones to obtain DH lines.

\section{References}

Gill B.S., Friebe B.R., Frank F. White F.F. Alien introgressions represent a rich source of genes for crop improvement. PNAS. 2011;19: 7657-7658. DOI 10.1073/pnas.1104845108.

Liu C.G., Wu Y.W., Hou H., Zhang C., Zhang Y., McIntosh R.A. Value and utilization of alloplasmic common wheats with Aegilops crassa cytoplasm. Plant Breed. 2002;121(5):407-410. DOI 10.1046/j. 1439-0523.2002.755374.x.

Liu Y., Tang L., Xu Q., Ma D., Zhao M., Sun J., Chen W. Experimental and genomic evidence for the indica-type cytoplasmic effect in Oryza sativa L. ssp. japonica. J Integrative Agriculture. 2016;15(10): 2183-2191. DOI 10.1016/S2095-3119(15)61190-X.

Oleszczuk S., Tyrka M., Zimny J. The origin of clones among androgenic regenerants of hexaploid triticale. Euphytica. 2014:198(3): 325-336. DOI 10.1007/s10681-014-1109-1.

Osadchaya T.S., Trubacheeva N.V., Kravtsova L.A., Belan I.A., Rosseeva L.P., Pershina L.A. Study of fertility and cytogenetic variability in androgenic plants $\left(\mathrm{R}_{0}\right.$ and $\left.\mathrm{R}_{1}\right)$ of the alloplasmic introgression lines of common wheat. Russian J Genetics: Applied Research. 2017:7(3):318-326. DOI 10.1134/S2079059717030121.

Pershina L.A., Belova L.I., Trubacheeva N.V., Osadchaya T.S., Shumny V.K., Belan I.A., Rosseeva L.P., Nemchenko V.V., Abakumov S.N. Alloplasmic recombinant lines (H. vulgare)-T. aestivum with 1RS.1BL translocation: initial genotypes for production of common wheat varieties. Vavilov J Gen Breed. 2018;22(5):544-552. DOI 10.18699/VJ18.393.

Seldimirova O.A., Titova G.T., Kruglova N.N. A complex morphohistological approach to the in vitro study of morphogenic structures in a wheat anther culture. Biol Bull. 2016:43(2):121-126. DOI $10.1134 /$ S1062359016020084.

Soltani A., Kumar A., Mergoum M., Pirseyedi S.M., Hegstad J.B., Mazaheri M., Kianian S.F. Novel nuclear-cytoplasmic interaction in wheat (Triticum aestivum) induces vigorous plants. Funct Integr Gen. 2016;16(2):171-182. DOI 10.1007/s10142-016-0475-2.

Trubacheeva N.V., Kravtsova L.A., Devyatkina E.P., Efremova T.T., Sinyavskaya M.G., Shumny V.K., Pershina L.A. Heteroplasmic and homoplasmic states of mitochondrial and chloroplast DNA regions in progenies of distant common wheat hybrids of different origins. Russ. J. Genet.: Appl. Res. 2012:2(6):494-500.

Acknowledgements. The work is supported by project No. 0324-20190039, RFBR grant No. 17-04-01738.

Conflict of interest. The authors declare no conflict of interest. 


\title{
Challenges and opportunities of breeding and genetic improvement of durum wheat in Russia
}

\author{
P.N. Mal'chikov ${ }^{1 *}$, M.A. Rozova ${ }^{2}$, A.I. Ziborov², M.G. Myasnikova ${ }^{1}$, T.V. Chakheeva ${ }^{1}$ \\ 1 Samara Research Institute of Agriculture named after N.M. Tulaikov, Bezenchuk, Russia \\ ${ }^{2}$ Federal Altai Scientific Centre of Agro-BioTechnologies, Barnaul, Russia
}

DOI 10.18699/ICG-PlantGen2019-67

(c) Autors, 2019

*e-mail: sagrs-mal@mail.ru

\begin{abstract}
Favorable soil and climatic environments of Russia are not sufficiently used for the production of high-quality grain of durum wheat. It is caused by a lower efficiency of its cultivation compared to other cereals. The development of varieties adapted to environmental fluctuations in the zones of their cultivation, with high grain quality, is taken as one of the major factor to solve the problem. Based on many-year experiments a breeding strategy for adaptation is suggested. It roots in the possibility to reinforce specific (regional) homeostasis with the genetic systems of cultivars living on a vast area, which are carriers of non-specific homeostasis, as well to increase resistance to diseases (foliar blights, blotches, stem rust, powdery mildew) and to lodging. Ways to enhance grain quality due to the use of germplasm with high levels of protein, gluten and carotenoid content are put forward. Problems of strengthening gluten quality of Russian durum wheat cultivars are discussed. For these purposes, cultivars from Italy, Canada and Australia should be widely used as basic material and the corresponding biochemical markers of the GLi-B1d, Glu-B1d, Glu-A3d loci would be quite valuable.

Key words: durum wheat; homeostasis; gluten quality; biochemical markers.
\end{abstract}

\section{Introduction}

Durum wheat acreage in Russia is $0.6-0.7$ million ha and $0.7-0.9$ million tons of grain is produced (data for the past 5 years), which is one-third as much as 30 years ago. The decline in durum wheat production took place at the transition of the economy towards market relations and was determined by a lower efficiency of its cultivation (demands in high agronomic requirements, decreased tolerance to stresses, necessity of additional inputs) compared to other cereals. Breeding can solve the problems to a large extent. Over the past decade, an increase in durum wheat cultivation area has been observed (Figure 1).

\section{Breeding rates}

At the moment, 45 cultivars are included in the State Register of Protected Breeding Achievements of Russia. Over the past 10 years, 14 cultivars have been registered, which is comparable to the results of the previous 10 years, when 16 varieties were registered. Thus, the intensity of the breeding process were not changed for long periods. This is because of the practices used (methods of traditional breeding) and the lack of increase in breeding scale (number of laboratories, volume of breeding material). Acceleration and the enhancement of breeding output are possible through the wide utilization of diploid technology of germplasm development and application of methods of marker-assisted selection (Leonova, 2013).

\section{Breeding activities}

\subsection{Adaptivity and stability of grain yield}

In Russia, durum wheat breeding has gone through several stages: from the first breeding cultivars selected from local landraces through the period of monopolistic cultivars cultivated in several regions on large areas ('Melanomus 69',
'Hordeiforme 10', 'Hordeiforme 189', 'Kharkovskaya 46', 'Bezenchukskaya 139', and 'Altaika') and up to the modern stage of the formation of local systems of cultivars. The first and foremost task of the perspective development of breeding is the improvement of the systems. The strategy is based on the use of cultivars living on a vast area, which carry gene blocks for adaptation and non-specific homeostasis, as basic genotypes. At the same time, regional cultivars of local value should be used as donors of genes for specific homeostasis (optimal vegetation period for the zone, stem parameters, heat- and drought tolerance, response to soil environments etc.). An ecological and geographic study of nurseries of the Kazakhstan-Siberian net of wheat improvement (KASIB), which consisted of the genotypes developed in Russia and Kazakhstan, was carried out at 9 ecological sites in 2015-2017. It appeared that 13 cultivars of different origin should be considered as forms living on a vast area. They are 'Leucurum 1307d-54', 'Leucurum 1469d-21', 'Leucurum 1594d-3', 'Leucurum 1429d-10', 'Leucurum 1506d-36', 'Hordeiforme 1591d-21' (Samara Research Institute of Agriculture), 'Hordeiforme 18585-2' (Scientific and Production Center of Soil Management and Plant Science), 'Hordeiforme 950/899' (Karabalyk Agricultural Research Station), 'Hordeiforme 01-115-5', 'Hordeiforme 05-42-12'(Omsk Agrarian Scientific Center), 'Kargala 66', 'Kargala 223' (Aktyubinsk Agricultural Research Station), 'Hordeiforme 178-05-2' (Scientific and Production Center of Grain Farming) (Mal'chikov, Rozova et al., 2018).

\subsection{Resistance to diseases}

The following diseases are common to the Russian regions where durum wheat is cultivated: foliar blights (Septoria, Pyrenophora, Bipolaris, Alternaria, Fusarium, powdery mildew (Blumeria graminis), stem rust (Puccinia graminis f.sp.tritici), 


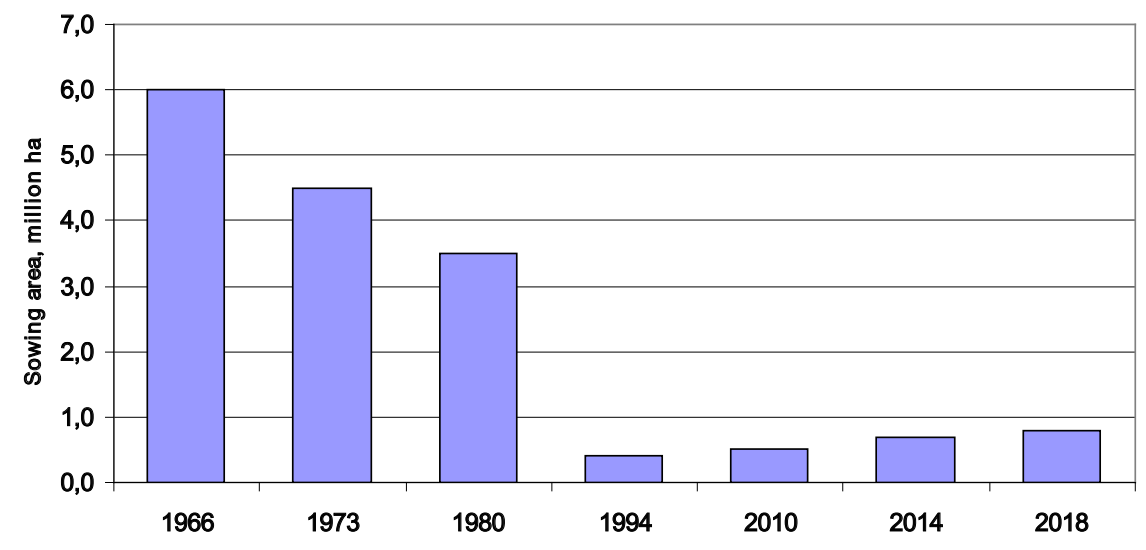

Figure 1. Dynamics of durum wheat sowing area in 1966-2018. leaf rust (Puccinia triticina Eriks.), Fusarium head blight (Fusarium spp.), black point (Alternaria alternata, Alternaria tenuis, Bipolaris sorokiniana) (Koishibaev, 2018). Pathogen species mostly have regional localization. Septoria spp., Puccinia graminis f.sp.tritici, Bipolaris sorokiniana, the agents of black points, occur more often in Western Siberia and in Altai. In the Volga region, epiphytoties of foliar diseases caused by Fusarium spp. and Pyrenophora occur frequently. In these regions, an effective breeding is carried out to develop resistance to the complexes of pathogens based on the formation of corresponding QTLs. Breeding on resistance to powdery mildew is effective in all breeding centers. Genetic donors of the trait are forms of durum wheat with translocations from another wheat species (Tr. dicoccum, Tr. timopheevii) and introgression of resistance from foreign cultivars (Italy, CIMMYT etc.). The problem of durum wheat resistance to leaf rust is most relevant for North-Caucasus region (Al'derov et al., 2000). The hazard of the disease in steppe regions seldom reaches the economic threshold, even in epiphytotic years. A sufficient number of resistant sources can be identified among local breeding lines and released cultivars adapted to local environmental constrains. The development of stem rust resistant cultivars is aggravated by the deficiency of a sufficient set of adapted parental stock at breeders' disposal. To solve the matter, donors from CIMMYT and possibilities of the KASIB program (the study and identification of resistant genotypes) have been involved.

\subsection{Incorporation of Rht genetic systems}

At present, in the State Register of Protected Breeding Achievements of Russia, the drought-tolerant reduced-height cultivars 'Bezenchukskaya zolotistaya' and 'Bezenchukskaya 210' are included. They carry the gene for plant height reduction RhtAnh (Anhinga, CIMMYT), which decreases the height by $15 \%$. The genetic system of plant height reduction in 'Omskaya yantarnaya' and 'Yasenka' has a similar effect. 'Bezenchukskaya 209' and the Italian cultivar 'Rusticano' carry a strong gene, $R h t B 1 b$. A new short-statue variety, 'Triada' $(R h t B 1 b)$, is promising for North-Caucasus, CentralChernozem regions and for Siberia (Mal'chikov, Sidorenko et al., 2017). Taking this into account, there is a real perspective to decrease durum wheat plant height almost in all regions of its breeding and cultivation (Table 1).

\subsection{Grain protein content}

This characteristic is in close correlation with gluten content and it determines $40 \%$ of the overall grain quality. It is controlled by the polygenic systems and depends to a great extent on environments. In the majority of Russian regions where durum wheat is cultivated, climate and soils enable the accumulation of more than $14 \%$ of protein in grain (Rozova, Mukhin, 2015; Mal'chikov et al., 2017). In favorable environments, for the trait to happen, this level can be reached by almost all cultivars. The problem of protein content in wheat grain as a breeding trait becomes more complicated for its negative correlation with grain yield. Nevertheless, there is a varietal differentiation. Mapping of the large-effect QTL on the 6B chromosome transferred from Tr. dicoccoides allowed analogues QTL to be identified in some other varieties (Joppa, Cantrell, 1990; Joppa et al., 1997). A possible way to overcome or to weaken the sharp contradiction of the trait with yield can be through the inclusion of "strong" gene blocks covering high protein content. Among modern Russian commercial cultivars, 'Solnechnaya 573', 'Oazis', 'Saratovskaya zolotistaya', 'Pamyatie Yanchenko', 'Salyut Altaya', 'Omsky korund', 'Bezenchukskaya krepost', 'Altaiskaya niva' stably form grains with a high protein content (Mal'chikov, Rozova et al., 2017). It is assumed that the cultivars carry a block of genes from $T r$. dicoccum or local varieties (landraces) and its effect can be similar to that of QTL on 6B chromosome of Tr. dicoccoides.

\subsection{Gluten quality}

Allele " $c$ " (according to the catalogue developed by A.M. Kudryavtsev, 1994) of the Gli-B1 ${ }^{d}$ locus containing electrophoretic component $\gamma-45$, closely linked with low-molecular glutenin of the second type (LMW-2), which functionally provides a good quality of gluten, occurs in the population of Russian commercial cultivars at a frequency of $0.46 \%$. This complex enables the formation of gluten strength at a value of $35-45 \mathrm{ml}$ after the SDS-sedimentation, test depending on environments. But the gluten index of such cultivars does not exceed $65 \%$, which does not correspond to the demands of modern industrial production of high quality pasta. Genetic systems, which include alleles $7+8$ and $6+8$ at the $G l u-B 1^{d}$ locus responsible for high-molecular subunits of glutenin, in combination with allele " $a$ " (after the nomenclature by Nieto - Taladriz et al., 
Table 1

Target regions for the adoption of short-statue cultivars

\begin{tabular}{lll}
\hline Genetic system of $R h t$ & Ecologically adapted donors of Rht genetic systems & Target regions \\
\hline RhtAhn & $\begin{array}{l}\text { Bezenchukskaya zolotistaya, Bezenchukskaya 210, } \\
\text { Pamyatie Chekhovicha }\end{array}$ & Volga region, Urals, Siberia, Altai \\
QTL & Omskaya yantarnaya & Siberia, Altai, Urals \\
QTL & Yasenka & North Caucasus, Volga region \\
RhtB1b & Bezenchukskaya 209, Triada & North Caucasus, Volga region, \\
& & Central Chernozem region, Altai \\
\hline
\end{tabular}

Table 2

Carotenoid content in grain of durum wheat cultivars of different countries, Bezenchuk, 2017-2018

\begin{tabular}{llll}
\hline Cultivar & Origin & Carotenoid content & \% to St. \\
\hline Bezenchukskaya zolotistaya, st. & & $\rho \rho m$ & 100.0 \\
Bezenchukskaya krepost' & Samara & 8.7 & 92.8 \\
Saratovskaya zolotistaya & Samara & 8.07 & 83.5 \\
Bezenchukskaya 210 & Saratov & 7.3 & 74.4 \\
Elizavetinskaya & Samara & 6.47 & 83.3 \\
Omsky korund & Saratov & 7.25 & 66.7 \\
Donela M & Omsk & 5.8 & 78.2 \\
Oazis & Rostov & 6.8 & 63.2 \\
Average over Russian cultivars & Altai & 5.5 & 80.6 \\
Achille & & 7.01 & 42.1 \\
Grecalle & Italy & 3.66 & 60.9 \\
Maestrale & Italy & 5.3 & 60.9 \\
Duroflaus & Italy & 5.3 & 83.9 \\
Duromax & Austria & 7.3 & 59.4 \\
Odisseo & Austria & 5.17 & 66.7 \\
Tamaroi & Italy & 5.8 & 62.0 \\
Hyperno & Australia & 5.39 & 92.1 \\
Average over foreign cultivars & Australia & 8.01 & 66.0 \\
HCP 0.05 & & 5.74 & \\
\hline & & 0.32 & \\
\hline
\end{tabular}

1997) in the Glu-A3 ${ }^{d}$ locus responsible for the low-molecular subunits of glutenin, allow the gluten index to be increased to $70-85 \%$ (Porceddu, Blanco, 2014). There is no published information on gluten indexes or on the profile of the Glu-A3, Glu-B1 allele loci of modern Russian cultivars (Shevchenko, Mal'chikov et al., 2018). Therefore, it is necessary to study the matters and to transfer effective alleles from cultivars of Italy, Canada and Australia.

\subsection{Carotenoid content in grain}

Russian commercial cultivars include an essential part of genotypes with high contents of carotenoid pigments. In environments of Volga region, the cultivars 'Saratovskaya zolotistaya', 'Bezenchukskaya zolotistaya', and 'Bezenchukskaya krepost" accumulate 5.5-9.0 $\rho \rho \mathrm{m}$ of yellow pigment, which is significantly more than do foreign varieties from Italy, Canada and Austria (Table 2). Nowadays, intensive breeding on the base of Russian original material is being carried out in a number of laboratories of Russian scientific centers: the Research Institute of Agriculture of the South-East (Saratov), the Samara Research Institute of Agriculture (Bezenchuk), Federal Altai Scientific Centre of Agro-BioTechnologies (Barnaul), Omsk Agrarian Scientific Center. To enhance the efficiency of the breeding direction, it is necessary to identify and to marker the corresponding QTL for the substantiation and application of MAS technologies.

\section{References}

Alderov A.A. Intraspecific diversity and genetic control of resistance of hard wheat to leaf rust. Proceedings on Applied Botany, Genetics and Breeding. 2000;158:37-40 (in Russian).

Joppa L.R., Cantrell R.G. Chromosomal location of genes for grain protein content of wild tetraploid wheat. Crop Sci. 1990;30(5):10591069.

Joppa L.R., Du C., Hart G.E., Harland G.A. Mapping gene(s) for grain protein in tetraploid wheat (Trticum turgidum L.) using a 
population of recombinant inbred chromosome lines. Crop Sci. 1997;37(5):1586-1589.

Kudryavtsev A.M. Genetics of gliadin of spring durum wheat (Triticum durum Desf.). Rus. J. Genet. 1994;30(1):77-84. (in Russian)

Koyshibaev M. Wheat diseases. Ankara: Food and Agriculture Organization of the United Nations (FAO). 2018;366 p.

Leonova I.N. Molecular markers: implementation in crop plant breeding for identification, introgressions and gene pyramiding. Vavilov J. Genet. Breed. 2013;17(2):314-325. (in Russian)

Mal'chikov P.N., Sidorenko V.S., Myasnikova M.G., Rozova M.A., Mudrova A.A., Tsygankov V.I., Mukhitov L.A. The results of breeding of spring durum wheat varieties with a shortened stem length. Zernobobovye i krupanie kul'tury. 2017:4:97-106. (in Russian)

Malchikov P.N., Rozova M.A., Myasnikova M.G., Shabolkina E.N. Protein accumulation in durum grain depending on genotype and environment. Izvestia Samara Scientific Center Russian Academy Sciences. 2017;19(2-4):620-628. (in Russian)

Mal'chikov P.N., Rozova M.A., Morgunov A.I., Myasnikova M.G., Zelensky Yu.I. Yield performance and stability of modern breeding stock of spring durum wheat (Triticum durum Desf.) from Russia and Kazakhstan. Vavilov. J. Genet. Breed. 2018;22(8):939-950.

Nieto-Taladriz M.T., Ruiz M., Martinez M.C., Vazquez J.F., Garillo J.M., Variation and classification of B low-molecular weight glutenin subunit alleles in durum wheat. Theor. Appl. Genet. 1997;95:1155-1160.

Porceddu E., Blanco A. Evolution of durum wheat breeding in Italy. Proceed. International Symposium of genetics and breeding of durum wheat. 2014;110:157-173.

Rozova M.A., Mukhin V.N. The influence of weather conditions on the content of protein, gluten and its quality in spring durum wheat grain in the conditions of the forest-steppe of the Altai region. Achievements Sci Technol. 2015;29(8):58-61. (in Russian)

Shevchenko S.N., Mal'chikov P.N., Myasnikova M.G., Natoli V., DeVita P., Giuliani M. Genetic methods for improving the quality of durum wheat adapted to the climatic conditions of Russia with special emphasis on grain commercial characteristics Izvestia Samara Scientific Center Russian Academy Sciences. 2018;20(2-2):220-230.

Conflict of interest. The authors declare no conflict of interest. 


\title{
Study of 8x and 6x triticale with dominant Vrn genes
}

\author{
P.I. Stepochkin \\ Siberian Research Institute for Plant Industry and Breeding - Branch of the Institute of Cytology and Genetics, SB RAS, Krasnoobsk, Novosibirsk region, Russia
}

DOI 10.18699/ICG-PlantGen2019-68

(c) Autor, 2019

*e-mail: petstep@ngs.ru

\begin{abstract}
Secondary hexaploid (6x) triticale plants made by hybridization of a $6 x$ winter triticale variety with octaploid (8x) triticale plants bearing the dominant Vrn1 gene have different "shoots - earing" interphase period durations, which forms the following series: $6 \times V r n D 4 \geq 6 \times V r n B 1>6 x V r n D 1 \geq 6 x V r n A 1$. Plants of $8 x$ triticale compared with $6 x$ ones have denser spikes and a higher seed set. Plants of line $8 \times V r n D 4$ had the longest "shoots - earing" interphase period ( $74.3 \pm 1.7$ days) among all $8 x$ triticale studied in 2018 , while $8 x V r n D 1$ triticale plants had the shortest one ( $49.5 \pm 2.6$ days). Plants of $6 \mathrm{xVrnA} 1$ triticale had the shortest "shoots-earing" interphase period ( $47.4 \pm 0.9$ days) among all $6 x$ triticale studied. Plants of the triticale $8 \times V r n D 1$ and $6 \times V r n D 1$ inherited, from the wheat 'Triple Dirk E', the Ne1 and $\mathrm{Ne} 2$ genes that accounted for the manifestation of leaf hybrid necrosis and a low seed set. Secondary $6 x$ triticale with the dominant VrnA1 gene possesses the shortest "shoots earing" interphase period and a good seed set and is used in triticale breeding programs. Key words: octaploid; hexaploid; triticale; Vrn genes; interphase period.
\end{abstract}

\section{Introduction}

There are three levels of ploidy of a synthetic wheat-rye allopolyploid or triticale ( $\times$ Triticosecale sp. Wittmack). They are tetraploid (4x), hexaploid (6x) and octaploid (8x). Although a lot of triticale varieties are of $6 \mathrm{x}$ level of ploidy, some octaploid triticale varieties were made in China (Zhi-Jun Cheng, Minoru Murata, 2002). According to the lifestyle and the type of plant development, there are winter, spring and winter-spring or alternative triticales. The spring- type development and the duration of the "shoots-earing" interphase are determined by dominant $\mathrm{Vr} n$ genes located on wheat chromosomes $5 \mathrm{~A}$, 5B and 5D (Fu et al., 2005; Yoshida et al., 2010) and on rye chromosome 5R (Plaschke et al., 1993). In this report, some results of studying $8 \mathrm{x}$ and $6 \mathrm{x}$ triticales with dominant $\mathrm{Vrn}$ genes are given and discussed.

\section{Materials and methods}

Triticale (Trl) of two ploidy levels was created and studied in the Siberian Research Institute of Plant Growing and Breeding, a branch of the Institute of Cytology and Genetics, SB RAS. In the octaploid (8x) triticale nursery in 2018, we studied 4 forms of primary $8 \mathrm{x}$ wheat-rye amphidiploids (WRA): $8 \mathrm{x}$ VrnAl (genotype VrnAlVrnA1 vrnBlvrnB1 vrnDlvrnD1 vrnD4vrnD4), 8xVrnD1 (genotype vrnA1vrnA1 vrnB1vrnB1 VrnD1VrnD1 vrnD4vrnD4), 8xVrnB1 (genotype vrnA1vrnA1 VrnB1VrnB1 vrnD1vrnD1 vrnD4vrnD4) and $8 \mathrm{x} V r n D 4$ (genotype vrnAlvrnAl vrnBlvrnB1 vrnDlvrnD1 VrnD4VrnD4) created by the artificial doubling of chromosome number of wheat-rye hybrids from crosses between the winter rye variety 'Korotkostebelnaya 69' (genotype $v r n R 1$ ) and four soft wheat lines, 'Triple Dirk D', 'Triple Dirk B', 'Triple Dirk E' and 'Triple Dirk F' as donors of four different dominant genes, $V r n-V r n A 1, V r n B 1, V r n D 1$ and $V r n D 4$, correspondently (Stepochkin, 2009). In the nursery of hexaploid (6x) triticale, we studied $\mathrm{F}_{6}$ hybrids obtained from crosses, in 2014, between four primary octaploid triticale $(8 \mathrm{x} \operatorname{VrnA1}, 8 \mathrm{x} \operatorname{Vrn} D 1,8 \mathrm{x} \operatorname{Vrn} B 1$ and $8 \mathrm{x} V r n D 4)$ and the winter hexaploid triticale 'Sirs 57' (6x winter Trl) bearing recessive vrn genes. In this nursery, we also studied the 6x triticale forms $6 \mathrm{x} \operatorname{Vrn} A 1,6 \mathrm{x} \operatorname{Vrn} B 1,6 \mathrm{x} \operatorname{Vrn} D 1$ and $6 \mathrm{x} V r n D 4$ derived from the populations of $8 \mathrm{x}$ triticale with dominant $V r n$ genes. During the vegetation period from shooting to ripening, we carried out phenological observations. Qualitative and quantitative traits were studied.

\section{Results and discussion}

Spikes of $6 x$ triticale morphologically differ from those of $8 x$ triticale and are close to those in rye (Figure 1).

Their ears are denser than those of the original 8x WRA and their seed set is almost two times higher than that of $8 \mathrm{x}$ triticale (Table 1). For these traits, the hexaploid triticale plants of both groups do not differ significantly from each other except for 6x VrnD1. Plants of this WRA, as well as those of the $\mathrm{F}_{6}$ hybrid $(8 \mathrm{x} V r n D 1 \times 6 \mathrm{x}$ winter $\mathrm{Trl})$ and the octaploid WRA $8 \times \mathrm{VrnD} 1$ have two qualitative traits, leaf necrosis and hairy glumes, inherited from the initial wheat line 'Triple Dirk E', the maternal parental form and the donor of the dominant $V r n D 1$ gene for producing the $8 \mathrm{x} V r n D 1$ triticale (Stepochkin, 2009). Leaf necrosis, perhaps, led to the low seed set in the spikes of plants of the WRA made on the basis the wheat line 'Triple Dirk E'. It is known that a hybrid leaf necrosis caused by a complementary action of the $\mathrm{Ne}_{1}$ and $\mathrm{Ne}_{2}$ genes leads to grain production problems in wheats developed by interspecies crosses or crosses between a winter and a spring variety (Hermsen, 1963). The wheat line 'Triple Dirk E' is of hybrid origin (Goncharov, 2012).

Triticale plants bearing the dominant $V r n A 1$ or $V r n D 1$ gene have a shorter "shoots - earing" interphase period than those that bear the dominant $\operatorname{VrnB1}$ or $\operatorname{VrnD} 4$ gene. The plants that have the dominant $\mathrm{VrnD} 4$ gene show the longest duration of this period. Both the hexaploid triticale and the primary octaploid triticale plants bearing the dominant $V r n$ gene have "shoots - earing" interphase period duration that forms the following series: $\operatorname{Trl} V r n D 4 \geq \operatorname{Trl} V r n B 1>\operatorname{Trl} V r n D 1 \geq \operatorname{Trl}$ $\operatorname{VrnA1}$. Plants of line $8 \mathrm{x} V r n D 4$ had the longest "shoots - earing" period ( $74.3 \pm 1.7$ days) among all $8 \mathrm{x}$ triticale studied, while $8 \mathrm{x} V r n D 1$ triticale plants had the shortest one $(49.5 \pm 2.6$ 


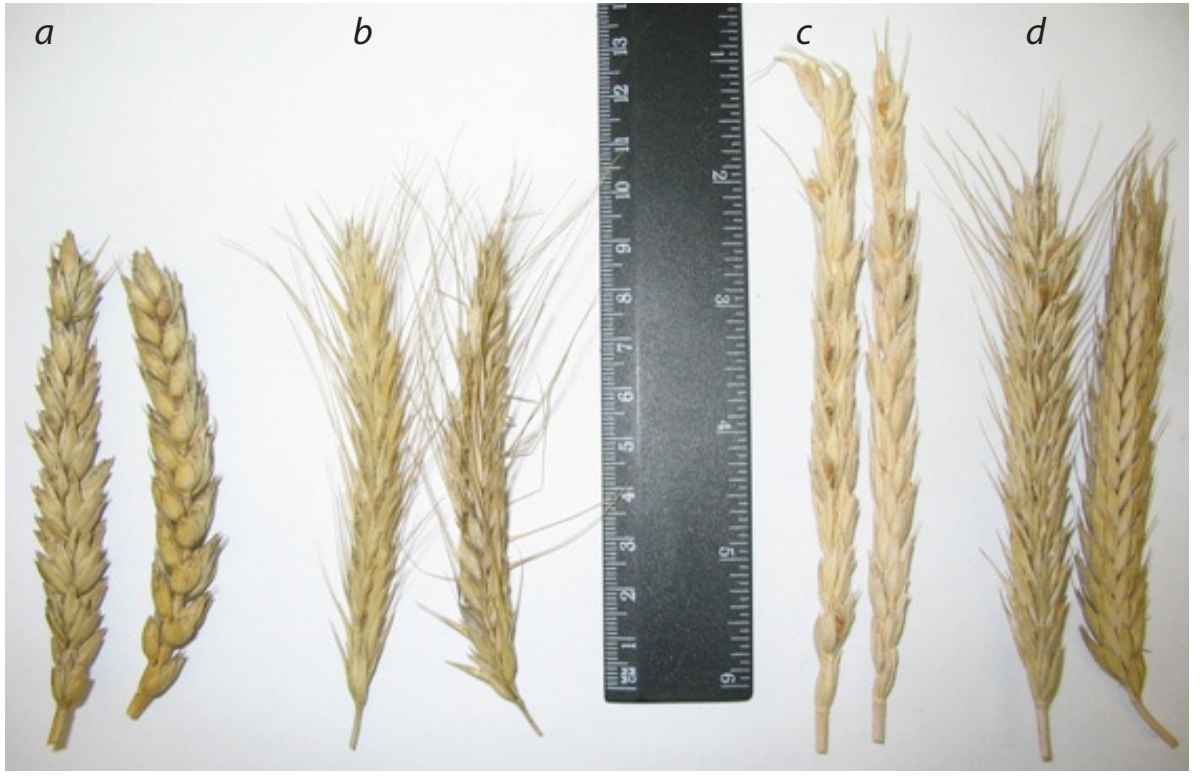

Figure 1. Spikes of common wheat 'Triple Dirk D' (a), winter rye 'Korotkostebelnaya' (b), $8 \mathrm{x}$ triticale $8 \mathrm{x} \operatorname{VrnA} 1$ (c) and $6 \mathrm{x}$ triticale 6xVrnA1.

Table 1

Duration of the "shoots - earing" period, spike density and spike grain number of 8x and 6x triticales with dominant Vrn genes

\begin{tabular}{|c|c|c|c|}
\hline Names of triticale & $\begin{array}{l}\text { Duration of the "shoots - earing" } \\
\text { period, days }\end{array}$ & $\begin{array}{l}\text { Spike density, number } \\
\text { of spikelets / length of spike }\end{array}$ & Spike grain number \\
\hline $8 x \operatorname{rnA} 1$ & $51.0 \pm 1.8$ & $1.89 \pm 0.02$ & $22.5 \pm 0.6$ \\
\hline 8xVrnD1 & $49.5 \pm 2.6$ & $1.74 \pm 0.03$ & $7.8^{*} \pm 1.3$ \\
\hline $8 x \operatorname{rnB} 1$ & $71.2 \pm 4.3$ & $1.87 \pm 0.03$ & $12.3 \pm 1.1$ \\
\hline $8 x \operatorname{VrnD} 4$ & $74.3^{*} \pm 1.7$ & $1.85 \pm 0.02$ & $11.0 \pm 0.7$ \\
\hline $8 x \operatorname{VrnA} 1 \times 6 x$ winter $\operatorname{Trl}$ & $45.1 \pm 2.5$ & $2.93 \pm 0.05$ & $38.9 \pm 3.0$ \\
\hline $8 \mathrm{xVrnD} 1 \times 6 \mathrm{x}$ winter $\mathrm{Trl}$ & $55.2 \pm 6.7$ & $2.98 \pm 0.06$ & $27.4^{*} \pm 2.7$ \\
\hline $8 \times \mathrm{VrnB} 1 \times 6 \times$ winter $\mathrm{Trl}$ & $56.4 \pm 2.1$ & $2.97 \pm 0.06$ & $42.9 \pm 1.7$ \\
\hline $8 x \operatorname{rnD} 4 \times 6 x$ winter $\mathrm{Trl}$ & $67.0 \pm 5.2$ & $2.85 \pm 0.13$ & $42.0 \pm 3.6$ \\
\hline $6 x \operatorname{VrnA} 1$ & $47.4 \pm 0.9$ & $3.00 \pm 0.06$ & $38.0 \pm 2.6$ \\
\hline $6 x \operatorname{VrnD} 1$ & $49.2 \pm 0.6$ & $3.17^{*} \pm 0.04$ & $28.0^{*} \pm 1.5$ \\
\hline $6 x \operatorname{VrnB1}$ & $58.9 \pm 0.4$ & $2.95 \pm 0.04$ & $35.0 \pm 1.6$ \\
\hline $6 x \operatorname{rnD} 4$ & $70.8^{*} \pm 0.7$ & $2.90 \pm 0.06$ & $42.8 \pm 2.7$ \\
\hline
\end{tabular}

* Significant difference at $p<0.05$.

days). Hexaploid triticales derived from octaploid WRA populations as a result of spontaneous depolyploidization and elimination of 14 chromosomes of the D genome (Stepochkin, 1978; Zhi-Jun Cheng, Minoru Murata, 2002; Li et al., 2015). They are of breeding interest. Plants of 6xVrnAl triticale had the shortest "shoots-earing" interphase period $(47.4 \pm 0.9$ days) among all $6 \mathrm{x}$ triticale studied. The $\mathrm{F}_{6}$ hybrid lines from cross of $8 \mathrm{x} V r n A 1 \times 6 \mathrm{x}$ winter triticale showed the shortest "shoots-earing" interphase period and a good seed set among all triticales studied, which also makes it promising for further breeding programs.

\section{Conclusions}

The results of the study of two-level ploidy triticales showed that the secondary hexaploid triticale plants made by hybridization of a $6 \mathrm{x}$ winter triticale variety with octaploid triticale plants bearing the dominant $\operatorname{Vrn} 1$ gene have different "shoots- earing" interphase period durations and form the following series: $6 \mathrm{x} V r n D 4 \geq 6 \mathrm{x} V r n B 1>6 \mathrm{x} V r n D 1 \geq 6 \mathrm{x} V r n A 1$. Plants of $8 \mathrm{x}$ triticale compared with $6 \mathrm{x}$ ones have denser spikes and a higher seed set. Plants of line $8 \mathrm{x} V r n D 4$ had the longest "shoots - earing" period ( $74.3 \pm 1.7$ days) among all $8 \mathrm{x}$ triticale studied in 2018, while $8 \times \operatorname{VrnDl}$ triticale plants had the shortest one $(49.5 \pm 2.6$ days). Plants of $6 x \operatorname{VrnA} 1$ triticale derived from the population of $8 \mathrm{x}$ triticale as a result of spontaneous depolyploidization and elimination of $\mathrm{D}$-genome chromosomes had the shortest "shoots - earing" interphase period (47.4 \pm 0.9 days) among all $6 \mathrm{x}$ triticale studied. $8 \mathrm{x} \operatorname{VrnD} 1$ and $6 \mathrm{x} \operatorname{VrnD} 1$ triticale plants inherited the $\mathrm{Ne}_{1}$ and $\mathrm{Ne}_{2}$ genes from the wheat 'Triple Dirk E', which accounted for the manifestation of leaf hybrid necrosis and a low seed set. As the secondary 6x triticale with the dominant $\operatorname{VrnAl}$ gene combines the shortest "shoots-earing" interphase period and a good seed set, it is used in triticale breeding programs. 


\section{References}

Fu D., Szücs P., Yan L., Helguera M., Skinner J.S., Zitzewitz J., Hayes P.M., Dubcovsky J. Large deletions within the first intron in VRN-1 are associated with spring growth habit in barley and wheat. Mol. Gen. Genomics. 2005;273:54-65.

Goncharov N.P. Comparative genetics of wheat and their related species. Novosibirsk: Academic publishing house "Geo", 2012 (in Russian).

Hermsen J.G.Th. Hybrid necrosis as a problem for the wheat breeder. Euphytica. 1963;12(1):1-16.

Li H., Guo X., Wang C., Ji W. Spontaneous and divergent hexaploid triticales derived from common wheat $\times$ rye by complete elimination of D-genome chromosomes. PLOS One. 2015:1-12. DOI:10.1371/ journal.pone.0120421.

Plaschke J., Börner A., Xie D.X., Koebner R.M.D., Schlegel R., Gale M.D. RFLP mapping of genes affecting plant height and growth habit in rye. Theor. Appl. Genet. 1993;85:1049-1054.
Stepochkin P.I. Development and study of a set of triticale forms as to the VRN genes. Sib. J Agricultural Sci. 2009;11:26-32 (in Russian).

Yoshida T., Nishida H., Zhu J., Nitcher R., Distelfeld A., Akashi Y., Kato K., Dubcovsky J. Vrn-D4 is a vernalization gene located on the centromeric region of chromosome 5D in hexaploid wheat. Theor. Appl. Genet. 2010;120:543-552.

Zhi-Jun Chen, Minoru Murata. Loss chromosomes 2R and 5RS in octoploid triticale selected for agronomic traits. Genes. Genet. Syst. 2002;7:23-29.

Acknowledgements. This work was supported by ICG budget project No. 0324-2019-0039 in part of field trial and experimental measurements.

Conflict of interest. The author declares no conflict of interest. 


\title{
Breeding of potato resistant to late blight using genetic resources and DNA markers
}

\author{
J. Śliwka*, M. Brylińska, E. Stefańczyk, J. Plich, P. Smyda-Dajmund, S. Sobkowiak \\ Plant Breeding and Acclimatization Institute - National Research Institute, Młochów Research Centre, Młochów, Poland
}

DOI 10.18699/ICG-PlantGen2019-69

(c) Autors, 2019

* e-mail: j.sliwka@ihar.edu.pl

\begin{abstract}
Potato (Solanum tuberosum L.) is the fourth most important crop plant worldwide and its economically most important disease, late blight, is caused by an Oomycete, Phytophthora infestans (Mont.) de Bary. Breeding potatoes resistant to the disease is a valid and environment-friendly alternative to the currently applied intensive chemical control. The pathogen is fast-evolving and can quickly adapt and infect new resistant cultivars of the host. Therefore new strategies of using late blight resistance (Rpi) genes in improving durability of the resistance are developed. The history of the search for Rpi genes, their mapping in Plant Breeding and Acclimatization Institute - National Research Institute and our current research are reported here.
\end{abstract}

Key words: potato; Solanum tuberosum L.; late blight resistance; DNA markers.

\section{Introduction}

There are around 240 wild Solanum species that produce tubers and that can be exploited for enrichment of the potato (Solanum tuberosum L.) gene pool (Hawkes 1990). The first important trait that was introduced to the cultivated potato from its wild relatives already in the beginning of the XX century was late blight resistance. The hexaploid wild species Solanum demissum was the source of the first 11 genes for resistance to Phytophthora infestans (Mont.) de Bary (Rpi genes: R1-R11) (Black 1952). The resistance provided by some of those genes $(R 1, R 3, R 4, R 10$ and $R 11)$ that were widely used in potato cultivars soon turned ineffective as new races of $P$. infestans quickly evolved. Since then, many new Rpi genes have been discovered in species such as: S. bulbocastanum, S. pinnatisectum, S. berthaultii, S. microdontum, S. stoloniferum, $S$. venturii and $S$. mochiquense, among others. New strategies have been proposed for applying those genes into practice in ways that should extend the durability of the provided resistance and prevent quick evolution of compatible $P$. infestans strains. Three most important ones are: 1 . pyramiding several Rpi genes in single potato cultivars, 2. growing mixtures of breeding lines/cultivars with different Rpi genes, 3 . growing cultivars with different Rpi genes, or better: gene pyramids, in different growing seasons so the $P$. infestans strains selected to overcome the resistance of a certain gene pyramid would perish in a next season when other Rpi genes are in action. All those strategies are based on the access to multiple Rpi genes and methods for their quick introduction to potato breeding lines such as marker-assisted selection (MAS). Here we present the history of the search for Rpi genes among wild potato relatives, their mapping and exploitation in potato breeding in Plant Breeding and Acclimatization Institute - National Research Institute, Poland.

\section{Materials and methods}

The sources of resistance were:

A hybrid of S. phureja $\times$ S. stenotomum obtained from the International Potato Centre (CIP, Lima, Peru) carrying the Rpi-phul gene (Śliwka et al., 2006, Foster et al., 2009).
Solanum michoacanum (Zoteyeva et al., 2012) obtained from the N.I. Vavilov Institute for Plant Genetic Resources (VIR), (Saint Petersburg, Russia) carrying the Rpi-mchl gene (Śliwka et al., 2012a).

Solanum ruiz-ceballosii Cárd. (Zoteyeva et al., 2012), obtained from the N.I. Vavilov Institute for Plant Genetic Resources (VIR), (Saint Petersburg, Russia), carrying the Rpi-rzcl gene (Śliwka et al., 2012b).

Cultivar Sárpo Mira from Hungarian breeding program, registered in UK in 2002, with at least five genes for late blight resistance: R3a, R3b, R4, Rpi-Smiral and Rpi-Smira2/ $R 8$ (Tomczyńska et al., 2014).

For screening for resistance and evaluation of mapping populations, detached leaflet, whole tuber and tubers slice tests were performed in laboratory conditions and with standardized inoculum. Selected genotypes were tested in the field under natural infection pressure. Virulence of Polish $P$. infestans population was monitored using detached leaflet tests. For mapping, targeted PCR markers (in the case of the Rpi-phul, Rpi-Smiral genes) or Diversity Array Technology (DArT) markers (Rpi-mchl and Rpi-rzcl) were used. For MAS, closely linked (Rpi-rzcl, Rpi-mch1, Rpi-Smiral) or gene-derived (Rpi-phul, R8) PCR markers were used.

\section{Results and discussion}

The spectrum and durability of resistance provided by different Rpi genes are monitored in the Polish population of $P$. infestans in virulence detached leaflet tests. Each year we collected 100-200 isolates of the pathogen and on the basis of Simple Sequence Repeat (SSR) markers their diversity is assessed and a representative sample is chosen. The results of the virulence tests of 70 P. infestans isolates representative for 2017 are shown in Figure 1. Black's differential R9, differentials with Rpi-phul and Rpi-rzcl genes, as well as the potato cultivars 'Carolus' (Netherlands 2013), 'Alouette' (with the Rpi-vnt1 gene, Netherlands 2014) and 'Gardena' (Poland, 2018) are infected by only a few (0-7) P. infestans isolates, indicating that genes underlying the resistance of those potato genotypes are still useful for breeding purposes. 


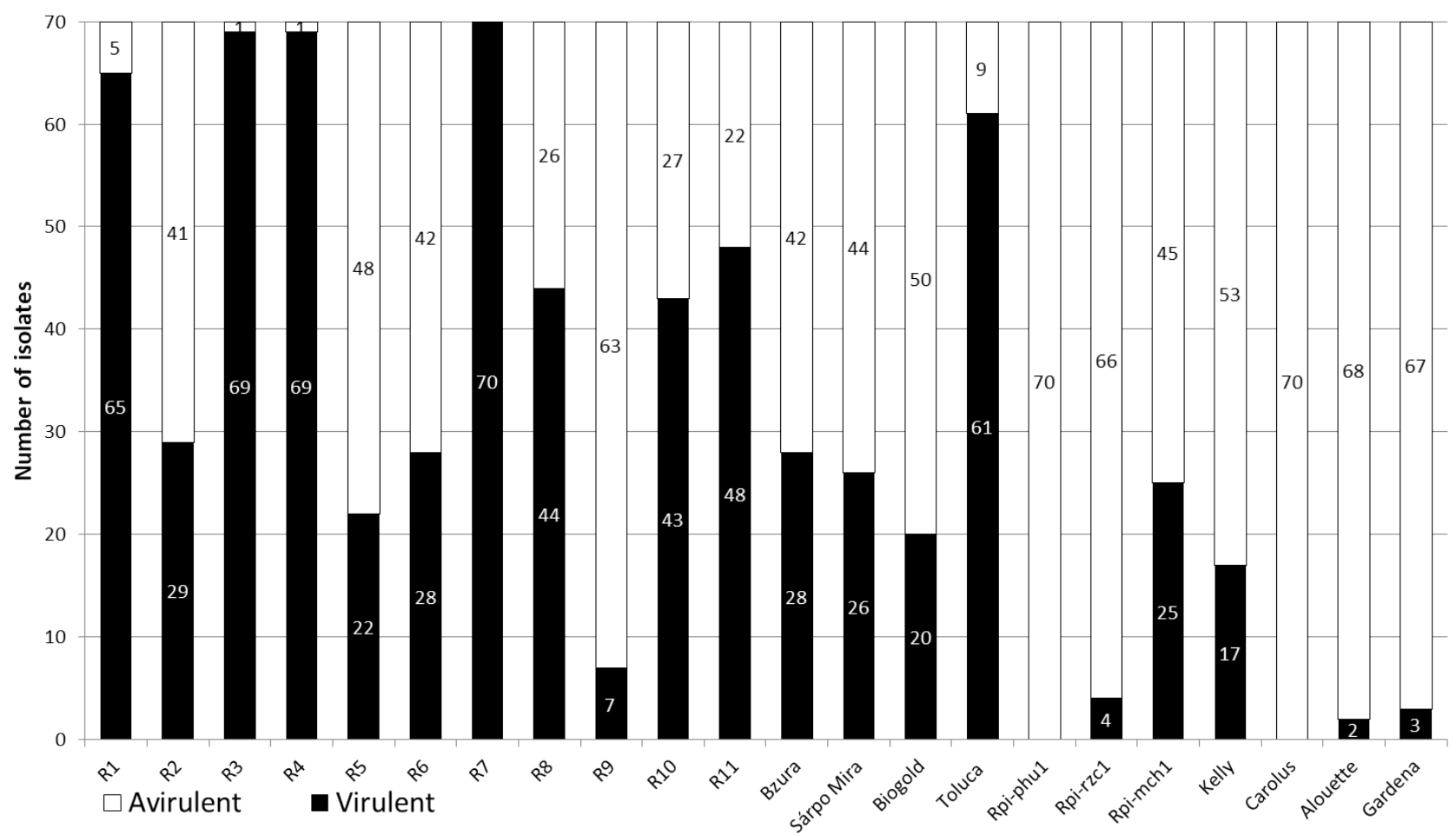

Figure 1. Virulence of 70 representative $P$. infestans isolates collected in Poland in 2017 on Black's differential set (R1-R11), new resistant cultivars and breeding lines carrying the Rpi-phu1, Rpi-rzc1 and Rpi-mch1 genes for late blight resistance. Results of detached leaflet assays.

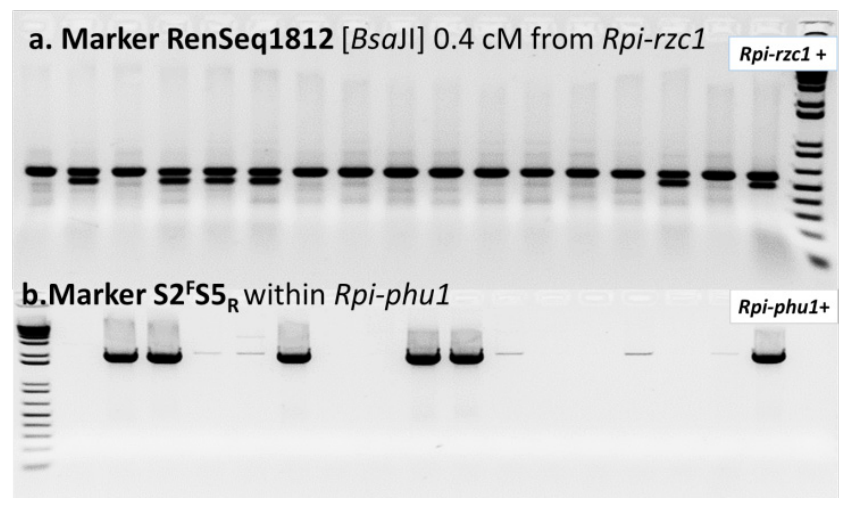

Figure 2. Marker-Assisted Selection of plants with the Rpi-rzc1 and Rpiphu1 genes.

The use of genetic markers such as RenSeq1812 linked to the Rpi-rzcl gene within $0.4 \mathrm{cM}$ (Figure 2,a) or the $\mathrm{S} 2 \mathrm{FS} 5_{\mathrm{R}}$ located within the Rpi-phul gene (Figure 2,b) allows MAS and pyramiding of the resistance genes even when the differential $P$. infestans isolates are not available, as well as it can make the breeding process faster and cheaper. The conventional pre-breeding and breeding process is extremely long when Solanum spp. other than S. tuberosum are used as resistance donors. It is well illustrated by an example of the Rpi-phul gene which was obtained from CIP in 1970, and although we mapped it in 2006 and sequenced it in 2009, only in 2018 the cultivar 'Gardena' carrying that was registered by Zamarte Potato Breeding Ltd. - Group IHAR. The Rpi-phul gene was pyramided with late blight resistance originating from the cultivar 'Sárpo Mira' using MAS for the Rpi-phul gene, Rpi-Smiral (Tomczyńska et al., 2014), and recently also using markers for R8/Rpi-Smira2. To learn more about how Rpi genes function, we performed an expression study in compatible and incompatible interactions between plants with the Rpi-phul gene and P. infestans. The results showed that when avirulent isolates were used, the Rpi-phul expression remained stable and low, while when the virulent isolates were infecting the plants, the expression of the resistance gene was enhanced, which may help the plant to defend itself in field conditions (Stefańczyk et al., 2017).

Our current research focuses on marker-assisted pyramiding of the Rpi-phul and Rpi-rzcl genes at diploid and tetraploid levels. We used three segregating diploid populations to test marker specificities and we performed interploid crosses. The presence of the Rpi-phul homologs in the Rpi-rzcl donor plants resulted in false positive results and required an adjustment of the Rpi-phul gene-derived marker to enhance its specificity.

\section{Conclusions}

The major genes for late blight resistance provide high levels of disease resistance and can be introduced into potato cultivars. Careful choice of effective Rpi genes and gene pyramiding can extend the durability of such resistance. Recently a number of new, highly resistant potato cultivars (e. g. 'Carolus', 'Alouette', 'Gardena') have been registered, offering potato growers an environment-friendly alternative for control of late blight. A conventional breeding process of exploiting various Solanum species is laborious and long. It could be accelerated by transfer of the Rpi genes using genetic modifications, if only this technique were to be broadly accepted. 


\section{References}

Black W. A genetic basis for the classification of strains of Phytophthora infestans. Proceedings of Royal Society B Edinburgh. 1952; 65:36-51.

Foster S.J., Park T.H., Pel M., Brigneti G., Śliwka J., Jagger L., van der Vossen E., Jones J.D. Rpi-vnt1.1, a Tm-2(2) homolog from Solanum venturii, confers resistance to potato late blight. Mol. Plant Microbe Interact. 2009;22:589-600.

Hawkes J.G. The potato, evolution, biodiversity and genetic resources. London: Belhaven Press, 1990.

Stefańczyk E., Sobkowiak S., Brylińska M., Śliwka J. Expression of the potato late blight resistance gene Rpi-phul and Phytophthora infestans effectors in the compatible and incompatible interactions in potato. Phytopathol. 2017;107:740-748.

Śliwka J., Jakuczun H., Lebecka R., Marczewski W., Gebhardt C., Zimnoch-Guzowska E. The novel, major locus Rpi-phul for late blight resistance maps to potato chromosome IX and is not correlated with long vegetation period. Theor. Appl. Gen. 2006;113:685-695.

Śliwka J., Jakuczun H., Chmielarz M., Hara-Skrzypiec A., Tomczyńska I., Kilian A., Zimnoch-Guzowska E. A new resistance gene against potato late blight originating from Solanum $\times$ michoaca- num maps to potato chromosome VII. Theor. Appl. Gen. 2012a;124: 397-406.

Śliwka J., Jakuczun H., Chmielarz M., Hara-Skrzypiec A., Tomczyńska I., Kilian A., Zimnoch-Guzowska E. Late blight resistance gene from Solanum ruiz-ceballosii is located on potato chromosome $\mathrm{X}$ and linked to violet flower colour. BMC Gen. 2012b;13(1):11.

Tomczyńska I., Stefańczyk E., Chmielarz M., Karasiewicz B., Kamiński P., Jones J.D.G., Lees A.K., Śliwka J. A locus conferring effective late blight resistance in potato cultivar Sárpo Mira maps to chromosome XI. Theor. Appl. Gen. 2014;127:647-657.

Zoteyeva N., Chrzanowska M., Flis B., Zimnoch-Guzowska E. Resistance to pathogens of the potato accessions from the collection of N.I. Vavilov Institute of Plant Industry (VIR). Am J Pot Res. 2012; 89:277-293.

Acknowledgements. The research on Rpi-phu1 and Rpi-rzc1 markerassisted pyramiding was funded within the G2P-SOL project (Title: Linking genetic resources, genomes and phenotypes of Solanaceous crops) which has received funding from the European Union's Horizon 2020 research and innovation programme under grant agreement No. 677379.

Conflict of interest. The authors declare no conflict of interest. 


\title{
Search for genomic regions associated with potato starch granules morphology of Solanum tuberosum L.
}

\author{
T.V. Erst ${ }^{1}$, I.V. Rozanova ${ }^{1,2}$, V.K. Khlestkin ${ }^{1,3}$, E.K. Khlestkina ${ }^{1,2}$ \\ ${ }^{1}$ Institute of Cytology and Genetics, SB RAS, Novosibirsk, Russia \\ ${ }^{2}$ N.I. Vavilov All-Russian Research Institute of Plant Genetic Resources (VIR), St. Petersburg, Russia \\ ${ }^{3}$ Russian Research Institute of Farm Animal Genetics and Breeding - Branch of the L.K. Ernst Federal Science Center for Animal Husbandry, St. Petersburg, Russia
}

DOI 10.18699/ICG-PlantGen2019-70

(c) Autors, 2019

*e-mail: erst@bionet.nsc.ru

\begin{abstract}
Potato (Solanum tuberosum L.) is one of the world's main crops for food and industrial applications. Potato starch consists of two types of glucose polymers, essentially linear amylose and highly branched amylopectin. Polymers comprising raw starch granules are packed in a layered structure consisting of alternating crystalline and amorphous layers. Average granule shape and size parameters vary for various varieties. The study of the morphological parameters of granules can provide a deeper understanding of the biochemical mechanisms of their formation and reactivity in (bio)chemical transformations. The morphology of starch granules are supposed to be primarily determined by starch biosynthesis genes, in particular, by genes that encode SBEI and SBEll enzymes (Starch Branching Enzyme). However, the set of genes affecting granule morphology is probably much wider. Different starch applications may require certain shapes and size of starch granules. To reveal genetic control of starch granule morphology, genome-wide association studies (GWAS) have been performed. For the morphological trait called the "circularity" character data analysis with the use of a Generalized Linear Model with Principal Component Analysis (GLM + PCA) revealed a significant association with a SNP located on chromosome 11. A detailed study of the identified genomic region is being conducted in order to design a proper diagnostic DNA-marker for further accelerated selection of plants with the required values of morphological starch granule parameters.
\end{abstract}

Key words: starch granule morphology; genome-wide association studies; potato starch.

\section{Introduction}

Potato (Solanum tuberosum L.) is one of the world's main crops for food and industrial applications. Potato is a food crop with a global production of 388 million tons in 2017 (http://www.fao.org/faostat/en/\#data/QC). The starch granules consist of amylose and amylopectin polymer molecules consisting of glucose residuals' monomers. There are several possible ways of starch industrial application. First, such applications may be based on the polymeric nature of starch: for food industry as a thickener, texturant, extender, low-calorie snacks; for paper industry: beater sizing, surface sizing, coating; for textile utilization: wrap sizing, finishing, printing; for polymer applying: absorbents, adhesives, biodegradable plastics. Second, starch may be applied after hydrolysis of its polymer molecules. Hydrolysis gives glucose, maltose or dextrins required by food industries as sweeteners or stabilizing agents; by fermentation process as a feedstock to produce ethanol, liquors, spirits, beer, etc.; by pharmaceutical application as a feedstock to produce drugs and medicine; by chemical industry as a feedstock to produce organic solvents or acids (Jansson et al., 1997; Geigenberger, Fernie, 2012).

\section{Granule morphology is related with starch properties}

Starch granules' shape and size can affect starch properties. Industries require starch with granules of certain shape and size. It is known that the paper industry requires that granules be uniform in size and spherical in shape. There is the absence of such uniform characteristics in native starch and to avoid further granule modification it is possible to cultivate certain granule shape and size variety (Guo et al., 2010). Viscosity of a starch paste is mainly a function of the size of swollen granules (Grommers, Krogt, 2009). Starch content increases with tuber growth. This increase is caused both by an increase in the number of granules and by an enlargement of granules. The size of potato starch granules in a mature tuber may range from $5 \mu \mathrm{m}$ to about $120 \mu \mathrm{m}$. The largest granules are often present in the large cells of the perimedullary zone. Small granules largely occur in the tissue around the vascular ring. The cells of the cortex contain the largest number of granules per cell; the smallest number of cells are found in pith and medullary rays. (Grommers, Krogt, 2009).

Considering the process of enzymatic hydrolysis of starch, in particular, the process of digestion in humans and other mammals, it is known that the rate of the process is affected by several factors. For example, high-amylose starches are more resistant to hydrolysis (Morita et al., 2007) in comparison to normal starches, where the percentage of amylose varies within $20-30 \%$. Crystallinity is generally considered to restrict hydrolysis (Ring et al., 1988; Planchot et al., 1997; Dhital et al., 2010), supramolecular structures such as amylose lipid complexes (Karkalas et al., 1992; Lauro et al., 1999) and phosphorylation of amylopectin (Sitohy et al., 2001) also affect the hydrolysis process. Starches of different potato varieties are similar in composition and structure. Thus, the size of the granules is the main morphological factor affecting starch degradation. On the one hand, if the processed starches 
are used in the human diet, then morphological factors become more or less unimportant for digestion. On the other hand, raw native starch contained in meals from unprocessed potatoes also presents in human nutrition. In addition, some products and therapies do contain native starches to control the release of glucose (Qi, Tester, 2005; Correia et al., 2008). Such products are designed to release glucose into the blood stream slowly with a decreased initial glucose spike (Qi, Tester, 2005; Correia et al., 2008). Besides size, some features of the surface of the granules affect the enzymatic hydrolysis of starch. Granule shape peculiarities affect the way enzymes attach and accelerate granules hydrolysis (Colonna et al., 1992). Starches consisting of small granules are digested in the human intestine to glucose faster than larger ones (Qi, Tester, 2005). Eating large starch granules can cause lesions in the intestine (Calvert et al., 1989). Therefore, the use of such large granules for food is undesirable.

\section{Genetic mechanisms}

\section{underlying granule morphology}

Starch granule morphology and crystallinity are regulated by starch biosynthesis genes (Yamamori et al., 2000). It is known that amylopectin chains branching, size (Hofvander et al., 2004) and irregular granule shape (Schwall et al., 2000) are affected by the $S B E I$ and $S B E I I$ genes (starch branching enzyme). Tuber starch content and irregular granule shape (Schwall et al., 2000) are likely to be affected by SSI-SSIV (starch synthases). However, it can be assumed that the set of genes affecting the morphology of the granules is wider than just the structural genes of starch biosynthesis.

The search for genomic regions associated with potato starch granule morphology can be provided in several ways: as quantitative trait locus (QTL) analysis (Werij et al., 2012) or genome-wide association studies (GWAS). In our research, we used the second approach.

Starch of 90 potato cultivars and hybrids from the collection of the Genetic Control Center «GenAgro» (IC\&G SB RAS) was extracted using a routine procedure described by Khlestkin, Erst (2017). Starch granule size and shape were measured, and the mean values were calculated. For example, the "circularity" trait (describes granule shape from 1 (ideal circle) to 0 (rectangle)) varies in the selection from 0.79 (cultivar 'Ladozhsky') to 0.87 (perspective line G.3-43-6). Thus, contrast phenotype samples were found. The set of 90 cultivars and lines was genotyped using the Illumina 22K SNP potato array (GGP Potato V3). Genotyping and phenotyping data were analyzed using Microsoft Excel, Tassel 5, and the R package. As a result, SNPs significant for starch granule morphology have been revealed on chromosomes 2, 4, 7, and 11 .

\section{Conclusions}

Our study demonstrated genetic diversity within the panel analyzed for starch granule morphology. Based on GWAS, significant SNPs were found on chromosomes 2, 4, 7, and 11. In the regions associated with starch granule morphology variation, candidate genes can be found in the future. Genetic markers found to be associated with certain traits of starch granules are important for further accelerated breeding of cultivars with the required starch properties.

\section{References}

Calvert R.J., Otsuka M., Satchithanandam S. Consumption of raw potato starch alters intestinal function and colonic cell proliferation in the rat. J. Nutr. 1989;1610-1616.

Colonna P., Leloup V., Buleon A., Limiting factors of starch hydrolysis. Eur. J. Clin. Nutr. 1992;46:S17-S32.

Correia C.E., Bhattacharya K., Lee P J., Shuster J.J. et al. Use ofmodified cornstarch therapy to extend fasting in glycogen storage disease types Ia and Ib. Am J. Clin Nutr. 2008;88:1272-1276.

Dhital S., Shrestha A.K., Gidley M.J., Relationship between granule size and in vitro digestibility of maize and potato starches. Carbohydr. Polym. 2010;82:480-488.

Geigenberger P., Fernie A.R. Starch Synthesis in the Potato Tuber. Food Biochemistry and Food Processing. 2012:613-626.

Grommers H.E., van der Krogt D.A. Potato Starch: Production, Modifications and Uses. In: Miller J., Whistler R. (Eds.). Starch Chemistry Technol. 3rd Edn. Elsevier Inc. 2009;511-539. ISBN: 978-0-12-746275-2.

Guo S., Tang J., Deng Y. et al. BMC Genomics. 2010;11(Suppl 2): S13. DOI 10.1186/1471-2164-11-S2-S13.

Hofvander P., Andersson M., Larsson C.-T., Larsson H. Field performance and starch characteristics of high amylose potatoes obtained by antisense gene targeting of two branching enzymes. Plant Biotechnol. J. 2004;2:311-320. DOI 10.1111/j.1467-7652.2004.00073.x.

Jansson C. et al. Cloning, characterisation and modification of genes encoding starch branching enzymes in barley. In: Frazier P.J. et al. (Eds.). Starch Structure and Functionality. The Royal Society of Chemistry, Cambridge. 1997;196-203.

Karkalas J., Tester R.F., Morrison W.R., Properties of damaged starch granules. I. Comparison of a micromethod for the enzymic determination of damaged starch with the standard AACC and Farrand methods. J. Cereal Sci. 1992;16:237-251.

Khlestkin V.K., Erst T.V. A practical guide to the starch granules' morphology study by microscopy. Vavilovskii Zhurnal Genetiki $i$ Selektsii = Vavilov Journal of Genetics and Breeding. 2017;21(6): 728-734. DOI 10.18699/VJ17.290 (in Russian).

Lauro M., Forssell P.M., Suortti M.T., Hulleman S.H.D., Poutenen K.S., Alpha-amylolysis of large barley starch granules. Cereal Chem. 1999;76:925-930.

Morita T., Ito Y., Brown I.L., Ando R., Kiriyama S. In vitro and in vivo digestibility of native maize starch granules varying in amylose contents. J. AOAC Int. 2007;90:1628-1634.

Planchot V., Colonna P., Buleon A., Gallant D.J. In: Frazier P.J., Donald A.M., Richmond P. (Eds.). Starch: Structure and Functionality, The Royal Society of Chemistry, Cambridge, UK, 1997;141-152.

Qi X., Tester R. T., Effect of native starch granule size on susceptibility to amylase hydrolysis. Starch = Stärke. 2016;68(9-10):807-810. DOI 10.1002/star.201500360.

Ring S.G., Gee J.M., Whittam M., Orford P., Johnson I.T. Resistant starch: Its chemical form in foodstuffs and effect on digestibility in vitro. Food Chem. 1988;28:97-109.

Schwall G.P., Safford R., Westcott R.J., Jeffcoat R., Tayal A., Shi Y.-Ch., Gidley M.J., Jobling S.A. Production of very-high-amylose potatostarch by inhibition of SBE A and B. Nat. Biotechnol. 2000;18: 551-554. DOI 10.1038/75427.

Sitohy M.Z, Ramadan M.F. Degradability of different phosphorylated starches and thermoplastic films prepared from corn starch phosphomonoesters. Starch = Stärke. 2001;53:317-322.

Werij J.S., Furrer H., van Eck H.J., Visser R.G.F., Bachem C.W.B. A limited set of starch related genes explain several interrelated traits in potato. Euphytica. 2012;186:501-516. DOI 10.1007/s10681-0120651-y.

Yamamori M., Fujita S., Hayakawa K., Matsuki J., Yasui T. Genetic elimination of a starch granule protein, SGP-1, of wheat generates an altered starch with apparent high amylose. Theor. Appl. Genet. 2000; 101:21-29. DOI 10.1007/s001220051444.

Acknowledgements. The work supported by a grant from the RFBR (No. 17-29-08006).

Conflict of interest. The authors declare no conflict of interest. 


\title{
Comprehensive evaluation of the Siberian gene pool of common bean (Phaseolus vulgaris L.) in the conditions of Western Siberia
}

\author{
O.E. Yakubenko ${ }^{1,2 *}$, O.V. Parkina ${ }^{2}$ \\ 1 Institute of Cytology of Genetics, SB RAS, Novosibirsk, Russia \\ ${ }^{2}$ Novosibirsk State Agrarian University, Russia
}

DOI 10.18699/ICG-PlantGen2019-71

Abstract: Evaluation of the gene pool of common beans for the main economically valuable traits in the conditions of Western Siberia was conducted. The object of research is 57 varieties of common bean vegetables and grain of various ecological and geographical origin. According to the results of research, genetic sources of economically valuable traits were identified: high yield, quality of the beans (color, shape of the bean), presence or absence of the parchment layer. The result of the research identified the most valuable common bean samples adapted to the conditions of Western Siberia.

Key words: common bean; Phaseolus vulgaris L.; agronomic traits.

\section{Introduction}

Common bean (Phaseolus vulgaris L.) is the most important food culture in the genus Phaseolus of the family Leguminosae, which includes more than 200 species and only 20 species are cultural, the others are wild. Functional products have a special value for human food. Cereals and legumes are of special interest. Common bean has a unique and balanced composition of seeds and green beans with high protein, vitamins, macro- and micro- element content. In many countries, common bean is the primary source of protein; common bean occupies the second place in area among grain crops in the world. In the Siberian region, vegetable beans are grown mainly in home gardens. One of the reasons for their low-scale production is the absence of high-yielding varieties consistent with industrial cultivation technology.

A feature of common beans is that among the most important food crops it has a high polymorphism of morphological characteristics and properties. Of great importance for creation of new varieties is the use of collection material of different ecological and geographic origin.

It is necessary to study and to replenish the gene pool of common bean for selection of source and donors of importance traits.

The purpose of the study is to evaluate of the gene pool and to select genetic sources of common bean by primary agronomic traits in the conditions of Western Siberia.

\section{Materials and methods}

For complex evaluation of variety samples of common bean, a collection nursery was laid on the experimental field of the training and production farm in the Novosibirsk SAU. A plot is located in Novosibirsk on the right bank of the Ob River.

The soil of the experimental plot is gray forest heavy loamy on carbon-free heavy loam. The climate is continental.

From 1997 to the present in the base department of breeding, genetics and forestry of Novosibirsk SAU, more than 150 breeding samples with various ecological and geographic origin were studied. The studied samples of a variety of vegetable bean are divided by origin as follows: most (51\%) are introduced, including $47 \%$ of European origin and $4 \%$ of
Asian origin, the others are of hybrid origin, obtained using the ecological-geographical principle. Breeding samples studied by primary agriculture traits: the length of the vegetation period, the nature of growth (type of growth), plant height and attachment of the lower beans, the shape, length and color of the beans, the presence of the parchment layer and fiber in the seam.

Object of research: 23 variety samples of vegetable bean and 34 samples of haricot bean. Standard for vegetable bean is the variety Solnishko of Siberian selection, standard for haricot bean is the variety Zolotistaya. Sowing was conducted in the second decade of May. Planting was by hand, by the wide-row method with a $70-\mathrm{cm}$ row spacing. Seeding quantity was 22 pieces $/ \mathrm{m}^{2}$.

Accounting of the yield of green beans was carried out in dynamics every 7 days three times during the growing season.

Observations, accountings and analyses were conducted using "Guidelines for the study of the collection of grain legumes", "Guidelines for the study of samples of the world bean collection" and "Guidelines for the use of the classifier Phaseolus L. (Haricot)".

Harvesting was conducted separately, the plants were uprooted and placed in rolls. After ripening, beans were threshed.

\section{Results and discussion}

To meet the needs of the consumer and the manufacturer, the breeder must consider the following parameters: plants in the form of a bush must be compact, with a height of attachment of the lower bean not less than $12 \mathrm{~cm}$, green or yellow color of the beans. All studied varieties had a compact deterministic bush form. Plant height varied from 37 ('Daria') to $51 \mathrm{~cm}$ ('Olhensia'). The height of attachment of the lower bean varied from 8 ('Cinderella') to $16 \mathrm{~cm}$ ('Yellow Octave'). More than $85 \%$ of the samples had a bottom bean attachment height of more than $12 \mathrm{~cm}$. The coefficient of variation is $12.6 \%$. Based on the duration of the vegetation period, the varieties were divided into 4 groups of ripeness (early maturing, $7 \%$ of which can be distinguished very early: 'Ukrainka', 'G32', 'Nika', 'Sekunda', 'Maxi'; 43 \%, medium early: 'Sunny', 'G135'; $37 \%$, middle ripening: 'Viola', 'G171'; and $13 \%$, 
late ripening). The color of beans is of commercial interest for the producers.

The results of the study show that five samples had yellow beans, one purple beans, and the others green beans. The crosssectional shape of the studied samples was observed rounded in $47 \%$ of the samples, flat-round in $40 \%$ of the varieties and flat in $13 \%$. The length of the beans varied from 8.2 ('Slav') to $17.9 \mathrm{~cm}$ ('Purple baby'). More than $80 \%$ of the samples match the production requirements for the optimal length of a bean of $10-13 \mathrm{~cm}$. The coefficient of variation was $19.1 \%$.

The largest quantities of formed beans was in 'Sunray' (31 pcs), while 'Magura' and 'Delinel' (17 pcs) had the smallest quantities of formed beans. The coefficient of variation was $32.9 \%$. The samples of 'Sekunda' ( $9.8 \mathrm{~g}$ ) had the largest mass of 1 bean, the lowest one was with 'Ukrainka' (4.6 g). The coefficient of variation was $17.3 \%$. The average number of formed beans per plant was 21 and the average weight of 1 bean per plant was $6.2 \mathrm{~g}$.

The most productive was the sample of 'Sunray' ( $3.3 \mathrm{~kg} /$ $\left.\mathrm{m}^{2}\right)$, and the low productive was 'Magura' $\left(1.9 \mathrm{~kg} / \mathrm{m}^{2}\right)$. The coefficient of variation was $27.5 \%$.

The results of the investigation show that the number of seeds per plant varied from 26 ('Ruby') to 44 pieces ('Bomba'). The coefficient of variation is $18.4 \%$. The seed mass per plant varied from $12.8 \mathrm{~g}$ ('Golden') to $23.6 \mathrm{~g}$ ('Red-motley'), the coefficient of variation was $19.4 \%$. The mass of 1000 seeds varied from $183.65 \mathrm{~g}$ (Sinelnikovskaya) to $662.45 \mathrm{~g}$ ('Zusha motley'). The coefficient of variation is $35.6 \%$. The seed yield varied from $62.7 \mathrm{~g} / \mathrm{m}^{2}$ ('Motolskaya white') to $281.64 \mathrm{~g} / \mathrm{m}^{2}$ ('Motley Romano'). The coefficient of variation is $23.8 \%$. The average yield by the varieties studied was $191.1 \mathrm{~g} / \mathrm{m}^{2}$.

\section{Conclusions}

On the base of results of a complex assessment of vegetable beans, samples were selected for the main economic and agriculture traits:

1. By precocity: early maturing: Magura, Daria, Orbel yellow; mid-season: Ukrainka, Sekunda, Slavyanka, Jubilee, Golden Mountain, Olhensia, Rocquentcant, Delinel.

2. By the height of attachment of the lower bean (more than $12 \mathrm{~cm}$ ): Magura, Daria, Orbel yellow, Sekunda, Slavyanka, Jubilee, Golden Mountain, Olhensia, Rocquentcant, Delinel, Purple Baby.
3. By the quantities and weight of the beans from the plant samples: Sekunda, Sunray, Morena, Jubilee, Rocquentcant.

4. By the technical quality of green pods: 17 varieties had green beans and 5, yellow beans; the absence of fiber in the seam: all the studied samples, except for Moscow greenhand, Morena, Magura.

5 . By the yield of beans: more than $2.7 \mathrm{~kg} / \mathrm{m}^{2}$ : Golden Mountain, Rocquentcant, Sunray, Daria, Sekunda, Morena, Jubilee.

6. For a set of economically valuable traits, samples identified were Rocquentcant, Daria, Sekunda.

7. For a set of economically valuable traits: samples of grain beans: Stringless, Black, Zusha motley, Oran, Rubin and Sinelnikovskaya, which can be recommended for inclusion in breeding programs and for cultivation in the conditions of Western Siberia.

The creation of varieties with a complex of certain breeding traits based on the available breeding samples of the Siberian gene pool for specific soil and climatic conditions will ensure high rates of productivity and quality.

\section{References}

Agoyi E.E., Mohammed K.E., Odong T.L., Tumuhairwe J.B., Chigeza G., Tukamuhabwa P. Mode of inheritance of promiscuous nodulation and combining abilities in soybean genotypes. Int. J. Agron. Agric. Res. 2016;9:73-82.

Belarmino D. Inheritance of resistance to common bacterial blight (Xanthomonas campestris pv. phaseoli) disease and yield of common bean. Master thesis. Makerere University, 2015.

Bernado R. Breeding for quantitative traits in plants. Stemma Press, Minnesota, 2010.

Guidelines for the study of the collection of grain legumes. SPb, 1974. $60 \mathrm{p}$.

Guidelines for the study of samples of the world collection of beans St. Petersburg, 1987. 60 p.

Singh S.P., Miklas P.N. Breeding common bean for resistance to common blight: A review. Crop Sci. 2015;55:971-984.

Trindade R.D.S., Rodrigues R., do Amaral Jùnior A.T., Gonçalves L.S.A., Viana J.M.S., Sudré C.P. Combining ability for common bacterial blight resistance in snap and dry bean (Phaseolus vulgaris L.). Acta Sci. Agron. 2014;37:37-43.

Zapata M., Beaver J.S., Porch T.G. Dominant gene for common bean resistance to common bacterial blight caused by Xanthomonas axonopodis pv. phaseoli. Euphytica. 2011;179:373-382.

Conflict of interest. The authors declare no conflict of interest. 


\title{
Peculiarities of heterosis manifested by yield and fruit quality traits in pepper $\mathrm{F}_{1}$ hybrids developed using classical and MAS methods
}

\author{
O.G. Babak ${ }^{1 *}$, T.V. Nikitinskaya ${ }^{1}$, N.A. Nevestenko², I.G. Puhacheva ${ }^{2}$, M.M. Dobrodkin ${ }^{2}$, L.V. Khotyleva ${ }^{1}$, A.V. Kilchevsky ${ }^{1}$ \\ 1 Institute of Genetics and Cytology, NASB, Minsk, Belarus \\ ${ }^{2}$ Belarusian State Agricultural Academy, Gorki, Belarus
}

DOI 10.18699/ICG-PlantGen2019-72

(c) Autors, 2019

*e-mail: babak_olgal@mail.ru

\begin{abstract}
Results of a three-year-long assessment of heterosis manifestation peculiarities in $F_{1} C$. annum hybrids based on fruit quality traits are presented. The selection of parental forms was carried out using forms with various alleles determining fruit quality ( $C \mathrm{cs}, \mathrm{Cl}$, norc, $A P R R-2)$ and disease resistance $(M e-1, p m)$. Analysis of high heterosis in the hybrids revealed its diversified character for the majority of the signs studied, depending on the vegetation period conditions. According to the three-year average, the most frequent inheritance of yield was the dominance and overdominance followed by an increase in trait, whereas the inheritance of most biochemical characteristic have intermediate and overdominance types accompanied by a decrease in indicators. Based on the test results, we were able to identify hybrids that combine a high yielding capacity, a biological value of fruits and a high heterotic effect.
\end{abstract}

Key words: pepper; heterosis; yield and fruit quality.

\section{Introduction}

C. annuum fruits contain a large number of biologically active substances, so this culture is important as the functional foods of people. An important direction in the breeding and genetics of this culture is the development of varieties and hybrids with a high yielding capacity and better biochemical characteristics. Considering that yielding capacity is a quantitative trait, where a summing effect of alleles leads to a high heterotic effect and quality traits are determined by a small number of alleles, some aspects of heterosis manifested by yield and fruit quality traits in $\mathrm{F}_{1} C$. annum hybrids are given a brief overview in our research.

\section{Materials and methods}

As an experimental material, 9 parental forms and $16 \mathrm{~F}$ hybrids of sweet pepper (crossing schemes $8 \times 1$ and $1 \times 8$ ) were studied in plastic unheated greenhouses (Table 1). Each line was selected using MAS methods with a specific set of genes for fruit quality and disease resistance: L 45-11 (1, ccs/ cl/norc427/pm), 'Zholty buket' (2, ZB, ccs/Cl/norc424/pm), L 160-10 (3, Ccs/Cl/norc427/Me1/pm), 'Shokoladnaya krasavitsa' (4, SK, cl/Ccs/Me1/pm/norc427), 'Cherniy Krasavec' (5, CK, Cl/Ccs/pm/norc427), 'Oranzhevoe naslazhdenie' (6, $\mathrm{ON}, \mathrm{ccs} / \mathrm{Cl} /$ norc $427 / \mathrm{Me} 1 / \mathrm{pm})$, 'Sireneviy' (7, Si, ccs/Cl/ norc424/APRR-2-like $\left.\mathrm{wh}_{\mathrm{wh}} \mathrm{pm}\right)$, L-80 (8, Ccs/Cl/norc427/pm), and L 140/10 (9, Ccs/Cl/norc427/pm). The Ccs allele provides for capsanthin and capsorubin accumulation in fruits, while ccs ensures their absence (Lang et al., 2004). The $c l$ allele slows down the destruction of chlorophyll (Borovsky et al., 2008); norc affects ontogenetic stages (Babak et al., 2019). The APRR-like (white) allele is associated with the low accumulation of pigments in fruits (Pan et al., 2013). The pm allele provides for resistance to powdery mildew (Paran et al., 2009) and the $\mathrm{Mel}$ allele determines nematode resistance (Fazari et al., 2012). The features of the traits' manifestation in hybrids were evaluated during a three-year period (2016-2018) by the value of a dominance degree (Hp, Zhuchenko, 1980). As a standard, the pepper variety 'Troika' was used.

\section{Results and discussion}

Fruit yield value is shown in Table 1 .

Based on the data presented, three hybrids surpassed the standard variety 'Troika' for their early yield and 10 hybrids, for their commercial and total yielding capacity. The fruit mass of all test forms was higher than that of the standard. Heterosis values in the hybrids varied depending on the conditions during the year. At the same time, according to average yield values, most hybrids showed dominance and overdominance towards the increased trait values, which is well illustrated by the peculiarities of the Hp value distribution in Figure 1.

Figure 2 shows the values of the measures reflecting the biochemical composition of the fruits.

By the content of dry matter, soluble carbohydrates and vitamin C, most hybrids were not comparable with the standard variety, but they were inferior to the standard by a carotenoid content. Based on the three-year test results, valuable $F_{1}$ hybrids were identified (L45-11 × 'Shokoladnaya krasavitsa', L45-11 × 'Zhelty buket', L45-11 × L140/0, L140/0 × L45-11), with a dry matter content of 8.18-8.77\%; carotene, 19.95$32.73 \mathrm{mg} / \mathrm{kg}$; vitamin C, $112.49-144.4 \mathrm{mg} / \mathrm{kg}$; and soluble carbohydrates, $4.36-4.77 \%$.

Figure 3 shows the inheritance of phenotypic manifestation of biochemical traits. According to the figures presented, heterosis effects in the hybrids studied are multidirectional, which is, in our opinion, determined by different compositions of fruit quality alleles. Furthermore, accumulation of dry matter and carotene in $50 \%$ of the hybrids was inherited intermediately. 
Table 1

Yield traits of pepper parental forms and their $F_{1}$ hybrids (the average for 2016-2018).

\begin{tabular}{|c|c|c|c|c|c|}
\hline \multirow[t]{2}{*}{$\mathrm{N}$} & \multirow[t]{2}{*}{ Sample designation } & \multicolumn{3}{|c|}{ Fruit yield, kg/m² } & \multirow[t]{2}{*}{$\mathrm{FW}^{*}, \mathrm{~g}$} \\
\hline & & $\mathrm{Y}^{*}$ & $C^{*}$ & $\mathrm{G}^{*}$ & \\
\hline 1 & L4511 & 0.15 & 2.93 & 3.01 & 113.7 \\
\hline 2 & ZB & 0.41 & 3.76 & 3.93 & 120.3 \\
\hline 3 & $\mathrm{~L} 160 / 10$ & 0.25 & 3.78 & 3.94 & 144.2 \\
\hline 4 & SK & 0.11 & 4.69 & 4.77 & 155.1 \\
\hline 5 & CK & 0.37 & 1.85 & 1.93 & 94.2 \\
\hline 6 & ON & 0.53 & 3.61 & 3.72 & 118.6 \\
\hline 7 & $\mathrm{Si}$ & 0.04 & 4.61 & 4.76 & 131.7 \\
\hline 8 & L80 & 0.24 & 3.50 & 3.64 & 157.3 \\
\hline 9 & L140/0 & 0.35 & 3.95 & 4.12 & 147.3 \\
\hline 10 & L4511 × L80 & 0.13 & 2.53 & 2.63 & 172.8 \\
\hline 11 & $\mathrm{~L} 4511 \times \mathrm{ON}$ & 0.93 & 4.33 & 4.43 & 146.7 \\
\hline 12 & $\mathrm{~L} 4511 \times \mathrm{Si}$ & 0.34 & 2.76 & 2.83 & 115.8 \\
\hline 13 & L4511 × SK & 0.68 & 4.16 & 4.27 & 162.1 \\
\hline 14 & $\mathrm{~L} 4511 \times \mathrm{L} 160 / 10$ & 0.77 & 4.97 & 5.01 & 175.4 \\
\hline 15 & L4511 × CK & 0.38 & 3.20 & 3.27 & 147.9 \\
\hline 16 & L4511 × ZB & 0.69 & 3.63 & 3.79 & 127.8 \\
\hline 17 & $\mathrm{~L} 4511 \times \mathrm{L} 140 / 0$ & 0.29 & 3.55 & 3.71 & 154.9 \\
\hline 18 & $\mathrm{~L} 80 \times \mathrm{L} 4511$ & 0.60 & 4.11 & 4.22 & 164.9 \\
\hline 19 & $\mathrm{~L} 140 / 0 \times \mathrm{L} 4511$ & 0.74 & 4.23 & 4.40 & 136.6 \\
\hline 20 & $\mathrm{ON} \times \mathrm{L} 4511$ & 0.08 & 4.37 & 4.45 & 128.7 \\
\hline 21 & Si $\times L 4511$ & 0.23 & 3.43 & 3.49 & 136.9 \\
\hline 22 & SK $\times$ L4511 & 0.57 & 4.81 & 4.94 & 169.0 \\
\hline 23 & $\mathrm{~L} 160 / 10 \times \mathrm{L} 4511$ & 0.37 & 5.70 & 5.89 & 158.8 \\
\hline 24 & $\mathrm{CK} \times \mathrm{L} 4511$ & 0.91 & 4.21 & 4.23 & 122.4 \\
\hline 25 & $\mathrm{ZB} \times \mathrm{L} 4511$ & 0.91 & 3.76 & 3.92 & 136.5 \\
\hline 26 & Troika (st) & 0.82 & 3.98 & 4.12 & 88.5 \\
\hline
\end{tabular}

*Y: yearly' C: commercial' G: gross; Fw: fruit weight.

Yearly fruit yield

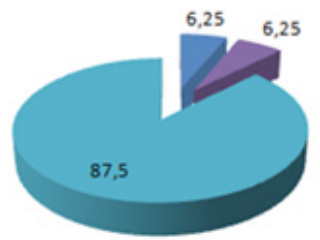

Gross fruit yield

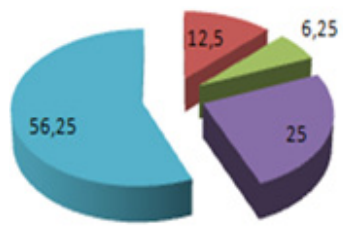

Commercial fruit yield

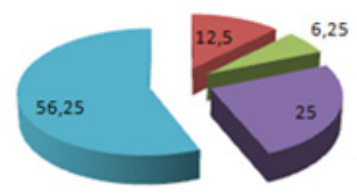

Fruit weight

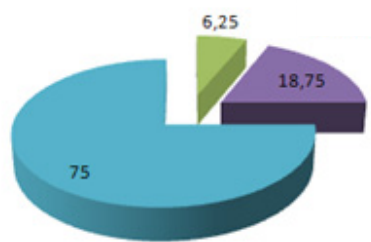

Dry matter, \%

$=H_{p}<-1$

$=-1<H p<0,5$

$=0,5<\mathrm{HP}<+0,5$

$=+0,5>\mathrm{Hp}<+1$

$=+1<\mathrm{Hp}$

Vitamin $C, \mathrm{mg} / 100 \mathrm{~g}$
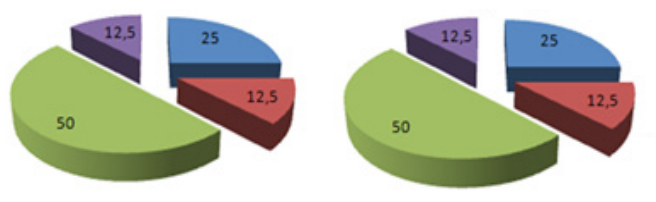

Soluble carbohydrates, $\%$
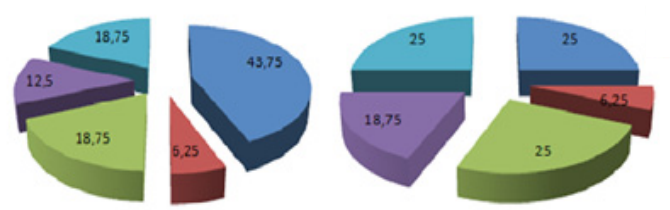

Figure 1. Peculiarities of dominance degree $(\mathrm{Hp})$ manifestation in pepper hybrids by yield traits (average for 2016-2018 in \%).
Figure 2. Manifestation of biochemical traits of the pepper parental forms and their $F_{1}$ hybrids (the average for 2016-2018). Numbering of samples as in Table 1. 

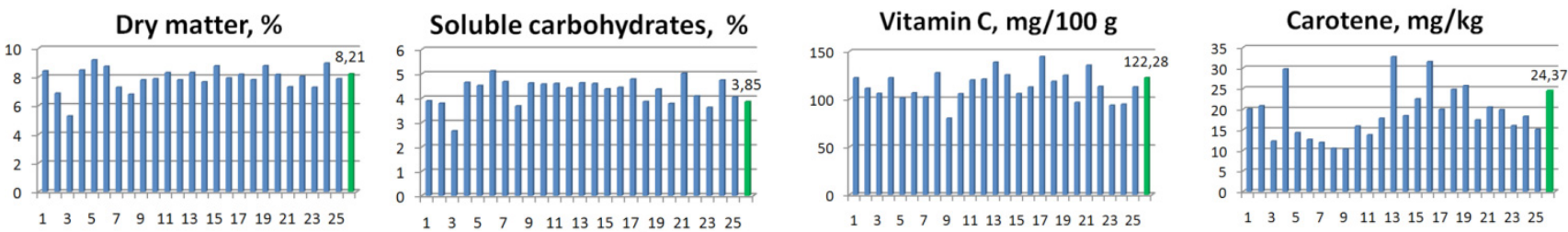

Figure 3. Level of dominance inheritance in manifestation of biochemical traits in pepper hybrids.

\section{Conclusions}

Our investigations generally show that, according to the threeyear average, the most frequent inheritance of yield was the dominance and overdominance followed by an increase in yield traits, whereas the manifestation of the most biochemical traits have an intermediate type and overdominance accompanied by a decrease in indicators.

In this regard, we recommend to combine - in order to develop highly productive hybrids with improved biochemical qualities and resistant to diseases - the methods of classical heterotic breeding to increase yielding capacity and MAS methods to enhance disease resistance and improve the biochemical composition of fruits.

Based on the test results, we were able to identify hybrids that combine a high yielding capacity, a biochemical value of fruits and a high heterotic effect. Three best hybrid combinations with a complex of biometric features were selected and transferred to the State Inspection for Testing and Protection of Plant Varieties of the Republic of Belarus.

\section{References}

Babak O.G., Nikitinskaya T.V., Nekrashevich N.A., Yatsevich K.K., Kilchevsky A.V. Comparative analysis of gene homology of the NAC-NOR transcription factor in tomato and pepper and its poly- morphism study. Molecular and Applied Genetics: Minsk. 2019;26: 7-18 (in Russian).

Borovsky Y., Paran I. Chlorophyll breakdown during pepper fruit ripening in the chlorophyll retainer mutation is impaired at the homo$\log$ of the senescence-inducible stay-green gene. Theor Appl Genet. 2008;117:235-240. DOI 10.1007/s00122-008-0768-5.

Fazari A., Palloix A., Wang L.H., Hua M.Y., Sage-Palloix A.M., Zhang B.X., Djian-Caporalino C. The root-knot nematode resistance $\mathrm{N}$-gene co-localizes in the $\mathrm{Me}$-genes cluster on the pepper (Capsicum aпnиит L.) P9 chromosome. Plant Breeding. 2012;131:665673. DOI 10.1111/j.1439-0523.2012.01994.x.

Lang Y.-Q., Yanagawa S., Sasanuma T., Sasakuma T. Orange fruit color in Capsicum due to deletion of capsanthin-capsorubin synthesis gene. Breeding Science. 2004;54:33-39. DOI 10.1270/jsbbs. 54.33 .

Pan Y., Bradley G., Pyke K., Ball G., Lu C., Fray R., Marshall A., Jayasuta S., Baxter C., Wijk R., Boyden L., Cade R., Chapman N.H., Frase P.D., Hodgman C., Seymour G.B. Network inference analysis identifies an APRR2-like gene linked to pigment accumulation in tomato and pepper fruits. Plant Physiology. 2013;161:1476-1485. DOI 10.1104/pp.112.212654.

Paran I., Benarous S., Ashkenazi V. Disease resistant pepper plants. 2009. Patent WO2009098685 A2.

Zhuchenko A.A. Ekologicheskaya genetika kulturnyh rastenij. Kishinev: Shtiintsa, 1980, 586 pp (in Russian).

Conflict of interest. The authors declare no conflict of interest. 


\title{
Key directions of breeding and seed production of alfalfa in European Russia
}

\author{
V.I. Cherniavskih*, E.V. Dumacheva ${ }^{1}$, Z.A. Borodaeva ${ }^{1}$, D.V. Dumachev $^{2}$ \\ 1 Belgorod State Research University, Belgorod, Russia \\ ${ }^{2}$ Belgorod Oncology Dispensary, Belgorod, Russia
}

DOI 10.18699/ICG-PlantGen2019-73

Abstract: The aim of the work is to study the varieties and breeding samples of alfalfa in various ecotopes. Analysis of variance of the two-factor experiment showed that the resultative property 'productivity' primarily depends on the factor "ecotope" (68.7\%), while the factor "grade" determines it slightly (4.7\%). Their interaction does not have a strong impact (10.9\%). The share of the year conditions influence averaged $0.48 \%$. Analysis of variance of the two-factor experiment showed that the resultative property "seed yield" primarily depends on the factor "ecotope" (63.58\%), while the contribution of the factor "grade" is $5.45 \%$; the interaction of these factors has a significant impact (25.5\%). The share of the year conditions influence averaged $1.01 \%$.

Key words: alfalfa; various ecotope; mf-mutation; breeding; seed production.

\section{Introduction}

Alfalfa is one of the most important widespread ancient world cultures, which is a companion of intensive commercial livestock and livestock production, requiring for its development a solid, stable and high-quality forage base. Alfalfa is a culture of multidisciplinary use. It is demanded both in agricultural production and in medicine and pharmacology. At the present stage, the most intensive breeding work is being carried out with several species of the genus Medicago: M. sativa L. and M. varia Mart. (Lamb et al., 2007; Kurkina et al., 2017).

An important direction in the global breeding of alfalfa is the study of forms carrying a recessive genetic mutation of multiflora (mf-mutation). This mutation is controlled by a recessive gene $(m j)$ and two genes that affect its expression (Bingham, Murphy, 1965; Petkova, 2010; Popescu et al., 2016). The mutation manifests most clearly in difficult environmental conditions and such forms show indicators of high quality (Dumacheva et al., 2018).

Successful breeding work requires the creation of a system of sustainable seed production as an economic basis for the effective implementation of scientific achievements. The close cooperation of scientists of the Belgorod State University with one of the largest enterprises of the region, ZAO "Prioskolye", enabled the creation of a system for primary and elite alfalfa seed production based on the author varieties. The area of alfalfa tested in some years has reached 1.5 thousand hectares and the production of seeds with high reproduction rate, 300 tons/year. The investment from the use and sale of seeds makes it possible to finance breeding programs that use the method of recurrent selection, the method of polycross, the method of hybridization using mf-mutations, microclonal reproduction.

The aim of the work is to study the varieties and breeding samples of alfalfa in various ecotopes; to elect source material for the selection of specialized varieties for special conditions of cultivation.

\section{Materials and methods}

The research was carried out in 2016-2018 in the Chernyansky branch of the experimental plots of ZAO "Krasnoyaruzh- skaya zernovaya kompaniya", Belgorod region, Chernyansky district.

The plants were sown in the standard trial design. The plot area was $2 \mathrm{~m}^{2}$. The repetition was fourfold. The plots were double-row. The row spacing in the plot was $25 \mathrm{~cm}, 45 \mathrm{~cm}$ between the plots. Control varieties were placed through 4 plots. As the standard, the variety Krasnoyaruzhskaya 1 was chosen, which was adopted as a regional standard during the State variety testing in 5 regions.

Trial variations:

A-factor (variety population):

A1: a zoned variety of $M$. varia Krasnoyaruzhskaya 1;

A2: a zoned variety of $M$. varia Krasnoyaruzhskaya 2;

A3: Vega 87;

A4: the breeding varieties of $M$. varia PPL 6/8;

A5: the variety population NZK $40 \mathrm{mf}$, which was obtained as a result of sampling from the local populations of $M$. varia growing in the floodplains of the Belgorod region on the basis of the presence of the mf-mutation. The selection condition was the expression of the mf-mutation above ' 3 ' and a high degree of wax on the leaves.

B: factor (ecotope, soil difference):

B1: soil: chernozem typical, heavy-loamy, which was in a field crop rotation. The humus content was $5.1 \%$, the content of easily hydrolyzed nitrogen was $182 \mathrm{mg} / \mathrm{kg}, \mathrm{P}_{2} \mathrm{O}_{5}$ concentration was $235 \mathrm{mg} / \mathrm{kg}, \mathrm{K}_{2} \mathrm{O}$ concentration was $292 \mathrm{mg} / \mathrm{kg}$, $\mathrm{pH}_{\mathrm{KCl}}$ was 6.5;

B2: meadow-gley, light-loamy soil, on the plowed meadow in the floodplain of the Oskol river;

B3: chernozem leached, sandy-loam, which was in the byfarm crop rotation. The humus content was $1.9 \%$, the content of easily hydrolyzed nitrogen was $1-84 \mathrm{mg} / \mathrm{kg}, \mathrm{P}_{2} \mathrm{O}_{5}$ concentration was $159 \mathrm{mg} / \mathrm{kg}, \mathrm{K}_{2} \mathrm{O}$ concentration was $140 \mathrm{mg} / \mathrm{kg}$, $\mathrm{pH}_{\mathrm{KCl}}$ was 6.3.

Agrochemical studies of experimental plots were performed according to standard methods adopted in agrochemistry: humus was analyzed by the Tyurin method; easily hydrolyzed nitrogen, by the Kornfield method; mobile phosphorus and potassium compounds, by the Chirikov method. For equalizing planting the white mustard culture was used. Sowing 
was carried out using a "Klen 5.4" electronic drill. Seeds were sown at a rate of 100 pieces per running meter.

The expression index was calculated as the sum of multiplication of number of plants (tillers) in each mf category on total number of plants (tillers) in population. Categories of mf: 0, lack of mutation; 1, 1 mf-leaf on one stalk; 2, 2-3 mf-leaves on one stalk; 3, 4-5 mf-leaves on one stalk; 4, 6-7 mf-leaves on one stalk; 5 , more than $8 \mathrm{mf}$-leaves on one stalk (Sheaffer et al., 1995). Statistical data processing was carried out with the use of the common software Microsoft Excel (2010).

\section{Results and discussion}

Selection work with alfalfa as a fodder crop is mainly aimed at achieving several main objectives: increasing the productivity of the forage mass in specific soil and climatic conditions, increasing the collection of protein per unit area and increasing the digestibility of the forage mass. In parallel, the work for increasing seed productivity as the basis for effective seed production is underway. The collection of dry matter obtained during the growing season of all variety samples in all studied ecotopes was calculated as an average for three years of research, which contributed to a full understanding of the processes of biomass formation during the growing season of alfalfa.

The first group included the variety samples both with a high rate of mf mutation (NZK $40 \mathrm{mf}, \mathrm{A} 5$ ) and a low gene expression ('Krasnoyaruzhskaya 2', A2), which have shown productivity at the standard level on average during the years of research. At the same time, on the chernozem soils, the variety Krasnoyaruzhskaya 2 (A2) had significantly exceeded the standard, by $24.7 \%(\mathrm{Cv}=0.1 \%)$, and NZK $40 \mathrm{mf}(\mathrm{A} 5)$ showed productivity at the standard level $(\mathrm{Cv}=3.5 \%)$.

The yield of dry phytomass from alfalfa of the NZK 40 mf variety sample (A5) on the meadow soil (an average over 3 years of research) was higher than the standard by $87.5 \%$ $(\mathrm{CV}=5.9 \%)$. In individuals of 'Krasnoyaruzhskaya 2' (A2), on a meadow soil, productivity remained at the level of the standard (the variety Krasnoyaruzhskaya 1). On the sandy soils, the individuals of the variety populations of this group were close to the standard in phytomass productivity and did not exceed it by more than 4.9-5.6 \% $(\mathrm{Cv}=16.7-17.9 \%)$.

The second group was formed by the variety Vega 87 (A3) and PPL 6/8 (A4) populations. On average, over the years of research in all ecotopes, they showed higher productivity than the standard. The variety Vega 87 (A3) population had shown productivity at the standard level only on the chernozem soils, and exceeded it by 22.3 and $10.2 \%$ on the meadow and sandy soils, respectively. Individuals of the PPL 6/8 variety population (A4) showed above-ground productivity above the standard by $41.4 ; 28.6$ and $10.5 \%$ in all ecotopes, respectively $(\mathrm{Cv}=2.2-14.2 \%)$.

One of the important directions of research was assessing the tolerance of varieties and variety populations in the same ecotope conditions based on the degree of yield reduction. The alfalfa variety populations studied in the experiment were divided into several groups according to seed yield under different ecotopes. The research results showed that such variety populations as Vega 87 (A3) and NZK $40 \mathrm{mf}$ (A5) had shown a good ecological suitability for meadow soils. Their average yield was $32.83 \mathrm{~g} / \mathrm{m}^{2}$ on the chernozem soils; on the sandy soils their productivity decreased by 50.2 and $70.3 \%$. On the meadow soils, the individuals had reduced their yield only by $13.97 \%$, and in the variety A5 yield it remained at the standard level $(\mathrm{Cv}=4.3 \%)$. These forms had a general morphological difference from other forms, a pronounced waxy coating on the leaves. In the areas with chernozem soil, a new promising variety sample, PPL 6/8 (A4), had shown its yield at the level of the varieties in the first group at $\mathrm{CV}=11.5 \%$. On sandy soil, the yield decreased by $36.56 \%(\mathrm{Cv}=6.1 \%)$; on meadow, by $72.4 \%(\mathrm{Cv}=33.1 \%)$.

\section{Conclusions}

The zoned varieties Krasnoyaruzhskaya 1 and Krasnoyaruzhskaya 2 are differentially recommended for cultivation in the conditions of intensive crop rotation and low-productivity soils.

Analysis of variance of the two-factor experiment showed that the resultative property "productivity" primarily depends on the factor "ecotope" (68.7\%), the factor "Grade" determines it slightly $(4.7 \%)$. Their interaction does not have a strong impact $(10.9 \%)$. The share of the year conditions influence averaged $0.48 \%$.

Analysis of variance of the two-factor experiment showed that the resultative property "seed yield" primarily depends on the factor "ecotope" $(63.58 \%)$, while the contribution of the factor "grade" is $5.45 \%$; the interaction of these factors has a significant impact $(25.5 \%)$. The share of the year conditions influence averaged $1.01 \%$.

\section{References}

Bingham E.T., Murphy R.P. Breeding and morphological studies on Multifoliolate selections of alfalfa Medicago sativa L. Crop. Sci. 1965;5:233-235.

Dumacheva E.V., Cherniavskih V.I., Gorbacheva A.A., Vorobyova O.V., Borodaeva Z.A., E.N. Bespalova and Ermakova L.R. Biological resources of the Fabaceae family in the cretaceous south of Russia as a source of starting material for drought-resistance selection. International J. Green Pharmacy. 2018;12(2):354-358. DOI 10.22377/ijgp.v12i02.1785

Kurkina Y.N., Huong N.T.L., Lazarev A.V., Dumacheva E.V., Cherniavskich V.I. Features of morphology and biology of broad bean samples in the south of the central black earth region (Russia). International J. Green Pharmacy. 2017;11(3):494-497. DOI 10.22377/ ijgp.v11i03.1163

Lamb J.F.S., Jung H.-J.G., Sheaffer C.C., Samac D.A. Alfalfa leaf protein and stem cell wall polysaccharide yields under hay and biomass management systems. Crop Science Society of America. 2007;47:1407-1415.

Petkova D. Multifoliate Alfalfa line with 23-24 leaves on a leaf stalk. $J$. Crop Weed. 2010; 6(1):1-5.

Popescu S., Boldura O.-M., Ciulca S. Evaluation of the geneticvariability correlated with multileaflet trait in alfalfa. AgroLife Scientific Journal. 2016;5(2):125-130.

Sheaffer C.C., McCaslin M., Volenec J.J., Cherney J.H., Johnson K.D., Woodward W.T., Viands D.R. Multifoliolate Leaf Expression (Leaves With Greater Than 3 Leaflets. Leaf). 1995:2.

Acknowledgements. The study was supported by the grants: for the research and development on priority directions of development of agro industrial complex of the Belgorod region (Agreement No. 2 dated November 12, 2018); grant No. 6.4854.2017/BCh.

Conflict of interest. The authors declare no conflict of interest. 


\section{GWAS for Dissecting Traits and Pinpoint Candidate Genes}




\title{
High-throughput technologies for sunflower oil improvement
}

\author{
A.I. Chernova*, E.U. Martynova \\ Skolkovo Institute of Science and Technology, Moscow, Russia
}

DOI 10.18699/ICG-PlantGen2019-74

(c) Autors, 2019

* e-mail: alin.chernova@gmail.com

\begin{abstract}
Cultivated sunflower in one of the key plants used by humans. Nowadays sunflower is planted mainly for the seed oil. It takes position number four on the global seed oil market. Selection of hybrids with increased oil content and changed oil properties is one of the basic directions in sunflower hybrid breeding. Due to the extensive climate change and the growing human population, selection time became a serious bottleneck on the way to the production of new cultivars. High-throughput genotyping and phenotyping technologies can push forward sunflower breeding and help reducing time required for the selection process.

Key words: sunflower; oil composition; marker-assisted selection; genomic selection; phenotyping technologies.
\end{abstract}

\section{Introduction}

Sunflower is one of the most important oilseed crops, which takes position four in the global production of vegetable oil after palm, soybean, and rapeseed. It is known that oilseed content is influenced by both environmental conditions and genetic factors (Rauf et al., 2017). That's why production of selection hybrids with changed oil properties is one of the key objectives of oilseed crop breeding (Jocic', Miladinovic', and Kaya 2015). Since the pioneering work of V.S Pustovoit in the 1960s high seed oil content has become one of the principal directions in sunflower breeding (Vear 2016). The second crucial sunflower oil characteristic is seed oil composition which was altered during the transformation of sunflower from the wild-type to domesticated oilseed crop (Putt 1997; Burke, Knapp, and Rieseberg 2005). The main components of sunflower oil are triglycerides (about 95\%), which are made up of three fatty acids (FAs) attached to glycerol by ester bonds. Nutritional and technical properties of sunflower oil are determined by the fatty acids (FA) composition (Garcés et al., 2009). Genetic markers associated with certain oil phenotypes can be implemented in marker-assisted (MAS) or genomic selection (GS) in order to speed up the selection of sunflower cultivars with desirable oil characteristics (Dimitrijevic and Horn 2018).

\section{Genetic markers for sunflower}

Before NGS sequencing became widely available, sunflower genotyping and mapping were performed using RAPD (Rieseberg et al., 1993), RFLP (Lai et al., 2005), AFLP (Gedil et al., 2001) and SSR markers (Tang et al., 2003). The availability of SNP-based markers revolutionized sunflower genetics. The first SNP study for sunflower was performed in 2005, 243 SNPs were mapped (Lai et al., 2005). This study was followed up by the design of Infinium Beadchip containing 9,480 SNPs (Bachlava et al., 2012) and 25K SNP array (Livaja et al., 2016).

Another step was made by the implementation of genome complexity reduction techniques such as RAD sequencing (Bowers et al., 2012; Talukder et al., 2014) and GBS sequenc- ing (Celik et al., 2016). Such approaches made it possible to avoid expensive whole genome sequencing providing at the same time more opportunities compared to microarray technologies since the former can obtain short sequences-reads, covering the major part of the genome. Sunflower genome full assembly published in 2017 (Badouin et al., 2017) made it possible to perform large-scale genome-wide association studies (GWAS).

\section{Phenotyping technologies}

Efficient genotyping technologies should run side by side with efficient oil phenotyping technologies. For a long period of time the most common ways for plant oil phenotyping were gas chromatography-mass spectrometry (GS-MS) or gas chromatography-flame ionization detection (GC-FID) methods (Li-Beisson et al., 2010).

As an alternative to this technique, NMR spectroscopy (Popescu et al., 2015) may be used. Another method combining the advantages of fast high-resolution chromatographic separation with high-sensitivity and selectivity of massspectrometric detection is UPLC-MS. This method was first proposed to be used for plant fatty acid profiling in Arabidopsis thaliana and diatoms (Bromke et al., 2013, 2015). Later, this method was validated for sunflower lipid oil profiling (Chernova et al., 2019).

\section{Genome-wide association studies}

High quality phenotype and genotype data can be used for genome wide association studies (GWAS). This analysis is a powerful tool for understanding the genetic content of complex traits. GWAS was successfully implemented to many plant species including sunflower. In the case of sunflower, GWAS gave a new insight into flowering time (Bonnafous et al., 2018), male fertility restoration (Goryunov et al., 2019), seedling growth (Masalia et al., 2018), plasticity of oil yield for combined abiotic stresses (Mangin et al., 2017), basal and apical branching (Nambeesan et al., 2015), flower morphological traits (Dowell et al., 2019), and others. 


\section{Conclusions}

According to the points discussed above, it can be concluded that NGS high-throughput genotyping can be combined with high-throughput molecular phenotyping technologies to perform GWAS in order to find significant associations between valuable oil characteristics and the genotype. Such associations can be implemented in sunflower genomic selection and push forward sunflower breeding strategies.

\section{References}

Bachlava E., Taylor C.A., Tang S., Bowers J.E., Mandel J.R., Burke J.M., Knapp S.J. SNP Discovery and development of a high-density genotyping array for sunflower. PLOS ONE. 2012;7(1):e29814. https:// doi.org/10.1371/journal.pone.0029814.

Badouin H., Gouzy J., Grassa C.J., Murat F., Staton S.E., Cottret L., Lelandais-Brière C. et al. The sunflower genome provides insights into oil metabolism, flowering and asterid evolution. Nature. 2017;546(7656):148-52. https://doi.org/10.1038/nature22380.

Bonnafous F., Fievet G., Blanchet N., Boniface M.-C., Carrère S., Gouzy J., Legrand L. et al. Comparison of GWAS models to identify non-additive genetic control of flowering time in sunflower hybrids. TAG. Theoretical and Applied Genetics. Theoretische Und Angewandte Genetik. 2018;131(2):319-32. https://doi.org/10.1007/ s00122-017-3003-4.

Bowers J.E., Bachlava E., Brunick R.L., Rieseberg L.H., Knapp S.J., Burke J.M. Development of a 10,000 locus genetic map of the sunflower genome based on multiple crosses. G3: Genes, Genomes, Genetics. 2012;2(7):721-729. https://doi.org/10.1534/g3.112. 002659.

Bromke M.A., Giavalisco P., Willmitzer L., Hesse H. Metabolic analysis of adaptation to short-term changes in culture conditions of the Marine Diatom Thalassiosira Pseudonana. PLOS ONE. 2013;8(6): e67340. https://doi.org/10.1371/journal.pone.0067340.

Bromke M.A., Hochmuth A., Tohge T., Fernie A.R., Giavalisco P., Burgos A., Willmitzer L., Brotman Y. Liquid chromatography high-resolution mass spectrometry for fatty acid profiling. The Plant Journal. 2015;81(3):529-536. https://doi.org/10.1111/tpj.12739.

Burke J.M., Knapp S.J., Rieseberg L.H. Genetic consequences of selection during the evolution of cultivated sunflower. Genetics. 2005; 171(4):1933-1940. https://doi.org/10.1534/genetics.104.039057.

Celik I., Bodur S., Frary A., Doganlar S. Genome-wide SNP discovery and genetic linkage map construction in sunflower (Helianthus Annuus L.) using a genotyping by sequencing (GBS) approach. Mol Breed. 2016;36(9):133. https://doi.org/10.1007/s11032-016-0558-8.

Chernova A., Mazin P., Goryunova S., Goryunov D., Demurin Y., Gorlova L., Vanyushkina A. et al. Ultra-performance liquid chromatography-mass spectrometry for precise fatty acid profiling of oilseed crops. PeerJ. 2019;7(March):e6547. https://doi.org/10.7717/ peerj.6547.

Dimitrijevic A., Horn R. Sunflower hybrid breeding: From markers to genomic selection. Frontiers in Plant Sci. 2018;8. https://doi. org/10.3389/fpls.2017.02238.

Dowell J.A., Reynolds E.C., Pliakas T.P., Mandel J.R., Burke J.M., Donovan L.A., Mason C.M. Genome-wide association mapping of floral traits in cultivated sunflower (Helianthus Annuus). The Journal of Heredity. 2019;110(3):275-286. https://doi.org/10.1093/ jhered/esz013.

Garcés R., Martínez-Force E., Salas J.J., Venegas-Calerón M. Current advances in sunflower oil and its applications. Lipid Technology. 2009;21(4):79-82. https://doi.org/10.1002/lite.200900016.
Gedil M.A., Wye C., Berry S., Segers B., Peleman J., Jones R., Leon A., Slabaugh M.B., Knapp S.J. An integrated restriction fragment length polymorphism - amplified fragment length polymorphism linkage map for cultivated sunflower." Genome. 2001;44(2):213-221. https://doi.org/10.1139/g00-111.

Goryunov D.V., Anisimova I.N., Gavrilova V.A., Chernova A.I., Sotnikova E.A., Martynova E.U., Boldyrev S.V. et al. Association mapping of fertility restorer gene for CMS PET1 in sunflower. Agronomy. 2019;9(2):49. https://doi.org/10.3390/agronomy9020049.

Jocić S., Miladinović D., Kaya Y. Breeding and genetics of sunflower. In Sunflower. 2015;1-25. Elsevier. https://doi.org/10.1016/B978-1893997-94-3.50007-6.

Lai Z., Livingstone K., Zou Y., Church S.A., Knapp S.J., Andrews J., Rieseberg L.H. Identification and mapping of SNPs from ESTs in sunflower. TAG. Theoretical and Applied Genetics. Theoretische Und Angewandte Genetik. 2005;111(8):1532-1544. https://doi. org/10.1007/s00122-005-0082-4.

Li-Beisson Y., Shorrosh B., Beisson F., Andersson M.X., Arondel V., Bates P.D., Baud S. et al. Acyl-lipid metabolism. The Arabidopsis Book. 2010;8:e133. https://doi.org/10.1199/tab.0133.

Livaja M., Unterseer S., Erath W., Lehermeier C., Wieseke R., Plieske J., Polley A. et al. Diversity analysis and genomic prediction of sclerotinia resistance in sunflower using a new $25 \mathrm{~K}$ SNP genotyping array. Theoretical Applied Genetics. 2016;129(2):317-329. https://doi.org/10.1007/s00122-015-2629-3.

Mangin B., Casadebaig P., Cadic E., Blanchet N., Boniface M.-C., Carrère S., Gouzy J. et al. Genetic control of plasticity of oil yield for combined abiotic stresses using a joint approach of crop modelling and genome-wide association. Plant, Cell Environment. 2017; 40(10):2276-2291. https://doi.org/10.1111/pce.12961.

Masalia R.R., Temme A.A., Torralba N.L., Burke J.M. Multiple genomic regions influence root morphology and seedling growth in cultivated sunflower (Helianthus Annuus L.) under well-watered and water-limited conditions. PloS One. 2018;13(9):e0204279. https:// doi.org/10.1371/journal.pone.0204279.

Nambeesan S.U., Mandel J.R., Bowers J.E., Marek L.F., Ebert D., Corbi J., Rieseberg L.H., Knapp S.J., Burke J.M. Association mapping in sunflower (Helianthus Annuus L.) reveals independent control of apical vs. basal branching. BMC Plant Biol. 2015;15(1):84. https:// doi.org/10.1186/s12870-015-0458-9.

Popescu R., Costinel D., Dinca O.R., Marinescu A., Stefanescu I., Ionete R.E. Discrimination of vegetable oils using NMR spectroscopy and chemometrics. Food Control. Recent Advances of Food Analysis, 2015;48(February):84-90. https://doi.org/10.1016/j.foodcont.2014.04.046.

Putt E.D. Early history of sunflower. Sunflower Technology Production. 1997; agronomymonogra (sunflowertechno):1-19. https://doi. org/10.2134/agronmonogr35.c1.

Rauf S., Jamil N., Tariq S.A., Khan M., Kausar M., Kaya Y. Progress in modification of sunflower oil to expand its industrial value. Journal of the Science of Food and Agriculture. 2017;97(7):1997-2006. https://doi.org/10.1002/jsfa.8214.

Rieseberg L.H., Choi H., Chan R., Spore C. Genomic map of a diploid hybrid species. Heredity. 1993;70(3):285. https://doi.org/10.1038/ hdy.1993.41.

Talukder Z.I., Gong L., Hulke B.S., Pegadaraju V., Song Q., Schultz Q., Qi L. A high-density SNP map of sunflower derived from RADsequencing facilitating fine-mapping of the rust resistance gene R12. PLoS ONE. 2014;9(7). https://doi.org/10.1371/journal.pone. 0098628. 
Tang S., Kishore V.K., Knapp S.J. PCR-multiplexes for a genome-wide framework of simple sequence repeat marker loci in cultivated sunflower. Theoretical Applied Genetics. 2003;107(1):6-19. https://doi. org/10.1007/s00122-003-1233-0.
Vear F. Changes in sunflower breeding over the last fifty years. $O C L$. 2016;23(2):D202. https://doi.org/10.1051/ocl/2016006.

Conflict of interest. The authors declare no conflict of interest. 


\title{
High-throughput genotyping for association mapping of agronomically important traits in rapeseed: a brief review of the current status
}

\author{
R.F. Gubaev ${ }^{1 *}$, S.V. Boldyrev ${ }^{1}$, D.V. Goryunov ${ }^{2}$, S.V. Goryunova ${ }^{3}$ \\ 1 Skolkovo Institute of Science and Technology, Moscow, Russia \\ ${ }^{2}$ Belozersky Institute of Physico-Chemical Biology, Moscow State University, Moscow Russia \\ ${ }^{3}$ Institute of General Genetics, Russian Academy of Science, Moscow, Russia
}

DOI 10.18699/ICG-PlantGen2019-75

(c) Autors, 2019

* e-mail: rimgubaev@gmail.com

\begin{abstract}
Rapeseed (Brassica napus) is one of the most important oilseed crops used for the production of vegetable oils. The key features that directly impact the quality and the quantity of the oil are agronomically important traits. The modern and effective approach that allows such traits to be improved is marker-assisted selection which relies on the socalled molecular markers, including DNA-based ones. In turn, to date, several approaches that facilitate the identification of a molecular marker, as well as genetic association mapping of phenotypical traits, have been implemented. Here we briefly review several recent studies devoted to association mapping of agronomically important traits in rapeseed by means of high-throughput genotyping technologies.

Key words: rapeseed; association studies; agronomically important traits; high throughput genotyping technologies.
\end{abstract}

\section{Introduction}

Rapeseed (Brassica napus) is an oilseed crop used worldwide for the production of vegetable oils. Rapeseed oil is the third most commonly produced vegetable oil in the world after palm and soy oil (List, 2016). In turn, the quality and the quantity of the oil are determined by phenotypic traits like plant architecture, oil composition, and resistance to unfavourable environmental conditions. Thus, the plant breeders try to improve such traits in order to increase the effectiveness of harvesting, quality and preservation of the yield. One of the ways to create lines with favourable properties is by marker-assisted selection. There are several types of molecular markers including microsatellites, single nucleotide polymorphisms (SNPs), restriction fragment length polymorphism. In the recent years, SNPs have become popular due to the rapid development of high-throughput genotyping techniques that are widely applied for association studies in rapeseed. These techniques could be conditionally separated into two types: those including high- and low-density DNA-based arrays and those based on high- throughput sequencing, include whole-genome sequencing (WGS), genotyping by sequencing (GBS), and associative transcriptomics (Perez-de-Castro et al., 2012). In the present review, several studies that implement high-throughput genotyping for association mapping of agronomically important traits in rapeseed are discussed.

\section{Plant architecture}

Traits related to plant architecture in rapeseed include plant height, primary branch number, branching angle. Plant architecture affects the effectiveness of photosynthesis, harvest convenience, and so several attempts have been made in order to determine underlying genetic factors. The SNPs associated with plant height were shown to be located close to the genes that encode enzymes related to the metabolism of gibberellins, which, in turn, regulate growth processes in plants $(\mathrm{Li}$ et al., 2016a). The novel markers for primary branch number were found in chromosome $\mathrm{C}$, all of them were adjacent to genes that encode transcription factors involved in plant development control (Li et al., 2016a). In the recent studies, Liu et al. (2016) identified potential markers associated with branch angle, the SNPs were located close to genes that encode enzymes for the metabolism of auxin which, in turn, regulates cell elongation. Another study by Li et al. (2017) also revealed several markers for the branch angle. It was demonstrated that potential candidate genes were presented by LAZY1 and TAC1 from the IGT gene family, which had been previously shown to control branch angle, leaf angle and shoot gravitropism in crops.

\section{Oil composition}

There are several compounds that are usually considered as ones affecting the quality of rapeseed's vegetable oil, namely fatty acid (oleic, linoleic, erucic acids), glucosinolates, tocopherols. Glucosinolates, the secondary metabolites produced by Brassicaceae plants, and erucic acid are the compounds that reduce the quality of the oil by making it toxic and inappropriate for baking. In contrast, unsaturated fatty acids, namely oleic and linoleic as well as tocopherols possessing vitamin $\mathrm{E}$ activity, are considered as beneficial components of the oil. Several studies indicate that glucosinolate content is related to SNP adjacent genes that encode glucosinolate transporters and various transcription factors (Qu et al., 2015, Li et al., 2014, Wei et al., 2019). Loci associated with erucic acid content were present on chromosomes A8, A9, A10, C3, C8, C9 (Li et al., 2014; Havlickova et al., 2017; Qu et al., 2017). The markers associated with fatty acid content were shown to be located close to the genes encoding fatty acid elongases, 3-ketoacyl-CoA synthases, and fatty acid desaturases (Gacek et al., 2017; Qu et al., 2017). Using the associative transcriptomics approach, the ortholog of the VTE gene, 
which encodes tocopherol methyl transferase, was shown to determine tocopherol compositions (Havlickova et al., 2017).

\section{Phenology}

Phenological traits that affect the potential of rapeseed yield include flowering time, maturity time, earliness; these traits generally determine how much time plants invest in vegetative growth as well as in seed formation. The trait 'flowering time' has been widely studied in rapeseeds. Thus, potential flowering time markers were found near the following genes: CONSTANS, PHYTOCHROME B, FRIGIDA, FLOWERING LOCUS T, FRUITFUL, FLOWERING LOCUS C, which has been previously demonstrated to regulate photoperiodic reactions in thale cress plants (Xu et al., 2015; Raman et al., 2016). Phenological traits were more deeply investigated by Zhou et al. (2017) who were searching for associations for the timing of initial flowering, maturity and final flowering as well as the flowering period. It was demonstrated that these traits are related to 131 SNPs located within the loci that contain genes responsible for the flowering process.

\section{Resistance to unfavourable environmental conditions}

One of the key features that determine the yield amount is the ability to resist to biotic as well as abiotic environmental factors, which include high salinity, freezes, pathogens. Several recent association studies revealed genes and potential markers responsible for resistance to pathogens and unfavourable abiotic factors. Markers significantly associated with the resistance of rapeseed to Sclerotinia stem rot were found adjacent to the genes related to lignin biosynthesis, jasmonic acid pathway, defence response (Wei et al., 2016). Another study revealed associations with clubroot disease, notably, all potential markers were shown to be located near the genes that encode disease resistance proteins of the TIR-NBS family (Li et al., 2016b). Salt resistance markers were found by Wan et al. (2017), all SNPs were adjacent to salt-stress related genes encoding aquaporins, enzymes involved in the biosynthesis of proline. Electrolyte leakage was assessed in order to reveal markers for the freezing tolerance of rapeseed, several associated loci were shown to contain genes that encode sulfur transport proteins, enzymes involved in abscisic acid biosynthesis, transcription factors related to development (Fiebelkorn et al., 2018).

\section{Conclusions}

Since rapeseed is an agronomically important plant for vegetable oil production, the number of studies on genetic factors underlying phenotype traits is constantly increasing. The most recent studies are generally devoted to traits related to plant architecture, oil composition, phenology and resistance to unfavourable environmental conditions. It should also be mentioned that modern high-throughput genotyping technologies have become more popular for these purposes due to high performance and relatively low costs. Recent insights in phenotype-genotype associations in rapeseed will facilitate the uncovering of new markers for agronomically important traits, which, in turn, will facilitate the improvement of rapeseed lines as well as the creation of new ones.

\section{References}

Fiebelkorn D., Horvath D., Rahman M. Genome-wide association study for electrolyte leakage in rapeseed/canola (Brassica napus L.). Mol. Breeding. 2018;38(11):129.

Gacek K., Bayer P.E., Bartkowiak-Broda I., Szala L., Bocianowski J., Edwards D., \& Batley, J. Genome-wide association study of genetic control of seed fatty acid biosynthesis in Brassica napus. Front. Plant Sci. 2017;7:2062.

Havlickova L., He Z., Wang L., Langer S., Harper A.L., Kaur H., Bancroft I. Validation of an updated Associative Transcriptomics platform for the polyploid crop species Brassica napus by dissection of the genetic architecture of erucic acid and tocopherol isoform variation in seeds. Plant Journal. 2018;93(1):181-192.

Li F., Chen B., Xu K., Gao G., Yan G., Qiao J., Zhang T. A genomewide association study of plant height and primary branch number in rapeseed (Brassica napus). Plant Sci. 2016a;242:169-177.

Li F., Chen B., Xu K., Wu J., Song W., Bancroft I., Wang N. Genomewide association study dissects the genetic architecture of seed weight and seed quality in rapeseed (Brassica napus L.). DNA Research. 2014;21(4):355-367.

Li H., Zhang L., Hu J., Zhang F., Chen B., Xu K., Wu X. Genome-wide association mapping reveals the genetic control underlying branch angle in rapeseed (Brassica napus L.). Front. Plant Sci. 2017;8:1054.

Li L., Luo Y., Chen B., Xu K., Zhang F., Li H., Li F. A genome-wide association study reveals new loci for resistance to clubroot disease in Brassica napus. Front. Plant Sci. 2016b;7:1483.

List G.R. Oilseed Composition and Modification for Health and Nutrition. Functional Dietary Lipids. Woodhead Publishing. 2016

Liu J., Wang W., Mei D., Wang H., Fu L., Liu D., Hu Q. Characterizing variation of branch angle and genome-wide association mapping in rapeseed (Brassica napus L.). Front. Plant Sci. 2016a;7:21.

Perez-de-Castro A., Vilanova S., Cañizares J., Pascual L., Blanca J., Diez M., Picó B. Application of genomic tools in plant breeding. Current Genomics. 2012;13(3):179-195.

Qu C., Jia L., Fu F., Zhao H., Lu K., Wei L., Li J. Genome-wide association mapping and Identification of candidate genes for fatty acid composition in Brassica napus L. using SNP markers. BMC Genomics. 2017;18(1):232.

Qu C.M., Li S.M., Duan X.J., Fan J.H., Jia L.D., Zhao H.Y., Wang R. Identification of candidate genes for seed glucosinolate content using association mapping in Brassica napus L. Genes. 2015;6(4): 1215-1229.

Raman H., Raman R., Coombes N., Song J., Prangnell R., Bandaranayak C., Dennis E.S. Genome-wide association analyses reveal complex genetic architecture underlying natural variation for flowering time in canola. Plant, Cell Environment. 2016;39(6):1228-1239.

Wan H., Chen L., Guo J., Li Q., Wen J., Yi B., Shen J. Genome-wide association study reveals the genetic architecture underlying salt tolerance-related traits in rapeseed (Brassica napus L.). Front. Plant Sci. 2017;8:593.

Wei D., Cui Y., Mei J., Qian L., Lu K., Wang Z.M., Qian W. Genomewide identification of loci affecting seed glucosinolate contents in Brassica napus L. J. Integrative Plant Biol. 2019;61(5):611-623.

Wei L., Jian H., Lu K., Filardo F., Yin N., Liu L., Li J. Genome-wide association analysis and differential expression analysis of resistance to Sclerotinia stem rot in Brassica napus. Plant Biotechnol. J. 2016;14(6):1368-1380.

Xu L., Hu K., Zhang Z., Guan C., Chen S., Hua W., Ma C. Genome-wide association study reveals the genetic architecture of flowering time in rapeseed (Brassica napus L.). DNA Research. 2015;23(1):43-52.

Zhou Q., Han D., Mason A.S., Zhou C., Zheng W., Li Y., Huang Y. Earliness traits in rapeseed (Brassica napus): SNP loci and candidate genes identified by genome-wide association analysis. $D N A$ Research. 2017;25(3):229-244.

Acknowledgements. This study was supported by the Ministry of Science and Higher Education of the Russian Federation (Grant No. 14.609.21.0099).

Conflict of interest. The authors declare no conflict of interest. 


\title{
Genomic analysis in soybean breeding
}

\author{
V.V. Barzanova*, A.A. Novikova \\ LLC "IC "Biruch-NT"',', Alekseevka, Russia
}

DOI 10.18699/ICG-PlantGen2019-76

(c) Autors, 2019

*e-mail:v.barzanova@brc.efko.ru

\begin{abstract}
Marker-assisted selection is a selection method, which use gains momentum within the framework of the current cultivated crops' selection programs. Microsatellite markers (SSR) belong to the class of rather informative, reproducible and inexpensive DNAmarkers and are deemed to be efficient enough for genetic diversity studies. The practice of GWAS-analysis represents a more powerful instrument for determination of genotypephenotype associations related to the economically valuable traits such as productivity, photoperiodicity, drought-resistance, protein content in the beans, short vegetation period. Key words: soy; genomic selection; SSR-markers; GWAS.
\end{abstract}

\section{Introduction}

Marker-assisted selection represents an efficient selection method, the role of which in the modern cultivated crops' selection programs is becoming more and more important. This selection type allows increasing efficacy of the selection process and shortening the time needed for developing new highly productive soybean varieties.

GWAS (Genome-Wide Association Studies) used for the search of the quantitative trait loci employing gene linkage disequilibrium among neighboring SNPs provides a powerful genetic tool for associating phenotypes and genotypes. It allows detecting the soybean genetic variants that include the highest number of phenotypic traits.

\section{Materials and methods}

Currently the scientific research programs conducted in the "Biruch" Innovative center actively revolve around genetic selection studies aiming to develop a new highly productive soybean variety acclimatized to the weather conditions of the Central Black Earth region. This project incorporates the following works: selection of highly productive and resistant varieties, their marker analysis, sequencing and further GWAS analysis. The results presented within the framework of this research paper represent a detailed description of a single project stage that will be followed by further studies in the nearest future.

Empirical research employed microsatellite analysis for the soybean varieties' genotyping for the protein content of the seeds and abortiveness of the ovaries. Markers were taken from open sources [2]. The analysis was based on the PCR method (C1000 Touch amplifier by BIO-RAD). Separation of DNA fragments of various sizes was carried out by means of electrophoresis on agarose gel ( $\%$ agarose solution) using an electrophoretic chamber with a power source (manufactured by BIO-RAD). Visualization of PCR products was carried out using the gel imaging documentation system GelDoc XR by BIO-RAD.

The next stage of work involved the preparation of DNA libraries of 140 soybean varieties. We selected 50 varieties that had the best performance against the following parameters: productivity, photoperiodicity, drought-resistance, protein content in the beans, short vegetation period. The sequencing of 50 samples was carried out using Illumina technology at the Skolkovo Science Center and at Novogen Company. After obtaining the sequences, the primary data processing was performed using the FastQC utility. The next stage concentrated on the selection of the suitable software based on the following criteria: the number of mapped reads, the number of properly paired reads, the time of mapping. As a result, BWA, Samtools, Hisat 2, and GATK software utilities were selected as the most efficient.

\section{Results and discussion}

Microsatellite markers (SSR) are considered the most informative, reproducible and relatively inexpensive class of DNA markers for genetic diversity studies. Therefore, the study of marker-associated economically valuable traits was performed using the method of microsatellite analysis.

Marker analysis of 30 soybean varieties was carried out within the framework of the present research work. Samples were selected on the basis of such characteristic as high adaptability to the soil and climatic conditions of the Belgorod region. These samples were tested for a group of markers responsible for the protein content of the beans and abortiveness of the ovaries:

The protein content: Satt 431; Satt 510; Satt 584; Satt 534; Satt 294; Satt 100; Satt 005; Satt 185; Satt 373; Satt 463; Satt 173; Satt 012; Satt 449; Pt 560; Sp; Pt 565 (Figure 1); abortiveness of the ovaries: Satt 150; Satt 291; Satt 567.

According to the results of the marker analysis focused on the size of amplicons after PCR, we obtained the following results:

- 1 sample shows a high number of protein markers (11 markers) and an average abortiveness rate (2 markers);

- 2 samples with an average number of protein markers (content greater than or equal to 7) and a low abortiveness rate (1 full marker, with a standard size, and 1 marker which size differs in electrophoresis detection);

- 10 samples show an average number of protein markers (content greater than or equal to 7) and the average abortiveness rate (2 markers);

- 8 samples have a low number of protein markers (from 2 to 5) and the average abortiveness rate (2 markers);

- 3 samples show a low indicator of the protein markers' number (from 2 to 5 ) and a high abortiveness rate (3 markers); 


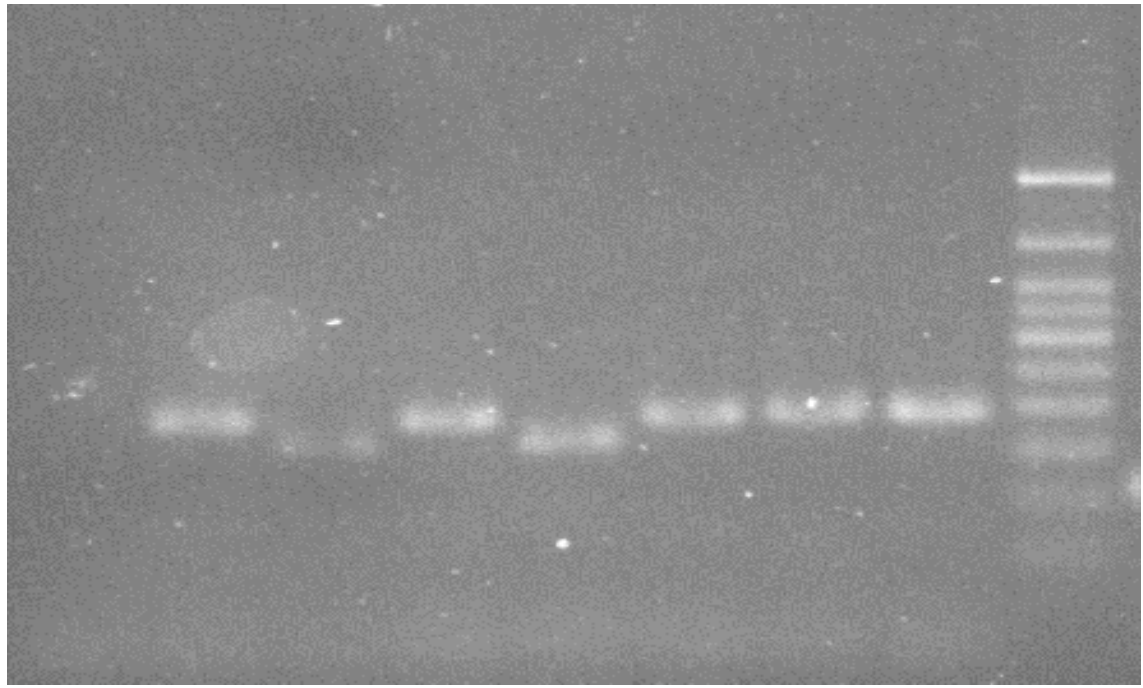

Figure 1. The results of electrophoresis in agarose gel with primers of microsatellite locus Pt 565 (fragment length 183 pairs nucleotides). Original.
- 2 samples show an average number of protein markers (from 5 to 8 ) and an average abortiveness rate (2 markers);

- 2 samples show a low indicator of the protein markers' number (from 2 to 5) and a low abortiveness rate (1 marker);

- 2 samples show a low indicator of the protein markers' number (from 2 to 5) and a high abortiveness rate (3 markers).

At present, the research in the sphere of genomic selection focuses mainly on finding additional microsatellite markers to increase the credibility of determination of sets of significant polymorphisms associated with certain traits. In prospect, it seems relevant to continue the studies and assess the influence of each marker on the manifestation of the certain traits. Alongside this process, we conduct the phenotyping of the varieties and identifying the most significant polymorphisms associated with economically valuable traits. The analysis results are summarized in a database for subsequent statistical data processing.

The determination of heterozygous plants (true hybrids) is conducted with the help of such markers as Satt 002, Satt 005, Satt 009, Satt 011, Satt 012, Satt 063, Satt 100, Satt 114, Satt 146, Satt 173, Satt 179, Satt 185, Satt 228, Satt 294, Satt 358, Satt 373, Satt 431, Satt 431, Satt 440, Satt 463, Satt 510, and Satt 547.

Another way to improve the credibility of determination of the sets of significant polymorphisms associated with a particular trait is through the use of the GWAS approach.

Currently, the sequencing of 50 soybean varieties has already been carried out and the samples were prepared for further GWAS analysis. Plant sequencing data was first processed using the FastQC utility. An array of the software packages tested for their efficiency in processing the data for comparison of the given samples with the reference sample included Hisat 2, BWA and Bowtie2. The results of the programms' comparison were as follows:

- HISAT2: 211,072,918 reads mapped, 167,295,328 properly coupled (79.26\%); mapping time $\sim 1$ hour.
- Bowtie2: 172,162,173 reads mapped; $154,655,842$ properly coupled (89.83\%); mapping time $\sim 6$ hours.

- BWA: 183,090,700 reads mapped: 163,507,646 properly coupled (90.40\%); mapping time $\sim 2$ hours.

After a thorough analysis, the BWA utility was chosen as the most productive of the data processing utilities. Samtools and Hisat 2 allowed us to prepare a reference genome, align the reads, convert them from sam* to bam* format, sort and index them. To obtain g.vcf* files, we used the GATK software. As a result, we obtained files containing information about the SNPs.

\section{Conclusions}

In order to increase the credibility of microsatellite analysis results, it is necessary to increase the number of markers used, assess the connection of each of them to the manifestation of certain traits and accumulate a statistically accurate database of phenotypic traits.

Another way to increase the effectiveness of the analysis of the genotype-phenotype associations (including quantitative traits) is through the use of GWAS analysis. To obtain a representative sample list, it is necessary to carry out the sequencing of other 90 variety samples.

When processing sequencing data, it is essential to use a set of utilities to improve the accuracy and speed of analysis.

\section{References}

Efremova V.V., Samelik E.G. Principles and practices of seed selection nowadays. Scientific Journal. 2015;106(02).

Perry CreganSoybean and Alfalfa Research Laboratory: https:// soybase.org/resources/ssrold.php.

Desta Z.A., Ortiz R. Genomic selection: genome-wide prediction in plantimprovement. Trends Plant Sci. 2014;19:592-601.

Newell M.A., Jannink J.L. Genomic selection in plant breeding. Methods Mol. Biol. 2014;1145:117-130.

Conflict of interest. The authors declare no conflict of interest. 


\section{Plant Cytogenetics in the Genomic and Postgenomic Era}




\title{
Molecular cytological analysis of alien introgressions in common wheat lines with T. kiharae genetic material
}

\author{
O.A. Orlovskaya ${ }^{1 *}$, N.I. Dubovets ${ }^{1}$, L.A. Solovey ${ }^{1}$, E.B. Bondarevich ${ }^{1}$, I.N. Leonova ${ }^{2}$ \\ ${ }^{1}$ Institute of Genetics and Cytology, National Academy of Sciences of Belarus, Minsk, Belarus \\ ${ }^{2}$ Institute of Cytology and Genetics, SB RAS, Novosibirsk, Russia
}

DOI 10.18699/ICG-PlantGen2019-77

(c) Autors, 2019

*e-mail: O.Orlovskaya@igc.by

\begin{abstract}
Monitoring of the process of the introgression of foreign chromatin in the genome of common wheat is the key to the success of the enrichment of the wheat gene pool of agronomically important genes from related species. In the karyotypes of the hybrid lines derived from crosses between common wheat varieties and T. kiharae, the presence of whole chromosomes of $T$. kiharae (intergenomic substitution 2G/2B), chromosome arm substitutions (centric translocation T2AtS:2AL) and large inserts in the form of intercalary translocations involving homoeologous group 1, 3 and 5 chromosomes of the B and $\mathrm{G}$ genomes using C-banding was found. Molecular markers revealed small introgressed fragments of $T$. kiharae into the genomes of common wheat varieties. The highest frequency of introgressions is shown for chromosomes 1A, 1B, 2A, 5B, and 6A. A high level of cytological stability (meiotic index was $88.18-93.0 \%$ ) was noted for the majority of introgression lines, which provides the formation of functional gametes in a number sufficient for successful reproduction. The exceptions are lines 34-1 and 34-2 with structural rearrangements of the chromosome $5 \mathrm{~B}$, affecting the functioning of the main genes for chromosome synapsis, which results in a significant decrease in meiotic index and negatively affects plant productivity.

Key words: T. aestivum; T. kiharae; wheat introgression lines; genomic structure; cytological stability.
\end{abstract}

\section{Introduction}

T. kiharae (A $\mathrm{A}^{\mathrm{t}} \mathrm{GGDD}, 2 n=42$ ) is of interest for the improvement of bread wheat as a source of high grain protein and gluten content and resistance to many diseases (Pukhalskiy, Odintsova, 2007). The use of T. kiharae to improve T. aestivum L. is complicated by the fact that the degree of chromosome homology between their genomes is low, which leads to an imbalance of sets of chromosomes in gametes of the first generations, and, therefore, and to their low fertility. As a result, the elimination of part of the genotypes in subsequent generations occurs, which reduces the range of inherited variety, and the possibility of selection of valuable forms with the required combinations of genes. The aim of this study was to analyze the genomic structure and cytological stability of hybrid forms obtained in crosses of common wheat varieties with T. kiharae.

\section{Materials and methods}

In this study, $\mathrm{F}_{10}$ lines were obtained at the Institute of Genetics and Cytology of NAS of Belarus from three cross combinations of common wheat $T$. aestivum varieties with T. kiharae: line 31 ('Rassvet' $\times$ T. kiharae); lines 19, 20-1, 25-2 (T. kiharae × 'Saratovskaya 29'); lines 28, 34-1, 34-2 (T. kiharae $\times$ 'Festivalnaya'). Cytological slides and the procedure of C-banding were conducted according to the methodology of Badaeva et al. (1994). The slides were analyzed using an Amplival microscope (Carl Zeiss Jena) with apochromatic 100x lens. Selected metaphase plates were photographed using a Leica DC 300 digital video camera. The images were processed using the Adobe Photoshop graphic editor. Genotyping of the lines and parental varieties was performed using SSR markers (WMC, GSM, GSM) mapped in the genome of hexaploid wheat (Somers et al., 2004). The conditions of polymerase chain reaction (PCR) are described in Röder et al. (1998). Separation of PCR fragments was performed on an ABI PRISM 3100 automatic sequencer (Applied Biosystems, USA). The program GenAlEx M. 6.5 (Peakall, Smouse, 2012) was used for processing the results of SSR analysis, for calculation of the number of alleles and the index of genetic diversity H. Microsporogenesis was studied on squash slides. For each cross combinations and parental forms, 30 plates of metaphase I and 50-80 cells of the following stages of meiosis were analyzed: anaphase I and II, metaphase II, tetrads. Statistical analysis of the data was carried out using Microsoft Excel.

\section{Results and discussion}

To identify the T. kiharae genetic material in the genome of the introgression lines, two approaches were used: C-banding and DNA markers with known chromosomal localization. A combination of both methods provides the most objective assessment of the genomic composition of the lines. Analysis of hybrids with the help of C-banding revealed only one event of introgression of the $\mathrm{A}^{\mathrm{t}}$ genome, the centric translocation T2AtS:2AL, which occurs in the disomic state in all plants of line 19. As for the $\mathrm{G}$ genome, the transfer of its chromatin was carried out mainly due to the formation of intercalary translocations, resulting in the formation of recombinant arms of the chromosome containing genetic material from both wheat species. In total, the lines studied revealed four types of translocations: T1BS.1BL-1GL in line 20-1, T3GS-3BS.3BL and T5GS.5GL-5BL in line 25-2 and T5BS.5BL-5GL in lines 34-1 and 34-2, and all these recombinant chromosomes were present in the karyotypes of plants in the disomic state. Only one line (28) showed introgression of the whole chromosome 
Table 1

Chromosome conjugation in metaphase I and the meiotic index in common wheat lines containing T. kiharae genetic material

\begin{tabular}{llll}
\hline Genotype & Bivalents, pcs & Univalents, pcs & Meiotic index \\
\hline 31 & $20.97 \pm 0.03$ & $0.07 \pm 0.06$ & 92.0 \\
19 & $20.9 \pm 0.06$ & $0.2 \pm 0.11$ & 93.0 \\
$20-1$ & $20.93 \pm 0.05$ & $0.13 \pm 0.09$ & 92.0 \\
$25-2$ & $20.77 \pm 0.10$ & $0.47 \pm 0.21$ & 90.91 \\
28 & $20.93 \pm 0.05$ & $0.13 \pm 0.09$ & 88.18 \\
$34-1$ & $20.7 \pm 0.09$ & $0.6 \pm 0.19$ & 77.0 \\
$34-2$ & $20.13 \pm 0.12$ & $1.8 \pm 0.26$ & 55.83 \\
'Rassvet' & $21.0 \pm 0$ & 0 & 99.0 \\
'Saratovskaya 29' & $20.97 \pm 0.03$ & $0.07 \pm 0.06$ & 99.0 \\
'Festivalnaya' & $20.97 \pm 0.03$ & $0.06 \pm 0.06$ & 84.55 \\
T.kiharae & $20.8 \pm 0.09$ & $0.4 \pm 0.18$ & 80.0 \\
\hline
\end{tabular}

from the $G$ genome in the form of intergenomic $2 \mathrm{G}(2 \mathrm{~B}) \mathrm{sub}$ stitution. At the same time, there were no changes in C-band pattern in line 31 compared with the parental wheat variety. This may be associated with a direction of crosses: in this case, the wheat variety served as the maternal component of hybridization.

Molecular analysis of the hybrid lines was carried out using 72 SSR markers, of which 59 revealed polymorphism between the parental wheat varieties and T. kiharae. The number of postulated introgression fragments expected in the analyzed lines varied from four to eight, with the greatest number noted in line 19. No alleles specific to T. kiharae were found in plants of line 31, which is consistent with the results of C-banding.

Using SSR markers, amplification of PCR fragments specific to T. kiharae was found in chromosome 1B (lines 19, 20-1, 25-2 and 28); in the short arm of chromosome 3B (lines 19 and 25-2). Single introgressed fragments in chromosomes 2BL, 6BS and 7BS were detected only in lines 28, 19 and 34-1, respectively. All lines except line 28 showed changes in the long arm of chromosome $5 \mathrm{~B}$. It can be noted that for the lines with introgression of large fragments of $T$. kiharae chromatin, data of microsatellite analysis coincide with the results of $\mathrm{C}$-banding. The results obtained indicate a high frequency of introgression of T. kiharae genetic material to the genomes of the lines studied with a predominance of short fragments detected by molecular markers.

One of the problems with hybrid forms of cereals is disruption of correct progression of meiosis with the formation of univalent and multivalent associations. In this regard, a comparative study of chromosome behavior at different stages of microsporogenesis in hybrid lines and their parental forms was of great interest. Analysis of the metaphase I stage revealed a high level of bivalent chromosome pairing in all $\mathrm{F}_{10}$ hybrid lines (Table 1).

The greatest number of pollen mother cells (PMC) with disorders at this stage of meiosis $(73.3 \%)$ and the maximum number of univalents $(6.0-3.3 \%$ of MCP) was found in line 34-2 containing a pair of aberrant T5BS.5BL-5GL chromosomes, which is probably associated with a change in the expression of the $\mathrm{Ph} 1$ locus caused by structural reorganiza- tions of chromosome 5B. At the same time, the negative effect of introgression of chromatin of chromosome $5 \mathrm{G}$ in the line 34-1 from the same combination of crosses with a similar intercalary translocation is less pronounced: the number of PMCs with disorders is $26.6 \%$, which, however, is 3-4 times higher than the indicator for the lines without introgressions in chromosome 5B. These dissimilarity may be due to different lengths of the translocated alien fragment.

The meiotic index of $F_{10}$ lines isolated from the 'Rassvet' $\times$ T. kiharae and T. kiharae $\times$ 'Saratovskaya 29' cross combination was 6-9\% lower than in the parental wheat varieties, but exceeded the $90 \%$ level. Even in line 25-2, for which in metaphase I of meiosis the weakening of synapsis was noted due to stabilization of structural reorganizations of the karyotype. The lowest meiotic index was pointed out in lines 34-1 and 34-2 from the T. kiharae $\times$ 'Festivalnaya' cross combination (77.0 and $55.83 \%$, respectively). This fact is in good agreement with the data obtained by analysis of the chromosome behavior of these lines at metaphase I and confirms the negative impact of structural rearrangements identified in chromosomes $5 \mathrm{~B}$ in these lines. The impact of the genetic background of the parental wheat variety 'Festivalnaya' on the cytological stability of these lines should not be excluded either. This wheat cultivar has the lowest meiotic index among the wheat varieties included in the hybridization (see Table 1). In general, the data obtained during the analysis of microsporogenesis allow us to conclude that the level of cytological stability achieved in $\mathrm{F}_{10}$ by the majority of the introgression lines ensures the formation of functional gametes in a number sufficient for the successful reproduction of the hybrid material.

\section{Conclusions}

The results of our study indicate that during the stabilization of the karyotypes of hybrids obtained from crossing common wheat varieties with Kiharae wheat, introgression of T. kiharae genetic material into the T. aestivum genome is carried out both as short translocated fragments, detected only with molecular markers, and as whole chromosomes (intergenomic substitutions) and large fragments (centric and intercalary translocations). The conditions for the preservation of alien substitu- 
tions and translocations in the genome of common wheat is a shift in the disomic state, as well as the participation in the formation of chromosomes of orthologous genomes. Under these conditions, there are no significant disturbances of the process of formation of gametes, which ensures the successful reproduction of introgression lines in a number of generations. The exception is introgressions affecting the functioning of the main genes for chromosome synapsis, which results in a significant decrease in meiotic index and negative effects on the productivity of plants.

\section{References}

Badaeva E.D., Badaev N.S., Gill D.S., Filatenko A.A. Intraspecific karyotype divergence in Triticum araraticum (Poaceae). Plant Syst. Evol. 1994;192(1):117-145. DOI 10.1007/BF00985912.

Badaeva E.D., Budashkina E.D., Bilinskaya E.N., Pukhalskiy V.A. Intergenomic chromosome substitutions in wheat interspecific hybrids and their use in the development of a genetic nomenclature of Triti- cum timopheevii chromosomes. Rus. J. Genet. 2010;46:769-785. DOI 10.1134/S102279541007001X.

Peakall R., Smouse R. GenAlEx 6.5: genetic analysis in Excel. Population genetic software for teaching and research - an update. Bioinformatics. 2012;28(19):2537-2539. DOI 10.1093/bioinformatics/ bts460.

Pukhalskiy V.A., Odintsova T.I. Problems of natural and acquired immunity of plants. To the development of ideas of N.I. Vavilov. Information Vestnik VOGIS. 2007;11(3/4):631-649 (In Russian).

Röder M.S., Korzun V., Wendehake K., Plaschke J., Tixier M.H., Leroy P., Ganal M.W. A microsatellite map of wheat. Genetics. 1998; 149:2007-2023.

Somers D.J., Isaac P., Edwards K. A high-density microsatellite consensus map for bread wheat (Triticum aestivum L.). Theor. Appl. Genet. 2004;109(6):1105-1114. DOI 10.1007/s00122-004-1740-7.

Acknowledgements. The work is supported by BRFBR (project No. B18R-028) and RFBR (project No. 18-516-00001).

Conflict of interest. The authors declare no conflict of interest. 


\title{
Expression profile of two CENH3 genes in different tissues of the Secale cereale
}

\author{
S.S. Gatzkaya*, E.V. Evtushenko, A.V. Vershinin \\ Institute of Molecular and Cellular Biology SB RAS, Novosibirsk, Russia
}

DOI 10.18699/ICG-PlantGen2019-78

(c) Autors, 2019

*e-mail: jait@mail.ru

\begin{abstract}
The assembly site for the kinetochore complex of active centromeres is defined by the chromosomal location of the centromeric modification of histone $\mathrm{H} 3$ (CENH3). The loss of CENH3 from centromeres leads to improper chromosomal segregation during cell division. Most of the diploid plant species, in which the structure and copy number of $\mathrm{CENH} 3$ genes have been determined, have this gene as a singleton. However, it has been found that some diploid species in the tribe Triticeae have two forms of CENH3. In this work we study the expression dynamics of the aCENH3 and $\beta C E N H 3$ forms in different tissues of the cultivated rye (Secale cereale L.) by performing of a comparative RT-PCR analysis. Key words: centromeric histone CENH3; rye; gene expression.
\end{abstract}

\section{Introduction}

In most species, centromere identity is defined by the presence of the centromere-specific variant of histone $\mathrm{H} 3$ denoted in plants as CENH3. In most diploid plant species, including cereals, maize and rice, CENH3 is encoded by a single gene (Talbert et al., 2002; Zhong et al., 2002; Nagaki et al., 2004). But some diploid species in the tribe Triticeae (Triticum, Hordeum, Aegilops) possess two CENH3 forms, $\alpha \mathrm{CENH} 3$ and $\beta C E N H 3$ (Yuan et al., 2015; Sanei et al., 2011). Previously we showed the occurrence of two main forms of protein for most rye (the genus Secale) species and subspecies. In the rye species, two $C E N H 3$ genes have different intron-exon structures and the nucleotide identity between $\alpha C E N H 3$ and $\beta C E N H 3$ is $81-83 \%$, with the main amino acid sequence difference in NTT domain and in $\alpha 1$-helix and loop 1 of the HFD domain (CATD) (Evtushenko et al., 2017). Because of the acquisition of the second form of the histone CENH3 ( $\beta C E N H 3)$ by some Triticeae species, it is of great interest to explore the functions of the two distinct forms of this central component of centromere identity. We suppose that a comparative study of the expression levels of $\alpha C E N H 3$ and $\beta C E N H 3$ in different tissues will shed light on this problem.

\section{Materials and methods}

Plant material. Leaves from tiller, stem, anther, carpel and grain tissue samples were collected from vernalized Secale cereale cv. 'Imperial' plants. Radicle, coleoptile and 3rd leaf tissue samples were collected from germinated grains. Tissues were characterized using the Zadoks two-digit code system (Zadoks et al., 1974).

RNA isolation and cDNA synthesis. Total RNA was isolated from individual plants using the TRIzol method (TRI Reagent, MRC) and treated by a DNA-free TM Kit (Invitrogen) according to the protocol. First-strand cDNA was synthesized from $3.6 \mu \mathrm{g}$ of total RNA by FireScript Reverse Transcriptase (BiolabMix).

RT-PCR analysis and primer design. $25 \mu \mathrm{l}$ of PCR mixture contained $1 \mu \mathrm{l}$ of diluted cDNA template, $12.5 \mu \mathrm{l}$ of BioMaster HS-qPCR SYBR Blue (2×) (BiolabMix) and $0.3 \mathrm{mM}$ of the each forward and reverse primers for each gene, except $\beta C E N H 3$ reverse primer $(0.2 \mathrm{mM})$. Reactions were performed in triplicate by the LightCycler ${ }^{\circledR} 480$ Instrument II (Roche) using the following conditions: $95^{\circ} \mathrm{C}$ for $5 \mathrm{~min}$, followed by 45 cycles at $95^{\circ} \mathrm{C}$ for $15 \mathrm{~s}$, at the annealing temperature of $62{ }^{\circ} \mathrm{C}$ for $20 \mathrm{~s}$, and at $72{ }^{\circ} \mathrm{C}$ for $30 \mathrm{~s}$. Melting curves were performed to control primer dimers. Three reference genes were used for normalization of the level of $\alpha C E N H 3$ and $\beta C E N H 3$ transcripts. References were selected according to the study of T. aestivum reference genes (Paolacci et al., 2009) (Table 1). Primers for amplifying reference transcripts were selected using contigs of the $S$. cereale genomic sequences of orthologous genes (BioSample: SAMEA3928734 BioProject: PRJEB13501).

Primers for amplifying $\alpha C E N H 3$ and $\beta C E N H 3$ transcripts were designed based on the nucleotide sequences of Secale cereale alpha and beta centromeric histone $\mathrm{H} 3$ mRNA previously obtained in our laboratory (MG384772.1, MG384763.1, MG384780.1, MG384775.1). Primers were selected preferentially on the boundaries of exons to avoid the influence of genomic DNA. Sequencing reactions of cloned amplicons were carried out to check the PCR products. The efficiency of both $\alpha \mathrm{CENH} 3$ and $\beta \mathrm{CENH} 3$ primers was determined by qRT-PCR using $5 \mathrm{X}$-dilution series of cDNA template. Melting curves were performed to control primer dimers. Experimental data were treated by LC480 software. Relative Quantification analysis with the high-confidence $2^{\text {nd }}$ Derivative max method was used.

\section{Results and discussion}

Previously two main variants of centromere-specific histone $\mathrm{H} 3$ proteins, $\alpha \mathrm{CENH} 3-\mathrm{v} 1$ and $\beta \mathrm{CENH} 3-\mathrm{v} 1$, and their two minor variants, $\alpha \mathrm{CENH} 3-\mathrm{v} 2$ and $\beta \mathrm{CENH} 3-\mathrm{v} 2$, were characterized in Secale species, according to the differences in size and amino acid substitutions (Figure 1) (Evtushenko et al., 2017). The $\alpha C E N H 3-v 1$ cDNA sequence in the cultivated rye Secale cereale is $501 \mathrm{bp}$ in length and the associated protein consists of 166 amino acids. $\beta C E N H 3-v 1$ is distinct from $\alpha C E N H 3-v 1$ in that the former has several deletions in the NTT and the insertion of three nucleotides in the HFD. Thus, $\beta C E N H 3-v 1$ has an overall length of $456 \mathrm{bp}$ and encodes a protein made up by 151 amino acids. Most of the NTT amino acid sequences in $\alpha \mathrm{CENH} 3$ and $\beta C E N H 3$ do not align well with each other. 
Table 1

List of references used in the work and their functions according to the Identification and validation of reference genes for quantitative RT-PCR normalization in wheat (Paolacci et al., 2009)

\begin{tabular}{lllll}
\hline $\begin{array}{l}\text { Ref. } \\
\text { gene }\end{array}$ & $\begin{array}{l}\text { T. aestivum } \\
\text { UniGene cluster }\end{array}$ & T. aestivum gene annotation & GO Biological Process & GO Molecular Function \\
\hline 1 & Ta2776 & $\begin{array}{l}\text { Similar to RNase L inhibitor-like } \\
\text { protein }\end{array}$ & Transport, protein folding & $\begin{array}{l}\text { ATP-binding, ATPase activity, Electron } \\
\text { carrier activity (ABC transporter) }\end{array}$ \\
2 & Ta54227 & $\begin{array}{l}\text { Cell division control protein } \\
\text { 48 homolog (AAA-superfamily of } \\
\text { ATPases) }\end{array}$ & Protein transport, cell division & $\begin{array}{l}\text { ATP binding, Nucleoside-triphosphate } \\
\text { activity }\end{array}$ \\
3 & Ta53967 & $\begin{array}{l}\text { Vacuolar ATP synthase 16 kDa proteo- } \\
\text { lipid subunit }\end{array}$ & $\begin{array}{l}\text { Proton transport (ATP synthesis } \\
\text { coupled proton transport) }\end{array}$ & $\begin{array}{l}\text { Hydrogen ion transporting ATPase } \\
\text { activity, rotational mechanism }\end{array}$ \\
\hline
\end{tabular}

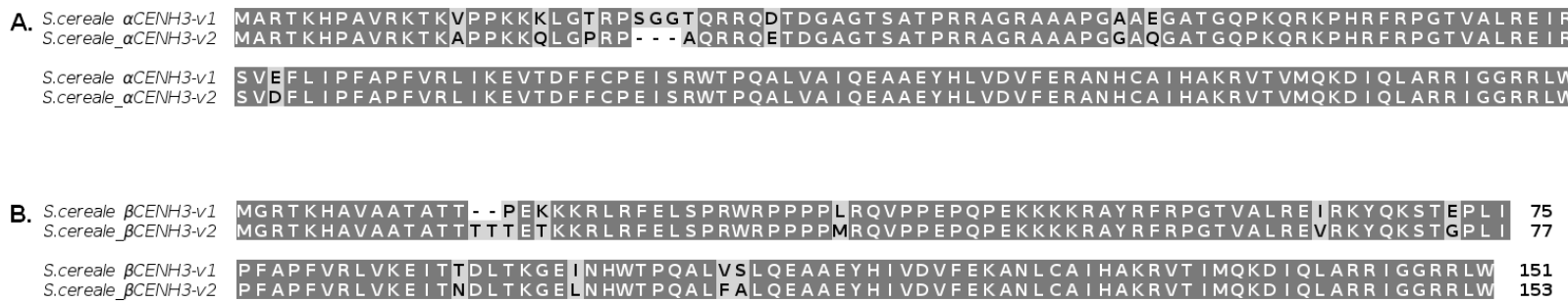

Figure 1. Alignment of the amino-acid sequences of two aCENH3 and $\beta C E N H 3$ variants existing in Secale cereale.

The $\alpha C E N H 3-v 2$ sequences were 492 bp in length, that is, they were shorter $\alpha C E N H 3-v 1$. These two $\alpha C E N H 3$ variants have different amino acids at some positions. The sequence of $\beta C E N H 3-v 2$ is 6 bp longer than $\beta C E N H 3-v 1$, so that it possesses two additional amino acid residues of threonine in the NTT domain, and furthermore both variants have different amino acids at some positions. Taking into account all the above, primers for comparative RT-PCR analysis in this work were designed in that manner to distinguish the $\alpha \mathrm{CENH} 3$ and $\beta C E N H 3$ forms but to consider the expression ratio of both respective variants, $\mathrm{v} 1$ and $\mathrm{v} 2$ of $\alpha \mathrm{CENH} 3$ and $\mathrm{v} 1$ and $\mathrm{v} 2$ of $\beta C E N H 3$.

The RT-PCR assay shows that both forms of the centromeric histone $\mathrm{H} 3, \alpha C E N H 3$ and $\beta C E N H 3$, are expressed in all investigated tissues of the rye Secale cereale subsp. cereale 'Imperial'. The highest level of expression of both forms, $\alpha C E N H 3$ and $\beta C E N H 3$, was observed in carpel tissue, where the value for the $\alpha C E N H 3$ product was nearly two times the value for $\beta C E N H 3-30 \%$ for $\alpha \mathrm{CENH} 3$ and $17 \%$ for $\beta C E N H 3$ (values in percentage represent average transcription levels normalized to the geometric mean of three references). The second place in terms of transcription level of CENH3 belongs to anther tissue, where expression level of $\alpha C E N H 3$ was equal to that of $\beta C E N H 3$ on average, unlike the carpel tissue ( $11 \%$ for $\alpha \mathrm{CENH} 3$ and $11 \%$ for $\beta \mathrm{CENH} 3$ ). Expression is also relatively high in radicle tissue $(7 \%$ for $\alpha \mathrm{CENH} 3$ and $3 \%$ for $\beta C E N H 3$ ) and tissue of grain (embryo and endosperm) that is just starting to develop ( $11 \%$ for $\alpha \mathrm{CENH} 3$ and $4 \%$ for $\beta C E N H 3$ ). In the other tissues investigated, namely coleoptile, tissue of third leaf, leaves from tillering plants and stem tissue, the lowest expression levels of both CENH3 forms were observed (not higher than $4 \%$ ).
It was previously shown that both $\alpha \mathrm{CENH} 3$ and $\beta C E N H 3$ forms are included in barley centromeres during cell division (Ishii et al., 2015). Similar results were obtained for rye centromeres in our laboratory. Thus, both these forms are involved in the process of cell division. Moreover, it was demonstrated that the levels of expression of two CENH3 forms vary across different tissues of barley (Ishii et al., 2015). Similarly, we demonstrate that the expression ratio of $\alpha C E N H 3$ and $\beta C E N H 3$ of rye varies depending on the type of tissue. However, our RT-PCR assay does not show any dramatic differences in the expression of $\alpha C E N H 3$ and $\beta C E N H 3$ that are characteristic of barley, where the transcription level of $\beta C E N H 3$ significantly exceeded the transcription level of $\alpha C E N H 3$ in all tissues. The expression levels of both $C E N H 3$ forms show not equal but comparable values in most rye tissues. Probably the variations in the expression ratio reflect tissue-specific requirements for CENH3 forms in rye.

\section{Conclusions}

We demonstrate that the expression ratio of $\alpha C E N H 3$ and $\beta C E N H 3$ of rye varies depending on the type of tissue. The expression levels of both $C E N H 3$ forms show not equal but comparable values in most Secale cereale tissues.

\section{References}

Evtushenko E.V., Elisafenko E.A., Gatzkaya S.S., Lipikhina Y.A., Houben A., Vershinin A.V. Conserved molecular structure of the centromeric histone CENH3 in Secale and its phylogenetic relationships. Scientific Reports. 2017;7:17628. DOI 10.1038/s41598-01717932-8.

Ishii T., Karimi-Ashtiyani R., Banaei-Moghaddam A.M., Schubert V., Fuchs J., Houben A. The differential loading of two barley CENH3 variants into distinct centromeric substructures is cell type- and 
development-specific. Chromosome Res. 2015;23:277-284. DOI 10.1007/s10577-015-9466-8

Nagaki K., Cheng Z., Ouyang S., Talbert P.B., Kim M., Jones K.M., Henikoff S., Buell C.R., Jiang J. Sequencing of a rice centromere uncovers active genes. Nat. Genet. 2004;36:138-145.

Paolacci A.R., Tanzarella O.A., Porceddu E., Ciaffi M. Identification and validation of reference genes for quantitative RT-PCR normalization in wheat. BMC Mol. Biol. 2009;10:11. DOI 10.1186/14712199-10-11.

Sanei M., Pickering R., Kumke K., Nasuda S., Houben A. Loss of centromeric histone $\mathrm{H} 3$ (CENH3) from centromeres precedes uniparental chromosome elimination in interspecific barley hybrids. Proc. Nat. Acad. Sci. USA. 2011;108:498-505.

Talbert P.B., Masuelli R., Tyagi A.P., Comai L., Henikoff S. Centromeric localization and adaptive evolution of an Arabidopsis histone H3 variant. Plant Cell. 2002;14:1053-1066.
Yuan J., Guo X., Hu J., Lv Z., Han F. Characterization of two CENH3 genes and their roles in wheat evolution. New Phytol. 2015;206: 839-851.

Zadoks J.C., Chang T.T., Konzak C.F. A decimal code for the growth stages of cereals. Weed Research. 1974;14:415-421.

Zhong C.X., Marshall J.B., Topp C., Mroczek R., Kato A., Nagaki K., Birchler J.A., Jiang J., Dawe R.K. Centromeric retroelements and satellites interact with maize kinetochore protein CENH3. Plant Cell. 2002;14:2825-2836.

Acknowledgements. This research was financially supported by the Russian Fundamental Scientific Research Program (project 03102019-0003) and the Russian Foundation for Basic Research (grant 1704-00748a).

Conflict of interest. The authors declare no conflict of interest. 


\title{
Chromosome constitution and activity of the centromeric histone $\mathrm{H3}$ (CENH3) variants in octoploid triticale lines
}

\author{
E.V. Evtushenko ${ }^{1 *}$, Yu.A. Lipikhina ${ }^{1}$, P.I. Stepochkin ${ }^{2}$, A.V. Vershinin ${ }^{1}$ \\ ${ }^{1}$ Institute of Molecular and Cellular Biology, SB RAS, Novosibirsk, Russia \\ ${ }^{2}$ Institute of Cytology and Genetics, SB RAS, Novosibirsk, Russia
}

DOI 10.18699/ICG-PlantGen2019-79

(c) Autors, 2019

* e-mail: evt@mcb.nsc.ru

\begin{abstract}
Hybrids between wheat and rye (Triticale) are a promising biologic model for studying genetic and epigenetic changes associated with remote crossing in Triticeae. Newly synthesized wheat-rye allopolyploids were obtained from Triticum aestivum 'Triple Dirk D' $\times$ S. cereale 'Korotkostebel'naya $69^{\prime}$ and investigated by fluorescent in situ hybridization (FISH). FISH with the highly repetitive DNA probe pSc200 allows identification of all rye chromosomes and shows identical hybridization patterns in hybrids with different numbers of chromosomes $(2 n=42-56)$. In hybrids, including plants that have lost entire genomes, we revealed that only wheat chromosomes were eliminated. Yet the nucleotide structure of the centromeric histone $\mathrm{H} 3$ (CENH3) was studied in allopolyploids and their parental forms. The synthesis of CENH3 copies with the rye-characteristic SNPs increases in hybrids continuously from $\mathrm{F}_{3}$ to $\mathrm{F}_{5}$, regardless of the chromosome number.

Key words: wheat-rye allopolyploids; remote hybridization; centromeric histone H3 (CENH3).
\end{abstract}

\section{Introduction}

Triticale derived from crossing wheat and rye is the first synthetic allopolyploid cereal. The main impetus for the development of triticale was the idea of obtaining a wheatrye hybrid that combines a high yield and grain quality as in wheat with adaptation and tolerance to abiotic and biotic factors as in rye. Yet triticale is a promising model for studying the rapid changes in the hybrid genomes associated with severe rearrangements in the genomes of the parental forms, which is the most vivid manifestation of the "genomic shock" which occurs when the parents' genomes are combined in a hybrid cell (McClintock, 1984) and is accompanied by various chromosomal abnormalities, including those affecting the centromere structure. Incompatibility of centromeres of different species seems to be the main reason for the chromosome elimination of one of the parental genomes in the hybrids (Sanei et al., 2011; Ishii et al., 2015). In the present study we carry on a karyotypic analysis of octoploid triticale derived from common wheat 'Triple Dirk D' $\times$ rye 'Korotkostebel'naya 69'. Then, we performed a comparative analysis of the nucleotide sequences of the N-terminal tail of the $C E N H 3$ genes in wheat-rye allopolyploids of various ploidy as well as their parental forms.

\section{Materials and methods}

Allopolyploids (genome AABBDDRR) were synthesized by crossing isogenic line Triple Dirk D (Triticum aestivum L.) (AABBDD) with the rye (Secale cereale L.) cv. Korotkostebelnaya $69(\mathrm{RR})$. Young $\mathrm{F}_{1}$ seedlings were treated with $0.05 \%$ colchicine solution, and allopolyploids were obtained after chromosome doubling. Although most of the $F_{1}$ plants were sterile, a few $F_{2}$ seeds were obtained and $\mathrm{F}_{2}$ seedlings carrying more than 5-7 seeds were chosen for further work. Primary octoploid triticale from the 'Triple Dirk D' $\times$ 'Korotkostebel'naya 69' cross was designated as TDK. The lines were propagated for several generations by strict self-pollination. Three lines of $\mathrm{F}_{3}-\mathrm{F}_{6}$ plant generations were analyzed: TDK 92, 94 and 96 . The chromosome number was determined by staining chromosomes after Feulgen (De Tomasi, 1936). The DNA probes for FISH-assisted identification of rye chromosomes were $\mathrm{pSc} 200, \mathrm{pTa} 71$. The tandem repetitive sequence, $\mathrm{pSc} 200$ and the clone $\mathrm{pTa} 71$ were labeled by biotin-16-dUTP (Roche) and digoxigenin-11-dUTP (Roche for FISH analysis. These probes were hybridized to mitotic metaphase chromosomes of the parental rye and allopolyploids. Total RNA was isolated from young leaves of rye, wheat and allopolyploids using TriReagent (MRC); cDNA was created and used in a PCR series as a template with primers synthesized specially for amplification of the N-terminal tail (NTT) of rye $\alpha C E N H 3(\alpha \mathrm{ScCENH} 3)$. The product was $268 \mathrm{bp}$ in size. PCR products were cloned into plasmid pTZ57R/T and Sanger-sequenced.

\section{Results and discussion}

We performed a karyotypic analysis of 30 plants of wheat-rye allopolyploids, $\mathrm{F}_{3}$ generation. The chromosome number in the somatic cells of these plants was different, ranging from 52 to 56 chromosomes. Then two $F_{3}$ plants were chosen for further analysis and designated as TDK 94 (55 chromosomes) and TDK 96 (56 chromosomes). The progenies of these plants were analyzed in $F_{4}, F_{5}$ and $F_{6}$ generations. The total number of chromosomes and the number of rye chromosomes were determined in the lines in each generation. Two plants of TDK 96 (TDK 96.1 and TDK 96.2) preserve the full sets of 56 chromosomes in $\mathrm{F}_{4}-\mathrm{F}_{6}$, while the progenitors of the third plant (TDK 96.3) lose individual chromosomes in subsequent generations with the minimum chromosome number 41 in $\mathrm{F}_{6}$. DNA probe pSc200 gives a chromosome-specific FISH pattern allowing identification of all rye chromosomes. FISH signals of probe pSc200 are localized at both arms of all 14 chromosomes of the parental rye 'Korotkostebel'naya 69' (Figure 1,a). Additionally, pTa71 was used for identification of chromosome 

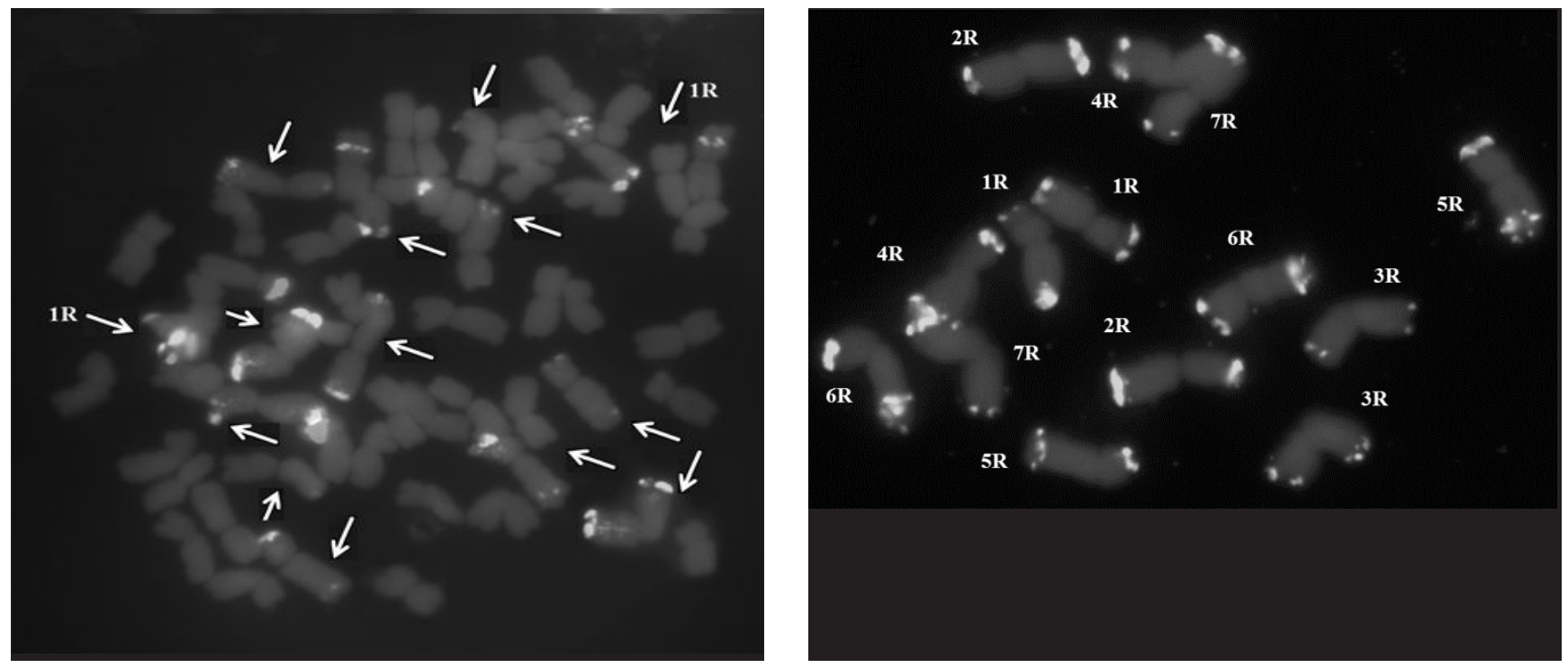

Figure 1. Fluorescent in situ hybridization (FISH) of pSc200 and pTa71 on the spreads of metaphase chromosomes of a root tip of (a) Secale cereale cultivar Korotkostebel'naya 69 (b) octoploid triticale $(2 n=56$, line TDK 96F3). Note: White arrows point to rye chromosomes.

Table 1

Distribution of specific non-synonymous SNPs across the N-tail of CENH3 of wheat, diploid rye and octoploid triticale

\begin{tabular}{|c|c|c|c|c|c|c|c|c|c|c|c|c|}
\hline \multirow[t]{2}{*}{ Plants } & \multirow{2}{*}{$\begin{array}{l}\text { Number } \\
\text { of clones }\end{array}$} & \multicolumn{11}{|c|}{ Number of forms with SNPs at positions of ORFs, $\%$} \\
\hline & & 28 & 32 & 50 & 56 & 73 & 82 & 84 & 99 & 122 & 130 & 145 \\
\hline T. aestivum Triple Dirk D (AABBDD), $2 n=42$ & 18 & & 11.1 & & 5.6 & & 55.6 & 55.6 & 27.8 & & & \\
\hline Korotkostebel'naya $69(R R)$ diploid rye, $2 n=14$ & 23 & & & & & 8.7 & 7.4 & 7.4 & 30.4 & & & 21.7 \\
\hline \multicolumn{13}{|l|}{ Octoploid triticale $\mathrm{F}_{3}$ : } \\
\hline plant $1,(2 n=56)$, TDK 96_1 & 18 & 5.6 & & 5.6 & & 16.7 & 5.6 & 5.6 & 11.1 & 5.6 & & 5.6 \\
\hline plant $2(2 n=52)$, TDK 92 & 6 & 17 & & 16.7 & & & & & 16.7 & 33.3 & & \\
\hline plant $3(2 n=54)$, TDK 92 & 10 & 30 & 10 & & & & 10 & & & & & \\
\hline \multicolumn{13}{|l|}{ Octoploid triticale $F_{4}$ (derived from $F_{3}$ plant 1): } \\
\hline plant $1(2 n=56)$,TDK 96_1 & 20 & 5 & & 5 & & 35 & 10 & 10 & 10 & 15 & & 5 \\
\hline plant $2(2 n=56)$, TDK 96_2 & 20 & 10 & & & 5 & 30 & 10 & 10 & & 10 & & \\
\hline plant $3(2 n=49)$, TDK 96_3 & 15 & & 6.7 & & & 33.3 & 6.7 & 6.7 & 6.7 & & 6.7 & 6.7 \\
\hline \multicolumn{13}{|l|}{ Octoploid triticale $F_{5}$ (derived from $F_{4}$ plant 2): } \\
\hline plant $1(2 n=56)$,TDK 96_1 & 14 & & 7.1 & & & 50 & & & & & 7.1 & \\
\hline plant $2(2 n=43)$, TDK 96 & 15 & & & & & 57.1 & & 7.1 & & 14.3 & & 14.3 \\
\hline
\end{tabular}

$1 \mathrm{R}$ in the allopolyploids. Stable octoploid triticales $(2 n=56)$ preserved the R genome chromosomes throughout generations $\mathrm{F}_{3}-\mathrm{F}_{5}$ (Figure $1, b$ ). Unstable triticales produced by lines 92 , 94 and plant 96.3 have lost chromosome arms, individual chromosomes and sets of seven chromosomes.

An interesting fact is that only wheat chromosomes are eliminated, while the whole set of the rye chromosomes is present in all analyzed plants including those that have lost entire wheat genomes $(2 n=41,42,49)$. FISH with pTa71 demonstrated that rye chromosome $1 \mathrm{R}$ carrying the genes coding for centromeric histone $\mathrm{CENH} 3$ is present in all studied lines (see Figure 1, b).

To uncover possible relationships between chromosome elimination and $\mathrm{CENH} 3$ activity in triticale, the coding sequences of the $\alpha C E N H 3$ NTT were analyzed in $8 \mathrm{~F}_{3}-\mathrm{F}_{5}$ hybrid plants with different chromosome numbers $(2 n=43-56)$ and in their parental forms. The sequencing of randomly selected clones from wheat and diploid rye revealed $99 \%$ identity between parental $C E N H 3$ s at a nucleotide level. However, CENH3 rye and wheat variants have specific positions (Table 1). The top number of SNPs in wheat is mapped to nucleotide positions 82 and 84 (55.6\% of wheat clones). These substitutions in rye $C E N H 3$ are very rare. SNPs at four rye-specific positions $(28,73,122$, and $145 \mathrm{bp})$ were identified within CENH3 ORFs. These substitutions are nonsynonymous. We revealed that the wheat-rye allopolyploids contain all nucleotide substitutions that are specific for the parental rye form. This implies that rye-specific CENH3 forms are successfully synthesized in the wheat cytoplasm. The distribution of rye-specific and wheat-specific SNPs 
in $C E N H 3$ sequencesfrom the triticale hybrids suggests a preferred synthesis of rye CENH3. This conclusion is in a good agreement with the fact that $C E N H 3$ genes are located on chromosome 1R (Lipikhina et al., 2017). A special case is the rye-specific substitution at position 73 of the $\alpha C E N H 3$ nucleotide sequence, which is not present in the parental wheat cultivar. $\mathrm{F}_{3}-\mathrm{F}_{5}$ triticale plants increase the synthesis of $\mathrm{CENH3}$ copies with SNPs at position $73 \mathrm{bp}$, typical of rye $C E N H 3$ (16-57\% in the clones) (see Table 1).

With this substitution, CENH3 loses the only serine phosphorylation site predicted for the rye $\mathrm{N}$-tail. It is possible that the lack of posttranslational CENH3 modifications reduces the diversity of $C E N H 3$ forms and assists the meiosis setting of a complex hybrid genome.

\section{Conclusions}

Fluorescence in situ hybridization (FISH) karyotyping of primary octoploid triticale revealed that individual chromosomes and whole genome chromosomes were eliminated, but the chromosomes of $\mathrm{R}$ genome were retained in triticale lines through generations $\mathrm{F}_{3}-\mathrm{F}_{6}$. Both rye and wheat variants of $\mathrm{CENH} 3$ were expressed in the wheat-rye allopolyploids, regardless of how many chromosomes were ultimately lost. However, it is not yet clear whether all the expressed $\mathrm{CENH} 3$ variants are integrated in the centromeres of the hybrids' chromosomes. Taken together, our results provide evidence for the involvement of the $C E N H 3 \mathrm{~N}$-tail structure in the formation of new hybrid genomes.

\section{References}

De Tomasi J.A. Improving the technic of the feulgen stain. Biotech. Histochem.1936;11:137-144.doi.org/10.3109/10520293609110513.

Ishii T., Karimi-Ashtiyani R., Houben A. Haploidization via chromosome elimination: Means and Mechanisms. Ann. Rev. Plant Biol. 2016;67:421-438. DOI 10.1146/annurev-arplant-043014-114714.

Lipikhina Y.A., Evtushenko E.V., Elisafenko E.A., Vershinin A.V. Chromosomal assignment of centromere-specific histone $\mathrm{CENH} 3$ genes in rye (Secale cereale L.) and their phylogeny. Comp. Cytogenet. 2017;11(4):821-832. DOI 10.3897/CompCytogen.v11i4.19953.

McClintock B. The significance of responses of the genome to challenge. Sci. 1984:226(4676):792-80. DOI 10.1126/science.15739260.

Sanei M., Pickering R., K. Kumke K., Nasuda S., Houben A. Loss of centromeric histone $\mathrm{H} 3$ (CENH3) from centromeres precedes uniparental chromosome elimination in interspecific barley hybrids. Proc. Natl. Acad. Sci. USA. 2011;108(33):E498-E505. DOI 10.1073/pnas. 1103190108 .

Acknowledgements. The work is supported by the Russian Fundamental Research Program, project 0310-2019-0003, project No. 0324-2019-0039 and the Russian Foundation for Basic Research, project No. 18-54-00013.

Conflict of interest. The authors declare no conflict of interest. 


\title{
Karyotyping of triticale-wheat hybrid lines with the sham ramification of spike
}

\author{
I.G. Adonina ${ }^{1 *}$, S.P. Mehdiyeva ${ }^{2}$, M.V. Prokopjeva ${ }^{3}$, N.Kh. Aminov ${ }^{2}$, E.A. Salina ${ }^{1}$ \\ 1 Institute of Cytology and Genetics, SB RAS, Novosibirsk, Russia \\ ${ }^{2}$ Genetic Resources Institute of ANAS, Baku, Azerbaijan \\ ${ }^{3}$ Novosibirsk State University, Novosibirsk, Russia
}

DOI 10.18699/ICG-PlantGen2019-80

(c) Autors, 2019

* e-mail: adonina@bionet.nsc.ru

\begin{abstract}
Triticale-wheat hybrid lines from collection of the Genetic Resources Institute of ANAS (Azerbaijan) significantly differ in the ear morphology (manifestation of the vaviloid type of spike branching), in some quantitative traits, and in karyotypes. Karyotypic differences are mainly associated with chromosomes of the second homeologous group. The chromosomes $2 \mathrm{D}$ are replaced by a pair of rye chromosomes, presumably $2 \mathrm{R}$ in all the studied lines. Some lines have telocentric chromosomes, presumably corresponding to the short arm of a wheat chromosome 2D. We also observed rye chromosomes variability in different lines: loss of one arm or the deletion of subtelomeric heterochromatin accompanied by the loss of the pSc119.2 signal.
\end{abstract}

Key words: triticale-wheat hybrid lines; vaviloid type of spike branching; karyotype; FISH.

\section{Introduction}

The wheat forms with the spike branching are studying already about a hundred years. However, there is still a lot of unexplained. Sham ramification (Martinek, 1998) or vaviloid type of branching is trait in species Triticum vavilovii (Thum.) Jakubz. (BBAADD). In this case, additional spikelets on the rachis node do not develop, but lengthening of the spike axis, on which many flowers form, is observed. Sham ramification was also found in tetraploid wheat T. jakubzineri Udacz. et Schachm. $(2 n=4 x=28)$. Aliyeva and Aminov (2013) showed that forms with a vaviloid type of spike branching can occur as a result of distant hybridization. This article is dedicated to the study of the triticale-wheat hybrid lines with the vaviloid type of spike branching.

\section{Materials and methods}

The collection of wheat forms with the vaviloid type of spike branching consists of lines obtained from crossing a stable wheat-rye amphiploid (triticale) BBAARR $(2 n=6 x=42)$, used as the maternal form with the local variety of common wheat T. aestivum var. velutinum $(2 \mathrm{n}=6 \mathrm{x}=42$, BBAADD). Triticale was obtained by Professor Aminov in 1975 from hybridization of synthetic wheat BBAADD (T. durum $\times$ Ae. tauschii var. meyeri, catalog number in VIR $-\mathrm{k}-45918)$ with weed rye Secale cereale $\mathrm{ssp}$. segetale $(2 \mathrm{n}=2 \mathrm{x}=14, \mathrm{RR})$. Hybrid populations were studied for 10 years in an open field at the Absheron experimental base of the Genetic Resources Institute of ANAS. The forms with the vaviloid type of spike branching began to appear from the generation F4. Estimation of the morphological and quantitative traits of these lines was conducted.

A molecular-cytological analysis of the lines was carried out using the methods of genomic in situ hybridization (GISH) with $S$. cereale genomic DNA and fluorescent in situ hybridization (FISH) with probes that allow the identification of wheat and rye chromosomes:

pAs1 - a 1-kb fragment derived from Ae. tauschii, which allows the identification of the D-genome chromosomes (Rayburn and Gill, 1986b);
pSc119.2 - a 120-bp-long sequence isolated from rye (Bedbrook et al., 1980), which hybridizes mainly to the B-genome chromosomes (Mukai et al., 1993).

\section{Results and discussion}

Aliyeva and Aminov (2011) showed that sham ramification or vaviloid type of branching controlled by one recessive gene. Subsequently, Amagai et al. (2014) localized the sham ramification 1 (shrl) gene, which controls the false branching of the T. jakubzineri spike, on the long arm of chromosome $5 \mathrm{~A}$. In the same work, it is shown that the recessive gene, shr2, localized on the long arm of chromosome $2 \mathrm{~A}$, controls the false branching of T. turgidum spike. However, differences are found between the phenotypes of T. turgidum and T. jakubzineri after a detailed analysis of the spike structure. The trait controlled by the $s h r 2$ gene is isolated into a separate morphotype - false-true ramification (Amagai et al., 2017).

The rye has forms with the spike branching too. One of the genes associated with the emergence of such forms, monstrosum ear 1 ( $\mathrm{mol}$ ), was mapped in the short arm of the $2 \mathrm{R}$ chromosome (Benito et al., 1991).

Dobrovolskaya et al. identified key regulators of cereal inflorescence development - the Wheat FRIZZY PANICLE homoeologous genes (WFZP-A, WFZP-B and WFZP-D) in the genome of common wheat (Dobrovolskaya et al., 2015). They found that mutations in the functional domain of the $W F Z P-D$ and WFZP-A genes result to the formation of additional supernumerary spikelets and the branched spike. It was detected that the contribution of the WFZP-A,WFZP-D and $W F Z P-B$, localized on $2 \mathrm{AS} / 2 \mathrm{BS} / 2 \mathrm{DS}$, in the genetic control of the trait "supernumerary spikelets" of common wheat is not the same. The most functionally active copy of the gene, WFZP-D, belongs to the subgenome D. Research of different "supernumerary spikelets" wheat lines done by Dobrovolskaya and co-authors showed that replacement of the 2D chromosome and deletions in the short arm of this chromosome can affect the spike morphology. The appearance of wheat forms with supernumerary spikelets or branched spike in result of distant 


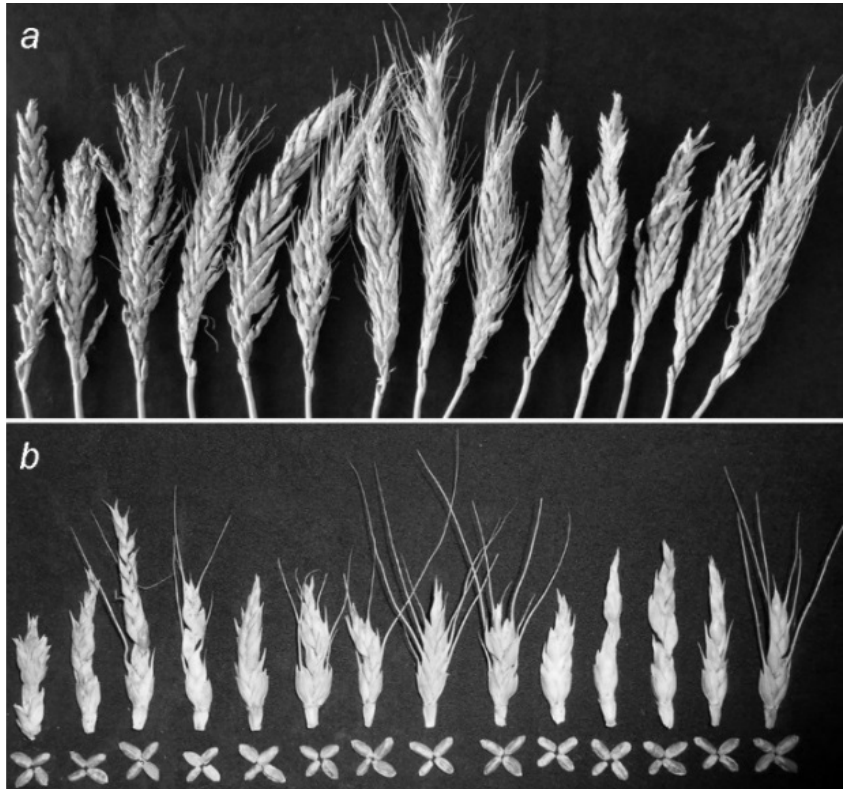

Figure 1. Manifestation of the vaviloid type of spike branching trait in different triticale-wheat hybrid lines. Spikes (a) and spikelets (b).

Figure 2. Examples of karyotypes of different hybrid lines: $2 n=39 W+2 R-$ del $+2 \mathrm{tW}(a) ; 2 \mathrm{n}=40 \mathrm{~W}+2 \mathrm{R}-\mathrm{del}+1 \mathrm{tW}(b) ; 2 \mathrm{n}=41 \mathrm{~W}+2 \mathrm{R}$-del $+1 *(c) ; 2 \mathrm{n}=$ $40 \mathrm{~W}+1 \mathrm{R}+1 \mathrm{tR}(d)$. The probes: pAs1 - red; pSc119.2 - green $(\mathrm{a}, \mathrm{b}, \mathrm{c})$; rye DNA - green (d).

Note: $\mathrm{W}$ - wheat, $\mathrm{R}$ - rye, $\mathrm{t}$ - telocentric chromosome, $\mathrm{R}$-del - rye chromosome with deletion of subtelomeric heterochromatin; the arrows indicate wheat telecentrics; the asterisk indicates chromosome, which was apparently formed because the centric fusion of two wheat telocentrics.

hybridization can serve as a marker of rearrangements of the second homeologous group of chromosomes.

Triticale-wheat hybrid lines with the vaviloid type of spike branching obtained in the Genetic Resources Institute of ANAS (Azerbaijan) are significantly different in morphological characteristics of the ear (Figure 1) and in some quantitative traits, such as the number of grains in main spike, the grain weight in main spike. The number of grains in main spike varies between 27-123 in different lines, the grain weight in main spike ranges from 1-4.5 grams.

The lines karyotype analysis revealed a chromosomal instability, the number of chromosomes varies from 42 to 44 (Figure 2). Molecular-cytological analysis showed that the chromosomes of the B-genome are not changed. The chromosomes 2D are replaced by a pair of rye chromosomes, presumably $2 \mathrm{R}$ in all the studied lines. The number of Agenome chromosomes varies from 12 to 14 . In addition, some lines have telocentric chromosomes, with the subtelomeric hybridization signals of pSc119.2 (see Figure $2, a, b$ ). Presumably, these telocentrics correspond to the short arm of wheat chromosome 2D. In one of the lines, we found a chromosome without pair, which was apparently formed because the centric fusion of two telocentrics (see Figure 2,c).

We also observed rye chromosomes variability. We detected the loss of one arm (see Figure 2, $d$ ) or the deletion of subtelomeric heterochromatin accompanied by the loss of the pSc119.2 signal (see Figure 2, $a-c$ ) in different lines. Earlier,
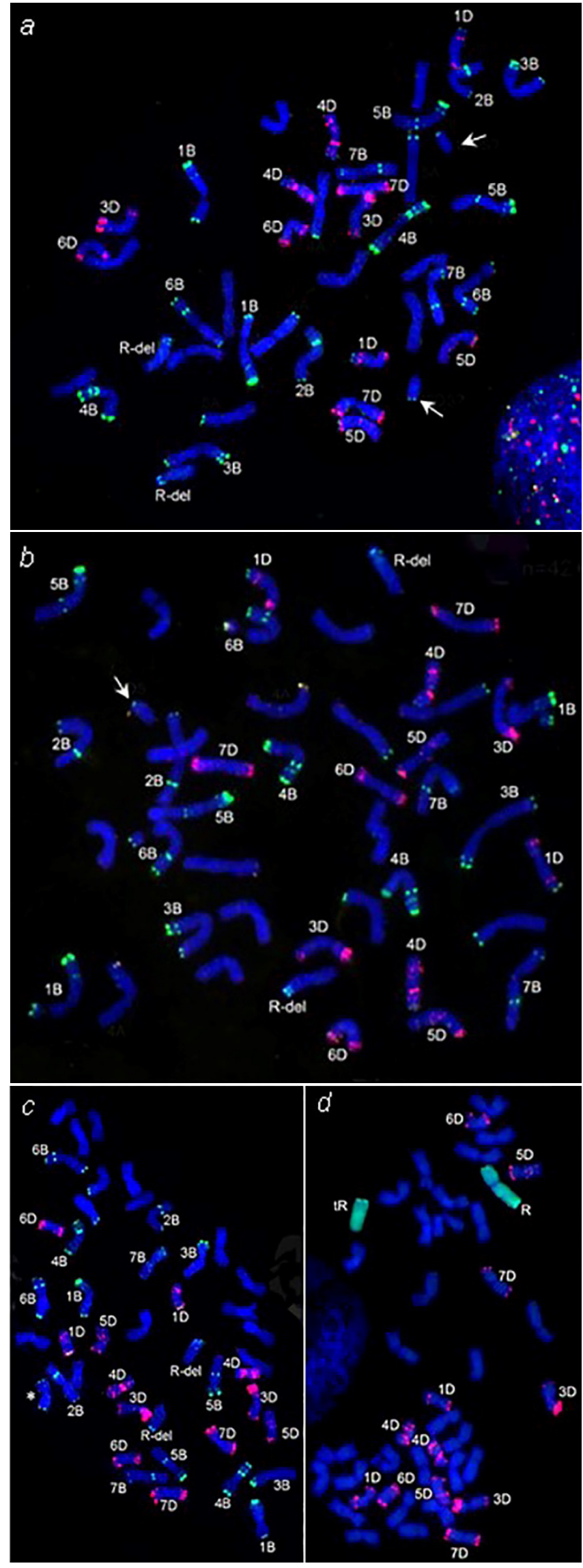
Alkhimova with co-authors (Alkhimova et al., 1999) observed similar changes when studying rye chromosome variability in wheat-rye addition and substitution lines.

\section{Conclusions}

Thus, at this stage of the study, we found that the triticalewheat hybrid lines from collection of the Genetic Resources Institute of ANAS (Azerbaijan) significantly differ in the ear morphology (manifestation of the spike branching trait), in some quantitative traits, and in karyotypes. Karyotypic differences are mainly associated with chromosomes of the second homeologous group. We also found that the lines themselves are heterogeneous in karyotypic characteristics (the number of chromosomes, the presence of telocentrics). Therefore, we plane to choose contrasting lines in terms of the manifestation of the spike branching trait and characterize the individual plants at the next stage of the work. Molecular-genetic analysis is also required for accurate identification the rye chromosomes and wheat telocentric chromosome.

\section{References}

Aliyeva A.J., Aminov N.Kh. Inheritance of the branching in hybrid populations among tetraploid wheat species and the new branched spike line 166-Schakheli. Genet. Res. Crop Evol. 2011;58: 621-628.

Alieva A.J., Aminov N.Kh. Influence of D genome of wheat on expression of novel type spike branching in hybrid populations of 171 ACS line. Russian Journal Genet. 2013;49(11):1119-1126. DOI: 10.1134/ S1022795413110021.

Alkhimova A.G., Heslop-Harrison J.S., Shchapova A.I., Vershinin A.V. Rye chromosome variability in wheat-rye addition and substitution lines. Chromosome Research. 1999;7:205-212.
Amagai Y., Aliyeva A.J, Aminov N.Kh, Martinek P., Watanabe N., Kuboyama T. Microsatellite mapping of the genes for sham ramification and extra glume in spikelets of tetraploid wheat. Genet. Resour. Crop Evol. 2014;61:491-498.

Amagai Y., Gowayed S., Martinek P., Watanabe N. The third glume phenotype is associated with rachilla branching in the spikes of tetraploid wheat (Triticum L.). Genet. Resour. Crop Evol. 2017; 6435-842.

Bedbrook J.R., Jones J., O’Dell M., Thompson R.J., Flavell R.B. A molecular description of telomeric heterochromatin in Secale species. Cell. 1980;19:545-560.

Benito C., Zaragoza C., Gallego F.J., De la Pena A., Figueiras A.M. A map of rye chromosome $2 \mathrm{R}$ using isozyme and morphological markers. Theor. Appl. Genet. 1991;82:112-116.

Dobrovolskaya O., Pont C., Sibout R., Martinek P., Badaeva E. et al. FRIZZY PANICLE drives supernumerary spikelets in bread wheat (T. aestivum L.). Plant Physiol. 2015;167:189-199.

Martinek P. Gene resources with non-standard spike morphology in wheat. Proc. 9th Intern. Wheat Genetics Symposium. - Saskatoon. Saskatchewan. Canada. 1998;2:286-288.

Mukai Y., Nakahara Y., Yamamoto M. Simultaneous discrimination of the three genomes in hexaploid wheat by muilticolor fluorescence in situ hybridization using total genomic and highly repeated DNA pribes. Genome. 1993;36:489-494.

Rayburn A.L., Gill B.S. Isolation of a D genome specific repeated DNA sequence from Aegilops squarrosa. Plant Mol. Biol. Rep. 1986; 4:102-109.

Acknowledgements. We are grateful to the Common Use Center of Microscopy of Biologic Objects SB RAS for the provided equipment (http://www.bionet.nsc.ru/microscopy/).

The work was supported by grant No. 0324-2019-0039.

Conflict of interest. The authors declare no conflict of interest. 


\title{
Identification of univalent chromosomes in monosomic lines of the Gossypium hirsutum L. cotton type with the help of cytogenetic markers
}

\author{
M.F. Sanamyan*, Sh.U. Bobokhujayev \\ National University of Uzbekistan named after M. Ulugbek, Tashkent, Uzbekistan
}

DOI 10.18699/ICG-PlantGen2019-81

(c) Autors, 2019

* e-mail: sanam_marina@rambler.ru

\begin{abstract}
The lack of clear morphological markers of cotton chromosomes contributed to the development of an unconventional method for marking chromosomes using translocations. Cytogenetic identification and numbering of univalent chromosomes in 25 monosomic lines of the NUU cytogenetic collection using a set of test lines with identified chromosomes made it possible to establish that four monosomic lines have univalent of chromosome 2; 15 lines, of chromosome 4; four lines, of chromosome 6; one line, of Atsubgenome chromosome 7; and one line, of cotton Dt-subgenome chromosome 18 . The remaining 21 lines were duplicates of the three non-homologous chromosomes.
\end{abstract}

Key words: cotton (G. hirsutum L.); translocation lines; identification of univalent chromosomes.

\section{Introduction}

Works on the creation of translocation tester sets, which were obtained from five plant species - maize, barley, pea, rye, and tomato - are widespread. M.S. Brown et al. (1980) obtained 62 G. hirsutum translocation lines using X-, $\gamma$, Bikini radiation and irradiation of seeds or pollen of various varieties with fast neutrons, as well as several lines. In 58 of these lines, two nonhomologous chromosomes were involved; in three, three chromosomes in each; and in one, four. For identification and numbering of chromosomes, studies were conducted on the assignment of translocated chromosomes to subgenomes. As a result of the identification, it turned out that chromosome 26 was not involved in any of the translocations and was determined by the exclusion method.

For many years, the National University of Uzbekistan has been conducting studies on the induction of cotton plants with various chromosomal aberrations using various methods of induced mutagenesis. As a result, a unique cotton cytogenetic collection was created, including monosomic, monotelodisomic and translocation lines (Sanamyan et al., 2014). This article discusses the unified identification of univalent chromosomes in monosomic cotton lines using a well-defined tester set of cotton translocation lines with identified chromosomes.

\section{Materials and methods}

Hybrid monosomic cotton plants obtained from crossing monosomic lines of the cytogenetic collection of cotton G. hirsutum L. of the National University of Uzbekistan (NUUz) with a well-defined tester set of cotton translocation lines from the Cotton Cytogenetic Collection at Texas A\&M AgriLife Research served as material for research. Cytogenetic translocation markers were kindly provided by Professor David Stelly through the ARS-USDA exchange program. In the process of cytological analyses, meiosis was studied at the stage of metaphase 1 (MI) in pollen mother cells (PMC).

\section{Results and discussion}

As a result of cytogenetic analysis of hybrids obtained from crossing monosomic cotton lines with the tester set of translocation lines with identified chromosomes, it turned out that in the case of crosses with six translocation lines - TT 2L-6R, TT 2L-3Lb, TT 2R-3La, TT 2R-8Ra, TT 2R-8Rb and TT 2R$14 \mathrm{R}$ - homology of univalent chromosomes was established in four monosomic lines (Mo11, Mo16, Mo19 and Mo93) and one of the translocated chromosomes in the above translocations, since 24 bivalent plus one trivalent translocations in MI meiosis were observed (Figure 1,a). In the tester line TT2L-6R, chromosomes 2 and 6 are involved in translocation; in the TT2L-3Lb and TT2R-3La lines, chromosomes 2 and 3 are involved in translocation; in the TT2R-8Ra and TT 2R$8 \mathrm{Rb}$ lines, chromosomes 2 are involved in translocation with chromosome 8; and in the TT2R-14R line, chromosomes 2 and 14 are involved in translocation. Therefore, one of these chromosomes is homologous to the univalent chromosome in the monosomic lines Mo11, Mo16, Mo19 and Mo93. Since in six translocation lines one common chromosome 2 is involved, the univalent chromosomes in the monosomic lines Mo11, Mo16, Mo19 and Mo93 are chromosome 2 of the At subgenome of cotton, and these monosomic lines are duplicates. In the analysis of hybrids obtained from crosses of seven cotton monosomic lines (Mo31, Mo70, Mo72, Mo73, Mo75, Mo76, Mo89) with two tester translocation lines, TT4L-19R and TT4R-15L, the homology of the univalents of these seven lines with one of the translocated chromosomes was established since monosomic translocation hybrids in MI meiosis showed 24 bivalents plus one trivalent.

In the tester line TT4L-19R, chromosomes 4 and 19 are involved in translocation, and in TT4R-15L, chromosomes 4 and 15 are involved in translocation, therefore, one of these three chromosomes is homologous to the univalent chromosome in the monosomic lines Mo31, Mo70, Mo72, Mo73, Mo75, Mo76, and Mo89. Since one common chromosome 4 

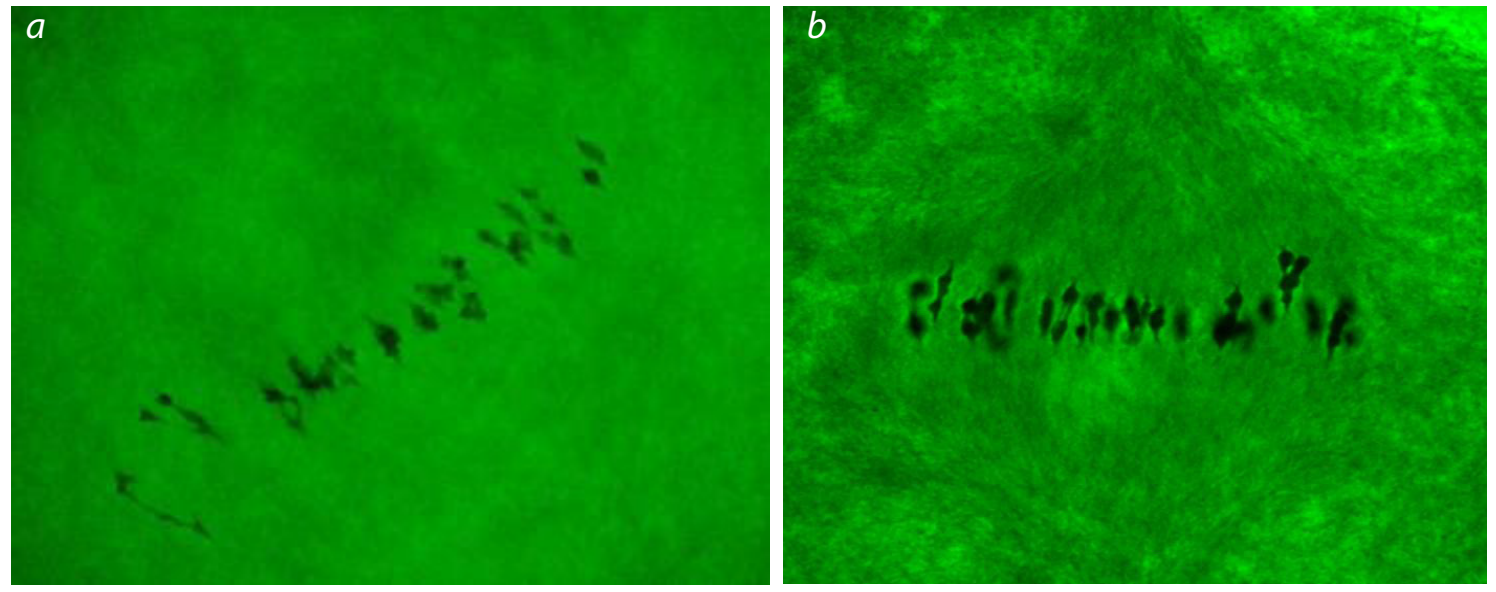

Figure 1. "Critical configurations" of the chromosomes at meiotic metaphase 1 , showing 24 bivalents and 1 trivalent in cotton $\mathrm{F}_{1}$ hybrid monosomic plants from the crosses: $a-$ Mo16 ×TT2R-8Rb; $b$ - Mo58 × TT4L-19R (24" + 1"').

is involved in both translocation lines, the univalent chromosomes of the monosomic lines Mo31, Mo70, Mo72, Mo73, Mo75, Mo76, Mo89 are cotton At-subgenome chromosome 4, and these monosomic lines are duplicates.

The study of hybrids of the other eight monosomic lines of cotton (Mo7, Mo38, Mo58, Mo59, Mo60, Mo69, Mo71 and Mo81) was carried out with only one of two translocation lines, TT4L-19R or TT4R-15L. As a result, the homology of the univalents of these eight lines with one of the translocated chromosomes was established, since monosomic translocation hybrids in MI meiosis showed 24 bivalents plus one trivalent (Figure 1, b). Since chromosomes 4 and 19 are involved in translocation in the tester line TT4L-19R, and chromosomes 4 and 15 are involved in translocation in the TT4R-15L line, therefore, one of these three chromosomes is homologous to the monosomics Mo7, Mo38, Mo58, Mo59, Mo60, Mo69, Mo71 and Mo81. Since one common chromosome 4 is involved in both translocation lines, it can be assumed that the univalent chromosomes in Mo7, Mo38, Mo58, Mo59, Mo60, Mo69, Mo71 and Mo81 are chromosome 4 of the cotton Atsubgenome, and these monosomic lines are duplicates. The chromosomal locations of chromosome-specific SSR markers on $\mathrm{F}_{1}$ hybrids with the participation of lines Mo7, Mo38, Mo58, Mo59, Mo60, Mo69, Mo71 and Mo81 confirmed these data (Sanamyan et al., 2016).

In the study of four monosomic cotton lines (Mo13, Mo34, Mo67, Mo95) using four translocation lines, TT 3L-6L, TT 6L7L, TT 6L-10R, and TT 6L-14L, the homology of the univalent chromosomes of these four monosomic lines was established and one of the translocated chromosomes in the above-listed translocations, since 24 bivalents plus one trivalent were observed in monosomic translocation hybrids in MI. Since one common chromosome 6 participates in four translocation lines, the univalent chromosomes of the monosomic lines Mo13, Mo34, Mo67, Mo95 are chromosome 6 of the cotton At subgenome, and these monosomic lines are duplicates.

The study of the monosomic line Mo27 in four crosses, Mo27×TT 1L-7L, Mo27×TT 7L-12R, Mo27×TT 7R-11R and Mo27 $\times$ TT 7R-21R, revealed univalent chromosome and one of the translocated chromosomes, because monosomic hybrids in MI showed pairing chromosomes in the form of 24 bivalents and one trivalent. Since one common chromosome 7 is involved in the four translocation lines, the univalent chromosome in the monosomic line Mo27 is cotton At-subgenome chromosome 7.

In the study of the monosomic line Mo 48 in one variant of crossing with the translocation line TT7L-18R in the MI of meiosis, 24 bivalents plus one trivalent were found, which indicated the homology of the univalent chromosome in Mo48 and one of translocated chromosomes in translocation line TT7L-18R. Because in the tester line TT7L-18R, chromosomes 7 and 18 are involved in translocation, the univalent chromosome in the monosomic line Mo48 is homologous to one of the two chromosomes. Unfortunately, there is no second translocation line in the tester set of lines with identified chromosomes that involved chromosome 18 . Therefore, to determine to which of the two chromosomes of this translocation line the univalent chromosome of Mo48 is homologous, molecular genetic analysis of the monosomic interspecific $\mathrm{F}_{1}$ hybrid (Mo48 $\times$ Pima3-79) was used, which showed the presence of only a $G$. barbadense-specific SSR marker band (BNL3280) and the absence of the respective G. hirsutum allele (Sanamyan et al., 2016). Because this SSR marker had previously been assigned to chromosome 18 of the Dt subgenome of cotton, we can assume that the monosomic line Mo48 of the NUU collection has a monosomy on chromosome 18 of the Dt subgenome.

\section{Conclusion}

The use of translocation lines with identified chromosomes allowed us to bring the numbering of univalent chromosomes in the monosomic lines of our collection to conformity with the generally accepted nomenclature. Cytogenetic identification and numbering of univalent chromosomes in 25 monosomic lines of the cytogenetic collection of NUU allowed us to establish that four monosomic lines have univalent of chromosome 2; 15 lines, of chromosome 4; four lines, of chromosome 6; one line, of At-subgenome chromosome 7; and one line, of cotton Dt-subgenome chromosome 18. The overwhelming majority of monosomic lines were detected 
by the most frequently registered cotton monosomics - by chromosomes 2,4 and 6.

A comparative analysis of the first 20 identified monosomics of cotton obtained in the USA revealed similar trends, since the study revealed 7 monosomics on chromosome 2 , seven on chromosome 4 , three on chromosome 6 and one on chromosomes 1, 17 and 18 (Brown, Endrizzi, 1964). The similarity of the data obtained in the study of different collections indicates that, despite the differences in genotypic environments and methods for producing monosomics, cotton has a surprising coincidence of data on a higher frequency of monosomics appearing precisely on chromosomes 2, 4 and 6, while monosomics on other chromosomes of the set appear at a much lower frequency, and eight non-homologous chromosomes (At-subgenome 5, 8, 13 and cotton Dt-subgenome 14, 15, 19, 22 and 24) have never been detected (Saha et al., 2012). Apparently, the centromeric regions of certain chromosomes are subject to more frequent breakdown events and the genome as a whole remains tolerant to the loss of large At-subgenome chromosomes without much effect on viability and fertility, while the chromosomes of some small Dt-subgenome chromosomes are not subject to any changes due to incompatibility with vitality.

\section{References}

Brown M.S., Endrizzi J.E. The origin, fertility and transmission of monosomic in Gossypium. Amer. J. Bot. 1964;51(1):108-115.

Brown M.S. Identification of the chromosomes of Gossypium hirsutum L. by means of translocations. J. Hered. 1980;71(4):266-274.

Saha S., Stelly D.M., Raska D.A., Wu J., Jenkins J.N., McCarty J.C., Makamov A. Chapter 6. Chromosome substitutions lines: concept, development and utilization in the genetic improvement of upland cotton. In: Abdurakhmonov I.Y. (Ed). Plant Breeding. In Tech: Croatia, 2012;107-128.

Sanamyan M.F., Petlyakova J., Rakhmatullina E.M., Sharipova E. Chapter 10. The Cytogenetic Collection of Uzbekistan. In: Abdurakhmonov I.Y. (Ed). World Cotton Germplasm Resources. In Tech: Croatia, 2014;247-287.

Sanamyan M.F., Makamov A.K., Bobokhujaev Sh.U., Usmonov D.E., Buriev Z.T., Saha S., Stelly D.M. Chapter 8. The utilization of the translocation lines and microsatellite markers for the identification of unknown cotton monosomic lines. In: Abdurakhmonov I.Y. (Ed). Cotton Research. In Tech: Croatia, 2016;167-183.

Acknowledments. This work was supported by the Committee on Science and Technology and the Ministry of Innovations of the Republic of Uzbekistan (grants F-5-31 and OT-A-KH-2018-379).

Conflict of interest. The authors declare no conflict of interest. 


\section{Author index}

Abakumov S.N. 187

Adonina I.G. 61, 244

Afonnikov D.A. 117, 162

Agakhanov M.M. 42

Ageeva E.V. 36

Aidarkhanova G.S. 107

Akhmetova A.B. 80

Alekseev V.U. 77

Alexandrova A.M. 143

Ali S. 66

Aminov N.Kh. 244

Amstislavskaya T.G. 15

Anapiyayev B.B. 80

Antipin M.I. 173

Artemova G.V. 24

Artyukhin A.E. 44

Askhadullin D-1.F. 19, 34

Askhadullin D-r.F. 19, 34

Atishova M.N. 66

Avagyan I.A. 107

Babak O.G. 221

Badaeva E.D. 196

Bagavieva E.Z. 19

Baranova O.A. 52, 64

Barsukova E.N. 49

Barzanova V.V. 232

Bazhenov M.S. 190

Bebykina I.V. 58

Beisenbek E.B. 80

Belan I.A. 187, 205

Belenikin M.S. 166, 173

Belkov V.I. 101, 169

Beniaminov A.D. 158

Berezhneva 135

Bechtold N.P. 74

Blokhina N.P. 187

Bobokhujayev Sh.U. 247

Boiko N.I. 61

Boldakov D.M. 58, 199

Boldyrev S.V. 230

Bome N.A. 92

Bondarevich E.B. 235

Borisenko A.Yu. 184

Borodaeva Z.A. 224

Bragina M.K. 117

Brailko V.A. 95

Brylinska M. 214
Burkhanova G.F. 69, 77

Chakheeva T.V. 207

Cherniavskih V.I. 224

Chernook A.G. 190, 199

Chernova A.I. 227

Chibizova A.S. 49

Chirkov S.V. 95

Chumanova E.V. 120

Churikova O.A. 166

Davoyan E.R. 58, 199

Davoyan R.O. 58, 199

Divashuk M.G. 190, 199

Dmitriev A.A. 83, 153, 158, 179

Dobrodkin M.M. 221

Dolgov S.V. 126

Druzhin A.E. 52

Duarte G.T. 177

Dubovets N.I. 235

Dumachev D.V. 224

Dumacheva E.V. 224

Dzhioev Yu.P. 184

Dzhos E.A. 146

Efimova M.V. 98

Efremova L.N. 133

Efremova T.T. 120

Elkonin L.A. 129

Erst T.V. 217

Esenbaeva G.L. 113

Evtushenko E.V. 238, 241

Fisenko P.V. 49

Fotev Y.V. 12

Galycin G.Y. 24

Garnik E.Yu. 101, 169

Gatzkaya S.S. 238

Geras'kin S.A. 177

Gerashchenkov G.A. 129

Glagoleva A.Y. 89, 162

Golovanov Y.M. 156

Goncharov N.P. 24, 30, 202

Gorbenko I.V. 169

Gordeeva E.I. 15

Goryunov D.V. 230

Goryunova S.V. 230 
Graskova I.A. 110

Gubaev R.F. 230

Gvozdeva L.M. 46

Humood B.M.H. 150

Iskakov B.K. 143

Iskakova K.M. 80

Ivanova E.A. 87

Ivashchenko A.T. 104

Kadikov R.K. 187

Karnoukhova O.G. 184

Karpova O.V. 143

Katyshev A.I. 169

Kazakova O.A. 72

Kelbin V.N. 56

Kenzhegulov O.A. 129

Kershanskaya O.I. 113

Kezimana P. 83, 153, 179

Khlestkin V.K. 46, 217

Khlestkina E.K. 15, 46, 89, 162, 217

Khotyleva L.V. 221

Khusainova I.I. 19

Kilchevsky A.V. 221

Kiselev K.V. 140

Klementyeva A.A. 126

Klykov A.G. 49

Kochieva E.Z. 146

Kokhmetova A.M. 66

Kolokolova N.N. 92

Kolomeichuk L.V. 98

Komakhin R.A. 133

Konopatskaia I. 202

Konorov E.A. 166, 173

Konstantinov A.V. 137

Konstantinov Yu.M. 101, 169

Korolev K.P. 92

Koulintchenko M.V. 169

Kovalenko N.M. 64

Kovtun I.S. 98

Kozlov K.N. 181

Kozlov V.I. 24

Krasnov G.S. 83, 153, 158, 179

Krinitsina A.A. 166, 173

Kryldakov R.V. 143

Kryukova A.V. 156

Kudryavtseva L.P. 83, 179

Kulagin D.V. 137

Kuluev B.R. 44, 135

Kuptsov S.V. 173

Kurkova S.V. 30

Leonova I.N. 36, 61, 193, 235
Likhenko I.E. 24, 36

Lipikhina Yu.A. 241

Logacheva M.D. 166, 173

Lozhnikova L.F. 187

Maksimov I.V. 69, 77

Mal'chikov P.N. 207

Markova Ju.A. 184

Martynova E.U. 227

Mazitova A.A. 77

Mehdiyeva S.P. 244

Melnikova N.V. 83, 153, 158, 179

Mesyats N.V. 95

Mikhaylova E.V. 44, 135, 156

Mikov D.S. 58, 199

Minasbekyan L.A. 107

Mironenko N.V. 64

Miroshnichenko D.N. 126

Mitrofanova I.V. 95

Mitrofanova O.P. 64

Mitrofanova O.V. 95

Mukin K.B. 21

Mukiyanova G.S. 113

Murgan O.K. 98

Musin Kh.G. 135

Musinov K.K. 24

Mustafina A.N. 156

Muterko A. 124

Myasnikova M.G. 207

Nabiyeva N.A. 39

Nargilova R.M. 143

Nazarova L.A. 190

Nelidov S.N. 113

Nelidova D.S. 113

Nemchenko V.V. 187

Nemtsev A.B. 30

Nemtsev B.F. 30

Nesterov M.A. 56

Nevestenko N.A. 221

Nikitinskaya T.V. 221

Nityagovsky N.N. 140

Novakovskiy R.O. 83, 153, 158, 179

Novikova A.A. 232

Novokhatin V.V. 28

Nozhkina O.A. 110

Nuzhdin S.V. 181

Nuzhnaya T.V. 69

Omarova A.S. 80

Omelchenko D.O. 173

Oreshkova N.V. 137

Orlova E.A. 74 
Orlovskaya O.A. 235

Osadchaya T.S. 196, 205

Otmakhova Y.S. 15

Padutov V.E. 137

Panin V.M. 129

Park M.E. 137

Parkina O.V. 219

Pavelek M. 153

Peretolchina N.P. 184

Perfileva A.I. 110

Pershina L.A. 187, 196, 205

Piskarev V.V. 61, 72

Plich J. 214

Ponomarenko V.I. 24

Portnaia I.A. 184

Potokina E.K. 42

Povkhova L.V. 83, 153, 158, 179

Prokopjeva M.V. 244

Puhacheva I.G. 221

Pushkova E.N. 83, 153, 158, 179

Pyrkova A.U. 104

Rahimova G.K. 39

Rakhmetullina A.K. 104

Razmakhnin E.P. 24

Razmakhnina T.M. 24

Reva O.N. 184

Romanova E.V. 153

Rosseeva L.P. 187, 205

Rozanova I.V. 46, 217

Rozhmina T.A. 83, 153, 179

Rozova M.A. 207

Sagimbayeva A.M. 80

Salina E.A. 36, 56, 61, 117, 126, 193, 244

Samsonova M.G. 181

Sanamyan M.F. 247

Sergeeva E.M. 56

Shchennikova A.V. 146

Shevchuk O.M. 12

Shmakov N.A. 162

Shoeva O.Y. 15, 89

Sibikeev S.N. 52

Skolotneva E.S. 56

Śliwka J. 214

Slugina M.A. 146

Smyda-Dajmund P. 214

Sobkowiak S. 214

Solovey L.A. 235

Sorokan A.V. 77
Speranskaya A.S. 166, 173

Stasyuk A.I. 61, 193

Stefanczyk E. 214

Stepanenko L.A. 184

Stepochkin P.I. 211, 241

Stepochkina N.I. 24

Strelnikova S.R. 133

Sukhov B.G. 110

Suleimenova M.Sh. 21

Surnachev A.A. 24

Syso A.I. 12

Tarasenko V.I. 169

Tazutdinova M.R. 19

Tenditnik M.V. 15

Tetyannikov N.V. 92

Tikhonova M.A. 15

Toropova E.Yu. 72

Tretyakova I.N. 137

Trubacheeva N.V. 187, 196, 205

Tyunin A.P. 140

Usenko N.I. 15

Vafin R.R. 34

Vafina G.Kh. 87

Valiyeva L.S. 39

Vasiliev G.V. 117, 162

Vasilova N.Z. 19, 34

Vavilova V. 202

Vershinin A.V. 238, 241

Veselova S.V. 69

Vidich S. 56

Volkov V.A. 42

Volkova P.Yu. 177

Weisfeld L.I. 92

Yakubenko O.E. 219

Yessimbekova M.A. 21

Yudakova O.I. 150

Zaikina E.A. 135

Zhuchenko A.A. 83

Ziborov A.I. 207

Zinchenco A.N. 58

Zlobin V.I. 184

Zubanova Y.S. 58, 199

Zuev E.V. 19 